Portland State University

PDXScholar

Winter 4-23-2014

\title{
Gender Representations in U.S. Ed.D. Dissertations: A Feminist Content Analysis
}

Debora Kay Nelli

Portland State University

Follow this and additional works at: https://pdxscholar.library.pdx.edu/open_access_etds

Part of the Educational Leadership Commons, and the Feminist, Gender, and Sexuality Studies Commons

Let us know how access to this document benefits you.

\section{Recommended Citation}

Nelli, Debora Kay, "Gender Representations in U.S. Ed.D. Dissertations: A Feminist Content Analysis" (2014). Dissertations and Theses. Paper 1700.

https://doi.org/10.15760/etd.1699

This Dissertation is brought to you for free and open access. It has been accepted for inclusion in Dissertations and Theses by an authorized administrator of PDXScholar. Please contact us if we can make this document more accessible: pdxscholar@pdx.edu. 
Gender Representations in U.S. Ed.D. Dissertations: A Feminist Content Analysis

by

Debora Kay Nelli

A dissertation submitted in partial fulfillment of the requirements for the degree of

\section{Doctor of Education}

in

Educational Leadership: Postsecondary Education

Dissertation Committee:

Jacqueline B. Temple

Samuel Henry

Michael J. Smith

Yves Labissiere

Portland State University

2014 


\title{
GENDER REPRESENTATIONS IN ED.D. DISSERTATIONS
}

\author{
Abstract \\ Educational access, achievement and opportunity for students and \\ educators in U.S. educational institutions is influenced and often limited by \\ gender. Although the U.S. Glass Ceiling Commission reports that the gender \\ equity values, beliefs and commitments of institutional leaders are a key factor \\ in reducing institutional gender inequities (U.S. Dept of Labor, 1995), very little \\ is known about the current preparation or evaluation of educational leadership \\ values, especially at the doctoral level (Hess \& Kelly, 2007, Grogan \& Andrews, \\ 2002; Levine, 2005; Murphy \& Vriesenga, 2004). \\ This study utilized feminist content analysis as a conceptual framework \\ and research methodology to examine the collective gender equity values, \\ beliefs and commitments of educational leaders represented in a key textual \\ artifact of doctoral study, the Educational Doctorate (Ed.D.) dissertation. \\ This sequential mixed method content analysis examines 15,014 \\ dissertation titles of Ed.D dissertations completed from 112 U.S. public doctoral \\ granting institutions between 1998-2007 to identify 1185 dissertations indicating \\ gender in their title. A purposeful sample of 177 abstracts was selected from \\ emergent themes for further analysis. The final research phase examined a
}




\section{GENDER REPRESENTATIONS IN ED.D. DISSERTATIONS}

purposeful sample of 9 complete dissertation texts selected from the analysis of the abstracts. The research focused on two questions, 1.) How prevalent is gender focused inquiry in recent Ed.D. dissertation scholarship, from 19982007? 2.) What are the cultural gender beliefs and gender conceptualizations represented in Ed.D. dissertation scholarship from 1998-2007?

The findings indicate gender focused inquiry is not prevalent in Ed.D. dissertation titles, in public doctoral granting institutions from 1998-2007; only $7.4 \%$ indicated any mention of gender. The findings also revealed great institutional variation in the prevalence of gender focused dissertations in the 112 institutions examined.

Three themes also emerged from patterns of representations illuminating problematic gender cultural beliefs, 1,) male leadership and intellectual authority is privileged, 2.) Black males are "othered", 3.) Latinas are silenced. Three additional problematic themes of gender bias are revealed because of scanty representation in the sample, 1.) LGTBIQ issues silenced, 2.) Title IX trivialized and 3.) Feminism marginalized. Each of these three gender focused categories represented less than $1 \%$ of the Ed.D. dissertations completed in U.S. public doctoral granting universities between 1998-2007. 


\section{GENDER REPRESENTATIONS IN ED.D. DISSERTATIONS}

The findings have implications for program planning of doctoral Ed. D. programs for the development of gender equity dispositions. The findings also contribute to the discipline by adding to the knowledge of Ed. D. dissertation content. This report includes recommendation for future research and practice. 


\title{
GENDER REPRESENTATIONS IN ED.D. DISSERTATIONS
}

\author{
Dedication
}

This dissertation is dedicated to my children, Ryan and Tony, who are a constant source of inspiration and joy. Follow your passion, run your own race and enjoy the adventure. 


\section{GENDER REPRESENTATIONS IN ED.D. DISSERTATIONS}

\section{Acknowledgements}

I'd like to express my appreciation to the educators, scholars and diversity advocates who served on my dissertation committee: Dr. Jacqueline Temple for her patient reading and timely, valuable feedback throughout my qualifying exams and dissertation writing process, Dr. Michael Smith for his consistent support and encouragement throughout my doctoral studies, Dr. Samuel Henry for always having an open door, heart and mind to graduate students and Dr. Yves Labissierre for understanding and supporting scholarship that illuminates systemic and institutional inequities.

I'd also like to acknowledge and thank several people whose friendship and support sustained me throughout this journey, Andrew, Tiffany, Donna, Todd, Sarmila and Shobo, friends and supporters for listening to my academic stories and their flexibility with my study needs. I thank Amy Riggs, my data coder extraordinaire, for her diligence in helping code data for this project. I'd like to offer special thanks to my sister Dawn, and my friend Zaffreen who were always ready and willing to talk about the adventure. I am very grateful for the love and support of my sons, Ryan and Tony who never complained about my academic commitments and the inherent investment of family time and treasure diverted towards my scholarly interests. 
GENDER REPRESENTATIONS IN ED.D. DISSERTATIONS

\section{Table of Contents}
Abstract
i
Dedication iv
Acknowledgements $\quad \mathrm{v}$
List of Tables $\quad$ xii
List of Figures $\quad$ xiii

\section{Introduction}

Introduction

Purpose Statement 3

Research Questions 3

Key Terms

Conceptual Framework 6

$\begin{array}{lr}\text { Study Rationale } & 8\end{array}$

$\begin{array}{ll}\text { Organization of the Study } & 10\end{array}$

\section{Review of Literature}

Values in Educational Leadership Programs 13

Aggregated values data and low values focus $\quad 15$

Gender equity values: Doctoral socialization 16

Gender equity values: Educational leadership programs $\quad 20$

Perceptions on salience of gender equity values 22

$\begin{array}{ll}\text { Challenges to supporting gender equity values } & 27\end{array}$ 
GENDER REPRESENTATIONS IN ED.D. DISSERTATIONS

Summary of Values Literature $\quad 28$

Disciplinary Call for Development of Leadership Values $\quad 29$

K-12 leadership values $\quad 29$

Postsecondary leadership values $\quad 30$

Ed.D. Dissertations as Repository Educational Leadership Values 35

Content Analysis as Method to Assess Cultural Values 37

Feminist content analysis $\quad 40$

Strengths of content analysis for this study 41

Feminist content analysis of education journals $\quad 43$

Importance feminist content analysis academic literature $\quad 48$

\section{Methodology}

Mixed Method Design Overview 51

Standards of Evidence and Methodological Pluralism 52

Analytical transparency through appendices. 53

Transparency of Ed. D. dissertations as public documents. 54

Phase I-Quantitative Sample-E.D. Dissertation Titles 55

Phase I- Data Analysis-Dissertation Titles 58

Phase I-Quantitative Content Analysis Research Quality Standards 58

Standard of Stability $\quad 58$

Standard of Reproducibility $\quad 59$

Standard of Accuracy $\quad 60$

Phase II- Qualitative Sample $\quad 62$ 
GENDER REPRESENTATIONS IN ED.D. DISSERTATIONS

Phase III-Qualitative Sample $\quad 64$

Phase II \& III-Qualitative Data Analysis 66

Tetreault's Feminist Phase Theory 66

Altheide's Emergent Document Analysis $\quad 70$

Phase II \& III-Interpretive Standards of Evidence $\quad 71$

Human Subjects Review Considerations $\quad 72$

Delimitations $\quad 72$

$\begin{array}{ll}\text { Limitations } & 74\end{array}$

\section{Description of Findings}

Phase I. Q. 1. Prevalence of Gender Focus 76

Variances of prevalence of gender focus.

Phase I-Q. 2. Beliefs \& Gender Conceptualizations 81

Finding 1. Q.2. Masculine leaders,scholarship privileged 82

Finding 2. Q.2.Black males “ Othered” 84

Finding 3. Q. 2. Latinas silenced 85

Finding 4. Q.2. Title IX trivialized 85

Finding 5. Q.2. LGTBIQ silenced 85

Finding 6. Q.2. Feminism marginalized 85

Phase II-Findings Q.2. Beliefs \& Gender Conceptualization 86

Phase III-Findings Q. 2. Beliefs \&Gender Conceptualization 87

$\begin{array}{ll}\text { LGTBIQ dissertations. } & 87\end{array}$ 
GENDER REPRESENTATIONS IN ED.D. DISSERTATIONS

Male v. female leaders dissertation $\quad 88$

Black male dissertations $\quad 89$

Emergent theme-fear, silencing \& recommendations $\quad 90$

5. Summary Discussion and Recommendations 92

Question 1. Prevalence of Gender Focus 93

Q.1. Finding 1. Low Prevalence Gender Focus 93

Q. 1 Finding 2. Institutional Variation of Gender Focus 97

Q.1. Finding 3. Correlation Gender \& Inst. Research 98

Question 2. Cultural Beliefs \& Gender Conceptualizations $\quad 99$

Q .2 Finding 1. Masculine leadership, scholars privileged 99

Q. 2 Finding 2. Black males "Othered" 102

Q. 2. Finding 3. Latinas silenced 106

Q. 2. Finding 4. Title IX trivialized 109

Q. 2 Finding 5. LGTBIQ silenced 112

Q. 2 Finding 6. Feminism marginalized 114

Question 2. Cultural Beliefs \& Gender Conceptualizations: 117

Tetreault's Phase Theory 117

Fear, silencing and discrimination $\quad 121$

$\begin{array}{ll}\text { Summary Discussion } & 122\end{array}$

Doctoral Program Planning \& Practice Recommendations $\quad 123$

Doctoral Program Gender Focus Research Recommendations $\quad 125$

Research Recommendation: Low prevalence gender focus 126 
GENDER REPRESENTATIONS IN ED.D. DISSERTATIONS

Research Recommendation: Institutional focus variation 128 Research Recommendation: Gender institutional research 128

\section{References}

Appendix A. Tetreault Coding Rubric

Appendix B. Coding Dictionary

Appendix C. Coder Instructions

Appendix D. Human Subjects Application \& Waiver 165

Appendix E. Carnegie Public Doctoral Institutions 171

Appendix F. Carnegie DRU with dissertation \& gender focus 176

Appendix G. Carnegie RUH with dissertation gender focus 177

Appendix H. Carnegie RUVH with dissertation gender focus 179

Appendix I. Gender focused dissertations 180

Appendix J. Institutional Gender focus w/Carnegie classification 278

Appendix K. List of 177 Abstracts $\quad 281$

Appendix L. Coding memo 3 dissertation LGTBIQ 301

Appendix M. Coding memo 3 dissertation Black Males 304

Appendix N Coding memo 3 dissertation Male v Female Leaders 307

Appendix O. Male v Female Tetreault Coding 310

Appendix P. Black Males Tetreault Coding 313

Appendix Q. Latino/a Tetreault Coding 317

Appendix R. LGTBIQ Tetreault Coding 322

Appendix S. Title IX Tetreault Coding 325 
GENDER REPRESENTATIONS IN ED.D. DISSERTATIONS

Appendix T. Feminist Tetreault Coding 327

Appendix U. Male Gender focus with ethnicity 329 
GENDER REPRESENTATIONS IN ED.D. DISSERTATIONS

\section{List of Tables}

Table $2.1 \quad$ Newspaper articles gender composition superintendents 26

Table $2.2 \quad$ Published Feminist content analysis studies literature 47

$\begin{array}{lll}\text { Table } 3.2 & \text { Coding Dictionary } & 61\end{array}$

$\begin{array}{lll}\text { Table } & 3.3 & \text { Tetreault's Feminist Phase Theory }\end{array}$

Table 4.1 Doctoral institutions with the highest gender focus 78

Table 4.2 Doctoral institutions with the lowest gender focus 79

Table 4.3 Range of gender focus in Ed.D. sample 112 institutions 80

$\begin{array}{lll}\text { Table } & 4.4 & \text { Abstract Tetreault coding }\end{array}$ 


\section{GENDER REPRESENTATIONS IN ED.D. DISSERTATIONS}

\section{List of Figures}

Figure 4.1 \% of total Ed.D. Dissertations for each category gender 78

Figure 4.2 Gender focus as \% of total dissertations by Carnegie 81 


\section{GENDER REPRESENTATIONS IN ED.D. DISSERTATIONS}

\section{Chapter 1. Introduction}

An individual's gender influences and often limits their educational access, achievement, and opportunities in U.S. educational institutions. Gender discrimination can impact the emotional, social and economic lives of the students who attend U.S. educational institutions and the educators who work within them (ASHE, 2007; Glass, 2000; Kindland \& Thompson, 2002; Pollack, 2002; Sadker \& Sadker 1994).

Gender discrimination occurs in observable examples of differential expectations and treatment of students such as: a.) underestimating the intellectual abilities of female students in comparison to males (American Association of University Women, 1991; Bombardieri, 2005; Kerr, 1994; Sadker \& Sadker, 1994; Sandler, Silverberg \& Hall, 1996), b.) targeting male students for special education and behavior referrals (Sadker \& Sadker, 1994; Sandler, 1984; Sandler, Silverberg \& Hall, 1996), and c.) persecuting LGTBIQ (Lesbian, Gay, Transgender, Bisexual, Intersexed or Queer/Questioning) students (Kosciw \& Diaz, 2005). Since educational leaders are charged with the responsibility for students in their care, gender discrimination towards students should be an issue that merits attention.

Additionally, educational leaders are not only charged with the responsibility for students in their care, in like manner, their values, beliefs and commitments impact the gender equity climate for employees in educational 


\section{GENDER REPRESENTATIONS IN ED.D. DISSERTATIONS}

institutions (ASHE, 2007; Glass, 2000). Educators and administrators in U.S.

educational institutions often experience differential expectations and treatment because of their gender. For example, female postsecondary educators are less likely to obtain positions, receive tenure or advance into higher ranks in prestigious higher education institutions than their male colleagues (AAUW, 2004; AAUP, 2006; Banerji, 2006; Wilson, 2006). Additionally, female faculty pay is only $81 \%$ of male faculty pay, representing a gendered pay gap that has been constant for over 30 years (Banerji, 2006).

In 2000 Glass reported that while $75 \%$ of K-12 public school employees were female and $90 \%$ of elementary teachers were female, only $13 \%$ of school superintendents were female (Glass, 2000). Nearly a decade later the American Association of School Administrators report that progress has been made towards gender equity in K-12 school leadership; $22 \%$ of school superintendents are now female, but at the current rate of change it will take 3 decades before females and males achieve parity in top educational leadership positions (Holland, 2011).

These examples indicate that gender inequity is a problem for students, faculty and administrators in U.S. educational institutions. However, findings of the 1995 U.S. Glass Ceiling Commission identified key factors in ameliorating institutional gender discrimination were the values, beliefs, and commitments of the institution's leaders (U.S. Dept of Labor, 1995). The pivotal role leaders play in 


\section{GENDER REPRESENTATIONS IN ED.D. DISSERTATIONS}

either reproducing or disrupting institutional gender inequity makes it essential to examine academic cultural artifacts for insights into the expressed and implied values, beliefs and commitments of future educational leaders regarding gender issues.

\section{Purpose Statement}

Understanding the values, beliefs and commitments of future educational leaders is a crucial first step to creating graduate programs and professional socialization experiences that can prepare educational leaders to recognize, address and ameliorate gender discrimination in U.S. educational institutions.

This study will examine gender focused Ed.D. dissertation scholarship from U.S. public doctoral granting institutions between 1998-2007, as indicated by the dissertation title. Feminist content analysis will be utilized as a conceptual framework and research methodology to examine the gender consciousness, cultural beliefs and gender conceptualization of future educational leaders as represented in a key textual culminating artifact of doctoral study, the Educational Doctorate (Ed.D.) dissertation.

\section{Research Questions}

This inquiry into the values, beliefs and commitments of future educational leaders will focus on two questions, 1.) How prevalent is gender focused inquiry in recent Ed.D. dissertation scholarship, from 1998-2007? 2.) What are the cultural 


\section{GENDER REPRESENTATIONS IN ED.D. DISSERTATIONS}

gender beliefs and gender conceptualizations represented in Ed.D. dissertation scholarship from 1998-2007?

\section{Key Terms}

The following section will define and explain the key terms as they are used in this research study.

Educational leader, as used in this study, denotes graduates of Ed.D. doctoral programs and encompasses a wide range of leadership roles including: K12 administrators, teacher-leaders, postsecondary faculty, administrators or student services personnel, training and professional development personnel, public, private, philanthropic or governmental educational institution advisory and support staff, educational researchers and educational policymakers.

Academic socialization refers to the process where a discipline's behavioral norms, standards and values are internalized by graduate students during their doctoral study. It includes information about values and norms received from course content, disciplinary research, academic professional organizations, advising relationships, formal instructional and informal conversations with faculty, administrators and graduate peers.

Gender, as used in this study, is not a signifier of biological difference, but is a socially constructed category that prescribes certain behaviors and privileges based on that categorization. 


\section{GENDER REPRESENTATIONS IN ED.D. DISSERTATIONS}

Gender equity means attaining parity between humans in "quality of life, academic and work outcomes valued in our society without limitations associated with gender stereotypes, gender roles or prejudices" whether they define themselves as male, female, or refuse traditional binary gender categorizations (Klein, Kramarae \& Richardson, 2007, p.2.)

Gender discrimination is synonymous with the absence of gender equity and describes the differential assignment of rights, privileges and responsibilities on the basis of gender or gender expression.

$L G T B I Q$ is an acronym that describes individuals who identify as Lesbian, Gay, Transgendered, Bisexual, Inter-sexed or Queer.

Gender focused study indicates gender is used as either a category of analysis, sampling criteria, variable examined, or gendered representation of a person, theory, program or building named as subject of study, or other salient gender issue in the dissertation research as indicated by the Ed.D. dissertation title. The term gender focused study for this project includes research that examines female, male or LGTBIQ issues.

Gender consciousness refers to an ideological awareness of how gender shapes the lives and fortunes of males and females differently (Gurin,1985). This study quantifies gender focused dissertation study titles to indicate gender consciousness. 


\section{GENDER REPRESENTATIONS IN ED.D. DISSERTATIONS}

Cultural gender beliefs are a "culture's shared beliefs about the roles, behavior, and personality traits of males and females" (Klein, et al. p.26). Cultural gender beliefs are often synonymous with stereotypes. This study examines explicit and implicit cultural gender beliefs represented in the sample. Tetreault's Phase Theory is one of the tools used in this study to assess cultural gender beliefs.

Gender conceptualization refers to how educational leaders and scholars represent their understanding and categorization of gender. Examples of gender conceptualization include representations of gender as a biological reality or social construction, or representations of gender as dual categories with prescribed gender roles and attributes. Identification of representations of gender conceptualization is informed by Tetreault's Phase Theory which is explained more fully in Chapter 3.

Androcentrism describes a system of thinking and behaving where the assumptions, concepts, beliefs, arguments, theories, methods, laws, policies, and institutions are gendered and privilege males at the expense of females (Bem, 1993; Hawkesworth, 1994).

\section{Conceptual Framework}

Maxwell (2005) describes a study's conceptual framework as the "system of concepts, assumptions, expectations, beliefs and theories that support and inform" (p.33) the research. There are three key concepts that support and inform this research, a.) values, beliefs and commitments of educational leaders can either 


\section{GENDER REPRESENTATIONS IN ED.D. DISSERTATIONS}

foster or inhibit the creation and maintenance of gender equitable institutions, b.) content analysis provides a useful tool to assess individual and collective cultural values, beliefs and commitments and, c.) feminist research methodology offers a useful analytical lens to examine gender representations in text and can provide a valuable counter-narrative to the dominant discourse in academic literature.

Additionally, the conceptual framework for this proposed project is informed by feminist research principles. Feminist research methodology offers an overall approach that is not limited to one specific method or epistemological position; rather it is a holistic approach that incorporates all states of the research process from the foundation of framing the research questions through the write up of findings (Brooks \& Hess-Biber, 2007).

Although there are as many diverse definitions and approaches to feminist research as there are feminists, tenets of feminist research methodology that are central to this research project are, a.) a commitment to ending gender inequity, b.) an examination of gendered policies and practices, c.) an assumption that there are no value-free research projects recognizing that all claims to truth are partial, provisional understandings from a particular position, and d.) an appreciation for epistemological diversity. (Bensimon \& Marshall, 2003; Haraway, 1988; Harding, 1986; Hawkesworth, 1994; hooks, 2000). 


\section{GENDER REPRESENTATIONS IN ED.D. DISSERTATIONS}

Additionally, although feminist research has a great history of focusing on women and issues of importance to women, hooks (2000) reminds us that "feminism is a movement to end sexism, sexist exploitation and oppression" (p.1) and as such includes examining the gender myths that impact all of humanity. hooks' (2000) inclusive version of feminism is also reflected in the conceptual framework and design of this proposed study by including male and LGTBIQ gender focused studies as well as female gender focused studies in the sample.

This study's inclusion of male and LGTBIQ issues in the analysis of gender in this study also parallels national shifts in university women's studies departments nationally and in national policy groups such as the National Science Foundation, (NSF) who as of 2006, was the primary government funder of gender equity programs (Klein, Kramarae \& Richardson, 2007; Nash, Klein, Bitters, Howe, Hobbs, Shevitz, Wharton \& Smeal, 2007). NSF changed the naming and framing of prior programs for women and minorities to the more inclusive focus of gender equity programs.

\section{Study Rationale}

Educational leaders play an important role in reproducing or disrupting gender inequity. Understanding the current state of gender consciousness, cultural gender beliefs and gender conceptualizations of the discipline's leaders and 


\section{GENDER REPRESENTATIONS IN ED.D. DISSERTATIONS}

scholars is an essential first step in developing graduate programs and designing research to support gender equity in educational institutions.

Klein, Kramarae and Richardson (2007) state that creating a comprehensive research and program infrastructure that can effectively address gender inequities require a coherent strategy that builds on existing knowledge (Klein, et al, 2007). However, existing literature examining the values and dispositions of educational leaders regarding gender equity is scant. This study will help address that gap in the literature.

Textual academic artifacts can provide valuable data on the gender consciousness, cultural gender beliefs and gender conceptualizations of educational leaders. Ed.D. dissertations offer a unique, high quality text because of the consistent nature of dissertation reporting and the dissertation's prominence in academic literature in the discipline of education. Dissertations provide the primary source of scholarship in the field of educational leadership and in the area of gender in education (Murphy \& Vriesenga, 2006; Shakeshaft, Brown, Irby, Grogan \& Ballenger, 2007).

Findings from this feminist content analysis study of Ed.D. dissertations contribute to the discipline in several important ways by: a.) providing valuable insights on the gender consciousness, cultural gender beliefs and gender conceptualization represented in a key text created and used by future educational 
GENDER REPRESENTATIONS IN ED.D. DISSERTATIONS

leaders, b.) addressing the paucity of studies of Ed. D. dissertation scholarship, c.) Including male and LGTBIQ gender focused scholarship into the discipline of education's content analysis discourse, and d.) updating and adding to existing feminist content analysis studies in the discipline of education.

\section{Organization of Study}

This study is organized into five chapters. Chapter 1, introduces the research and includes the purpose statement, research questions, definition of key terms, conceptual framework, and study rationale.

Chapter 2, reviews relevant literature supporting the conceptual framework for this study including: a.) what is known about educational leadership values and gender equity values in preparation programs b.) Ed.D. dissertations as a quality document to analyze, c.) the definition, history and utility of content analysis to assess values, d.) use of feminist content analysis studies in the discipline of education, e.) the necessity of ongoing feminist content analysis to identify behaviors that act as barriers or supports to gender equity, and f.) Tetreault's Feminist Phase Theory as a tool to assess the integration of gender consciousness, cultural beliefs and gender conceptualization in academic disciplines.

Chapter 3. discusses the methodology and procedures used in this study and includes: a.) mixed method design overview, b.) methodological pluralism and standards of evidence, c.) Phase I quantitative sample, d.) Phase I quantitative 


\section{GENDER REPRESENTATIONS IN ED.D. DISSERTATIONS}

descriptive data analysis e.) Phase I Quantitative Content analysis research quality standards, f.) emergent categories informing Phase II sampling, g.) Phase II qualitative sample, h.) Phase II and Phase III qualitative interpretive data analysis, i.) Tetreault Feminist Phase Theory, j.) Altheide's emergent qualitative document analysis, k.) Phase III sample, 1.) Phase II and III qualitative interpretive, feminist content analysis standards of evidence, m.) unique transparency issues of public documents, $\mathrm{n}$.) human subjects review, o.) delimitations and limitations of this study.

Chapter 4. discusses findings from of each of the study's III Phases. The Phase I description of findings addresses the first research question; How prevalent is gender focused inquiry in Ed.D. dissertation scholarship, from 19982007? It includes a count of how many gender focused dissertations are found in E.D. dissertations from U.S. public doctoral granting institutions between 1998 and 2007 and percentile rankings of number of gender focused dissertations by institution. The description of findings also categorizes and reports on the proportions of gender focused dissertations examining female, male, LGTBIQ or other issues.

The Phase II description of findings addresses the second research question; What are the cultural gender beliefs and gender conceptualizations represented in 
GENDER REPRESENTATIONS IN ED.D. DISSERTATIONS

Ed.D. dissertation scholarship from 1998-2007? It includes the analysis of a theoretical sample of abstracts utilizing Tetreault's feminist phase theory.

The Phase III description of findings also addresses the second research question; What are the cultural gender beliefs and gender conceptualizations represented in Ed.D. dissertation scholarship from 1998-2007? It includes the analysis of a small theoretical sample of complete dissertations utilizing Tetreault's (1985) feminist phase theory and Altheide et.al's (2008) emergent qualitative document analysis (QDA).

Chapter 5. provides a summary discussion of the implications and significance of the findings. The paper concludes with suggestions for future research and recommendations for educational doctorate program planning. 


\section{GENDER REPRESENTATIONS IN ED.D. DISSERTATIONS}

\section{Chapter 2. Review of Literature}

\section{Values in Educational Leadership Programs}

The U.S. Department of Labor's Glass Ceiling Report's (1995) findings of

the centrality of leader's values, beliefs and commitments in advancing institutional gender equity makes it crucial to understand the gender equity values, beliefs and commitments of educational leaders.

However, a review of the literature indicates a paucity of research on either the preparation or evaluation of educational leaders, especially at the doctoral level (Grogan \& Andrews, 2002; Hess \& Kelly, 2007; Levine, 2005; Murphy \& Vriesenga, 2006; Nicholaides \& Gaynor, 1992). As Murphy and Vriesenga (2006) reveal, only $6.4 \%$ of the over 2000 articles published between 1975 and 2002, in four leading journals in school administration, Educational Administrator Quarterly, Journal of Educational Administration, Journal of School Leadership, Planning and Changing, address any aspects of leadership preparation, including the development of values or dispositions.

Along with light representation in the academic literature, scholars have also criticized a lack of research rigor and quality in published articles on educational leadership (Levine, 2005; Murphy \& Vriesenga, 2006). Less than 3\% of the published articles in Murphy \& Vriesenga's 1975 to 2002 sample of published articles were empirically based (Murphy \& Vriesenga, 2006). 


\section{GENDER REPRESENTATIONS IN ED.D. DISSERTATIONS}

These criticisms, along with concerns expressed by Interstate School Licensure Consortium (ISLLC) and the University Council for Educational Administration (UCEA) regarding the preparation and evaluation of future K-12 educational leaders acted as a catalyst to the UCEA's Special Interest Group (SIG) on Learning and Teaching in Educational Leadership to address the absence of quality research by conducting several studies on leadership preparation programs, published in a 2011special issue of Educational Administration Quarterly (Kottcamp, 2011).

In Kottcamp's (2011) introduction to the recent special issue of Educational Administration Quarterly, he confirms the bleak landscape of knowledge on preparation programs for educational leaders when he states:

This special issue breaks Educational Administration Quarterly's precedent, by publishing five empirical articles on evaluation of leadership preparation, it increases by $63 \%$ the total number of empirical articles on all aspects of school leadership preparation and preparation programs in the entire 45 year history of this journal. (Kottcamp, 2011, p. 3)

Although these recent efforts to increase understanding of the preparation and evaluation of educational leaders should be noted, none of the 2011 special 


\section{GENDER REPRESENTATIONS IN ED.D. DISSERTATIONS}

issue's five empirical additions to the literature address the preparation of educational leaders at the doctoral level, focus on the development of leadership values, or discuss gender equity (Fuller, Young \& Baker, 2011; Orr, 2011; Orr \& Orphanos, 2011; Perez, Uline, Johnson, James-Ward and Basom, 2011; Roach, Smith and Boutin, 2011).

\section{Aggregated values data and low values focus.}

Not only is literature on the preparation and evaluation of values in educational leaders scarce, examinations or discussions of gender equity values are frequently aggregated and subordinated under a larger social justice umbrella. Aggregation and subordination of gender equity themes under a broad social justice umbrella makes it difficult to ascertain whether preparation programs provide enough opportunity for emerging scholars and educational leaders to develop gender equity values.

Additionally, prior studies of educational leadership program content syllabi indicate a low priority and focus to the development of either diversity or gender equity values. Nicholaides \& Gaynor (1992) findings from an examination of doctoral course syllabi from 30 university leadership program reveal that 51 of 61 professors submitting syllabi offered no course content or planned discussions of gender. Additionally, the concept of leadership values never appears as a primary 


\section{GENDER REPRESENTATIONS IN ED.D. DISSERTATIONS}

topic and terms like culture, climate, values, gender or equity are subordinated and aggregated under broader topic headings.

Hess \& Kelly’s (2007) study of 2424 weeks of educational leadership syllabi content identify $12 \%$ of the weekly topics as addressing disciplinary norms and values. However, their broad categorization of norms and values include too many varied terms to adequately assess how much time is devoted to gender equity values. For example, Hess \& Kelly's disciplinary values category includes such varied terms as: social inequality, race, social class, social Darwinism, silenced voices, females, gay, impaired, over/underweight, bullying, biracial, homeless, transient, and even phonics versus whole language.

Additionally, although gender equity, social justice or diversity topics are often aggregated, Murphy \& Vriesenga's (2006) content analysis of educational leadership journals indicates these aggregated topics are poorly represented in the academic literature. Less than $1 \%$ of over 2000 educational leadership articles in Murphy and Vriesenga's (2006) sample address diversity issues and an additional $1 \%$, refer to social justice issues. Murphy and Vriesenga's (2004) study does not specifically delineate which, if any, of those articles discussed gender equity issues.

Although research on the preparation of educational leaders is scant, the available literature examining course syllabi (Hess \& Kelly, 2007; Nicholaides \& Gaynor, 1992) and published articles in disciplinary journals (Murphy \& 


\section{GENDER REPRESENTATIONS IN ED.D. DISSERTATIONS}

Vriesenga, 2004) indicates little attention is focused on diversity or social justice issues generally and on gender equity issues specifically. Marshall (2004) also states educational leadership preparation programs have a legacy of tokenism towards equity issues and she additionally cautions that a few mentions in course content cannot be taken seriously as an attempt or commitment to address inequity.

The aggregation of and subordination of gender equity values in curriculum content as summarized above exemplifies a key challenge to scholars interested in doing gender analysis in the field of education. Klein, Kramarae and Richardson (2007) also report these challenges to updating gender research findings for the $2^{\text {nd }}$ edition of the Handbook for Achieving Gender Equity because of the prevalence of aggregated data in educational institutional research.

\section{Gender equity values: doctoral socialization.}

Since the values and behaviors of scholars and educational leaders are developed during doctoral study, (Anderson \& Swazey, 1998; Austin, 2002; Baird, 1992; Boyer, 1990; Nettles \& Millet, 2006; Tierney \& Rhoades, 1994; Weidman, Twale \& Stein, 2001) an examination of academic socialization literature could provide insights into the development of gender equity values.

Tierney and Bensimon (1996) define academic socialization as a "ritualized process that involves transmission of the organizational culture" (p.36). Academic socialization includes, observing, listening and interacting with faculty, interacting 


\section{GENDER REPRESENTATIONS IN ED.D. DISSERTATIONS}

with peers, formal and informal conversations with instructors, advisors and supervisors. It also includes observations of policies and practices of resource allocation, inclusion and exclusion, rewards and sanctions (Austin, 2002). Socialization is a process where a culture's behavioral norms, standards and values are internalized by newcomers (Weidman, Twale \& Stein, 2001).

Unfortunately, problematic, discriminatory, stereotypical, gendered cultural beliefs can be part of the academic norms future educational leaders are expected to assimilate and internalize. An example of discriminatory, gendered cultural beliefs is illuminated by Dr. Lawrence Summers, former President of Harvard University's controversial public comments in 2005, citing female's inherently inferior intellectual abilities and unwillingness to undertake the difficult work of scholarly activity as the reason for their underrepresentation in the sciences (Bombardieri, 2005). When discriminatory public comments such these are made by a university administrator and educational leader from a prominent postsecondary educational institution it gives cause to examine gendered academic socialization practices.

Academic socialization is often experienced less positively by females (Kerlin, 1997; Kerlin, 1995; Kurtz-Costes, Helmke, Ule-Steiner, 2006). The problematic gendered academic socialization experiences of females include, a.) pressure to change to conform to prevailing academic cultural norms (Anthony, 2002; Reynolds, 1992), b.) perception of their doctoral programs as unsafe 


\section{GENDER REPRESENTATIONS IN ED.D. DISSERTATIONS}

environments to take scholarly risks (Weidman, Twale \& Stein, 2001, c.) higher levels of unsatisfactory interactions with faculty than male students (Nettles \& Millett, 2006), d.) higher doctoral attrition rates than their male colleagues (Kerlin, 1997), and e.) gender discrimination as a key factor in their doctoral attrition (Lovitts, 2001).

Anderson \& Swazey (1998) state that examining the socialization climate is integral to understanding the development of values and ethics in doctoral programs. Anderson \& Swazey's (1998) study surveying over 2000 doctoral students regarding their academic socialization experience reveals problematic implications for the socialization of graduate students towards equity values. Inclusive, respectful, and caring behavior, a hallmark of valuing equity, is often not modeled by faculty. For example: a.) when asked if faculty behaviors make students feel included as members of the department, 34\% report very little or not at all, b.) when asked if graduate students are respected, 30\% report very little or not at all and c.) when asked if faculty and student care about each other, $26 \%$ report very little or not at all.

Additionally, Anderson \& Swazey (1998) report only 52\% of doctoral students feel their program positively reinforces their values, self-image or way of thinking about the world; $48 \%$ respond their doctoral programs do not reinforce their values, self-image and way of thinking. Unfortunately, the survey does not 


\section{GENDER REPRESENTATIONS IN ED.D. DISSERTATIONS}

specify what the student's values were before, or after their doctoral experience and the research report includes aggregated responses that do not delineate respondents by gender or ethnicity.

Although academic socialization and doctoral attrition literature offer evidence of problematic gendered socialization experiences and non-inclusive learning environments, the utility of socialization literature for understanding the development of gender equity values of educational leaders also suffers from lack of specificity to the discipline of education.

Academic socialization scholars state that research on the preparation of future educators, faculty and scholars must be specific to the discipline to be truly useful (Austin, 2002; Golde, 2005). Unfortunately, socialization and doctoral attrition studies examining gender issues often do not delineate the experiences of students by their academic discipline. Doctoral study is both nationally and locally focused; it is national, because of its inherent integration with its academic discipline, yet local because of the important role the departmental faculty play in the socialization of graduate students (Golde, 2005, Weidman \& Stein, 2003). This study purports to address the discipline specific literature gap discussed above by examining gender representations from a national sample of artifacts from the discipline of education.

Gender equity values: Educational leadership programs. 


\section{GENDER REPRESENTATIONS IN ED.D. DISSERTATIONS}

Although studies on the development or evaluation of gender equity dispositions in educational leadership doctoral programs are scarce, studies that examine the experiences and perceptions of educational leadership program graduates report that gender is rarely discussed in the content of university leadership preparation programs and graduates feel underprepared to develop inclusive, gender equitable institutional environments (Iselt, Brown \& Irby, 2001; Lugg, 2003; Nicholaides \& Gaynor, 1992; Skrla, Reyes \& Scheurich, 2000).

Skrla, Reyes, and Scheurich‘s (2000) participants report a lack of gender discussion in their university preparation programs and at educational leadership professional associations. They also perceive gender as an unwelcome topic of discussion with school boards, state educational agencies and legislatures. In like manner, gender discrimination as a potentially risky subject of conversation can be inferred from the initial interview anxiety verbalized by female participants in Skrla, et al's (2000) qualitative study; the female educational leaders express reluctance to discuss their experiences and perceptions of gender discrimination fearing negative professional and personal repercussions as a result of their interviews.

Both male and female participants in Iselt, Brown \& Irby's (2001) study stated their leadership preparation programs had very little focus on changing institutional culture and understanding gender and ethnicity equity issues. 


\section{GENDER REPRESENTATIONS IN ED.D. DISSERTATIONS}

Additionally, LGTBIQ student graduates report leadership preparation programs rarely provide content or discussion opportunities for the prevention of bullying based on perceived sexual or gender identity, nor do they address how to nurture an institutional culture that accepts diverse gender expression (Lugg, 2003). Though not specific solely to schools of education, Golde \& Dore's (2004) study of over 4000 doctoral students in eleven disciplines revealed that although $74.2 \%$ of students reported being interested in creating inclusive educational environments, only $28 \%$ of doctoral students felt their programs prepared them for this role.

\section{Perceptions of salience of gender equity values}

Nicholaides \& Gaynor's (1992) content analysis of syllabi from doctoral educational leadership programs not only reveals a neglect of gender issues in the preparation of educational leaders, but shows marked differences in gender equity focus by male and female faculty. For example, of 55 syllabi submitted by male faculty, only 4 included topics, readings, or planned discussion on gender issues in educational institutions, whereas, in contrast, all 11 syllabi submitted by female professors included topics, subtopics and readings on gender issues.

A gendered perspective on the prevalence and tone of discussions on gender and race issues also occurs in Rusch's (2004) educational leadership faculty study. Rusch examines data from 114 faculty representing educational leadership programs about gender and race discourse in their programs. Rusch (2004) finds 


\section{GENDER REPRESENTATIONS IN ED.D. DISSERTATIONS}

that while $28.8 \%$ of female faculty report that conversations about race and gender conversations occur frequently, $57.4 \%$ of male faculty report gender and race conversations as a frequent occurrence. The rank ordering of responses in Rusch's (2004) study also reveals a gendered gap in perceptions; the top two responses of females are that gender and race conversations are participated in by a select few and the tone is uncomfortable and stilted, whereas males most frequently respond that conversations are open, and the tone is thought provoking and problem solving.

In contrast to the Nicolaides \& Gaynor (1992) and Rusch (2004) studies noting gendered perceptions of salience regarding gender issues, Brown, Irby \& Iselt's (2001) survey of 124 educational leaders, half female, half male, report equivalent perceptions of low emphasis in their preparation programs to gender or ethnicity issues.

Additionally in spite of research findings of differences between female and male perceptions of the importance of gender issues we cannot assume that education departments populated with female faculty will inherently be more conscious of or committed to addressing or ameliorating gender inequities. Nettles and Millet's (2006) study of 9000 doctoral students found that female students in schools of engineering and schools of education similarly expressed the lowest university-wide level of satisfaction with faculty interactions in spite of the fact that 


\section{GENDER REPRESENTATIONS IN ED.D. DISSERTATIONS}

engineering faculty are predominately male whereas schools of education faculty are predominately female. The prevalence of female faculty in schools of education did not impact female student's perceptions of positive faculty interactions.

Rusch's (2004) study also paints a mixed and complicated picture of the perceived importance of gender equity issues in various programs. Some of the faculty responses are very affirming of their program's attempts to address gender and race issues; they discuss alignments with university wide diversity initiatives, comment on administration commitments to open discussion, or funding of diversity efforts. However, other faculty responses in Rusch's (2004) study paint a more problematic view of the salience of equity issues with statements such as: "some people take it too seriously" (p.28), or " there is an "obsession with political correctness and other hypocrisy" (p.31). Additionally, 13\% of faculty in Rusch's (2004) study state that gender and race conversations are not important.

Perhaps some of this conflicting picture drawn from the literature regarding gender equity behaviors and the salience of such topics can be explained by study limitations of using reported perceptions of discrimination. Much of the existing socialization and department climate literature addressing gender equity issues is based on studies of reported perceptions. Data based on participant statements involving perceptions, intentions or memories may be less reliable than other types of evidence (Kolbe \& Burnett, 1991; Krippendorf, 2004; Weber 2004). Freud's 


\section{GENDER REPRESENTATIONS IN ED.D. DISSERTATIONS}

(1967) discussion of ego defense mechanisms reminds us humans may repress or distort memories of behaviors that could cause them discomfort, anxiety or embarrassment.

Additionally, many educators do not recognize incidences of gender discrimination, even when they are instructed to observe specific incidences on training tapes (Lundberg, 1997). Even when discriminatory gender behavior is witnessed or compelling evidence is offered, there is often no recognition or consensus among educators that anything significant or damaging has occurred. Knowledge is constructed under unique individual principles, assumptions and reasoning, which mean two people can see the same thing, but derive very different meanings of the event.

An example of how this impacts the reporting of gender discrimination follows in this summary of two recent newspaper articles reporting on the same statistic of gendered difference in male and female leadership employment from the recently published American Association of School Administrators (2010) decennial study of the superintendency. The report states females now comprise $24 \%$ of school superintendents nationwide. However, two newspaper articles reporting on these findings reach very different gender equity conclusions about the same data. Key points made by the reporters about the percentage of female superintendents nationwide are summarized in Table 2.1. 


\section{GENDER REPRESENTATIONS IN ED.D. DISSERTATIONS}

The Saint Louis Today headlines on January 24, 2011 state: “ Gender gap is narrowing in ranks of school chiefs" (Holland, 2011), whereas the Quincy Herald Whig headlines on January 29, 2011 state: "Study shows gender becomes non-issue as gender gap narrows among school superintendents" (Poletti, 2011). Further examination of the key points made in the two newspaper articles ostensibly discussing statistics from the same report, in Figure 2.1 exemplifies how people can construct completely different meanings from the same gender incident.

Table 2.1 Newspaper articles reporting on gender composition of superintendents

\begin{tabular}{lll}
\hline Saint Louis Today, by Elizabeth Holland & Quincy Herald Whig, by Mary Poletti, \\
$1 / 24 / 11$ & $1 / 29 / 11$ & \\
Gender gap narrowing & Gender becomes non-issue & \\
&
\end{tabular}

Quotes Executive Director of American Association of School Administrators "There is huge disparity there" especially since there's so many more women in education than men

Article reports there is still a gender bias regarding women when it comes to the selection of school superintendent

Cites reports findings that females are $2 \mathrm{x}$ as likely as males to have over 20 years experience before being hired as superintendent

Cites report findings that females report gender discrimination in their school leadership careers $3 \mathrm{x}$ as often as males
Reports gender gap among superintendent at times feels non-existent

Article reports one female superintendent states she thought any emphasis on her gender was strange

Article reports many female school leaders state being a female has never factored into their leadership

Reports another female superintendent states she doesn't pay any attention to gender at statewide meetings or in her job as a whole

This example reinforces the idea that incidences of gender discrimination may be occurring more frequently than participants consciously perceive or report. 


\section{GENDER REPRESENTATIONS IN ED.D. DISSERTATIONS}

The available academic literature on gender equity issues relies on participant memories, perceptions and interpretations of gender equity incidences.

This over-reliance on studies based on participant reports of memories and observations of gender inequity in the literature informs the methodology choice for this dissertation research. Content analysis of gender representations in existing academic text examines a documented behavior of the authors. This study's content analysis of gender representations in the existing, publicly documented dissertation research and writing behaviors of educational leaders could provide a useful gender analysis addition to discipline's literature.

\section{Challenges to supporting gender equity values.}

Faculty gender equity advocates who do have the desire, research, strategies and skills to integrate equity topics into the curriculum may not have departmental support, political connections or the personal resiliency to make the necessary changes. Literature suggests equity advocacy work is often left to a few faculty members to shoulder the burden of change efforts for their programs (Bronstein \& Ramaley, 2002; Rusch, 2004). Often these faculty advocates are either female, minorities or new (Rusch, 2004).

It can be risky for female, minority or new faculty to advocate for curricular equity changes without a similar value commitment by departmental colleagues and administration. Gender equity activities are often not recognized positively or 


\section{GENDER REPRESENTATIONS IN ED.D. DISSERTATIONS}

rewarded in tenure decisions (Bronstein \& Ramaley, 2002; Rusch, 2004). New

faculty may also feel pressured to avoid politically sensitive topics because some student's resistance to change can result in negative teaching evaluations (Bronstein \& Ramaley, 2002; Rusch, 2004).

\section{Summary of Values Literature}

In summary, there is currently little published research on development or evaluation of educational leadership values in doctoral programs. It also difficult to ascertain the level of attention to gender equity values because discussions of gender equity issues are often aggregated with other social justice, diversity or miscellaneous topics.

Additionally, existing content analysis studies of course syllabi and published journal articles in the discipline of education suggest little attention is paid to gender equity or other social justice issues in leadership preparation programs. Graduates of educational leadership programs also report preparation programs provided inadequate preparation to understand or address gender equity issues. Faculty of preparation programs report mixed perceptions on the prevalence, importance or departmental commitment of addressing gender equity issues.

The literature also suggests faculty who are conscious of gender inequity and could act as advocates and change agents often fear negative career 


\section{GENDER REPRESENTATIONS IN ED.D. DISSERTATIONS}

repercussions from addressing politically sensitive topics in their classes, research and departmental discussions.

Additionally, much of the existing literature on academic socialization or gender equity climate in graduate school is not education discipline specific making it less useful for planning programs for educational leaders. The existing literature also primarily relies on data from memories, perceptions and interpretations of gender equity issues, which can be unreliable since many educators often do not recognize gender discrimination.

\section{Disciplinary Call for Development of Leadership Gender Equity Values \\ K-12 leadership values.}

In spite of a dearth of research on the development or evaluation of diversity values and commitments in educational leader preparation programs, the 1998 Interstate School Licensure Consortium (ISLLC) report, jointly sponsored by the Council of Chief State School Officers and the National Policy Board for Educational Administrators, expressly state the importance of values and dispositions in the skills needed for contemporary educational leaders (Murphy \& Shyman, 1998). The ISLLC report states that knowledge, dispositions and behaviors are inextricably intertwined and leadership dispositions are a primary determinant of leadership behaviors. The ISLLC position is reinforced by the report's recommendation that educational leadership preparation programs shift 


\section{GENDER REPRESENTATIONS IN ED.D. DISSERTATIONS}

their focus from concentration on technical business management skills to greater emphasis on leadership values (Murphy \& Shyman, 1998).

The values and beliefs of educational leaders are important not only to the advancement of disciplinary scholarship and educational policies, but also to the training, mentoring and supervision of fellow educators. Those who hire, train, supervise and evaluate teachers should also be expected to model appropriate diversity values and equity behaviors.

The National Council Accreditation of Teacher Education (NCATE) specifically recommends that professional education programs for teachers "understand the importance of discrimination based on race, class, gender, disability, exceptionality, sexual orientation and language on students and their learning" (National Council for the Accreditation of Teachers, 2010, p.8). NCATE also requires accredited preparation programs to evaluate the knowledge, and application of educators on these values and dispositions.

\section{Postsecondary leadership values.}

Although the ILLSC and NCATE offer useful guidelines for attending to the values component of leadership preparation in K-12 institutional settings, the discussion of values preparation for educational leaders for this study is necessarily broader and more encompassing than K-12 policy recommendations. Ed.D. graduates of doctoral programs are not limited to administrative and teacher-leader 
GENDER REPRESENTATIONS IN ED.D. DISSERTATIONS

positions in K-12 institutions. Ed.D. graduates also provide leadership and educational scholarship through their roles as faculty, administrators and student affairs personnel in postsecondary institutions, non-profit literacy agencies and public and private professional development and vocational educational institutions.

In like manner, professional organizations that serve postsecondary institutional leaders and training and professional development educators, such as the American Society for Higher Education (ASHE), American Society for Training and Development (ASTD) and American Educational Research Association (AERA) also recommend members attend to values, diversity and accountability in their programs.

The American Society of Higher Education (ASHE) consistently calls for greater attention to gender and racial equity issues in the training of higher education faculty, scholars and leaders in their Higher Education Reports. The 2001 ASHE Higher Education Report Easing the Perilous Passage: Socialization of Graduate and Professional Students in Higher Education (Weidman, Twale \& Stein, 2001) suggests the need for modification of doctoral program cultural norms to address the lack of support perceived by female and minority students (Weidman, Twale \& Stein, 2001). They also specifically recommend providing 


\section{GENDER REPRESENTATIONS IN ED.D. DISSERTATIONS}

workshops for graduate program faculty and administrators on sexual harassment, diversity and ethics.

The 2007 ASHE Diversity Report entitled Theoretical Framework: Psychosocial Oppression and Diversity critiques the persistence of subtle organizational barriers that hinder females and minorities in higher educational institutions (ASHE, 2007). Additionally, the ASHE's 2006 monograph entitled Revolutionary Concepts in Leadership reminds those who prepare educational leaders and serve in those roles, that leadership is value laden activity and ethical values are central to the task. The monograph also reiterates the necessity for renewed commitment to fair and socially just organizational activities (2006) and leadership initiated accountability systems to monitor progress and ensure compliance. These example monographs sponsored by the American Society for Higher Education (ASHE) encourage educational leaders to commit to gender equity and other diversity values and to examine their progress towards those commitments.

The American Educational Research Association (AERA), in 2006, reaffirmed its position on social justice with a specific mission statement that commits to a.) promote diversity and inclusiveness in AERA membership, b.) promote social justice principles and policies in the conduct of research and training, c.) promote activities that foster a diverse community of educational 


\section{GENDER REPRESENTATIONS IN ED.D. DISSERTATIONS}

researchers, and d.) disseminate and promote the use of research knowledge and stimulate interest in research in social justice issues in education (American Educational Research Association, 2011).

Additionally, in the past the AERA has awarded research awards to scholars on gender equity research, notably Sadker, Sadker \& Kline in 1992, for their chapter entitled: The issue of gender in elementary education and secondary education, and Sadker \& Sadker in 1995 for their book, Failing at Fairness: How America's Schools Cheat Girls. AERA also has a standing committee devoted to gender advocacy, Scholars and Advocates for Gender Equity (SAGE), and a special interest group (SIG) focusing on gender equity, Research on Women in Education (Sadker, Zittelman, Earley, McCormick, Strawn \& Preston, 2007).

The American Society for Training and Development (ASTD) is the world's largest organization that serves adult educators focusing on professional development and workplace learning and performance. ASTD lists as its Mission's first canon, "recognizing the rights and dignities of each individual" (ASTD, 2011). The ASTD (2011) website also reports it has recently increased its focus and attention on program evaluation for enhanced accountability.

The common themes occurring in recommendations from the spectrum of professional organizations serving educational leaders and scholars is the centrality of values, attention to gender equity and diversity issues and the importance of 


\section{GENDER REPRESENTATIONS IN ED.D. DISSERTATIONS}

strategies for accountability. Although the NCATE standards on diversity

dispositions are specific to the education of $\mathrm{K}-12$ teachers, it is reasonable to expect that educational leaders responsible for the hiring and supervising of teachers, teacher training program faculty, scholars researching educational issues, postsecondary student affairs personnel, educational policy makers and professional development educators in the discipline of education should also understand and exemplify similar diversity values.

Even though the institutional scope of leadership, scholarship, supervision and mentoring undertaken by graduates of Ed.D. programs is broader than the K-12 scope envisioned by NCATE for teacher training programs, the evaluation strategy utilized by NCATE assessors to assess a teacher's values also has potential to assess the values of educational leaders.

NCATE assessors examine student's work samples and academic artifacts for evidence of appropriate socialization of future educators towards the diversity values represented in NCATE standards. It is considered a key component of NCATE educational training program evaluation to determine: What do educators know about diversity issues and how is that knowledge applied and represented in their work samples (NCATE, 2008)?

Although NCATE's examination of diversity values through student work samples is a worthwhile strategy to consider, NCATE's aggregation of knowledge 


\section{GENDER REPRESENTATIONS IN ED.D. DISSERTATIONS}

about gender equity under the broader theme of diversity is inadequate to the analysis of gender equity dispositions. I propose a more appropriate gender equity evaluation for educational leaders could be undertaken by reframing NCATE"s teaching work sample question to: What do educational leaders know about gender equity issues and how is that knowledge applied and represented in their work samples? The following section will discuss the potential and utility of Ed. D. dissertations as key academic socialization artifact and work sample that can be used to assess the gender representations of educational leaders.

\section{Ed. D. Dissertations as a Repository of Educational Leadership Values}

Doctoral dissertations represent "the intellectual culmination of the graduate school experience" (Boyer, 1990, p.74). Mauch and Birch (1998) reiterate the important integrative nature of dissertation scholarship and state that dissertations, "should build on a synthesis of all earlier courses, readings and professional experience that the candidate brings to the task" (p.45). The integrative and culminating nature of the dissertation gives this academic artifact unique descriptive potential to examine gender representations of future educational leaders.

Ed. D. dissertations are also an essential component of academic literature and as such, make a significant contribution to foundational knowledge in the discipline of education. Scholars initiating an academic research project would 


\section{GENDER REPRESENTATIONS IN ED.D. DISSERTATIONS}

consider dissertation scholarship an integral source of relevant material for a literature review (Mauch \& Birch, 1998). In fact, doctoral faculty advisors often inform candidates that making a significant contribution to the discipline's knowledge base is an essential requirement of a successful dissertation proposal (Madsen, 1992; Mauch \& Birch, 1998; Sternberg, 1981).

Additionally, dissertation research plays a highly prominent role in the academic literature in the field of educational leadership. Murphy and Vriesenga (2006) state that less than $3 \%$ of 2000 articles published between 1975 and 2002 in four of the leading educational leadership journals were empirically based and dissertations have been the primary source of empirical research about the field for decades. Dissertations also provide the bulk of research about gender equity in educational leadership programs (Shakeshaft, Brown, Irby, Grogan \& Ballenger, 2007). Additionally, Immegart (1990) states that many educational leaders do not conduct or publish research after they finish their graduate programs, which makes dissertation research a key resource in the academic literature.

In spite of the significance of dissertation scholarship as both an individual, integrative academic work product and a foundational component of academic literature in the discipline of education, there has been little research on the content of dissertation scholarship produced and used as a resource by educational leaders. Content analysis can provide a useful analytical tool to uncover the gender 


\section{GENDER REPRESENTATIONS IN ED.D. DISSERTATIONS}

representations of future educational leaders in this key culminating academic artifact.

\section{Content Analysis as Method to Assess Cultural Values}

Leavy (2007) defines content analysis as "the systematic study of texts and other cultural products or nonliving data forms" (p.227). Content analysis is an overall research approach, encompassing both method and analytic strategy to systematically examine and document patterns in existing communication artifacts (Marshall \& Rossman, 1995, Weber, 2004).

The research methodology of content analysis developed from the idea that valuable cultural information can be obtained through an examination of cultural communication artifacts (Krippendorf, 2004; Leavy, 2007). Early pioneering research in the United States supporting the use of content analysis as a method to assess cultural values, beliefs and attitudes in communications was done by Dr. Harold Laswell, Chief of Experimental Division for the Study of Wartime Communication in the U.S. Library of Congress during World War II. Dr. Laswell was a political sociologist and communication theorist with expertise in the identification of wartime propaganda during both World War I and World War II (Neuendorff, 2004).

According to Laswell, through content analysis, not only can we infer messages about the values and motives of the message sender, but communication 


\section{GENDER REPRESENTATIONS IN ED.D. DISSERTATIONS}

contents also reflect the social organization and value system of their originating group (Janowitz, 1968). Additionally, communication contents are not merely a descriptive element of the group, they also act as a purposeful agent in maintaining or modifying group values (Janowitz, 1968).

Lasswell (1949) states content analysis has great utility as a social science research method to assess the values and attitudes of message senders. Content analysis provides a valuable analytical tool for readers to systematically reveal problematic beliefs and biases in messages to critically evaluate the information's credibility. Laswell (1949) reiterates that "whatever improves our understanding of attitude" provides a potentially useful tool for humanity (p.9).

Laswell's insight regarding the utility of content analysis to assess the political nature of communication is especially salient for feminist content analysis projects. Although feminist research is often critiqued because of its overt political commitment to end gender inequity, feminist researchers remind us all research is inherently imbedded with political values. Harding (1986) describes research as a social activity and states "products of thought bear the mark of their collective and individual creators (p.15).” It follows that Ed.D. dissertations also bear the influence of their collective and individual creators, including values of the discipline, and leadership program as well as those represented by the individual researcher. 


\section{GENDER REPRESENTATIONS IN ED.D. DISSERTATIONS}

According to Krippendorf (2004), the utility of content analysis as an effective tool to assess cultural beliefs is predicated on five indices with a long history of use in communications research: a.) the presence or absence of a reference or a concept indicates awareness or consciousness, b.) the frequency with which an idea, topic or concept occurs in a stream of messages is taken to mean the importance or emphasis on that idea, topic or concept, c.) the numbers of favorable and unfavorable characteristics attributed to an idea, topic or concept are indicators of the attitudes held by the writer, the readers and their common culture. d.) the kinds of qualifications, adjectives or qualifiers used in statements about an idea, topic or concept are indicators of intensity, strength or ambiguity associated with the beliefs, motivations and commitments signified by the idea, topic or concept e.) The frequency of co-occurrence of two concepts indicates strength of association between those two concepts in the minds of the members of a culture, authors and readers.

To summarize, content analysis has been historically used as a research method to examine and describe the consciousness and importance accorded to an issue, attitudes of the author and the common culture in regards to the issue, strength or ambiguity of author's and common cultural beliefs, motivations and commitments, and the unification of concepts. This makes it makes it an 


\section{GENDER REPRESENTATIONS IN ED.D. DISSERTATIONS}

appropriate methodology to assess the gender equity values of educational leaders and their discipline through dissertation texts.

\section{Feminist content analysis.}

Feminist content analysis infuses the method of content analysis with a feminist analytical lens. A feminist analytical lens examines and illuminates gendered policies and practices that can impact individual and collective advancement and development (Bensimon \& Marshall,1997; Marshall \& GerstlPepin, 2005). Feminist content analysis provides a useful tool to assess cultural artifacts for evidence of feminist ideology and conversely, cultural gender beliefs or stereotypes (Leavy, 2007).

Cultural gender beliefs represented in communication artifacts are not solely individual expressions, but are also imbedded in the institutional policies and disciplinary practice norms that inform, produce and disseminate the artifacts (Reinharz, 1992). Stein (2004) reminds us that although policy is often thought of as a formal legislative or administrative action, it is more than that; policy consists of both formal and informal "systems of thought and action used to regulate and organize behavior" (p.5). Disciplinary academic norms and institutional policies regulate and organize dissertation research behaviors. Although dissertations represent the scholarly work of a single individual, they also represent the institutional and disciplinary environment from which they originate, rendering a 


\section{GENDER REPRESENTATIONS IN ED.D. DISSERTATIONS}

potentially rich repository of individual, institutional and disciplinary cultural gender equity values, beliefs and commitments.

Feminist content analysis of Ed.D. dissertations can provide a systematic process to illuminate individual gendered cultural beliefs and gendered institutional policies, practices and disciplinary norms. Additionally, using content analysis to examine the textual cultural artifacts created and disseminated by future educational leaders is an appropriate methodology for a feminist research project. There is often a tension between doctoral socialization's primary purpose of imparting academic traditions and feminist ideals of questioning, revealing and resisting traditions that reproduce inequalities. Giroux (1983) states that although institutions of higher education are considered to be a center of a society's cultural knowledge and scholars are positioned as a culture's legitimate storytellers, scholars can also be a perpetuator of myths masquerading as truth (Giroux, 1983). The Ed.D. dissertation is a traditional academic cultural artifact and textual repository of gender stories told by educational leaders.

\section{Strengths of content analysis for this study.}

Kolbe and Burnett (1991) discuss three unique strengths of content analysis as a methodology in its ability to: a.) present an unobtrusive historical appraisal of textual communication and avoids potential researcher influence on participant responses, b.) assess cultural variables on textual content, and c.) provide an 


\section{GENDER REPRESENTATIONS IN ED.D. DISSERTATIONS}

empirical starting point for generating new research about the nature and potential effect of specific communications.

The first strength offered by Kolbe and Burnett (1991) underscores the benefits of unobtrusive historical appraisal of existing documents as potentially a more accurate portrayal of behaviors and events than participant statements that involve perceptions, intentions or memories (Kolbe \& Burnett, 1991, Krippendorf, 2004, Weber, 2004). Freud's (1967) discussion of ego defense mechanisms discusses the human propensity of humans to repress or distort memories of behaviors that could cause them discomfort, anxiety or embarrassment. Asking educational leaders to self report their beliefs, perceptions or behaviors regarding gender equity through interviews or surveys may be an unreliable data source. However, an examination of pre-existing Ed.D. dissertation documents could reveal imbedded gender values.

The second strength of content analysis is its utility in assessing cultural values. Since the primary focus of this proposed study is uncovering the cultural gender values and beliefs of future educational leaders content analysis offers a uniquely appropriate method for this study.

Lastly, Kolbe and Burnett (1991) reiterate the suitability of content analysis for supporting theory development when they state, "The need for systematic study and information acquisition, part of the initial steps in theory development, can be 


\section{GENDER REPRESENTATIONS IN ED.D. DISSERTATIONS}

readily provided by content analysis research". Kolbe \& Burnett's (1991) point about the strength of content analysis as an empirical starting point to develop theory and generate new research is especially salient for this proposed study because of the paucity of research on gender representations in the content of Ed. D. dissertation scholarship.

\section{Feminist content analysis of education journals.}

Historically, content analysis studies examining gender focused studies in the published academic literature have primarily focused on females. Consequently, noticeably absent in this literature review of published content analysis studies is a discussion of gender focused research representing males or LGTBIQ populations; there is currently a dearth of publication of educational journal content analysis studies that examine gender equity issues in these populations. A more complete picture of the values of educational leaders and scholars regarding gender issues would include an examination of research representations that focus on male subjects or LGTBIQ issues.

The published literature on feminist content analysis of educational journals consists primarily of female gender focused articles. A review of published content analysis studies in academic journals reveals an under-representation of scholarship focusing on gender and rarely features articles that offer a feminist perspective (Bensimon \& Marshall, 1997; Hart, 2006; Hayes \& Smith, 1994; Parson \& Ward, 


\section{GENDER REPRESENTATIONS IN ED.D. DISSERTATIONS}

2001; Townsend, 1993; Twombly,1993; Wolgemuth, Kees \& Safarik, 2003).

Additionally, the published female gender-focused research frequently perpetuates gendered stereotypes, (Hayes \& Smith, 1994 1993;Wolgemuth, Kees \& Safarik, 2003) and often conceptualizes women as a homogenous group (Twombly, 1993).

Discussion of content analysis studies done in education journals is discussed below and a summary of the study dates, journals sampled and salient findings is provided in Figure 1.

Townsend's study (1993) of published research in three mainstream higher education journals, The Journal of Higher Education, The Review of Higher Education and Research in Higher Education from the late 60's to the late 80's, 1969-1989 revealed of the 772 articles in the journals in this time period, only 30 , or approximately $4 \%$, focused on females.

Parson and Ward's (2001) more recent study focused on articles published from 1980-1996 in eight journals, The Journal of Higher Education, The Review of Higher Education and Research in Higher Education, Educational Evaluation and Policy Analysis, Educational Policy, Policy Sciences, Policy Studies Journal, and Policy Studies Review. Parson and Ward's (2001) content analysis examined 4,183 articles and only 58 articles, or approximately $1 \%$, took the standpoint of starting research from a woman's perspective, or made gender central to the research problem. 


\section{GENDER REPRESENTATIONS IN ED.D. DISSERTATIONS}

Hart's study (2006) focused on articles published from 1990-2002 in The Journal of Higher Education, The Review of Higher Education and Research in Higher Education. Of the 1065 articles, Hart (2006) identified 186 articles, or $17.5 \%$ that stated they were explicitly about women's issues. However, upon closer inspection, only 7 of 1065 , or less than $1 \%$ of the published higher education articles explicitly mentioned a feminist perspective in the article's title or abstract. The data findings from the later content analysis studies, Hart (2006) and Parson and Ward, 2001) showed little improvement in the number of female gender focused studies from Townsend's (1993) study of earlier decades.

Along with being under-represented, females continue to remain poorly represented in a large portion of the articles that are female focused. Feminist analysis of published scholarship that does represent females or claim to offer a feminist perspective often reveals problematic gendered cultural stereotypes. For example, Hayes and Smith's (1994) study examined articles from Adult Education Quarterly, Adult Leadership and Lifelong Learning, Adult Education, and Studies on the Education of Adults published during 1966 -1990. Hayes and Smith's (1994) analysis found that a dominant gender theme, represented by 50 out of 112 articles in the sample portray female adult learners as deficient to male norms, or represent females' psychosocial adaptive issues regarding change, learning and multiple roles. Commitment to gender equity advocacy and feminist research ethics remind 


\section{GENDER REPRESENTATIONS IN ED.D. DISSERTATIONS}

us that feminist research is more than merely research about females, research framing should be mindful not to support negative gendered stereotypes that subordinate an individual on the basis of their gender.

The theme of women as deficient, needy, insecure, fearful, or stressed, was also prominent in Wolgemuth, Kees and Safarik's (2003) more contemporary study of The Community College Journal of Research and Practice done a decade later. Wolgemuth et al, collected articles from 1990-2000 and only 15 of 491, or around $3 \%$ of the articles were female gender focused and additional 11 of the sample of 491, or around $2 \%$ included females as one variable in a larger multivariate analysis.

Twombly (1993) used feminist content analysis to examine how females in community colleges were conceptualized in the academic literature from 19701989. Using descriptors indicating topics or subjects focused on females and community colleges through Educational Research Information Clearinghouse (ERIC), 174 published articles were reviewed. Her study found women are most often conceptualized as a homogenous group and gender studies about females rarely consider multiple intersections of identity, such as race, ethnicity, class or sexual orientation.

Additionally, Twombly's (1993) study indicates a waning interest in feminist topics in community college literature; Feminist thinking was more 


\section{GENDER REPRESENTATIONS IN ED.D. DISSERTATIONS}

prevalent in the 70 's than in the 80 's. Not only were there less articles published about females after 1984 , in the 80 's only $11 \%$ of any of the female gender focused articles utilized a feminist perspective.

In spite of the increase of women studies on college campuses and evolving curriculum that is more inclusive of women, the current gendered state of knowledge as represented by published scholarship in the discipline of education remains problematic for supporting gender equity. Even more disturbing is that the findings from feminist content analysis studies done in the late 80's and 90's show little improvement since the 70's and 80's in either the number of gender focused studies or problematic stereotypical representations from earlier studies.

A summary of the journals examined and their salient findings is provided in Table 2.2

Table 2.2 Published Feminist Content Analysis:Education Literature

\begin{tabular}{|c|c|c|c|}
\hline $\begin{array}{l}\text { Content } \\
\text { Analysis }\end{array}$ & Journal articles & Years & Findings \\
\hline Hart (2006) & $\begin{array}{l}\text { Journal of Higher Education } \\
\text { The Review of Higher } \\
\text { Education } \\
\text { Research in Higher Education }\end{array}$ & $\begin{array}{l}1990- \\
2002\end{array}$ & $\begin{array}{l}\text { Although } 17.5 \% \text { state } \\
\text { women focus, less } \\
\text { than } 1 \% \text { specific } \\
\text { feminist focus. }\end{array}$ \\
\hline $\begin{array}{l}\text { Parson \& Ward } \\
\text { (2001) }\end{array}$ & $\begin{array}{l}\text { Journal of Higher Education } \\
\text { The Review in Higher } \\
\text { Education } \\
\text { Research in Higher Education } \\
\text { Educational Evaluation /Policy } \\
\text { Analysis } \\
\text { Educational Policy } \\
\text { Policy Sciences } \\
\text { Policy Studies journal } \\
\text { Policy Studies Review }\end{array}$ & $\begin{array}{l}1980- \\
1996\end{array}$ & $\begin{array}{l}\text { Only } 1 \% \text { made } \\
\text { gender central to } \\
\text { problem or used a } \\
\text { feminist perspective. }\end{array}$ \\
\hline
\end{tabular}




\section{GENDER REPRESENTATIONS IN ED.D. DISSERTATIONS}

\begin{tabular}{|c|c|c|c|}
\hline $\begin{array}{l}\text { Wolgemuth, Kees } \\
\text { \& Safarik (2003) }\end{array}$ & $\begin{array}{l}\text { Community College Journal of } \\
\text { Research \& Practice }\end{array}$ & $\begin{array}{l}1990- \\
1999\end{array}$ & $\begin{array}{l}3 \% \text { of articles women } \\
\text { focused, additional } \\
2 \% \text { use women as } \\
\text { other variable. } \\
\text { Dominant theme of } \\
\text { women as deficient. }\end{array}$ \\
\hline $\begin{array}{l}\text { Hayes \& Smith } \\
\text { (1994) }\end{array}$ & $\begin{array}{l}\text { Adult Education/Adult Ed } \\
\text { Quarterly } \\
\text { Adult Leadership/Lifelong } \\
\text { Learning } \\
\text { Adult Education } \\
\text { Studies in the Education of } \\
\text { Adults }\end{array}$ & $\begin{array}{l}1966- \\
1990\end{array}$ & $\begin{array}{l}50 / 112 \text { articles } \\
\text { portray women } \\
\text { learners as deficient } \\
\text { or with psychosocial } \\
\text { adaptation issues. }\end{array}$ \\
\hline Townsend (1993) & $\begin{array}{l}\text { The Journal of Higher } \\
\text { Education } \\
\text { The Review of Higher } \\
\text { Education } \\
\text { Research in Higher Education }\end{array}$ & $\begin{array}{l}1969- \\
1989\end{array}$ & $\begin{array}{l}\text { Only } 4 \% \text { focus on } \\
\text { women. }\end{array}$ \\
\hline Twombly (1993) & $\begin{array}{l}\text { ERIC citation retrieval } \\
\text { Social Sciences Index }\end{array}$ & $\begin{array}{l}1971- \\
1989\end{array}$ & $\begin{array}{l}\text { More articles \& } \\
\text { feminist focus in } 70 \text { 's } \\
\text { than } 80 \text { s. No } \\
\text { intersections of race, } \\
\text { class, ethnicity, or } \\
\text { sexual orientation. }\end{array}$ \\
\hline
\end{tabular}

\section{Importance of feminist content analysis of academic literature.}

Feminist content analysis of academic literature, such as educational journals and dissertation scholarship is vital for two reasons, a.) the role of academic literature in educational leadership training and socialization and, b.) the role of academic literature in future educational policy agenda setting. The presence or absence of gender focused inquiry in the academic literature has both a descriptive and prescriptive element, it describes the current cultural norms of the 


\section{GENDER REPRESENTATIONS IN ED.D. DISSERTATIONS}

discipline of education and informs and prescribes the future agenda for educational program and policy plans.

Academic literature is a key text in graduate study curriculum (Grise-

Owens, 2000). Because of the importance of academic literature in shaping a discipline's body of knowledge and the socialization of educational leaders to the profession, the absence or inadequacy of gender focused research in the literature limits opportunities for educational leaders to develop the dispositions to recognize and address gender inequity in their future roles.

The lack of attention to gender issues during graduate study also potentially has a negative impact on future research and publication. Parson and Ward (2001) state graduate socialization is one of the primary factors supporting the exclusion of feminist philosophical and methodological perspectives into the practice of researchers and educational leaders.

Additionally, academic literature plays a key role in agenda setting for future educational policies because it defines important issues and frames disciplinary discussions (Spender, 1981). The educational policy agenda parallels disciplinary topics and issues under serious discussion as presented in academic literature or at professional conferences (Fowler, 2004; Spender 1981).

The presence or absence of gender focused scholarship and the gender values represented in the text of academic literature, whether it is Ed.D. dissertation 
GENDER REPRESENTATIONS IN ED.D. DISSERTATIONS

scholarship or published journal articles, makes an implicit statement about the current cultural relevance of ideas, theories and questions regarding gender issues in the discipline's knowledge base. Content analysis of academic literature can provide enhanced understanding of the consciousness, cultural gender beliefs and gender conceptualization of future educational leaders. 


\section{GENDER REPRESENTATIONS IN ED.D. DISSERTATIONS}

\section{Chapter 3. Methodology}

To better understand educational leader's values, beliefs and commitments

to gender equity, this study examines the gender consciousness, cultural beliefs and gender conceptualization of educational leaders as represented by a key textual disciplinary artifact, the Educational Doctorate (Ed.D.) dissertation. The two guiding questions of this inquiry are: 1.) How prevalent is gender focused inquiry in Ed.D. dissertation scholarship from 1998-2007; and 2.) What are the cultural gender beliefs and gender conceptualizations represented in Ed.D. dissertation scholarship from leaders graduating in 1998-2007?

\section{Mixed Method Design Overview}

Mixed method research is defined by Johnson and Onwuegbuzie (2004) as "the class of research where the researcher mixes or combines quantitative and qualitative research techniques, methods, approaches, concepts or language into a single study"(p.17). I used a sequential mixed method approach in this study, incorporating three stages of sampling, data collection, reduction and analysis. Findings from each phase, inform the sampling decisions for each successive phase.

I used a quantitative method and descriptive approach in Phase I to identify and count titles of gender focused Ed. D. dissertation studies to address the first 
GENDER REPRESENTATIONS IN ED.D. DISSERTATIONS

research question: How prevalent is gender focused inquiry in Ed.D. dissertation scholarship completed between 1998-2007?

I used a qualitative interpretive method in Phase I and Phase II to address the second research question: What are the cultural gender beliefs and gender conceptualizations represented in Ed.D. dissertation scholarship from leaders graduating in the last decade, 1998-2007? In Phase II, I examine a purposeful theoretical sample of 186 dissertation abstracts and in Phase III, I examine a smaller theoretical sample of 9 complete dissertations to develop a fuller understanding of the phenomenon.

\section{Standards of Evidence and Methodological Pluralism}

The American Educational Research Association (AERA) is committed to methodological pluralism and they specifically state that assessment of educational research quality should use criteria appropriate to the type of research methodology (Freeman, deMarais, et al, 2007). Since this study includes a quantitative descriptive phase and qualitative interpretive phases, I utilize research quality assurance strategies that adhere to the disciplinary evidentiary standards appropriate for each method.

The quantitative, descriptive Phase I of this content analysis primarily uses stability, reproducibility and accuracy as the key quality standards, whereas the qualitative, interpretive phases II and III use public justifiability as the key quality 


\section{GENDER REPRESENTATIONS IN ED.D. DISSERTATIONS}

standard. Public justifiability requires that enough of the context, coding and data reduction is provided in the description of findings for readers to make their own decisions on the legitimacy of the narrative (Ahuvia, 2000, Anfara, Brown \& Mangione, 2002). Both of these strategies are described in more detail later in this chapter.

Additionally, Wilson (as cited by Freeman, deMarais, et al, 2007) offers 5 essential criteria to assess the credibility and strength of qualitative research evidence which inform this study. Wilson states, the evidence should be a.) congruent with the chosen research epistemology, b.) observable, c.) collected and analyzed systematically, d.) made public and e), compelling. Wilson's criteria provide the framework for the documentation and research reporting rationale used in this study.

\section{Analytical transparency through appendices.}

I include several appendices with this study to support analytical transparency as Wilson suggests in his framework for assessing research quality (as cited by Freeman, deMarais, et al, 2007). In addition to Wilson's suggestions, Freeman, deMarrais, Pressle, Roulston and St.Pierre, (2007) recommend researchers provide adequate information so readers can assess the researcher's assertions and interpretations. They state, not only should research reports include descriptions and inclusion of data to support the claims, but ideally, data and 


\section{GENDER REPRESENTATIONS IN ED.D. DISSERTATIONS}

analytical decisions can be made available for review. Several data appendices and coding memos are included with this study.

This level of transparency is appropriate for this study because feminist interpretive studies are often contested. However, the contested nature of data evaluation is not limited solely to feminist analysis or interpretive studies; it is also an inherent feature of any textual content analysis. Texts do not have just one single meaning and the meaning of any text is not necessarily shared (Ahuvia, 2000, Freeman, deMarrais, et al., 2007; Krippendorf, 2004).

However, the inclusion of coding appendices is not intended to ensure all readers reach the same conclusions, but simply to provide enough information for readers to assess if the researcher's interpretations are justified by the data. Public justifiability does not strive for public agreement or consensus. In fact the inherent nature of interpretive research rejects the assumption that all readers will reach the same conclusion on the evidence presented (Ahuvia, 2000).

The inclusion of appropriate appendices aligns with Wilson's criteria for assessing research quality by providing evidence to support that the data analysis is systematic, public and compelling.

\section{Transparency of Ed.D. dissertations as public documents.}

The use of public documents as data additionally inherently supports transparency and disclosure to the reader and supports "public justifiability" 


\section{GENDER REPRESENTATIONS IN ED.D. DISSERTATIONS}

(Ahuvia, 2000). Using public documents as a data source provides a higher evidentiary standard than interview transcripts or observer field notes because those type of qualitative data documents are generally not available to readers. Altheide, et al (2008) report that "documents are more stable, more reflective of social organization, activities, meanings and social rules than most other forms of data used by social scientists" (p132).

Additionally, document analysis of dissertations differs from transcripted interviews in the necessity for member checks to ensure clarity. Dissertations, unlike interview notes, are more than written memos of extemporaneous statements. Dissertations are the result of careful deliberations and intentional attempts to ensure that the written text accurately communicates the writer's message. The completed text of a dissertation represents the writer's reflection process as well as the peer review process by the dissertation committee. The nature of the dissertation norms of the writing and defense process provide an inherent member check.

\section{Phase I: Quantitative Sample- Ed.D. Dissertation Titles}

The quantitative Phase I of this study focuses on determining the prevalence of gender focused inquiry in Ed.D scholarship. Since there is currently not an existing database that lists all the Ed.D. dissertations from public doctoral granting institutions, I examine and combine results from two databases, Carnegie 


\section{GENDER REPRESENTATIONS IN ED.D. DISSERTATIONS}

Classification System for postsecondary educational institutions and UMI Proquest Dissertations and Thesis database to determine the U.S. public doctoral granting universities with Ed.D. dissertations completed during 1998-2007.

For the first step, I identified all the U.S. public doctoral granting universities through the Carnegie classification system database. Carnegie has been collecting educational institutional characteristics for over 30 years and is considered a reliable source of postsecondary institutional data (Douglass, 2005). Using the search filter for public doctoral granting universities eliminated private doctoral granting institutions to provide a more manageable sample. An alphabetical list of the complete listing of 173 public doctoral granting universities is included as Appendix E.

After identifying the 173 public doctoral granting institutions through Carnegie's database, I examined each of these institutions through the UMI ProQuest Dissertations and Thesis database using the search criteria of Ed.D. for degree type, and the specific dates of 1998-2007 to identify the sample of public doctoral institutions with Ed.D dissertations completed between 1998 through 2007. Public doctoral granting universities that offered only Ph.d degrees were eliminated from the sample, leaving 112 institutions with Ed.D.dissertations from 1998-2007. 


\section{GENDER REPRESENTATIONS IN ED.D. DISSERTATIONS}

The Carnegie Classification System lists and categorizes the U.S. public doctoral granting institutions by three levels of intensity of research focus, a.) (DRU) Doctoral Research University, b.) (RUH) Research University High, and c.) (RUVH) Research University, Very High. Carnegie classifies and lists the institutions in this way to aide researchers in comparing similar institutions. Since the data was reported this way, I found it convenient to initially sort and systematically examine dissertations from the institutions in this manner.

I examined Ed.D. dissertations from 26 Carnegie classified DRU institutions, 45 Carnegie classified RUH institutions, and 41 Carnegie classified RUVH institutions for a total of 112 public doctoral granting institutions examined. An alphabetical list of the each of the Carnegie categories of public doctoral granting universities offering an Ed.D. between 1998-2007 is included as Appendices F, G, and $\mathrm{H}$ respectively. I examined each of these 112 institutions to identify a sample of 15,014 dissertation titles to review for Phase I of this study.

Because of the paucity of research on Ed.D. dissertation scholarship, I decided to include the entire census of 112 institutions and 15,014 titles in the sample. This sampling decision provides the most thorough investigation of an under-researched phenomena and eliminates generalizability issues from sampling error in the quantitative phase of the study. Using the entire census eliminates 
GENDER REPRESENTATIONS IN ED.D. DISSERTATIONS

concern regarding whether the sample is representative of the population because the sample $i$ s the population.

\section{Phase I Data Analysis-Dissertation Titles}

I used two trained coders to examine the 15,014 dissertation titles to identify and quantify the prevalence of gender focused scholarship. Krippendorf (2004) recommends for content analysis coders to be trained and tested enhancing intercoder and intracoder reliability (Krippendorf, 2004). The coder training instructions are included as Appendix $\mathrm{C}$ and tests for intercoder and intracoder reliability will be discussed further below under the discussion of research quality standards.

\section{Phase I Quantitative Content Analysis Research Quality Standards}

Krippendorf (2005) states there are three types of reliability as standards to assess rigor and defensibility in quantitative content analysis studies: a.) stability, b.) reproducibility and c.) accuracy. The following section describes the strategies I used to address these three reliability standards in Phase I of this study.

\section{Standard of stability.}

The first reliability standard, stability is described by Krippendorf (2005) as "the degree to which a process is unchanging over time" (p.215). I attended to the stability standard by performing a test-retest on a random sample of titles coded by each coder after several weeks elapsed. The test -retest on coder \#1 included 500 
GENDER REPRESENTATIONS IN ED.D. DISSERTATIONS

titles and was accurate to $99.4 \%$. The test-retest on coder \#2 included 500 titles and was accurate to $100 \%$.

\section{Quantitative content analysis reliability standard: Reproducibility.}

The second reliability standard, reproducibility is also known as intercoder reliability and considered a key standard of rigor for quantitative content analysis (Krippendorf, 2005; Weber, 2004). Intercoder reliability is the degree to which a process can be repeated by different coders working independently to achieve the same results (Krippendorf, 2005).

I utilized the complete sample of dissertations which was be coded by both coders and examined for intercoder reliability. Intercoder reliability was calculated as the simple percentage of agreement between two coders by counting the number of mutual agreements divided by the total number of titles examined. The coders agreed 14,812 times of 15014 for $98.7 \%$ intercoder reliability. Although the literature varies on acceptable percentages for intercoder reliability, most content analysis researchers agree that percentages over $80 \%$ indicate high reliability (Krippendorf, 2004).

Strategies for enhancing intercoder reliability in this study included, a.) provision of a predetermined coding dictionary, included as Appendix B, b.) coder training with written instructions to ensure consistency in decision making, 


\section{GENDER REPRESENTATIONS IN ED.D. DISSERTATIONS}

included as Appendix B. and c.) coder practice on similar sample coding sheets of private institutions.

Coding for Phase I of the study was done by two coders working individually to identify gender focused titles. Identification was based solely from text in the titles and the list of gendered words or expressions provided by the coding dictionary, illustrated in Table 3.2

Additionally, a provision was provided in the coder training for the handling of potentially gendered words not indicated on the coding dictionary; a potentially gendered term not in the coding dictionary was marked to be either confirmed against the second coder's written coding sheet observations, or disconfirmed as a coder disagreement. All incidences of agreement or disagreement were reported and calculated for intercoder reliability.

\section{Standard of accuracy.}

The final reliability standard, accuracy, primarily requires skills of organization of data records and careful attention to detail. Neuendorff (2004) reports the coding task for categorizing and counting manifest content is primarily one of thorough and accurate clerical recording.

Each of the 112 doctoral granting institutions in the sample was assigned a file that included, a.) institutional computer printout from UMI Proquest listing all 


\section{GENDER REPRESENTATIONS IN ED.D. DISSERTATIONS}

dissertation titles for the time period 1998-2007, b.) coding sheets from both coders identifying gender focused titles, and c.) notes identifying any coder disagreements.

The institutional files were also color coded and categorized by Carnegie classification of research intensity for ease in comparing institutional variances.

All the coding counts were double checked and verified for accuracy.

Table 3.2 Coding Dictionary

Terms indicating gender focus

Female girl, woman, mother, sister, aunt, grandmother, wife, feminine, femininity, feminist, headmistress, maternal, matriarchy, sorority, her, she

anatomical/biological terms or specific medical conditions

such as: vagina, breast, ovary, uterus, pregnancy, menstrual, , breastfeeding, ovary, ovarian cancer, menopause

Ethnic gendered references such as: Chicana, Latina

Female names such as: Superintendent Susan Castillo, Senator Patty Murray, bell hooks

Male boy, man, father, brother, uncle, grandfather, husband, masculine, masculinity, headmaster, paternal, patriarchy, fraternity, his, he

anatomical/biological terms or specific medical conditions such as: penis, testicle, testicular cancer, prostrate cancer, erectile dysfunction

Ethnic gendered references such as: Chicano, Latino

Male names such as: U.S. Secretary of Education Arne Duncan, President Barack Obama, John Dewey

LGTBIQ lesbian, gay, transvestite, transsexual, transgendered, bisexual, inter-sexed, queer, homosexual, homophobia, butch, dyke

Other gender, gender equity, discrimination, gender discrimination, gender neutrality, gender blindness, gender gap, gendered sex, sexual harassment, sexual abuse, sexual assault, rape, Title IX, glass ceiling, pink collar ghetto, separate sex, single sex, co-educational, sexual orientation, sexuality, 


\section{GENDER REPRESENTATIONS IN ED.D. DISSERTATIONS}

sexual expression, heterosexual, hetero-normative, feminism, feminist

\section{Phase II-Qualitative Sample}

During the examination of dissertation titles, I used an analytical approach informed by Altheide, Coyle, DeVriese and Schneider's (2008) Qualitative Document Analysis (QDA) to allow relevant categories to emerge. QDA offers a flexible and reflexive approach to investigate and pursue patterns in textual data through deep immersion and interaction with documents. Emergent qualitative document analysis (QDA) incorporates an investigative eye and reflexivity throughout the entire process of sampling and data analysis. A more complete discussion of this approach is discussed later in this chapter description of the data analysis. My examination of the dissertation titles identified six relevant emergent categories that were used to inform the subsequent theoretical sampling of the abstracts.

I selected a smaller, purposeful, theoretical sample of 177 abstracts consisting of the 6 emergent categories for the qualitative Phase II of the study. Theoretical sampling is purposeful sampling that selects cases to help the researcher generate theory or illuminate specific concepts within the theory (Cresswell, 2005). The sample of 177 dissertation abstracts was informed by observations and categories emerging from the Phase I data analysis. Abstracts were selected to examine gendered cultural beliefs and gender conceptualizations in 


\section{GENDER REPRESENTATIONS IN ED.D. DISSERTATIONS}

six thematic areas, a.) gendered leadership, b.)Black males, c) Latino/as, d.)LGTBIQ, e) Title IX, and f.) Feminism.

I selected all of the dissertation titles that represented each of these themes from the pool of 1185 gender focused titles that were identified in Phase I. This selection process resulted in a sample of 177 abstracts that included 24 abstracts describing male and female leadership comparative studies, 43 abstracts describing Black male studies, 44 abstracts describing Latino/a studies, 32 abstracts describing LGTBIQ studies, 15 studies describing Title IX studies, and 19 abstracts describing Feminist studies.

The selection of 177 abstracts for more in depth examination addresses the study's $2^{\text {nd }}$ research question, What are the cultural gender beliefs and gender conceptualizations represented in Ed.D. dissertation scholarship from leaders graduating in 1998-2007?

I examined each of these abstracts using Tetreault's (1985) phase theory as a lens to illuminate cultural gender beliefs and conceptualizations. I used a coding rubric detailing Tetreault's (1985) phase theory to guide my coding with each of the abstracts examined. Tetreault's (1985) phase theory offers a tool that has been widely used to assess awareness and integration of feminist theory into academic disciplines. A complete description of Tetreault's (1985) phase theory is provided later in this chapter in the description of data analysis procedures. 


\section{GENDER REPRESENTATIONS IN ED.D. DISSERTATIONS}

The appendix providing a list of the 177 abstract sample is included as

Appendix K, The Tetreault phase theory coding rubric is included as Appendix A and the coding notes for representations gender beliefs and conceptualizations in the 6 emergent categories are included as Appendices $\mathrm{O}$ through $\mathrm{T}$, respectively entitled, O.) Male v Female Leader Tetreault coding, P.) Black Males Tetreault coding, Q). Latino/a Tetreault coding, R).LGTBIQ Tetreault coding, , S).Title IX Tetreault coding, and T). Feminism Tetreault coding.

\section{Phase III-Qualitative Sample}

After examining the 177 abstracts, I then selected a purposeful, theoretical sample of 9 complete dissertation texts. I examined nine complete dissertations consisting of Ed. D. dissertations with similar topics on three subgroups a.) dissertations that compared male and female leadership, b.) dissertations that examined Black male students from a deficiency perspective, and c.) dissertations that examined LGTBIQ support through GSA clubs. Altheide, et. al. (2008) recommend a sample size of 6-10 documents for in depth qualitative document analysis. Their recommendation and time constraints were decisive in limiting my full text examination of dissertations to 9 documents. I primarily examined the documents for representations relating to the 6 emergent themes and gender cultural beliefs and conceptualizations reflected in Tetreaults' Feminist Phase theory. 


\section{GENDER REPRESENTATIONS IN ED.D. DISSERTATIONS}

The examination's primary intention was to address the study's $2^{\text {nd }}$ research question, What are the cultural gender beliefs and gender conceptualizations represented in Ed.D. dissertation scholarship from leaders graduating in 19982007? To identify cultural gender beliefs and conceptualizations, each of these 9 complete dissertations was initially coded using Tetreault's feminist phase theory, then each was examined again more fully using Altheide et al's (2008) qualitative document analysis (QDA) as a framework to uncover emergent themes. Coding rubrics and coding memos for the 9 complete dissertations are provided as Appendices L). LGTBIQ GSA clubs, M.) Comparisons of male v female leadership, and N).Black male student achievement

I initially read each complete dissertation to gain an overall impression of its representations of cultural gender beliefs and gender conceptualizations. Then I re-read each dissertation page by page noting any pages or paragraphs that represented themes from Tetreault's (1985) phase theory rubric. I examined each of those paragraphs more closely sentence by sentence and phrase by phrase to reaffirm passages that represented gender cultural beliefs or conceptualizations as described by Tetreault (1985). I indicate representations of Tetreault themes on the coding rubrics.

The texts were also reviewed again comparing and contrasting themes to develop coding memos of emergent categories. Those emergent codes are included 
GENDER REPRESENTATIONS IN ED.D. DISSERTATIONS

in the coding memos included as Appendices L). LGTBIQ GSA clubs, M.)

Comparisons of male $\mathrm{v}$ female leadership, and $\mathrm{N}$ ). Black male student achievement.

\section{Phase II \& Phase III- Qualitative Data Analysis}

Qualitative content analysis offers an interpretive approach to rearticulate textual data into meaningful new narratives (Krippendorf, 2004). The qualitative data analysis in this study is informed by Tetreault's (1985) feminist phase theory which is used as an analytical tool to identify and categorize cultural gender beliefs and gender conceptualizations. Along with examination through the lens of Tetreault's feminist phase theory, the qualitative data analysis for this study uses emergent qualitative document analysis (QDA) (Altheide, Coyle, DeVriese \& Schneider's, 2008) which provides a flexible yet systematic approach to allow for emergent themes. These analytical tools and approaches are described further in the following sections.

\section{Tetreault's feminist phase theory.}

Tetreault's (1985) Feminist Phase Theory is an analytical model based on the evolution of gender consciousness and feminist thought on gendered traditions, history and experiences in selected academic disciplines. During the 1980's feminist scholars saw the need for evaluation models to assess the impact of women studies and the ensuing evolution and proliferation of gender scholarship on college campuses (Minnich,1990; Schuster \& Van Dyne, 1984). Analytical tools 


\section{GENDER REPRESENTATIONS IN ED.D. DISSERTATIONS}

like Tetreault's Phase Theory (1985) were developed and utilized in evaluating the integration of feminist scholarship into academic curriculum transformation projects disciplines to assess progress toward a more gender balanced view of human knowledge (Schuster \& Van Dyne, 1984, Tetreault 1985).

Tetreault's (1985) feminist phase theory model offers a useful tool to identify and categorize stages of inclusion of feminist theory into disciplinary scholarship and can illuminate problematic stereotypical representations, cultural beliefs and gender conceptualizations. Tetreault's feminist phase theory (1985) has had widespread use in the discipline of education in content analysis studies of textbooks (Coghlin, 2007), curriculum evaluation, (Chuppa-Cornell, 2005), school leaders selection processes (Gerber, 1999; Tanner, 2000) and journal articles (Hayes \& Smith, 1994; Twombly, 1993). Tetreault's (1985) model has been used to examine history, literature and science curriculum in K-12 educational settings and higher education disciplines of anthropology, psychology, history and literature. Hayes and Smith (1994) report that "Tetreault presents one of the most comprehensive and detailed models for analyzing scholarship on women" (p.203).

Table 3.3 summarizes Tetreault's phase theory and informs the coding rubric. The coding rubric for categorizing text according to Tetreault's phase theory model is included as Appendix A.

Table 3. 3 Tetreault's (1985) Feminist Phase Theory categorization 
GENDER REPRESENTATIONS IN ED.D. DISSERTATIONS

\begin{tabular}{ll}
\hline $\begin{array}{l}\text { Feminist Phase } \\
\text { Theory }\end{array}$ & Explanation of categories \\
\hline $\begin{array}{l}\text { Phase 1 } \\
\text { Male scholarship }\end{array}$ & Androcentric. Male experience is the universal norm \\
$\begin{array}{l}\text { Phase 2 } \\
\text { Compensatory } \\
\text { scholarship }\end{array}$ & $\begin{array}{l}\text { Acknowledgement of male \& female difference } \\
\text { Exceptional women are added to the male cultural story } \\
\text { Biological differences }\end{array}$ \\
$\begin{array}{l}\text { Phase 3 } \\
\text { Bifocal scholarship }\end{array}$ & $\begin{array}{l}\text { Gender as social construction } \\
\text { Mablic vs private as dual categories }\end{array}$ \\
Agentic or community aspects of gender
\end{tabular}

Tetreault's (1985) feminist phase theory model compares a text's representations with five different phases of the evolution of gender conceptualization in feminist scholarship: a.) phase one is male scholarship, b.) phase two is compensatory scholarship, c.) phase three is bifocal scholarship, d.) phase four is feminist scholarship, and e.) phase five is multifocal or relational scholarship. A summary of Tetreault's model is provided in Table 3.

Phase one, the male scholarship model can also be described as androcentric. This perspective exhibits little consciousness of women having a different lived experience than men. It is assumed male experience is universal, 


\section{GENDER REPRESENTATIONS IN ED.D. DISSERTATIONS}

male history is the history of humanity and legitimate knowledge is primarily by men and about men.

Phase two, compensatory scholarship awareness increases that women's experiences may be missing and although studies begin to consider the female experience the focus continues to compare women to male norms. Studies often center on biological differences or female deficiencies to the gender socialized norm. Compensatory scholarship also considers exceptional or special women as added characters to the male-centered cultural story.

Phase three, bifocal scholarship begins to assert that males and females have different experiences and women may be disadvantaged under present social systems and institutional norms. The bifocal perspective sees men and women as dual categories of humanity. Bifocal scholarship accentuates and problematizes gendered socialization issues such as private vs. public spheres, or agentic vs. community aspects of self for females.

Phase four, feminist scholarship recognizes multiple intersections of diversity are factors impacting women's experiences, such as race, ethnicity, religion, sexual preference, or social class. An additional focus of the feminist scholarship phase is an analysis of women's experience within the social historical, political and economic context. 


\section{GENDER REPRESENTATIONS IN ED.D. DISSERTATIONS}

Phase five, multifocal or relational scholarship is a gender balanced perspective that shows the commonality as well as the particularity of men and women's experience. It questions the social construction of masculinity and femininity and advocates for a more fluid and holistic approach. This approach also examines historical, political and economic context and both private sphere and public sphere activities for a more complete view of human experience.

Tetreault's model is not meant to be rigid, linear or categorically mutually exclusive. Gender focused research, curriculum or other texts may not always evolve sequentially and can also be representative of more than one category. This model provides a framework and analytical tool to examine the texts for the inclusion of feminist thought and to illuminate cultural gender beliefs and gender conceptualizations.

\section{Altheide's emergent qualitative document analysis (QDA).}

Along with coding of the abstracts and complete dissertations texts using Tetreault's (1985) feminist phase theory, throughout the study I also utilized strategies from (QDA) qualitative document analysis (Altheide, et al., 2008) to identify emergent themes. QDA offers an emergent approach rather than a rigid set of procedures which include strategies such as "immersion in the subject matter, conceptually informed conversation with numerous documents and examples, and 


\section{GENDER REPRESENTATIONS IN ED.D. DISSERTATIONS}

theoretical sampling for systemic and constant comparison” (Altheide, 1987, p.127).

Although data analysis of data gathered from a prior protocol like Tetreault's Phase Theory can support a theoretically informed account of content, Altheide (1987) states that using a structured protocol alone can obscure critical questions and issues that fall outside of the pre-determined categories (Altheide, 1987). Since this study definition of gender is intentionally more inclusive than other prior studies that have used Tetreault's feminist phase theory for analysis, the addition of the flexible yet systematic approach to data analysis provided by Altheide, et al.'s (2008) emergent qualitative document analysis is appropriate.

\section{Phase II \& III- Interpretive Standards of Evidence}

Interpretive methods necessarily have interpretive standards for assessing research quality (Freeman, deMarais et al, 2007). The interpretive nature of qualitative content analysis substitutes "public justifiability" (Ahuvia, 2000, p. 146) for the standard of replicability used in quantitative approaches to content analysis. Public justifiability requires that enough of the context, coding and data reduction is provided in the description of findings for readers to make their own decisions on the legitimacy of the narrative (Ahuvia, 2000, Anfara, Brown \& Mangione, 2002).

The primary strategy for supporting public justifiability in the qualitative Phases II and III of this study is through transparent disclosure of interpretative 
GENDER REPRESENTATIONS IN ED.D. DISSERTATIONS

decision making in appendices (Ahuvia, 2001). Coding memos are included as appendices and available for readers to help make the researcher's perspective clear and support assertions that the researcher's intepretations are compellingly justified by the data.

Systematic and careful documentation of procedures provide a record to both support adequate researcher reflectivity and enhance the credibility of the study (Freeman, deMarais, et al, 2007; Strauss \& Corbin 1990). The use of coding rubrics utilizing Tetreault's (1985) feminist phase theory along with memos for Altheide, et al's (2008) (QDA) approach to emergent qualitative document analysis supports systematic analysis and documentation.

\section{Human Subjects Review Considerations}

Since the sample consists of pre-existing publicly available documents, Ed.D. Dissertations, I requested and received a waiver of review from Portland State University. The public nature of these pre-existing documents and the normative non-confidential nature of Ed.D. dissertation authorship qualified the study for an exemption claim for waived review under the Portland State University HRRSC guidelines. The application for waived review is included as Appendix D.

\section{Delimitations}




\section{GENDER REPRESENTATIONS IN ED.D. DISSERTATIONS}

This study's parameters include Ed.D. dissertations from public doctoral granting universities from 1998-2007 in digital format available through UMI

Proquest Thesis and Dissertation database. If a dissertation from a public doctoral institution completed during that time period was not available to download electronically by UMI Proquest it may not be included in the sample.

This research examines Ed.D. dissertations only and purposely excludes Ph.D. dissertations in the discipline of education. Although Ph.D dissertations could also provide a rich source of data, search parameters of the UMI Proquest database for the $\mathrm{Ph} . \mathrm{D}$ degree also includes $\mathrm{Ph} . \mathrm{D}$ recipients from all other disciplines which must be manually examined and excluded. Although, the UMI Proquest database features department as an additional search parameter, the lack of conformity in naming education departments offering a $\mathrm{Ph} . \mathrm{D}$. in education makes inclusion of Ph.D. dissertations in the sample too time consuming and unfeasible for this study.

The study is also limited to U.S. public doctoral granting institutions as listed by the Carnegie Institutional Classification. This would specifically exclude institutions classified as Masters degree institutions that may also offer the Ed.D. degree, such as Alabama State, Texas A \& M, Corpus Christi, University of West Georgia, Southern Connecticut State and other Carnegie classified M.S. institutions. 


\section{GENDER REPRESENTATIONS IN ED.D. DISSERTATIONS}

Additionally, it should be noted that there are many private doctoral institutions with a long tradition of offering Ed.D. programs that grant a significant number of degrees annually. It would be beneficial for future studies to include Ed.D.dissertation scholarship from private Doctoral granting institutions in the sample. However, private institutions and Masters level institutions offering the Ed. D. degree were not included in this study to keep the sample size more manageable.

\section{Limitations}

The UMI Proquest database used for sample selection is widely used by U.S doctoral granting institutions, however, if an institution had not reported a dissertation completed between 1998 and 2007 to the database, or Proquest has not made the dissertation available during the data collection period of this study in 2010, it could be missing from the sample.

The unit of analysis for the initial quantitative phase of this study utilizes dissertation titles to ascertain a gender focus in the study, which assumes dissertation titles actually reflect the dissertation contents. Although research reporting guidelines for dissertations recommend titles reflect the central phenomenon, theories, variables or participants being studied (American Psychological Association, 2009; Creswell, 2005), non-conforming or unusual dissertation titles that do not explicitly state the gendered terms from the coding dictionary in their title would be excluded, if the dissertations does examine gender. 
GENDER REPRESENTATIONS IN ED.D. DISSERTATIONS

Additionally, findings from the small purposeful, theoretical sample of 9

dissertation texts in the qualitative phase III of the study are not meant to be

representative of the population and findings should not be considered

generalizable. 


\section{GENDER REPRESENTATIONS IN ED.D. DISSERTATIONS}

\section{Chapter 4. Description of Findings}

This chapter presents the findings in a format that provides insights into the original research questions for each successive three phases of the study. The following narrative also includes tables and charts to illustrate the findings.

\section{Phase I-Question 1. Prevalence of Gender Focus}

Phase I of this content analysis primarily focused on describing and quantifying data to address the first research question 1.) How prevalent is gender focused inquiry in recent Ed.D. dissertation scholarship, from 1998-2007.

Of the sample of 15,014 Ed. D dissertation titles examined 1185, or a total of $7.9 \%$ indicated a gender focus. However, of the 1185 gender focused titles, 64 dissertations were included even though gender was not the primary focus, but was one of multiple variables examined in the study such as: The difference in physical fitness levels of fifth graders according to socioeconomic groups and gender (Wolford, 1998) or An investigation of the learning styles of ninth grade public school students: black and white, male and female, general level and gifted, magnet (Cozens, 1999).

Additionally 145 of the 1185 gender focused titles were selected because of a gendered proper name such as: Heritage to Legacy: A content analysis of the Coretta Scott King award winning picture book from 1976-2004 (Abdel-Malik, 
GENDER REPRESENTATIONS IN ED.D. DISSERTATIONS

2004) or Leadership styles of interdisciplinary health science education leaders of Quentin Burdick programs (Sasnett,2006).

The design of this study purposely cast a wide net to ensure any potential gender focused studies were included in the examination. The significance and implications of the findings in light of this inclusive approach will be discussed further in Chapter 5.

The 1185 gender focused studies consisted of 655 female focused studies, 248 male focused studies, 32 LGTBIQ focused studies and 250 coded as other. The category of other in this study includes studies that refer to both genders or are nonspecific in gender focus exemplified by studies such as: Five public school principal's perceptions of student to student sexual harassment (Clements, 1999). A chart illustrating each of the categories as a percentage of the total number of gender focused dissertations is below as Figure 4.1. Since LGTBIQ gender focused studies were less than $1 \%$ of the total number of gender focused studies, their representation is barely visible on the chart.

\section{Variances of prevalence of gender focus}

Although examination of the entire sample of 15, 014 titles indicated an overall $7.9 \%$ gender focus, there was a wide range of variation in percentage of gender focused dissertation scholarship in the 112 public doctoral granting institutions examined. In the sample of 112 institutions, the 10 institutions with the highest concentration of gender focused dissertations ranged from $14.2 \%$ to $57.1 \%$ and are listed below in Table 4.1. 
GENDER REPRESENTATIONS IN ED.D. DISSERTATIONS

Figure 4.1. \% of total Dissertations for each category of gender

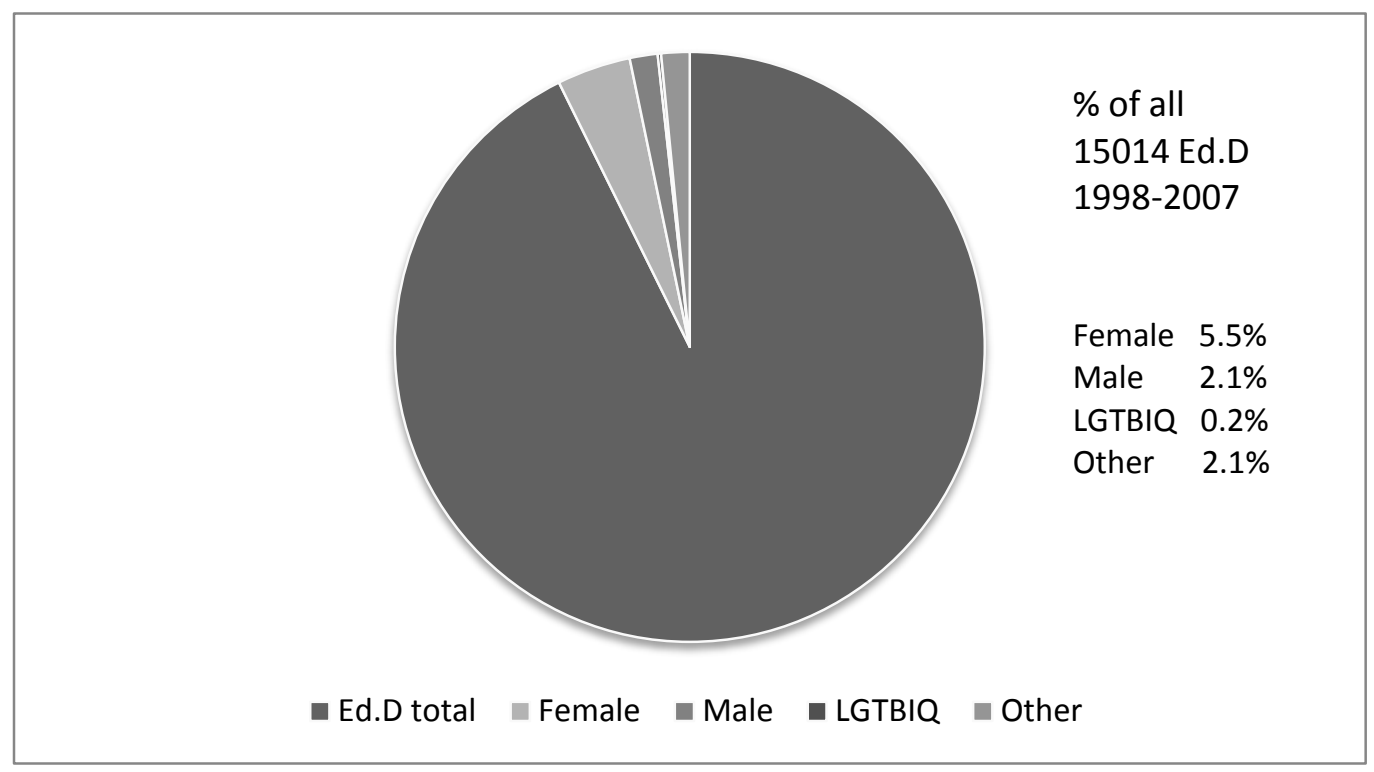

Table 4.1. Doctoral institutions with highest dissertation gender focus

\begin{tabular}{llr}
\hline 10 Institutions with highest gender focus & $\begin{array}{l}\% \\
\text { gender }\end{array}$ & $\begin{array}{l}\text { Carnegie } \\
\text { Classification }\end{array}$ \\
\hline University of Oregon & $57.1 \%$ & RUH \\
Pennsylvania State University & $28.8 \%$ & RUVH \\
Ohio University & $23.0 \%$ & RUH \\
University of Cincinnati & $18.4 \%$ & RUVH \\
University of Massachusetts-Amherst & $18.0 \%$ & RUVH \\
Georgia Southern University & $16.4 \%$ & DRU \\
University of Kentucky & $16.4 \%$ & RUVH \\
Texas Woman's University & $14.3 \%$ & DRU \\
University of Southern Carolina & $14.3 \%$ & RUVH \\
University of Massachusetts-Boston & $14.2 \%$ & DRU \\
\hline
\end{tabular}




\section{GENDER REPRESENTATIONS IN ED.D. DISSERTATIONS}

Furthermore, of the 112 doctoral institutions in the sample, the 10 institutions with the lowest concentration of gender focus revealed a disturbing finding of zero gender focus in any of the Ed. D. dissertations completed at those institutions during 1998 through 2007, the years examined in this study. These institutions are listed in Table 4.2.

The ten institutions that revealed zero gender focused dissertations amount to $9 \%$ of the sample of 112 institutions examined. Nearly a third, 37 of the institutions, had 4-8\% gender focus in their E.D. dissertations. Additionally, 63 of the 112 institutions, or $56 \%$ had an Ed.D. dissertation gender focus ranging between 4 and $12 \%$. The range of gender focus in the 112 institutions examined is listed in Table 4.3. Additionally, the ranking list of all 112 institutions with gender focused totals and percentages is included as Appendix $\mathrm{J}$.

Table 4.2. Doctoral institutions with lowest dissertation gender focus

\begin{tabular}{lcr}
\hline 10 Institutions with lowest gender focus & $\%$ & $\begin{array}{c}\text { Carnegie } \\
\text { Classification }\end{array}$ \\
\hline University of Oklahoma & $0 \%$ & RUH \\
George Mason University & $0 \%$ & RUH \\
University of Connecticut & $0 \%$ & RUVH \\
University of Idaho & $0 \%$ & RUVH \\
University of Mississippi & $0 \%$ & RUH \\
University of Nebraska & $0 \%$ & RUH \\
University of New Orleans & $0 \%$ & RUH \\
University of Toledo & $0 \%$ & RUH \\
University of Vermont & $0 \%$ & RUH
\end{tabular}


GENDER REPRESENTATIONS IN ED.D. DISSERTATIONS

Wichita University Kansas $\quad 0 \% \quad$ RUH

Furthermore, institutional variances in the prevalence of gender focused dissertation scholarship varied and corresponded with institutional research focus according to Carnegie's classification. Institutions with the lowest research focus also had the lowest dissertation gender focus.

Table 4.3 Range of gender focus exhibited in the sample of 112 institutions

\begin{tabular}{lrr}
\hline Range of gender focus & $\begin{array}{c}\text { \# of doctoral } \\
\text { institutions }\end{array}$ & $\begin{array}{c}\% \text { of } \\
\text { institutions }\end{array}$ \\
\hline$-0-$ gender focus & 10 institutions & $9 \%$ \\
$1-4 \%$ & 20 institutions & $18 \%$ \\
$4-8 \%$ & 37 institutions & $33 \%$ \\
$8-12 \%$ & 26 institutions & $23 \%$ \\
$12-16 \%$ & 12 institutions & $11 \%$ \\
$16-20 \%$ & 4 institutions & $3 \%$ \\
$20-24 \%$ & 2 institutions & $2 \%$ \\
$24-30 \%$ & 0 institutions & $0 \%$ \\
$>30 \%$ & 1 institutions & $1 \%$ \\
\hline
\end{tabular}

The mean gender focus in institutions with Carnegie classification DRU, the lowest institutional research focus was $6.6 \%$, the mean gender focus in institutions with Carnegie classification RUH, the middle range institutional research focus was $7.1 \%$, and the Carnegie classification with the highest research focus, RUVH reported the highest mean percentage of gender focused dissertations at $9.5 \%$. The mean for the entire sample of 112 institutions was 7.8\%. A graph of the percentage of gender focused dissertations in each Carnegie institutional research classification is included as Figure 4.2 
GENDER REPRESENTATIONS IN ED.D. DISSERTATIONS

Figure 4.2. Gender focus \% of dissertations by Carnegie Classification

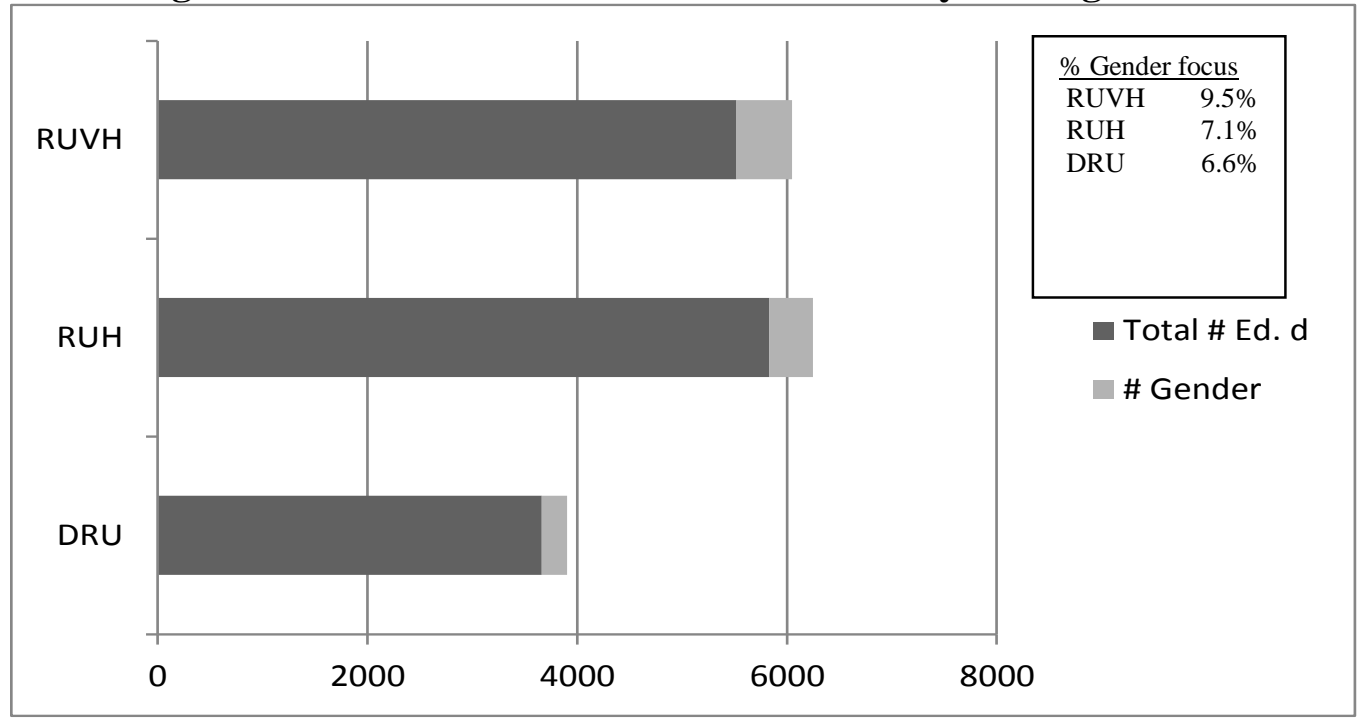

\section{Phase I-Question 2-Beliefs and Gender Conceptualizations}

In addition to illuminating the initial research question about the

prevalence of gender focused Ed.D. scholarship, the quantitative content analysis of phase I of this research also uncovered patterns and themes that related to the second research question; What are the cultural gender beliefs and gender conceptualizations represented in Ed.D. dissertation scholarship from 1998-2007?

Patterns and themes emerging from examining the 1185 gender focused dissertations informed the selected purposeful sample of abstracts examined in Phase II of this study. Three emergent themes representing problematic gender cultural beliefs and conceptualizations examined were: a.) masculine leadership privileged.b.) Black males "othered" c.) Latinas silenced. 


\section{GENDER REPRESENTATIONS IN ED.D. DISSERTATIONS}

Since scholars state the absence of a topic is also an indicator of the cultural consciousness and commitment to the issue (Krippendorf, 2004, Leavy 2007), three emergent themes with scanty representation were also included for further examination in the abstracts. The findings also revealed these three themes which were noticeably under- represented in the Ed.D. scholarship, a.) LGTBIQ silenced, b.) Title IX trivialized, and c.) Feminism marginalized. Findings regarding each of these six themes follow.

\section{Finding 1. Masculine leaders privileged}

Although the dissertations identified by coders because they included a gendered proper name may not directly be a gender focused study, an examination of who is listed in this dissertation scholarship and how they are represented illuminates a pattern of gendered cultural beliefs. Krippendorf (2004) states that co-occurrence of two concepts, or an association of favorable or unfavorable characteristics with a topic is an indicator of a cultural belief. Additionally, the frequency of co-occurrence indicates the strength of association of the concept in the culture.

Gendered and masculine portrayals of leadership, intellectual authority and eminence were evident in the examination of the 145 dissertation titles containing gendered proper names. If it was not clear by the dissertation title alone if the proper name referred to a male of female the dissertation text was consulted to 


\section{GENDER REPRESENTATIONS IN ED.D. DISSERTATIONS}

properly categorize this emergent theme. The proper names were disproportionately associated with males in positions of leadership, intellectual authority and eminence in comparison to females as will be detailed in the following paragraphs.

The emergent category leadership included terms associated with the name such as leadership, legacy, influence, contributions, and job titles such as Dean, or President. Notably, males were associated directly 8 times with the specific word leadership whereas women were only associated with leadership 5 times, and usually peripherally. All 5 female associations with the specific word leadership were indirect or included qualifiers, such as: a.) symbolic leadership, b.) leading explorer, c.) leadership path, d.) spiritual leader and e.) religious leader. However, the 8 studies associating a male name with leadership were more direct and two also used additional positive adjectives such as: a) transformational leadership, b.) active positive leader, c.) Christian leader, d.) leadership, e.) leadership, f.) leadership, g.) leadership, and h.) leadership.

Males were also associated with the position of Dean or President 4 times, whereas females only were once. However, males were associated with influence, contributions or legacy 5 times, and similarly, females were associated 5 times with these terms.

The emergent category of intellectual authority included associations such as philosopher, intellectual, doctor, scientist, scholar, and also included theories or 


\section{GENDER REPRESENTATIONS IN ED.D. DISSERTATIONS}

methods named after the originator. Male names were associated with theories 15 times, but females only twice.

Additionally, the term intellectual was associated 4 times with males, but never with females. In like fashion, males were also associated with the term philosophy or philosopher 2 times, but females were never associated with these terms in the 145 dissertations with proper names.

The term Doctor or scholar was associated 2 times with males, never with females. A similar term scientist was associated with a female, but like the findings of the usage of the word leadership, when the term scientist was used with a female it also had an indirect qualifier, scientific habit.

Males were associated once with curriculum as were females. Males were associated with technique 2 times, and females had associations with two similar terms, typology, once and decree, once.

\section{Finding 2. Black males "othered"}

Of the studies that were male gender focused, when ethnicity was cited, it was predominately examining males of color. They were also usually Black males; of the 115 male gender focused studies mentioning ethnicity, 69 were studies of Black males, 29 focused on Hispanic/Latino males, 3 focused on Chinese males, 1 Filipino, 1 Indian and 1 Saudi. In only 2 studies, did the title specify White males. 
GENDER REPRESENTATIONS IN ED.D. DISSERTATIONS

Additionally, 20 of the studies focusing Black males examined the issue from a deviancy or deficiency perspective.

\section{Finding 3. Latinas silenced}

Subordination and silencing of Latinas was also indicated from the examination of the titles. Because of the linguistic norm of the Spanish language of using Latino to describe populations of mixed gender, it was difficult to ascertain from the titles whether these studies referred to males, females, or both. A sample of Latina/o dissertation titles were purposefully selected to examine the abstracts which will be detailed further under the findings of Phase II.

\section{Finding 4. Title IX trivialized}

The examination of dissertation titles revealed a paucity of studies on Title IX, of the Educational Amendments of 1972, federal gender equity legislation. Of the 15, 014 gender focused titles identified, only 15 dissertations mentioned Title IX in the title, or less than $1 / 10^{\text {th }}$ of $1 \%$. Abstracts were examined for all 15 of the dissertations using Title IX as a descriptor in the dissertation title.

\section{Finding 5. LGTBIQ silenced}

Additionally, 32 Ed.D. dissertations, or .2\% of the gender focused dissertations identified examine LGTBIQ issues. Abstracts were examined for all 32 gender focused dissertations focusing on LGTBIQ populations.

Finding 6. Feminism marginalized 


\section{GENDER REPRESENTATIONS IN ED.D. DISSERTATIONS}

In similar fashion, the term feminist or feminism was noticeably scanty in the sample. Only 19 dissertation titles were found using the term feminist or feminism to describe their research or analysis, or approximately .1\% of the 15 , 014 dissertations in the sample. Abstracts were examined for all 19 of the gender focused dissertations using feminist or feminism as a descriptor in the title.

\section{Phase II- Findings-Gender Cultural Beliefs and Conceptualizations}

An examination of the 6 categories of abstracts using the lens of Tetreault's phase theory provided insight into the second research question: What are the gender cultural gender beliefs and gender conceptualizations represented in the sample? Findings are detailed in Table 4.4 below. Most of the abstracts examined had representations of gender cultural beliefs and gender conceptualizations that fall into the lowest two phases of Tetreault's Feminist Phase Theory, 204 of the 362 representations, or $56 \%$ fall in Tetreault phases 1 and 2 .

Table 4. 4 Abstract categories with Tetreault Coding

\begin{tabular}{|c|c|c|c|c|c|}
\hline $\begin{array}{l}\text { Emergent } \\
\text { themes } \\
\text { Abstracts }\end{array}$ & $\begin{array}{l}\text { Phase 1 } \\
\text { Male } \\
\text { scholarship }\end{array}$ & $\begin{array}{l}\text { Phase } 2 \\
\text { Compensatory } \\
\text { scholarship }\end{array}$ & $\begin{array}{l}\text { Phase 3 } \\
\text { Bifocal } \\
\text { Scholarship }\end{array}$ & $\begin{array}{l}\text { Phase 4 } \\
\text { Feminist } \\
\text { scholarship }\end{array}$ & $\begin{array}{l}\text { Phase 4 } \\
\text { Multifocal } \\
\text { Scholarship }\end{array}$ \\
\hline $\begin{array}{l}\mathrm{M} v \mathrm{~F} \\
\text { Leaders }\end{array}$ & 0 & 31 & 10 & & 0 \\
\hline $\begin{array}{l}\text { Black } \\
\text { Males }\end{array}$ & 17 & 26 & 1 & 41 & 0 \\
\hline Latino/a & 50 & 28 & 3 & 16 & 5 \\
\hline
\end{tabular}




\begin{tabular}{|c|c|c|c|c|c|}
\hline LGTBIQ & 0 & 14 & 12 & 26 & 3 \\
\hline Title IX & 2 & 18 & 6 & 2 & 2 \\
\hline Feminist & 0 & 18 & 13 & 9 & 9 \\
\hline $\begin{array}{c}\text { Phase } \\
\text { totals }\end{array}$ & 69 & 135 & 45 & 96 & 17 \\
\hline
\end{tabular}

Although there were also a large number of representations in Tetreault's Phase 4, we should be mindful that these were primarily in the Black males, Latino and LGTBIQ abstracts that were selected purposefully to examine these issues of implied intersectionality.

\section{PHASE III. Findings Cultural Gender Beliefs \& Conceptualizations LGTBIQ dissertations.}

I selected three dissertations that examined Gay Straight Alliance clubs (GSA)'s. Gay straight alliance clubs support LGTBIQ students and engage heterosexual students in advocacy. The findings of phase I titles of this study revealed a silencing of LGTBIQ issues, indicating a biased cultural belief that privileges heterosexuality. The full text examination confirmed this finding.

Talone's (2006) case study interviewed GSA advisors, GSA Presidents and assistant principals at four sites. Doppler's (2000) study interviewed current and former staff members of the Massachusetts Department of Education, Gay Lesbian 
GENDER REPRESENTATIONS IN ED.D. DISSERTATIONS

and Straight Education Network, and Governor's Commission on Gay and Lesbian and surveyed GSA advisors. Shore's (2007) study interviewed GSA advisors and surveyed student participants.

The three dissertations revealed great similarities in their representations of cultural gender beliefs and gender conceptualization. They recognized gender as a social construction which corresponds to Bifocal Scholarship, Phase 3 of Tetreault's model. In addition to recognizing gender as a social construction, all three of the GSA dissertations critiqued the social construction of masculinity and femininity, corresponding to Multifocal or Relational scholarship, Phase 5 of Tetreault's model. Additionally, although this topic inherently represents Feminist scholarship, Tetreault's Phase 4, because of the focus on gender identity and sexual orientation, these three dissertations offered little discussion of intersecting identity variables such as race, ethnicity, class, religion, abilities, or other factors.

\section{Male v. female leader dissertations.}

I selected three dissertations that examine the gendered cultural belief that males and females exhibit different leadership attributes. The findings of phase I of this study revealed a biased gender cultural belief that privileges male leadership.

Clisbee's (2004) dissertation examined gender based differences of 100 school superintendents and 425 administrators who report to them using a 


\section{GENDER REPRESENTATIONS IN ED.D. DISSERTATIONS}

quantitative design and data collected from 3 surveys. Halloran's (2007)

dissertation examined perceived differences in leadership practices of male and female superintendents as identified by a survey of 375 Massachusetts K-12 public school committee members. Pasteris's (1998) dissertation surveyed 152 principals and 501 teachers regarding leadership effectiveness.

The dissertations revealed great similarities in their literature review representations of cultural gender beliefs and gender conceptualization with varied levels of critique. All three of the dissertations examining gendered leadership recognized gender as a social construction which corresponds to Bifocal Scholarship, Phase 3 of Tetreault's model. However, Clisbee's (2004) dissertation offered strong critique of the social construction of gender which corresponds to Phase 5, multifocal scholarship. However, all of these dissertations provided little discussion of the complex intersections of diversity that is indicative of Tetreault's Phase 4, Feminist Scholarship.

\section{Black male dissertations}

I selected three dissertations that similarly examined academic achievement and school adaptation for Black males. I selected these because they use individual personality traits to examine academic challenges faced by Black males. The phase 


\section{GENDER REPRESENTATIONS IN ED.D. DISSERTATIONS}

I findings of this study indicated black males experience "othering" which implies a gender cultural belief that Black males are deficient.

Crawford's (2002) dissertation examined attitudes of Black males towards academic learning as an impact on academic achievement. Marshall's (2003) dissertation examines locus of control on the academic achievement of Black males. Likewise, Salley’s (2005) dissertation examined relationships between persistence, resilience and academic achievement among high school Black males.

Each of these dissertations primarily and implicitly represents Feminist Scholarship, indicated by Phase 4 of Tetreault's phase theory because they examine race as it intersects with gender in Black males. However, little explicit discussion is referenced to how being a Black male in the US educational system is different than being a Black female. Additionally, these three studies varied considerably in their reporting and level of critique of the gendered cultural beliefs represented in the review of literature that informed the research.

\section{Emergent themes of fear, silencing and discrimination}

Although these did not specifically address the research questions of this study, additional emergent interconnected themes of fear, silencing and discrimination were present in all of full text dissertations in varying levels of intensity. Themes were on a represented on a continuum through overt acts of 
GENDER REPRESENTATIONS IN ED.D. DISSERTATIONS

silencing and threats of social or economic harm or violence by others or strategies of self-silencing to prevent negative consequences from gender expressions counter to cultural norms. Coding memos for the full text dissertations are included as Appendices L.) LBTBIQ dissertations, M.) Male v Female Leader Dissertations, and O.) Black Male Dissertations. 


\section{GENDER REPRESENTATIONS IN ED.D. DISSERTATIONS}

\section{Chapter 5: Summary Discussion and Recommendations}

This final chapter of the dissertation begins with a restatement of the research purpose, conceptual framework and original research questions. It will continue with a discussion of the overall implications of the findings in relation to the conceptual framework and existing academic literature. The format of the discussion of findings will follow the same structure as Chapter 4. where insights into the research questions are discussed for each successive phase of the study. The implications of each of the emergent themes will be presented with suggestions for practice and future research. The conclusion will summarize the contribution this study makes to the discipline.

The purpose of this study was to gain better understanding of the gender equity values, beliefs and commitments of educational leaders as represented in a key textual artifact of doctoral study and essential component of educational academic literature, the Ed.D. dissertation. Content analysis with a feminist analytical lens examined the manifest and latent content of the Ed.D. dissertation scholarship to provide insight into the two research questions, 1.) How prevalent is gender focused inquiry in Ed.D. dissertation scholarship from 1998-2007?, and 2.) What are the cultural gender beliefs and gender conceptualizations represented in Ed.D. dissertation scholarship from 1998-2007 ? 


\section{GENDER REPRESENTATIONS IN ED.D. DISSERTATIONS}

The conceptual framework for this study was provided by three concepts, a.) leadership, values, beliefs and commitments are key to gender equitable institutions,(U.S. Department of Labor, 1995). b.) values, beliefs and commitments of individuals and their culture are represented in textual artifacts, (Krippendorf, 2004; Laswell, 1949; Leavy, 2007) c.) feminist analysis provides a useful tool to illuminate gendered practices (Leavy, 2007; Bensimon \& Marshall,1997; Marshall \& Gerstl-Pepin, 2005).

\section{Question 1. Finding 1: Low Prevalence of Gender Focus}

Phase I of this study primarily focused on addressing the first research question 1.) How prevalent is gender focused inquiry in recent Ed.D. dissertation scholarship, from 1998-2007?

The findings indicate that gender focused inquiry is not prevalent in this sample of dissertations from 1998-2007. Of the 15,014 dissertations completed during this period only $7.9 \%$ of the titles indicate any possible inclusion or examination of gender. These findings do not represent a high consciousness or commitment to gender equity issues in the Ed.D. dissertation scholarship from 1998 to 2007 in U.S. public doctoral granting institutions. As Krippendorf, (2004) states us, the presence or absence of a concept in a body of text is an indicator of cultural consciousness and the frequency of the concept's occurence is an indicator of priority, emphasis and commitment. 


\section{GENDER REPRESENTATIONS IN ED.D. DISSERTATIONS}

Additionally, because of the intentional, conservative design of this study, the prevalence of dissertation studies that intentionally or specifically examine gender is actually less than the $7.9 \%$ represented by the total findings in this study. This study purposely cast a wide net in the Phase I sample selection to include as many gendered terms as possible that could indicate a potential gender focus. This intentionally inclusive approach overstates the number of gender focused dissertations found because studies were included where gender was incidental rather than intentional and not the primary focus of the dissertation.

Two examples of this type of incidental or secondary gender focus are in the studies selected because of gendered proper names, such as The perceived effectiveness of Milton Erickson's hypnotic communication patterns in counselor supervision (Burow, 1998) or studies with multiple variables that include gender such as, Differences in learning style preference among students of diverse ethnicities, gender, academic placement level and academic achievement, (McGraw,2005). Although, the inclusion of these types of titles is important to get a fuller picture of how gender is represented in this body of educational scholarship, these types of studies often are not an intentional examination of gender.

Furthermore, the intentional inclusion of male gender focused studies and LGTBIQ focused studies in this study's design makes it more challenging to 


\section{GENDER REPRESENTATIONS IN ED.D. DISSERTATIONS}

compare the findings with prior similar content analysis studies conducted on educational journal articles. Most of the previous studies in the literature focus solely on examining the prevalance of female gender focused research in journal articles (Hart, 2006, Hayes \& Smith, 1994, Parson \& Ward, 2001, Townsend, 1993, Twombley, 1993, Wolgemuth, Kees \& Safarik, 2003).

Comparing the total $7.9 \%$ aggregated female, male and LGTBIQ, and other/all inclusive gender focused findings of this study with previous literature of female focused only studies could give the illusion of progress with an increase in gender focused scholarship. However, when the female gender focused findings of this study are considered separately there has been no increase in female gender focused scholarship from the time of Wolgemuth, Kees \& Safarik's (2003) study of publications in the 1990's or even Townsend's (1993) study of published educational scholarship from the 70's and 80's.

The scanty representation of gender focus in of dissertation scholarship by educational leaders in the findings of this study gives cause for concern in light of the importance of Ed.D. dissertation research. Dissertations are a key component of educational leadership academic literature, a significant source of gender equity research and a vital policy resource in the discipline of education (Murphy \& Vriesenga, 2006; Shakeshaft, Brown, et al, 2007). 


\section{GENDER REPRESENTATIONS IN ED.D. DISSERTATIONS}

Dissertations are individual products of original scholarship. Dissertations represent the synthesis and culmination of the coursework, academic study, and the professional experiences of doctoral candidates (Boyer, 1990; Mauch \& Birch, 1998). If the dissertation is truly a representative artifact of individual academic insights and scholarly identity, the scanty representation of gender focused scholarship in this study's findings does not inspire confidence about the collective gender equity consciousness and commitment of the future educational leaders receiving Ed.D. doctorates from U.S. public universities during 1998-2007.

Additionally, research and communication contents exemplify both the values and beliefs of the originator and reflect the social values and cultural beliefs of their group (Harding, 1986, Janowitz, 1968, Laswell, 1949). Academic socialization literature states the values, beliefs and behaviors of scholars and educational leaders are developed during doctoral study (Anderson \& Swazey, 1998; Austin, 2002; Baird, 1992; Boyer, 1990; Nettles \& Millet, 2006; Tierney \& Rhoades, 1994; Weidman, Twale \& Stein, 2001). The scanty prevalence of gender focused dissertation scholarship also implies a low group cultural consciousness and commitment to gender issues transmitted through Ed.D. academic socialization.

Since the findings of this study overall show so few of the 15,014 Ed.D. dissertations from the 112 U.S. public doctoral granting institutions indicate any 


\section{GENDER REPRESENTATIONS IN ED.D. DISSERTATIONS}

type of gender focus, this has problematic implications for the credibility and accountability of doctoral training programs in regards to the development of gender equity values. Doctoral training programs have a responsibility to support the development of values (Walker, Golde, Jones, Bueschel, \& Hutchings, 2008). The Carnegie Foundation for the Advancement of Teaching's (2008) study of doctoral programs states that doctoral education is more than merely the development of intellectual expertise, but is inherently "the growth of the personality, character, habits of heart and mind" (Walker ,Golde, Jones, Bueschel, \& Hutchings, 2008, p.8). The findings of this study in light of the academic socialization and doctoral preparation literature suggests a need to examine doctoral programs in regards to the development of gender equity values in educational leaders. Recommendations for future research are provided at the end of this chapter.

\section{Question 1. Finding 2: Institutional Variation of Gender Focus}

The recommendation for future research to examine and compare educational leadership doctoral programs is also indicated by the second finding from Phase I ; The findings also showed great institutional variance in the prevalence of gender focused dissertation research.

Although examination of the entire sample of 15, 014 dissertation titles indicated an overall low prevalence of gender focus at $7.9 \%$, the findings showed a 


\section{GENDER REPRESENTATIONS IN ED.D. DISSERTATIONS}

wide range of variation in percentage of gender focused dissertation scholarship in the 112 public doctoral granting institutions examined. The 10 institutions with the highest gender focus in their dissertations were all over $14 \%$. In contrast, a problematic finding was that $9 \%$ of 112 doctoral granting institutions preparing educational leaders and scholars revealed a disturbing finding of zero gender focused dissertations in the entire 10 year period from 1998-2007. The educational doctorates graduating from these 10 institutions did not submit even 1 dissertation research study in 10 years where gender was included as one of multiple research variables. This absence of any mention of gender in the dissertation scholarship of an entire decade for $9 \%$ of all the US public doctoral granting institutions does not inspire confidence in the dispositions of educational leaders towards gender equity. Recommendations for future institutional and program research are provided at the end of this chapter.

\section{Question.1. Finding 3. Correlation Gender Focus \& Institutional Research}

Another interesting finding is that the institutional variances in the

prevalence of gender focused dissertation scholarship directly corresponded with the institutions overall research focus and intensity according to the Carnegie Classification System. The institutions with the lowest research focus also had the lowest gender focus in the dissertation research. The Carnegie classifications, DRU, the lowest institutional research focus was $6.6 \%$, RUH, the middle range 
GENDER REPRESENTATIONS IN ED.D. DISSERTATIONS

institutional research focus was $7.1 \%$, and RUVH, the highest institutional research focus was $9.5 \%$.

This finding of a correlation of higher percentages of gender focused scholarship with more research intensive universities is in contrast with previous smaller qualitative studies which suggest institutions with a more intensive research focus may place more pressure and offer more hostile environments to scholars working on gender issues (Gumport, 1990; Safarik,2003 ).

\section{Question 2. Cultural Gender Beliefs and Gender Conceptualizations}

The findings of Phase I also provided insights into the second research question; What are the cultural gender beliefs and gender conceptualizations represented in Ed.D. dissertation scholarship from 1998-2007? The six key findings representing gendered cultural beliefs and conceptualizations in the Phase I findings are discussed below.

\section{Finding 1. Masculine leadership and scholarship privileged.}

The Ed.D. dissertation scholarship examined in this study represents a strong gendered cultural belief that educational leadership, intellectual authority and eminence is associated with males. The findings indicate that in the gender focused titles identified through gendered proper names male names are 4 times as frequently as females to be attributed with the favorable qualities of leadership, intellectual authority and eminence. 


\section{GENDER REPRESENTATIONS IN ED.D. DISSERTATIONS}

The number of favorable or unfavorable characteristics attributed to a concept are indicators of the values and beliefs of the writer, the readers and their common culture (Krippendorf, 2004). Additionally, the frequency of the attributions are indicators of the strength or intensity of the attitudes held by those in the culture (Krippendorf, 2004).

The 1185 gender focused studies identified are more than $2 \mathrm{x}$ as likely to be about females, (655 females,) than males, (285 males). However, the 145 dissertations with gendered proper names in the title underrepresent females in association with leadership, intellectual authority and eminence in comparison to males. Although more than twice as many of all the gender focused dissertations in the entire sample referred to females rather than males, the studies with gendered proper names representing the positive characteristics of leadership, intellectual authority, or eminence were associated with males four times as often as females.

The disproportional underrepresentation of female proper names associated with leadership and intellectual authority in the research findings gives cause for concern. Because dissertations are a key component of the academic literature, and as such, impact the knowledge base of educational leaders and policymakers, the predominant representation of males in positions of leadership and intellectual authority provides strong reinforcement for male privilege and institutional gender inequity. Fowler (2004) states "among the most important messages communicated 


\section{GENDER REPRESENTATIONS IN ED.D. DISSERTATIONS}

by institutions that shape consciousness are messages about who should hold leading positions in society and who should be dominated by others" (p.59).

The underrepresentation of females implies that males are the legitimate knowledge experts of the discipline to study and emulate and the paucity of females represented in roles of leadership and expertise implies there are none, or they have nothing credible to add to the discourse (Code, 1991; Sandler, Silverberg \& Hall, 1996).

These representations illuminated in these findings perpetuate problematic biased gender cultural beliefs. Literature indicates males are perceived as more competent and legitimate as leaders (Carli \& Eagly, 2001). Academic scholarship has a history of equating males with credibility, value and authority; whereas, female claims to knowledge and expertise are often trivialized or discredited because of gender stereotypes (Code, 1991, 1995a, 1995b; Harding, 1986).

The findings also mirror prior findings in the literature that gendered representations in educational leadership journal articles privilege males for leadership positions (Epp, Sackney and Kustachey, 1994).

The representations of these biased cultural beliefs is problematic in light of the literature's reporting of disproportional underrepresentation of females in the superintendency, (Glass, 2000: Holland, 2011), legacy of comparably lower wages for female faculty, (Banerji, 2006) employment, promotion and tenure inequities 


\section{GENDER REPRESENTATIONS IN ED.D. DISSERTATIONS}

for female faculty (AAUW, 2004; AAUP, 2006; Banerji, 2006: Wilson, 2006), and female educational leaders and scholars fear of negative career repercussions from addressing gender equity issues (Bronstein \& Romaley, 2002; Rusch, 2004; Skrla, Reyes \& Scheurich, 2000).

Additionally, studies of females in the superintendency suggest that many female educational leaders have challenges in seeing themselves as leaders, developing a leadership identity and feeling confident about their career preparation (Scherr, 1995). Improving the representation of females as leaders, intellectual authority and eminence in the collective body of educational leadership scholarship could make it easier for females to see themselves in this role and increase overall perceptions of the public of females in roles of leadership intellectual authority and eminence.

\section{Question 2. Finding 2. Black males "othered"}

The findings in this study represent a gendered cultural belief that white males are the universal male and males of color are the "other". McDowell and Sharp (1999) define othering as "as related to another person or persons existing distinct from oneself, different in identity, kind or quality" (p.194). The concept of otherness exists in opposition to the concept of universal and creates a binary categorization of individuals characterized as either the norm or deviant cases from the norm. 


\section{GENDER REPRESENTATIONS IN ED.D. DISSERTATIONS}

McIntosh (2001) states that Whites are conditioned to think their lives as normative with no racial identity and only "others" are described in racial terms. Of the 115 male focused studies, mentioning ethnicity, only 2 times did the research specifically indicate it was a study of White males. However, in contrast, 69 indicated they were studies of Black males, 29 Hispanic/Latino males, 3 Chinese males, 1 Indian male, 1 Filipino, and 1 Saudi. Black males were also portrayed as deviant or deficient 20 times.

The concept of other as one that is different in kind or quality from the mythical norm is salient when reviewing the findings of male focused gender dissertations because when race is mentioned it is predominately males of color and it is often represented from a different, deviant or deficient perspective. For example:

The attitudes of rural eight grade Black males towards academic learning and its impact on academic achievement (Crawford, 2002), Raising Abel: What do African American single mothers do to raise successful African American middle school boys? (Rascoe, 2003), or Social cognition and language: Abusive language and the African-American juvenile transgressor (Bibb,1999).

Sometimes titles imply that individual or family deficiencies are the cause of academic achievement issues. Although not all of the titles that focus on the study of black males represent the deficiency or deviancy perspective, there are 


\section{GENDER REPRESENTATIONS IN ED.D. DISSERTATIONS}

enough problematic representations to reinforce negative gendered cultural beliefs about Black males.

Feminist and postcolonial scholars critique the act of othering as a discursive practice which serves to reinforce power relations of dominance (Dines \& Humez, 2002; Harding, 1998; Said, 1978). The production of knowledge about those not in power by representing them as inferior others has historically been utilized by White, upper class, males of European descent as members of the ruling class, to maintain the status quo (McDowell and Sharp, 1999). The discursive practice of othering was used in popular upper class $19^{\text {th }}$ century media such as Harpers Weekly in the US and Punch in the UK to reinforce unjust policies and practices that oppressed non-dominant groups (Dines \& Humez, 2002).

Hurtado (2001) states "Each oppressed group in the United States is positioned in a particular and distinct relationship to white men, and each form of subordination is shaped by this relationship" (p.152). The commonality sexism, racism, classism and other forms of oppression share is inequity based on hierarchal social categorization and the ability of those in power to effectively maintain it (Dines \& Humez, 2002). Othering males of color and othering females is not merely about race and gender, it is about who has the cultural power to influence opinion through access to media and other forums of representation. 


\section{GENDER REPRESENTATIONS IN ED.D. DISSERTATIONS}

Historically, males of color and females have been compared and both represented as deficient and deviant others as a means of social control. Harding (1998) describes how sexist, racist and orientalist discourses of $19^{\text {th }}$ century colonialist science projects informed each other and served to legitimize relations of power. Stephan (1996) offers the example of Carl Vogt's scientific comparisons of brain weights and skull sizes of females with male Africans and infants as a form of legitimation and rationalization for maintaining subordinate roles to those in power.

In this way the findings regarding males of color in this study parallel findings from previous feminist content analysis studies of journal articles about females; they were both marginalized and represented as deviant or deficient to a mythical norm (Hayes \& Smith, 1994; Wolgemuth, Kees \& Safarik, 2003). Hayes and Smith (1994) remind us feminist scholarship needs to be more than just scholarship about gendered people, it needs to have a critical consciousness to represent them fairly without perpetuating problematic cultural beliefs that support gender inequities.

It is problematic that this discursive practice is represented in the findings because dissertation scholarship exemplifies the production of knowledge in the discipline of education. The perceived legitimacy of academic literature makes its' discursive power even more insidious as a means of reproducing inequities. 


\section{GENDER REPRESENTATIONS IN ED.D. DISSERTATIONS}

\section{Finding 3. Latinas silenced}

The findings illuminate an androcentric linguistic pattern that although it also represents a cultural norm for the Spanish language, silences and subordinates Latina voices. The male term Latino is used to describe samples that consist of both males and females. In some instances the androcentric term Latino is used to describe studies consisting of predominately female participants (Chowdhurey, 2006; Hernandez, 2005; Riviera, 2007; Robles-Goodwin, 2001).

This finding is very provocative and illuminates both the commonalities and conflicting tension that often exist between multiculturalism and feminism. A postcolonial and indigenous research perspective may critique research requirements for sample participant descriptions and research reporting that does not consider and respect their cultural linguistic traditions.

However, I think a legal analogy could be an appropriate lens to view some of these tensions regarding research norms or reporting rules and to guide a researcher: Does this behavior of silencing Latinas comply with the letter of the law, or the intention of the law? If the intention of a postcolonial research perspective is to protect the rights of non-dominant cultures to accurately represent themselves and their knowledge, we must also ask, is the intention being honored or the knowledge accurately represented if the cultural norms silence participants because of their gender? 


\section{GENDER REPRESENTATIONS IN ED.D. DISSERTATIONS}

Of course, a critical, postcolonial perspective might also ask "whose law"? Who created these norms and who benefits by their continuation? It does provoke researcher reflexivity on how should research proceed when scientific reporting norms and cultural norms conflict? Cannella and Manuelito remind us of the challenges of transnational feminist interpretations when they state, "we recognize we always run the risk of privileging certain perspectives and marginalizing, essentializing or even erasing others" (2008, p.46).

Although, as a feminist researcher I wish to respect indigenous traditions and multicultural perspectives, I believe it is also important to illuminate cultural traditions that subordinate and silence groups of people because of their gender. Harding (1998) reminds us, just because research represents a certain cultural perspective, it doesn't mean that it is accurate, fair or empowering. Males cannot be fairly or even rationally positioned as the definitive voice of knowledge, when female voices are a main contributor to that knowledge, but are silenced because of linguistic cultural traditions.

This distorted representation of the experiences and perceptions of Latina females usurped under the androcentric term Latino reinforces cultural gender beliefs that males are the creators and envoys of cultural knowledge. As Sandra Harding (1985) remarks, "only women are assumed to be the bearers of gender and only men are the bearers of culture" (p.90). 


\section{GENDER REPRESENTATIONS IN ED.D. DISSERTATIONS}

Using the masculine term Latino to describe a mixed population sample falsely assumes and represents a mythical gender neutrality. However, gender is often one of the most valuable explanatory variables in examining social patterns (Harding, 1986). Ignoring potential gender differences and overgeneralizing research findings to describe a mythical genderless human has been critiqued by feminist scholars as bad science (Fox Keller, 1996; Haraway, 1996; Harding, 1986).

Accurate sample description not only a scholarly obligation, but an ethical one; the use of biased androcentric language in reporting research can privileges males at the expense of females (Harding, 1986). Language that privileges males devalues females and serves to maintain and reinforce sexist behaviors and perceptions (Briere \& Lanktree, 1983).

The findings that many of the dissertations involving Latinos and Latinas use a Spanish linguistic cultural norm with androcentric bias in assigning titles to their studies and describing their samples is troubling. The literature finds the use of biased language is more likely to be associated with those who hold sexist beliefs. For example, Jacobsen and Insko (1985) found that writers with stereotypically sexist attitudes and beliefs were more likely to use sexist pronouns and descriptors in their writing. Additionally, those who endorse sexist beliefs 


\section{GENDER REPRESENTATIONS IN ED.D. DISSERTATIONS}

were less likely to recognize sexist language or to register it as problematic (Swim, Mallett \& Stangor, 1994).

In the findings representing dissertation research about Latinas, basic research reporting improvements such as improved sample description, elimination of biased language and avoidance of overgeneralizations would be an improvement for gender equity. As was mentioned earlier in this report in the previous discussion of institutional variances, the literature from feminist empiricists suggest some androcentric bias can be eliminated by stricter adherence to methodological and research standards (Fox Keller, 1996; Harding, 1986). Accurately describing samples, eliminating biased language and avoiding overgeneralizations are also basic research reporting standards endorsed in the Publication Manual of the American Psychological Association, $6^{\text {th }}$ Edition, which establishes academic writing norms in the discipline of education (American Psychological Association, 2009).

\section{Finding 4. Title IX trivialized}

Since the frequency of a topic's occurrence is an indicator of the cultural consciousness and commitment to the topic, the findings of this study do not indicate the discipline of education has a high consciousness or commitment to understanding or implementing Title IX federal legislation gender equity policy. 


\section{GENDER REPRESENTATIONS IN ED.D. DISSERTATIONS}

This implies a cultural belief that gender equity is not a topic of concern or high priority in the discipline of education.

The scanty representation of dissertations examining federal educational gender equity policy is of concern since, the frequency of a concept or idea in a body of text indicates consciousness and commitment to the idea (Krippendorf, 2004). This conclusion also mirrors concerns expressed by scholars in the 2007 Handbook for Achieving Gender Equity through Education; They state "Over the past 20 years, there have been indicators of continued ignorance and neglect by educators about their gender equity responsibilities and knowledge of Title IX" (Klein, Homer, Kramarae, Nash, Burger, \& Shevitz, 2007, p. 656).

Of the 15,014 dissertations completed between 1998 and 2007, less than 1\%, could be found mentioning Title IX, of the Education Amendments of 1972 (Title IX). Title IX is a comprehensive federal law that prohibits discrimination on the basis of gender in any education program in institutions that receive federal funds (U.S. Department of Justice, 2010). The U.S. Department of Justice official website (2010) states, “ The principal objective of Title IX is to avoid the use of federal money to support sexually discriminatory practices in education programs such as sexual harassment and employment discrimination and to provide individual citizens effective protection against those practices". 


\section{GENDER REPRESENTATIONS IN ED.D. DISSERTATIONS}

Not only is federal gender equity policy rarely examined in this sample of Ed.D. dissertation scholarship, the Title IX research represented in the sample also trivializes issues of gender inequity by offering a narrow policy framing that focuses inquiries solely on athletic program gender equity. Although Title IX encompasses a wide range of gender equity compliance issues as indicated in the prior paragraph, 10 of the 12 dissertations addressing title IX issues focused solely on athletic program gender equity.

In addition, during the same frame as the Ed.D. research in this sample, the U.S. Office of Civil Rights reported that gender discrimination cases in educational institutions comprised 7\% of the civil rights complaints in 2001, 2002 and 2003 (Nash, Klein, Bitters, Hobbs, Howe, Shevitz, \& Wharton, 2007). During 3 of the years included in this study's sample, 1997, 2004, and 2006, of the Department of Education's Office for Civil Rights also sent reminder letters to all state and local school superintendents and college presidents requesting educational leaders pay attention to issues of gender inequity, and specifically to review Title IX policies and grievance procedures (Nash, Klein, Bitters, et al, 2007).

Educational leaders are charged with the ensuring fair treatment for the students, teachers and staff in their institutions as well as implementing federal and state educational policies that govern their institutions. It should be of concern that the findings of this study show such scanty representation of research studies 


\section{GENDER REPRESENTATIONS IN ED.D. DISSERTATIONS}

focusing on the most significant gender equity legislation to be enacted in the United States in over 40 years.

In light of the prominent role dissertation scholarship plays in the discipline of educational leadership (Murphy \& Vriesenga, 2006) and gender equity in education (Shakeshaft, Brown, et al, 2007), the paucity of Ed.D. dissertation scholarship from U.S. public doctoral granting institutions of this key federal civil rights and gender equity education policy illuminates a problematic research gap that should be of concern to leaders and scholars in the discipline of education.

\section{Finding 5. LGTBIQ Issues Silenced}

The scarcity of dissertations examining LGTBIQ issues in the findings also implies an overall conceptualization of gender as a heterosexual issue, pertaining primarily to biological and binary categories of male and female. This gender conceptualization silences and marginalizes individuals whose sexual orientation, gender identity or gender expression does not align with hetero-normative cultural beliefs. Kosciw, Byard, Fischer and Joslin (2007) state " one of the most common methods of perpetuating heterosexist norms is by ignoring LGBT issues altogether, thereby sending out the message that non-heterosexual individuals do not exist or are not to be acknowledged" (p.563).

The finding that less than $1 \%$ of the 1185 titles gender focused titles examined mentioned LGTBIQ issues in the dissertation titles has problematic 


\section{GENDER REPRESENTATIONS IN ED.D. DISSERTATIONS}

implications for the safety and well-being of staff and educators employed in educational institutions and the students entrusted to their care.

The literature indicates educational leaders report their preparation programs rarely provide content or discussion regarding the prevention of bullying based on perceived gender identity (Lugg, 2003), yet there is overwhelming evidence that LGTBIQ students are frequently targeted for harassment and even violence by classmates (Kosciw \& Diaz, 2005; Kosciw,Greytak, Diaz, Bartkiew, 2010). Kimmel and Mahler's (2003) study of the 28 school shootings from 19822001 concluded that homophobic acts of bullying precipitated each of these violent acts.

The 2005 National School Climate Survey (Kosciw \& Diaz, 2005) reports that $75 \%$ of students report routinely hearing derogatory remarks about gender expression or sexual orientation. Additionally, when discriminatory and derogatory remarks are made in the presence of teachers or staff, only $16.5 \%$ of students report intervention by school personnel. Furthermore, $18.6 \%$ of students report that discriminatory and derogatory gender terms and remarks are made by teachers and school staff.

More recently, the 2010 GLSEN National School Climate Survey report that 62.4\% of LGTBIQ students do not report acts of harassment because they feel staff 


\section{GENDER REPRESENTATIONS IN ED.D. DISSERTATIONS}

would not intervene and $33.9 \%$ of LGTBIQ students who do report incidences, report a lack of response by educational staff in their schools.

Kosciw et al (2007) surmised that a possible reason for a lack of support and intervention by educators and staff may be the fear of reprisals and negative consequences from school administrators or community members. Teachers have found they can suffer negative repercussions for LGTBIQ advocacy efforts and for introducing controversial topics to their students. A Laramie high school teacher was terminated after pressures from the School board and community for initiating classroom activities and discussion based on the play The Laramie Project, which tells the story of the brutal murder of Matthew Shepard, a gay youth (Toppo, 2009).

In light of literature discussing gender inequity, oppression and violence towards LGTBIQ identified individuals in educational institutions, the Ed.D. dissertation scholarship is problematically nearly silent on these issues with less than $1 \%$ dissertations providing voice to these concerns.

\section{Finding 6. Feminism marginalized}

The findings of this study do not indicate the discipline of education has a high consciousness or commitment to feminist research methods or analysis in Ed.D. dissertation scholarship. When comparing the findings of this study with the prior literature it also confirms a diminishing focus in feminist inquiry. 


\section{GENDER REPRESENTATIONS IN ED.D. DISSERTATIONS}

Krippendorff's (2004) states the presence of absence of a topic indicates the cultural awareness and consciousness and the frequency of occurrence in a body of text is an indicator of its cultural importance. The findings of this study indicate educational leaders completing a dissertation in U.S. public doctoral granting institutions in 1998 to 2007 implies a cultural lack of consciousness regarding feminist inquiry or that feminism is considered unimportant or unnecessary in the creation of knowledge about teaching, learning and administration in US educational institutions.

When we compare these findings to the literature it also shows a disturbing trend of diminishing interest in feminist analysis in spite of continuing gender discrimination and inequities in US institutions as detailed in the introduction and literature review of this study. Twombly's (1993) study indicates feminist thinking was more prevalent in the 70's than in the 80 's. She found less gender focused articles published after 1984, in the 80 's where only $11 \%$ of any of the female gender focused articles utilized a feminist perspective.

As time goes on, it appears the landscape of feminist inquiry becomes more bleak. The findings of this study of Ed.D. dissertations parallels findings of Parson and Ward's (2001) and Hart's (2006) feminist content analysis of journals in the paucity of studies examining feminism or using a feminist analytical lens. Parson and Ward's (2001) study focusing on articles published from 1980-1996 in 


\section{GENDER REPRESENTATIONS IN ED.D. DISSERTATIONS}

eight journals, The Journal of Higher Education, The Review of Higher Education and Research in Higher Education, Educational Evaluation and Policy Analysis, Educational Policy, Policy Sciences, Policy Studies Journal, and Policy Studies Review also found that approximately $1 \%$ utilized a feminist perspective.

Hart's study (2006) focused on articles published from 1990-2002 in The Journal of Higher Education, The Review of Higher Education and Research in Higher Education. Of the 1065 articles, Hart found less than 1\% of the published higher education articles explicitly mentioned a feminist perspective in the article's title or abstract. The data findings from this study along with the Hart (2006) and Parson and Ward, 2001) journal content analysis studies show diminishing focus in the number of feminist inquiries since Townsend's (1993) study completed in the 70's and 80's.

Reflection on the scanty representation of Ed. D dissertations mentioning feminism or feminist analysis in light of previous literature we must consider these findings could represent a fear of academic and professional backlash against feminist scholarship. For example, Skrla, Reyes, and Scheurich`s (2000) findings report female educational leaders perceive gender as an unwelcome and risky topic of discussion with school boards, state educational agencies and legislatures which could result in negative professional, economic and personal repercussions. Additionally, studies have found faculty often avoid engaging in overt gender 


\section{GENDER REPRESENTATIONS IN ED.D. DISSERTATIONS}

equity activities because they can result in negative teaching evaluations and negatively impact promotion and tenure decisions (Bronstein \& Ramaley, 2002; Rusch, 2004).

\section{Question. 2. Gender Beliefs \& Conceptualizations: Tetreault's Phase Theory}

The findings from closer examination of the sample through the purposefully selected 185 abstracts and the full text from 9 selected dissertations continue to reveal and exemplify a low level of integration of feminist theory in the discipline of education's Ed.D. dissertation scholarship. Tetreault 's feminist phase theory provides a systematic guide to assess curricular and scholarly integration of gender scholarship and evolving gender conceptualization into the disciplinary canon (Tetreault, 1985). Deeper examination of the abstracts confirmed the problematic cultural gender beliefs and conceptualizations found in Phase I of the study.

Abstracts from three of the emergent categories were selected because pattern of problematic gender conceptualization emerged such as, a.) privileging masculine leadership, b.) Othering Black males, and c.) silencing Latinas. Abstracts from the other three emergent categories were selected because of a pattern of scanty representation such as a.) silencing LGTBIQ, b.) Title IX trivialization, and c.) feminist marginalization. 


\section{GENDER REPRESENTATIONS IN ED.D. DISSERTATIONS}

Comparisons of the abstracts and full dissertation text with Tetreault's (1985) guide confirmed patterns of problematic gender bias and representations indicating cultural gender beliefs and conceptualizations in the earlier phases of Tetreault's (1985) feminist phase theory, especially in the dissertation scholarship on gendered leadership and Latino/a issues.

Tetreault's Phase I, androcentric knowledge, is represented in the abstracts of Latino/a studies that conceptualize knowledge as androcentric, where male experience is the universal norm. This is exemplified in subordinating and silencing the voice of Latina research subjects by aggregating their experience with males and labeling it as Latino knowledge.

Additionally, the findings revealed a prevalence of Phase II and Phase III representations in the abstracts on gendered leadership which serve to reinforce biased gendered cultural beliefs that males and females exhibit different leadership traits and have differing abilities to lead. The representations of Tetreault's Phase II and III include the framing of studies to examine cultural beliefs regarding females versus male leadership qualities, or discussions of agentic vs community aspects of leadership behaviors.

Even the abstracts selected because the title indicated feminist or feminism were mixed in the integration of feminist theory into the scholarship. Many of these abstracts also had a high number of representations in the lower phases of 


\section{GENDER REPRESENTATIONS IN ED.D. DISSERTATIONS}

Tetreault's phase theory. Although lower phases recognizes male and female difference, which provides a good start in understanding gender difference that can lead to gender inequities, these phases do not critique the social construction of gender or gender roles. Additionally, the lower phases of Tetreault do not recognize other complex intersections of identity that impact gender equity.

Phase three of Tetreault begins to discuss gender as a social construction but has varying degrees of criticism or acceptance of that conceptualization. For example representations in the initial levels of phase three describe the different roles that males and female occupy and often these representation are uncritically examined. The representations exemplified in phase three often examine or describe agentic versus communal behavioral traits or discuss tensions and issues between responsibilities in either the public or private spheres.

Phase 3 representations of female role responsibilities in the private sphere as a factor in leadership, without a corresponding representation of male role responsibilities in the private sphere reinforces biased cultural beliefs that maintaining the physical home space and caring for family members is only a female problem.

Although the purposefully selected sampling of abstracts identified to illuminate and exemplify themes of problematic gender bias does not allow for generalization, there are enough cases of dissertations representing biased gendered 


\section{GENDER REPRESENTATIONS IN ED.D. DISSERTATIONS}

cultural beliefs and conceptualizations in the sample for concern. It indicates that even when scholars intentionally represent that their study looks at gender, they can still inadvertently reinforce problematic gender cultural beliefs.

For example, when dissertations examining gendered leadership discuss the challenges of maintaining a home and attending to childcare issues when discussing female leaders, often exemplified by Tetreault's phases 2 and 3, yet these facets of the life are ignored when discussing male leaders it reinforces gendered cultural beliefs about gender roles and appropriate gendered behavior. Additionally, when intersecting variables of identity are ignored when examining gender, Tetreault's phase 4 , it can paint a false picture of progress in gender equity in educational institutions when some groups such as white, upper class, heterosexual, young women make incremental gender equity advancements in access to and benefits from education, when a more critical examination can reveal continuing discrimination.

The use of the sequential phases in Tetreault's (1985) feminist phase theory as a curriculum or disciplinary assessment tool provides a useful guide to not only assess where are we at, but also provides a glimpse into where we might go next to integrate a more gender fair perspective into our work. As the work of scholars and educators progresses towards the higher Tetreault Phases, 4 and 5, it begins to be more representative of integration of gender theory into the canon. The intention of 


\section{GENDER REPRESENTATIONS IN ED.D. DISSERTATIONS}

categorizing gender focused scholarship is not to be too critical of curricular or scholarly attempts to address gender equity, but to serve as an indicator of where we are and illuminate a potential path to progression.

Huestis (2004) describes the introduction of Tetreault's phases into the disciplinary canon and discourse on a continuum of either gender indoctrination or gender liberation, where the earliest phases of Tetreault's continue to represent gender biased beliefs and conceptualizations of gender, whereas the later phases represent more gender equitable beliefs and conceptualizations. Additionally, Nielson and Abromit (1993) state that explicit critique and resistance to gender performance norms in the academic disciplinary canon doesn't occur until the later portions of Tetreault's Phase 3, Bifocal scholarship, and in the Feminist scholarship, Phase 4, and Multifocal scholarship, Phase 5.

\section{Fear, silencing and discrimination}

The findings of this study along with reflection on existing literature reaffirms, "we're not there yet" as a discipline in the representations of gendered cultural beliefs and conceptualizations in the body of literature that informs our field. The implication that "we are not there yet" when it comes to a disciplinary consciousness and commitment to gender equity, not only parallels the literature that informed this study, but was also exemplified in the final phase of this study, the review of 9 full text dissertations. 


\section{GENDER REPRESENTATIONS IN ED.D. DISSERTATIONS}

The 9 dissertations represent three categories of individuals that frequently experience gender discrimination, females in educational leadership positions, Black males in academic settings and LGTBIQ students in our educational institutions. The examination of the complete dissertations affirmed findings from the abstracts and additionally revealed a common interconnected theme of fear, silencing and discrimination related to cultural gender beliefs and gender conceptualizations. The fear of social stigma, negative career repercussions and even violence resulting from the perceived failure to conform to cultural gender expectations in educational institutions has a stifling impact on the realization of human potential.

Although, the small purposefully selected sample of 9 dissertations is not generalizable, as educational leaders entrusted with the care and safety of students and faculty in our nation's educational institutions, the representations of fear, discrimination and reports of protective self-silencing present in the dissertation scholarship matters. A summary discussion with recommendations for doctoral program planning and research follows.

\section{Summary Discussion}

Gender focus in Ed.D. Dissertation is not prevalent, especially when considering the sampling strategies in this study purposely included several studies who only incidentally or peripherally indicated gender. Additionally, problematic 


\section{GENDER REPRESENTATIONS IN ED.D. DISSERTATIONS}

biases were revealed in the representations of gender cultural beliefs and conceptualizations during closer examinations of the abstracts and full text.

The findings of scanty and problematic representations of values, beliefs and commitments to gender equity from this examination of Ed.D. dissertations, a culminating document produced, disseminated and utilized by educational leaders, are troubling. Especially since, the U.S. Department of Labor Glass Ceiling Commission (1995) cites the critical nature of leadership values, beliefs and commitments in creating and maintaining gender fair institutions.

Additionally, professional educational associations from K-12, postsecondary and adult education and training in the discipline of education unanimously report the need for greater attention and improvements in the preparation and evaluation of educational leaders in the development of equity values and commitments.

My recommendations based on the findings, previous literature and my personal experiences encompass increasing the focus on gender equity in doctoral program planning and evaluation activities and undertaking gender focused institutional and program research.

\section{Doctoral Program Planning, Practice and Evaluation Recommendations}

The findings have significant implications for planning and evaluation of doctoral training programs in the discipline of education. The low prevalence of 


\section{GENDER REPRESENTATIONS IN ED.D. DISSERTATIONS}

gender focused scholarship and concentration of representations of problematic

biased gender beliefs and conceptualizations suggests a need for curriculum improvements.

We must also question why so few dissertations examined LGTBIQ issues, Title IX, or utilized a Feminist analytical lens. The scanty representation of research in these three key areas that support gender equity issues and advocacy is cause for concern.

Additionally, themes of silencing, and self-silencing out of fear of stigmatization or negative consequences resulting from gender equity advocacy in the full text dissertations examined suggests a need for attending to doctoral programs' gender equity climate. Doctoral programs should increase their attention on both including gender scholarship into program content and creating an inclusive climate for gender focused scholars. My specific practice recommendations include:

- Include gender scholarship in educational doctorate course content.

- Develop professional learning communities that foster interdisciplinary collaborations with gender studies scholars.

- Hire faculty with evidence of gender equity values and commitments. 


\section{GENDER REPRESENTATIONS IN ED.D. DISSERTATIONS}

- Imbed evidence of equity commitments into faculty promotion and tenure review process.

- Initiate and support faculty professional development in gender focused research projects.

- Encourage and support doctoral candidates engaged in gender focused research.

- Systematically and periodically review Ed.D scholarship emanating from the program for evidence of gender equity values, beliefs and commitments.

\section{Doctoral Program Gender Focused Research Recommendations}

I recommend undertaking institutional research to better understand factors that support or inhibit gender focused scholarship. Considering the findings in light of previous literature, several research avenues could be productive areas of inquiry to add to existing knowledge, such as:

- How is the topic gender equity introduced into course content in doctoral programs?

- What are current socialization norms of doctoral students and new faculty in regards to gender equity discourse and research? 


\section{GENDER REPRESENTATIONS IN ED.D. DISSERTATIONS}

- What types of curriculum and program evaluations are being done at the doctoral level to assess leadership values regarding gender equity?

- What are the differences between institutions that have a high scholarly gender focus in dissertations and institutions with little or no gender focus in dissertations?

- What is the impact of dissertation advising on gender focused scholarship?

The catalyst for these research questions stems from the three key findings of, a.) low prevalence of gender focus, b.) institutional variance in gender focus, and c.) correlation of gender focus with overall institutional research focus. Reflection on these findings in light of the current literature follows.

\section{Research recommendation: Low prevalence of gender focus.}

In light of the evidence of continued gender inequities in US educational institutions discussed in this dissertation's literature review, a natural question arising from the findings is :Why is there so little gender focus overall in the Ed.D. dissertation scholarship represented in this large 10 year sample?

Since the values, beliefs and commitments of an institutions's leadership are key to developing gender fair institutions (US Department of Labor, 1995) and the values, beliefs and commitments of educational leaders are developed during their 


\section{GENDER REPRESENTATIONS IN ED.D. DISSERTATIONS}

academic socialization (Anderson \& Swazey, 1998; Austin, 2002; Baird, 1992;

Boyer, 1990; Nettles \& Millet, 2006; Tierney \& Rhoades, 1994; Weidman, Twale $\&$ Stein, 2001), it would be useful for future research studies to examine educational doctorate programs to assess how educational leaders are prepared in regards to gender equity.

Examining the gender equity consciousness and committments in doctoral training programs could be a productive area of inquiry since prior studies also determined, a.) educational leadership course syllabi devote little attention to gender issues, (Hess \& Kelly, 2004 ; Nicholaides \& Gaynor, 1992), b.) gender equity, social justice and diversity topics are poorly represented in educational leadership journals (Murphy \& Vriesenga, 2004), c.) educational leadership students report little gender discussion in their programs (Iselt, Brown \& Irby, 2001 ; Lugg, 2003 ; Skrla, Reyes \& Scheurich, 2000), d.) doctoral students report negative and gendered academic socialization experiences (Kerlin, 1997 ; Kerlin, 1995 ;Kurtz-Costes, Helmke, Ule-Steiner, 2006) and e.) educational leadership faculty often report that conversations in their departments about gender or race issues are infrequent and unproductive (Rusch, 2004) and f.) doctoral educational leader preparation and evaluation research is scanty (Grogan \& Andrews, 2002; Hess \& Kelly, 2007; Levine, 2005; Murphy \& Vriesenga, 2006; Nicholaides \& Gaynor, 1992). 


\section{GENDER REPRESENTATIONS IN ED.D. DISSERTATIONS}

\section{Research recommendations: Institutional focus variation}

I recommend future research to compare and contrast institutions with higher percentages of gender focused research to those with lower percentages to better understand these variances. The wide range of varied prevalence of gender focus in dissertation scholarship in the findings leads to further questions about the multiple factors that may either support or constrain gender focused dissertation scholarship.

Klein, Kramarae and Richardson (2007) remind us that we must build strategies and infrastructure that can address gender inequities on existing knowledge. Devising appropriate interventions to increase gender equity consciousness and commitments in educational leaders and improving gender representations in the discipline's academic literature will require specific knowledge of not only individual research choices, but also of advising, program, institutional and community factors that influence educational doctorate scholarship.

\section{Research recommendation: Gender \& institutional research.}

The difference between $6.6 \%$ gender focus for the lowest research intensive institutions as compared $9.5 \%$ for the highest research focused institutions leads to speculation on possible causes for the discrepancy. One possible explanation could be that institutions that are more research intensive may also have more 


\section{GENDER REPRESENTATIONS IN ED.D. DISSERTATIONS}

departmental research resources, more experienced research faculty and greater expectations for doctoral candidate research that impact and improve the dissertation research process overall which may have an unintended consequence of enhancing gender equity.

Feminist scholars that embrace a feminist empiricist view of research claim that much of the gender inequity found in research studies can be eliminated simply by stricter adherence to methodological and research standards (Fox Keller, 1996; Harding, 1986). Some examples of research quality improvements feminist empiricists suggest include improved sample selection and description, elimination of biased language and careful reporting of findings to avoid generalization.

Future research could examine whether greater research resources, more experienced research faculty and higher research expectations of students lead to more gender consciousness in dissertation research. This avenue of research could have significant implications for faculty development and research support through program funding as a critical social justice issue.

In conclusion, the centrality of values beliefs and commitments of educational leaders to gender fair institutions and the centrality dissertations have in the disciplines knowledge base makes examination of dissertations for representations of gender cultural beliefs and conceptualization a valuable task to understand the persistent social problem of gender inequity. 
GENDER REPRESENTATIONS IN ED.D. DISSERTATIONS

These findings make a contribution to the discipline by adding to the

literature in the areas of a.) Ed.D. dissertation content, b.) institutional variations in scholarly gender focus, and c.) gender representations in the scholarship of educational leaders. The findings also make potential contributions through the implications for practice in doctoral program planning and recommendations for future research. 


\section{GENDER REPRESENTATIONS IN ED.D. DISSERTATIONS}

\section{References}

Abdel-Malik, K. (2004). Heritage to legacy: A content analysis of the Coretta Scott King award-winning picture books from 1976--2004. West Virginia University. ProQuest Dissertations and Theses, Retrieved from http://search.proquest.com/docview/305107789?accountid=15006. (305107789).

Ahuvia, A. (2000). Traditional, interpretive and reception based content analysis: Improving the ability of content analysis to address issues of pragmatic and theoretical concern. Social Indicators Research, 54, 139-172. Retrieved from http://www.springer.com/social+sciences/sociology/journal/11205

Apple, M. (1992). The text and cultural politics. Educational Researcher 21, 4-19.

Altheide, D.L. (1987). Ethnographic content analysis. Qualitative Sociology. 10, 65-77. Retrieved from http://www.springer.com/social+sciences/sociology/journal/11133

Altheide, D., Coyle, M., DeVriese, K. \& Schneider, C. (2008). Emergent qualitative document analysis. In S.N. Hesse-Biber \& P.Leavy (Eds.), Handbook of emergent methods (pp. 127-151). NY: The Guilford Press. 


\section{GENDER REPRESENTATIONS IN ED.D. DISSERTATIONS}

American Association of University Women. (2004). Tenure denied: A case of sex discrimination in academia. Washington, D.C.:American Association of University Women Educational Foundation and American Association of University Women Legal Advocacy Fund. Retrieved from http://www.aauw.org/research/all.cfm

American Association of University Professors. (2006). American Association of University Professors Faculty Gender Equity Indicators 2006. Washington, D.C. : American Association of University Professors Retrieved from http://www.aaup.org/AAUP/pubsres/research/geneq2006

American Association of University Women (1991) Shortchanging girls, shortchanging America. Washington D.C: AAUW.

American Educational Research Association (2011). Social Justice Mission Statement. As Retrieved from the Internet from http://www.aera.net/AboutAERA/KeyPrograms/SocialJustice/SocialJustice MissionStatement/tabid/10950/Default.aspx

Anderson, M. S. \& Swazey, J.P. (1998). Reflections on the graduate student experience: an overview, New Directions for Higher Education, no.101, 313. 


\section{GENDER REPRESENTATIONS IN ED.D. DISSERTATIONS}

Anfara, V.A., Brown, K.M., \& Mangione, T.L. (2002). Qualitative analysis on stage: Making the research process more public. Educational Researcher. 31, 28-38. Retrieved from http://edr.sagepub.com/

Anthony, J (2002) Reexamining doctoral student socialization and professional development: Moving beyond the congruence and assimilation orientation. In J. Smart and W. Tierney (Eds.) Higher Education: Handbook of Theory and Research Vol. XVII (pp349-380). NY: Agathon Press.

Association for the Study of Higher Education. (2007). The theoretical framework: Psychosocial oppression and diversity. Las Vegas, NV: ASHE Higher Education Report. doi:10.1002/aehe.3301

Association for the Study of Higher Education. (2006). Revolutionary concepts of leadership. ASHE Higher Education Report.31, 71-99.

American Society for Training and Development (2011) as retrieved from the internet http://www.astd.org/ASTD/aboutus/missionAndVision/

Austin, A. (2002). Preparing the next generation of faculty. Journal of Higher Education, 3, 94-122.

Baird, L. L. (1992). The stages of the doctoral career: Socialization and its consequences. Paper presented at the American Research Association (San Francisco, CA, April 20-24, 1992). ED 348925. 


\section{GENDER REPRESENTATIONS IN ED.D. DISSERTATIONS}

Banerji, S. (2006, November, 16) AAUP: Women professors lag in tenure, salary. Diverse Issues in Higher Education. 23, 27. Retrieved from http://www.highbeam.com/Diverse+Issues+in+Higher+Education/publicati $\underline{\text { ons.aspx }}$

Bell, J. C. (1999). Five public school principals' perceptions of student-to-student sexual harassment. The University of Alabama at Birmingham. ProQuest Dissertations and Theses, Retrieved from http://search.proquest.com/docview/304492032?accountid=15006. (304492032).

Bem, S.L. (1993) The lenses of gender: Transforming the debate on sexual inequality. New Haven, CT: Yale University Press.

Bensimon, E.M. \& Marshall, C. (1997). Policy analysis for postsecondary education: Feminist and critical perspectives. In C. Marshall (Ed.), Feminist critical policy analysis: A perspective from postsecondary education (pp.123). London and Washington, DC: Falmer Press.

Bensimon, E.M.\& Marshall, C. (2003). Like it or not: Critical feminist policy analysis matters. Journal of Higher Education, 74, 337-349. Retrieved from http://www.ohiostatepress.org/Journals/JHE/jhemain.htm

Bibb, I. (1999). Social cognition and language: Abusive language and the AfricanAmerican male juvenile transgressor. Northern Illinois University. 
GENDER REPRESENTATIONS IN ED.D. DISSERTATIONS

ProQuest Dissertations and Theses, Retrieved from

http://search.proquest.com/docview/304513926?accountid=15006.

(304513926).

Bombardieri, M. (Jan, 17, 2005). Summer's remarks draw fire. The Boston Globe, Jan 17, 2005, Retrieved from http://www.boston.com/news/local/articles/2005/01/17/summers_remarks_ on_women_draw_fire/

Boyer, E. (1990). Scholarship reconsidered: Priorities of the professoriate. San Francisco: Jossey-Bass.

Briere, J., \& Lanktree, C. (1983). Sex-Role Related Effects of Sex Bias in Language. Sex Roles, 9(5), 625-632.

Brooks, A. \& Hesse-Biber, S. N. (2007). An invitation to feminist research. In S. N. Hesse Biber \& P.L. Leavy (Eds.), Feminist Research Practice (pp.1-26). Thousand Oaks, CA: Sage Publications.

Bronstein \& Ramaley (2002). In J.E. Cooper and D.D. Stevens (Eds.) Tenure in the sacred grove: issues and strategies for women and minority faculty (pp. NY: State University of New York Press.

Burow, D. P. (1998). The perceived effectiveness of Milton Erickson's hypnotic communication patterns in counselor supervision. University of South Dakota. ProQuest Dissertations and Theses, , 145-145 p. Retrieved from 
GENDER REPRESENTATIONS IN ED.D. DISSERTATIONS

http://search.proquest.com/docview/304454048?accountid=15006. (304454048).

Canella, G.S \& Manuelito, K.D. (2008). Feminisms from unthought locations: Indigenous worldviews, marginalized feminisms, and revisioning an anticolonial social science. In N.K. Denzin,,Y.S. Lincoln, \& L.T. Smith (Eds.). Handbook of critical and indigenous methodologies (pp. 45-59). Thousand Oaks, CA: Sage.

Carli, L. L., \& Eagly, A. H. (2001). Gender, Hierarchy, and Leadership: An Introduction. Journal Of Social Issues, 57(4), 629.

Carnegie Foundation for the Advancement of Teaching. (2010). Carnegie Classifications of Institutions of Higher Education. Stanford, CA: Carnegie Foundation for the Advancement of Teaching. Retrieved from http://classifications.carnegiefoundation.org/

Chowdhury, J.(2006). Factors affecting retention of first-year Latino students in a private university. (Unpublished doctoral dissertation) Morgan State University, Maryland.

Chuppa-Cornell, K. (2005).The conditions of difficulty and struggle: A discovered theme of curriculum transformation and women studies discourse. NWSA, 17, 23-44. Retrieved from http://muse.jhu.edu/journals/nwsa/ 


\section{GENDER REPRESENTATIONS IN ED.D. DISSERTATIONS}

Clisbee, M. A. (2004). Leadership style: Do male and female school superintendents lead differently? University of Massachusetts Lowell. ProQuest Dissertations and Theses, Retrieved from http://search.proquest.com/docview/305173664 accountid=15006. (305173664).

Code, L (1991). What can she know: Feminist theory and the construction of knowledge. Ithaca and London: Cornell University Press.

Code, L.(1995a). Rhetorical spaces: Essays on gendered locations. NY and London: Routledge.

Code, L. (1995b). How do we know: Questions of method in feminist practice. In L. Code, and S. Burt (Eds.) Changing methods: Feminists transforming practice (pp13-44). Ontario, Canada: Broadview Press.

Collins, P.H. (2000). Black feminist thought: Knowledge, consciousness and the politics of empowerment., $2^{\text {nd }}$ edition. NY:Routledge.

Coughlin, M. (2007). Women and history: Outside the academy, The History Teacher, 40, 471-479. Retrieved from http://www.thehistoryteacher.org/

Cozens, G. A. (1999). An investigation of the learning styles of ninth-grade public school students: Black and white, male and female, general level and gifted/magnet. University of Georgia. ProQuest Dissertations and Theses, Retrieved from 
GENDER REPRESENTATIONS IN ED.D. DISSERTATIONS

http://search.proquest.com/docview/304501053?accountid=15006. (304501053).

Crawford, Q. L. (2002). The attitudes of rural eighth-grade black males toward academic learning and its impact on academic achievement. South Carolina State University. ProQuest Dissertations and Theses, Retrieved from http://search.proquest.com/docview/305437250?accountid=15006. (305437250).

Cresswell, J.W. (2005). Educational Research: Planning, conducting, and evaluating quantitative and qualitative research, $2^{\text {nd }}$ edition. Upper Saddle River New Jersey: Pearson Merrill Prentice Hall.

Denzin, N. (2009). The elephant in the living room: Or extending the conversation about the politics of evidence. Qualitative Researcher, 9, 139-160.

Retrieved from doi:10:1177/146794108098034

DeVault, M.L. (1999). Liberating methods: Feminism and social research. Philadelphia, PA: Temple University Press.

Dines, G. \& Humez, J.M. (2002). Gender, race and class in media: A text reader. Thousand Oaks, CA: Sage.

Doppler, J. E. (2000). A description of gay/straight alliances in the public schools of Massachusetts. University of Massachusetts Amherst. ProQuest Dissertations and Theses, , 187-187 p. Retrieved from 
GENDER REPRESENTATIONS IN ED.D. DISSERTATIONS

http://search.proquest.com/docview/304606555?accountid=15006. (304606555).

Douglass, J.A. (2005). The Carnegie Commission and Council on Higher Education: A retrospective. Research and Occasional Paper Series: CSHE.14.05. Berkeley, CA: Center for Studies in Higher Education.

Eagly, A.H. (2007). Female leadership advantage and disadvantage: Resolving the contradictions. Psychology of Women Quarterly. 31, 1-12.

Epp, J., \& Sackney, L. E. (1994). Reassessing levels of androcentric bias in educational.. Educational Administration Quarterly, 30(4), 451.

Fowler, F.C. (2004). Policy studies for educational leaders. $2^{\text {nd }}$ edition. Upper Saddle River, NJ: Pearson.

Fox Keller, E. (1996) Feminism and science in E. Fox Keller \& H. E. Longino (Eds.). Feminism and Science. (pp.28-40). Oxford \& NY: Oxford University Press.

Freeman, M., deMarrais, K., Preissle, J. Roulston, K. \& St. Pierre, E.A. (2007). Standards of evidence in qualitative research : An incitement to discourse. Educational Researcher. 36, 25-32. doi:10.3102/0013189X06298009

Freud, A. (1967). The ego and the mechanism of defense. Madison, CT: International Universities Press. 


\section{GENDER REPRESENTATIONS IN ED.D. DISSERTATIONS}

Fuller, E., Young, M., \& Baker, B. D. (2011). Do Principal Preparation Programs Influence Student Achievement Through the Building of Teacher-Team Qualifications by the Principal? An Exploratory Analysis. Educational Administration Quarterly, 47(1), 173-216. doi:10.1177/0011000010378613

Gerber, B. S. M. (1999). The selection of high school principals: An examination of the process using feminist phase theory. Oklahoma State University. ProQuest Dissertations and Theses, Retrieved from http://search.proquest.com/docview/304551568?accountid=15006. (304551568).

Giroux, H.A. (1983). Theory and resistance in education: A pedagogy for the opposition. South Hadley, MA: Bergin \& Garvey.

Glass. T.E. (2000). Where are all the women superintendents? The School Administrator, Retrieved from http://www.aasa.org/publications/saarticledetail.cfm?ItemNumber=4046

Golde, C. M. (2004). The responsibility of doctoral programs for the career preparation of future faculty. Peer Review, 6.3, 26-30.

Golde, C. M. \& Dore, T.M. (2004). The survey of doctoral education and career preparation: The importance of disciplinary contexts. In D. Wulff, A. Austin and Associates (Eds). Paths to the professoriate: Strategies for 


\section{GENDER REPRESENTATIONS IN ED.D. DISSERTATIONS}

enriching the preparation of future faculty (pp.19-44).San Francisco: Jossey-Bass.

Grise-Owens, E.Y. (2000). An exploration of gender in/equity in the university curriculum: A content analysis of the "Journal of Social Work Education", 1998-1999. (Doctoral dissertation). Available from ProQuest Dissertation and Thesis database. (AAT 9962321).

Grogan, M. \& Andrews, R. (2002). Defining preparation and professional development for the future. Educational Administration Quarterly. 38, 233256. doi: $10.1177 / 0013161 X 02382007$

Gumport (1991) E Pluribus Unum? Academic structure, culture, and the case for feminist scholarship. The Review of Higher Education 15, 9-29.

Gurin, P. (1985). Women's gender consciousness. Public Opinion Quarterly. 49, 143-163. Retrieved from http://poq.oxfordjournals.org/

Halloran, S. J. (2007). Are there differences in the perceived leadership practices of female and male superintendents as identified by school committee members? University of Massachusetts Lowell. ProQuest Dissertations and Theses, Retrieved from http://search.proquest.com/docview/304847669?accountid=15006. (304847669). 


\section{GENDER REPRESENTATIONS IN ED.D. DISSERTATIONS}

Haraway, D. (1988). Situated knowledge: The science question in feminism and the privilege of partial perspective. Feminist Studies, 14, 575-599. Retrieved from http://www.feministstudies.org/home.html

Haraway, D. (1996). Situated knowledges: The science question in feminism and the privilege of partial perspective. In E. Fox Keller \& H. E. Longino (Eds.).Feminism and science. (pp. 249-263). Oxford \& NY: Oxford University Press.

Harding, S. (1986). The science question in feminism. Ithaca and London: Cornell University Press.

Harding, S. (1998). Is science multicultural? Postcolonialisms, feminisms, and epistemologies. Bloomington, IN:Indiana University Press.

Hart, J. (2006). Women and feminism in higher education scholarship: an analysis of three core journals. The Journal of Higher Education, 77, 1, 40-61. Retrieved from http://www.ohiostatepress.org/Journals/JHE/jhemain.htm

Hawkesworth, M. (1994). Policy studies within a feminist frame. Policy Sciences, 27, 97-118. Retrieved from http://www.springer.com/social+sciences/political+science/journal/11077

Hayes, E. R. \& Smith, L. (1994). Women in adult education: An analysis of perspectives in major journals. Adult Education Quarterly.44, 201, 201-220. Retrieved from http://aeq.sagepub.com/ 


\section{GENDER REPRESENTATIONS IN ED.D. DISSERTATIONS}

Hernandez, R. (2005). College Latino students: cultural integration, retention, and successful completion. (Unpublished doctoral dissertation). Northern Illinois University, Illinois.

Hess, F.M. \& Kelly, A.P. (2007). Learning to lead: What gets taught in principal preparation programs. Teachers College Record, 109, 244-274. Retrieved from http://www.tcrecord.org/

Hesse Biber, S.N. (2007). Putting it all together: Feminist research praxis. In S. N. Hesse Biber \& P.L. Leavy (Eds.), Feminist Research Practice (pp.329-350). Thousand Oaks, CA: Sage Publications.

Holland, E. (2011, January, 24). Gender Gap is narrowing in ranks of school chiefs. St. Louis Today.

hooks, b.(2000). Passionate politics: Feminism is for everybody. Cambridge, MA: South End Press.

Hurtado,A. (2001). The color of privilege. In P. S. Rothenberg, (Ed.) Race, class and gender in the United States, $5^{\text {th }}$ Edition (pp. 152-163). NY: Worth.

Immegart, G. L. (1990). What is truly missing in advanced preparation in educational administration? Journal of Educational Administration. 28, 513.

Iselt, C. C., Brown, G. \& Irby, B. (2001). Gender differences in superintendents' perceptions of superintendent preparation programs. In C.C. Brunner \& L. 


\section{GENDER REPRESENTATIONS IN ED.D. DISSERTATIONS}

G. Bjork (Eds.), Advances in research and theories of school management and educational policy vol. 6, the New Superintendency; pp. 55-75). NY: JAI Elsevier Science.

Jacobson, M. B., \& Insko Jr., W. R. (1985). Use of Nonsexist Pronouns as a Function of One's Feminist Orientation. Sex Roles, 13(1/2), 1-7.

Janowitz, M. (1968). Harold D. Lasswell's Contribution to Content Analysis. Public Opinion Quarterly, 32(4), 646-658.

Johnson, R.B. \& Onwiegbuzie, A. J.(2004). Mixed method research: A research paradigm whose time has come. Educational Researcher. 33, 14-26.

Kerlin, S. (1995). Surviving the doctoral years: Critical perspectives. Educational Policy Analysis, 3, 1-37.

Kerlin, R.A. (1997). Breaking the silence: Towards a theory of women's doctoral persistence. An unpublished dissertation. University of Victoria, BC., Canada.

Kerr, B.A. (1994). Smart girls: A new psychology of girls, women and giftedness. Scottsdale, AZ: Gifted Psychology Press.

Kimmel, M.S. \& Mahler, M. (2003) Adolescent masculinity, homophobia and violence: Random school shootings, 1982-2001. American Behavioral Scientist. 46, 1439-1458. 


\section{GENDER REPRESENTATIONS IN ED.D. DISSERTATIONS}

Kindland, D. \& Thompson, M. (2002). Thorns among roses: The struggle of young boys in early education. In S. Bailey (Ed.), Jossey-Bass reader on gender in education (pp.153-181). San Francisco: Jossey-Bass.

Klein, S.S., Kramarae, C. \& Richardson, B. (2007). Examining the achievement of gender equity in and through education. In S. Klein (Ed.) Handbook for Achieving Gender equity through education. (pp. 1-13). Mahway, NJ: Lawrence Erlbaum Associates, Publishers.

Klein, S.S., Ortman, P.E., Campbell, P. Greenberg, S., Hollingsworth, S., Jacobs, J., Kachuk, B. McClelland, A., Pollard, D., Sadker, D., Sadker, M., Schmuck, P., Scott, E., Wiggins, J. (2004). Continuing the journey towards gender equity. Educational Researcher, 23, 8, 13-21.

Kolbe, R.H. \& Burnett, M.S. (1991). Content analysis research: An examination of applications with directives for improving research reliability and effectivity. Journal of Consumer Research. 18, 243-251. Retrieved from http://www.journals.uchicago.edu/toc/jcr/current?cookieSet=1

Kosciw, J.G. \& Diaz, E.M. (2005). The 2005 National School Climate Survey: The experiences of lesbian, gay, bisexual and transgendered youth in our schools. NY: GLSEN. 
GENDER REPRESENTATIONS IN ED.D. DISSERTATIONS

Kosciw, J. G. Byard,E.S., Fisher, S. N., \& Joslin, C. (2010). The 2010 National

School Climate Survey: The experiences of lesbian, gay, bisexual and transgendered youth in our schools. NY: GLSEN.

Kosciw, J.G., Greytak, E. A. , Diaz, E. M. \& Bartkiewicz (2009). The 2009

National School Climate Survey: The experiences of Lesbian, Gay, Bisexual \& Transgender Youth in our Nation's Schools. NY:GLSEN.

Kottkamp, R. B. (2011). Introduction: Leadership Preparation in Education. Educational Administration Quarterly, 47(1), 3-17. doi:10.1177/0011000010378609

Krippendorf, K. (2004). Content analysis: An introduction to its methodology, $2^{\text {nd }}$ edition. Thousand Oaks, CA: Sage.

Kurtz-Costes, B., Helmke, L.A., \& Ulku-Steiner, B. (2006). Gender and doctoral studies: The perceptions of Ph.D students in an American university. Gender and Education, 18, 137-155.

Laswell, H. (1949).Why be quantitative? In H. Laswell \& N. Leites \& Associates (Eds.) Language of politics: Studies in Quantitative Semantics. (pp.40-52). Cambridge, MA: MIT Press.

Leavy, P.L. (2007). The feminist practice of content analysis. In S.N. Hesse-Biber \& P.L. Leavy (Eds.), Feminist research practice: A primer (pp. 223-248). Thousand Oaks, CA: Sage Publications. 


\section{GENDER REPRESENTATIONS IN ED.D. DISSERTATIONS}

Levine, A. (2005). Educating School Leaders. Washington, D.C.: The Education School Project. Retrieved from http://www.edschools.org/reports_leaders.htm

Lincoln, Y. (1995). Emerging criteria for qualitative in qualitative and interpretive research, Qualitative Inquiry, 1, 275-288.

DOI:10.1177/107778004950010031.

Lovitts, B. E. ( 2001). Leaving the ivory tower: The causes and consequences of departure from doctoral study. Lanham, MD: Rowman and Littlefield.

Lugg, C. A. (2003). Sissies, Faggots, Lezzies, and Dykes: Gender, sexual orientation, and a new politics of education?. Educational Administration Quarterly, 39(1), 95.

Lundeberg, M.J. (1997). "You guys are over-reacting: Teaching prospective teachers about subtle gender bias”. Journal of Teacher Education, 48, 5561.

Madsen, D. (1992). Successful dissertation and theses: A guide to graduate study research from proposal to completion. San Francisco: Jossey-Bass.

Marshall, C., \& Gerstl-Pepin, C. (2005). Re-framing educational politics for social justice. NY: Pearson.

Marshall. C., \& Rossman. G. B. (1995) Designing Qualitative Research, 2nd Edition. Thousand Oaks, CA: Sage Publications. 


\section{GENDER REPRESENTATIONS IN ED.D. DISSERTATIONS}

McDowell, L. \& Sharp, J.P. (1999). A feminist glossary of human geography. NY: Oxford University Press.

McGraw, M. B. (2005). Differences in learning style preference among students of diverse ethnicities, gender, academic placement level, and academic achievement. Florida International University. ProQuest Dissertations and Theses, Retrieved from http://search.proquest.com/docview/305380624?accountid=15006. (305380624).

McIntosh, P. (2001). White privilege: Unpacking the invisible knapsack. In P. S. Rothenberg, (Ed.) Race, class and gender in the United States, $5^{\text {th }}$ Edition (pp. 163-167). NY: Worth.

Minnich, E. K. (1990). Transforming knowledge. Philadelphia: Temple University Press.

Marshall, W. L. (2003). The impact of locus of control on the academic achievement of African American males. South Carolina State University). ProQuest Dissertations and Theses, Retrieved from http://search.proquest.com/docview/305233149?accountid=15006. (305233149).

Mauch, J.E. \& Birch, J.W. (1998). Guide to the successful thesis and dissertation: A handbook for students and faculty. NY: M. Dekker. 


\section{GENDER REPRESENTATIONS IN ED.D. DISSERTATIONS}

Maxwell, J. A. (2005). Qualitative research design: an interactive approach $2^{\text {nd }}$ Edition. Thousand Oaks, CA: Sage Publishing.

McGraw, M. B. (2005). Differences in learning style preference among students of diverse ethnicities, gender, academic placement level, and academic achievement. Florida International University. ProQuest Dissertations and Theses, Retrieved from http://search.proquest.com/docview/305380624? accountid=15006. (305380624).

Murphy, J. \& Shipman, N. (1998).The Interstate Leaders Licensure Consortium: A standards based approach to strengthening educational leadership. Paper presented at the American Educational Research Association in San Diego, CA.

Murphy, J. \& Vriesenga, M. (2006). Research on school leadership preparation in the United States: An analysis, School Leadership and Management, 26, 183-195. doi: 10:1083/13634230600589758

Nash, M. A., Klein, S.S., Bitters,,B., Hobbs, S. Howe, W., Shevitz, L., Wharton, L. \& Smeal, E. (2007). The role of government in advancing gender equity in education. In S.S. Klein (Ed.) Handbook for achieving gender equity through education $2^{\text {nd }}$ Edition (pp. 63-102). Mahwah, NJ: Lawrence Erlbaum Associates. 
GENDER REPRESENTATIONS IN ED.D. DISSERTATIONS

National Council for Accreditation for Teacher Education (2008). Standards.

Washington, D.C. : National Council for Accreditation for Teacher

Education. Retrieved from

http://www.ncate.org/public/standards.aspCouncil

Nettles, M. T. \& Millett, C. M. (2006). Three magic letters: Getting to Ph.D.

Baltimore, MD: John Hopkins Press.

Neuendorf, K. A. ( 2004). The content analysis guidebook. Thousand oaks, CA: Sage.

Nicolaides, N. \& Gaynor, A. K. ( 1992). The knowledge base informing the teaching of administrative and organizational theory in UCEA universities: A descriptive and interpretive survey: Educational Administrative Quarterly, 28, 237-265.

Nielson, J. M. \& Abromeit, J. (1993) Paradigm shifts, feminist phase theory and the missing variable in women's studies curriculum transformation projects. Sociological Forum, 8, 73-91.

Orr, M. (2011). Pipeline to Preparation to Advancement: Graduates’ Experiences In, Through, and Beyond Leadership Preparation. Educational Administration Quarterly, 47(1), 114-172. doi:10.1177/0011000010378612

Orr, M., \& Orphanos, S. (2011). How graduate-level preparation influences the effectiveness of school leaders: A comparison of the outcomes of 


\section{GENDER REPRESENTATIONS IN ED.D. DISSERTATIONS}

exemplary and conventional leadership preparation programs for principals. Educational Administration Quarterly, 47(1), 18-70.

doi:10.1177/0011000010378610

Parsons, M., and Ward, E.R. (2001). The roaring silence: Feminist revisions in the policy literature. Policy Studies Review, 18.2, 46-64. Retrieved from http://www.wiley.com/bw/journal.asp?ref=1541-132x

Pasteris, P. J. (1998). Investigating the differences in leadership styles and effectiveness between male and female public high-school principals in Illinois. Northern Illinois University. ProQuest Dissertations and Theses, Retrieved from http://search.proquest.com/docview/304440632?accountid=15006. (304440632).

Perez, L. G., Uline, C. L., Johnson, J. F., James-Ward, C., \& Basom, M. R. (2011). Foregrounding fieldwork in leadership preparation: The transformative capacity of authentic inquiry. Educational Administration Quarterly, 47(1), 217-257. doi:10.1177/0011000010378614

Pollack, W. (2002). Real boys: The truth behind myths. In S. Bailey (Ed.), JosseyBass reader on gender in education (pp.88-100). San Francisco: JosseyBass. 


\section{GENDER REPRESENTATIONS IN ED.D. DISSERTATIONS}

Poletti, M. (2011, January, 29). Study shows gender becomes non-issue as gender gap narrows among school superintendents. Quincy Herald Whig.

Proquest. (2010). UMI dissertation publishing. Ann Arbor, MI : Proquest. Retrieved from http://www.proquest.com/en-US/products/dissertations/

Rascoe, L. E. (2003). Raising abel: What do African American single mothers do to raise successful African American middle school boys. Indiana University. ProQuest Dissertations and Theses, Retrieved from http://search.proquest.com/docview/305335817?accountid=15006. (305335817).

Reinharz, S. (1992). Feminist research methods in the social sciences. NY:Oxford University Press.

Rivera, R. (2000). Latino community college transfer students in engineering: Transition experiences and academic success at a large research university. (Unpublished doctoral dissertation). Arizona State University, Arizona.

Roach, V., Smith, L., \& Boutin, J. (2011). School leadership policy trends and developments: policy expediency or policy excellence?. Educational Administration Quarterly, 47(1), 71-113. doi:10.1177/0011000010378611

Robles-Godwin, P.J. (2001). An investigation into the perceptions of Latino parents of young children in urban, suburban and rural school settings. (Unpublished doctoral dissertation). Texas Women's University, Texas. 


\section{GENDER REPRESENTATIONS IN ED.D. DISSERTATIONS}

Rusch, E. A. (2004). Gender and race in leadership preparation: A constrained discourse. Educational Administration Quarterly, 40(1), 16-48. doi: $10.1177 / 0013161 X 03259110$

Sadker, M. \& Sadker, D. (1994). Failing at fairness: How our schools cheat girls. NY:Simon \& Schuster.

Sadker, D., Zittleman, K. , Earley, P., McCormick, T. , Strawn, C. \& Preston, J. A. (2007). The treatment of gender equity in teacher education. In S. Klein (Ed.) Handbook for Achieving Gender equity through education. (pp. 131150). Mahway, NJ: Lawrence Erlbaum Associates, Publishers.

Said, E. (1978) Orientalism: Western conceptions of the Orient. London: Routledge \& Kegan Paul.

Salley, L. D. (2005). Exploring the relationship between personal motivation, persistence, and resilience and their effects on academic achievement among different groups of African-American males in high schools. University of Maryland, College Park. ProQuest Dissertations and Theses, Retrieved from http://search.proquest.com/docview/304994117?accountid=15006. (304994117). 


\section{GENDER REPRESENTATIONS IN ED.D. DISSERTATIONS}

Sandler, B.R., Silverberg, L.A., and Hall, R.M. (1996). The chilly classroom climate: A guide to improve the education of women. Washington DC: National Association for Women's Education.

Safarik, L. (2003). Feminist transformation in higher education: Discipline, structure and institution. The Review of Higher Education, 26, 419-445.

Sasnett, B. (2006). Leadership styles of interdisciplinary health science education leaders of Quentin Burdick programs. East Carolina University. ProQuest Dissertations and Theses, Retrieved from http://search.proquest.com/docview/304937299?accountid=15006. (304937299).

.Scherr, M. W. (1995). The glass ceiling reconsidered: Views from below. In P. M. Dunlap \& P.A.Schmuck (Eds). Women leading education. (pp. 313-323). Albany, NY: State University of New York.

Schuster, M.R. \& Van Dyne, S. (1984). Placing women in the liberal arts: Stages of curriculum transformation. Harvard Educational Review, 54, 413-428. Retrieved from http://www.hepg.org/main/her/Index.html

Shakeshaft, C., Brown, g. , Irby, B. J., Grogan, M. \& Ballenger, J. (2007). Increasing gender equity in educational leadership. In S. Klein (Ed.) Handbook for Achieving Gender equity through education. (pp. 103-129). Mahway, NJ: Lawrence Erlbaum Associates, Publishers. 


\section{GENDER REPRESENTATIONS IN ED.D. DISSERTATIONS}

Shores, J. L. (2007). A feeling of belonging: Impacts of gay-straight alliances on high school students. Arizona State University. ProQuest Dissertations and Theses, Retrieved from http://search.proquest.com/docview/304896107?accountid=15006. (304896107).

Skrla, L., Reyes, P. \& Scheurick, J.J. (2000). Sexism, silence and solutions; women superintendents speak up and speak out. Education Administration Quarterly. 36, 44-75.

Spender, D. (1981). The gatekeepers: A feminist critique of academic publishing in H. Roberts (Ed.), Doing feminist research (pp. 186-202). London: Routledge and Kegan Paul.

Stein, S.J. (2004). The culture of education policy. NY: Teachers College Press. Stephan, N. L. (1998) Race and gender: the role of analogy in science in E. Fox Keller \& H.E. Longino (Eds.).Feminism and Science. (pp 121-136). Oxford \& NY: Oxford University Press.

Sternberg, D. (1981). How to complete and survive a doctoral dissertation. NY: St. Martin's Press.

Strauss, A. \& Corbin, J. (1990). Basics of qualitative research: Grounded theory procedures and techniques. Newbury Park, CA: Sage Publications. 


\section{GENDER REPRESENTATIONS IN ED.D. DISSERTATIONS}

Swim, J. K., Mallett, R., \& Stangor, C. (2004). Understanding Subtle Sexism: Detection and Use of Sexist Language. Sex Roles, 51(3/4), 117-128.

Talone, C. J. (2006). Gay-straight alliances in high schools: A case study of four urban, public schools. University of California, Los Angeles. ProQuest Dissertations and Theses, Retrieved from http://search.proquest.com/docview/305340417? accountid=15006. (305340417).

Tanner, J. C. (2000). A feminist phase theory exploration of the development of levels of gender awareness in the superintendency. Oklahoma State University. ProQuest Dissertations and Theses, Retrieved from http://search.proquest.com/docview/304653374?accountid=15006. (304653374).

Tetreault, M.K. (1985). Feminist phase theory: An experience based evaluation model. Journal of Higher Education, 56, 363-384. Retrieved from http://www.ohiostatepress.org/Journals/JHE/jhemain.htm

Tierney, W.G. \& Bensimon, E.M. (1996). Promotion and tenure: Community and socialization in academe. NY: State University of New York Press.

Tierney, W.G. and Rhoads, R.A. (1994). Faculty socialization as a cultural process: A mirror of institutional commitment. ASHE-ERIC Higher 


\section{GENDER REPRESENTATIONS IN ED.D. DISSERTATIONS}

Education Report No.93-6. Washington, D.C.: The George Washington University, School of Education and Human Development.

Toppo,G. (2009, March, 17). Gay-themed film cost Oklahoma teacher her job. USA Today. Retrieved from the internet http://usatoday30.usatoday.com/news/education/2009-03-16-teacherlaramie_N.htm

Townsend, B.K. (1993). Feminist scholarship in core higher education journals. The Review of Higher Education. 17, 1, 21-41. Retrieved from http://www.press.jhu.edu/journals/review_of_higher_education/

Twombly, S. (1993). What we know about women in community colleges: An examination of literature using feminist phase theory. Journal of Higher Education, 63, 186-210. Retrieved from http://www.ohiostatepress.org/Journals/JHE/jhemain.htm

United States Department of Labor. (1995). A fact-finding report of the Federal Glass Ceiling Commission. Washington, D.C: U.S. Department of Labor.

Walker, G.E., Golde, C.M., Jones, L. Conklin Bueschel, A. \& Hutchings, P. (2008). The formation of scholars: Rethinking doctoral education in the twenty-first century. San Francisco: Jossey Bass.

Weber, R. P. (2004). Content analysis in C. Seale (Ed.) Social Research Methods: A Reader. (pp.117-124). 


\section{GENDER REPRESENTATIONS IN ED.D. DISSERTATIONS}

Weidman, J. C. and Stein, E. (2003). Socialization of doctoral students to academic norms. Research in Higher Education. 44, 641-656.

Weidman, J.C. ,Twale, D. J. \& Stein, E.L. (2001). Socialization of graduate and professional students in higher education: A perilous passage? ASHE/ERIC Higher Education Report 28, no.3. San Francisco: Jossey Bass.

Wilson, R. (2004, December, 3) Where the elite teach, it's still a man's world. Chronicle of Higher Education, 51, pA8-A14. Retrieved from http://chronicle.com/section/Home/5

Wolford, N. (1998). The difference in physical fitness levels of fifth graders according to socioeconomic groups and gender. University of Kansas. ProQuest Dissertations and Theses, Retrieved from http://search.proquest.com/docview/304429289?accountid=15006. (304429289).

Wolgemuth, J.H., Kees, N.L. \& Safarik, L.(2003). A critique of research on women published in the Community College Journal of Research and Practice, 1990-2000. Community College Journal of Research and Practice, 27, 757767. Retrieved from http://www.tandf.co.uk/journals/tf/10668926.html 
GENDER REPRESENTATIONS IN ED.D. DISSERTATIONS

Appendix A. Tetreault's Feminist Phase Theory Coding Rubric

\begin{tabular}{|c|c|c|}
\hline \multicolumn{2}{|c|}{$\begin{array}{l}\text { Tetreault's Feminist Phase Theory Coding } \\
\text { Rubric }\end{array}$} & Dissertation Text \\
\hline $\begin{array}{l}\text { Phase 1 } \\
\text { Male } \\
\text { scholarship }\end{array}$ & $\begin{array}{l}\text { 1.a. Androcentric } \\
\text { 1.b. Male experience is the } \\
\text { universal norm. }\end{array}$ & \\
\hline $\begin{array}{l}\text { Phase } 2 \\
\text { Compensatory } \\
\text { scholarship }\end{array}$ & $\begin{array}{l}\text { 2.a. Acknowledgement of male } \\
\text { \& female difference. } \\
\text { 2.b. Female experiences } \\
\text { compared to male norms. } \\
\text { 2.c. Exceptional women added to } \\
\text { male cultural story. } \\
\text { 2.d. Biological difference }\end{array}$ & \\
\hline $\begin{array}{l}\text { Phase } 3 \\
\text { Bifocal } \\
\text { scholarship }\end{array}$ & $\begin{array}{l}\text { 3.a. Gender as social } \\
\text { construction. } \\
\text { 3.b. Male \& female dual } \\
\text { categories } \\
\text { 3.c. Public vs Private spheres } \\
\text { 3.d. Agentic vs. Community } \\
\text { aspects of gender. }\end{array}$ & \\
\hline $\begin{array}{l}\text { Phase } 4 \\
\text { Feminist } \\
\text { scholarship }\end{array}$ & $\begin{array}{l}\text { 4.a. Recognition of complex } \\
\text { multiple intersections of } \\
\text { diversity impacting gender } \\
\text { experiences, such as race, } \\
\text { ethnicity, religion, sexual } \\
\text { preference, or social class. }\end{array}$ & \\
\hline $\begin{array}{l}\text { Phase } 5 \\
\text { Multifocal or } \\
\text { relational } \\
\text { scholarship }\end{array}$ & $\begin{array}{l}\text { 5.a. Gender balanced perspective } \\
\text { of commonality as well as } \\
\text { particularity of male/female } \\
\text { experience } \\
\text { 5.b. Critiques social construction } \\
\text { of masculinity \& femininity }\end{array}$ & \\
\hline
\end{tabular}


GENDER REPRESENTATIONS IN ED.D. DISSERTATIONS

Appendix B. Coding Dictionary

\begin{tabular}{|l|l|}
\hline Female & Terms indicating gender focus \\
& $\begin{array}{l}\text { girl, woman, mother, sister, aunt, grandmother, wife, feminine, } \\
\text { femininity, feminist, headmistress, maternal, matriarchy, } \\
\text { sorority, her, she } \\
\text { anatomical/biological terms or specific medical conditions } \\
\text { such as: vagina, breast, ovary, uterus, pregnancy, menstrual, } \\
\text { breastfeeding, ovary, ovarian cancer, menopause } \\
\text { Ethnic gendered references such as: Chicana, Latina } \\
\text { Female names such as: Superintendent Susan Castillo, Senator } \\
\text { Patty Murray, bell hooks }\end{array}$ \\
\hline Male & $\begin{array}{l}\text { boy, man, father, brother, uncle, grandfather, husband, } \\
\text { masculine, masculinity, headmaster, paternal, patriarchy, } \\
\text { fraternity, his, he } \\
\text { anatomical/biological terms or specific medical conditions such } \\
\text { as: penis, testicle, testicular cancer, prostrate cancer, erectile } \\
\text { dysfunction } \\
\text { Ethnic gendered references such as: Chicano, Latino } \\
\text { Male names such as: U.S. Secretary of Education Arne Duncan, } \\
\text { President Barack Obama, John Dewey }\end{array}$ \\
\hline LGTBIQ & $\begin{array}{l}\text { lesbian, gay, transvestite, transsexual, transgendered, bisexual, } \\
\text { intersexed, queer, homosexual, homophobia, butch, dyke }\end{array}$ \\
\hline Other & $\begin{array}{l}\text { gender, gender equity, discrimination, gender discrimination, } \\
\text { gender neutrality, gender blindness, gender gap, gendered sex, } \\
\text { sexual harassment, sexual abuse, sexual assault, rape, Title IX, } \\
\text { glass ceiling, pink collar ghetto, separate sex, single sex, co- } \\
\text { educational, sexual orientation, sexuality, sexual expression, } \\
\text { heterosexual, heteronormative, feminism, feminist }\end{array}$ \\
\hline Lations
\end{tabular}


GENDER REPRESENTATIONS IN ED.D. DISSERTATIONS

\section{Appendix C. Coder Training \& Instructions}

\section{Coding Instructions:}

1. Review the list of words and expressions indicating gender focus from the coding dictionary supplied in Table A.

2. Examine each individual Ed. D. dissertation title for terms from the dictionary indicating gender focus.

3. Mark the coding sheet in the left hand box near each individual title if the title includes terms indicating gender focus. See example \# 3 on Table A.

4. Leave the left hand box near the title blank if the title does not include terms indicating gender focus. See example \#4 on Table A.

5. Count the number of gender focused titles on each page and report the count on top right hand side of each individual page. See example \#5 on Table A.

6. Mark and add a question mark next to an individual title that has an ambiguous term not listed in the coding dictionary that might indicate gender. See example \#6

7. Report separately at the top left hand side of the page any potential gender focused titles containing ambiguous words or phrases not in the coding dictionary. See example \#7 on Table A.

8. Sign and date each individual page of the coding sheets near the reported page count. See example \#8 on Table A.

9. Take a 10 minute break every two hours 
GENDER REPRESENTATIONS IN ED.D. DISSERTATIONS

Appendix C. Coding Instructions-Phase I (p.2. of 4.)

Coding Dictionary: Words \& Phrases Indicating Gender Focus

\begin{tabular}{|c|c|}
\hline & Terms indicating gender focus \\
\hline Female & $\begin{array}{l}\text { girl, woman, mother, sister, aunt, grandmother, wife, } \\
\text { feminine, femininity, feminist, headmistress, maternal, } \\
\text { matriarchy, sorority, her, she } \\
\text { anatomical/biological terms or specific medical } \\
\text { conditions } \\
\text { such as: vagina, breast, ovary, uterus, pregnancy, } \\
\text { menstrual, , breastfeeding, ovary, ovarian cancer, } \\
\text { menopause } \\
\text { Ethnic gendered references such as: Chicana, Latina } \\
\text { Female names such as: Superintendent Susan Castillo, } \\
\text { Senator Patty Murray, bell hooks }\end{array}$ \\
\hline Male & $\begin{array}{l}\text { boy, man, father, brother, uncle, grandfather, husband, } \\
\text { masculine, masculinity, headmaster, paternal, patriarchy, } \\
\text { fraternity, his, he } \\
\text { anatomical/biological terms or specific medical } \\
\text { conditions such as: penis, testicle, testicular cancer, } \\
\text { prostrate cancer, erectile dysfunction } \\
\text { Ethnic gendered references such as: Chicano, Latino } \\
\text { Male names such as: U.S. Secretary of Education Arne } \\
\text { Duncan, President Barack Obama, John Dewey }\end{array}$ \\
\hline LGTBIQ & $\begin{array}{l}\text { lesbian, gay, transvestite, transsexual, transgendered, } \\
\text { bisexual, intersexed, queer, homosexual, homophobia, } \\
\text { butch, dyke }\end{array}$ \\
\hline Other & $\begin{array}{l}\text { gender, gender equity, discrimination, gender } \\
\text { discrimination, gender neutrality, gender blindness, gender } \\
\text { gap, gendered sex, sexual harassment, sexual abuse, } \\
\text { sexual assault, rape, Title IX, glass ceiling, pink collar } \\
\text { ghetto, separate sex, single sex, co-educational, sexual } \\
\text { orientation, sexuality, sexual expression, heterosexual, } \\
\text { heteronormative, feminism, feminist }\end{array}$ \\
\hline
\end{tabular}


GENDER REPRESENTATIONS IN ED.D. DISSERTATIONS

\section{Appendix C. Coding Instructions-Phase I (p.3. of 4.)}

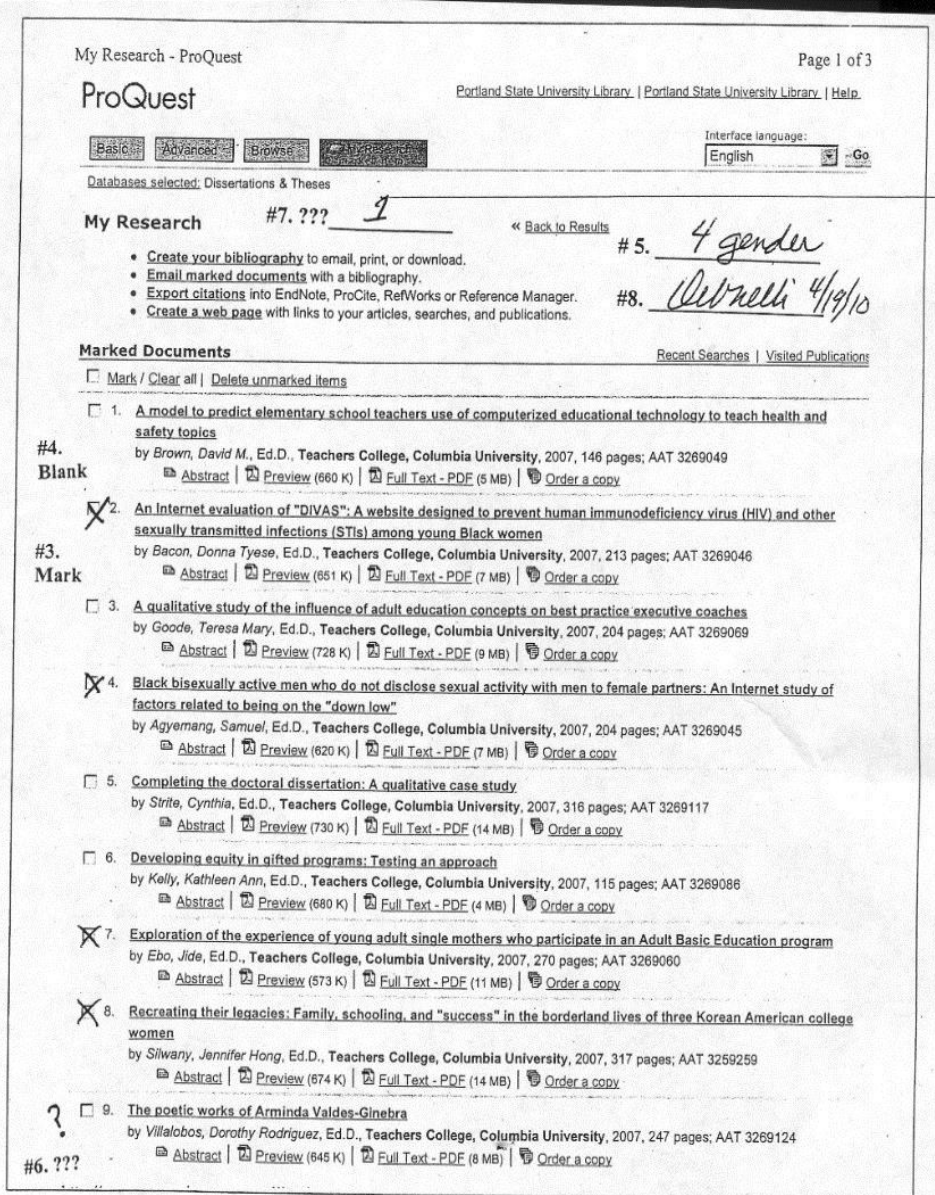


GENDER REPRESENTATIONS IN ED.D. DISSERTATIONS

Appendix C. Coding Instructions-Phase I (p. 4. of 4.)

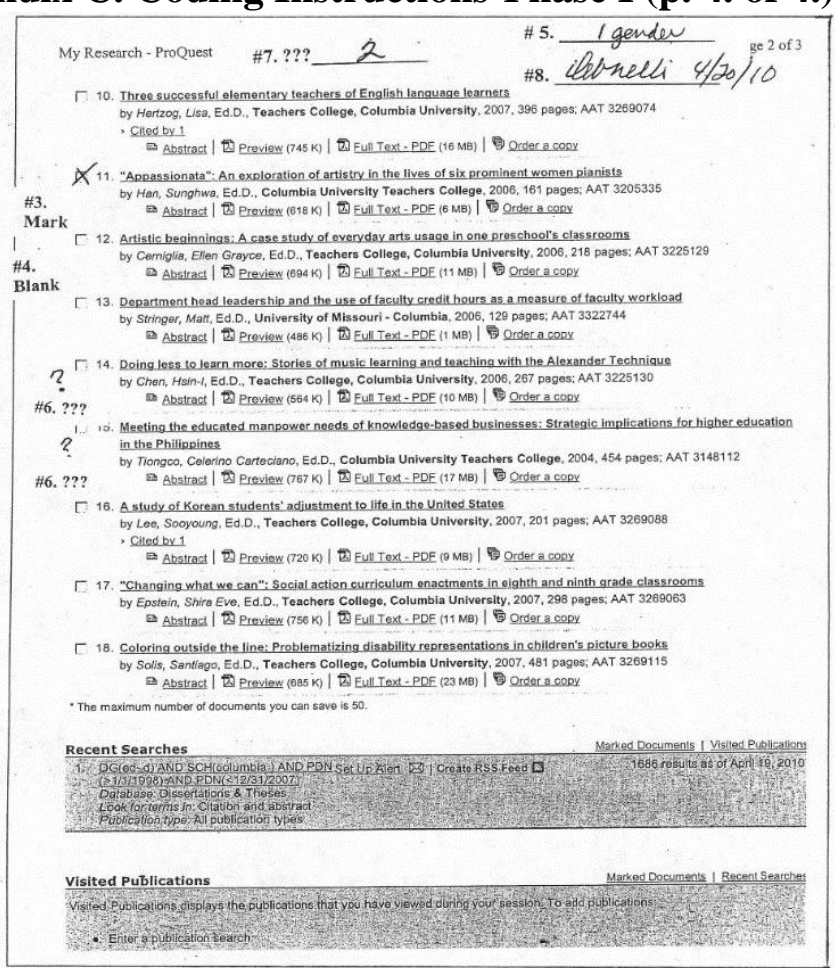


GENDER REPRESENTATIONS IN ED.D. DISSERTATIONS

Appendix D. PSU Human Subjects Waived Review Application

\section{S E C T I O N I}

$\Delta \quad$ Investigator's Assurance

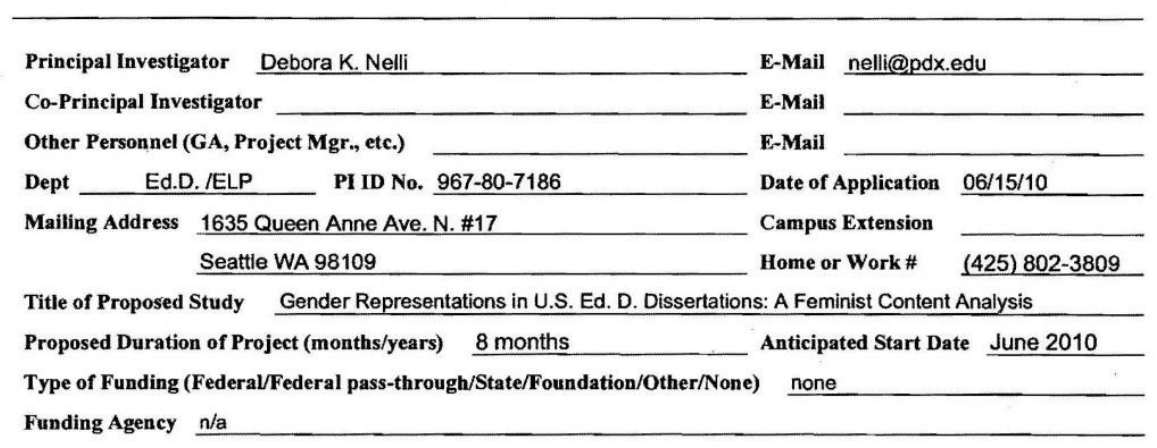

DPlease note that data collection cannot begin until approval is granted by the HSRRC

INVESTIGATOR'S ASSURANCE

A. I will promptly report changes in the proposed study and any unanticipated problems involving risk to subjects, including adverse reactions, to the Human Subjects Review Committee. In case of DHHS supported activities, I will also report these problems to the Department of Health and Human Services (through the respective granting office).

B. I assure that documentary evidence of informed consent will be retained for at least three years after the proposed study has been completed or discontinued.

C. Since the Committee is obligated to review this activity at least on an annual basis, I will furnish it with a progress report no later than six weeks prior to the expiration of my project's approval.

D. I, the undersigned, will be responsible for the ethical standards of this project, and for protecting the rights and welfare of

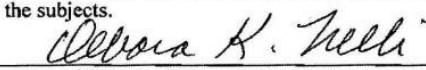

Signature of Principal Investigator

I have reaptapd approved this proposgl? Departiment Head (PRINT)

If this is part of a thesis/dissertation/project, the proposal must be approved PRIOR to HSRRC Review.

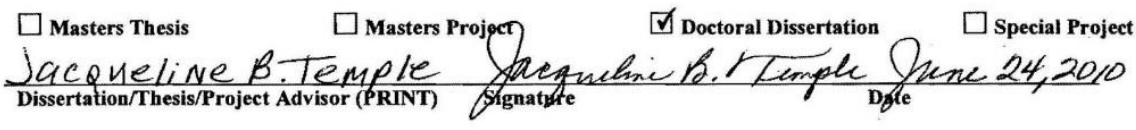

Advisor's E-Mail Address: templej@pdx.edu

$\square$ Please complete and return this form, along with your HSRRC application, and copies to the HSRRC, Office of Research \& Sponsored Projects (ORSP), 600 Unitus Bldg., Portland State University Phone: (503) 725-4288 / 1-877-480-4400 
GENDER REPRESENTATIONS IN ED.D. DISSERTATIONS

II. Project Title and Prospectus

\section{Gender Representations in Ed.D. Dissertations : A Feminist Content Analysis}

The U.S. Glass Ceiling Commission identified key factors in ameliorating institutional gender discrimination were the values, beliefs and commitments of the institution's leaders (U.S. Dept of Labor, 1995). However, little is known about the preparation or evaluation of educational leaders, especially at the doctoral level (Hess \& Kelly, 2007, Grogan \& Andrews, 2002; Levine, 2005; Murphy \& Vriesenga, 2004). In spite of the significance of dissertation scholarship as both a textual representation of the values of educational leaders and a key academic literature artifact, dissertations are an under examined resource.

This research uses sequential mixed method feminist content analysis to examine the gender values, beliefs and commitments represented by future educational leaders in Ed.D. Dissertations. Two questions guiding this inquiry are: 1.) How prevalent is gender focused inquiry in Ed.D. dissertation scholarship from 1998-2007? 2.) What are the cultural gender beliefs and gender conceptualizations represented in Ed.D. dissertation scholarship from 1998-2007?

The initial quantitative phase will use a large sample composed of the entire census of Ed.D. dissertations from U.S. public doctoral granting 


\section{GENDER REPRESENTATIONS IN ED.D. DISSERTATIONS}

institutions between 1998-2007. Trained coders will examine titles Ed. D. dissertations to identify and quantify gender focused scholarship to address the prevalence of gender focus.

The following qualitative phase selects a small sample from the initial quantitative phase findings to examine for in depth analysis. The qualitative data analysis is primarily informed by Tetreault's (1985) feminist phase theory used as an analytical tool to categorize representations of gender cultural beliefs and gender conceptualizations from the text of selected gender focused dissertations. The qualitative data analysis will also be informed by Altheide, Coyle, DeVriese and Schneider's (2008) emergent qualitative document analysis, utilizing a grounded theory approach to data analysis to uncover emergent themes.

\section{Exemption Claim for Waiver of Review}

This proposed research project requests a waiver of review. The Application Guidelines for Research Involving Human Subjects (Portland State University, 2006) specify under provision number 4, the following criteria for a waived review:

Research involving the collection or study of existing data, documents, records, pathological specimens, or diagnostic specimens, if these sources are publicly available, or if the information is recorded by the investigator in such a manner that subjects cannot be identified directly or through identifiers linked to 


\section{GENDER REPRESENTATIONS IN ED.D. DISSERTATIONS}

the subjects. Secondary data that has identifiers falls under waived (p.9).

This research project involves the study of existing documents that are publicly available, Ed.D.Dissertations. Although dissertation documents do con contain a key identifier, the author's name, it is not private information, The public nature of these pre-existing documents and the normative non-confidential nature of Ed.D. dissertation authorship should qualify the proposed study for an exemption claim for waived review.

Additionally, the textual content of Ed.D. dissertations would be considered secondary data, since the textual content is pre-existing and distributed publicly, which would also qualify this study for a waived review, under current Portand State University HRRSC guidelines.

IV. Subject Recruitment

No human subjects will be recruited for participation in this study.

\section{Informed Consent}

No human subjects will be recruited for participation in this study.

\section{First Person Scenario}

No human subjects will be recruited for participation in this study.

VII. Potential Risks and Safeguards

No human subjects will be recruited for participation in this study.

VIII. Potential Benefits

No human subjects will be recruited for participation in this study.

IX. Confidentiality, Records and Distribution 
GENDER REPRESENTATIONS IN ED.D. DISSERTATIONS

In a content analysis of existing public documents, there is no expectation of anonymity or confidentiality, since these types of documents and accompanying identifying information are already accessible to the public.

To comply with federal regulations on data storage, all data coding sheets, data analysis records and research memos will be kept for at least three years and stored in a locked file cabinet in my home office, with limited access.

\section{Appendices}

References cited in the application are included. 


\section{GENDER REPRESENTATIONS IN ED.D. DISSERTATIONS}

\section{References}

Altheide, D., Coyle, M., DeVriese, K. \& Schneider, C. (2008). Emergent qualitative document analysis. In S.N. Hesse-Biber \& P.Leavy (Eds.), Handbook of emergent methods (pp. 127-151). NY:The Guilford Press.

Grogan, M. \& Andrews, R. (2002). Defining preparation and professional development for the future. Educational Administration Quarterly. 38, 233-256. doi:10.1177/0013161X02382007

Hess, F.M. \& Kelly, A.P. (2007). Learning to lead: What gets taught in principal preparation programs. Teachers College Record, 109, 244-274. Retrieved from http://www.tcrecord.org/

Levine, A. (2005). Educating School Leaders. Washington, D.C.: The Education School Project. Retrieved from http://www.edschools.org/reports_leaders.htm

Murphy, J. \& Vriesenga, M. (2006). Research on school leadership preparation in the United States: An analysis, School Leadership and Management, 26, 183-195. doi: 10:1083/13634230600589758

Tetreault, M.K. (1985). Feminist phase theory: An experience based evaluation model. Journal of Higher Education, 56, 363-384. http://www.ohiostatepress.org/Journals/JHE/jhemain.htm United States Department of Labor. (1995). A fact-finding report of the Federal Glass Ceiling Commission. Washington, D.C: U.S. Department of Labor. 
GENDER REPRESENTATIONS IN ED.D. DISSERTATIONS

Appendix E. Alphabetical list 173 Carnegie US public doctoral Inst.

\begin{tabular}{|l|l|l|l|l|}
\hline$\#$ & Public Doctoral Institution & Carnegie & $\begin{array}{l}\text { Ed.D } \\
1998-2007\end{array}$ & $\begin{array}{l}\text { \# with } \\
\text { Ed.D }\end{array}$ \\
\hline 1 & Air Force Institute of Tech & DRU & None & NA \\
\hline 2 & Arizona State U-Tempe & RUVH & 276 & 28 \\
\hline 3 & Auburn U & RUH & None & NA \\
\hline 4 & Ball State U & DRU & 187 & 12 \\
\hline 5 & Bowie State U & DRU & None & NA \\
\hline 6 & Bowling Green State U & RUH & 62 & 3 \\
\hline 7 & Central Michigan University & DRU & 32 & 3 \\
\hline 8 & Clemson U & RUH & 35 & 1 \\
\hline 9 & Cleveland State University & RUH & None & NA \\
\hline 10 & College of William \& Mary & RUH & 65 & 4 \\
\hline 11 & Colorado School of Mines & RU/H & None & NA \\
\hline 12 & Colorado State & RUVH & None & NA \\
\hline 13 & CUNY Grad Schoool \& University & RUVH & None & NA \\
\hline 14 & East Carolina U & DRU & 117 & 8 \\
\hline 15 & East Tennessee State U & DRU & 258 & 15 \\
\hline 16 & Florida Agricultural \& Mechanical & DRU & None & NA \\
\hline 17 & Florida Atlantic U & RUH & 141 & 5 \\
\hline 18 & Florida International & RUH & 208 & 14 \\
\hline 19 & Georgia Institute of Technology & RUVH & None & NA \\
\hline 20 & George Mason & RUH & 1 & 0 \\
\hline 21 & Georgia State & RUVH & None & NA \\
\hline 22 & Georgia Southern & DRU & 146 & 24 \\
\hline 23 & Idaho State & DRU* & 88 & 2 \\
\hline 24 & Illinois State & DRU & 153 & 2 \\
\hline 25 & Indiana U- Bloomington & RUVH & None & NA \\
\hline 26 & Indiana U-Purdue & RUH & 133 & 12 \\
\hline 27 & Indiana U of Pennsylvania & DRU & 97 & 12 \\
\hline 28 & Indiana State & DRU & None & NA \\
\hline 29 & Iowa State U & RUVH & None & NA \\
\hline 30 & Jackson State U & RUH & None & NA \\
\hline 31 & Kansas State U & RUH & 88 & 3 \\
\hline 32 & Kent State U & DRU & None & NA \\
\hline 33 & Lamar U & RUVH & None & NA \\
\hline 34 & Louisiana State \& Agriculture & DRU & 41 & 1 \\
\hline 35 & Louisiana Tech & RUH & None & NA \\
\hline 36 & Miami University -Oxford & & & \\
\hline & & & & \\
\hline
\end{tabular}


GENDER REPRESENTATIONS IN ED.D. DISSERTATIONS

\begin{tabular}{|c|c|c|c|c|}
\hline 37 & Michigan State U & RUVH & None & NA \\
\hline 38 & Michigan Technology University & RUH & None & NA \\
\hline 39 & Middle Tennessee State & DRU & None & NA \\
\hline 40 & Mississippi State U & RUH & 41 & 1 \\
\hline 41 & Morgan State & DRU & 127 & 13 \\
\hline 42 & Montana State & RUVH & 105 & 6 \\
\hline 43 & New Jersey Institute of Technology & RUH & None & NA \\
\hline 44 & New Mexico State University & RUH & 66 & 7 \\
\hline 45 & North Carolina A \& T State U & DRU & None & NA \\
\hline 46 & North Carolina State U -Raleigh & RUVH & 299 & 33 \\
\hline 47 & North Dakota State U-Main & RUVH & None & NA \\
\hline 48 & Northern Arizona U & RUH & 234 & 19 \\
\hline 49 & Northern Illinois University & RUH & 607 & 77 \\
\hline 50 & Oakland University & DRU & None & NA \\
\hline 51 & Ohio State U & RUVH & None & NA \\
\hline 52 & Ohio U & RUH & 13 & 3 \\
\hline 53 & Oklahoma State Main & RUH & 424 & 25 \\
\hline 54 & Old Dominion U & RUH & None & NA \\
\hline 55 & Oregon State U & RUVH & 76 & 9 \\
\hline 56 & Pennsylvania State-Main & RUVH & 21 & 5 \\
\hline 57 & Portland State U & DRU & 69 & 2 \\
\hline 58 & Purdue U -Main & RUVH & None & NA \\
\hline 59 & Rutgers U-New Brunswick & RUVH & 250 & 32 \\
\hline 60 & Rutgers U -Newark & RUH & None & NA \\
\hline 61 & Sam Houston State U & DRU & 102 & 7 \\
\hline 62 & San Diego State & RUH & 23 & 2 \\
\hline 63 & South Carolina State U & DRU & 150 & 13 \\
\hline 64 & South Dakota State U & RUH & None & NA \\
\hline 65 & $\begin{array}{l}\text { Southern Illinois University } \\
\text { Carbondale }\end{array}$ & RUH & None & $\mathrm{NA}$ \\
\hline 66 & Stony Brook U & RUVH & None & NA \\
\hline 67 & SUNY-Albany & RUVH & 31 & 1 \\
\hline 68 & SUNY-Binghampton & RUH & 40 & 5 \\
\hline 69 & SUNY-Buffalo & RUVH & 41 & 1 \\
\hline 70 & Temple U & RUH & 310 & 32 \\
\hline 71 & Tennessee State U & DRU & 316 & 21 \\
\hline 72 & $\begin{array}{l}\text { Texas A \& M University-College } \\
\text { Station }\end{array}$ & RUVH & 94 & 11 \\
\hline 73 & Texas A \& M University-Commerce & DRU & 317 & 23 \\
\hline
\end{tabular}


GENDER REPRESENTATIONS IN ED.D. DISSERTATIONS

\begin{tabular}{|c|c|c|c|c|}
\hline 74 & Texas A \& M University-Corpus Ch & DRU & None & NA \\
\hline 75 & Texas A \& M University-Kingsville & DRU & 209 & 3 \\
\hline 76 & Texas Southern U & DRU & 167 & 15 \\
\hline 77 & Texas Tech U & RUVH & 161 & 11 \\
\hline 78 & Texas Woman's U & DRU & 14 & 2 \\
\hline 79 & The Florida State University & RUVH & 62 & 7 \\
\hline 80 & The U of Montana & RUVH & YES & \\
\hline 81 & The U of Texas-Arlington & RUH & None & NA \\
\hline 82 & The U of Texas Dallas & RUH & None & NA \\
\hline 83 & The U of Texas-El Paso & RUH & 55 & 4 \\
\hline 84 & The U of Texas-San Antonio & RUH & None & NA \\
\hline 85 & The U of West Florida & DRU & 10 & 1 \\
\hline 86 & U of Akron & RUH & 64 & 8 \\
\hline 87 & The U of Alabama & RUH & 219 & 15 \\
\hline 88 & U of Alabama-Birmingham & RUVH & 36 & 2 \\
\hline 89 & U of Alaska-Fairbanks & RUH & None & NA \\
\hline 90 & U of Arizona-Tucson & RUVH & 70 & 4 \\
\hline 91 & U of Arkansas & RUH & 111 & 12 \\
\hline 92 & U of Arkansas- LR & DRU & 72 & 1 \\
\hline 93 & U of Buffalo & RUVH & None & NA \\
\hline 94 & U of C- Berkeley & RUVH & 23 & 3 \\
\hline 95 & U of C-Davis & RUVH & 81 & 5 \\
\hline 96 & $\mathrm{U}$ of C. Irvine & RUVH & $* * \mathrm{~b}$ & $* * \mathrm{~b}$ \\
\hline 97 & U of C- Los Angeles & RUVH & $268^{\mathrm{b}}$ & 31 \\
\hline 98 & Uof C-Riverside & RUVH & None & NA \\
\hline 99 & U of C-San Diego & RUVH & None & NA \\
\hline 100 & U of C-Santa Cruz & RUVH & None & $\mathrm{NA}$ \\
\hline 101 & U of Central Florida & RUH & 383 & 12 \\
\hline 102 & U of Cinncinnati-Main & RUVH & 282 & 52 \\
\hline 103 & U Colorado-Boulder & RUVH & None & NA \\
\hline 104 & U Colorado-Denver & RUH & None & NA \\
\hline 105 & U of Connecticut & RUVH & 12 & 0 \\
\hline 106 & U of Delaware & RUVH & 153 & 13 \\
\hline 107 & U of Florida & RUVH & 127 & 2 \\
\hline 108 & U of Georgia & RUVH & 222 & 19 \\
\hline 109 & U of Hawaii-Manoa & RUVH & None & NA \\
\hline 110 & U of Houston & RUH & 453 & 44 \\
\hline 111 & U of Idaho & RUH & 26 & 0 \\
\hline 112 & U of Illinois-Chicago & RUVH & None & $\mathrm{NA}$ \\
\hline
\end{tabular}


GENDER REPRESENTATIONS IN ED.D. DISSERTATIONS

\begin{tabular}{|l|l|l|l|l|}
\hline 113 & U of Illinois-Urbana/Champaign & RUVH & None & NA \\
\hline 114 & U of Iowa & RUVH & None & NA \\
\hline 115 & U of Kansas & RUVH & 132 & 10 \\
\hline 116 & U of Kentucky-Lexington & RUVH & 184 & 25 \\
\hline 117 & U of Louisianna-Lafayette & RUH & None & NA \\
\hline 118 & U of Louisville & RUH & 96 & 9 \\
\hline 119 & U of Maine & RU/H & 55 & 7 \\
\hline 120 & U of Maryland-Baltimore County & RU/H & None & NA \\
\hline 121 & U of Maryland-College Park & RUVH & 48 & 3 \\
\hline 122 & U of Massachusetts-Amherst & RUVH & 377 & 70 \\
\hline 123 & U of Massachusetts-Boston & DRU & 85 & 12 \\
\hline 124 & U of Massachusetts-Lowell & DRU & 148 & 10 \\
\hline 125 & U of Memphis & RUH & 236 & 19 \\
\hline 126 & U of Michigan-Ann Arbor & RUVH & 66 & 74 \\
\hline 127 & U of Minnesota-Twin Cities & RUVH & None & NA \\
\hline 128 & U of Mississippi-Main & RUH & 36 & 0 \\
\hline 129 & U of Missouri-Columbia & RUVH & 243 & 76 \\
\hline 130 & U of Missouri-Kansas City & RUH & 13 & 1 \\
\hline 131 & U of Missouri-St Louis & RUH & None & NA \\
\hline 132 & U of Nebraska-Lincoln & RUVH & 173 & 10 \\
\hline 133 & U of Nebraska-Omaha & DRU & 63 & 0 \\
\hline 134 & U of Nevada-Las Vegas & RU/H & 111 & 5 \\
\hline 135 & U of Nevada-Reno & RU/H & 15 & 1 \\
\hline 136 & U of New Hampshire & RU/H & None & NA \\
\hline 137 & U of New Mexico-Main & RU/VH & 65 & 5 \\
\hline 138 & U of New Orleans & RU/V & 2 & 0 \\
\hline 139 & U of North Carolina-Chapel Hill & RU/VH & 97 & 13 \\
\hline 140 & U of North Carolina-Charlotte & DRU & 83 & 3 \\
\hline 141 & U of North Carolina-Greensboro & RU/H & 80 & 8 \\
\hline 142 & U of North Dakota & RU/H & 44 & 5 \\
\hline 143 & U of North Texas & RU/H & 183 & 12 \\
\hline 144 & U of Northern Colorado & DRU & 173 & 17 \\
\hline 145 & U of Oklahoma-Norman & RUH & 25 & 1 \\
\hline 146 & U of Oregon & RUH & 7 & 4 \\
\hline 147 & U of Pittsburgh & RUVH & 337 & 23 \\
\hline 148 & U of Rhode Island & RUH & None & NA \\
\hline 149 & U of South Alabama & RUH & None & NA \\
\hline 150 & U of South Carolina-Columbia & RU/VH & 112 & 16 \\
\hline 151 & U of South Dakota & DRU & 426 & 18 \\
\hline & & & & \\
\hline
\end{tabular}


GENDER REPRESENTATIONS IN ED.D. DISSERTATIONS

\begin{tabular}{|l|l|l|l|l|}
\hline 152 & U of South Florida & RU/VH & 64 & 5 \\
\hline 153 & U of Southern Mississippi & RU/H & 46 & 3 \\
\hline 154 & U of Tennessee & RU/VH & 181 & 16 \\
\hline 155 & U of Texas-Austin & RU/VH & 95 & 13 \\
\hline 156 & U of Toledo & RU/H & 12 & 0 \\
\hline 157 & U of Utah & RU/VH & 32 & 2 \\
\hline 158 & U of Vermont & RU/H & None & NA \\
\hline 159 & U of Vermont State Agricultural & RUH & 3 & 0 \\
\hline 160 & U of Virginia-Main & RU/VH & 216 & 8 \\
\hline 161 & U of Washington & RU/VH & 69 & 3 \\
\hline 162 & U of Wisconsin-Madison & RU/VH & None & NA \\
\hline 163 & U of Wisconsin-Milwaukee & RU/H & None & $?$ \\
\hline 164 & U of Wyoming & RU/H & 39 & 1 \\
\hline 165 & Utah State U & RU/H & 13 & 1 \\
\hline 166 & Virginia Commonwealth U & RU/VH & None & NA \\
\hline 167 & Virginia Polytechnic \& State U & RU/VH & 208 & 16 \\
\hline 168 & Washington State U & RU/VH & 50 & 3 \\
\hline 169 & Wayne State U & RU/VH & 189 & 12 \\
\hline 170 & West Virginia U & RU/H & 382 & 18 \\
\hline 171 & Western Michigan U & RU/H & 86 & 5 \\
\hline 172 & Wichita State U & RU/H & 49 & 0 \\
\hline 173 & Wright State U & RU/H & None & NA \\
\hline & & & & \\
\hline
\end{tabular}


GENDER REPRESENTATIONS IN ED.D. DISSERTATIONS

Appendix F. Carnegie DRU Institutions w/gender focus, \% gender \& type

\begin{tabular}{|c|c|c|c|c|c|c|c|c|}
\hline \multicolumn{2}{|c|}{$\begin{array}{l}\text { Carnegie } \\
\text { DRU-Institutions }\end{array}$} & \multirow{2}{*}{$\begin{array}{l}\# \\
E d . D \\
187 \\
\end{array}$} & \multirow{2}{*}{$\begin{array}{l}\# \\
\text { Gender } \\
12 \\
\end{array}$} & \multirow{2}{*}{$\begin{array}{r}\% \\
\text { Gender } \\
6.4 \\
\end{array}$} & \multirow{2}{*}{$\begin{array}{l}F \\
10 \\
\end{array}$} & & \multirow{2}{*}{$\begin{array}{l}\text { LGTBIQ } \\
0 \\
\end{array}$} & \multirow{2}{*}{$\begin{array}{l}\text { Other } \\
0 \\
\end{array}$} \\
\hline 1 & Ball State U & & & & & & & \\
\hline 2 & Central Michigan U & 32 & 3 & 9.4 & 2 & 1 & 0 & 0 \\
\hline 3 & East Carolina U & 117 & 8 & 6.8 & 4 & 2 & 1 & 1 \\
\hline 4 & East Tennessee State U & 258 & 15 & 5.8 & 9 & 1 & 0 & 5 \\
\hline 5 & Georgia Southern U & 146 & 24 & 16.4 & 18 & 3 & 0 & 3 \\
\hline 6 & Idaho State U & 88 & 2 & 2.3 & 2 & 0 & 0 & 0 \\
\hline 7 & Illinois State & 153 & 2 & 1.3 & 1 & 1 & 0 & 0 \\
\hline 8 & Indiana $\mathrm{U}$ of PA & 97 & 12 & 12.4 & 4 & 2 & 0 & 6 \\
\hline 9 & Louisiana Tech & 41 & 1 & 2.4 & 1 & 0 & 0 & 0 \\
\hline 10 & Morgan State U & 127 & 13 & 10.2 & 5 & 4 & 0 & 4 \\
\hline 11 & Portland State U & 69 & 2 & 2.9 & 1 & 0 & 0 & 1 \\
\hline 12 & Sam Houston State & 102 & 7 & 6.9 & 3 & 1 & 0 & 3 \\
\hline 13 & South Carolina State & 150 & 13 & 8.7 & 3 & 5 & 0 & 5 \\
\hline 14 & Tennessee State & 316 & 21 & 6.7 & 9 & 3 & 0 & 9 \\
\hline 15 & Texas A \& M Commerce & 317 & 23 & 7.3 & 8 & 6 & 0 & 9 \\
\hline 16 & Texas A \& M Kingsville & 209 & 3 & 1.4 & 1 & 0 & 0 & 2 \\
\hline 17 & Texas Southern U & 176 & 15 & 8.5 & 8 & 3 & 1 & 3 \\
\hline 18 & Texas Woman's U & 14 & 2 & 14.3 & 0 & 1 & 0 & 1 \\
\hline 19 & Uof Arkansas-Little Rock & 72 & 1 & 1.4 & 1 & 0 & 0 & 0 \\
\hline 20 & U of Massachusetts-Boston & 85 & 12 & 14.2 & 5 & 4 & 1 & 2 \\
\hline 21 & U of Massachusetts-Lowell & 148 & 10 & 6.8 & 4 & 3 & 0 & 3 \\
\hline 22 & U of Nebraska- Omaha & 67 & 0 & 0 & 0 & 0 & 0 & 0 \\
\hline 23 & U of N. Carolina-Charlotte & 83 & 3 & 3.7 & 1 & 2 & 0 & 0 \\
\hline 24 & U of Northern Colorado & 173 & 17 & 9.8 & 12 & 1 & 0 & 4 \\
\hline 24 & U of S. Dakota & 426 & 18 & 4.2 & 9 & 7 & 0 & 2 \\
\hline 26 & U of West Florida & 10 & 1 & 10.0 & 1 & 0 & 0 & 0 \\
\hline \multicolumn{2}{|c|}{ Totals } & 3663 & 240 & 180.2 & 122 & 52 & 3 & 63 \\
\hline
\end{tabular}


GENDER REPRESENTATIONS IN ED.D. DISSERTATIONS

Appendix G. Carnegie RUH Institutions w/ gender focus, \% gender \& type

\begin{tabular}{|c|c|c|c|c|c|c|c|c|}
\hline \multicolumn{2}{|c|}{$\begin{array}{l}\text { Carnegie } \\
\text { RUH-Institutions }\end{array}$} & \multirow{2}{*}{$\begin{array}{l}\# \\
E d . D . \\
62 \\
\end{array}$} & \multirow{2}{*}{$\begin{array}{l}\begin{array}{l}\text { H } \\
\text { Gender }\end{array} \\
3\end{array}$} & \multirow{2}{*}{$\begin{array}{l}\begin{array}{l}\% \\
\text { Gender } \\
4.8\end{array}\end{array}$} & \multirow{2}{*}{$\begin{array}{l}F \\
2\end{array}$} & \multirow{2}{*}{$\begin{array}{l}M \\
1\end{array}$} & \multirow{2}{*}{$\begin{array}{l}\text { LGTBIQ } \\
0\end{array}$} & \multirow{2}{*}{$\begin{array}{l}\text { Other } \\
0\end{array}$} \\
\hline 1 & Bowling Green State & & & & & & & \\
\hline 2 & Clemson U & 35 & 1 & 2.9 & 1 & 0 & 0 & 0 \\
\hline 3 & College Wm/ Mary & 65 & 4 & 6.2 & 2 & 0 & 0 & 2 \\
\hline 4 & Florida Atlantic-Boca & 141 & 5 & 3.6 & 1 & 2 & 0 & 2 \\
\hline 5 & Florida International & 208 & 14 & 6.7 & 7 & 2 & 1 & 4 \\
\hline 6 & George Mason U & 1 & 0 & 0 & 0 & 0 & 0 & 0 \\
\hline 7 & Indiana U -Purdue & 133 & 12 & 9.0 & 6 & 4 & 0 & 2 \\
\hline 8 & Mississippi State U & 41 & 1 & 2.4 & 0 & 0 & 0 & 1 \\
\hline 9 & New Mexico State & 66 & 7 & 10.6 & 4 & 2 & 0 & 1 \\
\hline 10 & Northern Arizona U & 234 & 19 & 8.1 & 12 & 1 & 1 & 5 \\
\hline 11 & Northern Illinois U & 607 & 77 & 12.7 & 46 & 17 & 3 & 11 \\
\hline 12 & Ohio U & 13 & 3 & 23.1 & 1 & 1 & 0 & 1 \\
\hline 13 & Oklahoma State & 424 & 25 & 5.9 & 15 & 4 & 0 & 6 \\
\hline 14 & San Diego State & 23 & 2 & 8.7 & 1 & 0 & 0 & 1 \\
\hline 15 & SUNY Binghampton & 40 & 5 & 12.5 & 3 & 1 & 0 & 1 \\
\hline 16 & Temple U & 310 & 32 & 10.3 & 20 & 4 & 2 & 6 \\
\hline 17 & Texas Tech U & 161 & 11 & 6.8 & 8 & 0 & 2 & 1 \\
\hline 18 & U of Akron & 64 & 8 & 12.5 & 6 & 2 & 0 & 0 \\
\hline 19 & U of Alabama & 219 & 15 & 6.9 & 4 & 2 & 0 & 9 \\
\hline 20 & U of Arkansas & 111 & 12 & 10.8 & 7 & 2 & 0 & 3 \\
\hline 21 & U of Central Florida & 383 & 12 & 3.1 & 8 & 2 & 0 & 2 \\
\hline 22 & U of Houston & 453 & 44 & 9.7 & 27 & 11 & 1 & 5 \\
\hline 23 & U of Idaho & 26 & 0 & 0 & 0 & 0 & 0 & 0 \\
\hline 24 & U of Louisville & 96 & 9 & 9.4 & 2 & 2 & 1 & 4 \\
\hline 25 & U of Maine & 55 & 7 & 12.7 & 4 & 2 & 1 & 0 \\
\hline 26 & $\mathrm{U}$ of Memphis & 236 & 19 & 8.1 & 8 & 4 & 1 & 6 \\
\hline 27 & U of Mississippi & 36 & 0 & 0 & 0 & 0 & 0 & 0 \\
\hline 28 & U of Missouri-KC & 13 & 1 & 7.7 & 0 & 1 & 0 & 0 \\
\hline 29 & U of Nevada LV & 111 & 5 & 4.5 & 2 & 2 & 0 & 1 \\
\hline 30 & U of Nevada Reno & 15 & 1 & 6.7 & 1 & 0 & 0 & 0 \\
\hline 31 & U of New Orleans & 2 & 0 & 0 & 0 & 0 & 0 & 0 \\
\hline 32 & U North CarolinaGRN & 80 & 8 & 10.0 & 5 & 2 & 0 & 1 \\
\hline 33 & U North Dakota & 44 & 5 & 11.4 & 2 & 0 & 0 & 3 \\
\hline 34 & U North Texas & 183 & 12 & 6.6 & 8 & 2 & 0 & 2 \\
\hline 35 & U of Oklahoma & 449 & 1 & $0 /(.002)$ & 1 & 0 & 0 & 0 \\
\hline 36 & U of Oregon & 7 & 4 & 57.1 & 3 & 0 & 0 & 1 \\
\hline 37 & U Southern Mississippi & 46 & 3 & 6.5 & 2 & 0 & 0 & 1 \\
\hline 38 & U Texas- El Paso & 55 & 4 & 7.3 & 3 & 1 & 0 & 0 \\
\hline 39 & U of Toledo & 12 & 0 & 0 & 0 & 0 & 0 & 0 \\
\hline 40 & U Vermont State/Agr & 3 & 0 & 0 & 0 & 0 & 0 & 0 \\
\hline 41 & U Wyoming & 39 & 1 & 2.6 & 0 & 1 & 0 & 0 \\
\hline 42 & Utah State & 13 & 1 & 7.7 & 0 & 1 & 0 & 0 \\
\hline
\end{tabular}


GENDER REPRESENTATIONS IN ED.D. DISSERTATIONS

\begin{tabular}{|l|l|l|l|r|l|l|l|l|}
\hline 43 & West Virginia U & 382 & 18 & 4.7 & 11 & 3 & 0 & 4 \\
\hline 44 & Western Michigan & 86 & 5 & 2.7 & 2 & 0 & 0 & 3 \\
\hline 45 & Wichita U & 49 & 0 & 0 & 0 & 0 & 0 & 0 \\
\hline Totals & 5832 & 416 & 343 & 235 & 79 & 13 & 89 \\
\hline
\end{tabular}




\section{GENDER REPRESENTATIONS IN ED.D. DISSERTATIONS}

\section{Appendix H. Carnegie RUVH Institutions with gender \% gender \& type}

\begin{tabular}{|c|c|c|c|c|c|c|c|c|}
\hline \multicolumn{2}{|c|}{$\begin{array}{l}\text { Carnegie } \\
\text { RUVH-Institutions }\end{array}$} & \multirow{2}{*}{$\begin{array}{l}\# \\
\text { Ed.D. } \\
276 \\
\end{array}$} & \multirow{2}{*}{$\begin{array}{l}\begin{array}{l}\text { \# } \\
\text { Gender }\end{array} \\
28 \\
\end{array}$} & \multirow{2}{*}{$\begin{array}{l}\begin{array}{l}\% \\
\text { Gender } \\
10.1\end{array}\end{array}$} & \multirow{2}{*}{$\begin{array}{l}F \\
17\end{array}$} & \multirow{2}{*}{$\begin{array}{l}M \\
8\end{array}$} & \multirow{2}{*}{\begin{tabular}{|l} 
LGTBIQ \\
1 \\
\end{tabular}} & \multirow{2}{*}{$\begin{array}{l}\text { Other } \\
2\end{array}$} \\
\hline 1 & Arizona State U & & & & & & & \\
\hline 2 & Florida State & 62 & 7 & 11.3 & 4 & 1 & 1 & 1 \\
\hline 3 & Kansas State & 88 & 3 & 3.4 & 0 & 0 & 0 & 3 \\
\hline 4 & Montana State & 105 & 6 & 5.7 & 4 & 1 & 0 & 1 \\
\hline 5 & North Carolina State-R & 299 & 33 & 11.0 & 24 & 3 & 0 & 6 \\
\hline 6 & Oregon State U & 76 & 9 & 11.8 & 6 & 2 & 1 & 0 \\
\hline 7 & Pennsylvania State & 21 & 5 & 28.8 & 2 & 3 & 0 & 0 \\
\hline 8 & Rutgers-New Brunswick & 250 & 32 & 12.8 & 13 & 11 & 0 & 8 \\
\hline 9 & SUNY-Albany & 31 & 1 & 3.2 & 1 & 0 & 0 & 0 \\
\hline 10 & SUNY-Buffalo & 41 & 1 & 2.4 & 0 & 0 & 0 & 1 \\
\hline 11 & Texas A \& M Main & 94 & 11 & 11.7 & 8 & 2 & 0 & 1 \\
\hline 12 & U Alabama-Birmingham & 32 & 2 & 6.2 & 0 & 1 & 0 & 1 \\
\hline 13 & University of Arizona & 70 & 4 & 5.7 & 2 & 1 & 0 & 1 \\
\hline 14 & UC Berkeley & 23 & 3 & 13.0 & 0 & 2 & 0 & 1 \\
\hline 15 & UC Davis & 81 & 5 & 6.2 & 2 & 2 & 0 & 1 \\
\hline 16 & UCLA/Irvine & 268 & 31 & 11.6 & 12 & 11 & 1 & 7 \\
\hline 17 & U Cincinnati & 282 & 52 & 18.4 & 32 & 13 & 0 & 7 \\
\hline 18 & U of Connecticut & 12 & 0 & 0 & 0 & 0 & 0 & 0 \\
\hline 19 & U of Delaware & 153 & 13 & 8.5 & 3 & 9 & 0 & 1 \\
\hline 20 & U of Florida & 127 & 2 & 1.6 & 2 & 0 & 0 & 0 \\
\hline 21 & $\mathrm{U}$ of Georgia & 222 & 19 & 8.6 & 11 & 3 & 2 & 3 \\
\hline 22 & U of Kansas & 132 & 10 & 7.6 & 3 & 0 & 0 & 7 \\
\hline 23 & U of Kentucky & 152 & 25 & 16.4 & 17 & 5 & 0 & 3 \\
\hline 24 & U of Maryland & 48 & 3 & 6.3 & 2 & 1 & 0 & 0 \\
\hline 25 & U Massachusetts-Am & 377 & 68 & 18.0 & 46 & 8 & 3 & 11 \\
\hline 26 & U of Michigan & 66 & 2 & 3.0 & 0 & 1 & 1 & 0 \\
\hline 27 & U-Missouri-Columbia & 243 & 9 & 3.7 & 2 & 1 & 0 & 6 \\
\hline 28 & U Nebraska-Lincoln & 173 & 10 & 5.8 & 5 & 2 & 0 & 3 \\
\hline 29 & U New Mexico & 65 & 5 & 7.7 & 4 & 0 & 0 & 1 \\
\hline 30 & U North Carolina-CHil & 97 & 13 & 13.4 & 6 & 3 & 1 & 3 \\
\hline 31 & U Pittsburgh & 337 & 23 & 6.8 & 16 & 4 & 0 & 3 \\
\hline 32 & U South Carolina & 112 & 16 & 14.3 & 12 & 4 & 0 & 0 \\
\hline 33 & U South Florida & 64 & 5 & 7.9 & 2 & 0 & 0 & 3 \\
\hline 34 & U Tennessee Knoxvl & 181 & 16 & 8.8 & 9 & 1 & 1 & 5 \\
\hline 35 & U Texas Austin & 95 & 13 & 13.7 & 8 & 4 & 0 & 1 \\
\hline 36 & University of Utah & 32 & 2 & 6.3 & 1 & 1 & 0 & 0 \\
\hline 37 & University of Virginia & 216 & 8 & 3.7 & 6 & 0 & 0 & 2 \\
\hline 38 & U of Washington & 69 & 3 & 4.3 & 0 & 1 & 0 & 2 \\
\hline 39 & Virginia Polytechnic & 208 & 16 & 7.7 & 10 & 3 & 0 & 3 \\
\hline 40 & Washington State U & 50 & 3 & 6.0 & 1 & 0 & 2 & 0 \\
\hline 41 & Wayne State U & 189 & 12 & 6.3 & 5 & 5 & 0 & 2 \\
\hline \multicolumn{2}{|c|}{ Total } & 5519 & 529 & 359.7 & 298 & 117 & 14 & 100 \\
\hline
\end{tabular}




\title{
GENDER REPRESENTATIONS IN ED.D. DISSERTATIONS
}

\section{Appendix I. Gender Focused Dissertation Titles w/categories \& Abstract Gendered Proper Names}

\author{
i. *am indicates male focus, \\ ii. *af indicates female focus, \\ iii. *ab indicates both
}

- Emergent categories for abstracts are delineated in caps \& boldface under title

○ M v F LEADERS, LATINO/A, BLACK MALES, LGTBIQ, TITLE IX, FEMINIST.

\begin{tabular}{|c|c|c|c|c|}
\hline Dissertation Title & $\begin{array}{l}\text { DRU- } \\
\text { Institution }\end{array}$ & $F$ & $M$ & $L$ \\
\hline $\begin{array}{l}\text { A phenomenological examination of tenure } \\
\text { track female faculty members socialization into } \\
\text { the culture of higher education }\end{array}$ & $\begin{array}{l}\text { Ball State U-2007 } \\
1\end{array}$ & $\mathrm{X}$ & & \\
\hline $\begin{array}{l}\text { The lived experience for women who have } \\
\text { experienced divorce: Grief and growth. A } \\
\text { phenomenological study. }\end{array}$ & $\begin{array}{l}\text { Ball State U-2006 } \\
2\end{array}$ & $\mathrm{X}$ & & \\
\hline $\begin{array}{l}\text { A study of Jay Kesler's leadership during his } 15 \\
\text { year tenure at Taylor University am }\end{array}$ & $\begin{array}{l}\text { Ball State U-2005 } \\
3\end{array}$ & & $\mathrm{X}$ & \\
\hline $\begin{array}{l}\text { Reflections of postsecondary educational } \\
\text { experiences of selected women of the United } \\
\text { Arab Emirates (UAE): A qualitative analysis } \\
\text { investigating the motivations, supports, rewards, } \\
\text { and challenges encountered by seven Emirati } \\
\text { women in the year } 2004\end{array}$ & $\begin{array}{l}\text { Ball State U-2004 } \\
4\end{array}$ & $\mathrm{X}$ & & \\
\hline $\begin{array}{l}\text { The Church of the United Brethren in Christ } \\
\text { support of the community education work of } \\
\text { Moy Ling among the Chinese on Portland } \\
\text { Oregon, 1882-1931:Impications for a } \\
\text { missological understanding of partnership am }\end{array}$ & $\begin{array}{l}\text { Ball State U-2005 } \\
5\end{array}$ & & $\mathrm{X}$ & \\
\hline $\begin{array}{l}\text { The lived experience of six women during } \\
\text { adjuvant chemotherapy for stage I or II breast } \\
\text { cancer }\end{array}$ & $\begin{array}{l}\text { Ball State U-2005 } \\
6\end{array}$ & $\mathrm{X}$ & & \\
\hline $\begin{array}{l}\text { Different personas and difficult diplomas: A } \\
\text { qualitative study of employed mothers pursuing } \\
\text { graduate degrees }\end{array}$ & $\begin{array}{l}\text { Ball State U-2004 } \\
7\end{array}$ & $\mathrm{X}$ & & \\
\hline $\begin{array}{l}\text { Female superintendent and school board } \\
\text { perceptions of leadership behaviors: A } \\
\text { descriptive study }\end{array}$ & $\begin{array}{l}\text { Ball State U-2004 } \\
8\end{array}$ & $\mathrm{X}$ & & \\
\hline $\begin{array}{l}\text { The lived experience of re-entry women in } \\
\text { traditional baccalaureate nursing education }\end{array}$ & $\begin{array}{l}\text { Ball State U-2004 } \\
9\end{array}$ & $\mathrm{X}$ & & \\
\hline $\begin{array}{l}\text { Low-income mother's expectations and } \\
\text { practices related to their child's accomplishment } \\
\text { of four developmental tasks }\end{array}$ & $\begin{array}{l}\text { Ball State U-2003 } \\
10\end{array}$ & $X$ & & \\
\hline
\end{tabular}




\section{GENDER REPRESENTATIONS IN ED.D. DISSERTATIONS}

\begin{tabular}{|c|c|c|c|c|c|}
\hline $\begin{array}{l}\text { Career paths of female senior students affairs } \\
\text { officers in America four year institutions of } \\
\text { higher education }\end{array}$ & $\begin{array}{l}\text { Ball State U -2001 } \\
11\end{array}$ & $\mathrm{X}$ & & & \\
\hline $\begin{array}{l}\text { A profile of female Indiana school } \\
\text { superintendents }\end{array}$ & $\begin{array}{l}\text { Ball State U-1998 } \\
\text { 12 } \text { Gender }^{\boldsymbol{b}} \\
\text { 10-F } \\
\text { 2-M } \\
0-\text { LGTBIQ } \\
0-\mathrm{O}\end{array}$ & $X$ & & & \\
\hline $\begin{array}{l}\text { A portrait of leadership: Reverend Theodore M. } \\
\text { Hesburgh, C.S.C. }{ }^{\text {am }}\end{array}$ & $\begin{array}{l}\text { Central Michigan } \\
\text { University-2007 } \\
1\end{array}$ & & $X$ & & \\
\hline $\begin{array}{l}\text { Educational leadership in the } 21^{\text {st }} \text { century: } \\
\text { Female elementary principals and appreciative } \\
\text { leadership attributes }\end{array}$ & $\begin{array}{l}\text { Central Michigan } \\
\text { University-2003 } \\
2\end{array}$ & $\mathrm{X}$ & & & \\
\hline $\begin{array}{l}\text { Women in athletic administration in community } \\
\text { colleges: Identification of career paths, strategies } \\
\text { and competencies found in preparation for } \\
\text { leadership roles in athletics }\end{array}$ & $\begin{array}{l}\text { Central Michigan } \\
\text { University-2003 } \\
\text { 3 Gender } \boldsymbol{b} \\
\text { 2-F } \\
\text { 1-M } \\
\text { 0-LGTBIQ } \\
0-\mathrm{O}\end{array}$ & $X$ & & & \\
\hline $\begin{array}{l}\text { Developmental needs of women in leadership in } \\
\text { higher education }\end{array}$ & $\begin{array}{l}\text { East Carolina U- } \\
2007 \\
1\end{array}$ & $\mathrm{X}$ & & & \\
\hline $\begin{array}{l}\text { The under-representation of African American } \\
\text { males in academically gifted programs: The } \\
\text { perceptions of teachers and administrators of } \\
\text { barriers to identification } \\
\text { BLACK MALE }\end{array}$ & $\begin{array}{l}\text { East Carolina U- } \\
2007 \\
2\end{array}$ & & $\mathrm{X}$ & & \\
\hline $\begin{array}{l}\text { Women dean's perceptions of their leadership } \\
\text { styles: A study based on Bolman and Deal's four } \\
\text { frame theory }\end{array}$ & $\begin{array}{l}\text { East Carolina U- } \\
2007 \\
3\end{array}$ & $X$ & & & \\
\hline $\begin{array}{l}\text { Leadership styles of interdisciplinary health } \\
\text { science education leaders of Quentin Burdick } \\
\text { Programs am }\end{array}$ & $\begin{array}{l}\text { East Carolina U- } \\
2006 \\
4\end{array}$ & & $\mathrm{X}$ & & \\
\hline $\begin{array}{l}\text { Factors influencing the design, establishment, } \\
\text { administration, and governance of correctional } \\
\text { education for females }\end{array}$ & $\begin{array}{l}\text { East Carolina U- } \\
2006 \\
5\end{array}$ & $X$ & & & \\
\hline $\begin{array}{l}\text { Employer liability for negligent hiring, retention } \\
\text { and referral of certified public school employees } \\
\text { involved in sexual misconduct with students }\end{array}$ & $\begin{array}{l}\text { East Carolina U- } \\
2004 \\
6 \\
\end{array}$ & & & & $\mathrm{X}$ \\
\hline $\begin{array}{l}\text { The undergraduate odyssey: The experiences of } \\
\text { older re-entry women }\end{array}$ & $\begin{array}{l}\text { East Carolina U- } \\
2004 \\
7\end{array}$ & $X$ & & & \\
\hline $\begin{array}{l}\text { The need for a diversity component, specific to } \\
\text { gay and lesbian students, in undergraduate }\end{array}$ & $\begin{array}{l}\text { East Carolina U- } \\
2001\end{array}$ & & & $\mathrm{X}$ & \\
\hline
\end{tabular}




\section{GENDER REPRESENTATIONS IN ED.D. DISSERTATIONS}

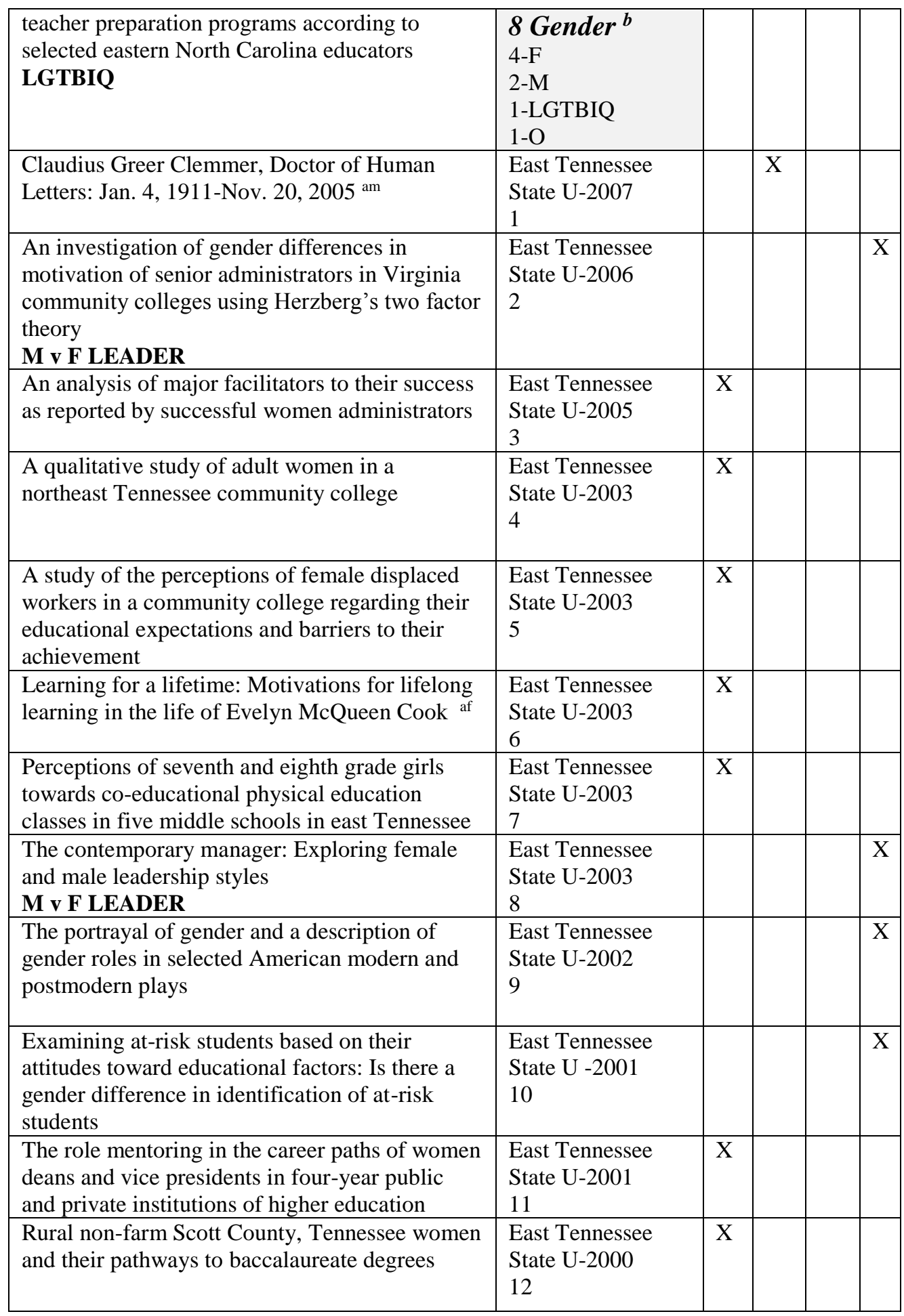




\section{GENDER REPRESENTATIONS IN ED.D. DISSERTATIONS}

\begin{tabular}{|c|c|c|c|c|}
\hline $\begin{array}{l}\text { Women's ways of leading? A qualitative content } \\
\text { analysis to determine leadership messages } \\
\text { contained in literature of National Panhellenic } \\
\text { Conference groups }\end{array}$ & $\begin{array}{l}\text { East Tennessee } \\
\text { State U-2000 } \\
13\end{array}$ & $\mathrm{X}$ & & \\
\hline $\begin{array}{l}\text { A comparison of teacher directed versus self } \\
\text { directed learning preferences of students at five } \\
\text { selected community colleges: Exploring the } \\
\text { relationships among age, gender and academic } \\
\text { majors }\end{array}$ & $\begin{array}{l}\text { East Tennessee } \\
\text { State U-1998 } \\
14\end{array}$ & & & $\mathrm{X}$ \\
\hline $\begin{array}{l}\text { A portrayal of the work life of tenured African } \\
\text { American female faculty working within } \\
\text { historically White public institutions of higher } \\
\text { education in Virginia }\end{array}$ & $\begin{array}{l}\text { East Tennessee } \\
\text { State U-1998 } \\
\text { 15 Gender }^{\boldsymbol{b}} \\
\text { 9-F } \\
\text { 1-M } \\
\text { 0-LGTBIQ } \\
\text { 5-O }\end{array}$ & $\mathrm{X}$ & & \\
\hline $\begin{array}{l}\text { An inquiry into the experiences of the African } \\
\text { American women principal: Critical race theory } \\
\text { and Black feminist principles } \\
\text { FEMINIST }\end{array}$ & $\begin{array}{l}\text { Georgia Southern } \\
\text { U-2004 } \\
1\end{array}$ & $\mathrm{X}$ & & \\
\hline $\begin{array}{l}\text { Cultivating literary imagination, developing } \\
\text { empathic understanding towards others: Using } \\
\text { Louise Rosenblatt's Reader Response Theory to } \\
\text { teach literature to eighth graders in southeast } \\
\text { Georgia af }\end{array}$ & $\begin{array}{l}\text { Georgia Southern } \\
\text { U-2004 } \\
2\end{array}$ & $X$ & & \\
\hline $\begin{array}{l}\text { An exploration of the impact of black female } \\
\text { caregivers on the lives of white female teachers }\end{array}$ & $\begin{array}{l}\text { Georgia Southern } \\
\text { U-2003 } \\
3\end{array}$ & $X$ & & \\
\hline $\begin{array}{l}\text { Postmodern feminist pedagogy in a first-year } \\
\text { writing class } \\
\text { FEMINIST }\end{array}$ & $\begin{array}{l}\text { Georgia Southern } \\
\text { U-2003 } \\
4\end{array}$ & $\mathrm{X}$ & & \\
\hline $\begin{array}{l}\text { Successful middle school girls: A qualitative } \\
\text { study of discourse and characteristics }\end{array}$ & $\begin{array}{l}\text { Georgia Southern } \\
\text { U-2003 } \\
5\end{array}$ & $\mathrm{X}$ & & \\
\hline $\begin{array}{l}\text { What influences girls' mathematics } \\
\text { achievement? Stories of six high-achieving } \\
\text { middle school females }\end{array}$ & $\begin{array}{l}\text { Georgia Southern } \\
\text { U-2003 } \\
6\end{array}$ & $X$ & & \\
\hline $\begin{array}{l}\text { The phenomenal "Harry Potter" books: A } \\
\text { cultural study of corporate influence on reading } \\
\text { instruction and image-making am }\end{array}$ & $\begin{array}{l}\text { Georgia Southern } \\
\text { U-2003 } \\
7\end{array}$ & & $\mathrm{X}$ & \\
\hline $\begin{array}{l}\text { W.E. B. Dubois and critical race theory: towards } \\
\text { a Du Boisian philosophy of education am }\end{array}$ & $\begin{array}{l}\text { Georgia Southern } \\
\text { U-2003 } \\
8\end{array}$ & & $X$ & \\
\hline $\begin{array}{l}\text { A descriptive analysis of women public school } \\
\text { superintendents in Georgia }\end{array}$ & $\begin{array}{l}\text { Georgia Southern } \\
\text { U-2002 } \\
9\end{array}$ & $\mathrm{X}$ & & \\
\hline $\begin{array}{l}\text { Costs of desire: How sexual labeling in school } \\
\text { influences life choices of women }\end{array}$ & $\begin{array}{l}\text { Georgia Southern } \\
\text { U-2002 }\end{array}$ & $\mathrm{X}$ & & \\
\hline
\end{tabular}




\section{GENDER REPRESENTATIONS IN ED.D. DISSERTATIONS}

\begin{tabular}{|c|c|c|c|c|}
\hline & 10 & & & \\
\hline $\begin{array}{l}\text { Creating space for the female adolescent voice: } \\
\text { The role of gender on mathematics achievement } \\
\text { and career choices }\end{array}$ & $\begin{array}{l}\text { Georgia Southern } \\
\text { U-2002 } \\
11\end{array}$ & & & $X$ \\
\hline $\begin{array}{l}\text { Messages for girls: Looking at the representation } \\
\text { of women's short fiction in American literature } \\
\text { high school anthologies }\end{array}$ & $\begin{array}{l}\text { Georgia Southern } \\
\text { U-2002 } \\
12\end{array}$ & $\mathrm{X}$ & & \\
\hline $\begin{array}{l}\text { Relationships between gender and teacher's } \\
\text { perceptions of principal effectiveness in Georgia } \\
\text { schools } \\
\text { M v F LEADER }\end{array}$ & $\begin{array}{l}\text { Georgia Southern } \\
\text { U-2002 } \\
13\end{array}$ & & & $\mathrm{X}$ \\
\hline $\begin{array}{l}\text { The challenges and successes of African } \\
\text { American women principals in Georgia: A } \\
\text { qualitative profile of lived experiences }\end{array}$ & $\begin{array}{l}\text { Georgia Southern } \\
\text { U-2002 } \\
14\end{array}$ & $\mathrm{X}$ & & \\
\hline $\begin{array}{l}\text { The motivational stories of how women become } \\
\text { scientists: A hermeneutic phenomenological } \\
\text { inquiry }\end{array}$ & $\begin{array}{l}\text { Georgia Southern } \\
\text { U-2002 } \\
15\end{array}$ & $X$ & & \\
\hline $\begin{array}{l}\text { The road seldom taken: Status of women in } \\
\text { mathematics departments in colleges and } \\
\text { universities in Georgia }\end{array}$ & $\begin{array}{l}\text { Georgia Southern } \\
\text { U-2002 } \\
16\end{array}$ & $\mathrm{X}$ & & \\
\hline $\begin{array}{l}\text { Trade winds: A critical narrative of "Black" } \\
\text { Caribbean immigrant women teachers }\end{array}$ & $\begin{array}{l}\text { Georgia Southern } \\
\text { U-2002 } \\
17\end{array}$ & $\mathrm{X}$ & & \\
\hline $\begin{array}{l}\text { East meets west: Desperately seeking David } \\
\text { Dean O'Keefe from Savannah to Yap am }\end{array}$ & $\begin{array}{l}\text { Georgia Southern } \\
\text { U-2001 } \\
18\end{array}$ & & & $\mathrm{X}$ \\
\hline $\begin{array}{l}\text { Retracing the Savannah River portion of John } \\
\text { Muir's "Thousand Mile Walk": An interpretive } \\
\text { regional study suggesting curriculum for } \\
\text { sustainability am }\end{array}$ & $\begin{array}{l}\text { Georgia Southern } \\
\text { U-2001 } \\
19\end{array}$ & & $X$ & \\
\hline $\begin{array}{l}\text { Science access, career choices, achievement and } \\
\text { motivation: Perceptions of female science } \\
\text { Olympians }\end{array}$ & $\begin{array}{l}\text { Georgia Southern } \\
\text { U-2001 } \\
20\end{array}$ & $\mathrm{X}$ & & \\
\hline $\begin{array}{l}\text { The personal and professional backgrounds of } \\
\text { Georgia's female high school principals }\end{array}$ & $\begin{array}{l}\text { Georgia Southern } \\
\text { U-2001 } \\
21\end{array}$ & $X$ & & \\
\hline $\begin{array}{l}\text { Women in public middle school administration } \\
\text { in Georgia: A feminist analysis of the } \\
\text { perceptions of women in power } \\
\text { FEMINIST }\end{array}$ & $\begin{array}{l}\text { Georgia Southern } \\
\text { U-2001 } \\
22\end{array}$ & $\mathrm{X}$ & & \\
\hline $\begin{array}{l}\text { Barriers to female principals: Perceptions of } \\
\text { female high school administrators in Georgia }\end{array}$ & $\begin{array}{l}\text { Georgia Southern } \\
\text { U-2000 } \\
23\end{array}$ & $\mathrm{X}$ & & \\
\hline $\begin{array}{l}\text { Telling stories, creating lives: Southern } \\
\text { women's autobiographies }\end{array}$ & $\begin{array}{l}\text { Georgia Southern } \\
\text { U-2000 } \\
\text { 24 Gender }{ }^{b} \\
\text { 18-F } \\
\text { 3-M }\end{array}$ & $\mathrm{X}$ & & \\
\hline
\end{tabular}




\section{GENDER REPRESENTATIONS IN ED.D. DISSERTATIONS}

\begin{tabular}{|c|c|c|c|c|}
\hline & $\begin{array}{l}\text { 0-LGTBIQ } \\
3-\mathrm{O}\end{array}$ & & & \\
\hline $\begin{array}{l}\text { An exploration of the barriers and supports } \\
\text { perceived by female faculty at three state } \\
\text { universities in Idaho as they write proposals to } \\
\text { secure external funds }\end{array}$ & $\begin{array}{l}\text { Idaho State U- } \\
2006 \\
1\end{array}$ & $\mathrm{X}$ & & \\
\hline $\begin{array}{l}\text { Women and the superintendency: Personal and } \\
\text { professional demographics and the } \\
\text { demographics and the perceptions of barriers } \\
\text { and strategies held by women superintendents }\end{array}$ & $\begin{array}{l}\text { Idaho State U- } \\
\text { 1998 } \\
\text { 2 } \text { Gender }^{\boldsymbol{b}} \\
\text { 2-F } \\
\text { 0-M } \\
\text { 0-LGTBIQ } \\
\text { 0-O }\end{array}$ & $\mathrm{X}$ & & \\
\hline $\begin{array}{l}\text { Women administrators perceptions of the } \\
\text { contribution of competitive sports experiences to } \\
\text { their career paths and leadership practices }\end{array}$ & $\begin{array}{l}\text { Illinois State U- } \\
2006 \\
1\end{array}$ & $\mathrm{X}$ & & \\
\hline $\begin{array}{l}\text { Knowledge and perceptions held by Latino } \\
\text { parents regarding the educational services for } \\
\text { LEP children with disabilities } \\
\text { LATINO/A }\end{array}$ & $\begin{array}{l}\text { Illinois State U- } \\
1999 \\
\text { 2 Gender } \\
\text { 1-F } \\
\text { 1-M } \\
\text { 0-LGTBIQ } \\
\text { 0-O }\end{array}$ & & $\mathrm{X}$ & \\
\hline $\begin{array}{l}\text { Trend analysis of instructional practices, } \\
\text { research production, service activities and job } \\
\text { satisfaction in female postsecondary faculty: } \\
\text { Findings from NSOPF } 93,99,04\end{array}$ & $\begin{array}{l}\text { Indiana U of PA- } \\
2007 \\
1\end{array}$ & $\mathrm{X}$ & & \\
\hline $\begin{array}{l}\text { Complying with Title IX: An analysis of } \\
\text { emergent leadership issued in an NCAA } \\
\text { Division I Institution } \\
\text { TITLE IX }\end{array}$ & $\begin{array}{l}\text { Indiana U of PA- } \\
2005 \\
2\end{array}$ & & & $\mathrm{X}$ \\
\hline $\begin{array}{l}\text { Performance differences on the computerized } \\
\text { version of the children's category test between } \\
\text { male controls and male children with attention } \\
\text { deficit hyperactivity disorder, learning disorder, } \\
\text { and borderline intellectual functioning }\end{array}$ & $\begin{array}{l}\text { Indiana U of PA- } \\
2003 \\
3\end{array}$ & & $\mathrm{X}$ & \\
\hline $\begin{array}{l}\text { Protégé and mentor experiences of three } \\
\text { outstanding female superintendents in } \\
\text { Pennsylvania }\end{array}$ & $\begin{array}{l}\text { Indiana U of PA- } \\
2002 \\
4\end{array}$ & $\mathrm{X}$ & & \\
\hline $\begin{array}{l}\text { The relative explanatory style, as a component } \\
\text { of the helplessness/hopelessness theory, to } \\
\text { depressive symptomology, life events, sex and } \\
\text { academic achievement in a New York City } \\
\text { adolescent population }\end{array}$ & $\begin{array}{l}\text { Indiana U of PA- } \\
2002 \\
5\end{array}$ & & & $\mathrm{X}$ \\
\hline $\begin{array}{l}\text { A qualitative case study of three beginning } \\
\text { female teachers secondary beliefs and their } \\
\text { classroom practices }\end{array}$ & $\begin{array}{l}\text { Indiana U of PA- } \\
2000 \\
6\end{array}$ & $\mathrm{X}$ & & \\
\hline The computer gender gap: quantitative and & Indiana U of PA- & & & $\mathrm{X}$ \\
\hline
\end{tabular}




\section{GENDER REPRESENTATIONS IN ED.D. DISSERTATIONS}

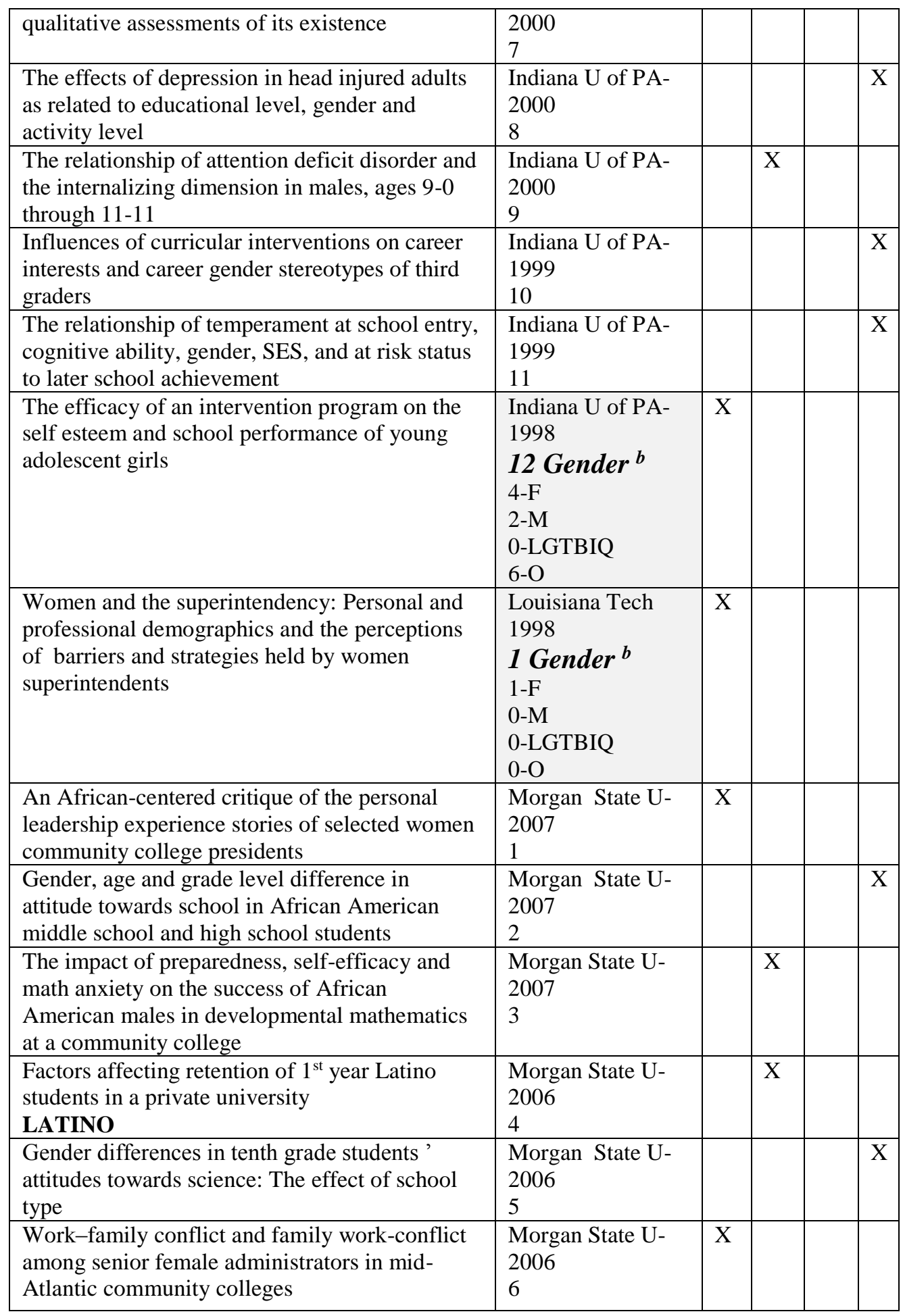




\section{GENDER REPRESENTATIONS IN ED.D. DISSERTATIONS}

\begin{tabular}{|c|c|c|c|c|}
\hline $\begin{array}{l}\text { Why can't brother man stay in school: A } \\
\text { phenomenological study of Black male student } \\
\text { attrition at a Black commuter college } \\
\text { BLACK MALE }\end{array}$ & $\begin{array}{l}\text { Morgan State U- } \\
2004 \\
7\end{array}$ & & $\mathrm{X}$ & \\
\hline $\begin{array}{l}\text { In their own words: A phenomenological } \\
\text { investigation of the lived experiences of selected } \\
\text { African-American male early school leavers in } \\
\text { Washington D.C. } \\
\text { BLACK MALE }\end{array}$ & $\begin{array}{l}\text { Morgan State U- } \\
2003 \\
8\end{array}$ & & $\mathrm{X}$ & \\
\hline $\begin{array}{l}\text { MSPAP mathematics performance of public } \\
\text { school students as a function of urbanicity, } \\
\text { ethnicity and gender }\end{array}$ & $\begin{array}{l}\text { Morgan State U- } \\
2003 \\
9\end{array}$ & & & $\mathrm{X}$ \\
\hline $\begin{array}{l}\text { Abused women in recovery: A qualitative study } \\
\text { of women in substance abuser recovery who are } \\
\text { abused, either physically or sexually as children }\end{array}$ & $\begin{array}{l}\text { Morgan State U- } \\
2002 \\
10\end{array}$ & $\mathrm{X}$ & & \\
\hline $\begin{array}{l}\text { Gender and the relationship between the } \\
\text { dimensions of teacher efficacy }\end{array}$ & $\begin{array}{l}\text { Morgan State U- } \\
2002 \\
11\end{array}$ & & & $\mathrm{X}$ \\
\hline $\begin{array}{l}\text { Women donors: an untapped resource for } \\
\text { community colleges }\end{array}$ & $\begin{array}{l}\text { Morgan State U- } \\
2002 \\
12\end{array}$ & $\mathrm{X}$ & & \\
\hline $\begin{array}{l}\text { A study of attachment to parents, attachments to } \\
\text { school, perception of blocked or limited } \\
\text { opportunities and companions as predictors of } \\
\text { adolescent female delinquent behavior }\end{array}$ & $\begin{array}{l}\text { Morgan State U- } \\
1999 \\
\text { 13 Gender } \\
\text { 5-F } \\
\text { 4-M } \\
\text { 0-LGTBIQ } \\
\text { 4-O } \\
\end{array}$ & $\mathrm{X}$ & & \\
\hline $\begin{array}{l}\text { Mother-infant interaction in the context of four } \\
\text { maternal risk factors }\end{array}$ & $\begin{array}{l}\text { Portland State U- } \\
2007 \\
1\end{array}$ & $X$ & & \\
\hline $\begin{array}{l}\text { The study of school climate, principals } \\
\text { communication style, principal's sex and school } \\
\text { level } \\
\text { M v F LEADER }\end{array}$ & $\begin{array}{l}\text { Portland State U- } \\
1999 \\
2 \text { Gender }^{\boldsymbol{b}} \\
\text { 1-F } \\
\text { 0-M } \\
\text { 0-LGTBIQ } \\
\text { 1-O }\end{array}$ & & & $\mathrm{X}$ \\
\hline $\begin{array}{l}\text { In their voices: A phenomenological multi-case } \\
\text { study related to talent and professional } \\
\text { development among gifted and talented young } \\
\text { women from five ethnic groups }\end{array}$ & $\begin{array}{l}\text { Sam Houston U } \\
2006 \\
1\end{array}$ & $\mathrm{X}$ & & \\
\hline $\begin{array}{l}\text { The effect of witnessing domestic violence on } \\
\text { male student's success: Implications for } \\
\text { professional development }\end{array}$ & $\begin{array}{l}\text { Sam Houston U } \\
2005 \\
2\end{array}$ & & $\mathrm{X}$ & \\
\hline $\begin{array}{l}\text { An analysis of gender differences public school } \\
\text { superintendents' conflict management modes in } \\
\text { relation to synergistic leadership theory }\end{array}$ & $\begin{array}{l}\text { Sam Houston U } \\
2004 \\
3\end{array}$ & & & $\mathrm{X}$ \\
\hline
\end{tabular}




\section{GENDER REPRESENTATIONS IN ED.D. DISSERTATIONS}

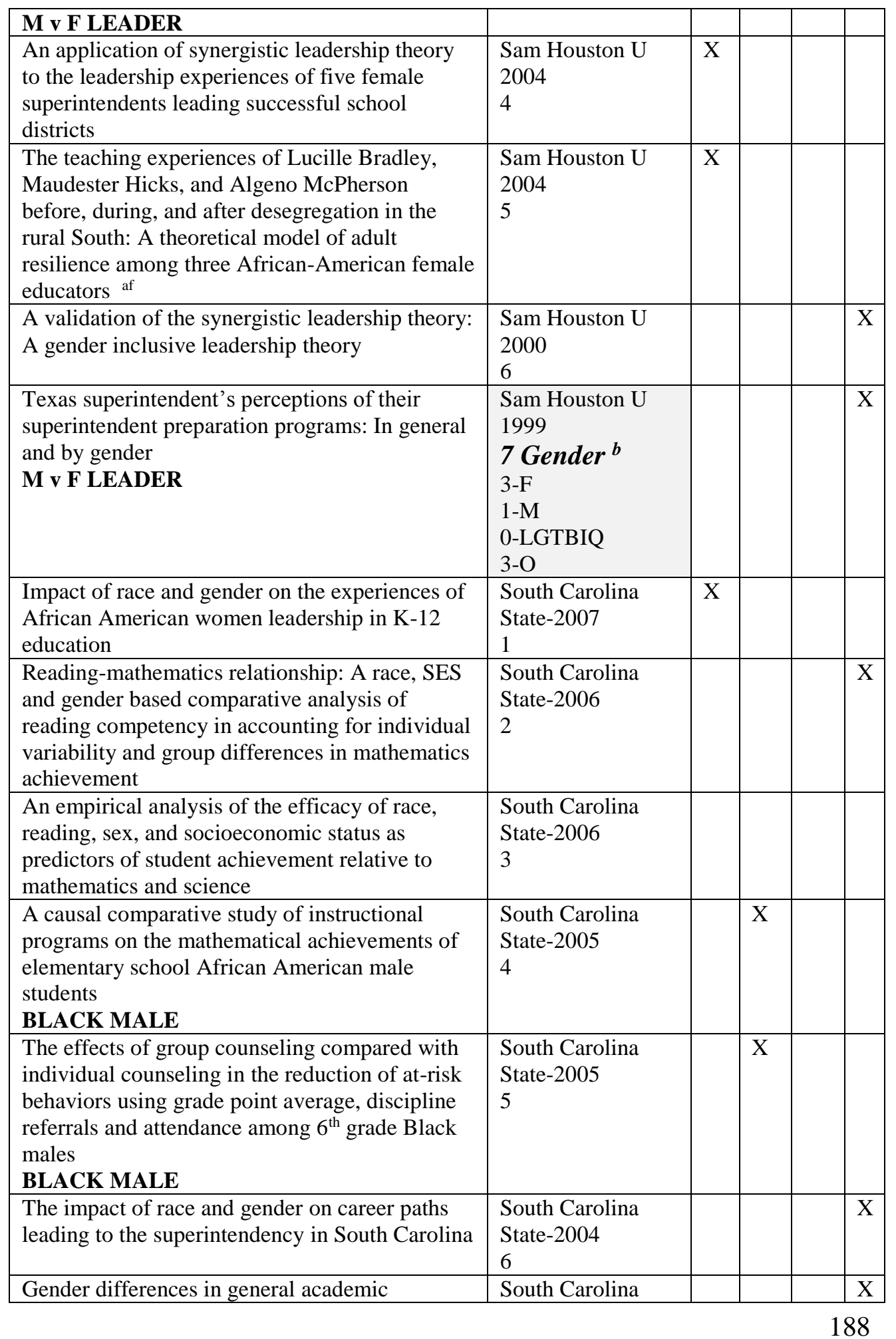




\section{GENDER REPRESENTATIONS IN ED.D. DISSERTATIONS}

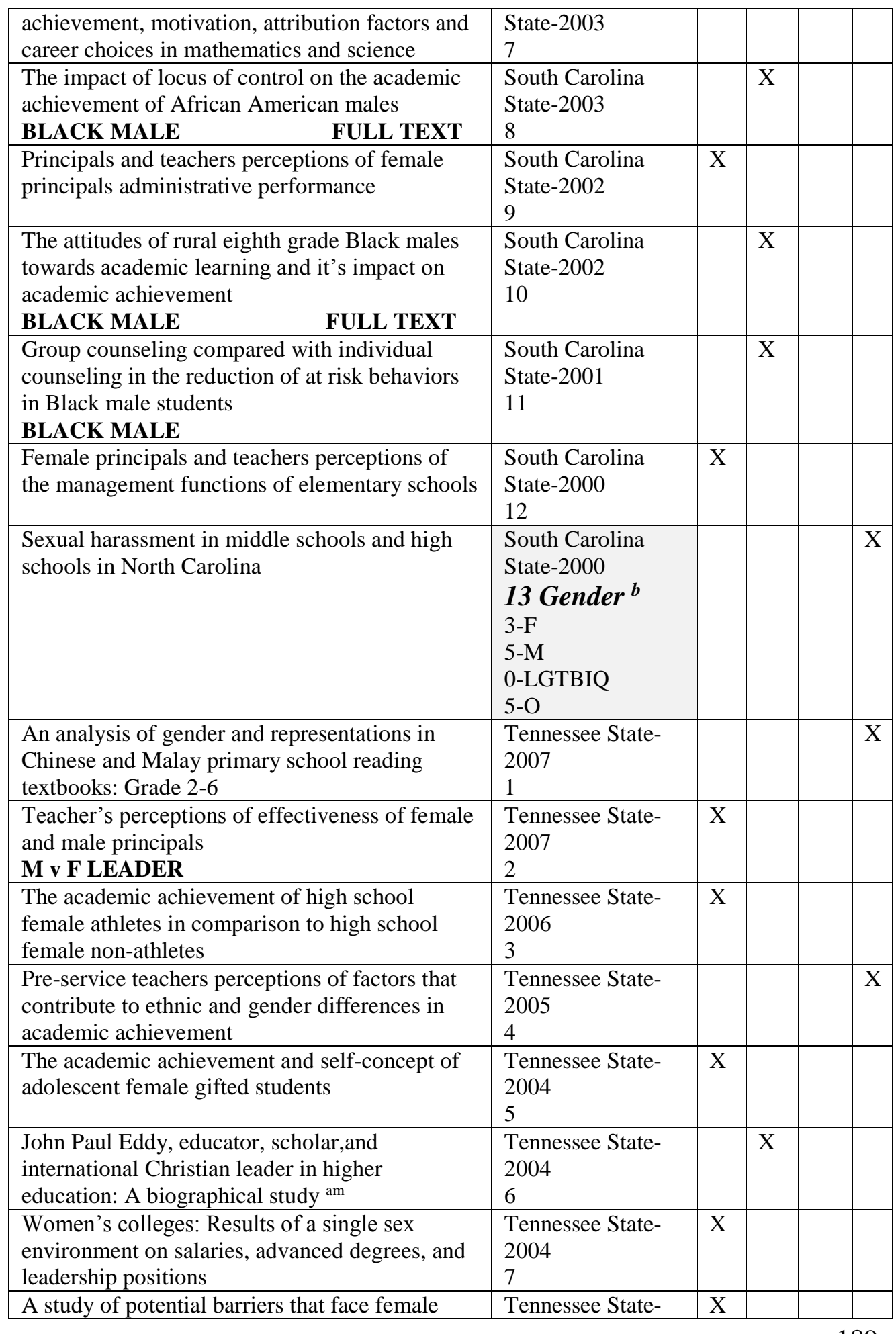




\section{GENDER REPRESENTATIONS IN ED.D. DISSERTATIONS}

\begin{tabular}{|c|c|c|c|c|}
\hline $\begin{array}{l}\text { administrators and aspirants in the state of } \\
\text { Alabama }\end{array}$ & $\begin{array}{l}2003 \\
8\end{array}$ & & & \\
\hline $\begin{array}{l}\text { Attributes of effective mentoring relationships } \\
\text { of female administrators in three Tennessee } \\
\text { school districts }\end{array}$ & $\begin{array}{l}\text { Tennessee State- } \\
2003 \\
9\end{array}$ & $X$ & & \\
\hline $\begin{array}{l}\text { Ethnic and gender disparity in TVAAS } \\
\text { achievement gains in reading and mathematics }\end{array}$ & $\begin{array}{l}\text { Tennessee State- } \\
2003 \\
10\end{array}$ & & & $\mathrm{X}$ \\
\hline $\begin{array}{l}\text { Has Title IX enforcement had an adverse effect } \\
\text { on the number of participation opportunities at } \\
\text { NCAA Division I institutions for male student } \\
\text { athletes? } \\
\text { TITLE IX }\end{array}$ & $\begin{array}{l}\text { Tennessee State- } \\
2003 \\
11\end{array}$ & & $\mathrm{X}$ & \\
\hline $\begin{array}{l}\text { Leadership styles of executive female } \\
\text { administrators in Tennessee community colleges }\end{array}$ & $\begin{array}{l}\text { Tennessee State- } \\
2003 \\
12\end{array}$ & $\mathrm{X}$ & & \\
\hline $\begin{array}{l}\text { Teacher perception of verbal reinforcement } \\
\text { versus tangible reinforcement with regard to } \\
\text { academic achievement for the African-American } \\
\text { middle school male } \\
\text { BLACK MALE }\end{array}$ & $\begin{array}{l}\text { Tennessee State- } \\
2003 \\
13\end{array}$ & & $\mathrm{X}$ & \\
\hline $\begin{array}{l}\text { A study of how kindergarten entry age and } \\
\text { gender effects middle school achievement }\end{array}$ & $\begin{array}{l}\text { Tennessee State- } \\
2002 \\
14\end{array}$ & & & $\mathrm{X}$ \\
\hline $\begin{array}{l}\text { Perceived leadership effectiveness of male and } \\
\text { female directors of schools in West and East } \\
\text { Tennessee } \\
\text { M v F LEADER }\end{array}$ & $\begin{array}{l}\text { Tennessee State- } \\
2001 \\
15\end{array}$ & & & $\mathrm{X}$ \\
\hline $\begin{array}{l}\text { A comparative study of the demographics for } \\
\text { Black female administrators and their peers } \\
\text { employed in the Tennessee Board of Regents } \\
\text { system }\end{array}$ & $\begin{array}{l}\text { Tennessee State- } \\
2000 \\
16\end{array}$ & $X$ & & \\
\hline $\begin{array}{l}\text { Linguistic differences between male and female } \\
\text { developmental writers }\end{array}$ & $\begin{array}{l}\text { Tennessee State- } \\
2000 \\
17\end{array}$ & & & $\mathrm{X}$ \\
\hline $\begin{array}{l}\text { Perceived leadership effectiveness of male and } \\
\text { female directors of schools } \\
\text { M v F LEADER }\end{array}$ & $\begin{array}{l}\text { Tennessee State- } \\
2000 \\
18\end{array}$ & & & $\mathrm{X}$ \\
\hline $\begin{array}{l}\text { The effect of left-handedness in females as a } \\
\text { determinant of mathematics achievement in } \\
\text { geography }\end{array}$ & $\begin{array}{l}\text { Tennessee State- } \\
2000 \\
19\end{array}$ & $\mathrm{X}$ & & \\
\hline $\begin{array}{l}\text { A study of peer sexual harassment in } \\
\text { metropolitan Nashville public High School }\end{array}$ & $\begin{array}{l}\text { Tennessee State- } \\
1999 \\
20\end{array}$ & & & $\mathrm{X}$ \\
\hline $\begin{array}{l}\text { Principal and counselor knowledge about } \\
\text { policies, programs and practices for pregnant } \\
\text { and parenting students }\end{array}$ & $\begin{array}{l}\text { Tennessee State- } \\
1999 \\
\text { 21 } \text { Gender }^{\boldsymbol{b}} \\
\text { 9-F }\end{array}$ & & & $\mathrm{X}$ \\
\hline
\end{tabular}




\section{GENDER REPRESENTATIONS IN ED.D. DISSERTATIONS}

\begin{tabular}{|c|c|c|c|c|}
\hline & $\begin{array}{l}\text { 3-M } \\
0-\mathrm{LGTBIQ} \\
\text { 9-O }\end{array}$ & & & \\
\hline $\begin{array}{l}\text { Gender issues and career advancement: } \\
\text { Perspectives of women in east Texas aspiring to } \\
\text { upper -level administration }\end{array}$ & $\begin{array}{l}\text { Texas A \& M } \\
\text { Commerce-2007 } \\
1\end{array}$ & $\mathrm{X}$ & & \\
\hline $\begin{array}{l}\text { Leadership and followership: A gender } \\
\text { perspective } \\
\text { M v F LEADER }\end{array}$ & $\begin{array}{l}\text { Texas A \& M } \\
\text { Commerce-2007 } \\
2\end{array}$ & & & $X$ \\
\hline $\begin{array}{l}\text { Successful male high school principals: Vital } \\
\text { experiences related to success }\end{array}$ & $\begin{array}{l}\text { Texas A \& M } \\
\text { Commerce-2007 } \\
3\end{array}$ & & $\mathrm{X}$ & \\
\hline $\begin{array}{l}\text { Superintendent gender and student achievement: } \\
\text { A postmodern perspective }\end{array}$ & $\begin{array}{l}\text { Texas A \& M } \\
\text { Commerce-2007 } \\
4\end{array}$ & & & $\bar{X}$ \\
\hline $\begin{array}{l}\text { A meta-study of dissertations related to Hispanic } \\
\text { female administrators }\end{array}$ & $\begin{array}{l}\text { Texas A \& M } \\
\text { Commerce-2006 } \\
5\end{array}$ & $X$ & & \\
\hline $\begin{array}{l}\text { Females who hold a superintendent's } \\
\text { certification and have not become } \\
\text { superintendents }\end{array}$ & $\begin{array}{l}\text { Texas A \& M } \\
\text { Commerce-2006 } \\
6\end{array}$ & $\mathrm{X}$ & & \\
\hline $\begin{array}{l}\text { Gender and conflict management styles of Texas } \\
\text { secondary school assistant principals: A } \\
\text { descriptive study } \\
\text { M v F LEADER }\end{array}$ & $\begin{array}{l}\text { Texas A \& M } \\
\text { Commerce-2005 } \\
7\end{array}$ & & & $\mathrm{X}$ \\
\hline $\begin{array}{l}\text { Male minority superintendents in four south } \\
\text { central states }\end{array}$ & $\begin{array}{l}\text { Texas A \& M } \\
\text { Commerce-2005 } \\
8\end{array}$ & & $X$ & \\
\hline $\begin{array}{l}\text { Assessing principal's perceptions of } \\
\text { heterosexism and homophobia in a large urban } \\
\text { public school district } \\
\text { LGTBIQ }\end{array}$ & $\begin{array}{l}\text { Texas A \& M } \\
\text { Commerce-2005 } \\
9\end{array}$ & & & $\mathrm{X}$ \\
\hline $\begin{array}{l}\text { A comparison of attrition rates of elementary } \\
\text { teacher's prepared through an alternative } \\
\text { certification program, an emergency } \\
\text { certification program, and a center for } \\
\text { professional development, and technology field - } \\
\text { based program by ethnicity, gender, age, and } \\
\text { certification examination procedures }\end{array}$ & $\begin{array}{l}\text { Texas A \& M } \\
\text { Commerce-2004 } \\
10\end{array}$ & & & $\mathrm{X}$ \\
\hline $\begin{array}{l}\text { A legal history and analysis of sexual } \\
\text { harassment in the public schools, } 1972-2002\end{array}$ & $\begin{array}{l}\text { Texas A \& M } \\
\text { Commerce-2003 } \\
11\end{array}$ & & & $\mathrm{X}$ \\
\hline $\begin{array}{l}\text { The contribution of Sylvanus Thayer and the } \\
\text { United States Military Academy to engineering } \\
\text { programs in higher education in the United } \\
\text { States am }\end{array}$ & $\begin{array}{l}\text { Texas A \& M } \\
\text { Commerce-2003 } \\
12\end{array}$ & & $X$ & \\
\hline $\begin{array}{l}\text { The retention of Black male students in Texas } \\
\text { public community colleges }\end{array}$ & $\begin{array}{l}\text { Texas A \& M } \\
\text { Commerce-2001 }\end{array}$ & & $\mathrm{X}$ & \\
\hline
\end{tabular}




\section{GENDER REPRESENTATIONS IN ED.D. DISSERTATIONS}

\begin{tabular}{|c|c|c|c|c|}
\hline BLACK MALE & 13 & & & \\
\hline $\begin{array}{l}\text { Vital experiences of successful female high } \\
\text { school principals: Adversities as they relate to } \\
\text { success }\end{array}$ & $\begin{array}{l}\text { Texas A \& M } \\
\text { Commerce-2001 } \\
14\end{array}$ & $\mathrm{X}$ & & \\
\hline $\begin{array}{l}\text { Pre-service teacher's beliefs about teaching and } \\
\text { learning before, during and after the application } \\
\text { of feminist pedagogies } \\
\text { FEMINIST }\end{array}$ & $\begin{array}{l}\text { Texas A \& M } \\
\text { Commerce-2000 } \\
15\end{array}$ & & & $\bar{X}$ \\
\hline $\begin{array}{l}\text { Women educators in Texas: Certified but } \\
\text { unemployed in administrative positions }\end{array}$ & $\begin{array}{l}\text { Texas A \& M } \\
\text { Commerce-1999 } \\
16\end{array}$ & $\mathrm{X}$ & & \\
\hline $\begin{array}{l}\text { Servant of beauty: Willa Cather and the } \\
\text { Aesthetic movement af }\end{array}$ & $\begin{array}{l}\text { Texas A \& M } \\
\text { Commerce-1999 } \\
17\end{array}$ & $\mathrm{X}$ & & \\
\hline $\begin{array}{l}\text { A comparison of attrition rates of elementary } \\
\text { teachers prepared through traditional } \\
\text { undergraduate campus-based programs and } \\
\text { elementary teachers prepared through Centers } \\
\text { for Professional Development and Technology } \\
\text { field-based programs by gender ethnicity, and } \\
\text { academic performance }\end{array}$ & $\begin{array}{l}\text { Texas A \& M } \\
\text { Commerce-1998 } \\
18\end{array}$ & & & $\mathrm{X}$ \\
\hline $\begin{array}{l}\text { Black male student achievement: A synthesis of } \\
\text { research in the "Journal of Negro Education" } \\
\text { BLACK MALE }\end{array}$ & $\begin{array}{l}\text { Texas A \& M } \\
\text { Commerce-1998 } \\
19\end{array}$ & & $\mathrm{X}$ & \\
\hline $\begin{array}{l}\text { The relationship between self-concept and } \\
\text { management aspirations in female prospective } \\
\text { teachers }\end{array}$ & $\begin{array}{l}\text { Texas A \& M } \\
\text { Commerce-1998 } \\
20\end{array}$ & $\mathrm{X}$ & & \\
\hline $\begin{array}{l}\text { The relationship of socioeconomic status, gender } \\
\text { and parenting styles to hyperactivity in children } \\
\text { grades } 4 \text { through } 6\end{array}$ & $\begin{array}{l}\text { Texas A \& M } \\
\text { Commerce-1998 } \\
21\end{array}$ & & & $\bar{X}$ \\
\hline $\begin{array}{l}\text { Daniel E. Griffiths: The influence of his work on } \\
\text { the study and practice of educational } \\
\text { administration am }\end{array}$ & $\begin{array}{l}\text { Texas A \& M } \\
\text { Commerce-1998 } \\
22\end{array}$ & & $\mathrm{X}$ & \\
\hline $\begin{array}{l}\text { Redeeming love: A thematic study of three } \\
\text { novels by Susan Hill af }\end{array}$ & $\begin{array}{l}\text { Texas A \& M } \\
\text { Commerce-1998 } \\
\text { 23 } \text { Gender }^{\boldsymbol{b}} \\
\text { 8-F } \\
\text { 6-M } \\
0-\mathrm{LGTBIQ} \\
9-0 \\
\end{array}$ & $\mathrm{X}$ & & \\
\hline $\begin{array}{l}\text { Factors influencing the underrepresentation of } \\
\text { Latinos in higher education } \\
\text { LATINO/A }\end{array}$ & $\begin{array}{l}\text { Texas A \& M } \\
\text { Kingsville-2006 } \\
1\end{array}$ & & $\mathrm{X}$ & \\
\hline $\begin{array}{l}\text { An exploratory examination of the relationships } \\
\text { among emotional intelligence, elementary } \\
\text { school science teacher self-efficacy, length of } \\
\text { teaching experience, race/ethnicity, gender and } \\
\text { age }\end{array}$ & $\begin{array}{l}\text { Texas A \& M } \\
\text { Kingsville-2004 } \\
2\end{array}$ & & & $\mathrm{X}$ \\
\hline
\end{tabular}




\section{GENDER REPRESENTATIONS IN ED.D. DISSERTATIONS}

\begin{tabular}{|c|c|c|c|c|}
\hline $\begin{array}{l}\text { A study of factors associated with gender } \\
\text { specific superintendents in public schools } \\
\text { M v F LEADER }\end{array}$ & $\begin{array}{l}\text { Texas A \& M } \\
\text { Kingsville-2002 } \\
\mathbf{3} \text { Gender }{ }^{\boldsymbol{b}} \\
\text { 1-F } \\
\text { 0-M } \\
\text { 0-LGTBIQ } \\
\text { 2-0 }\end{array}$ & & & $\mathrm{X}$ \\
\hline $\begin{array}{l}\text { An investigation into the perceptions of Latino } \\
\text { parents of young children in urban, suburban } \\
\text { and rural school settings } \\
\text { LATINO/A }\end{array}$ & $\begin{array}{l}\text { Texas Woman's } \\
\text { University-2001 } \\
1\end{array}$ & & $\mathrm{X}$ & \\
\hline $\begin{array}{l}\text { An investigation into the relationship of } \\
\text { ethnicity and gender on the social competencies } \\
\text { and social responsibilities of } 4 \text {-year olds }\end{array}$ & $\begin{array}{l}\text { Texas Woman's } \\
\text { University-1999 } \\
\mathbf{2} \text { Gender }{ }^{\boldsymbol{b}} \\
\text { 0-F } \\
\text { 1-M } \\
\text { 0-LGTBIQ } \\
\text { 1-O }\end{array}$ & & & $\mathrm{X}$ \\
\hline $\begin{array}{l}\text { Understanding the conditions that encourage the } \\
\text { persistence of women in science, mathematics, } \\
\text { and engineering pathways }\end{array}$ & $\begin{array}{l}\text { University of } \\
\text { Arkansas-Little } \\
\text { Rock-2002 } \\
\text { 1 Gender }{ }^{\boldsymbol{b}} \\
\text { 1-F } \\
\text { 0-M } \\
\text { 0-LGTBIQ } \\
0-\mathrm{O}\end{array}$ & $\mathrm{X}$ & & \\
\hline $\begin{array}{l}\text { The kids on the other side of the hallway: } \\
\text { Teacher's perspectives of the academic } \\
\text { achievement of Latino English language learners } \\
\text { LATINO/A }\end{array}$ & $\begin{array}{l}\text { University of } \\
\text { Massachusetts- } \\
\text { Boston-2007 } \\
1\end{array}$ & & $\mathrm{X}$ & \\
\hline $\begin{array}{l}\text { Establishing classroom contacts and } \\
\text { interactions: White educators' attitudes about } \\
\text { early adolescent Black males } \\
\text { BLACK MALE }\end{array}$ & $\begin{array}{l}\text { University of } \\
\text { Massachusetts- } \\
\text { Boston-2006 } \\
2\end{array}$ & & $\mathrm{X}$ & \\
\hline $\begin{array}{l}\text { Letters from four antebellum black women } \\
\text { educators to the American missionary } \\
\text { Association } 1863-1870 \text {. }\end{array}$ & $\begin{array}{l}\text { University of } \\
\text { Massachusetts- } \\
\text { Boston-2006 } \\
3\end{array}$ & $\mathrm{X}$ & & \\
\hline $\begin{array}{l}\text { The socialization experience of Cape Verdean, } \\
\text { Latina, and Portuguese women faculty at four } \\
\text { year institutions }\end{array}$ & $\begin{array}{l}\text { University of } \\
\text { Massachusetts- } \\
\text { Boston-2005 } \\
4\end{array}$ & $\mathrm{X}$ & & \\
\hline $\begin{array}{l}\text { Veteran teacher attitudes towards Blacks and } \\
\text { Latinos in urban self-contained special } \\
\text { education high school classrooms }\end{array}$ & $\begin{array}{l}\text { University of } \\
\text { Massachusetts- } \\
\text { Boston-2005 } \\
5\end{array}$ & & $\mathrm{X}$ & \\
\hline Institutionalization of women's studies program: & University of & $\mathrm{X}$ & & \\
\hline
\end{tabular}




\section{GENDER REPRESENTATIONS IN ED.D. DISSERTATIONS}

\begin{tabular}{|c|c|c|c|c|}
\hline $\begin{array}{l}\text { the relationship of program structure to long } \\
\text { term viability }\end{array}$ & $\begin{array}{l}\text { Massachusetts- } \\
\text { Boston-2004 } \\
6\end{array}$ & & & \\
\hline $\begin{array}{l}\text { Our experience says we know something: We } \\
\text { are still here. An autoethnographic study of } \\
\text { African-American women principals in } \\
\text { Massachusetts K-12 public schools }\end{array}$ & $\begin{array}{l}\text { University of } \\
\text { Massachusetts- } \\
\text { Boston-2004 } \\
7\end{array}$ & $\mathrm{X}$ & & \\
\hline $\begin{array}{l}\text { The involvement of African American Fathers in } \\
\text { the educational lives of their young children: } \\
\text { Beliefs, practices, and experiences in one } \\
\text { elementary school } \\
\text { BLACK MALE }\end{array}$ & $\begin{array}{l}\text { University of } \\
\text { Massachusetts- } \\
\text { Boston-2004 } \\
8\end{array}$ & & $\mathrm{X}$ & \\
\hline $\begin{array}{l}\text { Disadvantaged females and urban Catholic high } \\
\text { schools: A narrative inquiry }\end{array}$ & $\begin{array}{l}\text { University of } \\
\text { Massachusetts- } \\
\text { Boston-2003 } \\
9\end{array}$ & $X$ & & \\
\hline $\begin{array}{l}\text { An examination of factors by gender and } \\
\text { race/ethnicity influencing science, mathematics, } \\
\text { and engineering undergraduate degree recipients } \\
\text { to enroll in graduate study }\end{array}$ & $\begin{array}{l}\text { University of } \\
\text { Massachusetts- } \\
\text { Boston-2001 } \\
10\end{array}$ & & & \\
\hline $\begin{array}{l}\text { A case study of the perspectives of gay and } \\
\text { lesbian teachers: Overcoming heterosexism and } \\
\text { homophobia in the school community } \\
\text { LGTBIQ }\end{array}$ & $\begin{array}{l}\text { University of } \\
\text { Massachusetts- } \\
\text { Boston-1999 } \\
11\end{array}$ & & & \\
\hline $\begin{array}{l}\text { The economic returns to a college degree with } \\
\text { special reference to major field of study and } \\
\text { race/ethnicity and gender }\end{array}$ & $\begin{array}{l}\text { University of } \\
\text { Massachusetts- } \\
\text { Boston-1998 } \\
\text { 12 } \text { Gender }^{\boldsymbol{b}} \\
\text { 5-F } \\
\text { 4-M } \\
\text { 1-LGTBIQ } \\
\text { 2-O }\end{array}$ & & & \\
\hline $\begin{array}{l}\text { Are there differences in the perceived leadership } \\
\text { practices of female and male superintendents as } \\
\text { identified by school committee members } \\
\text { M v F LEADER } \\
\text { FULL TEXT }\end{array}$ & $\begin{array}{l}\text { University of } \\
\text { Massachusetts- } \\
\text { Lowell-2007 } \\
1\end{array}$ & & & \\
\hline $\begin{array}{l}\text { What is the role of mentoring in the professional } \\
\text { lives of female intercollegiate athletics } \\
\text { directors? }\end{array}$ & $\begin{array}{l}\text { University of } \\
\text { Massachusetts- } \\
\text { Lowell-2007 } \\
2\end{array}$ & $\mathrm{X}$ & & \\
\hline $\begin{array}{l}\text { Factors that motivate Hispanic middle school } \\
\text { males to achieve academically }\end{array}$ & $\begin{array}{l}\text { University of } \\
\text { Massachusetts- } \\
\text { Lowell-2005 } \\
3\end{array}$ & & $\mathrm{X}$ & \\
\hline $\begin{array}{l}\text { Privileged affluent fathers: Perspectives on } \\
\text { fathering and their children's schooling }\end{array}$ & $\begin{array}{l}\text { University of } \\
\text { Massachusetts- } \\
\text { Lowell-2005 } \\
4\end{array}$ & & $\mathrm{X}$ & \\
\hline
\end{tabular}




\section{GENDER REPRESENTATIONS IN ED.D. DISSERTATIONS}

\begin{tabular}{|c|c|c|c|c|}
\hline $\begin{array}{l}\text { Leadership style: Do male and female school } \\
\text { superintendents lead differently? } \\
\text { M v F LEADER } \\
\text { FULL TEXT }\end{array}$ & $\begin{array}{l}\text { University of } \\
\text { Massachusetts- } \\
\text { Lowell-2004 } \\
5\end{array}$ & & & X \\
\hline $\begin{array}{l}\text { A study of Massachusetts high school and } \\
\text { middle school nurses'perceptions of their role in } \\
\text { teaching their school offices about the } \\
\text { prevention of sexually transmitted diseases }\end{array}$ & $\begin{array}{l}\text { University of } \\
\text { Massachusetts } \\
\text { Lowell-2003 } \\
6\end{array}$ & & & $\mathrm{X}$ \\
\hline $\begin{array}{l}\text { Zilpah Polly Grant Banister, nineteenth century } \\
\text { seminary principal: An inquiry into her } \\
\text { contributions to and impact on the advancement } \\
\text { of higher education for women af }\end{array}$ & $\begin{array}{l}\text { University of } \\
\text { Massachusetts- } \\
\text { Lowell-1999 } \\
7\end{array}$ & $\mathrm{X}$ & & \\
\hline $\begin{array}{l}\text { The effects of collaborative concept mapping on } \\
\text { the achievement, science, self-efficacy and } \\
\text { attitude toward science of female eighth grade } \\
\text { students }\end{array}$ & $\begin{array}{l}\text { University of } \\
\text { Massachusetts- } \\
\text { Lowell-2003 } \\
8\end{array}$ & $\mathrm{X}$ & & \\
\hline $\begin{array}{l}\text { The involvement of fathers in their children's } \\
\text { education during the middle school years }\end{array}$ & $\begin{array}{l}\text { University of } \\
\text { Massachusetts- } \\
\text { Lowell-2000 } \\
9\end{array}$ & & $\mathrm{X}$ & \\
\hline $\begin{array}{l}\text { How women leaders define power: Case studies } \\
\text { of three women college presidents in New } \\
\text { England }\end{array}$ & $\begin{array}{l}\text { University of } \\
\text { Massachusetts- } \\
\text { Lowell-1998 } \\
\text { 10 Gender }{ }^{b} \\
\text { 4-F } \\
\text { 3-M } \\
\text { 0-LGTBIQ } \\
\text { 3-O }\end{array}$ & $\mathrm{X}$ & & \\
\hline $\begin{array}{l}\text { Exploratory study of the effects of parent } \\
\text { training on increasing Hispanic/Latino parent's } \\
\text { understanding, participation and satisfaction } \\
\text { with the Individual Education Program meeting } \\
\text { LATINO/A }\end{array}$ & $\begin{array}{l}\text { U of N. Carolina- } \\
\text { Charlotte-2007 } \\
1\end{array}$ & & $\mathrm{X}$ & \\
\hline $\begin{array}{l}\text { Factors that influence female educational leaders } \\
\text { in North Carolina to seek a position at the } \\
\text { central office especially the superintendency }\end{array}$ & $\begin{array}{l}\text { U of N. Carolina- } \\
\text { Charlotte-2004 } \\
2\end{array}$ & $\mathrm{X}$ & & \\
\hline $\begin{array}{l}\text { African-American males: What do schools and } \\
\text { teachers do to enhance academic achievement? } \\
\text { BLACK MALE }\end{array}$ & $\begin{array}{l}\text { U of N. Carolina- } \\
\text { Charlotte-2002 } \\
\text { 3 Gender }{ }^{\boldsymbol{b}} \\
\text { 1-F } \\
\text { 2-M } \\
\text { 0- LGTBIQ } \\
0-\mathrm{O} \\
\end{array}$ & & $\mathrm{X}$ & \\
\hline An evaluation of the quality of the practice & U of Northern & $\mathrm{X}$ & & \\
\hline
\end{tabular}




\section{GENDER REPRESENTATIONS IN ED.D. DISSERTATIONS}

\begin{tabular}{|c|c|c|c|}
\hline $\begin{array}{l}\text { regimen of an NCAA Division I women's tennis } \\
\text { team and the development of the Quality Tennis } \\
\text { Practice inventory }\end{array}$ & $\begin{array}{l}\text { Colorado-2007 } \\
1\end{array}$ & & \\
\hline $\begin{array}{l}\text { An exploration of campus topology and women } \\
\text { students: A query of fitness }\end{array}$ & $\begin{array}{l}\text { U of Northern } \\
\text { Colorado-2007 } \\
2\end{array}$ & $\mathrm{X}$ & \\
\hline $\begin{array}{l}\text { Reading experiences of adolescent boys as they } \\
\text { navigate the multiple discourses and social } \\
\text { contexts of school, home and rural community: } \\
\text { An ethnographic case study }\end{array}$ & $\begin{array}{l}\text { U of Northern } \\
\text { Colorado-2006 } \\
3\end{array}$ & $\mathrm{X}$ & \\
\hline $\begin{array}{l}\text { Female pursuit of and access to the } \\
\text { superintendency }\end{array}$ & $\begin{array}{l}\text { U of Northern } \\
\text { Colorado-2005 } \\
4\end{array}$ & $\mathrm{X}$ & \\
\hline $\begin{array}{l}\text { Fundraising and Division-I A college athletics: } \\
\text { A study of alumnus affiliation and gender of } \\
\text { donors }\end{array}$ & $\begin{array}{l}\text { U of Northern } \\
\text { Colorado-2004 } \\
5\end{array}$ & & $\mathrm{X}$ \\
\hline $\begin{array}{l}\text { An analysis of usability of womens' collegiate } \\
\text { basketball websites based on measurements of } \\
\text { effectiveness, efficiency and appeal }\end{array}$ & $\begin{array}{l}\text { U of Northern } \\
\text { Colorado-2002 } \\
6\end{array}$ & $\mathrm{X}$ & \\
\hline $\begin{array}{l}\text { Effects of a transtheoretical model intervention } \\
\text { program utilizing peer facilitation, teacher } \\
\text { facilitation, and combined peer and teacher } \\
\text { facilitation on physical activity level and } \\
\text { selected determinants of physical activity for } \\
\text { female high school students in Taiwan }\end{array}$ & $\begin{array}{l}\text { U of Northern } \\
\text { Colorado-2002 } \\
7\end{array}$ & & \\
\hline $\begin{array}{l}\text { A comparison of maternal parenting style } \\
\text { attitudes of grandmothers and mothers of young } \\
\text { children in Taiwan }\end{array}$ & $\begin{array}{l}\text { U of Northern } \\
\text { Colorado-2001 } \\
8\end{array}$ & $\mathrm{X}$ & \\
\hline $\begin{array}{l}\text { Effects of the transtheoretical model on physical } \\
\text { activity, determinants, and perceived barriers of } \\
\text { high school female students }\end{array}$ & $\begin{array}{l}\text { U of Northern } \\
\text { Colorado-2001 } \\
9\end{array}$ & $\mathrm{X}$ & \\
\hline $\begin{array}{l}\text { The relationship between moral orientation and } \\
\text { the health of the organizational culture as self- } \\
\text { reported by female superintendents }\end{array}$ & $\begin{array}{l}\text { U of Northern } \\
\text { Colorado-2000 } \\
10\end{array}$ & $\mathrm{X}$ & \\
\hline $\begin{array}{l}\text { The relationship between serum estrogen, } \\
\text { testosterone, and calcium concentration and } \\
\text { serum creatine kinase after high load eccentric } \\
\text { muscle contractions in high and low creatine } \\
\text { kinase responders }\end{array}$ & $\begin{array}{l}\text { U of Northern } \\
\text { Colorado-2000 } \\
11\end{array}$ & & $\mathrm{X}$ \\
\hline $\begin{array}{l}\text { Comparisons of selected student and teacher } \\
\text { variables: Attitudinal responses of female } \\
\text { students and teachers in seventh, eighth and } \\
\text { ninth grade all girls and coeducation physical } \\
\text { education environments }\end{array}$ & $\begin{array}{l}\text { U of Northern } \\
\text { Colorado-1999 } \\
12\end{array}$ & $\mathrm{X}$ & \\
\hline $\begin{array}{l}\text { The effects of a transtheoretical model physical } \\
\text { activity intervention program on the physical } \\
\text { activity level behavior of female adolescents }\end{array}$ & $\begin{array}{l}\text { U of Northern } \\
\text { Colorado-1999 } \\
13\end{array}$ & $\mathrm{X}$ & \\
\hline An analysis of the relationships between goal & U of Northern & & $X$ \\
\hline
\end{tabular}




\section{GENDER REPRESENTATIONS IN ED.D. DISSERTATIONS}

\begin{tabular}{|c|c|c|c|c|}
\hline $\begin{array}{l}\text { perspectives, perceived learning environment, } \\
\text { and intrinsic motivation by skill levels and } \\
\text { gender in adolescent boys and girls in Taiwan, } \\
\text { Republic of China }\end{array}$ & $\begin{array}{l}\text { Colorado-1998 } \\
14\end{array}$ & & & \\
\hline $\begin{array}{l}\text { Middle school physical education environments } \\
\text { in Colorado (separate sex, modified, and } \\
\text { coeducational): Practices and perceptions of } \\
\text { physical educators and principals }\end{array}$ & $\begin{array}{l}\text { U of Northern } \\
\text { Colorado-1999 } \\
15\end{array}$ & & & $\mathrm{X}$ \\
\hline $\begin{array}{l}\text { A case study: An examination of literary } \\
\text { transaction of four Chinese-American male } \\
\text { children responding to selected children's books }\end{array}$ & $\begin{array}{l}\text { U of Northern } \\
\text { Colorado-1998 } \\
16\end{array}$ & & $\mathrm{X}$ & \\
\hline $\begin{array}{l}\text { Muscle strength in osteoporotic women with and } \\
\text { without vertebral compression fractures }\end{array}$ & $\begin{array}{l}\text { U of Northern } \\
\text { Colorado-1998 } \\
\text { 17 Gender }{ }^{\boldsymbol{b}} \\
\text { 12-F } \\
\text { 1-M } \\
\text { 0-LGTBIQ } \\
\text { 4-O }\end{array}$ & $\mathrm{X}$ & & \\
\hline $\begin{array}{l}\text { Comparison of two forms of body composition } \\
\text { measurement and blood pressure of sixth and } \\
\text { ninth grade male physical education students }\end{array}$ & $\begin{array}{l}\text { University of S. } \\
\text { Dakota-2007 } \\
1\end{array}$ & & $\mathrm{X}$ & \\
\hline $\begin{array}{l}\text { Success factors single mothers attribute to their } \\
\text { program completion at a selected rural } \\
\text { university }\end{array}$ & $\begin{array}{l}\text { University of S. } \\
\text { Dakota-2007 } \\
2\end{array}$ & $\mathrm{X}$ & & \\
\hline $\begin{array}{l}\text { Student perception of computer anxiety: The } \\
\text { relationship of computer attitude, computer } \\
\text { experience, age, gender and socioeconomic } \\
\text { status }\end{array}$ & $\begin{array}{l}\text { University of S. } \\
\text { Dakota-2006 } \\
3\end{array}$ & & & $\mathrm{X}$ \\
\hline $\begin{array}{l}\text { Barriers male students } 45 \text { years of age and older } \\
\text { encounter while pursuing doctoral degrees }\end{array}$ & $\begin{array}{l}\text { University of S. } \\
\text { Dakota-2005 } \\
4\end{array}$ & & $\mathrm{X}$ & \\
\hline $\begin{array}{l}\text { Connection in the college classroom: A } \\
\text { phenomenological study of female college } \\
\text { students and the relational-cultural theory }\end{array}$ & $\begin{array}{l}\text { University of S. } \\
\text { Dakota-2005 } \\
5\end{array}$ & $\mathrm{X}$ & & \\
\hline $\begin{array}{l}\text { Women administrators' perceptions of career } \\
\text { progression in the Minnesota State college and } \\
\text { universities: Personal and structural }\end{array}$ & $\begin{array}{l}\text { University of S. } \\
\text { Dakota-2005 } \\
6\end{array}$ & $\mathrm{X}$ & & \\
\hline $\begin{array}{l}\text { Latino student leader perceptions of social } \\
\text { integration, academic success, and persistence } \\
\text { on college campuses } \\
\text { LATINO/A }\end{array}$ & $\begin{array}{l}\text { University of } \\
\text { South Dakota- } \\
2003 \\
7\end{array}$ & & & \\
\hline $\begin{array}{l}\text { Women in secondary educational } \\
\text { administration: Barriers or matter of choice }\end{array}$ & $\begin{array}{l}\text { University of S. } \\
\text { Dakota-2002 } \\
8\end{array}$ & $\mathrm{X}$ & & \\
\hline $\begin{array}{l}\text { The woman in the high school principal's office: } \\
\text { A reflective study }\end{array}$ & $\begin{array}{l}\text { University of S. } \\
\text { Dakota-2000 } \\
9\end{array}$ & $\mathrm{X}$ & & \\
\hline Reading and fetal alcohol syndrome in a male & University of S. & & $\mathrm{X}$ & \\
\hline
\end{tabular}




\section{GENDER REPRESENTATIONS IN ED.D. DISSERTATIONS}

\begin{tabular}{|c|c|c|c|c|}
\hline child: A case study & $\begin{array}{l}\text { Dakota-2000 } \\
10\end{array}$ & & & \\
\hline $\begin{array}{l}\text { Faculty attitudes and students perceptions of } \\
\text { faculty attitudes toward women at Christian } \\
\text { colleges }\end{array}$ & $\begin{array}{l}\text { University of S. } \\
\text { Dakota-2000 } \\
11\end{array}$ & $\mathrm{X}$ & & \\
\hline $\begin{array}{l}\text { Effects of video instruction on the performance } \\
\text { of female university students in beginning } \\
\text { badminton }\end{array}$ & $\begin{array}{l}\text { University of S. } \\
\text { Dakota-2000 } \\
12\end{array}$ & $\mathrm{X}$ & & \\
\hline $\begin{array}{l}\text { Male public secondary school administrators } \\
\text { perceptions regarding implementation and } \\
\text { support of gender violence prevention programs }\end{array}$ & $\begin{array}{l}\text { University of S. } \\
\text { Dakota-2002 } \\
13\end{array}$ & & $\mathrm{X}$ & \\
\hline $\begin{array}{l}\text { A comparison of the practice and skill training } \\
\text { conditions of expert and intermediate female } \\
\text { golfers }\end{array}$ & $\begin{array}{l}\text { University of S. } \\
\text { Dakota-1998 } \\
14\end{array}$ & $\mathrm{X}$ & & \\
\hline $\begin{array}{l}\text { The perceived effectiveness of Milton } \\
\text { Erickson's hypnotic communication patterns in } \\
\text { counselor supervision am }\end{array}$ & $\begin{array}{l}\text { University of S. } \\
\text { Dakota-1998 } \\
15\end{array}$ & & $\mathrm{X}$ & \\
\hline $\begin{array}{l}\text { A comparative study of perimenopausal } \\
\text { symptoms as perceived by South Dakota midlife } \\
\text { women, family practice, and } \\
\text { obstetric/gynecology physicians }\end{array}$ & $\begin{array}{l}\text { University of S. } \\
\text { Dakota-2001 } \\
16\end{array}$ & $\mathrm{X}$ & & \\
\hline $\begin{array}{l}\text { Effects of differential intensity exercise on } \\
\text { serum lipid and lipoprotein concentrations in } \\
\text { male university students }\end{array}$ & $\begin{array}{l}\text { University of S. } \\
\text { Dakota-2001 } \\
17\end{array}$ & & $\mathrm{X}$ & \\
\hline $\begin{array}{l}\text { Effects of gender and type of sport participation } \\
\text { on Taiwanese undergraduate student's physical } \\
\text { self-concept }\end{array}$ & $\begin{array}{l}\text { University of S. } \\
\text { Dakota-2001 } \\
\text { 18 Gender } \boldsymbol{b} \\
\text { 9-F } \\
\text { 7-M } \\
\text { 0-LGTBIQ } \\
\text { 2-O }\end{array}$ & & & $\mathrm{X}$ \\
\hline $\begin{array}{l}\text { The current status of African-American women } \\
\text { in institutions of higher education and their rate } \\
\text { of advancement into senior -level faculty and } \\
\text { administrative positions: A case study of } \\
\text { African-American women in Florida }\end{array}$ & $\begin{array}{l}\text { University of West } \\
\text { Florida-2001 } \\
\boldsymbol{1} \text { Gender } \boldsymbol{b} \\
\text { 1-F } \\
0-\mathrm{M} \\
\text { 0-LGTBIQ } \\
0-\mathrm{O}\end{array}$ & $\mathrm{X}$ & & \\
\hline
\end{tabular}


GENDER REPRESENTATIONS IN ED.D. DISSERTATIONS

\begin{tabular}{|c|c|c|c|c|c|}
\hline Dissertation Title & $\begin{array}{l}\text { RUH- } \\
\text { Institution }\end{array}$ & $F$ & $M$ & 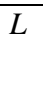 & $O$ \\
\hline $\begin{array}{l}\text { Effect of a computer based multimedia module } \\
\text { on knowledge of the menstrual cycle }\end{array}$ & $\begin{array}{l}\text { Bowling Green } \\
\text { State }-2007 \\
1\end{array}$ & $\mathrm{X}$ & & & \\
\hline $\begin{array}{l}\text { Lasting legacies: The effects of natural mentors } \\
\text { in the lives of at risk African -American male } \\
\text { adolescents } \\
\text { BLACK MALE }\end{array}$ & $\begin{array}{l}\text { Bowling Green } \\
\text { State-2006 } \\
2\end{array}$ & & $\mathrm{X}$ & & \\
\hline $\begin{array}{l}\text { The praxis of black female educational } \\
\text { leadership from a systems thinking perspective }\end{array}$ & $\begin{array}{l}\text { Bowling Green } \\
\text { State-2003 } \\
\mathbf{3} \text { Gender }^{\boldsymbol{b}} \\
\text { 2-F } \\
\text { 1-M } \\
\text { 0-LGTBIQ } \\
\text { 0-O }\end{array}$ & $\mathrm{X}$ & & & \\
\hline $\begin{array}{l}\text { Lipid treatment assessment in Women: Primary } \\
\text { Care practice and curricula implications for } \\
\text { South Carolina obstetricians/gynecologists }\end{array}$ & $\begin{array}{l}\text { Clemson } \\
\text { University-2001 }^{1} \text { Gender }^{\boldsymbol{b}} \\
\text { 1-F } \\
0-\mathrm{M} \\
0-\mathrm{LGTBIQ} \\
0-\mathrm{O}\end{array}$ & $\mathrm{X}$ & & & \\
\hline $\begin{array}{l}\text { Navigating the Academy: The career } \\
\text { advancement of Black and White women full } \\
\text { time faculty }\end{array}$ & $\begin{array}{l}\text { College of } \\
\text { William \& Mary- } \\
2006 \\
1\end{array}$ & $\mathrm{X}$ & & & \\
\hline $\begin{array}{l}\text { A study exploring the educational needs of } \\
\text { African-American pastor's wives within Baptist } \\
\text { congregations }\end{array}$ & $\begin{array}{l}\text { College of } \\
\text { William \& Mary- } \\
2004 \\
2\end{array}$ & $\mathrm{X}$ & & & \\
\hline $\begin{array}{l}\text { President J.A.C.Chandler and the first women } \\
\text { faculty at the College of William and Mary } \\
\text { (male \& female) am }\end{array}$ & $\begin{array}{l}\text { College of } \\
\text { William \& Mary- } \\
2004 \\
3\end{array}$ & & & & $\mathrm{X}$ \\
\hline $\begin{array}{l}\text { Effects of residential learning communities, on } \\
\text { campus housing, and gender on student's } \\
\text { perception of their living environment }\end{array}$ & $\begin{array}{l}\text { College of } \\
\text { William \& Mary- } \\
2003 \\
\mathbf{4} \text { Gender }^{b} \\
\text { 2-F } \\
0-\mathrm{M} \\
0-\mathrm{LGTBIQ} \\
\text { 2-O }\end{array}$ & & & & $\mathrm{X}$ \\
\hline Elementary teacher's perception of gender bias & $\begin{array}{l}\text { Florida Atlantic- } \\
\text { Boca } \\
2007 \\
1\end{array}$ & & & & $\mathrm{X}$ \\
\hline
\end{tabular}




\section{GENDER REPRESENTATIONS IN ED.D. DISSERTATIONS}

\begin{tabular}{|c|c|c|c|c|c|}
\hline $\begin{array}{l}\text { The impact of reading instructional } \\
\text { methodology on student achievement of Black } \\
\text { males based on the Florida comprehensive } \\
\text { assessment test } \\
\text { BLACK MALE }\end{array}$ & $\begin{array}{l}\text { Florida Atlantic } \\
\text { Boca } \\
2006 \\
2\end{array}$ & & $X$ & & \\
\hline $\begin{array}{l}\text { Building a template of electoral strategies for } \\
\text { women who aspire to the superintendency in } \\
\text { appointed school districts within the southern } \\
\text { United States }\end{array}$ & $\begin{array}{l}\text { Florida Atlantic } \\
\text { Boca } \\
2003 \\
3\end{array}$ & $X$ & & & \\
\hline $\begin{array}{l}\text { Gender equity at selected National Collegiate } \\
\text { Athletic Association Division III Institutions }\end{array}$ & $\begin{array}{l}\text { Florida Atlantic } \\
\text { Boca } \\
1999 \\
4\end{array}$ & & & & $\mathrm{X}$ \\
\hline $\begin{array}{l}\text { A comparison of academic success variables of } \\
\text { Black male high school graduates with other } \\
\text { racial and gender populations in the Broward } \\
\text { County School district Florida } \\
\text { BLACK MALE }\end{array}$ & $\begin{array}{l}\text { Florida Atlantic } \\
\text { Boca } \\
\mathbf{5}_{\text {Gender }} \boldsymbol{b} \\
\text { 1-F } \\
2-\mathrm{M} \\
0-\mathrm{L} \\
2-\mathrm{O}\end{array}$ & & $\mathrm{X}$ & & \\
\hline $\begin{array}{l}\text { Caring and being cared for: Perceptions of } \\
\text { adolescent males at risk for school failure }\end{array}$ & $\begin{array}{l}\text { Florida } \\
\text { International U- } \\
2005 \\
1\end{array}$ & & $\mathrm{X}$ & & \\
\hline $\begin{array}{l}\text { Differences in learning style preference among } \\
\text { students of diverse ethnicities, gender, academic } \\
\text { placement level and academic achievement }\end{array}$ & $\begin{array}{l}\text { Florida } \\
\text { International U- } \\
2005 \\
2\end{array}$ & & & & $\mathrm{X}$ \\
\hline $\begin{array}{l}\text { Gender differences in principal motivations } \\
\text { M v F LEADER }\end{array}$ & $\begin{array}{l}\text { Florida } \\
\text { International U- } \\
2005 \\
3\end{array}$ & & & & $\mathrm{X}$ \\
\hline $\begin{array}{l}\text { Women graduates academic resilience and their } \\
\text { personal strategies for doctoral success }\end{array}$ & $\begin{array}{l}\text { Florida } \\
\text { International U- } \\
2004 \\
4\end{array}$ & $\mathrm{X}$ & & & \\
\hline $\begin{array}{l}\text { Constructing literacy: Disadvantaged Irish } \\
\text { mother's attempts at developing literacy with } \\
\text { their preschool children during story book } \\
\text { reading and jigsaw puzzle building }\end{array}$ & $\begin{array}{l}\text { Florida } \\
\text { International U- } \\
2003 \\
5\end{array}$ & $X$ & & & \\
\hline $\begin{array}{l}\text { Heteronormativity and teaching: A } \\
\text { phenomenological study of lesbian teachers } \\
\text { LGTBIQ }\end{array}$ & $\begin{array}{l}\text { Florida } \\
\text { International U- } \\
2002 \\
6\end{array}$ & & & $\mathrm{X}$ & \\
\hline $\begin{array}{l}\text { Profile of Florida: Services in transnational } \\
\text { housing programs for homeless women with } \\
\text { children }\end{array}$ & $\begin{array}{l}\text { Florida } \\
\text { International U- } \\
2002\end{array}$ & $X$ & & & \\
\hline
\end{tabular}




\section{GENDER REPRESENTATIONS IN ED.D. DISSERTATIONS}

\begin{tabular}{|c|c|c|c|c|}
\hline & 7 & & & \\
\hline $\begin{array}{l}\text { Dean of the school board: An oral history of the } \\
\text { distinguished career of G. Holmes Braddock am }\end{array}$ & $\begin{array}{l}\text { Florida } \\
\text { International U- } \\
2001 \\
8\end{array}$ & & $\mathrm{X}$ & \\
\hline $\begin{array}{l}\text { A study of the differences among African- } \\
\text { American, Hispanic and Anglo women on the } \\
\text { perceived barriers and strategies to career } \\
\text { advancement in public school administration }\end{array}$ & $\begin{array}{l}\text { Florida } \\
\text { International U- } \\
1999 \\
9\end{array}$ & $\mathrm{X}$ & & \\
\hline $\begin{array}{l}\text { A study of the perceived effectiveness of } \\
\text { existing recruitment and general institution-wide } \\
\text { practices used to enhance women and minority } \\
\text { full time faculty representation at Florida's } \\
\text { public universities }\end{array}$ & $\begin{array}{l}\text { Florida } \\
\text { International U- } \\
1999 \\
10\end{array}$ & & & $\mathrm{X}$ \\
\hline $\begin{array}{l}\text { An investigation into factors that influence the } \\
\text { sense of competence of six high school girls }\end{array}$ & $\begin{array}{l}\text { Florida } \\
\text { International U- } \\
1999 \\
11\end{array}$ & $\mathrm{X}$ & & \\
\hline $\begin{array}{l}\text { Perceptions of family environment, body image, } \\
\text { and self esteem of eating disordered and non- } \\
\text { eating disordered women }\end{array}$ & $\begin{array}{l}\text { Florida } \\
\text { International U- } \\
1998 \\
12 \\
\end{array}$ & $X$ & & \\
\hline $\begin{array}{l}\text { Planning and evaluation of Business English } \\
\text { course in compliance with internationalization in } \\
\text { Taiwan: A case study of Taiwan Women's } \\
\text { College of Arts \& Technology }\end{array}$ & $\begin{array}{l}\text { Florida } \\
\text { International U- } \\
1998 \\
13\end{array}$ & $\mathrm{X}$ & & \\
\hline $\begin{array}{l}\text { Sexual Harassment of Miami-Dade County } \\
\text { public school students by school personnel }\end{array}$ & $\begin{array}{l}\text { Florida } \\
\text { International U- } \\
1998 \\
\text { 14 Gender }^{\boldsymbol{b}} \\
\text { 7-F } \\
\text { 2-M } \\
\text { 1-LGTBIQ } \\
\text { 4-O }\end{array}$ & & & $\mathrm{X}$ \\
\hline No gender found $5 / 4 / 2010$ & 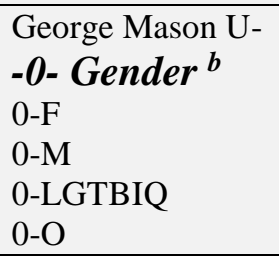 & & & \\
\hline $\begin{array}{l}\text { Korean immigrant mothers involvement in their } \\
\text { children's homework/home work }\end{array}$ & $\begin{array}{l}\text { Indiana U Purdue- } \\
2007 \\
1\end{array}$ & $\mathrm{X}$ & & \\
\hline $\begin{array}{l}\text { I don't need any help: What first year college } \\
\text { men say about interacting with faculty outside of } \\
\text { the classroom }\end{array}$ & $\begin{array}{l}\text { Indiana U Purdue- } \\
2007 \\
2\end{array}$ & & $\mathrm{X}$ & \\
\hline $\begin{array}{l}\text { Women's giving circles: A case study in higher } \\
\text { education philanthropy }\end{array}$ & $\begin{array}{l}\text { Indiana U Purdue- } \\
2006\end{array}$ & $\mathrm{X}$ & & \\
\hline
\end{tabular}


GENDER REPRESENTATIONS IN ED.D. DISSERTATIONS

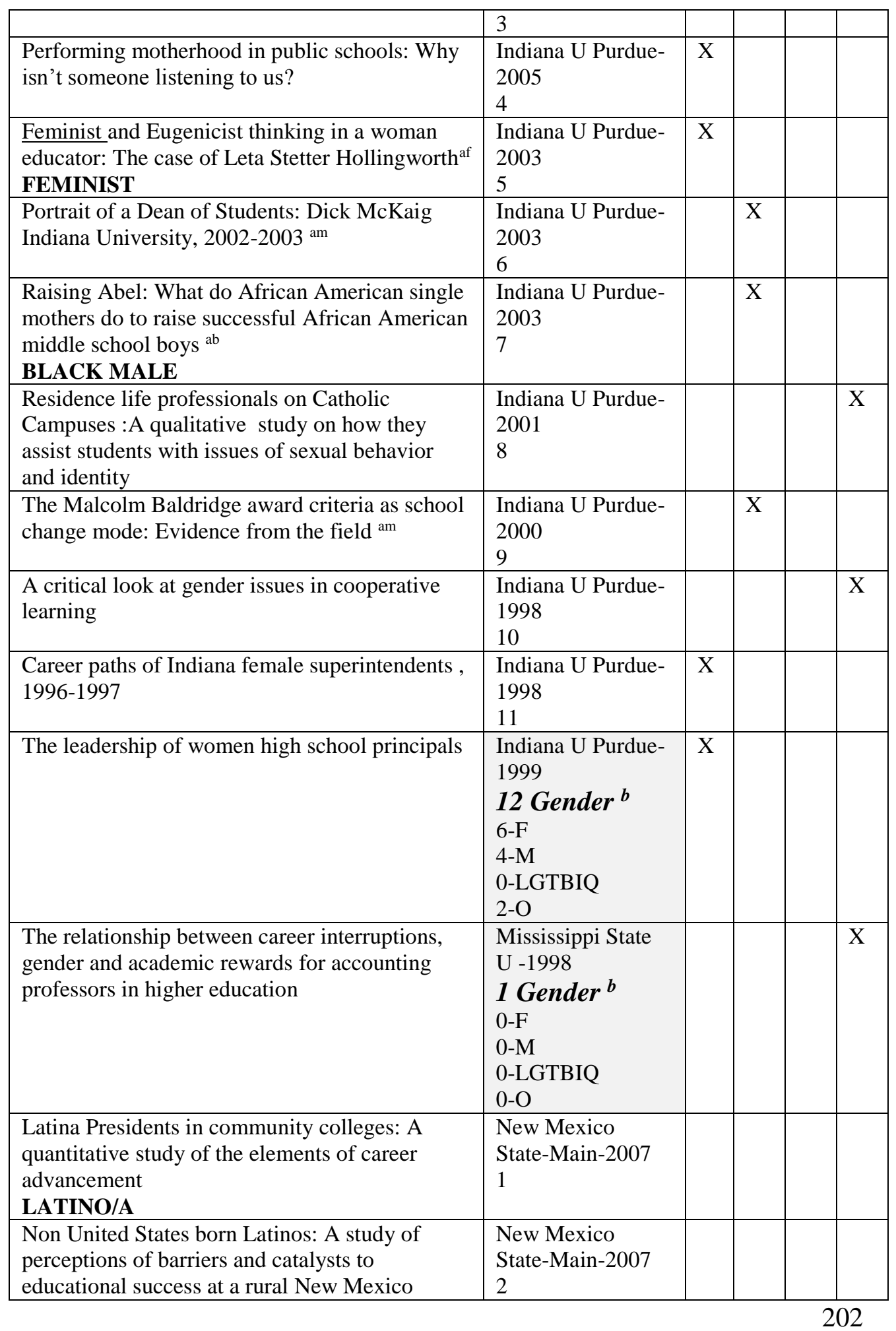




\section{GENDER REPRESENTATIONS IN ED.D. DISSERTATIONS}

\begin{tabular}{|c|c|c|c|c|c|}
\hline $\begin{array}{l}\text { community college } \\
\text { LATINO/A }\end{array}$ & & & & & \\
\hline $\begin{array}{l}\text { Transformational leadership and female } \\
\text { community college presidents: A gender focused } \\
\text { assessment }\end{array}$ & $\begin{array}{l}\text { New Mexico } \\
\text { State-Main-2006 } \\
3\end{array}$ & & & & \\
\hline $\begin{array}{l}\text { A qualitative study for the identification of } \\
\text { wives of enlisted military personnel as at risk } \\
\text { students for the development of a campus wide } \\
\text { support model for these students }\end{array}$ & $\begin{array}{l}\text { New Mexico } \\
\text { State-Main-2004 } \\
4\end{array}$ & & & & \\
\hline $\begin{array}{l}\text { A study of student's attitudes towards physics } \\
\text { and classroom environment based on gender and } \\
\text { grade level among senior secondary education } \\
\text { students in Indonesia }\end{array}$ & $\begin{array}{l}\text { New Mexico } \\
\text { State-Main-2002 } \\
5\end{array}$ & & & & \\
\hline $\begin{array}{l}\text { A case study on language proficiency with } \\
\text { Latino students in dual language setting } \\
\text { LATINO/A }\end{array}$ & $\begin{array}{l}\text { New Mexico } \\
\text { State-Main-2000 } \\
6\end{array}$ & & $\mathrm{X}$ & & \\
\hline $\begin{array}{l}\text { Tapestries of Mexican-American women } \\
\text { secondary teachers: A narrative experience }\end{array}$ & $\begin{array}{l}\text { New Mexico } \\
\text { State-Main-1998 } \\
7 \text { Gender }{ }^{\boldsymbol{b}} \\
\text { 4-F } \\
\text { 2-M } \\
\text { 0-LGTBIQ } \\
\text { 1-O }\end{array}$ & $\mathrm{X}$ & & & \\
\hline $\begin{array}{l}\text { Leadership styles of female educational leaders } \\
\text { and female police leaders: A comparative study }\end{array}$ & $\begin{array}{l}\text { Northern Arizona } \\
\text { U-2006 } \\
1\end{array}$ & $\mathrm{X}$ & & & \\
\hline $\begin{array}{l}\text { The impact of an instructional program on the } \\
\text { attitudes of girls towards mathematics and } \\
\text { technology }\end{array}$ & $\begin{array}{l}\text { Northern Arizona } \\
\text { U-2006 } \\
2\end{array}$ & $\mathrm{X}$ & & & \\
\hline $\begin{array}{l}\text { Asian American adolescents and the stress of } \\
\text { acculturation: Differences in gender and } \\
\text { generational levels }\end{array}$ & $\begin{array}{l}\text { Northern Arizona } \\
\text { U-2005 } \\
3\end{array}$ & $\mathrm{X}$ & & & \\
\hline $\begin{array}{l}\text { Leadership styles and philosophies of female } \\
\text { police leaders: A descriptive study }\end{array}$ & $\begin{array}{l}\text { Northern Arizona } \\
\text { U-2005 } \\
4\end{array}$ & $\mathrm{X}$ & & & \\
\hline $\begin{array}{l}\text { The leadership characteristics of women public } \\
\text { manager }\end{array}$ & $\begin{array}{l}\text { Northern Arizona } \\
\text { U-2004 } \\
5\end{array}$ & $\mathrm{X}$ & & & \\
\hline $\begin{array}{l}\text { Levels of family involvement and gender role } \\
\text { conflict among stay-at-home dads }\end{array}$ & $\begin{array}{l}\text { Northern Arizona } \\
\text { U-2003 } \\
6\end{array}$ & & $\mathrm{X}$ & & \\
\hline $\begin{array}{l}\text { Resilience in adult women students in higher } \\
\text { education : Implications for academic and } \\
\text { persistence }\end{array}$ & $\begin{array}{l}\text { Northern Arizona } \\
\text { U-2003 } \\
7\end{array}$ & $\mathrm{X}$ & & & \\
\hline $\begin{array}{l}\text { The gay and lesbian counseling experience triad: } \\
\text { Curriculum, service and satisfaction } \\
\text { LGTBIQ }\end{array}$ & $\begin{array}{l}\text { Northern Arizona } \\
\text { U-2003 } \\
8\end{array}$ & & & $\mathrm{X}$ & \\
\hline Variables influencing the career advancement of & Northern Arizona & $\mathrm{X}$ & & & \\
\hline
\end{tabular}




\section{GENDER REPRESENTATIONS IN ED.D. DISSERTATIONS}

\begin{tabular}{|c|c|c|c|c|c|}
\hline $\begin{array}{l}\text { full time tenure track Latinas in selected public } \\
\text { universities } \\
\text { LATINO/A }\end{array}$ & $\begin{array}{l}\text { U-2003 } \\
9\end{array}$ & & & & \\
\hline $\begin{array}{l}\text { The perceived impact of chance on careers and } \\
\text { its relationship to locus of control and gender }\end{array}$ & $\begin{array}{l}\text { Northern Arizona } \\
\text { U-2002 } \\
10\end{array}$ & & & & $X$ \\
\hline $\begin{array}{l}\text { A transformation of one's own: Women's } \\
\text { studies discourse in National Council of } \\
\text { Teachers of English }\end{array}$ & $\begin{array}{l}\text { Northern Arizona } \\
\text { U-2000 } \\
11\end{array}$ & $X$ & & & \\
\hline $\begin{array}{l}\text { Career perspectives of female superintendents in } \\
\text { the state of Arizona }\end{array}$ & $\begin{array}{l}\text { Northern Arizona } \\
\text { U-2000 } \\
12\end{array}$ & $X$ & & & \\
\hline $\begin{array}{l}\text { The effectiveness of NCAA Division I athletes } \\
\text { program leadership in assuring Title IX } \\
\text { Compliance } \\
\text { TITLE IX }\end{array}$ & $\begin{array}{l}\text { Northern Arizona } \\
\text { U-2000 } \\
13\end{array}$ & & & & $\mathrm{X}$ \\
\hline $\begin{array}{l}\text { Factors that influence minority participation in } \\
\text { predominately White fraternities and sororities }\end{array}$ & $\begin{array}{l}\text { Northern Arizona } \\
\text { U-2000 } \\
14\end{array}$ & & & & $\mathrm{X}$ \\
\hline $\begin{array}{l}\text { Contributing factors to success of Hispanic } \\
\text { female graduates of a community college }\end{array}$ & $\begin{array}{l}\text { Northern Arizona } \\
\text { U-1999 } \\
15\end{array}$ & $X$ & & & \\
\hline $\begin{array}{l}\text { Gender and interactions of children during free } \\
\text { play in a Montessori preprimary classroom }\end{array}$ & $\begin{array}{l}\text { Northern Arizona } \\
\text { U-1999 } \\
16\end{array}$ & & & & $\mathrm{X}$ \\
\hline $\begin{array}{l}\text { An investigation of gender differences and } \\
\text { leadership characteristics in the hospitality } \\
\text { industry }\end{array}$ & $\begin{array}{l}\text { Northern Arizona } \\
\text { U-1998 } \\
17\end{array}$ & & & & $X$ \\
\hline $\begin{array}{l}\text { Factors that influence career development of } \\
\text { university-educated Black Zimbabwean women }\end{array}$ & $\begin{array}{l}\text { Northern Arizona } \\
\text { U-1998 } \\
18\end{array}$ & $X$ & & & \\
\hline $\begin{array}{l}\text { Resiliency characteristics of women leaders in } \\
\text { education }\end{array}$ & $\begin{array}{l}\text { Northern Arizona } \\
\text { U-1998 } \\
\text { 19 Gender }{ }^{b} \\
\text { 12-F } \\
\text { 1-M } \\
\text { 1-L } \\
\text { 5-O }\end{array}$ & $X$ & & & \\
\hline $\begin{array}{l}\text { An analysis of adult African American men's } \\
\text { perceived susceptibility of prostate cancer and } \\
\text { perceived benefits and barriers to participation } \\
\text { in early detection methods: Implications for } \\
\text { community-based health promotion } \\
\text { BLACK MALE }\end{array}$ & $\begin{array}{l}\text { Northern Illinois- } \\
2007 \text { University } \\
1\end{array}$ & & $\mathrm{X}$ & & \\
\hline $\begin{array}{l}\text { Gay and lesbian school administrators: } \\
\text { Negotiating personal and professional roles and } \\
\text { responsibilities within hetero-normative }\end{array}$ & $\begin{array}{l}\text { Northern Illinois } \\
\text { University-2007 } \\
2\end{array}$ & & & $X$ & \\
\hline
\end{tabular}




\section{GENDER REPRESENTATIONS IN ED.D. DISSERTATIONS}

\begin{tabular}{|c|c|c|c|c|c|}
\hline $\begin{array}{l}\text { organizations } \\
\text { LGTBIQ }\end{array}$ & & & & & \\
\hline $\begin{array}{l}\text { Subcutaneous: The life experience of African } \\
\text { American transsexual college students } \\
\text { LGTBIQ }\end{array}$ & $\begin{array}{l}\text { Northern Illinois } \\
\text { University-2007 } \\
3\end{array}$ & & & $\mathrm{X}$ & \\
\hline $\begin{array}{l}\text { A case study of at risk adolescent females' } \\
\text { interpretations of heterosexuality in magazine } \\
\text { advertisements }\end{array}$ & $\begin{array}{l}\text { Northern Illinois } \\
\text { University-2006 } \\
4\end{array}$ & $\mathrm{X}$ & & & \\
\hline $\begin{array}{l}\text { An exploratory study of the experiences of } \\
\text { Mexican American women attending } \\
\text { community college }\end{array}$ & $\begin{array}{l}\text { Northern Illinois } \\
\text { University-2006 } \\
5\end{array}$ & $\mathrm{X}$ & & & \\
\hline $\begin{array}{l}\text { Defining mother-child interaction in an } \\
\text { childrens'museum: An in depth study of the } \\
\text { interaction between mothers and their preschool } \\
\text { children }\end{array}$ & $\begin{array}{l}\text { Northern Illinois } \\
\text { University-2006 } \\
6\end{array}$ & $\mathrm{X}$ & & & \\
\hline $\begin{array}{l}\text { Empowerment of low-income women in India: } \\
\text { Emergent feminist grassroots leaders in } \\
\text { Ahmedabad, Gujarat } \\
\text { FEMINIST }\end{array}$ & $\begin{array}{l}\text { Northern Illinois } \\
\text { University-2006 } \\
7\end{array}$ & $\mathrm{X}$ & & & \\
\hline $\begin{array}{l}\text { Factors influencing condom use among Latino } \\
\text { men who have sex with men } \\
\text { LGTBIQ }\end{array}$ & $\begin{array}{l}\text { Northern Illinois } \\
\text { University -2006 } \\
8\end{array}$ & & & $\mathrm{X}$ & \\
\hline $\begin{array}{l}\text { Female students adjustment to college: An } \\
\text { investigation of psychosocial factors }\end{array}$ & $\begin{array}{l}\text { Northern Illinois } \\
\text { University-2006 } \\
9\end{array}$ & $\mathrm{X}$ & & & \\
\hline $\begin{array}{l}\text { Joy and pain: Breaking through the myths of } \\
\text { breast cancer. An exploratory study with } \\
\text { implications for adult and health education }\end{array}$ & $\begin{array}{l}\text { Northern Illinois } \\
\text { University -2006 } \\
10\end{array}$ & $\mathrm{X}$ & & & \\
\hline $\begin{array}{l}\text { Rural women learning the American way: } \\
\text { Cooperative Extension Services and home } \\
\text { economics from 1960-1980. }\end{array}$ & $\begin{array}{l}\text { Northern Illinois } \\
\text { University-2006 } \\
11\end{array}$ & $\mathrm{X}$ & & & \\
\hline $\begin{array}{l}\text { Women's participation in advanced and } \\
\text { emerging technology program: Stories of } \\
\text { confidence and determination }\end{array}$ & $\begin{array}{l}\text { Northern Illinois } \\
\text { University -2006 } \\
12\end{array}$ & $\mathrm{X}$ & & & \\
\hline $\begin{array}{l}\text { A study of the relationship between resiliency } \\
\text { attitudes and selected risk factors of gang } \\
\text { involvement in adult Honduran males }\end{array}$ & $\begin{array}{l}\text { Northern Illinois } \\
\text { University -2005 } \\
13\end{array}$ & & $\mathrm{X}$ & & \\
\hline $\begin{array}{l}\text { A study of Josephine Locke, her influence on } \\
\text { elementary art education in the Chicago public } \\
\text { schools and her work at the Art Institute of } \\
\text { Chicago af }\end{array}$ & $\begin{array}{l}\text { Northern Illinois } \\
\text { University-2005 } \\
14\end{array}$ & $\mathrm{X}$ & & & \\
\hline $\begin{array}{l}\text { College Latino students: Cultural integration, } \\
\text { retention, and successful completion } \\
\text { LATINO/A }\end{array}$ & $\begin{array}{l}\text { Northern Illinois } \\
\text { University }-2005 \\
15\end{array}$ & & $\mathrm{X}$ & & \\
\hline $\begin{array}{l}\text { Negotiating identity in a second language } \\
\text { environment: A narrative study of nine East } \\
\text { Asian female international students }\end{array}$ & $\begin{array}{l}\text { Northern Illinois } \\
\text { University-2005 } \\
16\end{array}$ & $\mathrm{X}$ & & & \\
\hline Precursors to change and women coping & Northern Illinois & $\mathrm{X}$ & & & \\
\hline
\end{tabular}




\section{GENDER REPRESENTATIONS IN ED.D. DISSERTATIONS}

\begin{tabular}{|c|c|c|c|c|}
\hline successfully with multiple sclerosis & $\begin{array}{l}\text { University-2005 } \\
17\end{array}$ & & & \\
\hline $\begin{array}{l}\text { The African American church as a provider of } \\
\text { nonformal adult education in the Chicago } \\
\text { community under the leadership of Pastor } \\
\text { William Samuel Winston }\end{array}$ & $\begin{array}{l}\text { Northern Illinois } \\
\text { University-2005 } \\
18\end{array}$ & & $\mathrm{X}$ & \\
\hline $\begin{array}{l}\text { The impact of work requirements on quality of } \\
\text { life among female high school principals }\end{array}$ & $\begin{array}{l}\text { Northern Illinois } \\
\text { University }-2005 \\
19\end{array}$ & $\mathrm{X}$ & & \\
\hline $\begin{array}{l}\text { The influence of Lillian G. Katz on early } \\
\text { childhood education: An oral history }{ }^{a}\end{array}$ & $\begin{array}{l}\text { Northern Illinois } \\
\text { University-2005 } \\
20\end{array}$ & $\mathrm{X}$ & & \\
\hline $\begin{array}{l}\text { Women becoming mentors: Reflection and } \\
\text { mentor identity formation as a process of } \\
\text { lifelong learning }\end{array}$ & $\begin{array}{l}\text { Northern Illinois } \\
\text { University-2005 } \\
21\end{array}$ & $\mathrm{X}$ & & \\
\hline $\begin{array}{l}\text { Finding voice: Taking the lead. Experiences and } \\
\text { characteristics of African American women } \\
\text { leaders in Republican organizations: } \\
\text { Implications for adult education }\end{array}$ & $\begin{array}{l}\text { Northern Illinois } \\
\text { University-2004 } \\
22\end{array}$ & $\mathrm{X}$ & & \\
\hline $\begin{array}{l}\text { Exploring identities: An enquiry into the identity } \\
\text { reconstruction of adult immigrants of Filipino } \\
\text { heritage with implications for adult ESL } \\
\text { programs }\end{array}$ & $\begin{array}{l}\text { Northern Illinois } \\
\text { University -2004 } \\
23\end{array}$ & & $\mathrm{X}$ & \\
\hline $\begin{array}{l}\text { Menogogy as the art and science of becoming a } \\
\text { crone: Changing perspectives on women, aging } \\
\text { and adult education }\end{array}$ & $\begin{array}{l}\text { Northern Illinois } \\
\text { University-2004 } \\
24\end{array}$ & $\mathrm{X}$ & & \\
\hline $\begin{array}{l}\text { School organization of successful alternative } \\
\text { high schools serving Latino students in Chicago } \\
\text { LATINO/A }\end{array}$ & $\begin{array}{l}\text { Northern Illinois } \\
\text { University-2004 } \\
25\end{array}$ & & $\mathrm{X}$ & \\
\hline $\begin{array}{l}\text { The voices of women computer professionals: } \\
\text { Perspectives on achievement }\end{array}$ & $\begin{array}{l}\text { Northern Illinois } \\
\text { University-2004 } \\
26\end{array}$ & $\mathrm{X}$ & & \\
\hline $\begin{array}{l}\text { Women with doctorates in science: Perceptions } \\
\text { of facilitative factors and obstacles to their } \\
\text { success }\end{array}$ & $\begin{array}{l}\text { Northern Illinois } \\
\text { University-2004 } \\
27\end{array}$ & $\mathrm{X}$ & & \\
\hline $\begin{array}{l}\text { A study of female principals moral orientations } \\
\text { and reasoning through the use of self-generated } \\
\text { moral dilemmas }\end{array}$ & $\begin{array}{l}\text { Northern Illinois } \\
\text { University-2003 } \\
28\end{array}$ & $\mathrm{X}$ & & \\
\hline $\begin{array}{l}\text { Coming into their own: A study of a feminist } \\
\text { adult education program in Esteli, Nicaragua } \\
\text { FEMINIST }\end{array}$ & $\begin{array}{l}\text { Northern Illinois } \\
\text { University-2003 } \\
29\end{array}$ & $\mathrm{X}$ & & \\
\hline $\begin{array}{l}\text { Ida B. Wells "A Red Record" : A social justice } \\
\text { curriculum for educating the adult in post- } \\
\text { Reconstruction America af }\end{array}$ & $\begin{array}{l}\text { Northern Illinois } \\
\text { University-2003 } \\
30\end{array}$ & $\mathrm{X}$ & & \\
\hline $\begin{array}{l}\text { Lessons learned while suspended between two } \\
\text { cultures: The life history of a Latina adult } \\
\text { educator } \\
\text { LATINO/A }\end{array}$ & $\begin{array}{l}\text { Northern Illinois } \\
\text { University-2003 } \\
31\end{array}$ & $\mathrm{X}$ & & \\
\hline
\end{tabular}




\section{GENDER REPRESENTATIONS IN ED.D. DISSERTATIONS}

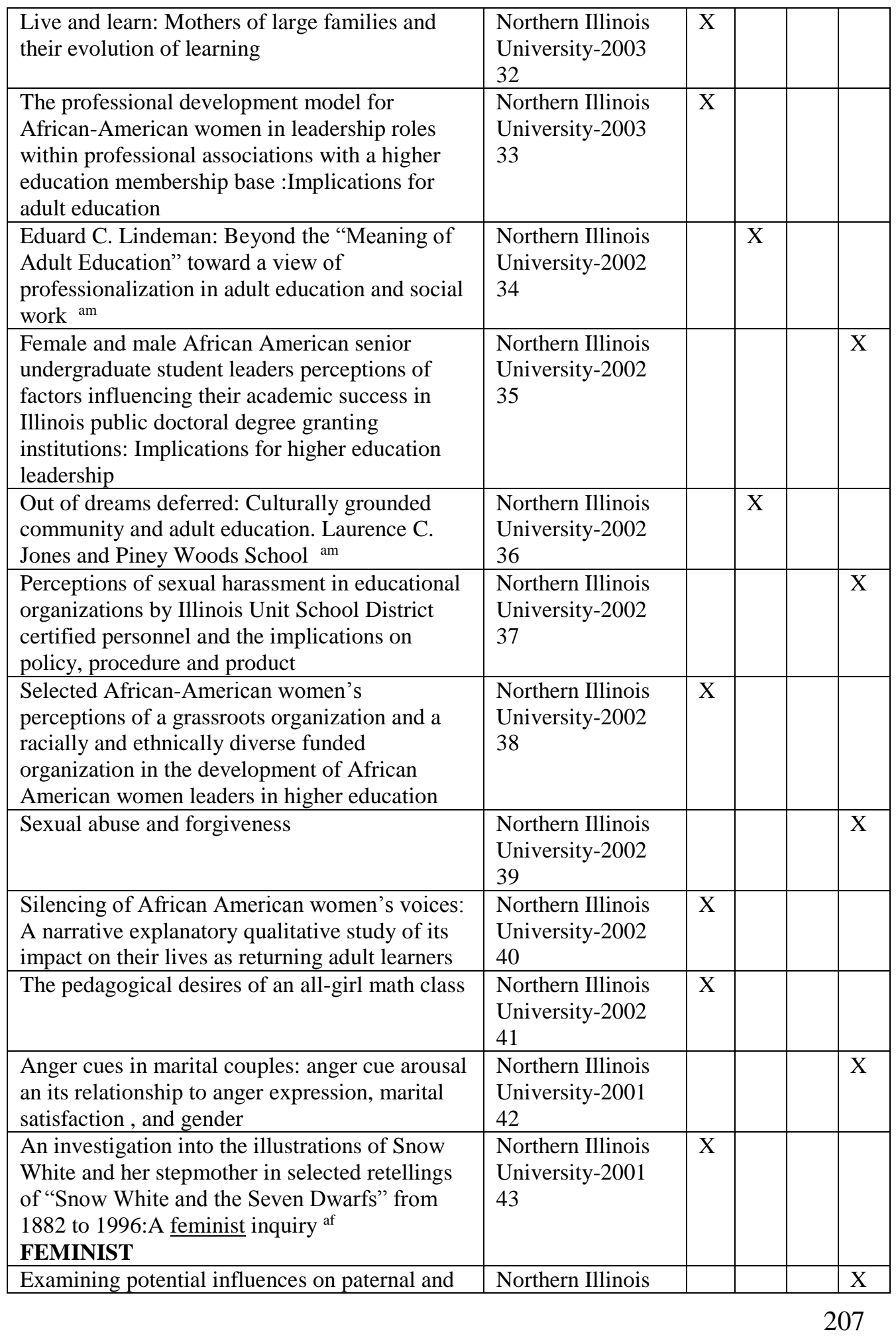




\section{GENDER REPRESENTATIONS IN ED.D. DISSERTATIONS}

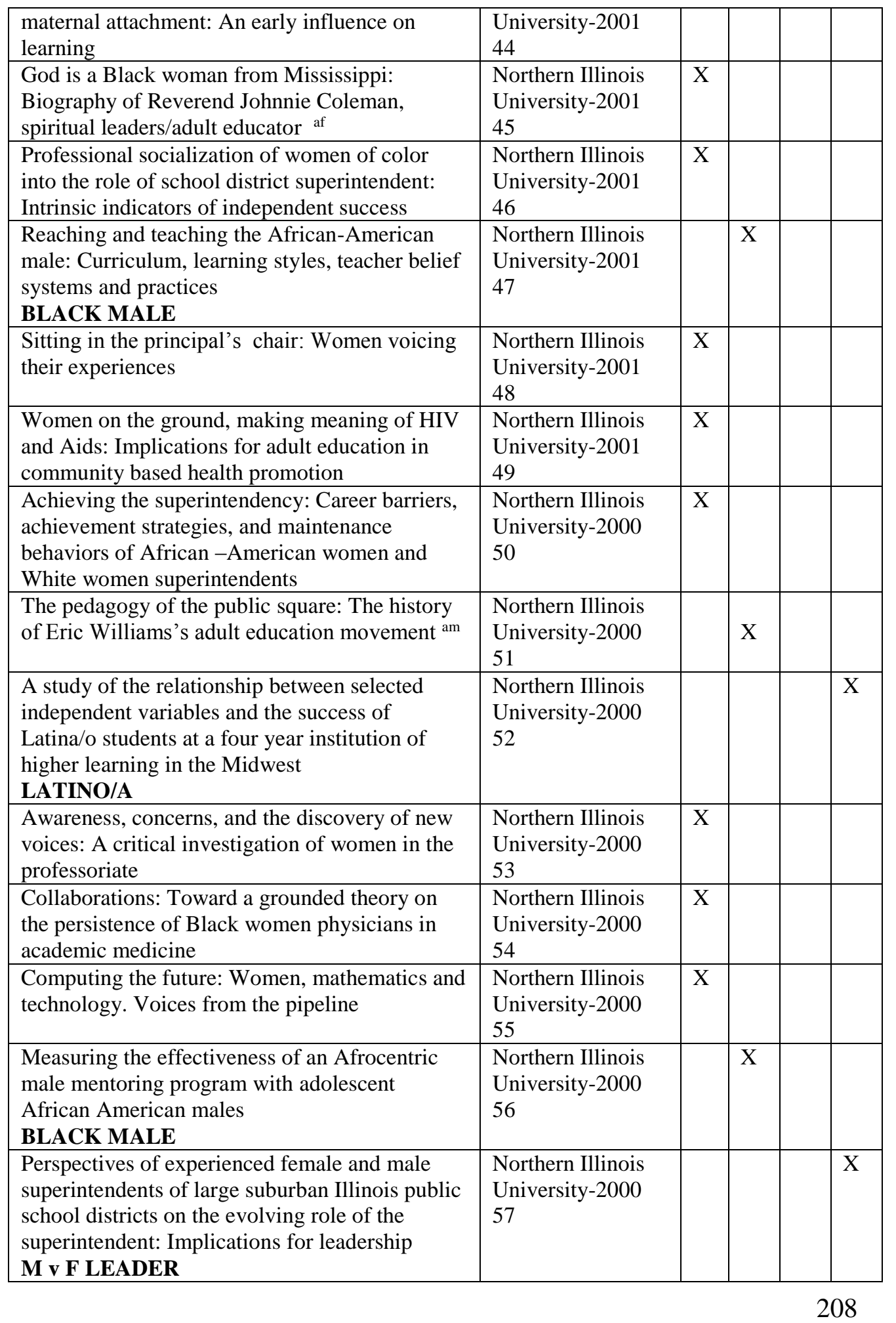




\section{GENDER REPRESENTATIONS IN ED.D. DISSERTATIONS}

\begin{tabular}{|c|c|c|c|c|}
\hline $\begin{array}{l}\text { Perspectives of experienced female and male } \\
\text { superintendents of small rural Illinois public } \\
\text { school districts on the evolving role of the } \\
\text { superintendent: Implications for leadership } \\
\text { M v F LEADER }\end{array}$ & $\begin{array}{l}\text { Northern Illinois } \\
\text { University-2000 } \\
58\end{array}$ & & & $\mathrm{X}$ \\
\hline $\begin{array}{l}\text { Rediscovering the essential nature of African } \\
\text { American male leadership: An Afrocentric } \\
\text { perspective } \\
\text { BLACK MALE }\end{array}$ & $\begin{array}{l}\text { Northern Illinois } \\
\text { University-2000 } \\
59\end{array}$ & & & $\mathrm{X}$ \\
\hline $\begin{array}{l}\text { Resurrection: A phenomenological investigation } \\
\text { of the transformational learning experiences of } \\
\text { women }\end{array}$ & $\begin{array}{l}\text { Northern Illinois } \\
\text { University-2000 } \\
60\end{array}$ & $\mathrm{X}$ & & \\
\hline $\begin{array}{l}\text { There are no crystal stairs here: A study of } \\
\text { African-American males in traditional and non } \\
\text { traditional program in a predominately White } \\
\text { institution of higher education } \\
\text { BLACK MALE }\end{array}$ & $\begin{array}{l}\text { Northern Illinois } \\
\text { University-2000 } \\
61\end{array}$ & & $\mathrm{X}$ & \\
\hline $\begin{array}{l}\text { An inductive case study of women leaders of } \\
\text { athletics at Northern Illinois University }\end{array}$ & $\begin{array}{l}\text { Northern Illinois } \\
\text { University-1999 } \\
62\end{array}$ & $\mathrm{X}$ & & \\
\hline An intellectual biography of Ivan Illich ${ }^{\text {am }}$ & $\begin{array}{l}\text { Northern Illinois } \\
\text { University-1999 } \\
63\end{array}$ & & $\mathrm{X}$ & \\
\hline $\begin{array}{l}\text { An investigation into the career paths and } \\
\text { leadership experiences of three female high } \\
\text { school principals }\end{array}$ & $\begin{array}{l}\text { Northern Illinois } \\
\text { University-1999 } \\
64\end{array}$ & $\mathrm{X}$ & & \\
\hline $\begin{array}{l}\text { Communication styles of elementary school } \\
\text { principals: Perception as function of biological } \\
\text { sex and gender }\end{array}$ & $\begin{array}{l}\text { Northern Illinois } \\
\text { University -1999 } \\
65\end{array}$ & & & $\mathrm{X}$ \\
\hline $\begin{array}{l}\text { Descriptions of the mentoring experiences of } \\
\text { female public school superintendents in the State } \\
\text { of Illinois }\end{array}$ & $\begin{array}{l}\text { Northern Illinois } \\
\text { University -1999 } \\
66\end{array}$ & $\mathrm{X}$ & & \\
\hline $\begin{array}{l}\text { Empowerment of Zulu women through popular } \\
\text { adult education in South Africa: A case study of } \\
\text { the National Association for Women's } \\
\text { empowerment program (NAWE) in KwaZulu- } \\
\text { Natal }\end{array}$ & $\begin{array}{l}\text { Northern Illinois } \\
\text { University }-1999 \\
67\end{array}$ & $\mathrm{X}$ & & \\
\hline $\begin{array}{l}\text { Irish-American female religious leaders, 1832- } \\
\text { 1902: Sisters of Charity of the Blessed Virgin } \\
\text { Mary af }\end{array}$ & $\begin{array}{l}\text { Northern Illinois } \\
\text { University -1999 } \\
68\end{array}$ & $\mathrm{X}$ & & \\
\hline $\begin{array}{l}\text { Moving off the ladder: Career decisions of } \\
\text { women in science and their implications for } \\
\text { adult continuing education }\end{array}$ & $\begin{array}{l}\text { Northern Illinois } \\
\text { University -1999 } \\
69\end{array}$ & $\mathrm{X}$ & & \\
\hline $\begin{array}{l}\text { Social cognition and language: Abusive } \\
\text { language and the African -American male } \\
\text { juvenile transgressor } \\
\text { BLACK MALE }\end{array}$ & $\begin{array}{l}\text { Northern Illinois } \\
\text { University-1999 } \\
70\end{array}$ & & $\mathrm{X}$ & \\
\hline The influence of perceived parental acceptance- & Northern Illinois & & $\mathrm{X}$ & \\
\hline
\end{tabular}




\section{GENDER REPRESENTATIONS IN ED.D. DISSERTATIONS}

\begin{tabular}{|c|c|c|c|c|}
\hline $\begin{array}{l}\text { rejection, parental control, and psychological } \\
\text { adjustment on job stability of men }\end{array}$ & $\begin{array}{l}\text { University-1999 } \\
71\end{array}$ & & & \\
\hline $\begin{array}{l}\text { Where have all the girls gone? : A study of } \\
\text { female perceptions of math success for female } \\
\text { high school students and implications for } \\
\text { leadership, policy and practice }\end{array}$ & $\begin{array}{l}\text { Northern Illinois } \\
\text { University-1999 } \\
72\end{array}$ & $X$ & & \\
\hline $\begin{array}{l}\text { Finishing what she started: Participation of } \\
\text { African American and Hispanic women students } \\
\text { in higher education reentry support programs }\end{array}$ & $\begin{array}{l}\text { Northern Illinois } \\
\text { University-1998 } \\
73\end{array}$ & $\mathrm{X}$ & & \\
\hline $\begin{array}{l}\text { Investigating the difference in leadership styles } \\
\text { and effectiveness between male and female } \\
\text { public high school principals in Illinois } \\
\text { M v F LEADER }\end{array}$ & $\begin{array}{l}\text { Northern Illinois } \\
\text { University-1998 } \\
74\end{array}$ & & & $\mathrm{X}$ \\
\hline $\begin{array}{l}\text { La pisca, la familia, y las schools: Personal } \\
\text { narratives of Tejana women in the Midwest and } \\
\text { the nature of adult education }\end{array}$ & $\begin{array}{l}\text { Northern Illinois } \\
\text { University-1998 } \\
75\end{array}$ & $\mathrm{X}$ & & \\
\hline $\begin{array}{l}\text { Malcolm X: An intellectual aesthetic for Black } \\
\text { adult education am }\end{array}$ & $\begin{array}{l}\text { Northern Illinois } \\
\text { University-1998 } \\
76\end{array}$ & & $X$ & \\
\hline $\begin{array}{l}\text { The development of faith maturity in men and } \\
\text { its implication for education in the local church }\end{array}$ & $\begin{array}{l}\text { Northern Illinois } \\
\text { University-1998 } \\
77 \text { Gender } \\
46-\mathrm{F} \\
17-\mathrm{M} \\
3-\mathrm{L} \\
11-\mathrm{O}\end{array}$ & & $\mathrm{X}$ & \\
\hline $\begin{array}{l}\text { Female dropouts in Botswana junior secondary } \\
\text { schools: How much of a crisis is it? }\end{array}$ & $\begin{array}{l}\text { Ohio U-Main- } \\
2007 \\
1\end{array}$ & $\mathrm{X}$ & & \\
\hline $\begin{array}{l}\text { School participants perceptions of gender equity } \\
\text { issues in school policies and practices: An } \\
\text { ethnographic case study of a public secondary } \\
\text { school in Malawi }\end{array}$ & $\begin{array}{l}\text { Ohio U-Main- } \\
2005 \\
2\end{array}$ & & & $X$ \\
\hline $\begin{array}{l}\text { Et in Arcadia Mattheus? An investigation of } \\
\text { educational equity in Kentucky's public } \\
\text { schools }{ }^{\mathrm{am}}\end{array}$ & $\begin{array}{l}\text { Ohio U-Main- } \\
2005 \\
\mathbf{3} \text { Gender }^{b} \\
\text { 1-F } \\
\text { 1-M } \\
0-\text { LGTBIQ } \\
1-\mathrm{O}\end{array}$ & & $\mathrm{X}$ & \\
\hline $\begin{array}{l}\text { Media representation of female body images in } \\
\text { women's magazines }\end{array}$ & $\begin{array}{l}\text { Oklahoma State- } \\
\text { Main-2006 } \\
1\end{array}$ & $\mathrm{X}$ & & \\
\hline $\begin{array}{l}\text { The influence of gender and ethnicity on } \\
\text { achievement and engagement levels of Upward } \\
\text { Bound students }\end{array}$ & $\begin{array}{l}\text { Oklahoma State- } \\
\text { Main-2006 } \\
2\end{array}$ & & & $\mathrm{X}$ \\
\hline
\end{tabular}




\section{GENDER REPRESENTATIONS IN ED.D. DISSERTATIONS}

\begin{tabular}{|c|c|c|c|c|}
\hline $\begin{array}{l}\text { The sexual harassment of human resource } \\
\text { professionals }\end{array}$ & $\begin{array}{l}\text { Oklahoma State- } \\
\text { Main-2006 } \\
3\end{array}$ & & & $\mathrm{X}$ \\
\hline $\begin{array}{l}\text { An exploratory study of well-being in middle } \\
\text { aged Navajo women living on the Navajo } \\
\text { Nation }\end{array}$ & $\begin{array}{l}\text { Oklahoma State- } \\
\text { Main-2005 } \\
4\end{array}$ & $\mathrm{X}$ & & \\
\hline Hungry ghosts: Ponca girls in two worlds & $\begin{array}{l}\text { Oklahoma State- } \\
\text { Main-2005 } \\
5\end{array}$ & $\mathrm{X}$ & & \\
\hline $\begin{array}{l}\text { Incoming college freshman's perceptions of } \\
\text { racial, religious, and sexual orientation groups }\end{array}$ & $\begin{array}{l}\text { Oklahoma State- } \\
\text { Main-2005 } \\
6\end{array}$ & & & $\mathrm{X}$ \\
\hline $\begin{array}{l}\text { Researching the experience of trust as lived by } \\
\text { women who teach nursing }\end{array}$ & $\begin{array}{l}\text { Oklahoma State- } \\
\text { Main-2005 } \\
7\end{array}$ & $\mathrm{X}$ & & \\
\hline $\begin{array}{l}\text { The effect of gender role orientation and } \\
\text { participation in a single sex outdoor recreation } \\
\text { program on self-efficacy }\end{array}$ & $\begin{array}{l}\text { Oklahoma State- } \\
\text { Main-2004 } \\
8\end{array}$ & & & $\mathrm{X}$ \\
\hline $\begin{array}{l}\text { The under-representation of women in the } \\
\text { superintendency: A study of accumulative } \\
\text { disadvantage }\end{array}$ & $\begin{array}{l}\text { Oklahoma State- } \\
\text { Main-2004 } \\
9\end{array}$ & $\mathrm{X}$ & & \\
\hline $\begin{array}{l}\text { A study of the elements and events that } \\
\text { influence leadership among women of color } \\
\text { administrators at Oklahoma technology centers }\end{array}$ & $\begin{array}{l}\text { Oklahoma State- } \\
\text { Main-2003 } \\
10\end{array}$ & $\mathrm{X}$ & & \\
\hline $\begin{array}{l}\text { Networks and the perpetuation of dominant } \\
\text { cultural roles: The technology gender gap and } \\
\text { the impact of teachers }\end{array}$ & $\begin{array}{l}\text { Oklahoma State- } \\
\text { Main-2003 } \\
11\end{array}$ & & & $\mathrm{X}$ \\
\hline $\begin{array}{l}\text { African-American male per-service teachers' } \\
\text { perceptions of elementary education: A multiple } \\
\text { case study } \\
\text { BLACK MALE }\end{array}$ & $\begin{array}{l}\text { Oklahoma State- } \\
\text { Main-2002 } \\
12\end{array}$ & & $\mathrm{X}$ & \\
\hline $\begin{array}{l}\text { Career success of black women administrators in } \\
\text { higher education }\end{array}$ & $\begin{array}{l}\text { Oklahoma State- } \\
\text { Main-2002 } \\
13\end{array}$ & $\mathrm{X}$ & & \\
\hline $\begin{array}{l}\text { Mentoring of female faculty in higher education: } \\
\text { An explanatory case study using Mary } \\
\text { Douglas's grid/group typology af }\end{array}$ & $\begin{array}{l}\text { Oklahoma State- } \\
\text { Main-2002 } \\
14\end{array}$ & $\mathrm{X}$ & & \\
\hline $\begin{array}{l}\text { Mexican American women in college: Factors } \\
\text { related to educational goals and occupational } \\
\text { aspirations }\end{array}$ & $\begin{array}{l}\text { Oklahoma State- } \\
\text { Main-2002 } \\
15\end{array}$ & $\mathrm{X}$ & & \\
\hline $\begin{array}{l}\text { Teaching citizenship: Civic values in the young } \\
\text { adult novels of Chris Crutcher am }\end{array}$ & $\begin{array}{l}\text { Oklahoma State- } \\
\text { Main-2002 } \\
16\end{array}$ & & $\mathrm{X}$ & \\
\hline $\begin{array}{l}\text { A voice from the shadows: A historical } \\
\text { educational case study of Julia Ann Christian af }\end{array}$ & $\begin{array}{l}\text { Oklahoma State- } \\
\text { Main-2001 } \\
17\end{array}$ & $\mathrm{X}$ & & \\
\hline $\begin{array}{l}\text { Comparison of a strength training program } \\
\text { performed on the concept } 2 \text { Dyno and Cybex }\end{array}$ & $\begin{array}{l}\text { Oklahoma State- } \\
\text { Main-2001 }\end{array}$ & & $\mathrm{X}$ & \\
\hline
\end{tabular}




\section{GENDER REPRESENTATIONS IN ED.D. DISSERTATIONS}

\begin{tabular}{|c|c|c|c|c|c|}
\hline chest press machine among college age men & 18 & & & & \\
\hline $\begin{array}{l}\text { A feminist phase theory exploration of the } \\
\text { development of levels of gender awareness in } \\
\text { the superintendency } \\
\text { FEMINIST }\end{array}$ & $\begin{array}{l}\text { Oklahoma State- } \\
\text { Main-2000 } \\
19\end{array}$ & $\mathrm{X}$ & & & \\
\hline $\begin{array}{l}\text { A study of social networks of female } \\
\text { superintendents }\end{array}$ & $\begin{array}{l}\text { Oklahoma State- } \\
\text { Main-2000 } \\
20\end{array}$ & $\mathrm{X}$ & & & \\
\hline $\begin{array}{l}\text { The influence of self-efficacy on academic } \\
\text { achievement and academic performance of } \\
\text { selected middle school African American girls }\end{array}$ & $\begin{array}{l}\text { Oklahoma State- } \\
\text { Main-2000 } \\
21\end{array}$ & $\mathrm{X}$ & & & \\
\hline $\begin{array}{l}\text { An active positive leader: Applying James } \\
\text { Barber to Theodore Roosevelt's life am }\end{array}$ & $\begin{array}{l}\text { Oklahoma State- } \\
\text { Main-1999 } \\
22\end{array}$ & & $\mathrm{X}$ & & \\
\hline $\begin{array}{l}\text { Gender equality in the classroom: An } \\
\text { application of perpetuation theory and the } \\
\text { influence of social networks }\end{array}$ & $\begin{array}{l}\text { Oklahoma State- } \\
\text { Main-1999 } \\
23\end{array}$ & & & & $\mathrm{X}$ \\
\hline $\begin{array}{l}\text { The selection of high school principals: An } \\
\text { examination of the process using feminist phase } \\
\text { theory } \\
\text { FEMINIST }\end{array}$ & $\begin{array}{l}\text { Oklahoma State- } \\
\text { Main-1999 } \\
24\end{array}$ & $\mathrm{X}$ & & & \\
\hline $\begin{array}{l}\text { A postmodern feminist text analysis of the } \\
\text { pedagogy of popular craft } \\
\text { FEMINIST }\end{array}$ & $\begin{array}{l}\text { Oklahoma State- } \\
\text { Main-1998 } \\
\text { 25 Gender }{ }^{\boldsymbol{b}} \\
\text { 15-F } \\
\text { 4-M } \\
\text { 0-LGTBIQ } \\
\text { 6-O }\end{array}$ & $\mathrm{X}$ & & & \\
\hline $\begin{array}{l}\text { Asian American females in educational } \\
\text { leadership in K-12 public schools }\end{array}$ & $\begin{array}{l}\text { San Diego State- } \\
2005 \\
1\end{array}$ & $\mathrm{X}$ & & & \\
\hline $\begin{array}{l}\text { Examining the lived experience of out gay and } \\
\text { lesbian K-12 educators } \\
\text { LGTBIQ }\end{array}$ & $\begin{array}{l}\text { San Diego State- } \\
2005 \\
2 \text { Gender } \\
\text { b-F } \\
0-\mathrm{M} \\
0-\mathrm{LGTBIQ} \\
1-\mathrm{O} \\
\end{array}$ & & & $\mathrm{X}$ & \\
\hline $\begin{array}{l}\text { Gender, identity, culture and education: An } \\
\text { ethnographic study of the discontinuity of } \\
\text { secondary schooling in Senegal, West Africa }\end{array}$ & $\begin{array}{l}\text { SUNY } \\
\text { Binghampton- } \\
2006 \\
1\end{array}$ & & & & $\mathrm{X}$ \\
\hline $\begin{array}{l}\text { Perceptions of Title IX and gender equity: the } \\
\text { influence of life histories, sports experiences, } \\
\text { and campus initiatives } \\
\text { TITLE IX }\end{array}$ & $\begin{array}{l}\text { SUNY } \\
\text { Binghampton } \\
2006 \\
2\end{array}$ & & & & $\mathrm{X}$ \\
\hline $\begin{array}{l}\text { Nurturance suffering in the maternal teacher: An } \\
\text { ethnofictive case study }\end{array}$ & $\begin{array}{l}\text { SUNY } \\
\text { Binghampton- }\end{array}$ & $\mathrm{X}$ & & & \\
\hline
\end{tabular}




\section{GENDER REPRESENTATIONS IN ED.D. DISSERTATIONS}

\begin{tabular}{|c|c|c|c|c|c|}
\hline & $\begin{array}{l}2006 \\
3\end{array}$ & & & & \\
\hline $\begin{array}{l}\text { A critical analysis of the concept of resilience: } \\
\text { Inquiry into the lives of female adolescents }\end{array}$ & $\begin{array}{l}\text { SUNY } \\
\text { Binghampton- } \\
2002 \\
4\end{array}$ & $X$ & & & \\
\hline $\begin{array}{l}\text { The civic imperative, Thomas Jefferson \& John } \\
\text { Dewey: A content analysis of "civitas" am }\end{array}$ & $\begin{array}{l}\text { SUNY } \\
\text { Binghampton- } \\
2001 \\
5\end{array}$ & & $\mathrm{X}$ & & \\
\hline $\begin{array}{l}\text { Women in the superintendency: A research } \\
\text { synthesis and biographical case study }\end{array}$ & $\begin{array}{l}\text { SUNY } \\
\text { Binghampton- } \\
2001 \\
\mathbf{6} \text { Gender }^{\boldsymbol{b}} \\
\text { 3-F } \\
\text { 1-M } \\
\text { 0-LGTBIQ } \\
\text { 2-O }\end{array}$ & $X$ & & & \\
\hline $\begin{array}{l}\text { Constant struggles: the effects of overseas study } \\
\text { on the identities of Japanese women }\end{array}$ & $\begin{array}{l}\text { Temple } \\
\text { University-2007 } \\
1\end{array}$ & $X$ & & & \\
\hline $\begin{array}{l}\text { Differential use of reactive tokens in Japanese } \\
\text { turn management and by gender }\end{array}$ & $\begin{array}{l}\text { Temple } \\
\text { University-2007 } \\
2\end{array}$ & & & & $X$ \\
\hline $\begin{array}{l}\text { Saying it loud: The cultural and socio-political } \\
\text { activism of choreographer Jawole Willa Jo } \\
\text { Zoller af }\end{array}$ & $\begin{array}{l}\text { Temple } \\
\text { University-2007 } \\
3\end{array}$ & $X$ & & & \\
\hline $\begin{array}{l}\text { Factors influencing academic success for high } \\
\text { school boys from low income environments :A } \\
\text { case study }\end{array}$ & $\begin{array}{l}\text { Temple } \\
\text { University-2006 } \\
4\end{array}$ & & $\mathrm{X}$ & & \\
\hline $\begin{array}{l}\text { Gender differences in mathematics achievement } \\
\text { and mathematics attitude through participation } \\
\text { in athletics }\end{array}$ & $\begin{array}{l}\text { Temple } \\
\text { University-2006 } \\
5\end{array}$ & & & & $X$ \\
\hline $\begin{array}{l}\text { Lesbian, gay, bisexual and transgender adult } \\
\text { and youth perceptions on school safety in central } \\
\text { Pennsylvania } \\
\text { LGTBIQ }\end{array}$ & $\begin{array}{l}\text { Temple } \\
\text { University-2006 } \\
6\end{array}$ & & & $\mathrm{X}$ & \\
\hline $\begin{array}{l}\text { Normative gender and sexuality in the lives of } \\
\text { teachers and students in Japan }\end{array}$ & $\begin{array}{l}\text { Temple } \\
\text { University-2006 } \\
7\end{array}$ & & & & $\mathrm{X}$ \\
\hline $\begin{array}{l}\text { Through their eyes: An analysis of male and } \\
\text { female students during their transition from } \\
\text { middle school to high school }\end{array}$ & $\begin{array}{l}\text { Temple } \\
\text { University-2006 } \\
8\end{array}$ & & & & $\mathrm{X}$ \\
\hline $\begin{array}{l}\text { Becoming an English teacher: The personal and } \\
\text { professional development of young women in a } \\
\text { teacher education program in Japan }\end{array}$ & $\begin{array}{l}\text { Temple } \\
\text { University-2004 } \\
9\end{array}$ & $\mathrm{X}$ & & & \\
\hline $\begin{array}{l}\text { A longitudinal study of the educational and } \\
\text { career trajectories of female participants of an }\end{array}$ & $\begin{array}{l}\text { Temple } \\
\text { University-2003 }\end{array}$ & $\mathrm{X}$ & & & \\
\hline
\end{tabular}




\section{GENDER REPRESENTATIONS IN ED.D. DISSERTATIONS}

\begin{tabular}{|c|c|c|c|c|c|}
\hline urban informal science education program & 10 & & & & \\
\hline $\begin{array}{l}\text { The effects of academic preparation course type, } \\
\text { and course length on the academic achievement } \\
\text { of African American adult female students }\end{array}$ & $\begin{array}{l}\text { Temple } \\
\text { University-2003 } \\
11\end{array}$ & $\mathrm{X}$ & & & \\
\hline $\begin{array}{l}\text { Situational, institutional and dispositional } \\
\text { barriers preventing or limiting participation in } \\
\text { intramural programs by adult female students } \\
\text { attending community college in Tennessee }\end{array}$ & $\begin{array}{l}\text { Temple } \\
\text { University-2003 } \\
12\end{array}$ & $\mathrm{X}$ & & & \\
\hline $\begin{array}{l}\text { A critical ethnographic investigation of Japanese } \\
\text { junior college female learner's attitudes towards } \\
\text { gender issues and education }\end{array}$ & $\begin{array}{l}\text { Temple } \\
\text { University-2002 } \\
13\end{array}$ & $\mathrm{X}$ & & & \\
\hline $\begin{array}{l}\text { An exploratory analysis of power, opportunity } \\
\text { and proportion as related to the careers of } \\
\text { women in leadership positions within } \\
\text { intercollegiate athletics }\end{array}$ & $\begin{array}{l}\text { Temple } \\
\text { University-2002 } \\
14\end{array}$ & $\mathrm{X}$ & & & \\
\hline $\begin{array}{l}\text { Anna Halprin's "Exorcism of Cancer" (1975) } \\
\text { and the surrounding discourses of dance as a } \\
\text { healing art in the United States af }\end{array}$ & $\begin{array}{l}\text { Temple } \\
\text { University-2001 } \\
15\end{array}$ & $\mathrm{X}$ & & & \\
\hline $\begin{array}{l}\text { Black ballerina's dancing on the edge: An } \\
\text { analysis of the cultural politics in Delores } \\
\text { Browne's and Raven Wilkinson's careers, 1954- } \\
1985 \text { af }\end{array}$ & $\begin{array}{l}\text { Temple } \\
\text { University-2001 } \\
16\end{array}$ & $\mathrm{X}$ & & & \\
\hline $\begin{array}{l}\text { Lay vice principals enactment of the philosophy } \\
\text { of education of a religious order of men }\end{array}$ & $\begin{array}{l}\text { Temple } \\
\text { University-2001 } \\
17\end{array}$ & & $\mathrm{X}$ & & \\
\hline $\begin{array}{l}\text { Perceptions of personal sporting experiences and } \\
\text { life projections among Caucasian urban at -risk } \\
\text { adolescent females }\end{array}$ & $\begin{array}{l}\text { Temple } \\
\text { University-2001 } \\
18\end{array}$ & $\mathrm{X}$ & & & \\
\hline $\begin{array}{l}\text { Sexual orientation and multiperspective identity } \\
\text { on a small Catholic campus: An analysis of the } \\
\text { cultural climate and multicultural organizational } \\
\text { change } \\
\text { LGTBIQ }\end{array}$ & $\begin{array}{l}\text { Temple } \\
\text { University-2001 } \\
19\end{array}$ & & & $\mathrm{X}$ & \\
\hline $\begin{array}{l}\text { A study of the attitudes and academic } \\
\text { achievement in biology of females in a single } \\
\text { sex school vs a coeducational school in the } \\
\text { Philadelphia Archdiocesan secondary schools }\end{array}$ & $\begin{array}{l}\text { Temple } \\
\text { University-2000 } \\
20\end{array}$ & $\mathrm{X}$ & & & \\
\hline $\begin{array}{l}\text { The ethic and care of female principals: A } \\
\text { qualitative study }\end{array}$ & $\begin{array}{l}\text { Temple } \\
\text { University-2000 } \\
21\end{array}$ & $\mathrm{X}$ & & & \\
\hline $\begin{array}{l}\text { The relationship between position longevity and } \\
\text { the use of social power by female community } \\
\text { college presidents }\end{array}$ & $\begin{array}{l}\text { Temple } \\
\text { University-2000 } \\
22\end{array}$ & $\mathrm{X}$ & & & \\
\hline $\begin{array}{l}\text { The State department sponsored tours of Jose } \\
\text { Limon and his modern dance company, } 1954 \\
\text { and 1957:Modern dance diplomacy and the cold } \\
\text { war am }\end{array}$ & $\begin{array}{l}\text { Temple } \\
\text { University-2000 } \\
23\end{array}$ & & $\mathrm{X}$ & & \\
\hline Title IX Compliance: A comparative analysis of & Temple & & & & $\mathrm{X}$ \\
\hline
\end{tabular}




\section{GENDER REPRESENTATIONS IN ED.D. DISSERTATIONS}

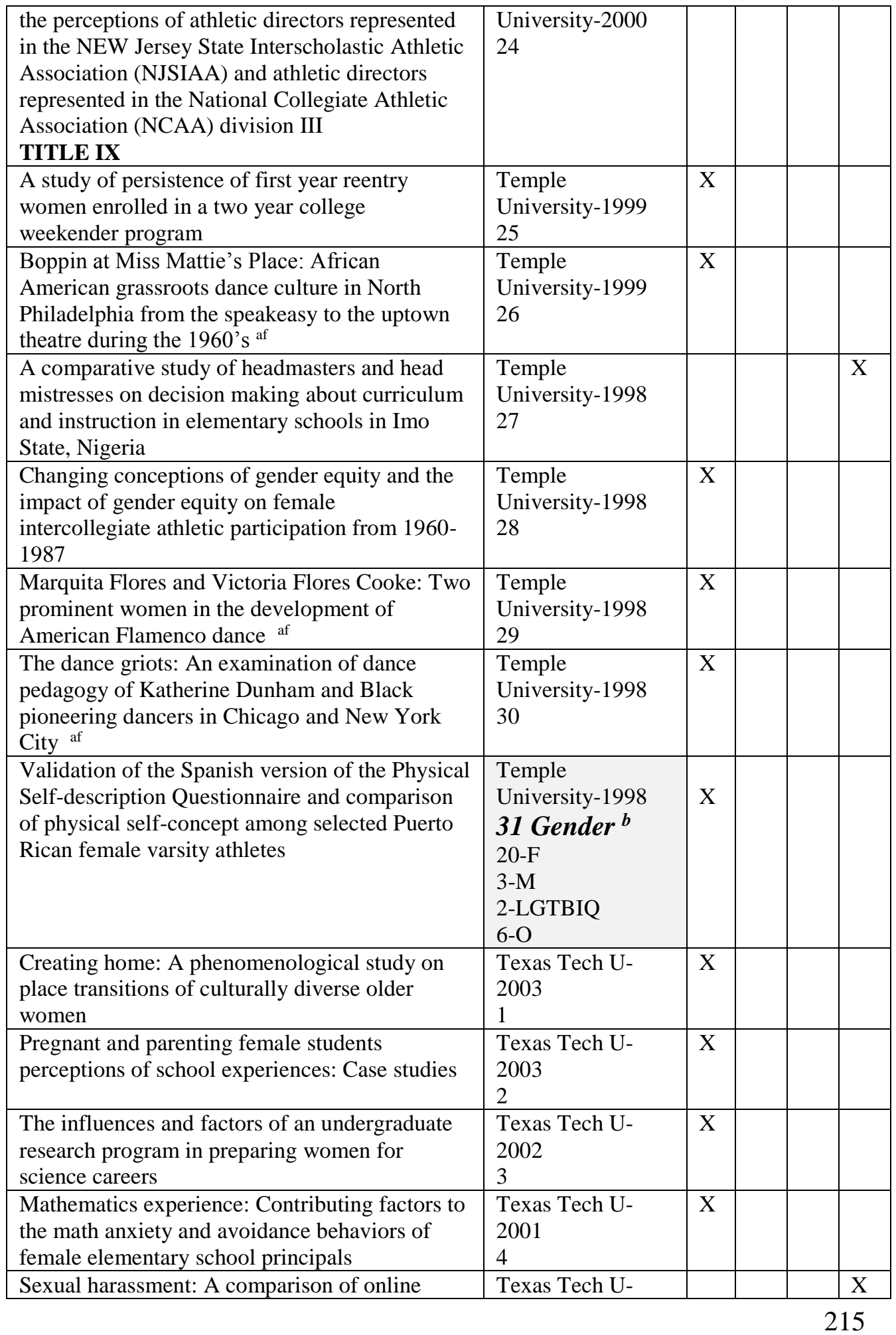




\section{GENDER REPRESENTATIONS IN ED.D. DISSERTATIONS}

\begin{tabular}{|c|c|c|c|c|}
\hline versus traditional training methods & $\begin{array}{l}2001 \\
5\end{array}$ & & & \\
\hline $\begin{array}{l}\text { A mother's experience with parenting children } \\
\text { with disabilities: Overwhelmed but growing }\end{array}$ & $\begin{array}{l}\text { Texas Tech U- } \\
2000 \\
6\end{array}$ & $\mathrm{X}$ & & \\
\hline $\begin{array}{l}\text { A phenomenological examination of tenure } \\
\text { track female faculty members socialization into } \\
\text { the culture of higher education }\end{array}$ & $\begin{array}{l}\text { Texas Tech U- } \\
2000 \\
7\end{array}$ & $\mathrm{X}$ & & \\
\hline $\begin{array}{l}\text { Women chief academic officers of public } \\
\text { community colleges: Career paths and mobility } \\
\text { factors }\end{array}$ & $\begin{array}{l}\text { Texas Tech U- } \\
2000 \\
8\end{array}$ & $\mathrm{X}$ & & \\
\hline $\begin{array}{l}\text { Eating disorders: A multiple-case investigation } \\
\text { of the internet e-mail correspondence of } \\
\text { women's lived experience }\end{array}$ & $\begin{array}{l}\text { Texas Tech U- } \\
1999 \\
9\end{array}$ & $\mathrm{X}$ & & \\
\hline $\begin{array}{l}\text { Heterosexism within educational institutions: } \\
\text { Coping efforts of lesbian, gay and bisexual } \\
\text { students in West Texas } \\
\text { LGTBIQ }\end{array}$ & $\begin{array}{l}\text { Texas Tech U- } \\
1998 \\
10\end{array}$ & & & $\mathrm{X}$ \\
\hline $\begin{array}{l}\text { The relationship between religious } \\
\text { fundamentalism and moral development on } \\
\text { homophobia in college undergraduates } \\
\text { LGTBIQ }\end{array}$ & $\begin{array}{l}\text { Texas Tech U- } \\
1998 \\
11 \text { Gender }^{b} \\
8-\mathrm{F} \\
0-\mathrm{M} \\
\text { 2-L } \\
1-0\end{array}$ & & & $\mathrm{X}$ \\
\hline $\begin{array}{l}\text { A case study of the presidency of Dr.Yvonne } \\
\text { Walker-Taylor: The first female president of } \\
\text { Wilburforce University (1984-1988) af }\end{array}$ & $\begin{array}{l}\text { University of } \\
\text { Akron-2001 } \\
1\end{array}$ & $\mathrm{X}$ & & \\
\hline $\begin{array}{l}\text { The dream and the dialogue: Women's narrative } \\
\text { reflection on the superintendency }\end{array}$ & $\begin{array}{l}\text { University of } \\
\text { Akron-2001 } \\
2\end{array}$ & $\mathrm{X}$ & & \\
\hline $\begin{array}{l}\text { Comparison of self reported transformational } \\
\text { leadership behaviors and outcomes of women } \\
\text { senior student affairs officers with immediate } \\
\text { staff member perceptions }\end{array}$ & $\begin{array}{l}\text { University of } \\
\text { Akron-2001 } \\
3\end{array}$ & $\mathrm{X}$ & & \\
\hline $\begin{array}{l}\text { The Brothers of Christian instruction at Walsh } \\
\text { College: Catholic college builders in a non- } \\
\text { sectarian era (1958-1992) am }\end{array}$ & $\begin{array}{l}\text { University of } \\
\text { Akron-2000 } \\
4\end{array}$ & & $\mathrm{X}$ & \\
\hline A case study of John H. Stanford am & $\begin{array}{l}\text { University of } \\
\text { Akron-1999 } \\
5\end{array}$ & & $\mathrm{X}$ & \\
\hline $\begin{array}{l}\text { A case study of women superintendents in the } \\
\text { state of Ohio in their roles as transformational } \\
\text { leaders in creating school district climate }\end{array}$ & $\begin{array}{l}\text { University of } \\
\text { Akron-1999 } \\
6\end{array}$ & $\mathrm{X}$ & & \\
\hline $\begin{array}{l}\text { Narrative case studies: A study of the under- } \\
\text { representation of African American females in } \\
\text { doctoral programs at predominately White } \\
\text { institutions }\end{array}$ & $\begin{array}{l}\text { University of } \\
\text { Akron-1999 } \\
7\end{array}$ & $\mathrm{X}$ & & \\
\hline
\end{tabular}




\section{GENDER REPRESENTATIONS IN ED.D. DISSERTATIONS}

\begin{tabular}{|c|c|c|c|c|}
\hline $\begin{array}{l}\text { Power as conceptualized and experienced by } \\
\text { select women assistant superintendents in Ohio }\end{array}$ & $\begin{array}{l}\text { University of } \\
\text { Akron-1999 } \\
\mathbf{8} \text { Gender }^{\boldsymbol{b}} \\
\text { 6-F } \\
\text { 2-M } \\
\text { 0-L } \\
\text { 0-O }\end{array}$ & $\mathrm{X}$ & & \\
\hline $\begin{array}{l}\text { The coach in the principal's office: An analysis } \\
\text { of the perceptions, practices, and beliefs of male } \\
\text { secondary principals in Alabama with a } \\
\text { background in athletic coaching }\end{array}$ & $\begin{array}{l}\text { University of } \\
\text { Alabama-2007 } \\
1\end{array}$ & & $\mathrm{X}$ & \\
\hline $\begin{array}{l}\text { The relationship of gender, socioeconomic } \\
\text { status, and attendance on mathematics } \\
\text { achievement of seventh grade students }\end{array}$ & $\begin{array}{l}\text { University of } \\
\text { Alabama-2006 } \\
2\end{array}$ & & & $\mathrm{X}$ \\
\hline $\begin{array}{l}\text { Teachers' perceptions of principals: Perceptions } \\
\text { of gender stereotypes among secondary school } \\
\text { teachers in the state of Alabama }\end{array}$ & $\begin{array}{l}\text { University of } \\
\text { Alabama-2005 } \\
3\end{array}$ & & & $\mathrm{X}$ \\
\hline $\begin{array}{l}\text { An examination of court cases involving sexual } \\
\text { harassment and their relevance to the public } \\
\text { school setting }\end{array}$ & $\begin{array}{l}\text { University of } \\
\text { Alabama-2003 } \\
4\end{array}$ & & & $\mathrm{X}$ \\
\hline $\begin{array}{l}\text { Perceptions of career path barriers to women in } \\
\text { educational fundraising at the University of } \\
\text { Alabama }\end{array}$ & $\begin{array}{l}\text { University of } \\
\text { Alabama-2003 } \\
5\end{array}$ & $\mathrm{X}$ & & \\
\hline $\begin{array}{l}\text { Student ratings of a community college English } \\
\text { course: the influence of author gender and } \\
\text { reading assignment }\end{array}$ & $\begin{array}{l}\text { University of } \\
\text { Alabama-2003 } \\
6\end{array}$ & & & $\mathrm{X}$ \\
\hline $\begin{array}{l}\text { The missing male voice in the early childhood } \\
\text { teaching profession }\end{array}$ & $\begin{array}{l}\text { University of } \\
\text { Alabama-2002 } \\
7\end{array}$ & $\mathrm{X}$ & & \\
\hline $\begin{array}{l}\text { Perceptions of African American female student } \\
\text { affairs administrators regarding barriers to } \\
\text { career advancement at four-year Alabama } \\
\text { colleges }\end{array}$ & $\begin{array}{l}\text { University of } \\
\text { Alabama-2002 } \\
8\end{array}$ & $\mathrm{X}$ & & \\
\hline $\begin{array}{l}\text { The effect of gender and the term a course is } \\
\text { taught in the block schedule structure on } \\
\text { Stanford Achievement Test Mathematics scores }\end{array}$ & $\begin{array}{l}\text { University of } \\
\text { Alabama-2000 } \\
9\end{array}$ & & & $\mathrm{X}$ \\
\hline $\begin{array}{l}\text { Factors that foster academic resilience in } \\
\text { African American male middle school students } \\
\text { from low-socioeconomic, single parent homes } \\
\text { BLACK MALE }\end{array}$ & $\begin{array}{l}\text { University of } \\
\text { Alabama-1999 } \\
10\end{array}$ & & $\mathrm{X}$ & \\
\hline $\begin{array}{l}\text { Five public school principals perceptions of } \\
\text { student to student sexual harassment }\end{array}$ & $\begin{array}{l}\text { University of } \\
\text { Alabama-1999 } \\
11\end{array}$ & & & $\mathrm{X}$ \\
\hline $\begin{array}{l}\text { Going it alone: The voices of single mother } \\
\text { students }\end{array}$ & $\begin{array}{l}\text { University of } \\
\text { Alabama-1999 } \\
12\end{array}$ & $\mathrm{X}$ & & \\
\hline Writing self efficacy, gender, aptitude, and & University of & & & $\mathrm{X}$ \\
\hline
\end{tabular}




\section{GENDER REPRESENTATIONS IN ED.D. DISSERTATIONS}

\begin{tabular}{|c|c|c|c|c|}
\hline $\begin{array}{l}\text { writing achievement among freshmen university } \\
\text { students }\end{array}$ & $\begin{array}{l}\text { Alabama-1998 } \\
13\end{array}$ & & & \\
\hline $\begin{array}{l}\text { A history and analysis of sports related Title IX } \\
\text { legislation and litigation from } 1972 \text { to } 1997^{\mathrm{d}}\end{array}$ & $\begin{array}{l}\text { University of } \\
\text { Alabama-1998 } \\
14\end{array}$ & & & $X$ \\
\hline $\begin{array}{l}\text { Differences in name calling and beliefs about } \\
\text { peers of elementary school children when } \\
\text { compared by grade level, gender and race }\end{array}$ & $\begin{array}{l}\text { University of } \\
\text { Alabama-1998 } \\
\text { 15 Gender }{ }^{\boldsymbol{b}} \\
\text { 4-F } \\
\text { 2-M } \\
\text { 0-LGTBIQ } \\
\text { 9-O }\end{array}$ & & & $X$ \\
\hline $\begin{array}{l}\text { Factors influencing female college choice at four } \\
\text { year public institutions in Arkansas }\end{array}$ & $\begin{array}{l}\text { University of } \\
\text { Arkansas-Main- } \\
2006 \\
1\end{array}$ & $\mathrm{X}$ & & \\
\hline $\begin{array}{l}\text { Factors that contribute to hazing practices by } \\
\text { collegiate Black Greek letter fraternities during } \\
\text { membership intake activities } \\
\text { BLACK MALE }\end{array}$ & $\begin{array}{l}\text { University of } \\
\text { Arkansas-Main- } \\
2006 \\
2\end{array}$ & & $\mathrm{X}$ & \\
\hline $\begin{array}{l}\text { Relationships between college entrance exam } \\
\text { scores and college freshmen GPA's with } \\
\text { graduation rates for male scholarship student } \\
\text { athletes at a Division One institutions }\end{array}$ & $\begin{array}{l}\text { University of } \\
\text { Arkansas-Main- } \\
2005 \\
3\end{array}$ & & $X$ & \\
\hline $\begin{array}{l}\text { An analysis of a woman administrator 's } \\
\text { leadership competency behavior }\end{array}$ & $\begin{array}{l}\text { University of } \\
\text { Arkansas-Main- } \\
2004 \\
4\end{array}$ & $\mathrm{X}$ & & \\
\hline $\begin{array}{l}\text { Learning style preferences of women } \\
\text { incarcerated in a Midwestern minimum security } \\
\text { prison }\end{array}$ & $\begin{array}{l}\text { University of } \\
\text { Arkansas-Main- } \\
2002 \\
5\end{array}$ & $\mathrm{X}$ & & \\
\hline $\begin{array}{l}\text { Understanding the conditions that encourage the } \\
\text { persistence of women in science, mathematics } \\
\text { and engineering career pathways }\end{array}$ & $\begin{array}{l}\text { University of } \\
\text { Arkansas-Main- } \\
2002 \\
6\end{array}$ & $\mathrm{X}$ & & \\
\hline $\begin{array}{l}\text { The use of career development programs in } \\
\text { meeting the perceived career development needs } \\
\text { of Mexican American women by manufacturers } \\
\text { in the greater Kansas City area }\end{array}$ & $\begin{array}{l}\text { University of } \\
\text { Arkansas-Main- } \\
2001 \\
7\end{array}$ & $\mathrm{X}$ & & \\
\hline $\begin{array}{l}\text { Frequency of serious disciplinary actions of } \\
\text { females in Arkansas junior high schools from } \\
\text { 1991-1995 }\end{array}$ & $\begin{array}{l}\text { University of } \\
\text { Arkansas-Main- } \\
2000 \\
8\end{array}$ & $\mathrm{X}$ & & \\
\hline $\begin{array}{l}\text { Recruitment, retention and mentoring of female } \\
\text { and minority students in higher education }\end{array}$ & $\begin{array}{l}\text { University of } \\
\text { Arkansas-Main- } \\
2000 \\
9\end{array}$ & $\mathrm{X}$ & & \\
\hline
\end{tabular}




\section{GENDER REPRESENTATIONS IN ED.D. DISSERTATIONS}

\begin{tabular}{|c|c|c|c|c|}
\hline $\begin{array}{l}\text { A comparative analysis of leadership attitudes of } \\
\text { male and female elementary public school } \\
\text { principals in Arkansas } \\
\text { M v F LEADER }\end{array}$ & $\begin{array}{l}\text { University of } \\
\text { Arkansas-Main- } \\
1998 \\
10\end{array}$ & & & $\mathrm{X}$ \\
\hline $\begin{array}{l}\text { A comparative study of the characteristics of } \\
\text { male and female secondary principals and } \\
\text { aspirants in the State of Arkansas } \\
\text { M v F LEADER }\end{array}$ & $\begin{array}{l}\text { University of } \\
\text { Arkansas-Main- } \\
1998 \\
11\end{array}$ & & & $\mathrm{X}$ \\
\hline $\begin{array}{l}\text { Gender equity in the staffing patterns of central } \\
\text { office positions in medium-sized school districts } \\
\text { in the United States }\end{array}$ & $\begin{array}{l}\text { University of } \\
\text { Arkansas-Main- } \\
1998 \\
\text { 12 Gender }{ }^{\boldsymbol{b}} \\
\text { 7-F } \\
\text { 2-M } \\
\text { 0-LGTBIQ } \\
\text { 3-O }\end{array}$ & & & $\mathrm{X}$ \\
\hline $\begin{array}{l}\text { An examination of time use patterns influence } \\
\text { on achievement among African American and } \\
\text { Hispanic male high school student athletes } \\
\text { BLACK MALE }\end{array}$ & $\begin{array}{l}\text { University of } \\
\text { Central Florida- } \\
2007 \\
1 \\
\end{array}$ & & $\mathrm{X}$ & \\
\hline $\begin{array}{l}\text { Science self-efficacy in tenth grade Hispanic } \\
\text { female high school students }\end{array}$ & $\begin{array}{l}\text { University of } \\
\text { Central Florida- } \\
2006 \\
2\end{array}$ & $\mathrm{X}$ & & \\
\hline $\begin{array}{l}\text { A healthy pregnancy curriculum for adolescent } \\
\text { mothers: Participants perceptions and effect on } \\
\text { infant's birth weight }\end{array}$ & $\begin{array}{l}\text { University of } \\
\text { Central Florida - } \\
2005 \\
3 \\
\end{array}$ & $\mathrm{X}$ & & \\
\hline $\begin{array}{l}\text { Attainment of doctoral degree for American } \\
\text { Indian and Alaska Native women }\end{array}$ & $\begin{array}{l}\text { University of } \\
\text { Central Florida- } \\
2005 \\
4\end{array}$ & $\mathrm{X}$ & & \\
\hline $\begin{array}{l}\text { A case study of a community college teacher } \\
\text { The relationship of her personal practical } \\
\text { theories to her teaching practice }\end{array}$ & $\begin{array}{l}\text { University of } \\
\text { Central Florida - } \\
2003 \\
5\end{array}$ & $\mathrm{X}$ & & \\
\hline $\begin{array}{l}\text { Alternative school success factors: A program } \\
\text { evaluation of PACE Center for Girls, RTM }\end{array}$ & $\begin{array}{l}\text { University of } \\
\text { Central Florida- } \\
2002 \\
6 \\
\end{array}$ & $\mathrm{X}$ & & \\
\hline $\begin{array}{l}\text { College students attitudes about computers } \\
\text { related to gender identity and learning style } \\
\text { interactions }\end{array}$ & $\begin{array}{l}\text { University of } \\
\text { Central Florida - } \\
2002 \\
7\end{array}$ & & & $\mathrm{X}$ \\
\hline $\begin{array}{l}\text { Effects of graphing calculators on students } \\
\text { confidence and performance in college algebra: } \\
\text { race and gender related differences }\end{array}$ & $\begin{array}{l}\text { University of } \\
\text { Central Florida - } \\
1999 \\
8 \\
\end{array}$ & & & $\mathrm{X}$ \\
\hline
\end{tabular}




\section{GENDER REPRESENTATIONS IN ED.D. DISSERTATIONS}

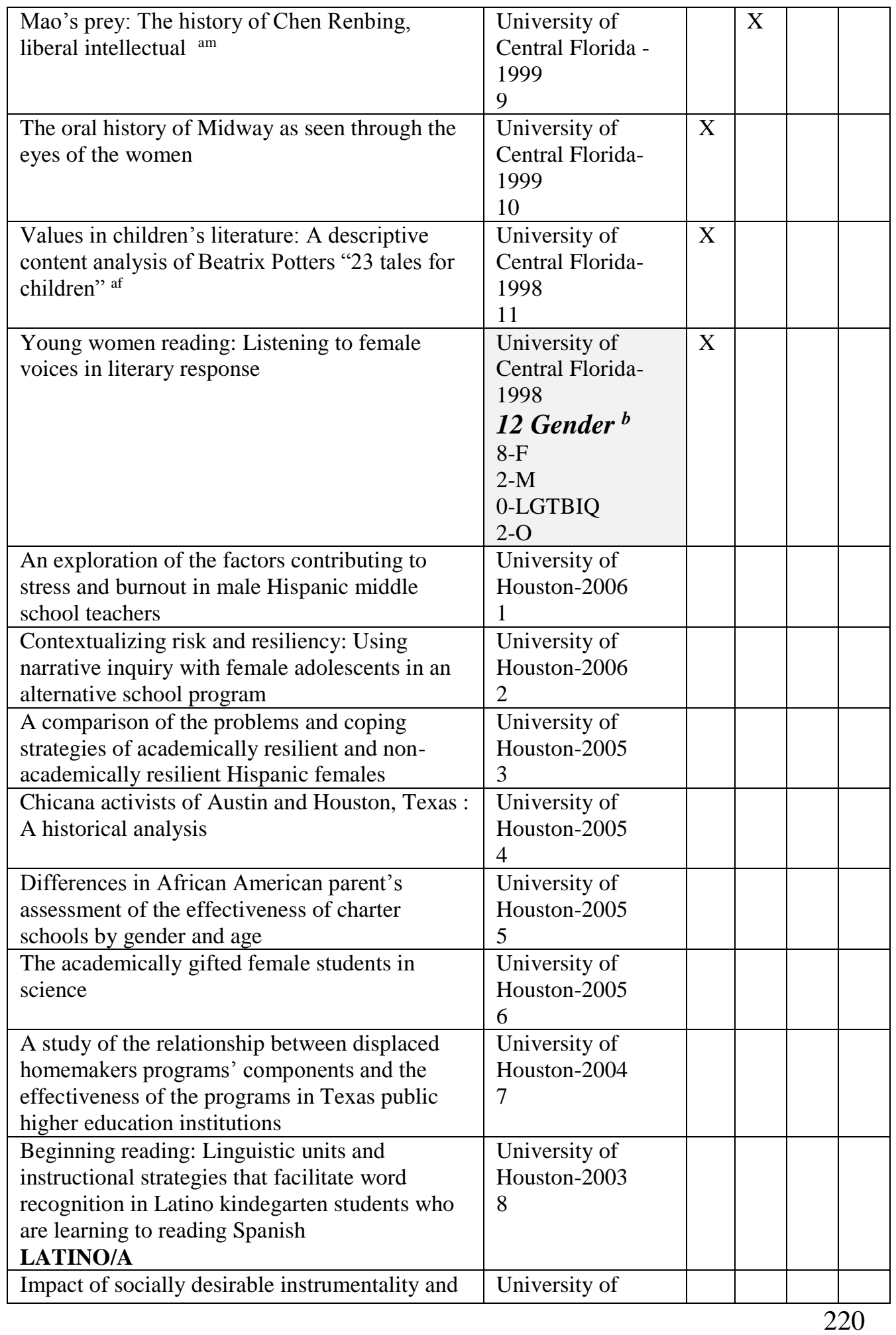




\section{GENDER REPRESENTATIONS IN ED.D. DISSERTATIONS}

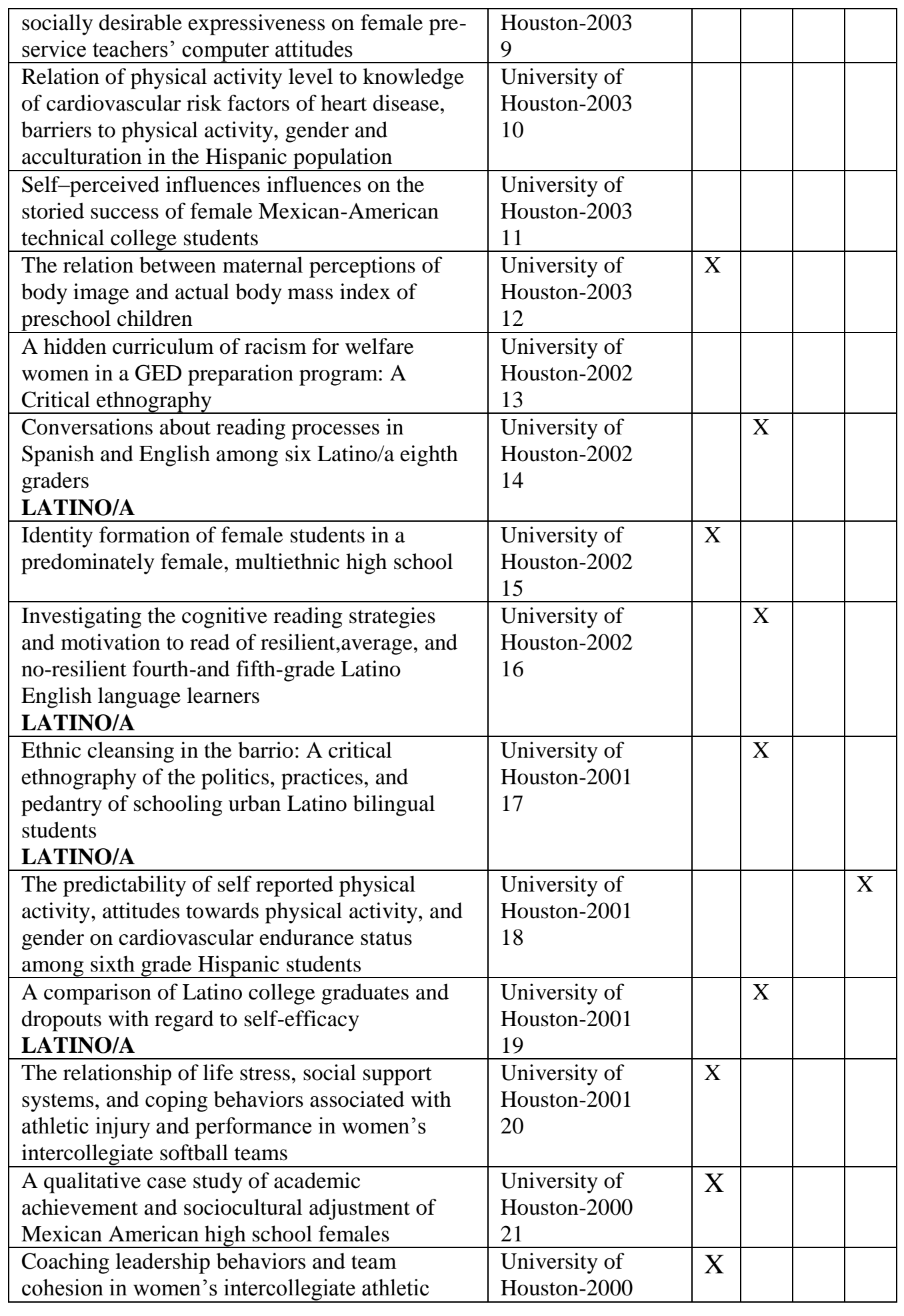




\section{GENDER REPRESENTATIONS IN ED.D. DISSERTATIONS}

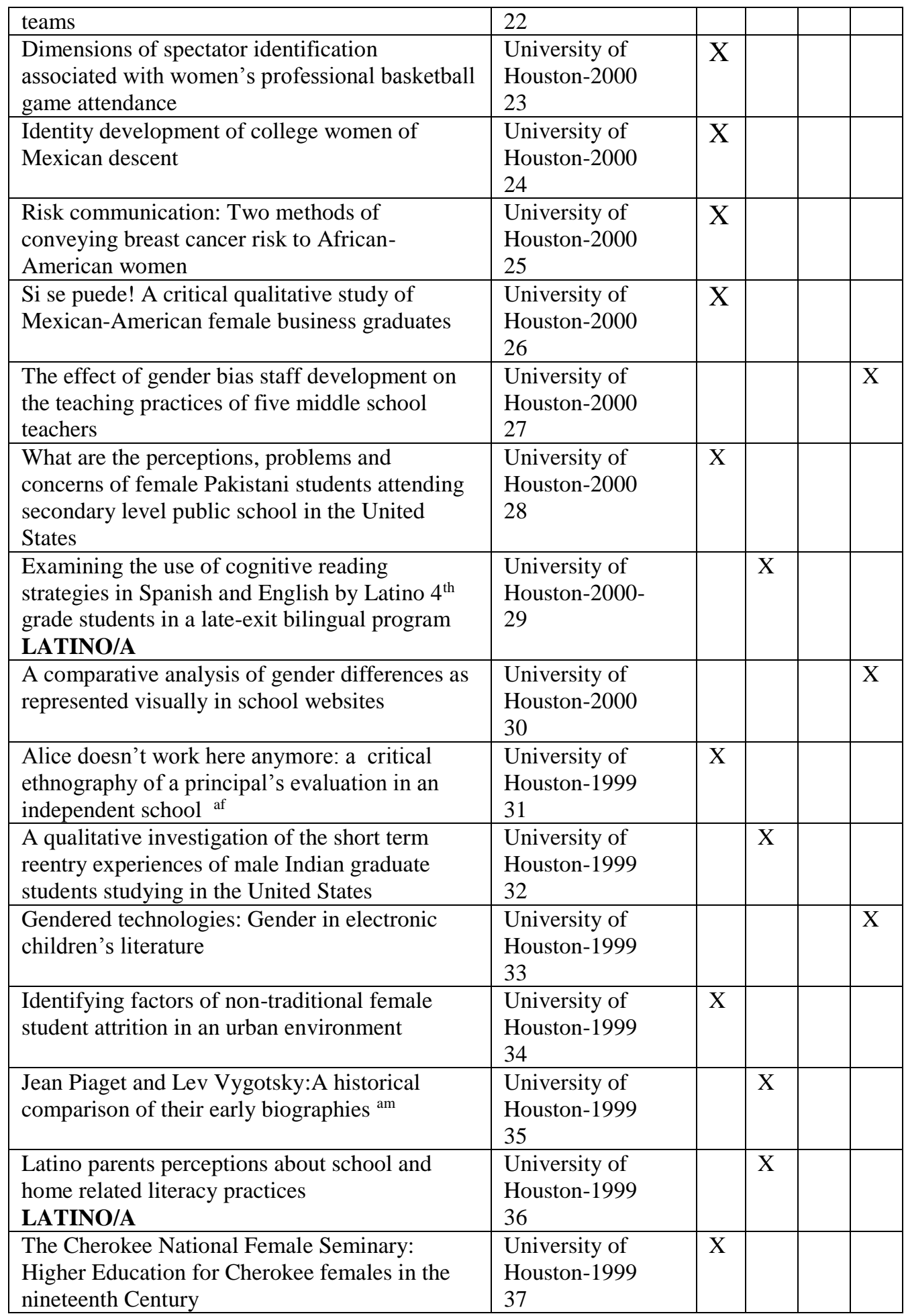




\section{GENDER REPRESENTATIONS IN ED.D. DISSERTATIONS}

\begin{tabular}{|c|c|c|c|c|}
\hline $\begin{array}{l}\text { The influence of different aerobic exercise } \\
\text { classes on exercise self-efficacy and perceived } \\
\text { competence in overweight women }\end{array}$ & $\begin{array}{l}\text { University of } \\
\text { Houston-1999 } \\
38\end{array}$ & $\mathrm{X}$ & & \\
\hline $\begin{array}{l}\text { The life histories of six African American } \\
\text { female principals }\end{array}$ & $\begin{array}{l}\text { University of } \\
\text { Houston-1999 } \\
39\end{array}$ & $\mathrm{X}$ & & \\
\hline $\begin{array}{l}\text { The local economic impact of the University of } \\
\text { Texas Medical Branch Regional Maternal and } \\
\text { Child Health Program }\end{array}$ & $\begin{array}{l}\text { University of } \\
\text { Houston-1999 } \\
40\end{array}$ & $\mathrm{X}$ & & \\
\hline $\begin{array}{l}\text { Lived experience and the power of relationships: } \\
\text { an ethnographic study of female Latina } \\
\text { graduates and dropouts in a south Texas border } \\
\text { high school } \\
\text { LATINO/A }\end{array}$ & $\begin{array}{l}\text { University of } \\
\text { Houston-1998 } \\
41\end{array}$ & $\mathrm{X}$ & & \\
\hline $\begin{array}{l}\text { John Henryism and occupational stress among } \\
\text { African American higher education faculty am } \\
\text { BLACK MALE }\end{array}$ & $\begin{array}{l}\text { University of } \\
\text { Houston-1998 } \\
42\end{array}$ & & $\mathrm{X}$ & \\
\hline $\begin{array}{l}\text { The effects of" women are scientists too" } \\
\text { program on middle school students perceptions } \\
\text { of scientists and their attitudes towards women } \\
\text { in science }\end{array}$ & $\begin{array}{l}\text { University of } \\
\text { Houston-1998 } \\
43\end{array}$ & $\mathrm{X}$ & & \\
\hline $\begin{array}{l}\text { The effects of science-technology-society issue } \\
\text { instruction on the attitudes of female middle } \\
\text { school students towards science }\end{array}$ & $\begin{array}{l}\text { University of } \\
\text { Houston-1998 } \\
\text { 44 Gender } \boldsymbol{b} \\
\text { 27-F } \\
\text { 11-M } \\
\text { 1-LGTBIQ } \\
\text { 5-O }\end{array}$ & $\mathrm{X}$ & & \\
\hline No gender found $5 / 3 / 1010$ & $\begin{array}{l}\text { University of } \\
\text { Idaho-NA } \\
\text { 0 Gender } \boldsymbol{b} \\
0-\mathrm{F} \\
0-\mathrm{M} \\
0-\mathrm{L} \\
0-\mathrm{O}\end{array}$ & & & \\
\hline $\begin{array}{l}\text { Working class and working college: A case } \\
\text { study of first generation working class, first year } \\
\text { white male college students }\end{array}$ & $\begin{array}{l}\text { University of } \\
\text { Louisville-2002 } \\
1\end{array}$ & & $\mathrm{X}$ & \\
\hline $\begin{array}{l}\text { Community college recruitment: The effects of } \\
\text { employment status, person characteristics and } \\
\text { gender of the applicant }\end{array}$ & $\begin{array}{l}\text { University of } \\
\text { Louisville-2002 } \\
2\end{array}$ & & & $\mathrm{X}$ \\
\hline $\begin{array}{l}\text { Custodial mother adjustment to divorce: Divorce } \\
\text { education, family functioning, and psychological } \\
\text { health }\end{array}$ & $\begin{array}{l}\text { University of } \\
\text { Louisville-2001 } \\
3\end{array}$ & $\mathrm{X}$ & & \\
\hline $\begin{array}{l}\text { Intergenerational comparisons of perceptions of } \\
\text { gender roles, dating and marriage among Asian } \\
\text { Indians living in the United States }\end{array}$ & $\begin{array}{l}\text { University of } \\
\text { Louisville-2001 } \\
4\end{array}$ & & & $\mathrm{X}$ \\
\hline Attachment styles and clinical symptoms of a & University of & & $\mathrm{X}$ & \\
\hline
\end{tabular}




\section{GENDER REPRESENTATIONS IN ED.D. DISSERTATIONS}

\begin{tabular}{|c|c|c|c|c|c|}
\hline $\begin{array}{l}\text { non-clinical sample of adult male sexual abuse } \\
\text { survivors }\end{array}$ & $\begin{array}{l}\text { Louisville-2000 } \\
5\end{array}$ & & & & \\
\hline $\begin{array}{l}\text { Complementarity in long term lesbian } \\
\text { relationships and non-lesbian female friendships } \\
\text { LGTBIQ }\end{array}$ & $\begin{array}{l}\text { University of } \\
\text { Louisville-2000 } \\
6\end{array}$ & & & $\mathrm{X}$ & \\
\hline $\begin{array}{l}\text { Relationship between domestic violence, abuse } \\
\text { and gender equity perceptions: A study of the } \\
\text { Appalachian region of Kentucky }\end{array}$ & $\begin{array}{l}\text { University of } \\
\text { Louisville-2000 } \\
7\end{array}$ & & & & $\mathrm{X}$ \\
\hline $\begin{array}{l}\text { African American women at midlife: The dance } \\
\text { between spirituality and life satisfaction }\end{array}$ & $\begin{array}{l}\text { University of } \\
\text { Louisville-1999 } \\
8 \text { Gender }\end{array}$ & $\mathrm{X}$ & & & \\
\hline $\begin{array}{l}\text { The application of selected federal non- } \\
\text { discrimination statutes to employees and } \\
\text { students of religiously affiliated postsecondary } \\
\text { educational institutions }\end{array}$ & $\begin{array}{l}\text { University of } \\
\text { Louisville-1998 } \\
\text { 9 Gender }{ }^{\boldsymbol{b}} \\
\text { 2-F } \\
\text { 2-M } \\
\text { 1-LGTBIQ } \\
4-\mathrm{O}\end{array}$ & & & & $\mathrm{X}$ \\
\hline $\begin{array}{l}\text { Constructing the experiences of gay and lesbian } \\
\text { high school students in Maine } \\
\text { LGTBIQ }\end{array}$ & $\begin{array}{l}\text { University of } \\
\text { Maine-2005 } \\
1\end{array}$ & & & $\mathrm{X}$ & \\
\hline $\begin{array}{l}\text { Girls in the woods: An exploration of the impact } \\
\text { of a wilderness program on adolescent girls } \\
\text { constructions of femininity }\end{array}$ & $\begin{array}{l}\text { University of } \\
\text { Maine-2005 } \\
2\end{array}$ & $\mathrm{X}$ & & & \\
\hline $\begin{array}{l}\text { Crystallizing Alex: A qualitative case study of } \\
\text { what influences one second grade teacher's } \\
\text { literacy instruction am }\end{array}$ & $\begin{array}{l}\text { University of } \\
\text { Maine-2003 } \\
3\end{array}$ & & $\mathrm{X}$ & & \\
\hline $\begin{array}{l}\text { Lessons from Ellen: A case study investigation } \\
\text { of comprehensive strategy instruction in action af }\end{array}$ & $\begin{array}{l}\text { University of } \\
\text { Maine-2003 } \\
4\end{array}$ & $\mathrm{X}$ & & & \\
\hline $\begin{array}{l}\text { Mutuality in a spiritual; group: A dialogue } \\
\text { between Karl Barth and relational theory am }\end{array}$ & $\begin{array}{l}\text { University of } \\
\text { Maine-1999 } \\
5\end{array}$ & & $\mathrm{X}$ & & \\
\hline $\begin{array}{l}\text { The balance and alteration of the negotiation } \\
\text { power of women in divorce mediation }\end{array}$ & $\begin{array}{l}\text { University of } \\
\text { Maine-1999 } \\
6\end{array}$ & $\mathrm{X}$ & & & \\
\hline $\begin{array}{l}\text { Putting our practice where our paradigms are: } \\
\text { Women educators test their vision and voice in a } \\
\text { summer literacy internship }\end{array}$ & $\begin{array}{l}\text { University of } \\
\text { Maine-1998 } \\
7 \text { Gender } \boldsymbol{b} \\
\text { 4-F } \\
\text { 2-M } \\
\text { 1-L } \\
0-\mathrm{O}\end{array}$ & $\mathrm{X}$ & & & \\
\hline $\begin{array}{l}\text { The rise and fall of Black women } \\
\text { superintendents }\end{array}$ & $\begin{array}{l}\text { University of } \\
\text { Memphis-2007 } \\
1\end{array}$ & $\mathrm{X}$ & & & \\
\hline An investigation into whether autonomy & University of & $\mathrm{X}$ & & & \\
\hline
\end{tabular}




\section{GENDER REPRESENTATIONS IN ED.D. DISSERTATIONS}

\begin{tabular}{|c|c|c|c|c|}
\hline $\begin{array}{l}\text { development is a predictor of eating attitudes in } \\
\text { female college students }\end{array}$ & $\begin{array}{l}\text { Memphis-2006 } \\
2\end{array}$ & & & \\
\hline $\begin{array}{l}\text { Readiness to change and locus of control in } \\
\text { female offenders }\end{array}$ & $\begin{array}{l}\text { University of } \\
\text { Memphis-2006 } \\
3\end{array}$ & $X$ & & \\
\hline $\begin{array}{l}\text { Gender differences regarding vocational } \\
\text { rehabilitation participants perceived } \\
\text { involvement in their program and their } \\
\text { employment outcomes }\end{array}$ & $\begin{array}{l}\text { University of } \\
\text { Memphis-2005 } \\
4\end{array}$ & & & $X$ \\
\hline $\begin{array}{l}\text { An analysis of the characteristics that lead to the } \\
\text { disenfranchisement of African Males between } \\
\text { the ages of } 18 \text { to } 35 \\
\text { BLACK MALE }\end{array}$ & $\begin{array}{l}\text { University of } \\
\text { Memphis-2004 } \\
5\end{array}$ & & $X$ & \\
\hline $\begin{array}{l}\text { An investigation of how African American } \\
\text { women overcome the barriers of race, gender } \\
\text { and class to pursue upward mobility }\end{array}$ & $\begin{array}{l}\text { University of } \\
\text { Memphis-2004 } \\
6\end{array}$ & $X$ & & \\
\hline $\begin{array}{l}\text { Dietary acculturation and obesity risk in } \\
\text { Mexican women in Memphis }\end{array}$ & $\begin{array}{l}\text { University of } \\
\text { Memphis-2004 } \\
7\end{array}$ & $X$ & & \\
\hline $\begin{array}{l}\text { Perspective transformation among mainland } \\
\text { Chinese fathers interacting with the American } \\
\text { K-12 educational system }\end{array}$ & $\begin{array}{l}\text { University of } \\
\text { Memphis-2004 } \\
8\end{array}$ & & $\mathrm{X}$ & \\
\hline $\begin{array}{l}\text { The effects of the options program on the } \\
\text { attitudes of ninth grade females towards } \\
\text { mathematics }\end{array}$ & $\begin{array}{l}\text { University of } \\
\text { Memphis-2004 } \\
9\end{array}$ & $\mathrm{X}$ & & \\
\hline $\begin{array}{l}\text { An analysis of the perceptions of administrators } \\
\text { in single sex elementary schools towards } \\
\text { including character education in the curriculum }\end{array}$ & $\begin{array}{l}\text { University of } \\
\text { Memphis-2003 } \\
10\end{array}$ & & & $X$ \\
\hline $\begin{array}{l}\text { Masculinities constructed and represented in } \\
\text { literature textbooks in grades seven thru twelve }\end{array}$ & $\begin{array}{l}\text { University of } \\
\text { Memphis-2003 } \\
11\end{array}$ & & $X$ & \\
\hline $\begin{array}{l}\text { An evaluation of an early intervention } \\
\text { residential treatment program on recidivism } \\
\text { rates of adolescent sexual offenders }\end{array}$ & $\begin{array}{l}\text { University of } \\
\text { Memphis-2002 } \\
12\end{array}$ & & & $\mathrm{X}$ \\
\hline $\begin{array}{l}\text { Do computer attitudes vary based on gender, } \\
\text { grade level and/or educational plan }\end{array}$ & $\begin{array}{l}\text { University of } \\
\text { Memphis-2002 } \\
13\end{array}$ & & & X \\
\hline $\begin{array}{l}\text { The academic success of at-risk men's football } \\
\text { and basketball players at a public university in } \\
\text { the mid-south }\end{array}$ & $\begin{array}{l}\text { University of } \\
\text { Memphis-2002 } \\
14\end{array}$ & & & \\
\hline $\begin{array}{l}\text { African American women and acute myocardial } \\
\text { infarction: Symptom recognition and assessing }\end{array}$ & $\begin{array}{l}\text { University of } \\
\text { Memphis-2001 } \\
15\end{array}$ & & & \\
\hline $\begin{array}{l}\text { A new model for explaining obesity in African } \\
\text { American Women: A blended approach }\end{array}$ & $\begin{array}{l}\text { University of } \\
\text { Memphis-2001 } \\
16\end{array}$ & $\mathrm{X}$ & & \\
\hline $\begin{array}{l}\text { Gender and mathematics attitudes of middle } \\
\text { school students in Arkansas }\end{array}$ & $\begin{array}{l}\text { University of } \\
\text { Memphis-2001 }\end{array}$ & & & X \\
\hline
\end{tabular}


GENDER REPRESENTATIONS IN ED.D. DISSERTATIONS

\begin{tabular}{|c|c|c|c|c|c|}
\hline & 17 & & & & \\
\hline $\begin{array}{l}\text { The preparation of undergraduate social work } \\
\text { students in same faith based institutions for } \\
\text { professional practice with gay and lesbian } \\
\text { persons: A qualitative study } \\
\text { LGTBIQ }\end{array}$ & $\begin{array}{l}\text { University of } \\
\text { Memphis-2001 } \\
18\end{array}$ & & & $\mathrm{X}$ & \\
\hline $\begin{array}{l}\text { Coping strategies in adult survivors of sexual } \\
\text { abuse }\end{array}$ & $\begin{array}{l}\text { University of } \\
\text { Memphis-1998 } \\
\text { 19 Gender } \boldsymbol{b}^{\circ} \\
\text { 8-F } \\
\text { 4-M } \\
\text { 1-LGTBIQ } \\
\text { 6-0 } \\
\end{array}$ & & & & \\
\hline No gender found 3/9/2010 & $\begin{array}{l}\text { University of } \\
\text { Mississippi-Main- } \\
\text { NA } \\
\text { 0 Gender } \\
\text { 0-F } \\
\text { 0-M } \\
\text { 0-LGTBIQ } \\
\text { 0-O } \\
\end{array}$ & & & & \\
\hline $\begin{array}{l}\text { Designed for failure: An analysis of African } \\
\text { American male students perception of the failure } \\
\text { of traditional school structures to successfully } \\
\text { educate them } \\
\text { BLACK MALE }\end{array}$ & $\begin{array}{l}\text { University of } \\
\text { Missouri-Kansas } \\
\text { City-2007 } \\
\mathbf{1} \text { Gender }^{\boldsymbol{b}} \\
\text { 0-F } \\
\text { 1-M } \\
0-\mathrm{L} \\
0-\mathrm{O}\end{array}$ & & $\mathrm{X}$ & & \\
\hline $\begin{array}{l}\text { Attitudes of diverse women superintendents } \\
\text { toward nine tenets of effective leadership }\end{array}$ & $\begin{array}{l}\text { University of } \\
\text { Nevada Las } \\
\text { Vegas-2007 } \\
1\end{array}$ & $\mathrm{X}$ & & & \\
\hline $\begin{array}{l}\text { Science education for girls: A partnership } \\
\text { between Girl Scouts and NASA }\end{array}$ & $\begin{array}{l}\text { University of } \\
\text { Nevada-Las } \\
\text { Vegas-2006 } \\
2\end{array}$ & $\mathrm{X}$ & & & \\
\hline $\begin{array}{l}\text { Critical analysis of university conduct codes as a } \\
\text { mechanism for remedying student's sexual } \\
\text { misbehavior }\end{array}$ & $\begin{array}{l}\text { University of } \\
\text { Nevada-Las } \\
\text { Vegas-2004 } \\
3\end{array}$ & & & & $\mathrm{X}$ \\
\hline $\begin{array}{l}\text { Written retellings of narrative and expository } \\
\text { texts: A case study of elementary primary grade } \\
\text { delayed male readers }\end{array}$ & $\begin{array}{l}\text { University of } \\
\text { Nevada-Las } \\
\text { Vegas-2000 } \\
4\end{array}$ & & $\mathrm{X}$ & & \\
\hline $\begin{array}{l}\text { Implementation of least restrictive endorsement } \\
\text { (LRE) in Nevada rural schools according to the }\end{array}$ & $\begin{array}{l}\text { University of } \\
\text { Nevada-Las }\end{array}$ & & & & \\
\hline
\end{tabular}


GENDER REPRESENTATIONS IN ED.D. DISSERTATIONS

\begin{tabular}{|c|c|c|c|c|}
\hline Rachel L. standard af & $\begin{array}{l}\text { Vegas-1998 } \\
\text { 5 Gender }{ }^{b} \\
2-\mathrm{F} \\
2-\mathrm{M} \\
0-\mathrm{L} \\
1-\mathrm{O}\end{array}$ & & & \\
\hline $\begin{array}{l}\text { African-American women administrators as } \\
\text { chief administrative officers of selected colleges } \\
\text { and universities: A qualitative study }\end{array}$ & $\begin{array}{l}\text { University of } \\
\text { Nevada-Reno- } \\
1998 \\
\text { 1 Gender }{ }^{\boldsymbol{b}} \\
\text { 1-F } \\
\text { 0-M } \\
\text { 0-LGTBIQ } \\
0-\mathrm{O}\end{array}$ & $\mathrm{X}$ & & \\
\hline No gender found $3 / 9 / 1010$ & $\begin{array}{l}\text { University of New } \\
\text { Orleans-NA } \\
\text { 0 Gender } \boldsymbol{b} \\
0-\mathrm{F} \\
0-\mathrm{M} \\
0-\mathrm{L} \\
0-\mathrm{O}\end{array}$ & & & \\
\hline $\begin{array}{l}\text { An investigation into the behavior of high } \\
\text { school leaders: Gender and its relationship to } \\
\text { leader orientations to persons and systems }\end{array}$ & $\begin{array}{l}\text { University of } \\
\text { N.Carolina - } \\
\text { Greensboro-2006 } \\
1\end{array}$ & & & $\mathrm{X}$ \\
\hline $\begin{array}{l}\text { Social reconstruction of African American } \\
\text { males at an urban middle school } \\
\text { BLACK MALE }\end{array}$ & $\begin{array}{l}\text { University of } \\
\text { N.Carolina - } \\
\text { Greensboro-2006 } \\
2\end{array}$ & & $\mathrm{X}$ & \\
\hline $\begin{array}{l}\text { Through their eyes: A look at the achievement } \\
\text { and success of selected African American male } \\
\text { youths } \\
\text { BLACK MALE }\end{array}$ & $\begin{array}{l}\text { University of } \\
\text { N.Carolina - } \\
\text { Greensboro-2006 } \\
3\end{array}$ & & $\mathrm{X}$ & \\
\hline $\begin{array}{l}\text { Tomorrow's leaders: Traversing the barriers that } \\
\text { lead to under representation of African- } \\
\text { American women in school leadership roles }\end{array}$ & $\begin{array}{l}\text { University of } \\
\text { N.Carolina- } \\
\text { Greensboro-2005 } \\
4\end{array}$ & $\mathrm{X}$ & & \\
\hline $\begin{array}{l}\text { Finding the self who leads: From one woman's } \\
\text { perspective }\end{array}$ & $\begin{array}{l}\text { University of } \\
\text { N.Carolina - } \\
\text { Greensboro-2004 } \\
5\end{array}$ & $\mathrm{X}$ & & \\
\hline $\begin{array}{l}\text { An investigation into understanding how work } \\
\text { requirements of principals effect their quality of } \\
\text { life: A case study of five women principals in } \\
\text { the Piedmont of North Carolina }\end{array}$ & $\begin{array}{l}\text { University of } \\
\text { N.Carolina - } \\
\text { Greensboro-2002 } \\
6\end{array}$ & $\mathrm{X}$ & & \\
\hline
\end{tabular}




\section{GENDER REPRESENTATIONS IN ED.D. DISSERTATIONS}

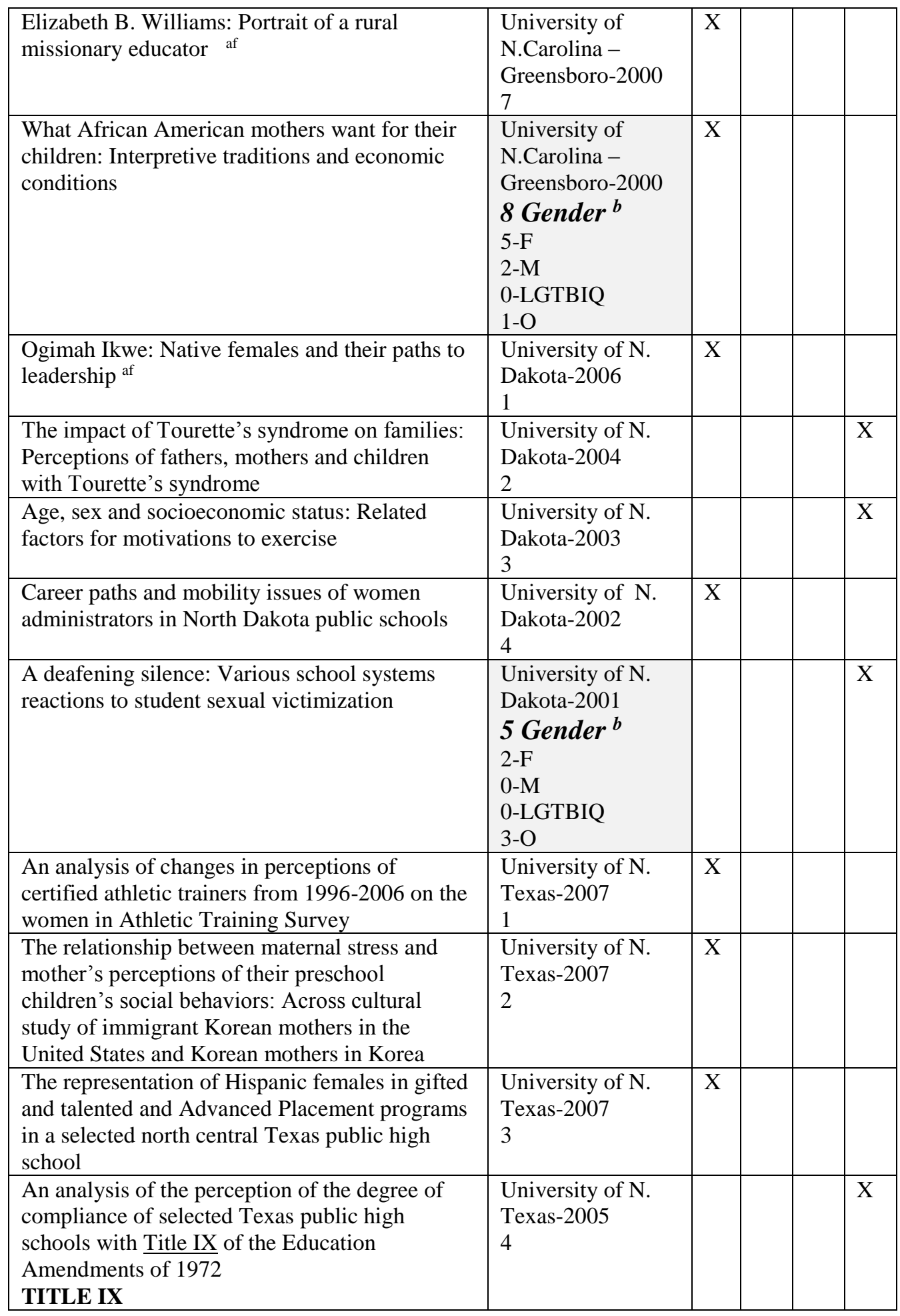


GENDER REPRESENTATIONS IN ED.D. DISSERTATIONS

\begin{tabular}{|c|c|c|c|c|}
\hline $\begin{array}{l}\text { The impact of Kolot's Rosh Hodesh: It's a girl } \\
\text { thing }\end{array}$ & $\begin{array}{l}\text { University of } \mathrm{N} \text {. } \\
\text { Texas-2005 } \\
5\end{array}$ & $\mathrm{X}$ & & \\
\hline $\begin{array}{l}\text { Contributions of W.A. Criswell to the } \\
\text { establishment and development of the Criswell } \\
\text { college }\end{array}$ & $\begin{array}{l}\text { University of } \mathrm{N} . \\
\text { Texas-2004 } \\
6\end{array}$ & & $\mathrm{X}$ & \\
\hline $\begin{array}{l}\text { Texas public school principals application of } \\
\text { procedures in identification and prevention of } \\
\text { sexual harassment }\end{array}$ & $\begin{array}{l}\text { University of } \mathrm{N} \text {. } \\
\text { Texas-2002 } \\
7\end{array}$ & & & $\mathrm{X}$ \\
\hline $\begin{array}{l}\text { Leadership frames of female presidents of } \\
\text { American Research Universities }\end{array}$ & $\begin{array}{l}\text { University of } \mathrm{N} \text {. } \\
\text { Texas-2002 } \\
8\end{array}$ & $\mathrm{X}$ & & \\
\hline $\begin{array}{l}\text { A study of freshmen interest groups and } \\
\text { leadership practices at Texas Women's } \\
\text { University }\end{array}$ & $\begin{array}{l}\text { University of } \mathrm{N} . \\
\text { Texas-2001 } \\
9\end{array}$ & $\mathrm{X}$ & & \\
\hline $\begin{array}{l}\text { The message and ministry of Howard G. } \\
\text { Hendricks in Christian higher education am }\end{array}$ & $\begin{array}{l}\text { University of } \mathrm{N} \text {. } \\
\text { Texas- } 2000 \\
10\end{array}$ & & $\mathrm{X}$ & \\
\hline $\begin{array}{l}\text { Virginia Carter Smith: Her career and } \\
\text { contributions to advancement in higher } \\
\text { education af }\end{array}$ & $\begin{array}{l}\text { University of } \mathrm{N} \text {. } \\
\text { Texas-2000 } \\
11\end{array}$ & $\mathrm{X}$ & & \\
\hline $\begin{array}{l}\text { Women in higher education administration: An } \\
\text { analysis for 1983-1998 }\end{array}$ & $\begin{array}{l}\text { University of N. } \\
\text { Texas-1998 } \\
\text { 12 Gender }{ }^{\boldsymbol{b}} \\
\text { 8-F } \\
\text { 2-M } \\
0-\mathrm{L} \\
2-\mathrm{O}\end{array}$ & $\mathrm{X}$ & & \\
\hline $\begin{array}{l}\text { Career development patterns of } \\
\text { Cheyenne/Arapaho women in rural Oklahoma }\end{array}$ & $\begin{array}{l}\text { University of } \\
\text { Oklahoma } \\
\text { Norman-1998 } \\
\text { 1 Gender }{ }^{\boldsymbol{b}} \\
\text { 1-F } \\
\text { 0-M } \\
\text { 0-LGTBIQ } \\
\text { 0-O }\end{array}$ & $\mathrm{X}$ & & \\
\hline $\begin{array}{l}\text { The post Title IX generation: Perceptions and } \\
\text { experiences of gender equity among new } \\
\text { university faculty } \\
\text { TITLE IX }\end{array}$ & $\begin{array}{l}\text { University of } \\
\text { Oregon-2004 } \\
1\end{array}$ & & & $\mathrm{X}$ \\
\hline Women in the Oregon superintendency & $\begin{array}{l}\text { University of } \\
\text { Oregon-2004 } \\
2\end{array}$ & $\mathrm{X}$ & & \\
\hline $\begin{array}{l}\text { Living la vida loca: How the life experiences of } \\
\text { seven young Mexican women impacted their } \\
\text { decision to drop out of high school, graduate and } \\
\text { or pursue higher education }\end{array}$ & $\begin{array}{l}\text { University of } \\
\text { Oregon-2004 } \\
3\end{array}$ & $\mathrm{X}$ & & \\
\hline Women and educational access: A case study of & University of & $\mathrm{X}$ & & \\
\hline
\end{tabular}


GENDER REPRESENTATIONS IN ED.D. DISSERTATIONS

\begin{tabular}{|c|c|c|c|c|}
\hline one community college & $\begin{array}{l}\text { Oregon-2002 } \\
\text { 4 Gender } \\
\text { 3-F } \\
\text { 0-M } \\
\text { 0-LGTBIQ } \\
\text { 1-O }\end{array}$ & & & \\
\hline $\begin{array}{l}\text { Female superintendents in Mississippi, } \\
\text { Alabama, and Florida: Personal and professional } \\
\text { characteristics }\end{array}$ & $\begin{array}{l}\text { University of } \\
\text { Southern } \\
\text { Mississippi-2005 } \\
1\end{array}$ & & & \\
\hline $\begin{array}{l}\text { In their own voices: The impact of the feminist } \\
\text { movement in adult education } \\
\text { FEMINIST }\end{array}$ & $\begin{array}{l}\text { University of } \\
\text { Southern } \\
\text { Mississippi-2005 } \\
2\end{array}$ & & & $\mathrm{X}$ \\
\hline $\begin{array}{l}\text { The scientific habit of mind: Ellen H. Richards } \\
\text { and the adult education movement af }\end{array}$ & $\begin{array}{l}\text { University of } \\
\text { Southern } \\
\text { Mississippi-2002 } \\
\mathbf{3} \text { Gender }^{\boldsymbol{b}} \\
\text { 2-F } \\
\text { 0-M } \\
\text { 0-LGTBIQ } \\
\text { 1-O }\end{array}$ & $\mathrm{X}$ & & \\
\hline $\begin{array}{l}\text { Where's the principal? An interpretive career } \\
\text { biography of retired female secondary school } \\
\text { principals }\end{array}$ & $\begin{array}{l}\text { University of } \\
\text { Texas-El Paso- } \\
2005 \\
1\end{array}$ & $\mathrm{X}$ & & \\
\hline $\begin{array}{l}\text { An examination of the graduation rates of the } \\
\text { Division I African American male basketball } \\
\text { student-athlete } \\
\text { BLACK MALE }\end{array}$ & $\begin{array}{l}\text { University of } \\
\text { Texas-El Paso- } \\
2004 \\
2\end{array}$ & & $\mathrm{X}$ & \\
\hline $\begin{array}{l}\text { Portraits of Hispanic females who have returned } \\
\text { to complete their high school diplomas after } \\
\text { dropping out }\end{array}$ & $\begin{array}{l}\text { University of } \\
\text { Texas-El Paso- } \\
2002 \\
3\end{array}$ & $\mathrm{X}$ & & \\
\hline $\begin{array}{l}\text { Career pathways and perceived barriers of } \\
\text { women superintendents }\end{array}$ & $\begin{array}{l}\text { University of } \\
\text { Texas-El Paso- } \\
2001 \\
\mathbf{4} \text { Gender }^{\boldsymbol{b}} \\
\text { 3-F } \\
\text { 1-M } \\
\text { 0-LGTBIQ } \\
0-\mathrm{O}\end{array}$ & $\mathrm{X}$ & & \\
\hline No gender found $3 / 9 / 1010$ & $\begin{array}{l}\text { University of } \\
\text { Toledo-NA } \\
\boldsymbol{0} \text { Gender } \boldsymbol{b} \\
\text { 0-F } \\
\text { 0-M }\end{array}$ & & & \\
\hline
\end{tabular}


GENDER REPRESENTATIONS IN ED.D. DISSERTATIONS

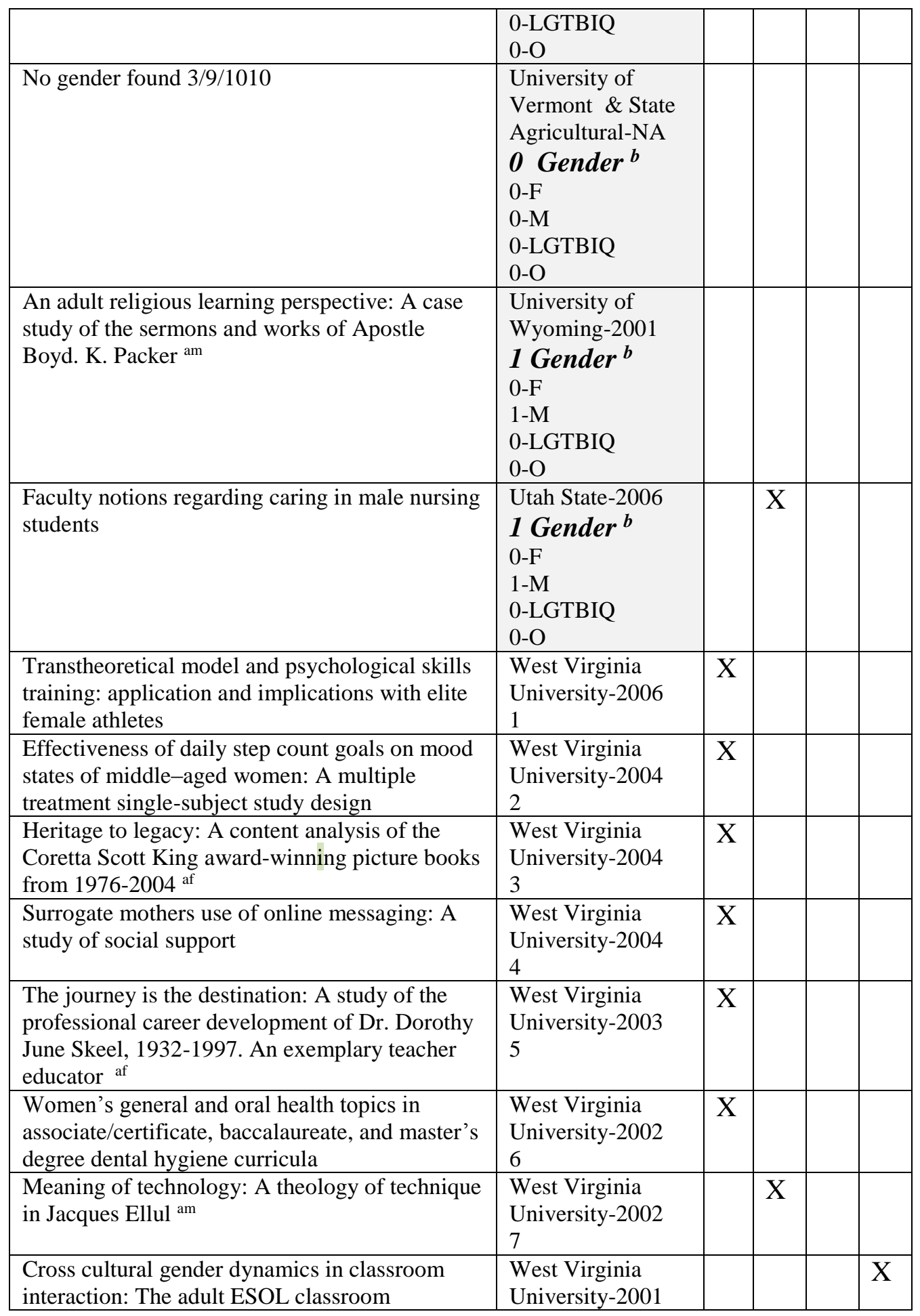




\section{GENDER REPRESENTATIONS IN ED.D. DISSERTATIONS}

\begin{tabular}{|c|c|c|c|c|}
\hline & 8 & & & \\
\hline $\begin{array}{l}\text { The effect of role, age, gender and years of } \\
\text { experience upon the perceived importance of } \\
\text { clinical teacher behavior categories in athletic } \\
\text { training education }\end{array}$ & $\begin{array}{l}\text { West Virginia } \\
\text { University-2001 } \\
9\end{array}$ & & & $X$ \\
\hline $\begin{array}{l}\text { The present status of geography education in } \\
\text { boy's intermediate schools of Riyadh, Saudi } \\
\text { Arabia }\end{array}$ & $\begin{array}{l}\text { West Virginia } \\
\text { University-2001 } \\
10\end{array}$ & & $X$ & \\
\hline $\begin{array}{l}\text { Breastfeeding personal efficacy beliefs of } \\
\text { women university students }\end{array}$ & $\begin{array}{l}\text { West Virginia } \\
\text { University-2000 } \\
11\end{array}$ & $X$ & & \\
\hline $\begin{array}{l}\text { "I'm right there": Central Appalachian women } \\
\text { in public school leadership }\end{array}$ & $\begin{array}{l}\text { West Virginia } \\
\text { University-2000 } \\
12\end{array}$ & $X$ & & \\
\hline $\begin{array}{l}\text { The effects of social support on men's exercise } \\
\text { related cardiovascular reactivity }\end{array}$ & $\begin{array}{l}\text { West Virginia } \\
\text { University-2000 } \\
13\end{array}$ & & $X$ & \\
\hline $\begin{array}{l}\text { A study of job satisfaction of female } \\
\text { administrators in the National Education } \\
\text { Association and its affiliates }\end{array}$ & $\begin{array}{l}\text { West Virginia } \\
\text { University-1998 } \\
14\end{array}$ & $X$ & & \\
\hline $\begin{array}{l}\text { Identification of content, priority and methods of } \\
\text { instructional delivery for a women's health } \\
\text { component in an internal medicine residency } \\
\text { program: A modified Delphi study }\end{array}$ & $\begin{array}{l}\text { West Virginia } \\
\text { University-1998 } \\
15\end{array}$ & $X$ & & \\
\hline $\begin{array}{l}\text { "The thing you least hear about in the dorm" } \\
\text { Cultural themes or academic activity in a } \\
\text { women's residence hall at a public } \\
\text { comprehensive university }\end{array}$ & $\begin{array}{l}\text { West Virginia } \\
\text { University-1998 } \\
16\end{array}$ & $X$ & & \\
\hline $\begin{array}{l}\text { The relationship between gender and math } \\
\text { achievement levels among fourth, fifth and sixth } \\
\text { grade students }\end{array}$ & $\begin{array}{l}\text { West Virginia } \\
\text { University-1998 } \\
17\end{array}$ & & & $\mathrm{X}$ \\
\hline $\begin{array}{l}\text { The relationship between gender, faculty } \\
\text { development and class size and sense of efficacy } \\
\text { of college mathematics teachers }\end{array}$ & $\begin{array}{l}\text { West Virginia } \\
\text { University-1998 } \\
\text { 18 Gender } \\
\text { 11-F } \\
\text { 3-M } \\
\text { 0-L } \\
\text { 4-O }\end{array}$ & & & $\mathrm{X}$ \\
\hline $\begin{array}{l}\text { Role that professional positioning and } \\
\text { professional socialization play in the career } \\
\text { paths of African American women } \\
\text { superintendents }\end{array}$ & $\begin{array}{l}\text { Western Michigan } \\
\text { University-2003 } \\
1\end{array}$ & $\mathrm{X}$ & & \\
\hline $\begin{array}{l}\text { The impact of values and gender on advising } \\
\text { satisfaction and persistence of African } \\
\text { Americans at predominantly white universities }\end{array}$ & $\begin{array}{l}\text { Western Michigan } \\
\text { University-2001 } \\
2\end{array}$ & & & $\mathrm{X}$ \\
\hline $\begin{array}{l}\text { Attitudes and perceptions of Michigan school } \\
\text { administrators towards female administrators }\end{array}$ & $\begin{array}{l}\text { Western Michigan } \\
\text { University-2000 }\end{array}$ & $\mathrm{X}$ & & \\
\hline
\end{tabular}


GENDER REPRESENTATIONS IN ED.D. DISSERTATIONS

\begin{tabular}{|c|c|c|}
\hline & 3 & \\
\hline $\begin{array}{l}\text { Research into the relationships among } \\
\text { multicultural training, racial and gender identity } \\
\text { attitudes and multicultural competencies for } \\
\text { counselors }\end{array}$ & $\begin{array}{l}\text { Western Michigan } \\
\text { University-2000 } \\
4\end{array}$ & $\mathrm{X}$ \\
\hline $\begin{array}{l}\text { A sense of entitlement to self in relationships: } \\
\text { An elaboration of attachment and feminist object } \\
\text { relations theory } \\
\text { FEMINIST }\end{array}$ & $\begin{array}{l}\text { Western Michigan } \\
\text { University-1998 } \\
\mathbf{5} \text { Gender }^{\boldsymbol{b}} \\
\text { 2-F } \\
\text { 0-M } \\
\text { 0-LGTBIQ } \\
\text { 3-0 }\end{array}$ & $\mathrm{X}$ \\
\hline No gender found 3/9/1010 & $\begin{array}{l}\text { Wichita State U- } \\
\text { NA } \\
\text { 0 Gender }{ }^{\boldsymbol{b}} \\
0-\mathrm{F} \\
0-\mathrm{M} \\
0-\mathrm{LGTBIQ} \\
0-\mathrm{O}\end{array}$ & \\
\hline
\end{tabular}




\section{GENDER REPRESENTATIONS IN ED.D. DISSERTATIONS}

\begin{tabular}{|c|c|c|c|c|c|}
\hline Dissertation Title & $\begin{array}{l}\text { RUVH- } \\
\text { Institution }\end{array}$ & $F$ & $M$ & $L$ & $O$ \\
\hline $\begin{array}{l}\text { A feeling of belonging: Impacts of gay-straight } \\
\text { alliances on high school students } \\
\text { LGTBIQ } \\
\text { FULL TEXT }\end{array}$ & $\begin{array}{l}\text { Arizona State- } \\
\text { Tempe-2007 } \\
1\end{array}$ & & & $X$ & \\
\hline $\begin{array}{l}\text { Latino community college transfer students in } \\
\text { engineering: Transition experiences and academic } \\
\text { success at a large research university } \\
\text { LATINO/A }\end{array}$ & $\begin{array}{l}\text { Arizona State- } \\
\text { Tempe-2007 } \\
2\end{array}$ & & $\mathrm{X}$ & & \\
\hline $\begin{array}{l}\text { African American women leaders in } \\
\text { predominately Caucasian schools }\end{array}$ & $\begin{array}{l}\text { Arizona State- } \\
\text { Tempe-2006 } \\
3\end{array}$ & $X$ & & & \\
\hline $\begin{array}{l}\text { A heuristic inquiry of three Navajo women in } \\
\text { educational leadership }\end{array}$ & $\begin{array}{l}\text { Arizona State- } \\
\text { Tempe-2006 } \\
4\end{array}$ & $\mathrm{X}$ & & & \\
\hline $\begin{array}{l}\text { Successful Latino students: A study of five } \\
\text { Mexican American families } \\
\text { LATINO/A }\end{array}$ & $\begin{array}{l}\text { Arizona State- } \\
\text { Tempe-2006 } \\
5\end{array}$ & & $\mathrm{X}$ & & \\
\hline $\begin{array}{l}\text { A case study of an effective and successful } \\
\text { women superintendent }\end{array}$ & $\begin{array}{l}\text { Arizona State- } \\
\text { Tempe-2005 } \\
6 \\
\end{array}$ & $\mathrm{X}$ & & & \\
\hline $\begin{array}{l}\text { The English legacy of Joseph Lancaster to the } \\
\text { Mexican philosophy of education am }\end{array}$ & $\begin{array}{l}\text { Arizona State- } \\
\text { Tempe-2005 } \\
7\end{array}$ & & $\mathrm{X}$ & & \\
\hline $\begin{array}{l}\text { Efficacy of student-related sexual harassment } \\
\text { policy of a large urban school district in the } \\
\text { Southwest }\end{array}$ & $\begin{array}{l}\text { Arizona State- } \\
\text { Tempe-2005 } \\
8\end{array}$ & & & & $\bar{X}$ \\
\hline $\begin{array}{l}\text { Four successful Apache women living in a } \\
\text { postmodern era }\end{array}$ & $\begin{array}{l}\text { Arizona State- } \\
\text { Tempe-2005 } \\
9\end{array}$ & $\mathrm{X}$ & & & \\
\hline $\begin{array}{l}\text { Mentoring Hispanic women: Mentors and } \\
\text { mentees perceptions of selected aspects of a } \\
\text { formal mentoring program }\end{array}$ & $\begin{array}{l}\text { Arizona State- } \\
\text { Tempe-2005 } \\
10\end{array}$ & $\mathrm{X}$ & & & \\
\hline $\begin{array}{l}\text { A female Hispanic school leaders experience in } \\
\text { an Native American community a heuristic } \\
\text { inquiry }\end{array}$ & $\begin{array}{l}\text { Arizona State- } \\
\text { Tempe-2004 } \\
11\end{array}$ & $\mathrm{X}$ & & & \\
\hline $\begin{array}{l}\text { African American women in public school } \\
\text { administration: A heuristic inquiry }\end{array}$ & $\begin{array}{l}\text { Arizona State- } \\
\text { Tempe-2004 } \\
12\end{array}$ & $X$ & & & \\
\hline $\begin{array}{l}\text { Gender by ethnic equity issues as they pertain to } \\
\text { success in science education }\end{array}$ & $\begin{array}{l}\text { Arizona State- } \\
\text { Tempe-2004 } \\
13\end{array}$ & & & & $\mathrm{X}$ \\
\hline $\begin{array}{l}\text { The personal and academic success of African } \\
\text { American males with specific learning disabilities } \\
\text { BLACK MALE }\end{array}$ & $\begin{array}{l}\text { Arizona State- } \\
\text { Tempe-2004 } \\
14\end{array}$ & & $\mathrm{X}$ & & \\
\hline $\begin{array}{l}\text { "Women hold up half the sky" Is principal } \\
\text { selection based on gender and leadership style }\end{array}$ & $\begin{array}{l}\text { Arizona State- } \\
\text { Tempe-2004 } \\
15\end{array}$ & $\mathrm{X}$ & & & \\
\hline
\end{tabular}




\section{GENDER REPRESENTATIONS IN ED.D. DISSERTATIONS}

\begin{tabular}{|c|c|c|c|c|}
\hline $\begin{array}{l}\text { Gender construction: Definitions of masculinity } \\
\text { and the influence of texts }\end{array}$ & $\begin{array}{l}\text { Arizona State- } \\
\text { Tempe-2003 } \\
16\end{array}$ & & $\mathrm{X}$ & \\
\hline $\begin{array}{l}\text { A prominent walk: Portraiture of three Mexican } \\
\text { American women }\end{array}$ & $\begin{array}{l}\text { Arizona State- } \\
\text { Tempe-2002 } \\
17\end{array}$ & $X$ & & \\
\hline $\begin{array}{l}\text { Profiles of Black Latinos in the academe: The } \\
\text { identity dilemma and the perception of self } \\
\text { LATINO/A }\end{array}$ & $\begin{array}{l}\text { Arizona State- } \\
\text { Tempe-2002 } \\
18\end{array}$ & & $\mathrm{X}$ & \\
\hline $\begin{array}{l}\text { The Latino/a faculty: A perilous journey to the } \\
\text { ivory tower in higher education } \\
\text { LATINO/A }\end{array}$ & $\begin{array}{l}\text { Arizona State- } \\
\text { Tempe-2002 } \\
19\end{array}$ & $\mathrm{X}$ & & \\
\hline $\begin{array}{l}\text { Responsiveness of five economically } \\
\text { disadvantaged minority females to traditional and } \\
\text { hands on teaching practices in math and science }\end{array}$ & $\begin{array}{l}\text { Arizona State- } \\
\text { Tempe-2002 } \\
20\end{array}$ & $\mathrm{X}$ & & \\
\hline $\begin{array}{l}\text { Chronically truant female middle school students, } \\
\text { victimization and the influence of social control }\end{array}$ & $\begin{array}{l}\text { Arizona State- } \\
\text { Tempe-2001 } \\
21\end{array}$ & $\mathrm{X}$ & & \\
\hline $\begin{array}{l}\text { Portraitures of four female delinquents in a } \\
\text { juvenile correctional institutions }\end{array}$ & $\begin{array}{l}\text { Arizona State- } \\
\text { Tempe-2001 } \\
22\end{array}$ & $X$ & & \\
\hline $\begin{array}{l}\text { Educating Mrs.Cran: A portraiture of the } \\
\text { educational experiences of the alingual child af }\end{array}$ & $\begin{array}{l}\text { Arizona State- } \\
\text { Tempe-2001 } \\
23\end{array}$ & $\mathrm{X}$ & & \\
\hline $\begin{array}{l}\text { The way out: African American male student } \\
\text { athletes in higher education } \\
\text { BLACK MALE }\end{array}$ & $\begin{array}{l}\text { Arizona State- } \\
\text { Tempe-2001 } \\
24\end{array}$ & & $X$ & \\
\hline $\begin{array}{l}\text { Shaping scholars: The learning and living } \\
\text { experiences of women doctoral students }\end{array}$ & $\begin{array}{l}\text { Arizona State- } \\
\text { Tempe-1999 } \\
25\end{array}$ & $\mathrm{X}$ & & \\
\hline $\begin{array}{l}\text { Factors which influence second level female } \\
\text { administrators in Arizona to apply for } \\
\text { superintendencies }\end{array}$ & $\begin{array}{l}\text { Arizona State- } \\
\text { Tempe-1998 } \\
26\end{array}$ & $\mathrm{X}$ & & \\
\hline $\begin{array}{l}\text { The impact of home environment of Black males } \\
\text { not pursuing higher education between 18-22 } \\
\text { BLACK MALE }\end{array}$ & $\begin{array}{l}\text { Arizona State- } \\
\text { Tempe-1998 } \\
27\end{array}$ & & $X$ & \\
\hline $\begin{array}{l}\text { Voice of spirit: The world view of urban Dine } \\
\text { women and it's role in learning }\end{array}$ & $\begin{array}{l}\text { Arizona State- } \\
\text { Tempe-1998 } \\
\text { 28 Gender }{ }^{b} \\
\text { 17-F } \\
\text { 8-M } \\
\text { 1-LGTBIQ } \\
\text { 2-O } \\
\end{array}$ & $\mathrm{X}$ & & \\
\hline $\begin{array}{l}\text { Organizational commitment of senior women } \\
\text { administrators }\end{array}$ & $\begin{array}{l}\text { Florida State- } \\
2007 \\
1\end{array}$ & $\mathrm{X}$ & & \\
\hline $\begin{array}{l}\text { Out of the closet and onto Fraternity Row: An } \\
\text { ethnographic study of heterosexism and }\end{array}$ & $\begin{array}{l}\text { Florida State- } \\
2006\end{array}$ & & & $\mathrm{X}$ \\
\hline
\end{tabular}




\section{GENDER REPRESENTATIONS IN ED.D. DISSERTATIONS}

\begin{tabular}{|c|c|c|c|c|}
\hline $\begin{array}{l}\text { homophobia in a college fraternity community } \\
\text { LGTBIQ }\end{array}$ & 2 & & & \\
\hline $\begin{array}{l}\text { Perceptions of career advancement factors held by } \\
\text { Black student affairs administrators: A gender } \\
\text { comparison }\end{array}$ & $\begin{array}{l}\text { Florida State - } \\
2006 \\
3\end{array}$ & & & $X$ \\
\hline $\begin{array}{l}\text { A critical examination of Milton Bradley's } \\
\text { contribution to kindergarten and art education in } \\
\text { the context of his time am }\end{array}$ & $\begin{array}{l}\text { Florida State- } \\
2005 \\
4\end{array}$ & & $X$ & \\
\hline $\begin{array}{l}\text { The organizational culture of women's colleges: } \\
\text { A multiple case study }\end{array}$ & $\begin{array}{l}\text { Florida State- } \\
2001 \\
5\end{array}$ & $\mathrm{X}$ & & \\
\hline $\begin{array}{l}\text { Leaders among women: An exploratory study of } \\
\text { the impact of sorority membership on women's } \\
\text { leadership development }\end{array}$ & $\begin{array}{l}\text { Florida State- } \\
1999 \\
6\end{array}$ & $\mathrm{X}$ & & \\
\hline $\begin{array}{l}\text { A study of female leadership techniques in public } \\
\text { school administration }\end{array}$ & $\begin{array}{l}\text { Florida State- } \\
1998 \\
7 \text { Gender }^{b} \\
\text { 4-F } \\
\text { 1-M } \\
\text { 1-LGTBIQ } \\
1-\mathrm{O}\end{array}$ & $\mathrm{X}$ & & \\
\hline $\begin{array}{l}\text { An empirical investigation of student sexual } \\
\text { harassment attitudes in relation to implementation } \\
\text { of sexual harassment policy }\end{array}$ & $\begin{array}{l}\text { Kansas State } \\
2003 \\
1\end{array}$ & & & $X$ \\
\hline $\begin{array}{l}\text { A study of knowledge acquisition by high school } \\
\text { students as a result of sexual harassment } \\
\text { prevention training }\end{array}$ & $\begin{array}{l}\text { Kansas State } \\
1999 \\
2\end{array}$ & & & $\mathrm{X}$ \\
\hline $\begin{array}{l}\text { A case study of the development and } \\
\text { implementation of a modified integrated thematic } \\
\text { instructional model for sexual harassment } \\
\text { prevention }\end{array}$ & $\begin{array}{l}\text { Kansas State } \\
\text { 1998 } \\
\text { 3 Gender } \boldsymbol{b} \\
\text { 0-F } \\
\text { 0-M } \\
\text { 0-LGTBIQ } \\
\text { 3-O }\end{array}$ & & & $\mathrm{X}$ \\
\hline $\begin{array}{l}\text { The boarding school legacy: Ten contemporary } \\
\text { Lakota women tell their stories }\end{array}$ & $\begin{array}{l}\text { Montana State- } \\
2007 \\
1\end{array}$ & $X$ & & \\
\hline $\begin{array}{l}\text { Barriers to women in educational leadership roles } \\
\text { in Montana }\end{array}$ & $\begin{array}{l}\text { Montana State- } \\
2004 \\
2\end{array}$ & $\mathrm{X}$ & & \\
\hline $\begin{array}{l}\text { Montana Boys State and Montana Girls State: } \\
\text { Political socialization of the adolescents in } \\
\text { transition to adulthood in the context of family, } \\
\text { school and community }\end{array}$ & $\begin{array}{l}\text { Montana State- } \\
2004 \\
3\end{array}$ & & & $\mathrm{X}$ \\
\hline $\begin{array}{l}\text { Experiences of women over } 70 \text { years of age } \\
\text { learning computer skills }\end{array}$ & $\begin{array}{l}\text { Montana State- } \\
2003 \\
4\end{array}$ & $\mathrm{X}$ & & \\
\hline
\end{tabular}




\section{GENDER REPRESENTATIONS IN ED.D. DISSERTATIONS}

\begin{tabular}{|c|c|c|c|c|}
\hline $\begin{array}{l}\text { Concept attainment: A case study comparing a } \\
\text { child profiled with Asperger syndrome and his } \\
\text { fifth grade classmates }\end{array}$ & $\begin{array}{l}\text { Montana State- } \\
2003 \\
5\end{array}$ & & $\mathrm{X}$ & \\
\hline $\begin{array}{l}\text { Perceptions of Native American women in } \\
\text { college of the impact of the teachers attitudes and } \\
\text { the classroom environment on their K-12 learning }\end{array}$ & $\begin{array}{l}\text { Montana State- } \\
1999 \\
\text { 6 Gender }{ }^{b} \\
4-\mathrm{F} \\
1-\mathrm{M} \\
0-\mathrm{L} \\
1-\mathrm{O}\end{array}$ & $X$ & & \\
\hline $\begin{array}{l}\text { Cyber connections across age and gender } \\
\text { differences: How communication technologies } \\
\text { enhance social communication in learning } \\
\text { communities in online college courses }\end{array}$ & $\begin{array}{l}\text { North Carolina } \\
\text { State-Raleigh- } \\
2006 \\
1\end{array}$ & & & $\mathrm{X}$ \\
\hline $\begin{array}{l}\text { Graduate education experiences and career paths } \\
\text { of women faculty in higher education } \\
\text { administration }\end{array}$ & $\begin{array}{l}\text { North Carolina } \\
\text { State-Raleigh- } \\
2006 \\
2\end{array}$ & $X$ & & \\
\hline $\begin{array}{l}\text { Educational experiences of first generation } \\
\text { women community college students of non- } \\
\text { traditional age }\end{array}$ & $\begin{array}{l}\text { North Carolina } \\
\text { State-Raleigh- } \\
2005 \\
3\end{array}$ & $X$ & & \\
\hline $\begin{array}{l}\text { Henry Leveke Kamphoefner, the modernist, dean } \\
\text { of North Carolina State University School of } \\
\text { Design, 1948-1972 am }\end{array}$ & $\begin{array}{l}\text { North Carolina } \\
\text { State-Raleigh- } \\
2005 \\
4\end{array}$ & & & \\
\hline $\begin{array}{l}\text { Decision-making, gender and field of academic } \\
\text { major choice }\end{array}$ & $\begin{array}{l}\text { North Carolina } \\
\text { State-Raleigh- } \\
2004 \\
5\end{array}$ & & & $\mathrm{X}$ \\
\hline $\begin{array}{l}\text { Differences in work ethic among jobseekers } \\
\text { grouped by employment status and age and } \\
\text { gender }\end{array}$ & $\begin{array}{l}\text { North Carolina } \\
\text { State-Raleigh- } \\
2004 \\
6\end{array}$ & & & $\mathrm{X}$ \\
\hline $\begin{array}{l}\text { Older re-entry community college women: Their } \\
\text { start, delay, choice and experiences }\end{array}$ & $\begin{array}{l}\text { North Carolina } \\
\text { State-Raleigh- } \\
2004 \\
7\end{array}$ & $X$ & & \\
\hline $\begin{array}{l}\text { The life changes that adult daughters go through } \\
\text { when they become primary caregivers to parents } \\
\text { with Alzheimer's disease }\end{array}$ & $\begin{array}{l}\text { North Carolina } \\
\text { State-Raleigh - } \\
2004 \\
8\end{array}$ & $X$ & & \\
\hline $\begin{array}{l}\text { A qualitative study of resilience among African- } \\
\text { American adolescent male students in North } \\
\text { Carolina } \\
\text { BLACK MALE }\end{array}$ & $\begin{array}{l}\text { North Carolina } \\
\text { State-Raleigh- } \\
2003 \\
9\end{array}$ & & $\mathrm{X}$ & \\
\hline $\begin{array}{l}\text { Ascension to the presidency: A descriptive study } \\
\text { of female presidents in the North Carolina }\end{array}$ & $\begin{array}{l}\text { North Carolina } \\
\text { State-Raleigh- }\end{array}$ & $X$ & & \\
\hline
\end{tabular}




\section{GENDER REPRESENTATIONS IN ED.D. DISSERTATIONS}

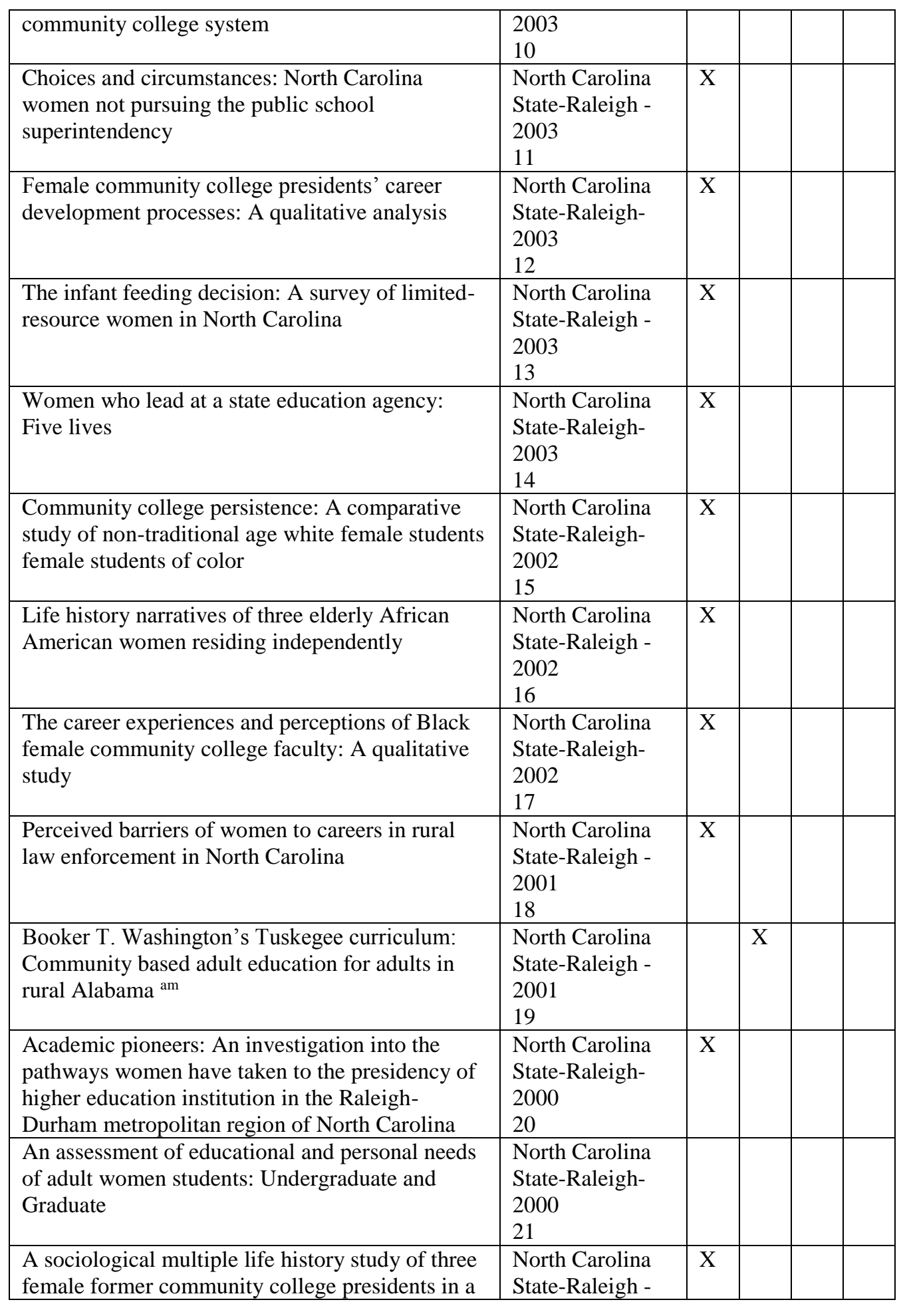




\section{GENDER REPRESENTATIONS IN ED.D. DISSERTATIONS}

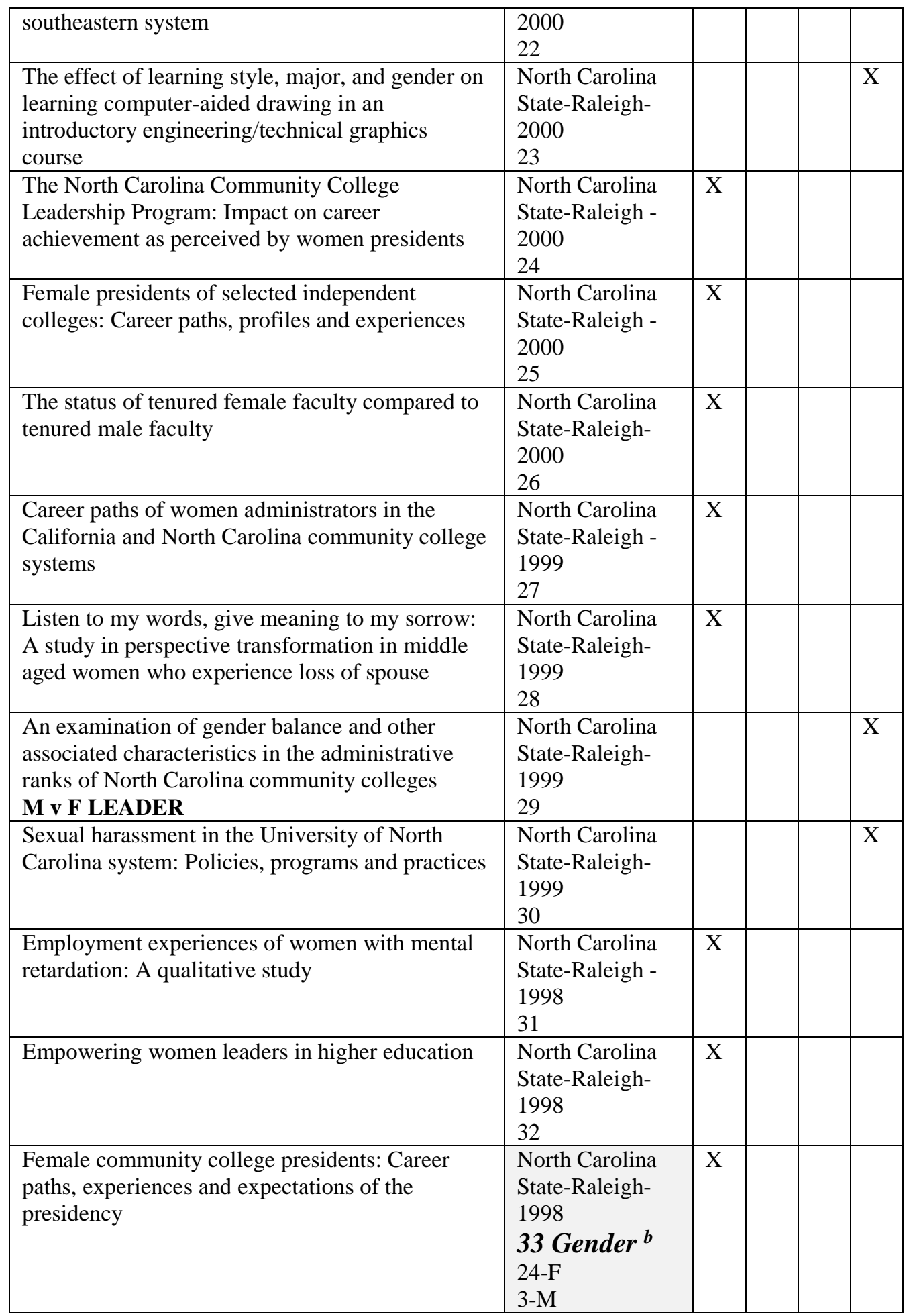




\section{GENDER REPRESENTATIONS IN ED.D. DISSERTATIONS}

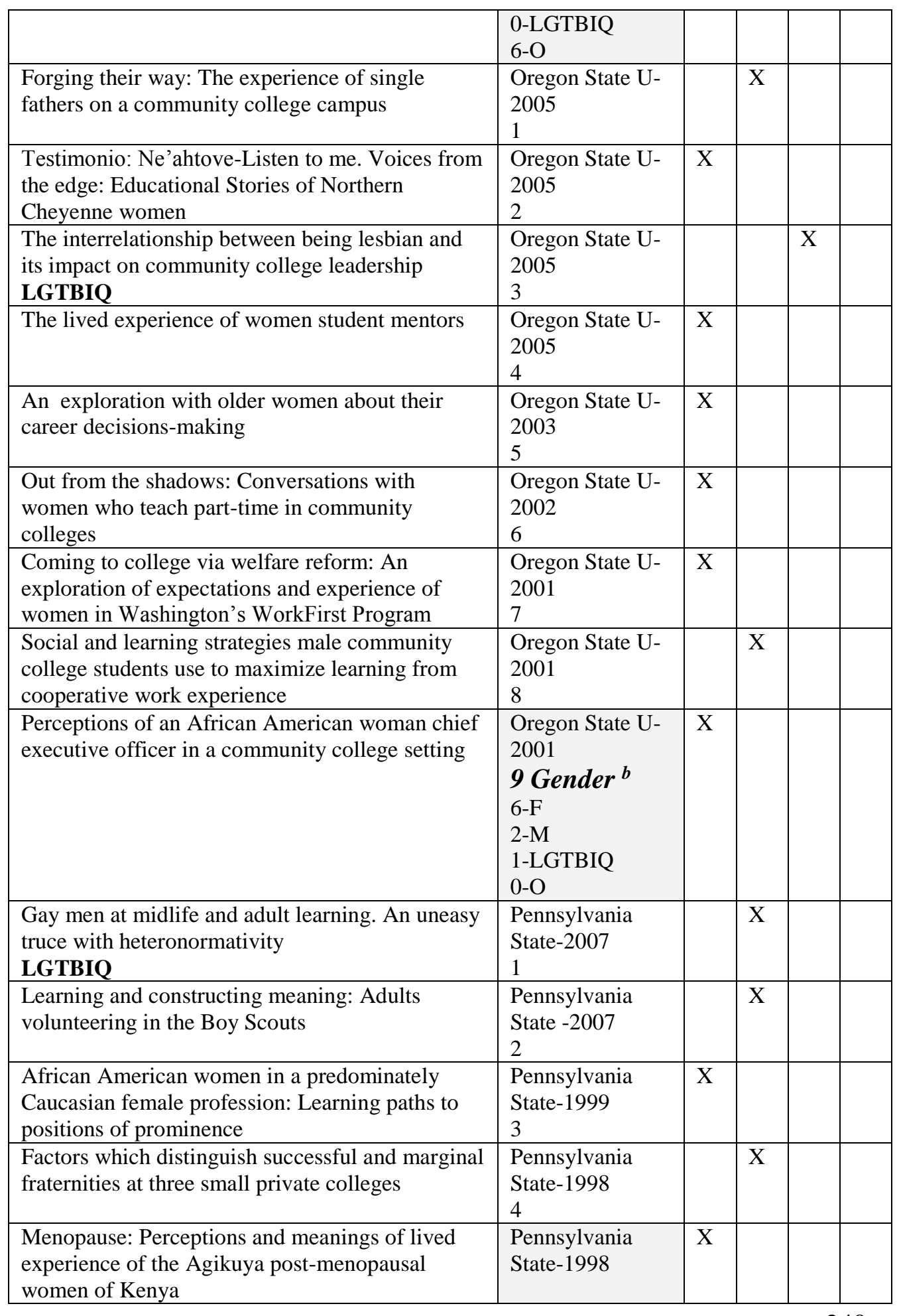




\section{GENDER REPRESENTATIONS IN ED.D. DISSERTATIONS}

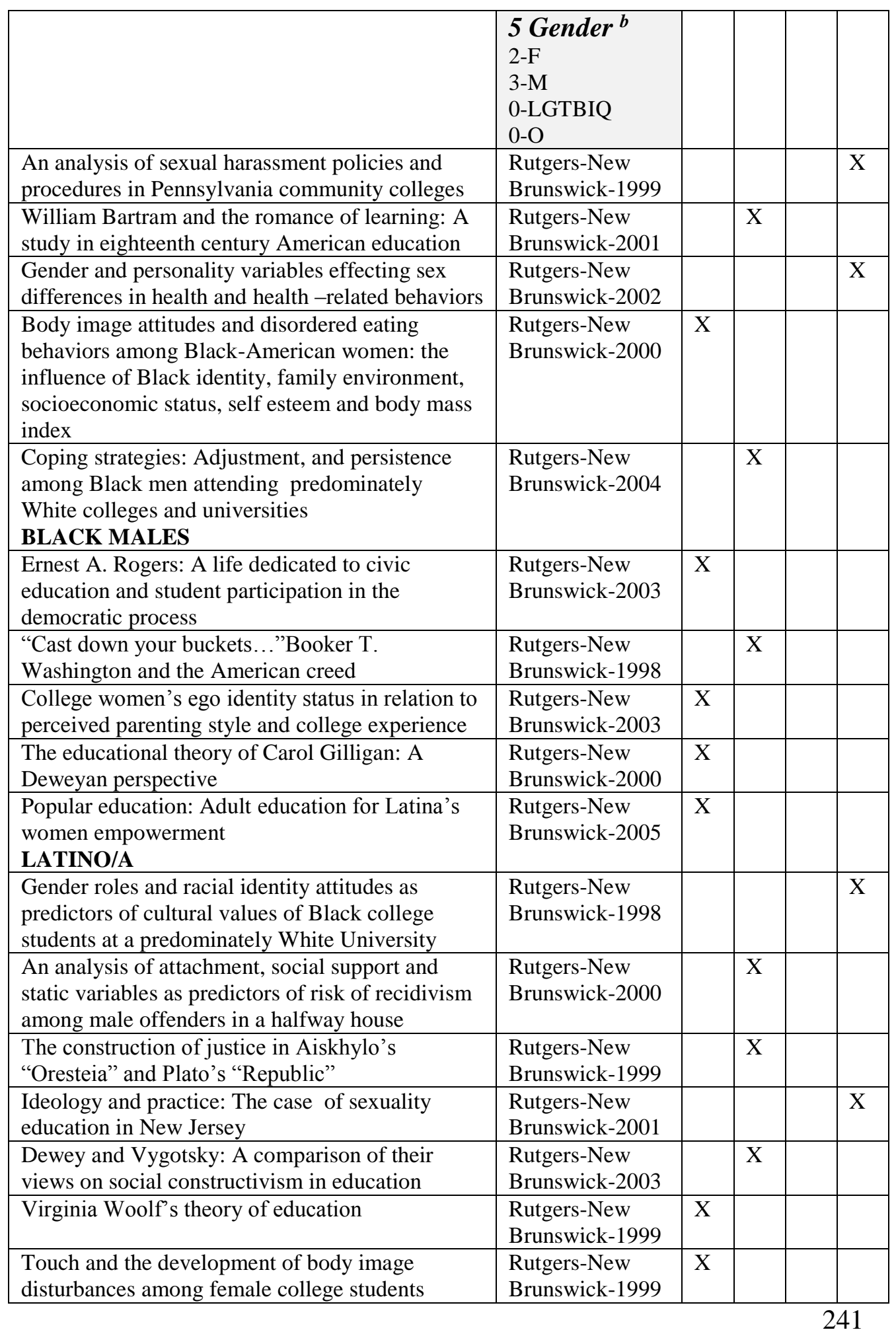




\section{GENDER REPRESENTATIONS IN ED.D. DISSERTATIONS}

\begin{tabular}{|c|c|c|c|c|c|}
\hline $\begin{array}{l}\text { Influences on how readers respond: An analysis } \\
\text { of nationality, gender, text, teacher and mode of } \\
\text { response in four secondary school literature } \\
\text { classrooms in the Netherlands and the United } \\
\text { States }\end{array}$ & $\begin{array}{l}\text { Rutgers-New } \\
\text { Brunswick-2002 }\end{array}$ & & & & $\mathrm{X}$ \\
\hline $\begin{array}{l}\text { Enhancing reading instruction: Results of a } \\
\text { fluency intervention model on the performance } \\
\text { and self perceptions of fourth grade male readers }\end{array}$ & $\begin{array}{l}\text { Rutgers-New } \\
\text { Brunswick-2004 }\end{array}$ & & $\mathrm{X}$ & & \\
\hline $\begin{array}{l}\text { Muslim women reflecting on American } \\
\text { education: Exploring the question of educational } \\
\text { identity }\end{array}$ & $\begin{array}{l}\text { Rutgers-New } \\
\text { Brunswick-2004 }\end{array}$ & $\mathrm{X}$ & & & \\
\hline $\begin{array}{l}\text { The experience of women college presidents: An } \\
\text { oral history }\end{array}$ & $\begin{array}{l}\text { Rutgers-New } \\
\text { Brunswick-2003 }\end{array}$ & $\mathrm{X}$ & & & \\
\hline $\begin{array}{l}\text { Leadership development in women: A case study } \\
\text { of a leadership program at a women's college }\end{array}$ & $\begin{array}{l}\text { Rutgers-New } \\
\text { Brunswick-1999 }\end{array}$ & $\mathrm{X}$ & & & \\
\hline $\begin{array}{l}\text { Volunteer leaders: Learning and development in } \\
\text { the League of Women Voters }\end{array}$ & $\begin{array}{l}\text { Rutgers-New } \\
\text { Brunswick-2002 }\end{array}$ & $\mathrm{X}$ & & & \\
\hline First grade African American girls' play patterns & $\begin{array}{l}\text { Rutgers-New } \\
\text { Brunswick-1999 }\end{array}$ & $\mathrm{X}$ & & & \\
\hline $\begin{array}{l}\text { Gender and level of acculturation as predictors of } \\
\text { attitudes towards seeking professional } \\
\text { psychological help and attitudes toward Indians } \\
\text { and Pakistanis in America }\end{array}$ & $\begin{array}{l}\text { Rutgers-New } \\
\text { Brunswick-2000 }\end{array}$ & & & & $\mathrm{X}$ \\
\hline $\begin{array}{l}\text { Stereotype threat and women's math } \\
\text { performance; the possible mediating factors of } \\
\text { test anxiety, test motivation and self-efficacy }\end{array}$ & $\begin{array}{l}\text { Rutgers-New } \\
\text { Brunswick-2005 }\end{array}$ & $\mathrm{X}$ & & & \\
\hline $\begin{array}{l}\text { Male gender role strain, coping and college } \\
\text { adjustment }\end{array}$ & $\begin{array}{l}\text { Rutgers-New } \\
\text { Brunswick-2005 }\end{array}$ & & $\mathrm{X}$ & & \\
\hline $\begin{array}{l}\text { Racial and gender equity in high school Navy } \\
\text { Junior ROTC units }\end{array}$ & $\begin{array}{l}\text { Rutgers-New } \\
\text { Brunswick-2004 }\end{array}$ & & & & $\mathrm{X}$ \\
\hline $\begin{array}{l}\text { Factors that influence Black professional } \\
\text { women's participation in continuing professional } \\
\text { education }\end{array}$ & $\begin{array}{l}\text { Rutgers-New } \\
\text { Brunswick-2000 }\end{array}$ & $\mathrm{X}$ & & & \\
\hline $\begin{array}{l}\text { Client sexual orientation and mental health } \\
\text { assessment }\end{array}$ & $\begin{array}{l}\text { Rutgers-New } \\
\text { Brunswick-2004 }\end{array}$ & & & $\mathrm{X}$ & \\
\hline $\begin{array}{l}\text { An analysis of the pedagogy of Robert B. Davis: } \\
\text { young children working on the tower of Hanoi } \\
\text { problem }\end{array}$ & $\begin{array}{l}\text { Rutgers-New } \\
\text { Brunswick- }\end{array}$ & & $\mathrm{X}$ & & \\
\hline $\begin{array}{l}\text { "And thus to raise my race" the early writings of } \\
\text { W.E. B. Dubois (1886-1903) }\end{array}$ & $\begin{array}{l}\text { Rutgers-New } \\
\text { Brunswick- } \\
32 \text { Gender } \\
14-\mathrm{F} \\
10-\mathrm{M} \\
1-\mathrm{LGTBIQ} \\
7-\mathrm{O}\end{array}$ & & $\mathrm{X}$ & & \\
\hline $\begin{array}{l}\text { Feminist popular education in Latin American: A } \\
\text { case study on the political empowerment of } \\
\text { women in the Dominican republic }\end{array}$ & $\begin{array}{l}\text { SUNY-Albany- } \\
1999 \\
\text { I Gender }^{b}\end{array}$ & $\mathrm{X}$ & & & \\
\hline
\end{tabular}




\section{GENDER REPRESENTATIONS IN ED.D. DISSERTATIONS}

\begin{tabular}{|c|c|c|c|c|}
\hline FEMINIST & $\begin{array}{l}1-\mathrm{F} \\
0-\mathrm{M} \\
0-\mathrm{LGTBIQ} \\
0-\mathrm{O}\end{array}$ & & & \\
\hline $\begin{array}{l}\text { A case study of gender in high school student } \\
\text { government leadership and a test of Rotter's and } \\
\text { Bandura's theories of social learning am }\end{array}$ & $\begin{array}{l}\text { SUNY-Buffalo- } \\
1999 \\
1 \text { Gender } \\
\text { 0-F } \\
\text { 0-M } \\
\text { 0-LGTBIQ } \\
\text { 1-O }\end{array}$ & & & $\mathrm{X}$ \\
\hline $\begin{array}{l}\text { The courage of our passion: Examining the } \\
\text { personal costs negotiated by the African } \\
\text { American women executive educational leaders } \\
\text { in urban contexts }\end{array}$ & $\begin{array}{l}\text { Texas A \& M- } \\
2007 \\
1\end{array}$ & $\mathrm{X}$ & & \\
\hline $\begin{array}{l}\text { The relationship between small learning } \\
\text { communities and student performance as } \\
\text { identified by the academic excellence indicator } \\
\text { system at Robert E. Lee high school in North East } \\
\text { Independent School District, San Antonio,Texas } \\
\text { am }\end{array}$ & $\begin{array}{l}\text { Texas A \& M } \\
2007 \\
2\end{array}$ & & $\mathrm{X}$ & \\
\hline $\begin{array}{l}\text { Middle class African American Mothers } \\
\text { perceptions of white teachers interactions with } \\
\text { their African American children in predominately } \\
\text { white suburban junior high schools }\end{array}$ & $\begin{array}{l}\text { Texas A \& M- } \\
2006 \\
3\end{array}$ & $\mathrm{X}$ & & \\
\hline $\begin{array}{l}\text { The effect of "Capturing kids hearts" staff } \\
\text { development program in fostering positive } \\
\text { teacher-student relationships at Jane Long } \\
\text { Middle School in Bryan ISD af }\end{array}$ & $\begin{array}{l}\text { Texas A \& M } \\
2004 \\
4\end{array}$ & $\mathrm{X}$ & & \\
\hline $\begin{array}{l}\text { Factors influencing career decisions to pursue the } \\
\text { position of superintendent as identified by } \\
\text { Hispanic and Anglo female administrators in the } \\
\text { Texas public schools }\end{array}$ & $\begin{array}{l}\text { Texas A \& M } \\
2002 \\
5\end{array}$ & $\mathrm{X}$ & & \\
\hline $\begin{array}{l}\text { An analysis of the Sam Houston State University } \\
\text { Educator Preparation Program and effect on } \\
\text { graduate's perceptions of preparedeness to teach } \\
\text { am }\end{array}$ & $\begin{array}{l}\text { Texas A \& M } \\
2001 \\
6\end{array}$ & & $\mathrm{X}$ & \\
\hline $\begin{array}{l}\text { Critical race theory on the African American } \\
\text { women principal: Alternative portrayals of } \\
\text { effective leadership practice in urban schools }\end{array}$ & $\begin{array}{l}\text { Texas A \& M- } \\
2001 \\
7\end{array}$ & $\mathrm{X}$ & & \\
\hline $\begin{array}{l}\text { The impart of relational demography on } \\
\text { important work-related outcomes in the NCAA } \\
\text { women's teams Head coach-Assistant coach dyad }\end{array}$ & $\begin{array}{l}\text { Texas A \& M- } \\
2001 \\
8\end{array}$ & $\mathrm{X}$ & & \\
\hline $\begin{array}{l}\text { The women in the principal's office: A } \\
\text { naturalistic study of the induction year }\end{array}$ & $\begin{array}{l}\text { Texas A \& M- } \\
2000 \\
9\end{array}$ & $\mathrm{X}$ & & \\
\hline
\end{tabular}


GENDER REPRESENTATIONS IN ED.D. DISSERTATIONS

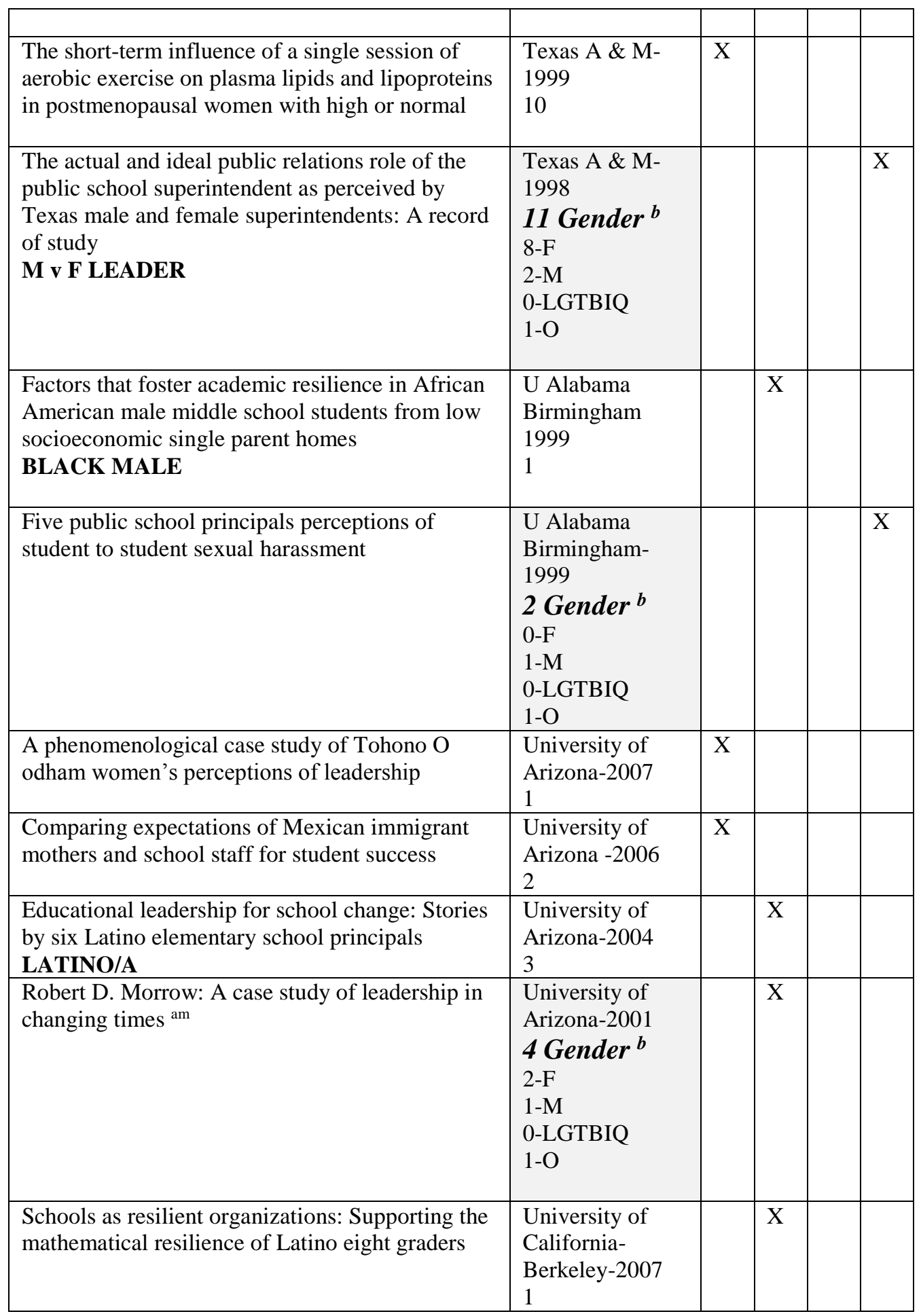




\section{GENDER REPRESENTATIONS IN ED.D. DISSERTATIONS}

\begin{tabular}{|c|c|c|c|c|}
\hline $\begin{array}{l}\text { Effective library education for the inner city } \\
\text { African-American male: Key elements of a } \\
\text { technology based program } \\
\text { BLACK MALE }\end{array}$ & $\begin{array}{l}\text { University of } \\
\text { California- } \\
\text { Berkeley-2005 } \\
2\end{array}$ & & $\mathrm{X}$ & \\
\hline $\begin{array}{l}\text { The gender regime and it's impact on student's } \\
\text { academic performance: An ethnographic study at } \\
\text { a co-educational Catholic High School }\end{array}$ & $\begin{array}{l}\text { University of } \\
\text { California- } \\
\text { Berkeley-2001 } \text { Gender }^{\boldsymbol{b}} \\
\text { 0-F } \\
\text { 2-M } \\
\text { 0-LGTBIQ } \\
\text { 1-O } \\
\end{array}$ & & & $\mathrm{X}$ \\
\hline $\begin{array}{l}\text { Factors that contribute towards and or impede } \\
\text { Hmong women from obtaining a higher education } \\
\text { degree }\end{array}$ & $\begin{array}{l}\text { University of } \\
\text { California- } \\
\text { Davis-2007 } \\
1 \\
\end{array}$ & $X$ & & \\
\hline $\begin{array}{l}\text { Effect of Hispanic national origin on salary } \\
\text { differential for male elementary school principals: } \\
\text { A structural analysis to explore the existence of } \\
\text { implications }\end{array}$ & $\begin{array}{l}\text { University of } \\
\text { California- } \\
\text { Davis-2006 } \\
2 \\
\end{array}$ & & $\mathrm{X}$ & \\
\hline $\begin{array}{l}\text { Successful African-American women: Influence } \\
\text { of personal, family, community and school } \\
\text { factors in overcoming "at risk" situations such as } \\
\text { severe poverty, racism, welfare dependency, teen } \\
\text { motherhood, and hostile school and community } \\
\text { environments }\end{array}$ & $\begin{array}{l}\text { University of } \\
\text { California- } \\
\text { Davis-2005 } \\
3\end{array}$ & $X$ & & \\
\hline $\begin{array}{l}\text { The relationship of stress and gender of university } \\
\text { academic deans to the development of minor and } \\
\text { major illness one year or most post appointment }\end{array}$ & $\begin{array}{l}\text { University of } \\
\text { California- } \\
\text { Davis-2004 } \\
4\end{array}$ & & & $\mathrm{X}$ \\
\hline $\begin{array}{l}\text { Latinos and access to higher education: Factors } \\
\text { that prevent pursuit of a college degree in } \\
\text { California rural San Joaquin Valley } \\
\text { LATINO/A }\end{array}$ & $\begin{array}{l}\text { University of } \\
\text { California- } \\
\text { Davis-2002 } \\
5 \text { Gender } \\
2-\mathrm{F} \\
2-\mathrm{M} \\
0-\mathrm{LGTBIQ} \\
1-0 \\
\end{array}$ & & $\mathrm{X}$ & \\
\hline $\begin{array}{l}\text { Influence of gender identity, families, peers, and } \\
\text { schools on academic success among high school } \\
\text { boys IRVINE \& UCLA }\end{array}$ & $\begin{array}{l}\text { University of } \\
\text { California-LA \& } \\
\text { Irvine-2007 } \\
1 \\
\end{array}$ & & & $\mathrm{X}$ \\
\hline $\begin{array}{l}\text { Meaning to read or reading for meaning: } \\
\text { Promoting reading comprehension proficiency of } \\
\text { Latino English learners IRVINE } \\
\text { LATINO/A }\end{array}$ & $\begin{array}{l}\text { University of } \\
\text { California-LA \& } \\
\text { Irvine }-2007 \\
2\end{array}$ & & $\mathrm{X}$ & \\
\hline $\begin{array}{l}\text { Raising the curtain on theatre arts for Latinos: } \\
\text { Finding voice, cultural capital, literacy, and ethnic }\end{array}$ & $\begin{array}{l}\text { University of } \\
\text { California-LA \& }\end{array}$ & & $X$ & \\
\hline
\end{tabular}




\section{GENDER REPRESENTATIONS IN ED.D. DISSERTATIONS}

\begin{tabular}{|c|c|c|c|c|c|}
\hline $\begin{array}{l}\text { identity in high school arts theatre classes } \\
\text { IRVINE } \\
\text { LATINO/A }\end{array}$ & $\begin{array}{l}\text { Irvine-2007 } \\
3\end{array}$ & & & & \\
\hline $\begin{array}{l}\text { Sally can skip but Jerome can't stomp: } \\
\text { Perceptions practice and school punishment } \\
\text { IRVINE \& UCLA }^{\text {ab }}\end{array}$ & $\begin{array}{l}\text { University of } \\
\text { California-LA \& } \\
\text { Irvine-2007 } \\
4\end{array}$ & & & & $\mathrm{X}$ \\
\hline $\begin{array}{l}\text { Technology and equity: Explaining differences } \\
\text { between elementary teachers use of computers in } \\
\text { low-income Latino and middle class-schools } \\
\text { IRVINE \& UCLA } \\
\text { LATINO/A }\end{array}$ & $\begin{array}{l}\text { University of } \\
\text { California-LA \& } \\
\text { Irvine-2007 } \\
5\end{array}$ & & $X$ & & \\
\hline $\begin{array}{l}\text { Capturing the stories of non-college preparatory } \\
\text { Latina/o high school graduates :reclaiming their } \\
\text { stake in education and their dreams UCLA } \\
\text { LATINO/A }\end{array}$ & $\begin{array}{l}\text { University of } \\
\text { California-LA \& } \\
\text { Irvine-2007 } \\
6\end{array}$ & & & & $\mathrm{X}$ \\
\hline $\begin{array}{l}\text { Gay straight alliances in high schools: A case } \\
\text { study of four urban, public schools UCLA } \\
\text { LGTBIQ } \\
\text { FULL TEXT }\end{array}$ & $\begin{array}{l}\text { University of } \\
\text { California-LA \& } \\
\text { Irvine-2006 } \\
7\end{array}$ & & & $\mathrm{X}$ & \\
\hline $\begin{array}{l}\text { Mi fuerza/my strength: The academic and } \\
\text { personal experiences of Chicana/Latina transfer } \\
\text { students in math and science IRVINE \& UCLA } \\
\text { LATINO/A }\end{array}$ & $\begin{array}{l}\text { University of } \\
\text { California-LA \& } \\
\text { Irvine-2006 } \\
8\end{array}$ & $X$ & & & \\
\hline $\begin{array}{l}\text { The development of social competence within } \\
\text { various classrooms of girls with } \\
\text { emotional/behavioral disorders IRVINE \& UCLA }\end{array}$ & $\begin{array}{l}\text { University of } \\
\text { California-LA \& } \\
\text { Irvine-2006 } \\
9\end{array}$ & $X$ & & & \\
\hline $\begin{array}{l}\text { The road less traveled: Latino students and the } \\
\text { impact of studying abroad UCLA } \\
\text { LATINO/A }\end{array}$ & $\begin{array}{l}\text { University of } \\
\text { California-LA \& } \\
\text { Irvine-2006 } \\
10\end{array}$ & & $\mathrm{X}$ & & \\
\hline $\begin{array}{l}\text { Identifying characteristics of successful schools in } \\
\text { Latino communities IRVINE } \\
\text { LATINO/A }\end{array}$ & $\begin{array}{l}\text { University of } \\
\text { California-LA \& } \\
\text { Irvine-2004 } \\
11\end{array}$ & & $X$ & & \\
\hline $\begin{array}{l}\text { Mothers Instilling Literacy in Kids (M.I.L.K. }{ }^{\mathrm{TM}} \text { ): } \\
\text { A program evaluation IRVINE \&UCLA }\end{array}$ & $\begin{array}{l}\text { University of } \\
\text { California-LA \& } \\
\text { Irvine-2004 } \\
12\end{array}$ & $\mathrm{X}$ & & & \\
\hline $\begin{array}{l}\text { Finding their way: Experiences of first-generation } \\
\text { Latina graduates UCLA } \\
\text { LATINO/A }\end{array}$ & $\begin{array}{l}\text { University of } \\
\text { California-LA \& } \\
\text { Irvine-2004 } \\
13 \\
\end{array}$ & $\mathrm{X}$ & & & \\
\hline $\begin{array}{l}\text { Lending a helping hand: Mentoring tomorrow's } \\
\text { Latina and Latino leaders into the } 21^{\text {st }} \text { century } \\
\text { UCLA } \\
\text { LATINO/A }\end{array}$ & $\begin{array}{l}\text { University of } \\
\text { California-LA \& } \\
\text { Irvine-2004 } \\
14\end{array}$ & & & & $\mathrm{X}$ \\
\hline
\end{tabular}




\section{GENDER REPRESENTATIONS IN ED.D. DISSERTATIONS}

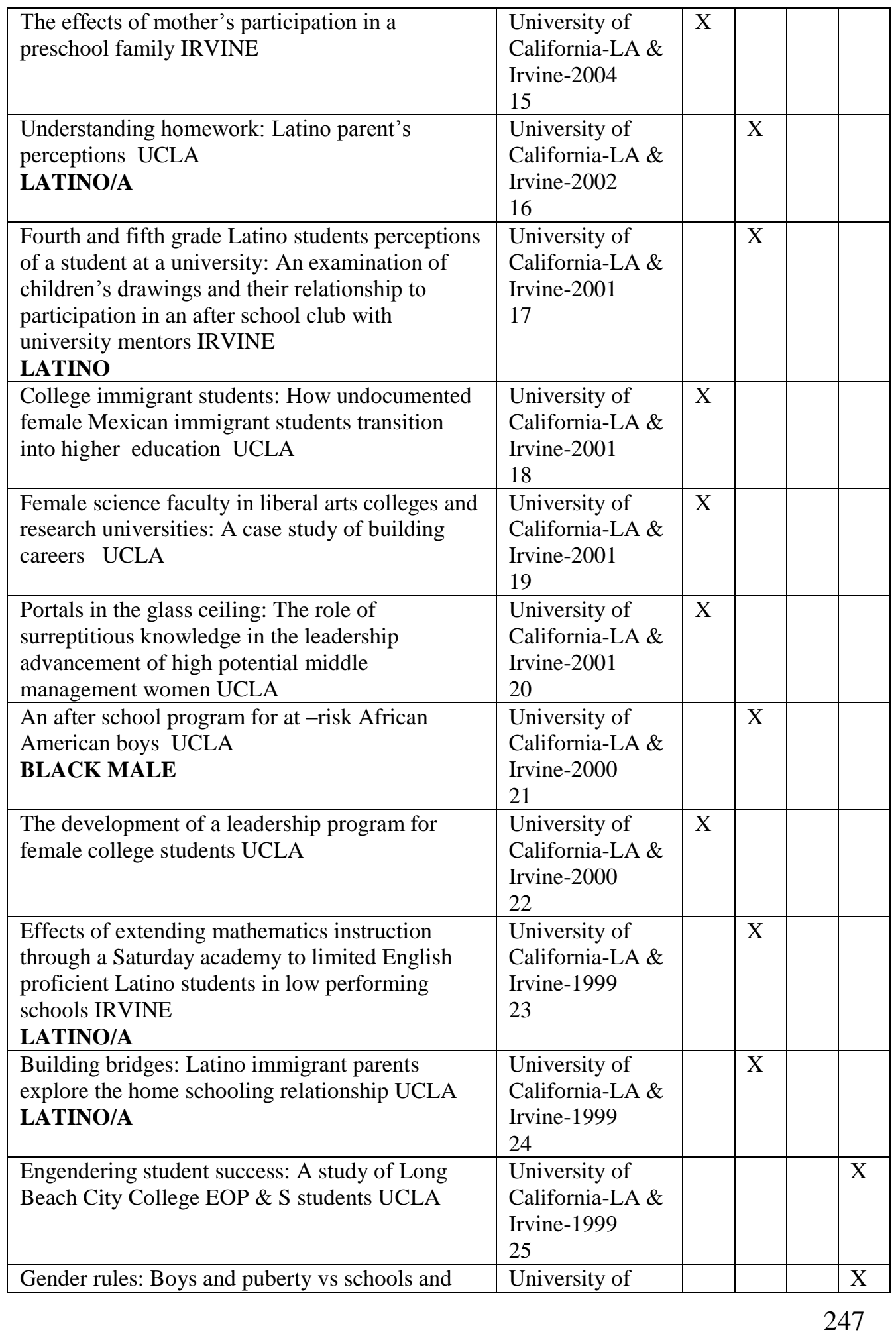




\section{GENDER REPRESENTATIONS IN ED.D. DISSERTATIONS}

\begin{tabular}{|c|c|c|c|c|}
\hline policy UCLA & $\begin{array}{l}\text { California-LA \& } \\
\text { Irvine-1999 } \\
26\end{array}$ & & & \\
\hline $\begin{array}{l}\text { Math enrichment to prepare Latino high school } \\
\text { students for university level mathematics UCLA } \\
\text { LATINO/A }\end{array}$ & $\begin{array}{l}\text { University of } \\
\text { California-LA \& } \\
\text { Irvine-1999 } \\
27\end{array}$ & & $\mathrm{X}$ & \\
\hline $\begin{array}{l}\text { Multimedia computer learning: An examination } \\
\text { of gender differences in computer learning } \\
\text { behaviors at the elementary grade level }\end{array}$ & $\begin{array}{l}\text { University of } \\
\text { California-LA \& } \\
\text { Irvine-1999 } \\
28\end{array}$ & & & $\mathrm{X}$ \\
\hline $\begin{array}{l}\text { A case study in compliance: A practical } \\
\text { application of the Chanda Smith consent decree } \\
\text { UCLA af }\end{array}$ & $\begin{array}{l}\text { University of } \\
\text { California-LA \& } \\
\text { Irvine-1998 } \\
29\end{array}$ & $\mathrm{X}$ & & \\
\hline $\begin{array}{l}\text { A comparison of girls' attitudes towards } \\
\text { mathematics in single-sex and coeducational } \\
\text { independent schools UCLA }\end{array}$ & $\begin{array}{l}\text { University of } \\
\text { California-LA \& } \\
\text { Irvine-1998 } \\
30\end{array}$ & $\mathrm{X}$ & & \\
\hline $\begin{array}{l}\text { Pathways to the California community college } \\
\text { presidency for African-American women UCLA }\end{array}$ & $\begin{array}{l}\text { University of } \\
\text { California-LA \& } \\
\text { Irvine-1998 } \\
\text { 31 Gender }{ }^{\boldsymbol{b}} \\
\text { 12-F } \\
\text { 11-M } \\
\text { 1-L } \\
\text { 7-O }\end{array}$ & $\mathrm{X}$ & & \\
\hline $\begin{array}{l}\text { Brother where art though? An examination of the } \\
\text { under representation of African American male } \\
\text { educators } \\
\text { BLACK MALE }\end{array}$ & $\begin{array}{l}\text { University of } \\
\text { Cincinnati-2006 } \\
1\end{array}$ & & $\mathrm{X}$ & \\
\hline $\begin{array}{l}\text { The experiences of low income women enrolled } \\
\text { in a GED program }\end{array}$ & $\begin{array}{l}\text { University of } \\
\text { Cincinnati-2006 } \\
2\end{array}$ & $\mathrm{X}$ & & \\
\hline $\begin{array}{l}\text { Where do we go from here? Understanding the } \\
\text { impact of racism and its influence on African } \\
\text { American male superintendents } \\
\text { BLACK MALE }\end{array}$ & $\begin{array}{l}\text { University of } \\
\text { Cincinnati-2006 } \\
3\end{array}$ & & $\mathrm{X}$ & \\
\hline $\begin{array}{l}\text { Conversations beyond the text: the influence of } \\
\text { gender and social class on literature circle } \\
\text { conversations }\end{array}$ & $\begin{array}{l}\text { University of } \\
\text { Cincinnati-2005 } \\
4\end{array}$ & & & $\bar{X}$ \\
\hline $\begin{array}{l}\text { Doing science: Lessons learned from the oral } \\
\text { histories of women scientists }\end{array}$ & $\begin{array}{l}\text { University of } \\
\text { Cincinnati-2005 } \\
4\end{array}$ & $\mathrm{X}$ & & \\
\hline $\begin{array}{l}\text { The effect of gender match on beginning teacher } \\
\text { mentoring processes and outcomes }\end{array}$ & $\begin{array}{l}\text { University of } \\
\text { Cincinnati-2005 } \\
6\end{array}$ & & & $\mathrm{X}$ \\
\hline Understanding the needs of rural women with low & University of & $\mathrm{X}$ & & \\
\hline
\end{tabular}




\section{GENDER REPRESENTATIONS IN ED.D. DISSERTATIONS}

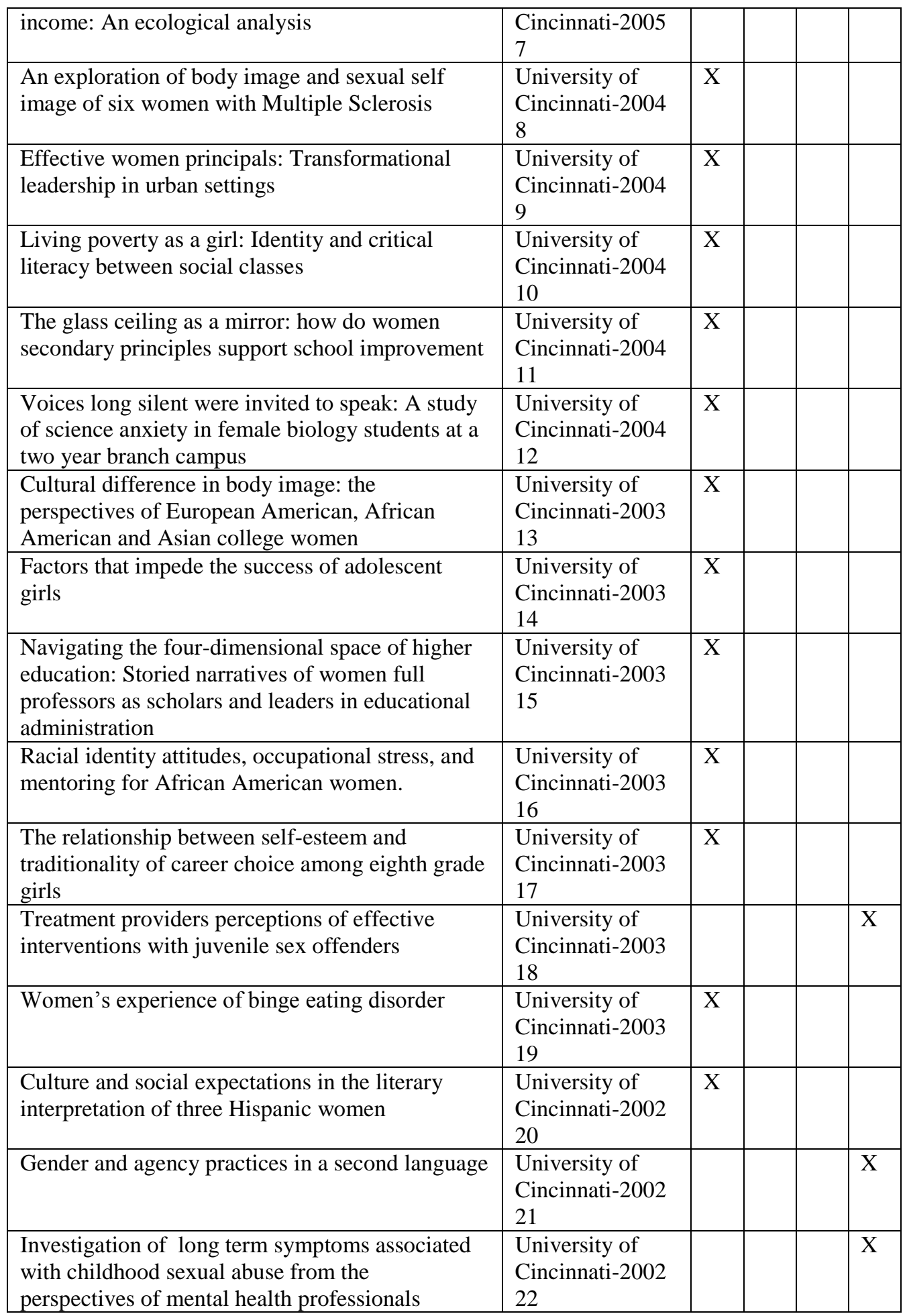




\section{GENDER REPRESENTATIONS IN ED.D. DISSERTATIONS}

\begin{tabular}{|c|c|c|c|c|}
\hline working in the field & & & & \\
\hline $\begin{array}{l}\text { Papa Mamadou: the social construction of } \\
\text { identity and power in the workplace am }\end{array}$ & $\begin{array}{l}\text { University of } \\
\text { Cincinnati-2002 } \\
23\end{array}$ & & $\mathrm{X}$ & \\
\hline $\begin{array}{l}\text { Student's perceptions of factors affecting L2 } \\
\text { writing. Japanese women's cultural identity issues }\end{array}$ & $\begin{array}{l}\text { University of } \\
\text { Cincinnati-2002 } \\
24\end{array}$ & & & \\
\hline $\begin{array}{l}\text { The acquisition of academic self-sufficiency } \\
\text { beliefs of adolescent girls with respect to } \\
\text { mathematics and English: A socio-cultural view }\end{array}$ & $\begin{array}{l}\text { University of } \\
\text { Cincinnati-2002 } \\
25\end{array}$ & $\mathrm{X}$ & & \\
\hline $\begin{array}{l}\text { Write me: A participatory action research project } \\
\text { with urban Appalachian girls }\end{array}$ & $\begin{array}{l}\text { University of } \\
\text { Cincinnati-2002 } \\
26\end{array}$ & $\mathrm{X}$ & & \\
\hline $\begin{array}{l}\text { The co-morbidity of substance abuse and mental } \\
\text { illness diagnosis among delinquent male youth, } \\
\text { its correlates and the interventions that are } \\
\text { typically employed }\end{array}$ & $\begin{array}{l}\text { University of } \\
\text { Cincinnati-2001 } \\
27\end{array}$ & & $\mathrm{X}$ & \\
\hline $\begin{array}{l}\text { A case study of an effective substance abuse } \\
\text { prevention program for adolescent males with } \\
\text { emotional behavioral disorders }\end{array}$ & $\begin{array}{l}\text { University of } \\
\text { Cincinnati-2001 } \\
28\end{array}$ & & $\mathrm{X}$ & \\
\hline Coping styles of women experiencing infertility & $\begin{array}{l}\text { University of } \\
\text { Cincinnati-2001 } \\
29\end{array}$ & $\mathrm{X}$ & & \\
\hline $\begin{array}{l}\text { The influence of upwardly mobile African } \\
\text { American women's racial identity development } \\
\text { on anticipated satisfaction of counseling services }\end{array}$ & $\begin{array}{l}\text { University of } \\
\text { Cincinnati-2001 } \\
30\end{array}$ & $\mathrm{X}$ & & \\
\hline $\begin{array}{l}\text { A study of classroom communication interactions } \\
\text { of a five year old profoundly deaf male }\end{array}$ & $\begin{array}{l}\text { University of } \\
\text { Cincinnati-2000 } \\
31\end{array}$ & & $\mathrm{X}$ & \\
\hline $\begin{array}{l}\text { An examination of the design, implementation } \\
\text { and evaluation of distance education courses at } \\
\text { Raymond Walters College }{ }^{\text {am }}\end{array}$ & $\begin{array}{l}\text { University of } \\
\text { Cincinnati-2000 } \\
32\end{array}$ & & $\mathrm{X}$ & \\
\hline $\begin{array}{l}\text { Interaction discourse used in book reading by } \\
\text { urban Appalachian mothers and their preschool } \\
\text { children }\end{array}$ & $\begin{array}{l}\text { University of } \\
\text { Cincinnati-2000 } \\
33\end{array}$ & $\mathrm{X}$ & & \\
\hline $\begin{array}{l}\text { From welfare to work for African-American } \\
\text { women }\end{array}$ & $\begin{array}{l}\text { University of } \\
\text { Cincinnati-2000 } \\
34\end{array}$ & $\mathrm{X}$ & & \\
\hline $\begin{array}{l}\text { The effect of child gender on maternal scaffolding } \\
\text { during joint book reading }\end{array}$ & $\begin{array}{l}\text { University of } \\
\text { Cincinnati-2000 } \\
35\end{array}$ & & & $\mathrm{X}$ \\
\hline $\begin{array}{l}\text { A comparative study of addicted African } \\
\text { American males in two drug court programs } \\
\text { BLACK MALE }\end{array}$ & $\begin{array}{l}\text { University of } \\
\text { Cincinnati-1999 } \\
36\end{array}$ & & $\mathrm{X}$ & \\
\hline $\begin{array}{l}\text { A descriptive study of the process that occurs } \\
\text { when adolescent African American males are } \\
\text { engaged in the study of multiethnic literature } \\
\text { BLACK MALE }\end{array}$ & $\begin{array}{l}\text { University of } \\
\text { Cincinnati-1999 } \\
37\end{array}$ & & $\mathrm{X}$ & \\
\hline
\end{tabular}




\section{GENDER REPRESENTATIONS IN ED.D. DISSERTATIONS}

\begin{tabular}{|c|c|c|c|c|}
\hline $\begin{array}{l}\text { The game of life: A naturalistic study of } \\
\text { communication patterns of a young boy with } \\
\text { obsessive compulsive disorder, his family and a } \\
\text { friend }\end{array}$ & $\begin{array}{l}\text { University of } \\
\text { Cincinnati-1999 } \\
38\end{array}$ & & $\mathrm{X}$ & \\
\hline $\begin{array}{l}\text { The transformational leadership and educational } \\
\text { philosophic legacy of Malcolm X am }\end{array}$ & $\begin{array}{l}\text { University of } \\
\text { Cincinnati-1999 } \\
39\end{array}$ & & $\mathrm{X}$ & \\
\hline $\begin{array}{l}\text { African-American women in school psychology: } \\
\text { The sociological framework of Black feminist } \\
\text { thought and development of role in practice } \\
\text { FEMINIST }\end{array}$ & $\begin{array}{l}\text { University of } \\
\text { Cincinnati-1998 } \\
40\end{array}$ & $\mathrm{X}$ & & \\
\hline $\begin{array}{l}\text { Against the odds: The educational experiences } \\
\text { and coping strategies of female students in rural } \\
\text { Ethiopia }\end{array}$ & $\begin{array}{l}\text { University of } \\
\text { Cincinnati-1998 } \\
41\end{array}$ & $\mathrm{X}$ & & \\
\hline $\begin{array}{l}\text { A woman leads us: Leadership for reform in } \\
\text { vocational education }\end{array}$ & $\begin{array}{l}\text { University of } \\
\text { Cincinnati-1998 } \\
42\end{array}$ & $\mathrm{X}$ & & \\
\hline $\begin{array}{l}\text { Mother's perceptions of children's early } \\
\text { educational experiences : A comparison of } \\
\text { children with and without disabilities }\end{array}$ & $\begin{array}{l}\text { University of } \\
\text { Cincinnati-1998 } \\
43\end{array}$ & $\mathrm{X}$ & & \\
\hline $\begin{array}{l}\text { Program evaluation of group treatment of } \\
\text { sexually abused children }\end{array}$ & $\begin{array}{l}\text { University of } \\
\text { Cincinnati-1998 } \\
44\end{array}$ & & & $\mathrm{X}$ \\
\hline $\begin{array}{l}\text { Resilience and agency : A case study of a cohort } \\
\text { of older post-baccalaureate women in an teacher } \\
\text { education program }\end{array}$ & $\begin{array}{l}\text { University of } \\
\text { Cincinnati-1998 } \\
45\end{array}$ & $X$ & & \\
\hline $\begin{array}{l}\text { The effects of socialization on African-American } \\
\text { women's decision to pursue a doctoral degree }\end{array}$ & $\begin{array}{l}\text { University of } \\
\text { Cincinnati-1998 } \\
46\end{array}$ & $\mathrm{X}$ & & \\
\hline $\begin{array}{l}\text { The portrayal of women on social studies and } \\
\text { history textbooks used in Botswana }\end{array}$ & $\begin{array}{l}\text { University of } \\
\text { Cincinnati-1998 } \\
47\end{array}$ & $\mathrm{X}$ & & \\
\hline $\begin{array}{l}\text { The relationship between father and father } \\
\text { figures, the level of criminality, response to } \\
\text { residential treatment, and other measures of } \\
\text { adjustment in adolescent male offenders }\end{array}$ & $\begin{array}{l}\text { University of } \\
\text { Cincinnati-1998 } \\
48\end{array}$ & & $\mathrm{X}$ & \\
\hline $\begin{array}{l}\text { The rhetoric and ideology of multicultural } \\
\text { education :Responses to Arthur M. Schlesinger, } \\
\text { Jr. am }\end{array}$ & $\begin{array}{l}\text { University of } \\
\text { Cincinnati-1998 } \\
49\end{array}$ & & $\mathrm{X}$ & \\
\hline $\begin{array}{l}\text { Urban Appalachian women: Changing the } \\
\text { barriers of oppression through re-entry education }\end{array}$ & $\begin{array}{l}\text { University of } \\
\text { Cincinnati-1998 } \\
50\end{array}$ & $\mathrm{X}$ & & \\
\hline Women in science: What keeps them interested? & $\begin{array}{l}\text { University of } \\
\text { Cincinnati-1998 } \\
51\end{array}$ & $\mathrm{X}$ & & \\
\hline $\begin{array}{l}\text { Women's perceptions of alcoholism treatment } \\
\text { experiences in federally subsidized residential } \\
\text { programs }\end{array}$ & $\begin{array}{l}\text { University of } \\
\text { Cincinnati-1998 } \\
52 \text { Gender }^{\boldsymbol{b}}\end{array}$ & $\mathrm{X}$ & & \\
\hline
\end{tabular}


GENDER REPRESENTATIONS IN ED.D. DISSERTATIONS

\begin{tabular}{|c|c|c|c|c|}
\hline & $\begin{array}{l}\text { 32-F } \\
\text { 13-M } \\
0-\text { LGTBIQ } \\
7-\mathrm{O}\end{array}$ & & & \\
\hline-0 - gender found $6 / 15 / 2010$ & $\begin{array}{l}\text { University of } \\
\text { Connecticut } \\
\text { 0 Gender } \boldsymbol{b} \\
\text { 0-F } \\
\text { 0-M } \\
\text { 0-LGTBIQ } \\
\text { 0-O }\end{array}$ & & & $\begin{array}{l}\mathrm{N} \\
\mathrm{A}\end{array}$ \\
\hline $\begin{array}{l}\text { A review of Rowan University's William G. } \\
\text { Rohrer College of Business academic review } \\
\text { process am }\end{array}$ & $\begin{array}{l}\text { University of } \\
\text { Delaware-2007 } \\
1\end{array}$ & & $\mathrm{X}$ & \\
\hline $\begin{array}{l}\text { Designing performance objectives to improve } \\
\text { English language proficiency: Conceptualizing a } \\
\text { call-integrated listening curriculum at Delaware } \\
\text { Technical and Community College, Jack F. } \\
\text { Owens Campus am }\end{array}$ & $\begin{array}{l}\text { University of } \\
\text { Delaware-2007 } \\
2\end{array}$ & & $\mathrm{X}$ & \\
\hline $\begin{array}{l}\text { High risk drinking among female athletes at the } \\
\text { University of Delaware: Reducing risk through } \\
\text { intervention }\end{array}$ & $\begin{array}{l}\text { University of } \\
\text { Delaware-2007 } \\
3\end{array}$ & $\mathrm{X}$ & & \\
\hline $\begin{array}{l}\text { Implementing Universal Design for Instruction } \\
\text { (UDI) principles to maximize learning for } \\
\text { students with disabilities at the Jack F. Owens } \\
\text { campus of Delaware Technical and Community } \\
\text { College am }\end{array}$ & $\begin{array}{l}\text { University of } \\
\text { Delaware-2007 } \\
4\end{array}$ & & $\mathrm{X}$ & \\
\hline $\begin{array}{l}\text { The development of an associate degree in } \\
\text { entrepreneurship at Delaware Technical and } \\
\text { Community College Jack F. Owens Campus } \\
\text { Business Administration Technology am }\end{array}$ & $\begin{array}{l}\text { University of } \\
\text { Delaware-2007 } \\
5\end{array}$ & & $\mathrm{X}$ & \\
\hline $\begin{array}{l}\text { The non-graduation of seniors at William Penn } \\
\text { High School am }\end{array}$ & $\begin{array}{l}\text { University of } \\
\text { Delaware-2007 } \\
6\end{array}$ & & $\mathrm{X}$ & \\
\hline $\begin{array}{l}\text { Academic integrity's impact on via the use of an } \\
\text { honor code at St. Thomas More Academy am }\end{array}$ & $\begin{array}{l}\text { University of } \\
\text { Delaware-2005 } \\
7\end{array}$ & & $\mathrm{X}$ & \\
\hline $\begin{array}{l}\text { A program audit of the John S. Charlton Program } \\
\text { in Delaware for students with autism and mental } \\
\text { disabilities am }\end{array}$ & $\begin{array}{l}\text { University of } \\
\text { Delaware-2005 } \\
8\end{array}$ & & $\mathrm{X}$ & \\
\hline $\begin{array}{l}\text { Improving writing instruction at Lulu Ross } \\
\text { Elementary, Milford School District af }\end{array}$ & $\begin{array}{l}\text { University of } \\
\text { Delaware }-2004 \\
9\end{array}$ & $\mathrm{X}$ & & \\
\hline $\begin{array}{l}\text { Integrating genetics content in nursing education } \\
\text { at Delaware Technical and Community College } \\
\text { Jack F. Owens Campus am }\end{array}$ & $\begin{array}{l}\text { University of } \\
\text { Delaware }-2004 \\
10\end{array}$ & & $\mathrm{X}$ & \\
\hline $\begin{array}{l}\text { Life in the blue room: A study of the Severely At- } \\
\text { Risk program at Caesar Rodney High School am }\end{array}$ & $\begin{array}{l}\text { University of } \\
\text { Delaware }-2003\end{array}$ & & $\mathrm{X}$ & \\
\hline
\end{tabular}


GENDER REPRESENTATIONS IN ED.D. DISSERTATIONS

\begin{tabular}{|c|c|c|c|c|}
\hline & 11 & & & \\
\hline $\begin{array}{l}\text { Coming to voice: Discourses identities and } \\
\text { achievement among women of color in the } \\
\text { community of college }\end{array}$ & \begin{tabular}{|l|} 
University of \\
Delaware -1998 \\
12
\end{tabular} & $\mathrm{X}$ & & \\
\hline $\begin{array}{l}\text { Teams on paper: Title IX compliance in the } \\
\text { Maryland Junior College Athletic Conference } \\
\text { TITLE IX }\end{array}$ & \begin{tabular}{|l|} 
University of \\
Delaware-1998 \\
13 Gender $\boldsymbol{b}^{-}$ \\
3-F \\
9-M \\
0-LGTBIQ \\
1-O
\end{tabular} & & & $\mathrm{X}$ \\
\hline $\begin{array}{l}\text { The mentoring experience for women leaders in } \\
\text { Florida's community colleges }\end{array}$ & \begin{tabular}{|l} 
University of \\
Florida-2003 \\
1
\end{tabular} & $\mathrm{X}$ & & \\
\hline $\begin{array}{l}\text { Incident rates of sexual harassment of female } \\
\text { instructional staff members in the Florida } \\
\text { community college system }\end{array}$ & $\begin{array}{l}\text { University of } \\
\text { Florida-1999 } \\
\text { 2 Gender } \boldsymbol{b} \\
\text { 2-F } \\
\text { 0-M } \\
\text { 0-LGTBIQ } \\
\text { 0-O }\end{array}$ & $\mathrm{X}$ & & \\
\hline $\begin{array}{l}\text { Learning and schooling experiences of Black, } \\
\text { deaf and hard-of-hearing adult male learners: A } \\
\text { narrative analysis } \\
\text { BLACK MALE }\end{array}$ & $\begin{array}{l}\text { University of } \\
\text { Georgia -2003 } \\
1\end{array}$ & & $\mathrm{X}$ & \\
\hline $\begin{array}{l}\text { The role of pop culture in the self development of } \\
\text { midlife women }\end{array}$ & $\begin{array}{l}\text { University of } \\
\text { Georgia-2003 } \\
2\end{array}$ & $\mathrm{X}$ & & \\
\hline $\begin{array}{l}\text { Comparing theories and practices of Tyler and } \\
\text { Dewey with expert and effective teaching today } \\
\text { am }\end{array}$ & $\begin{array}{l}\text { University of } \\
\text { Georgia }-2003 \\
3\end{array}$ & & $\mathrm{X}$ & \\
\hline $\begin{array}{l}\text { Negotiating feminist interests in elementary and } \\
\text { secondary schools } \\
\text { FEMINIST }\end{array}$ & $\begin{array}{l}\text { University of } \\
\text { Georgia }-2002 \\
4\end{array}$ & $\mathrm{X}$ & & \\
\hline $\begin{array}{l}\text { The silent voices of those who care: Cultural } \\
\text { learning of older, Black women caregivers of } \\
\text { Alzheimers family members }\end{array}$ & \begin{tabular}{|l} 
University of \\
Georgia-2002 \\
5
\end{tabular} & $\mathrm{X}$ & & \\
\hline $\begin{array}{l}\text { Marion Jennings Rice, philosophy and praxis: the } \\
\text { professional biography of a Georgia educator af }\end{array}$ & \begin{tabular}{|l} 
University of \\
Georgia-2001 \\
6
\end{tabular} & $\mathrm{X}$ & & \\
\hline $\begin{array}{l}\text { How can I make it here: The adaptation to rural } \\
\text { American life by Lao refugee women }\end{array}$ & $\begin{array}{l}\text { University of } \\
\text { Georgia-2000 } \\
7\end{array}$ & $\mathrm{X}$ & & \\
\hline $\begin{array}{l}\text { Influence of gender and power relationships } \\
\text { among human resource development managers }\end{array}$ & $\begin{array}{l}\text { University of } \\
\text { Georgia }-2000 \\
8\end{array}$ & & & $\mathrm{X}$ \\
\hline Playing the hand you are dealt: An investigator of & University of & $\mathrm{X}$ & & \\
\hline
\end{tabular}




\section{GENDER REPRESENTATIONS IN ED.D. DISSERTATIONS}

\begin{tabular}{|c|c|c|c|c|c|}
\hline $\begin{array}{l}\text { the classroom encounters of professional Black } \\
\text { women and the strategies they used to ensure a } \\
\text { successful academic experience }\end{array}$ & $\begin{array}{l}\text { Georgia-2000 } \\
9\end{array}$ & & & & \\
\hline Portraits of young women becoming teachers & $\begin{array}{l}\text { University of } \\
\text { Georgia-2000 } \\
10\end{array}$ & $\mathrm{X}$ & & & \\
\hline $\begin{array}{l}\text { Urban cowgirls: How lesbians learn to negotiate } \\
\text { the heterosexism of corporate American } \\
\text { LGTBIQ }\end{array}$ & $\begin{array}{l}\text { University of } \\
\text { Georgia-2000 } \\
11\end{array}$ & & & $\mathrm{X}$ & \\
\hline $\begin{array}{l}\text { A case study of introductory courses in twelve } \\
\text { women's studies programs in the Southeast } \\
\text { United States }\end{array}$ & $\begin{array}{l}\text { University of } \\
\text { Georgia-1999 } \\
12\end{array}$ & $\mathrm{X}$ & & & \\
\hline $\begin{array}{l}\text { An investigation of the learning styles of ninth } \\
\text { grade public school students: Black and white, } \\
\text { male and female, general level and gifted, magnet }\end{array}$ & $\begin{array}{l}\text { University of } \\
\text { Georgia-1999 } \\
13\end{array}$ & & & & $\mathrm{X}$ \\
\hline $\begin{array}{l}\text { The nature of career development for women who } \\
\text { telecommute }\end{array}$ & $\begin{array}{l}\text { University of } \\
\text { Georgia-1999 } \\
14\end{array}$ & $\mathrm{X}$ & & & \\
\hline $\begin{array}{l}\text { Title IX compliance and Georgia high school } \\
\text { athletic programs } \\
\text { TITLE IX }\end{array}$ & $\begin{array}{l}\text { University of } \\
\text { Georgia-1999 } \\
15\end{array}$ & & & & $\mathrm{X}$ \\
\hline $\begin{array}{l}\text { Weathered by their experiences: Black women } \\
\text { returning to RN completion programs }\end{array}$ & $\begin{array}{l}\text { University of } \\
\text { Georgia-1999 } \\
16\end{array}$ & $\mathrm{X}$ & & & \\
\hline $\begin{array}{l}\text { Living outside the circle: the politics of } \\
\text { HIV/AIDS education and the disenfranchisement } \\
\text { of HIV-negative gay men } \\
\text { LGTBIQ }\end{array}$ & $\begin{array}{l}\text { University of } \\
\text { Georgia-1999 } \\
17\end{array}$ & & & $\mathrm{X}$ & \\
\hline $\begin{array}{l}\text { Two male early childhood teachers perspectives } \\
\text { on their occupational specialty and caring: A } \\
\text { cross-national ethnographic case study }\end{array}$ & $\begin{array}{l}\text { University of } \\
\text { Georgia-1998 } \\
18\end{array}$ & & $\mathrm{X}$ & & \\
\hline Women high school band directors in Georgia & $\begin{array}{l}\text { University of } \\
\text { Georgia-1998 } \\
\text { 19 Gender }{ }^{b} \\
\text { 11-F } \\
\text { 3-M } \\
\text { 2-LGTBIQ } \\
\text { 3-O }\end{array}$ & $\mathrm{X}$ & & & \\
\hline $\begin{array}{l}\text { A comparative study of the impact on academic } \\
\text { and psychosocial development of eighth-grade } \\
\text { students involved in single-gender versus co- } \\
\text { educational classroom settings }\end{array}$ & $\begin{array}{l}\text { University of } \\
\text { Kansas-2006 } \\
1\end{array}$ & & & & $\mathrm{X}$ \\
\hline $\begin{array}{l}\text { Relationship between training approaches and } \\
\text { resident assistant's acceptance of rape myths, and } \\
\text { empathy towards rape victims and perpetrators }\end{array}$ & $\begin{array}{l}\text { University of } \\
\text { Kansas - } 2005 \\
2\end{array}$ & & & & $\mathrm{X}$ \\
\hline Effects of nutrition education and body image & University of & $\mathrm{X}$ & & & \\
\hline
\end{tabular}




\section{GENDER REPRESENTATIONS IN ED.D. DISSERTATIONS}

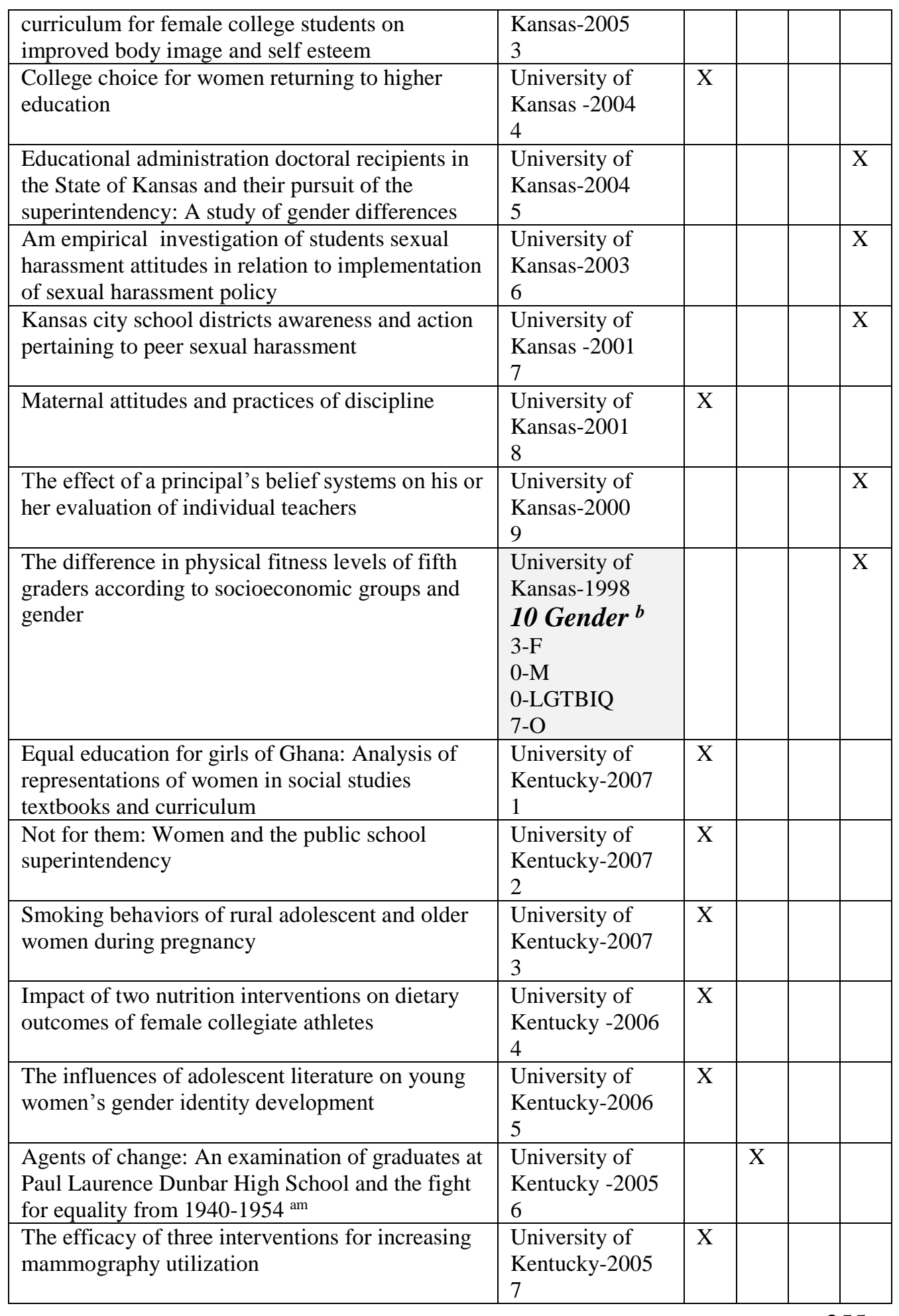




\section{GENDER REPRESENTATIONS IN ED.D. DISSERTATIONS}

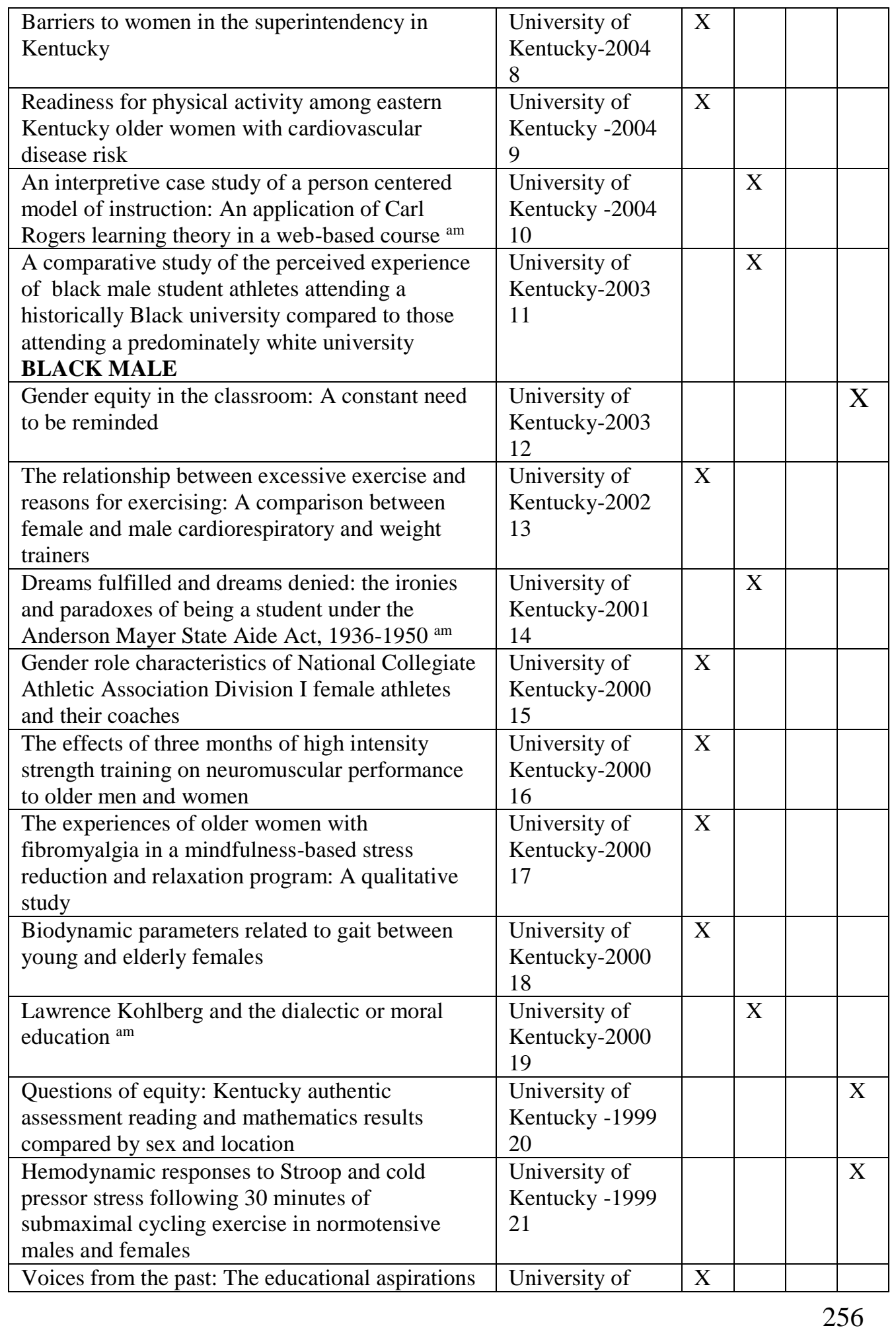




\section{GENDER REPRESENTATIONS IN ED.D. DISSERTATIONS}

\begin{tabular}{|c|c|c|c|c|}
\hline $\begin{array}{l}\text { and role identities of white Kentucky farm } \\
\text { women } 1920-1940\end{array}$ & $\begin{array}{l}\text { Kentucky-1999 } \\
22\end{array}$ & & & \\
\hline $\begin{array}{l}\text { Daring compassion: A case study of culturally } \\
\text { responsive pedagogy on a women's college } \\
\text { campus }\end{array}$ & $\begin{array}{l}\text { University of } \\
\text { Kentucky-1998 } \\
23\end{array}$ & $X$ & & \\
\hline $\begin{array}{l}\text { "That's not who I am": Contested definitions of } \\
\text { single motherhood }\end{array}$ & $\begin{array}{l}\text { University of } \\
\text { Kentucky }-1998 \\
24\end{array}$ & $X$ & & \\
\hline $\begin{array}{l}\text { The biomechanical effects of acute fatigue to the } \\
\text { lower extremity in female Kentucky high school } \\
\text { cheerleaders }\end{array}$ & $\begin{array}{l}\text { University of } \\
\text { Kentucky -1998 } \\
\text { 25 Gender }{ }^{\boldsymbol{b}} \\
\text { 17-F } \\
\text { 5-M } \\
\text { 0-LGTBIQ } \\
\text { 3-O }\end{array}$ & $\bar{X}$ & & \\
\hline $\begin{array}{l}\text { A narrative analysis of four African American } \\
\text { women's work experiences across four diverse } \\
\text { fields and meaning constructed at the intersection } \\
\text { of race and gender }\end{array}$ & $\begin{array}{l}\text { University of } \\
\text { Maryland-2007 } \\
1\end{array}$ & $\mathrm{X}$ & & \\
\hline $\begin{array}{l}\text { Exploring the relationship between personal } \\
\text { motivation, persistence, and resilience and their } \\
\text { effects on academic achievement among different } \\
\text { groups of African-American males in high school } \\
\text { BLACK MALE }\end{array}$ & $\begin{array}{l}\text { University of } \\
\text { Maryland }-2005 \\
2\end{array}$ & & $X$ & \\
\hline $\begin{array}{l}\text { An inquiry into the leadership orientations of } \\
\text { selected women school superintendents }\end{array}$ & $\begin{array}{l}\text { University of } \\
\text { Maryland -1998 } \\
\mathbf{3} \text { Gender }^{\boldsymbol{b}} \\
\text { 2-F } \\
\text { 1-M } \\
\text { 0-LGTBIQ } \\
\text { 0-O }\end{array}$ & $\mathrm{X}$ & & \\
\hline $\begin{array}{l}\text { Pathways to success in science: A } \\
\text { phenomenological study examining the life } \\
\text { experiences of African American women in } \\
\text { higher education }\end{array}$ & $\begin{array}{l}\text { University of } \\
\text { Massachusetts- } \\
\text { Amherst-2007 } \\
1\end{array}$ & $\mathrm{X}$ & & \\
\hline $\begin{array}{l}\text { "Ms. Cowey, I have a text to world connection." } \\
\text { Gabriell, first grade: Critical intertextuality in a } \\
\text { multicultural first grade classroom af }\end{array}$ & $\begin{array}{l}\text { University of } \\
\text { Massachusetts- } \\
\text { Amherst-2007 } \\
2\end{array}$ & $\mathrm{X}$ & & \\
\hline $\begin{array}{l}\text { Navigating bridges and barriers: A case study of } \\
\text { the James Baldwin Scholars program am }\end{array}$ & $\begin{array}{l}\text { University of } \\
\text { Massachusetts- } \\
\text { Amherst-2007 } \\
3\end{array}$ & & $X$ & \\
\hline $\begin{array}{l}\text { Perspectives on learning in the women's } \\
\text { economic and empowerment literacy program in } \\
\text { Nepal }\end{array}$ & $\begin{array}{l}\text { University of } \\
\text { Massachusetts- } \\
\text { Amherst-2007 } \\
4\end{array}$ & $\mathrm{X}$ & & \\
\hline
\end{tabular}




\section{GENDER REPRESENTATIONS IN ED.D. DISSERTATIONS}

\begin{tabular}{|c|c|c|c|c|c|}
\hline $\begin{array}{l}\text { Recruiting teachers of color: College age Latino/a } \\
\text { students share their voices and recommendations } \\
\text { for educator preparation programs } \\
\text { LATINO/A }\end{array}$ & $\begin{array}{l}\text { University of } \\
\text { Massachusetts- } \\
\text { Amherst }-2007 \\
5\end{array}$ & & & & $\mathrm{X}$ \\
\hline $\begin{array}{l}\text { Sisters in the struggle: Individual and } \\
\text { institutionalized factors effecting the persistence } \\
\text { of black female doctoral students at United Sates } \\
\text { predominately white institutions }\end{array}$ & $\begin{array}{l}\text { University of } \\
\text { Massachusetts- } \\
\text { Amherst-2007 } \\
6\end{array}$ & $\mathrm{X}$ & & & \\
\hline $\begin{array}{l}\text { Tibetan women and higher educational } \\
\text { experience: An exploratory study }\end{array}$ & $\begin{array}{l}\text { University of } \\
\text { Massachusetts- } \\
\text { Amherst -2007 } \\
7\end{array}$ & $\mathrm{X}$ & & & \\
\hline $\begin{array}{l}\text { Unexpected transitions moving beyond barriers: } \\
\text { Successful strategies of female technology } \\
\text { education leaders }\end{array}$ & $\begin{array}{l}\text { University of } \\
\text { Massachusetts- } \\
\text { Amherst-2007 } \\
8\end{array}$ & $\mathrm{X}$ & & & \\
\hline $\begin{array}{l}\text { Women's ways of drinking: College women, high } \\
\text { risk alcohol use and related consequences }\end{array}$ & $\begin{array}{l}\text { University of } \\
\text { Massachusetts- } \\
\text { Amherst-2007 } \\
9\end{array}$ & $\mathrm{X}$ & & & \\
\hline $\begin{array}{l}\text { Voices of rural women in Nepal: Impact of } \\
\text { literacy on the lives of women }\end{array}$ & $\begin{array}{l}\text { University of } \\
\text { Massachusetts- } \\
\text { Amherst }-2006 \\
10\end{array}$ & $\mathrm{X}$ & & & \\
\hline $\begin{array}{l}\text { Strangers in good company: The accuracy of } \\
\text { student's perception of peer attitudes towards } \\
\text { gays, lesbians and bisexuals } \\
\text { LGTBIQ }\end{array}$ & $\begin{array}{l}\text { University of } \\
\text { Massachusetts- } \\
\text { Amherst -2006 } \\
11\end{array}$ & & & $\mathrm{X}$ & \\
\hline $\begin{array}{l}\text { A comparison of boys and girls diagnosed with } \\
\text { oppositional defiant disorder in a public school } \\
\text { counseling program }\end{array}$ & $\begin{array}{l}\text { University of } \\
\text { Massachusetts- } \\
\text { Amherst }-2005 \\
12\end{array}$ & & & & $\mathrm{X}$ \\
\hline $\begin{array}{l}\text { Representin' for Latino students: Culturally } \\
\text { responsive pedagogies, teacher identities, and the } \\
\text { preparation of teachers for urban schools } \\
\text { LATINO/A }\end{array}$ & $\begin{array}{l}\text { University of } \\
\text { Massachusetts- } \\
\text { Amherst }-2005 \\
13\end{array}$ & & $X$ & & \\
\hline $\begin{array}{l}\text { The psychodynamics of white racism: an } \\
\text { historical exploration of white racial pathology as } \\
\text { elicited by prizefighters Jack Johnson and } \\
\text { Mohammed Ali am }\end{array}$ & $\begin{array}{l}\text { University of } \\
\text { Massachusetts- } \\
\text { Amherst }-2005 \\
14\end{array}$ & & $\mathrm{X}$ & & \\
\hline $\begin{array}{l}\text { Literacy and numeracy practices of market } \\
\text { women of Quetzaltenango, Guatemala }\end{array}$ & $\begin{array}{l}\text { University of } \\
\text { Massachusetts- } \\
\text { Amherst }-2005 \\
15\end{array}$ & $X$ & & & \\
\hline $\begin{array}{l}\text { Math stories: Troublesum relationships. A study } \\
\text { of the importance of relationships on women's } \\
\text { achievement in math at a rural community college }\end{array}$ & $\begin{array}{l}\text { University of } \\
\text { Massachusetts- } \\
\text { Amherst }-2005 \\
16\end{array}$ & $\mathrm{X}$ & & & \\
\hline
\end{tabular}




\section{GENDER REPRESENTATIONS IN ED.D. DISSERTATIONS}

\begin{tabular}{|c|c|c|c|c|c|}
\hline $\begin{array}{l}\text { Meiji maiden: Umeko Ysuda and the founding of } \\
\text { higher education for women in Japan af }\end{array}$ & $\begin{array}{l}\text { University of } \\
\text { Massachusetts- } \\
\text { Amherst }-2005 \\
17\end{array}$ & $\mathrm{X}$ & & & \\
\hline $\begin{array}{l}\text { Prepared for complexity: Multicultural women } \\
\text { teaching English as a second language }\end{array}$ & $\begin{array}{l}\text { University of } \\
\text { Massachusetts- } \\
\text { Amherst }-2005 \\
18\end{array}$ & $X$ & & & \\
\hline $\begin{array}{l}\text { Teachers who are mothers: Perceptions of } \\
\text { concurrent career and parenthood roles }\end{array}$ & $\begin{array}{l}\text { University of } \\
\text { Massachusetts- } \\
\text { Amherst-2005 } \\
19\end{array}$ & $\mathrm{X}$ & & & \\
\hline $\begin{array}{l}\text { The influence of mentoring in dyadic } \\
\text { relationships on the leadership development of } \\
\text { women college presidents }\end{array}$ & $\begin{array}{l}\text { University of } \\
\text { Massachusetts- } \\
\text { Amherst-2005 } \\
20\end{array}$ & $\mathrm{X}$ & & & \\
\hline $\begin{array}{l}\text { The intergenerational transmission of educational } \\
\text { values from working class mothers to their } \\
\text { adolescent daughters in two western } \\
\text { Massachusetts mill towns }\end{array}$ & $\begin{array}{l}\text { University of } \\
\text { Massachusetts- } \\
\text { Amherst-2005 } \\
21\end{array}$ & $\mathrm{X}$ & & & \\
\hline $\begin{array}{l}\text { Voices from the field: Auxiliary nurse-midwives } \\
\text { in Nepal }\end{array}$ & $\begin{array}{l}\text { University of } \\
\text { Massachusetts- } \\
\text { Amherst-2004 } \\
22\end{array}$ & $\mathrm{X}$ & & & \\
\hline $\begin{array}{l}\text { Listening to the voices of inner city, low income, } \\
12^{\text {th }} \text { grade, Black males: A phenomenological } \\
\text { study if their educational experiences } \\
\text { BLACK MALE }\end{array}$ & $\begin{array}{l}\text { University of } \\
\text { Massachusetts- } \\
\text { Amherst-2004 } \\
23\end{array}$ & & $X$ & & \\
\hline $\begin{array}{l}\text { Problems and possibilities: The complexities of } \\
\text { accessing higher education for Puerto Rican } \\
\text { women in the United States }\end{array}$ & $\begin{array}{l}\text { University of } \\
\text { Massachusetts- } \\
\text { Amherst-2004 } \\
24\end{array}$ & $\mathrm{X}$ & & & \\
\hline $\begin{array}{l}\text { Boy, walk with a purpose: a postmodern study of } \\
\text { the conversation between the discourses of } \\
\text { secondary English education }\end{array}$ & $\begin{array}{l}\text { University of } \\
\text { Massachusetts- } \\
\text { Amherst-2003 } \\
25\end{array}$ & & $X$ & & \\
\hline $\begin{array}{l}\text { Off that spectrum entirely: A study of female- } \\
\text { bodied transgendered-identified individuals } \\
\text { LGTBIQ }\end{array}$ & $\begin{array}{l}\text { University of } \\
\text { Massachusetts- } \\
\text { Amherst-2003 } \\
26\end{array}$ & & & $\mathrm{X}$ & \\
\hline $\begin{array}{l}\text { Quantitative evaluation of gender differences, } \\
\text { cognitive development differences and software } \\
\text { effectiveness for an elementary mathematics } \\
\text { intelligent tutoring system }\end{array}$ & $\begin{array}{l}\text { University of } \\
\text { Massachusetts- } \\
\text { Amherst-2003 } \\
27\end{array}$ & & & & $\mathrm{X}$ \\
\hline $\begin{array}{l}\text { Sudanese refugee women becoming activists: The } \\
\text { role of popular education }\end{array}$ & $\begin{array}{l}\text { University of } \\
\text { Massachusetts- } \\
\text { Amherst-2003 } \\
28\end{array}$ & $\mathrm{X}$ & & & \\
\hline
\end{tabular}




\section{GENDER REPRESENTATIONS IN ED.D. DISSERTATIONS}

\begin{tabular}{|c|c|c|c|c|}
\hline $\begin{array}{l}\text { The adoptive parenting process: A study of the } \\
\text { experiences of parents who adopt infant girls } \\
\text { from China }\end{array}$ & $\begin{array}{l}\text { University of } \\
\text { Massachusetts- } \\
\text { Amherst-2003 } \\
29\end{array}$ & $\mathrm{X}$ & & \\
\hline $\begin{array}{l}\text { The journey of Latinas in undergraduate schools } \\
\text { of nursing: Roadblocks and bridges } \\
\text { LATINO/A }\end{array}$ & $\begin{array}{l}\text { University of } \\
\text { Massachusetts- } \\
\text { Amherst-2003 } \\
30\end{array}$ & $\mathrm{X}$ & & \\
\hline $\begin{array}{l}\text { Assessing changes in bystander intervention: the } \\
\text { impact of an undergraduate educational program } \\
\text { on peer sexual harassment }\end{array}$ & $\begin{array}{l}\text { University of } \\
\text { Massachusetts- } \\
\text { Amherst-2002 } \\
31\end{array}$ & & & $X$ \\
\hline $\begin{array}{l}\text { Making science accessible through collaborative } \\
\text { science teacher action research on feminist } \\
\text { pedagogy } \\
\text { FEMINIST }\end{array}$ & $\begin{array}{l}\text { University of } \\
\text { Massachusetts- } \\
\text { Amherst-2002 } \\
32\end{array}$ & & & $\mathrm{X}$ \\
\hline $\begin{array}{l}\text { Contributions of friendship: The variability in the } \\
\text { experiences of early adolescents with opposite- } \\
\text { sex friendships }\end{array}$ & $\begin{array}{l}\text { University of } \\
\text { Massachusetts- } \\
\text { Amherst-2002 } \\
33\end{array}$ & & & $\mathrm{X}$ \\
\hline $\begin{array}{l}\text { Neonatal behavior and maternal representations } \\
\text { over the first month postpartum: A short-term } \\
\text { longitudinal study with Puerto Rican infants and } \\
\text { their mothers }\end{array}$ & $\begin{array}{l}\text { University of } \\
\text { Massachusetts- } \\
\text { Amherst-2002 } \\
34\end{array}$ & $\mathrm{X}$ & & \\
\hline $\begin{array}{l}\text { Perceptions of Black male students and their } \\
\text { parents about the academic achievement gap } \\
\text { between Black and white students at the } \\
\text { elementary school level }\end{array}$ & $\begin{array}{l}\text { University of } \\
\text { Massachusetts- } \\
\text { Amherst-2002 } \\
35\end{array}$ & & $X$ & \\
\hline $\begin{array}{l}\text { Unheard voices: Toward a therapy of liberation. } \\
\text { Six low income Puerto Rican migrant women tell } \\
\text { their stories }\end{array}$ & $\begin{array}{l}\text { University of } \\
\text { Massachusetts- } \\
\text { Amherst-2002 } \\
36\end{array}$ & $X$ & & \\
\hline $\begin{array}{l}\text { The natural context of mother-toddler play } \\
\text { interactions in a rural Nepali community }\end{array}$ & $\begin{array}{l}\text { University of } \\
\text { Massachusetts- } \\
\text { Amherst-2002 } \\
37\end{array}$ & $X$ & & \\
\hline $\begin{array}{l}\text { Women of color staking a claim for cyber } \\
\text { domain: Unpacking the racial/gender gap in } \\
\text { science, mathematics, engineering and technology } \\
\text { (SMET) }\end{array}$ & $\begin{array}{l}\text { University of } \\
\text { Massachusetts- } \\
\text { Amherst-2002 } \\
38\end{array}$ & $X$ & & \\
\hline $\begin{array}{l}\text { College persistence among TANF single female } \\
\text { parents :An exploratory study }\end{array}$ & $\begin{array}{l}\text { University of } \\
\text { Massachusetts- } \\
\text { Amherst-2001 } \\
39\end{array}$ & $X$ & & \\
\hline $\begin{array}{l}\text { Vietnamese young women from the third wave of } \\
\text { immigration: Their struggle for higher education }\end{array}$ & $\begin{array}{l}\text { University of } \\
\text { Massachusetts- } \\
\text { Amherst-2001 } \\
40\end{array}$ & $X$ & & \\
\hline
\end{tabular}




\section{GENDER REPRESENTATIONS IN ED.D. DISSERTATIONS}

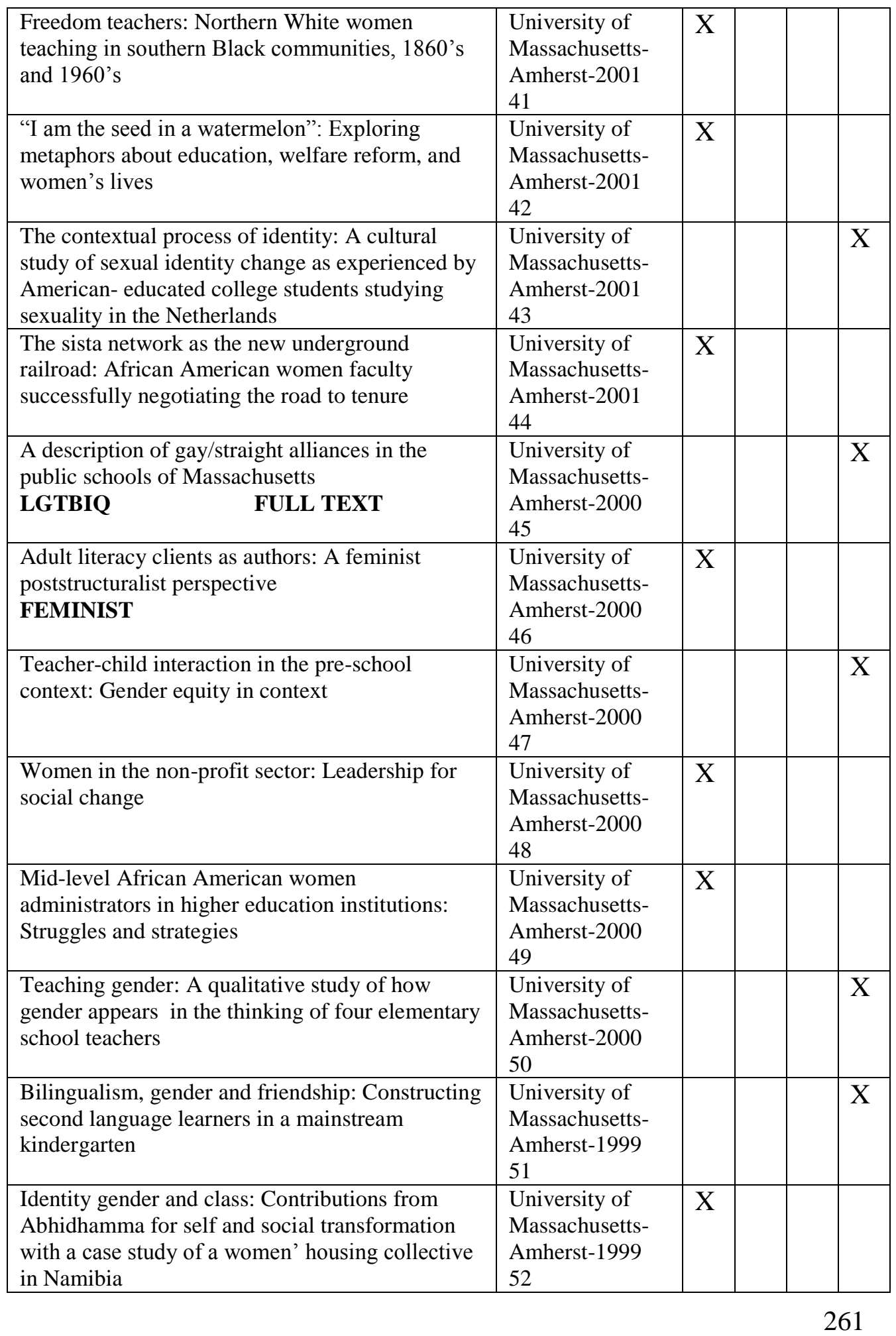




\section{GENDER REPRESENTATIONS IN ED.D. DISSERTATIONS}

\begin{tabular}{|c|c|c|c|c|c|}
\hline $\begin{array}{l}\text { The FotoDialogo Method: Using pictures and } \\
\text { storytelling to promote dialogue and self } \\
\text { discovery among Latinas within a community } \\
\text { based organization in Massachusetts } \\
\text { LATINO/A }\end{array}$ & $\begin{array}{l}\text { University of } \\
\text { Massachusetts- } \\
\text { Amherst-1999 } \\
53\end{array}$ & $\mathrm{X}$ & & & \\
\hline $\begin{array}{l}\text { Latina Girls of Puerto Rican origin who Are } \\
\text { successful in science and mathematics high } \\
\text { school courses } \\
\text { LATINO/A }\end{array}$ & $\begin{array}{l}\text { University of } \\
\text { Massachusetts- } \\
\text { Amherst-1999 } \\
54\end{array}$ & $\mathrm{X}$ & & & \\
\hline $\begin{array}{l}\text { Perceptions of young African American males } \\
\text { about rap music and its impact on their attitudes } \\
\text { about women } \\
\text { BLACK MALE }\end{array}$ & $\begin{array}{l}\text { University of } \\
\text { Massachusetts- } \\
\text { Amherst-1999 } \\
55\end{array}$ & & $\mathrm{X}$ & & \\
\hline $\begin{array}{l}\text { A multicultural organization development } \\
\text { examination of school based change strategies to } \\
\text { address needs of gay youth } \\
\text { LGTBIQ }\end{array}$ & $\begin{array}{l}\text { University of } \\
\text { Massachusetts- } \\
\text { Amherst }-1998 \\
56\end{array}$ & & & $\mathrm{X}$ & \\
\hline $\begin{array}{l}\text { Computer shop girls: An ethnographic study of } \\
\text { gendering positionings in a vocational high } \\
\text { school }\end{array}$ & $\begin{array}{l}\text { University of } \\
\text { Massachusetts- } \\
\text { Amherst }-1998 \\
57\end{array}$ & $X$ & & & \\
\hline $\begin{array}{l}\text { Constructing ritual space for displaced teen } \\
\text { voices: A study of power and pedagogy using } \\
\text { theatre and interactive television with adolescent } \\
\text { young women }\end{array}$ & $\begin{array}{l}\text { University of } \\
\text { Massachusetts- } \\
\text { Amherst-1998 } \\
58\end{array}$ & $\mathrm{X}$ & & & \\
\hline $\begin{array}{l}\text { Coping with war-enforced separation: A pilot } \\
\text { study on the account of wives of Puerto Rican } \\
\text { civilian soldiers }\end{array}$ & $\begin{array}{l}\text { University of } \\
\text { Massachusetts- } \\
\text { Amherst }-1998 \\
59\end{array}$ & $X$ & & & \\
\hline $\begin{array}{l}\text { A study of expectant mother's knowledge choice } \\
\text { and practice of infant feeding }\end{array}$ & $\begin{array}{l}\text { University of } \\
\text { Massachusetts- } \\
\text { Amherst-1998 } \\
60\end{array}$ & $X$ & & & \\
\hline $\begin{array}{l}\text { Developmental challenges and barriers: How } \\
\text { senior executive women cope with difficult } \\
\text { situations in their careers }\end{array}$ & $\begin{array}{l}\text { University of } \\
\text { Massachusetts- } \\
\text { Amherst }-1998 \\
61\end{array}$ & $X$ & & & \\
\hline $\begin{array}{l}\text { Empowerment, literacy and community } \\
\text { organization: A case study of self-help womens' } \\
\text { groups in rural Nepal }\end{array}$ & $\begin{array}{l}\text { University of } \\
\text { Massachusetts- } \\
\text { Amherst }-1998 \\
62\end{array}$ & $X$ & & & \\
\hline $\begin{array}{l}\text { Macro micro linkages in Caribbean Community } \\
\text { development: The impact of global trends, state } \\
\text { policies and a non-formal education project on } \\
\text { rural women in St.Vincent (1974-1994) ab }\end{array}$ & $\begin{array}{l}\text { University of } \\
\text { Massachusetts- } \\
\text { Amherst-1998 } \\
63\end{array}$ & $X$ & & & \\
\hline $\begin{array}{l}\text { Taking care: Women high school teachers at } \\
\text { midlife and midcareer }\end{array}$ & $\begin{array}{l}\text { University of } \\
\text { Massachusetts- }\end{array}$ & $\mathrm{X}$ & & & \\
\hline
\end{tabular}


GENDER REPRESENTATIONS IN ED.D. DISSERTATIONS

\begin{tabular}{|c|c|c|c|c|c|}
\hline & $\begin{array}{l}\text { Amherst-1998 } \\
64\end{array}$ & & & & \\
\hline $\begin{array}{l}\text { The cultural context of parenting and infant with } \\
\text { developmental disabilities: Irish mother's } \\
\text { perspective }\end{array}$ & $\begin{array}{l}\text { University of } \\
\text { Massachusetts- } \\
\text { Amherst }-1998 \\
65\end{array}$ & $X$ & & & \\
\hline $\begin{array}{l}\text { The experiences of Puerto Rico female students in } \\
\text { United States public secondary schools }\end{array}$ & $\begin{array}{l}\text { University of } \\
\text { Massachusetts- } \\
\text { Amherst }-1998 \\
66\end{array}$ & $X$ & & & \\
\hline $\begin{array}{l}\text { The incarcerated male adolescents' view of the } \\
\text { meaning of his experience: A phenomenological } \\
\text { study }\end{array}$ & $\begin{array}{l}\text { University of } \\
\text { Massachusetts- } \\
\text { Amherst }-1998 \\
67\end{array}$ & & $\mathrm{X}$ & & \\
\hline $\begin{array}{l}\text { Witness to war: the war stories of women } \\
\text { Vietnam veterans }\end{array}$ & $\begin{array}{l}\text { University of } \\
\text { Massachusetts- } \\
\text { Amherst -1998 } \\
\boldsymbol{6 8} \text { Gender }^{\boldsymbol{b}} \\
46-\mathrm{F} \\
\text { 8-M } \\
\text { 3-LGTBIQ } \\
\text { 11-O }\end{array}$ & $X$ & & & \\
\hline $\begin{array}{l}\text { Re-Sallying Quids: Resilience of queer youth in } \\
\text { school } \\
\text { LGTBIQ }\end{array}$ & $\begin{array}{l}\text { University of } \\
\text { Michigan -2001 } \\
1\end{array}$ & & & $\mathrm{X}$ & \\
\hline $\begin{array}{l}\text { The history of the Henry Ford Trade School, } \\
\text { 1919to } 1952 \text { am }\end{array}$ & $\begin{array}{l}\text { University of } \\
\text { Michigan -2001 } \\
2 \text { Gender }{ }^{\boldsymbol{b}} \\
0-\mathrm{F} \\
\text { 1-M } \\
\text { 1-LGTBIQ } \\
0-\mathrm{O}\end{array}$ & & $X$ & & \\
\hline $\begin{array}{l}\text { Small rural Missouri public school female } \\
\text { superintendent career stories: An exploration of } \\
\text { guiding compasses }\end{array}$ & $\begin{array}{l}\text { University of } \\
\text { Missouri- } \\
\text { Columbia }-2006 \\
1\end{array}$ & $X$ & & & \\
\hline $\begin{array}{l}\text { A survey of elementary teacher attitudes: } \\
\text { perceptions and knowledge of African American } \\
\text { male language usage in fourth grade classrooms } \\
\text { BLACK MALE }\end{array}$ & $\begin{array}{l}\text { University of } \\
\text { Missouri- } \\
\text { Columbia }-2005 \\
2\end{array}$ & & $X$ & & \\
\hline $\begin{array}{l}\text { Gender employment equity power status among } \\
\text { Missouri superintendents of public schools }\end{array}$ & $\begin{array}{l}\text { University of } \\
\text { Missouri- } \\
\text { Columbia-2002 } \\
3\end{array}$ & & & & X \\
\hline $\begin{array}{l}\text { Administrator gender differences in conflict } \\
\text { management style and the relationship to school } \\
\text { culture }\end{array}$ & $\begin{array}{l}\text { University of } \\
\text { Missouri- } \\
\text { Columbia-2002 }\end{array}$ & & & & $X$ \\
\hline
\end{tabular}




\section{GENDER REPRESENTATIONS IN ED.D. DISSERTATIONS}

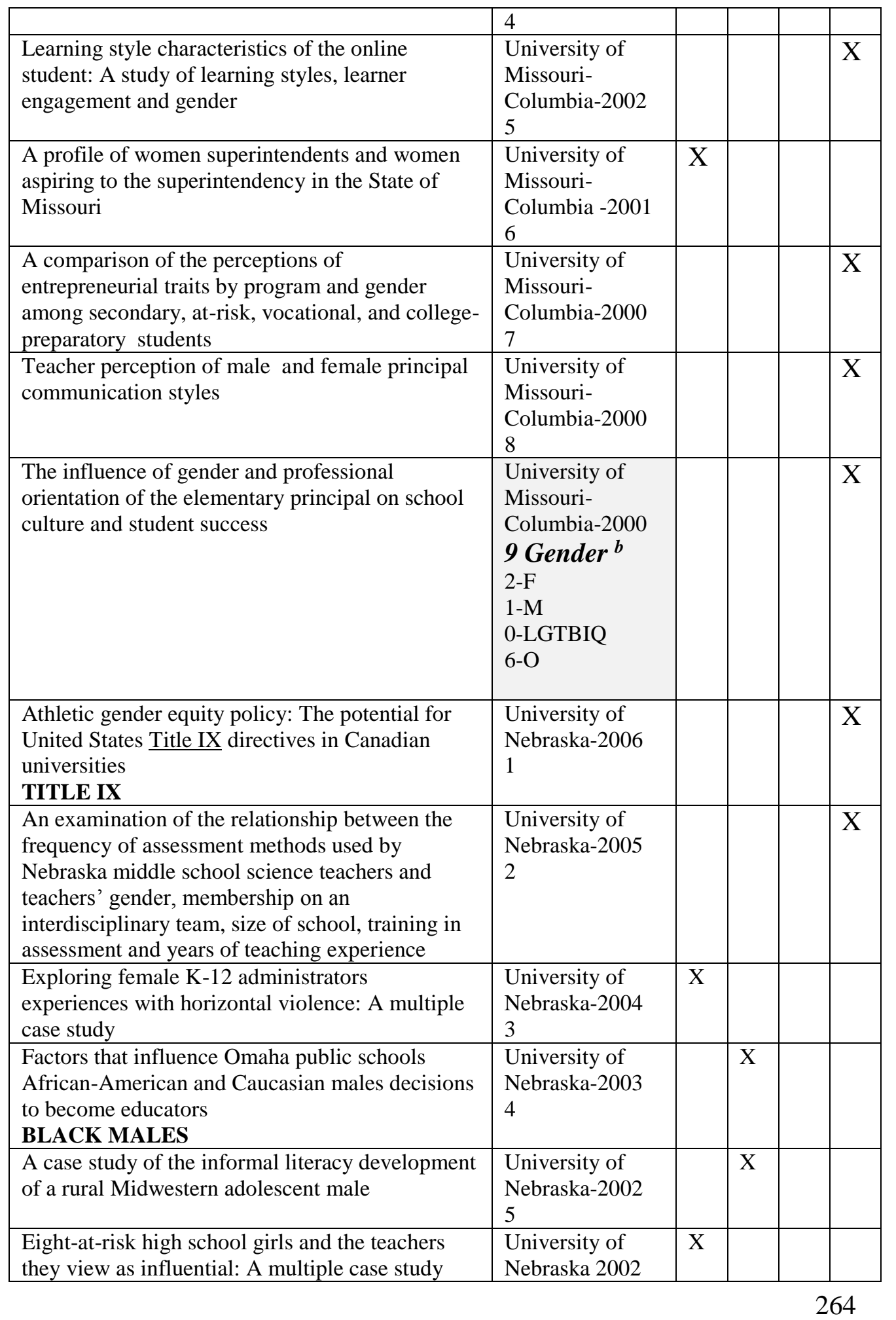


GENDER REPRESENTATIONS IN ED.D. DISSERTATIONS

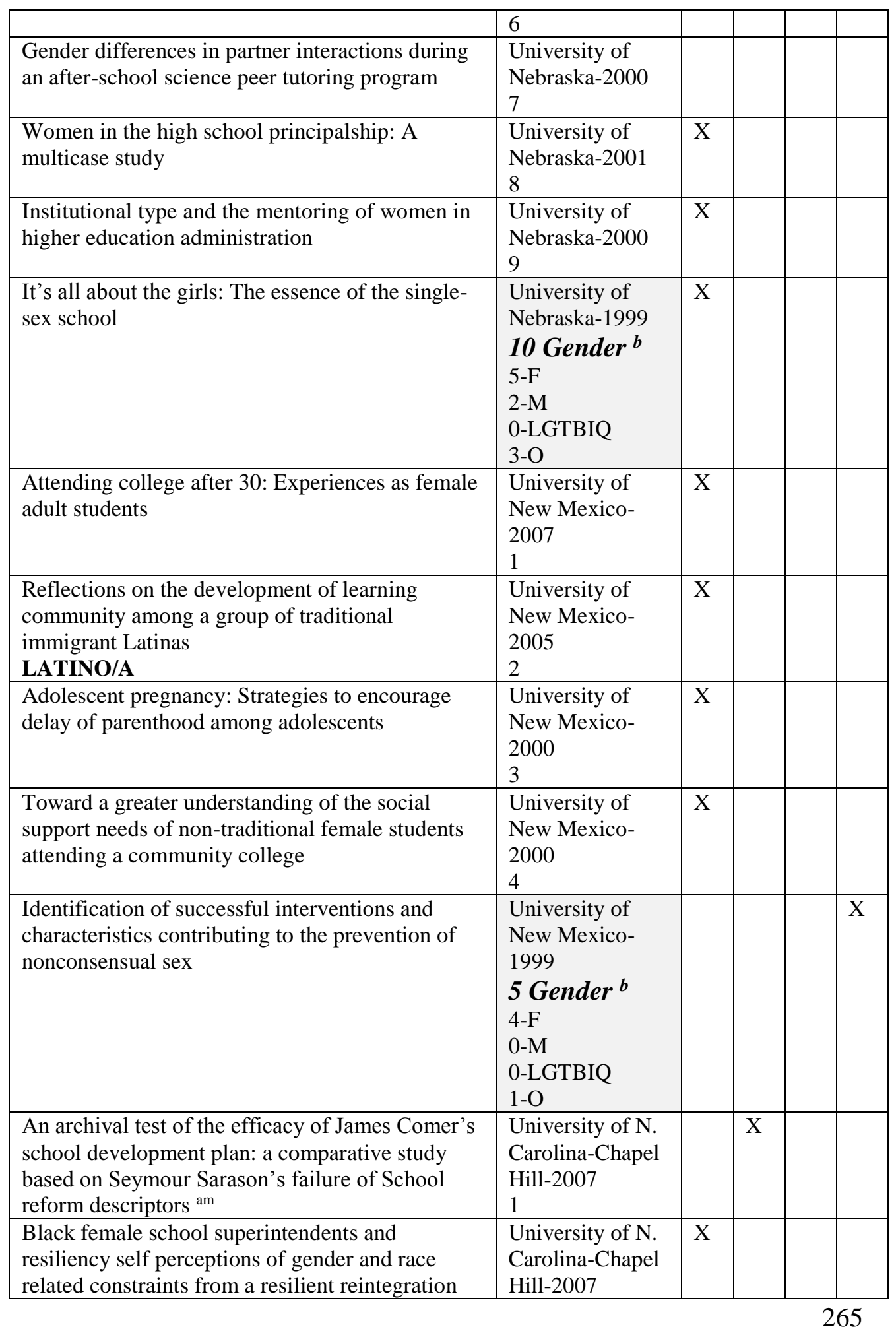




\section{GENDER REPRESENTATIONS IN ED.D. DISSERTATIONS}

\begin{tabular}{|c|c|c|c|c|c|}
\hline perspective & 2 & & & & \\
\hline $\begin{array}{l}\text { Teacher predictions of student achievement based } \\
\text { on student gender, ethnicity, and socioeconomic } \\
\text { status in high school mathematics }\end{array}$ & $\begin{array}{l}\text { University of N. } \\
\text { Carolina-Chapel } \\
\text { Hill-2007 } \\
3\end{array}$ & & & & $X$ \\
\hline $\begin{array}{l}\text { How teachers in a resiliency building school } \\
\text { promote resiliency within African American male } \\
\text { students } \\
\text { BLACK MALE }\end{array}$ & $\begin{array}{l}\text { University of N. } \\
\text { Carolina-Chapel } \\
\text { Hill-2006 } \\
4\end{array}$ & & $X$ & & \\
\hline $\begin{array}{l}\text { Latino/a students knowledge about American } \\
\text { citizenship, citizenship education and relevant } \\
\text { socio cultural factors } \\
\text { LATINO/A }\end{array}$ & $\begin{array}{l}\text { University of N. } \\
\text { Carolina-Chapel } \\
\text { Hill-2006 } \\
5\end{array}$ & & & & $X$ \\
\hline $\begin{array}{l}\text { Activism for LGTB rights: How participation } \\
\text { affects the lives of activist educators } \\
\text { LGTBIQ }\end{array}$ & $\begin{array}{l}\text { University of N. } \\
\text { Carolina-Chapel } \\
\text { Hill-2005 } \\
6\end{array}$ & & & $\mathrm{X}$ & \\
\hline $\begin{array}{l}\text { A multi-year study of the impact of retention on } \\
\text { elementary African American males achievement } \\
\text { in math and reading in one North Carolina School } \\
\text { District } \\
\text { BLACK MALE }\end{array}$ & $\begin{array}{l}\text { University of N. } \\
\text { Carolina-Chapel } \\
\text { Hill-2005 } \\
7\end{array}$ & & $X$ & & \\
\hline $\begin{array}{l}\text { Site-based voices: Dilemmas of educators who } \\
\text { engage in activism against student to student } \\
\text { sexual harassment }\end{array}$ & $\begin{array}{l}\text { University of N. } \\
\text { Carolina-Chapel } \\
\text { Hill-2005 } \\
8\end{array}$ & & & & $\mathrm{X}$ \\
\hline $\begin{array}{l}\text { Female community college presidents' perception } \\
\text { of effective leadership: Leadership practices and } \\
\text { behaviors }\end{array}$ & $\begin{array}{l}\text { University of N. } \\
\text { Carolina-Chapel } \\
\text { Hill-2004 } \\
9\end{array}$ & $\mathrm{X}$ & & & \\
\hline $\begin{array}{l}\text { Leadership-skilled women teachers who choose } \\
\text { the classroom over administration: A case of } \\
\text { career choice or career constraint }\end{array}$ & $\begin{array}{l}\text { University of N. } \\
\text { Carolina-Chapel } \\
\text { Hill-2003 } \\
10\end{array}$ & $\mathrm{X}$ & & & \\
\hline $\begin{array}{l}\text { Quiet activists: Women in educational } \\
\text { administration }\end{array}$ & $\begin{array}{l}\text { University of N. } \\
\text { Carolina-Chapel } \\
\text { Hill-2003 } \\
11\end{array}$ & $\mathrm{X}$ & & & \\
\hline $\begin{array}{l}\text { The schooling experiences of Latina immigrant } \\
\text { high school students } \\
\text { LATINO/A }\end{array}$ & $\begin{array}{l}\text { University of N. } \\
\text { Carolina-Chapel } \\
\text { Hill-2003 } \\
12\end{array}$ & $\mathrm{X}$ & & & \\
\hline $\begin{array}{l}\text { North Carolina women superintendents and the } \\
\text { boards that select them }\end{array}$ & $\begin{array}{l}\text { University of N. } \\
\text { Carolina-Chapel } \\
\text { Hill-2001 } \\
\text { 13 Gender } \\
\text { 6-F } \\
\text { 3-M }\end{array}$ & $\mathrm{X}$ & & & \\
\hline
\end{tabular}




\section{GENDER REPRESENTATIONS IN ED.D. DISSERTATIONS}

\begin{tabular}{|c|c|c|c|c|}
\hline & $\begin{array}{l}\text { 1-LGTBIQ } \\
3-\mathrm{O}\end{array}$ & & & \\
\hline $\begin{array}{l}\text { Mentoring relationships and the career } \\
\text { advancement of African American female } \\
\text { administrators in higher education: Exploring } \\
\text { intersections of race and gender }\end{array}$ & $\begin{array}{l}\text { University of } \\
\text { Pittsburgh-2007 } \\
1\end{array}$ & $X$ & & \\
\hline $\begin{array}{l}\text { Women and politics: A study of women trained in } \\
\text { a political leadership setting }\end{array}$ & $\begin{array}{l}\text { University of } \\
\text { Pittsburgh-2007 } \\
2\end{array}$ & $X$ & & \\
\hline $\begin{array}{l}\text { Supervisory practices of three female principals in } \\
\text { the era of No Child Left Behind }\end{array}$ & $\begin{array}{l}\text { University of } \\
\text { Pittsburgh-2005 } \\
3\end{array}$ & $\mathrm{X}$ & & \\
\hline $\begin{array}{l}\text { African American female school principal's } \\
\text { leadership stories: Toward a substantive grounded } \\
\text { theory inquiry }\end{array}$ & $\begin{array}{l}\text { University of } \\
\text { Pittsburgh-2004 } \\
4\end{array}$ & $\mathrm{X}$ & & \\
\hline $\begin{array}{l}\text { Financial aide packaging and undergraduate } \\
\text { enrollment at a women's college }\end{array}$ & $\begin{array}{l}\text { University of } \\
\text { Pittsburgh-2004 } \\
5\end{array}$ & $X$ & & \\
\hline $\begin{array}{l}\text { An examination of reading interactions between } \\
\text { mothers and daughters in grades four through six }\end{array}$ & $\begin{array}{l}\text { University of } \\
\text { Pittsburgh-2003 } \\
6\end{array}$ & $\mathrm{X}$ & & \\
\hline $\begin{array}{l}\text { An exploration of the differences in female and } \\
\text { male self perception of presidential leadership } \\
\text { styles at colleges and universities in West } \\
\text { Virginia } \\
\text { M v F LEADER }\end{array}$ & $\begin{array}{l}\text { University of } \\
\text { Pittsburgh-2003 } \\
7\end{array}$ & & & $X$ \\
\hline $\begin{array}{l}\text { The influence of the cultural and linguistic } \\
\text { orientations of Omani female college students on } \\
\text { their response to literature }\end{array}$ & $\begin{array}{l}\text { University of } \\
\text { Pittsburgh-2003 } \\
8\end{array}$ & $\mathrm{X}$ & & \\
\hline $\begin{array}{l}\text { The rise of Robert Morris from a junior college to } \\
\text { a graduate institutions, 1967-1989: The Sewall } \\
\text { years am }\end{array}$ & $\begin{array}{l}\text { University of } \\
\text { Pittsburgh-2003 } \\
9\end{array}$ & & & \\
\hline $\begin{array}{l}\text { A descriptive analysis of female English language } \\
\text { teachers attitudes towards the story-based } \\
\text { approach to grammar teaching in foreign } \\
\text { language learning in Saudi Arabian secondary } \\
\text { schools and their attitudes towards their } \\
\text { leadership roles in curriculum change }\end{array}$ & $\begin{array}{l}\text { University of } \\
\text { Pittsburgh-2002 } \\
10\end{array}$ & $\mathrm{X}$ & & \\
\hline $\begin{array}{l}\text { Principal's and teacher's attitudes towards } \\
\text { implementing cooperative learning methods at } \\
\text { girls' private middle schools in Jeddah, Saudi } \\
\text { Arabia }\end{array}$ & $\begin{array}{l}\text { University of } \\
\text { Pittsburgh-2002 } \\
11\end{array}$ & $X$ & & \\
\hline $\begin{array}{l}\text { A qualitative study of Saudi female twelfth grad } \\
\text { student's and teachers' perceptions of motivating } \\
\text { influences upon the student's academic } \\
\text { achievement }\end{array}$ & $\begin{array}{l}\text { University of } \\
\text { Pittsburgh-2001 } \\
12\end{array}$ & $X$ & & \\
\hline $\begin{array}{l}\text { Factors that support Arab Muslim women in their } \\
\text { career roles }\end{array}$ & $\begin{array}{l}\text { University of } \\
\text { Pittsburgh-2001 }\end{array}$ & $X$ & & \\
\hline
\end{tabular}




\section{GENDER REPRESENTATIONS IN ED.D. DISSERTATIONS}

\begin{tabular}{|c|c|c|c|c|}
\hline & 13 & & & \\
\hline $\begin{array}{l}\text { Socialization at two Black women's universities: } \\
\text { Bennett College and Spelman College }\end{array}$ & $\begin{array}{l}\text { University of } \\
\text { Pittsburgh-2001 } \\
14\end{array}$ & $\mathrm{X}$ & & \\
\hline $\begin{array}{l}\text { The leadership development of women at three } \\
\text { liberal arts colleges }\end{array}$ & $\begin{array}{l}\text { University of } \\
\text { Pittsburgh-2001 } \\
15\end{array}$ & $\mathrm{X}$ & & \\
\hline $\begin{array}{l}\text { A clash of rights on campus: Preventing and } \\
\text { responding to the sexual harassment of students } \\
\text { and protecting constitutional rights in the higher } \\
\text { education environment }\end{array}$ & $\begin{array}{l}\text { University of } \\
\text { Pittsburgh-2000 } \\
16\end{array}$ & & & $\mathrm{X}$ \\
\hline $\begin{array}{l}\text { Social capital: The link that bridges risk to } \\
\text { resilience in primary grade African American } \\
\text { males }\end{array}$ & $\begin{array}{l}\text { University of } \\
\text { Pittsburgh-2000 } \\
17\end{array}$ & & $\mathrm{X}$ & \\
\hline $\begin{array}{l}\text { Title IX intent vs action: Compliance and equity } \\
\text { in Allegheny public schools } \\
\text { TITLE IX }\end{array}$ & $\begin{array}{l}\text { University of } \\
\text { Pittsburgh-2000 } \\
18\end{array}$ & & & $\mathrm{X}$ \\
\hline $\begin{array}{l}\text { A comparison of student development outcomes } \\
\text { among male revenue athletes, non-revenue } \\
\text { athletes, and club sport athletes at an NCAA } \\
\text { Division I university }\end{array}$ & $\begin{array}{l}\text { University of } \\
\text { Pittsburgh-1999 } \\
19\end{array}$ & & $\mathrm{X}$ & \\
\hline $\begin{array}{l}\text { The leadership styles and career development of } \\
\text { ten female superintendents and assistant female } \\
\text { superintendents in Western Pennsylvania: A } \\
\text { qualitative study }\end{array}$ & $\begin{array}{l}\text { University of } \\
\text { Pittsburgh-1999 } \\
20\end{array}$ & $\mathrm{X}$ & & \\
\hline $\begin{array}{l}\text { African American women in higher education: } \\
\text { Barriers African American women overcome in } \\
\text { achieving the ultimate degree }\end{array}$ & $\begin{array}{l}\text { University of } \\
\text { Pittsburgh-1999 } \\
21\end{array}$ & $\mathrm{X}$ & & \\
\hline $\begin{array}{l}\text { Body mapping: An instructional strategy for } \\
\text { teaching the Alexander technique to music } \\
\text { students am }\end{array}$ & $\begin{array}{l}\text { University of } \\
\text { Pittsburgh-1999 } \\
22\end{array}$ & & & \\
\hline $\begin{array}{l}\text { Women in collegiate sports: The struggle for } \\
\text { equity since the } 1972 \text { Title IX Education } \\
\text { Amendment } \\
\text { TITLE IX }\end{array}$ & $\begin{array}{l}\text { University of } \\
\text { Pittburgh-1998 } \\
\text { 23 Gender }{ }^{\boldsymbol{b}} \\
\text { 16-F } \\
\text { 4-M } \\
\text { 0-LGTBIQ } \\
\text { 3-O }\end{array}$ & $\mathrm{X}$ & & \\
\hline $\begin{array}{l}\text { Music, management and magic :Virginia Uldrich } \\
\text { and the South Carolina's Governors School for } \\
\text { the Arts and Humanities af }\end{array}$ & $\begin{array}{l}\text { University of } \\
\text { S. Carolina- } \\
\text { Columbia-2006 } \\
1\end{array}$ & $\mathrm{X}$ & & \\
\hline $\begin{array}{l}\text { Septima P.Clark and the citizenship schools: } \\
\text { Implications for critical pedagogy af }\end{array}$ & $\begin{array}{l}\text { University of } \\
\text { S. Carolina- } \\
\text { Columbia-2005 } \\
2\end{array}$ & $\mathrm{X}$ & & \\
\hline William Van Til: the public intellectual am & $\begin{array}{l}\text { University of } \\
\text { S. Carolina- }\end{array}$ & & $\mathrm{X}$ & \\
\hline
\end{tabular}




\section{GENDER REPRESENTATIONS IN ED.D. DISSERTATIONS}

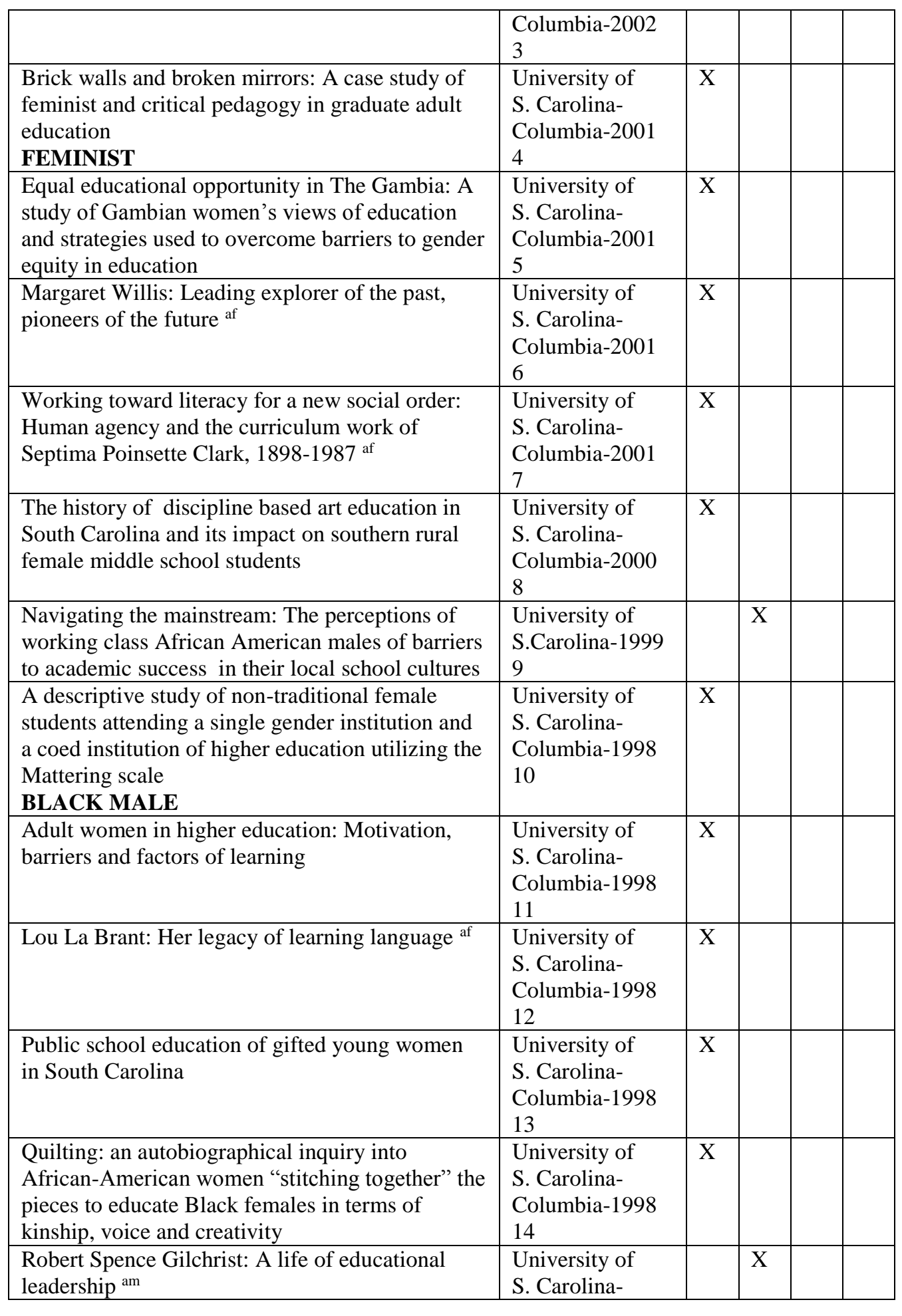




\section{GENDER REPRESENTATIONS IN ED.D. DISSERTATIONS}

\begin{tabular}{|c|c|c|c|c|}
\hline & $\begin{array}{l}\text { Columbia-1998 } \\
15\end{array}$ & & & \\
\hline $\begin{array}{l}\text { The relation between the perceptions of sixth and } \\
\text { seventh grade African American males and the } \\
\text { perceptions of their teachers of academic ability, } \\
\text { motivation, attitudes and efforts } \\
\text { BLACK MALE }\end{array}$ & $\begin{array}{l}\text { University of } \\
\text { S. Carolina- } \\
\text { Columbia-1998 } \\
\text { 16 Gender }{ }^{\boldsymbol{b}} \\
\text { 12-F } \\
\text { 4-M } \\
\text { 0-LGTBIQ } \\
\text { 0-O }\end{array}$ & & $X$ & \\
\hline $\begin{array}{l}\text { Factors perceived to contribute to mathematics } \\
\text { avoidance or mathematics confidence in non- } \\
\text { traditional age women attending a community } \\
\text { college }\end{array}$ & $\begin{array}{l}\text { University of } \\
\text { South Florida- } \\
2007 \\
1\end{array}$ & $X$ & & \\
\hline $\begin{array}{l}\text { School principal's knowledge and understanding } \\
\text { of educator sexual misconduct against students }\end{array}$ & $\begin{array}{l}\text { University of } \\
\text { South Florida- } \\
2006 \\
2\end{array}$ & & & X \\
\hline $\begin{array}{l}\text { Gender and generational differences in the self } \\
\text { ratings of leadership practices by elementary } \\
\text { school administrators within four Florida counties } \\
\text { M v F LEADER }\end{array}$ & $\begin{array}{l}\text { University of } \\
\text { South Florida- } \\
2005 \\
3\end{array}$ & & & X \\
\hline $\begin{array}{l}\text { The community college presidency for the } 21^{\text {st }} \\
\text { century : Female leadership in higher education }\end{array}$ & $\begin{array}{l}\text { University of } \\
\text { South Florida- } \\
2002 \\
4\end{array}$ & $\mathrm{X}$ & & \\
\hline $\begin{array}{l}\text { The effects of socioeconomic status, gender and } \\
\text { age on reported performance in the contemporary } \\
\text { social roles of parent, spouse, partner and worker }\end{array}$ & $\begin{array}{l}\text { University of } \\
\text { South Florida- } \\
2002 \\
\mathbf{5} \text { Gender } \\
\text { 2-F } \\
\text { 0-M } \\
\text { 0-LGTBIQ } \\
\text { 3-O }\end{array}$ & & & X \\
\hline $\begin{array}{l}\text { Female school superintendents in Tennessee: } \\
\text { Overcoming barriers }\end{array}$ & $\begin{array}{l}\text { University of } \\
\text { Tennessee- } \\
\text { Knoxville-2006 } \\
1\end{array}$ & $\mathrm{X}$ & & \\
\hline $\begin{array}{l}\text { Predicting the academic achievement of African } \\
\text { American women to two predominately white } \\
\text { women's colleges }\end{array}$ & $\begin{array}{l}\text { University of } \\
\text { Tennessee- } \\
\text { Knoxville-2005 } \\
1\end{array}$ & $\mathrm{X}$ & & \\
\hline $\begin{array}{l}\text { No-traditional female students enrolled in } \\
\text { developmental English courses at Roane State } \\
\text { Community College }\end{array}$ & $\begin{array}{l}\text { University of } \\
\text { Tennessee- } \\
\text { Knoxville-2003 } \\
3\end{array}$ & $X$ & & \\
\hline $\begin{array}{l}\text { A case study exploration of the symbolic } \\
\text { leadership of Jean Byers Sampson: Civil rights }\end{array}$ & $\begin{array}{l}\text { University of } \\
\text { Tennessee- }\end{array}$ & $\mathrm{X}$ & & \\
\hline
\end{tabular}


GENDER REPRESENTATIONS IN ED.D. DISSERTATIONS

\begin{tabular}{|c|c|c|c|c|c|}
\hline activist and educator ${ }^{\text {af }}$ & $\begin{array}{l}\text { Knoxville-2002 } \\
4\end{array}$ & & & & \\
\hline $\begin{array}{l}\text { Attitudes of educators/administrators towards } \\
\text { lesbian, gay, bisexual and transgendered students } \\
\text { LGTBIQ }\end{array}$ & $\begin{array}{l}\text { University of } \\
\text { Tennessee- } \\
\text { Knoxville-2002 } \\
5\end{array}$ & & & $\mathrm{X}$ & \\
\hline $\begin{array}{l}\text { A study of the novels of Harry Mayer and Norma } \\
\text { Fox Mayer and their place in young adult } \\
\text { literature ab }\end{array}$ & $\begin{array}{l}\text { University of } \\
\text { Tennessee- } \\
\text { Knoxville-2001 } \\
6\end{array}$ & & & & $\mathrm{X}$ \\
\hline $\begin{array}{l}\text { Anticipated life paths: A study of male and } \\
\text { female college students }\end{array}$ & $\begin{array}{l}\text { University of } \\
\text { Tennessee- } \\
\text { Knoxville-2000 } \\
7\end{array}$ & & & & $\mathrm{X}$ \\
\hline $\begin{array}{l}\text { Differences in language learning strategies } \\
\text { between male and female and also between Asian } \\
\text { and Latino ESL students } \\
\text { LATINO/A }\end{array}$ & $\begin{array}{l}\text { University of } \\
\text { Tennessee- } \\
\text { Knoxville }-2000 \\
8\end{array}$ & & & & $\mathrm{X}$ \\
\hline $\begin{array}{l}\text { Sex-role stereotyping: Changes in attitudes of } 3,4 \\
\text { and } 5 \text { year old children }\end{array}$ & $\begin{array}{l}\text { University of } \\
\text { Tennessee- } \\
\text { Knoxville -2000 } \\
9\end{array}$ & & & & $\mathrm{X}$ \\
\hline $\begin{array}{l}\text { A history of the } 1970 \text { Office of Women's } \\
\text { Programs at the University of Tennessee } \\
\text { Knoxville: A forerunner to change }\end{array}$ & $\begin{array}{l}\text { University of } \\
\text { Tennessee- } \\
\text { Knoxville }-1999 \\
10\end{array}$ & $\mathrm{X}$ & & & \\
\hline A post hoc study of young motherhood & $\begin{array}{l}\text { University of } \\
\text { Tennessee- } \\
\text { Knoxville }-1999 \\
11 \\
\end{array}$ & $\mathrm{X}$ & & & \\
\hline $\begin{array}{l}\text { The influence of the undergraduate chemistry } \\
\text { department on female chemistry majors }\end{array}$ & $\begin{array}{l}\text { University of } \\
\text { Tennessee- } \\
\text { Knoxville -1999 } \\
12 \\
\end{array}$ & $\mathrm{X}$ & & & \\
\hline $\begin{array}{l}\text { Women in philanthropy: Making a difference in } \\
\text { higher education }\end{array}$ & $\begin{array}{l}\text { University of } \\
\text { Tennessee- } \\
\text { Knoxville-1999 } \\
13\end{array}$ & $\mathrm{X}$ & & & \\
\hline Aidan Chambers: A critical biography ${ }^{\text {am }}$ & $\begin{array}{l}\text { University of } \\
\text { Tennessee- } \\
\text { Knoxville }-1998 \\
14\end{array}$ & & $\mathrm{X}$ & & \\
\hline $\begin{array}{l}\text { Sexual risk behaviors and knowledge of } \\
\text { STD's/AIDs reported by tractor trailer drivers: A } \\
\text { baseline for educators }\end{array}$ & $\begin{array}{l}\text { University of } \\
\text { Tennessee- } \\
\text { Knoxville }-1998 \\
15\end{array}$ & & & & $\mathrm{X}$ \\
\hline $\begin{array}{l}\text { Significant leadership development experiences } \\
\text { of five pioneering women executives in higher }\end{array}$ & $\begin{array}{l}\text { University of } \\
\text { Tennessee- }\end{array}$ & $\mathrm{X}$ & & & \\
\hline
\end{tabular}




\section{GENDER REPRESENTATIONS IN ED.D. DISSERTATIONS}

\begin{tabular}{|c|c|c|c|c|}
\hline education & $\begin{array}{l}\text { Knoxville-1998 } \\
\text { 16 Gender }{ }^{\boldsymbol{b}} \\
\text { 9-F } \\
\text { 1-M } \\
\text { 1-LGTBIQ } \\
\text { 5-O }\end{array}$ & & & \\
\hline $\begin{array}{l}\text { A partnership of education and entertainment: A } \\
\text { case study of the Larry Gatlin School of } \\
\text { Entertainment technology at Guilford Technical } \\
\text { Community College }\end{array}$ & $\begin{array}{l}\text { University of } \\
\text { Texas-Austin- } \\
2007 \\
1\end{array}$ & & $\mathrm{X}$ & \\
\hline $\begin{array}{l}\text { What works: Factors influencing community } \\
\text { college Hispanic female academic achievement } \\
\text { and persistence to graduation }\end{array}$ & $\begin{array}{l}\text { University of } \\
\text { Texas-Austin- } \\
2007 \\
2\end{array}$ & $\mathrm{X}$ & & \\
\hline $\begin{array}{l}\text { Ethnically diverse principals and male Hispanic } \\
\text { superintendents' perceptions of the } \\
\text { superintendent's leadership }\end{array}$ & $\begin{array}{l}\text { University of } \\
\text { Texas-Austin- } \\
2006 \\
3\end{array}$ & & $X$ & \\
\hline $\begin{array}{l}\text { African American male participation at Tomball } \\
\text { college: Barriers, outreach and retention } \\
\text { BLACK MALE }\end{array}$ & $\begin{array}{l}\text { University of } \\
\text { Texas-Austin- } \\
2004 \\
4\end{array}$ & & $\mathrm{X}$ & \\
\hline $\begin{array}{l}\text { An investigation of reading without sound: A } \\
\text { story about Michael am }\end{array}$ & $\begin{array}{l}\text { University of } \\
\text { Texas-Austin- } \\
2002 \\
5\end{array}$ & & $\mathrm{X}$ & \\
\hline $\begin{array}{l}\text { Public school district organizational culture and } \\
\text { decision making: An African American female } \\
\text { perspective }\end{array}$ & $\begin{array}{l}\text { University of } \\
\text { Texas-Austin- } \\
2002 \\
6\end{array}$ & $\mathrm{X}$ & & \\
\hline $\begin{array}{l}\text { Effects of media representation of a cultural idea } \\
\text { of feminine beauty on self body image in college } \\
\text { aged women: An interactive qualitative analysis }\end{array}$ & $\begin{array}{l}\text { University of } \\
\text { Texas-Austin- } \\
2001 \\
7\end{array}$ & $\mathrm{X}$ & & \\
\hline $\begin{array}{l}\text { Mexican American college women beliefs, } \\
\text { attitudes and practices related to weight loss }\end{array}$ & $\begin{array}{l}\text { University of } \\
\text { Texas-Austin- } \\
2000 \\
8\end{array}$ & $\mathrm{X}$ & & \\
\hline $\begin{array}{l}\text { An exploration of physical activity in the lives of } \\
\text { older, minority women diagnosed at risk for } \\
\text { diabetes }\end{array}$ & $\begin{array}{l}\text { University of } \\
\text { Texas-Austin- } \\
1999 \\
9\end{array}$ & $\mathrm{X}$ & & \\
\hline $\begin{array}{l}\text { In an exquisite voice (en una voz exquisite): A } \\
\text { case study of one Latina community college } \\
\text { chancellor } \\
\text { LATINO/A }\end{array}$ & $\begin{array}{l}\text { University of } \\
\text { Texas-Austin- } \\
1999 \\
10\end{array}$ & $\mathrm{X}$ & & \\
\hline $\begin{array}{l}\text { Intersection of hope: the stories of Christina and } \\
\text { Mark and an after school tutoring intervention ab }\end{array}$ & $\begin{array}{l}\text { University of } \\
\text { Texas-Austin- }\end{array}$ & & & $\mathrm{X}$ \\
\hline
\end{tabular}


GENDER REPRESENTATIONS IN ED.D. DISSERTATIONS

\begin{tabular}{|c|c|c|c|c|}
\hline & $\begin{array}{l}1999 \\
11\end{array}$ & & & \\
\hline $\begin{array}{l}\text { Learning well: the social-literacy of some } \\
\text { incipient literate women in a Ghanaian } \\
\text { community }\end{array}$ & $\begin{array}{l}\text { University of } \\
\text { Texas-Austin- } \\
1999 \\
12\end{array}$ & $X$ & & \\
\hline $\begin{array}{l}\text { Fluid identities, adaptable lives: the impact of } \\
\text { educational and career experiences on the identity } \\
\text { development of Latina corporate managers } \\
\text { LATINO/A }\end{array}$ & $\begin{array}{l}\text { University of } \\
\text { Texas-Austin- } \\
1999 \\
\text { 13 Gender }{ }^{\boldsymbol{b}} \\
\text { 8-F } \\
\text { 4-M } \\
\text { 0-LGTBIQ } \\
\text { 1-O }\end{array}$ & $X$ & & \\
\hline $\begin{array}{l}\text { A monitoring system to achieve success and } \\
\text { increased structural diversity for students of color } \\
\text { and women }\end{array}$ & $\begin{array}{l}\text { University of } \\
\text { Utah-2006 } \\
1\end{array}$ & $\mathrm{X}$ & & \\
\hline $\begin{array}{l}\text { Faculty notions regarding caring in male nursing } \\
\text { students }\end{array}$ & $\begin{array}{l}\text { University of } \\
\text { Utah-2006 } \\
2 \text { Gender } \boldsymbol{b} \\
\text { 1-F } \\
\text { 1-M } \\
0-\text { LGTBIQ } \\
0-\mathrm{O}\end{array}$ & & $X$ & \\
\hline $\begin{array}{l}\text { Stakeholder perspectives of the impact of a none } \\
\text { to one obiquitous laptop environment in an } \\
\text { independent girls school }\end{array}$ & $\begin{array}{l}\text { University of } \\
\text { Virginia-Main- } \\
2007 \\
1\end{array}$ & $\mathrm{X}$ & & \\
\hline $\begin{array}{l}\text { Examining the relationship between maternal } \\
\text { parenting, ethnicity and classroom behavior } \\
\text { among children }\end{array}$ & $\begin{array}{l}\text { University of } \\
\text { Virginia-Main- } \\
2006 \\
2\end{array}$ & $\mathrm{X}$ & & \\
\hline $\begin{array}{l}\text { Four Virginia female superintendents: } \\
\text { Perceptions of barriers and career opportunities }\end{array}$ & $\begin{array}{l}\text { University of } \\
\text { Virginia-Main- } \\
2004 \\
3\end{array}$ & $\bar{X}$ & & \\
\hline $\begin{array}{l}\text { A cross-case study of six women who } \\
\text { experienced layoffs in the apparel industry and } \\
\text { enrolled in retraining programs at a Southwest } \\
\text { Virginia Community College }\end{array}$ & $\begin{array}{l}\text { University of } \\
\text { Virginia-Main- } \\
2003 \\
4\end{array}$ & $\mathrm{X}$ & & \\
\hline $\begin{array}{l}\text { A study of the perceptions of teen mothers } \\
\text { following their participation in a teen mother } \\
\text { program }\end{array}$ & $\begin{array}{l}\text { University of } \\
\text { Virginia-Main- } \\
2002 \\
5\end{array}$ & $\mathrm{X}$ & & \\
\hline $\begin{array}{l}\text { Academic performance of students in single sex } \\
\text { and coed classes in one public middle school }\end{array}$ & $\begin{array}{l}\text { University of } \\
\text { Virginia-Main- } \\
2001 \\
6\end{array}$ & & & $\mathrm{X}$ \\
\hline
\end{tabular}


GENDER REPRESENTATIONS IN ED.D. DISSERTATIONS

\begin{tabular}{|c|c|c|c|c|}
\hline Mother child interactions and learning to read & $\begin{array}{l}\text { University of } \\
\text { Virginia-Main- } \\
2001 \\
7\end{array}$ & $\mathrm{X}$ & & \\
\hline $\begin{array}{l}\text { Virginia male public school superintendent's } \\
\text { attitudes towards the rights and roles of women in } \\
\text { contemporary society }\end{array}$ & $\begin{array}{l}\text { University of } \\
\text { Virginia-Main- } \\
\text { 2001 } \\
\mathbf{8} \text { Gender }^{b} \\
\text { 6-F } \\
\text { 0-M } \\
\text { 0-L } \\
\text { 2-O }\end{array}$ & & & $\mathrm{X}$ \\
\hline $\begin{array}{l}\text { Latina/os constructing educational leadership: } \\
\text { Cultivating the fields of leadership } \\
\text { LATINO/A }\end{array}$ & $\begin{array}{l}\text { University of } \\
\text { Washington- } \\
\text { Seattle-2007 } \\
1\end{array}$ & & & $\mathrm{X}$ \\
\hline $\begin{array}{l}\text { Influencing children's gendered play preferences } \\
\text { through play interventions }\end{array}$ & $\begin{array}{l}\text { University of } \\
\text { Washington- } \\
2001 \\
2\end{array}$ & & & $\mathrm{X}$ \\
\hline $\begin{array}{l}\text { Comparative study of professional development } \\
\text { proposed by Buddha and John Dewey am }\end{array}$ & $\begin{array}{l}\text { University of } \\
\text { Washington- } \\
\text { Seattle-1998 } \\
\mathbf{3} \text { Gender }^{\boldsymbol{b}} \\
\text { 0-F } \\
\text { 1-M } \\
\text { 0-LGTBIQ } \\
\text { 2-O }\end{array}$ & & $\mathrm{X}$ & \\
\hline $\begin{array}{l}\text { The effects of single sex and coeducational } \\
\text { environments on the self-efficacy of middle } \\
\text { school girls }\end{array}$ & $\begin{array}{l}\text { Virginia } \\
\text { Polytechnic \& } \\
\text { State U-2006 } \\
1\end{array}$ & $\mathrm{X}$ & & \\
\hline $\begin{array}{l}\text { Title IX compliance in Virginia high schools } \\
\text { TITLE IX }\end{array}$ & $\begin{array}{l}\text { Virginia } \\
\text { Polytechnic \& } \\
\text { State U-2006 } \\
2\end{array}$ & & & $\mathrm{X}$ \\
\hline $\begin{array}{l}\text { Women in high school principalships: A } \\
\text { comparison of four case studies from a Virginia } \\
\text { public school district from 1979-2000 }\end{array}$ & $\begin{array}{l}\text { Virginia } \\
\text { Polytechnic \& } \\
\text { State U-2004 } \\
3\end{array}$ & $\mathrm{X}$ & & \\
\hline $\begin{array}{l}\text { Challenges of studying attributes associated with } \\
\text { African American males who are not successful } \\
\text { with testing measures } \\
\text { BLACK MALE }\end{array}$ & $\begin{array}{l}\text { Virginia } \\
\text { Polytechnic \& } \\
\text { State U-2002 } \\
4\end{array}$ & & $\mathrm{X}$ & \\
\hline $\begin{array}{l}\text { Math attitudes of gifted students: A focus on } \\
\text { gifted girls in the elementary grades }\end{array}$ & $\begin{array}{l}\text { Virginia } \\
\text { Polytechnic \& } \\
\text { State U-2002 } \\
5\end{array}$ & $\mathrm{X}$ & & \\
\hline
\end{tabular}




\section{GENDER REPRESENTATIONS IN ED.D. DISSERTATIONS}

\begin{tabular}{|c|c|c|c|c|}
\hline $\begin{array}{l}\text { Effects of educational kinesiology, previous } \\
\text { performance, gender and socioeconomic status on } \\
\text { phonological awareness literacy screening scores } \\
\text { of kindergarten students }\end{array}$ & $\begin{array}{l}\text { Virginia } \\
\text { Polytechnic \& } \\
\text { State U-2001 } \\
6\end{array}$ & & & $\mathrm{X}$ \\
\hline $\begin{array}{l}\text { Mothers' perceptions of the transition process } \\
\text { from early intervention to early childhood special } \\
\text { education: Related stressors, supports, and coping } \\
\text { skills }\end{array}$ & $\begin{array}{l}\text { Virginia } \\
\text { Polytechnic \& } \\
\text { State U-2001 } \\
7\end{array}$ & $X$ & & \\
\hline $\begin{array}{l}\text { Charlotte Mason: An introductory analysis of her } \\
\text { educational theories and practices af }\end{array}$ & $\begin{array}{l}\text { Virginia } \\
\text { Polytechnic \& } \\
\text { State U-2000 } \\
8\end{array}$ & $X$ & & \\
\hline $\begin{array}{l}\text { Non-verbal behaviors of effective teachers of at- } \\
\text { risk African American male middle school } \\
\text { students } \\
\text { BLACK MALE }\end{array}$ & $\begin{array}{l}\text { Virginia } \\
\text { Polytechnic \& } \\
\text { State U-2000 } \\
9\end{array}$ & & $X$ & \\
\hline $\begin{array}{l}\text { A qualitative study of female superintendents: } \\
\text { Leadership behaviors in context }\end{array}$ & $\begin{array}{l}\text { Virginia } \\
\text { Polytechnic \& } \\
\text { State U-1999 } \\
10\end{array}$ & $\mathrm{X}$ & & \\
\hline $\begin{array}{l}\text { A case study of the implementation of Ernest } \\
\text { Boyer's basic school framework in an elementary } \\
\text { school am }\end{array}$ & $\begin{array}{l}\text { Virginia } \\
\text { Polytechnic \& } \\
\text { State U-1998 } \\
11\end{array}$ & & $X$ & \\
\hline $\begin{array}{l}\text { Experiences of African American women in } \\
\text { doctoral programs }\end{array}$ & $\begin{array}{l}\text { Virginia } \\
\text { Polytechnic \& } \\
\text { State U-1998 } \\
12\end{array}$ & $\mathrm{X}$ & & \\
\hline $\begin{array}{l}\text { Handbooks as a format for learning: } \\
\text { Understanding handbooks through a systematic } \\
\text { analysis of handbooks of minister's wives }\end{array}$ & $\begin{array}{l}\text { Virginia } \\
\text { Polytechnic \& } \\
\text { State U-1998 } \\
13\end{array}$ & $\mathrm{X}$ & & \\
\hline $\begin{array}{l}\text { Increasing stages of social activism and } \\
\text { responsiveness to the national agenda: How } \\
\text { women experience membership in branches of the } \\
\text { American Association of University Women }\end{array}$ & $\begin{array}{l}\text { Virginia } \\
\text { Polytechnic \& } \\
\text { State U-1998 } \\
14\end{array}$ & $X$ & & \\
\hline $\begin{array}{l}\text { The development of a professional identity of } \\
\text { women who attain the superintendency }\end{array}$ & $\begin{array}{l}\text { Virginia } \\
\text { Polytechnic \& } \\
\text { State U-1998 } \\
15\end{array}$ & $\mathrm{X}$ & & \\
\hline $\begin{array}{l}\text { The whole world was their classroom: The } \\
\text { contributions of Harry and Bonoro Overstreet to } \\
\text { the field of adult education ab }\end{array}$ & $\begin{array}{l}\text { Virginia } \\
\text { Polytechnic \& } \\
\text { State U-1998 } \\
\text { 16 Gender }{ }^{\boldsymbol{b}} \\
\text { 10-F } \\
\text { 3-M } \\
\text { 0-LGTBIQ } \\
\text { 3-O }\end{array}$ & & & $\mathrm{X}$ \\
\hline
\end{tabular}




\section{GENDER REPRESENTATIONS IN ED.D. DISSERTATIONS}

\begin{tabular}{|c|c|c|c|c|c|}
\hline Latinas aspiring to the superintendency & $\begin{array}{l}\text { Washington } \\
\text { State-2007 } \\
1\end{array}$ & $\mathrm{X}$ & & & \\
\hline $\begin{array}{l}\text { Lesbian, gay, bisexual, and transgender equity } \\
\text { issues: A study of preservice teacher's } \\
\text { perceptions of current practices in teacher } \\
\text { education }\end{array}$ & $\begin{array}{l}\text { Washington } \\
\text { State-2002 } \\
2\end{array}$ & & & $\mathrm{X}$ & \\
\hline $\begin{array}{l}\text { The impact of youth centered groups on the self- } \\
\text { efficacy of gay and lesbian youth }\end{array}$ & $\begin{array}{l}\text { Washington } \\
\text { State-2000 } \\
\mathbf{3} \text { Gender }{ }^{\boldsymbol{b}} \\
1-\mathrm{F} \\
0-\mathrm{M} \\
2-\mathrm{L} \\
0-\mathrm{O}\end{array}$ & & & $\mathrm{X}$ & \\
\hline $\begin{array}{l}\text { Elementary teachers perceptions of the relevance } \\
\text { of John Dewey's philosophy of experiential } \\
\text { learning in the twenty first century am }\end{array}$ & $\begin{array}{l}\text { Wayne State U - } \\
2007 \\
1\end{array}$ & & $\mathrm{X}$ & & \\
\hline $\begin{array}{l}\text { Case studies of transactions between boys' lived } \\
\text { experiences and art }\end{array}$ & $\begin{array}{l}\text { Wayne State U- } \\
2006 \\
2\end{array}$ & & $\mathrm{X}$ & & \\
\hline $\begin{array}{l}\text { A qualitative study on the role of African } \\
\text { American fathers and their influence on their } \\
\text { child's early literacy development } \\
\text { BLACK MALE }\end{array}$ & $\begin{array}{l}\text { Wayne State U - } \\
2005 \\
3\end{array}$ & & $\mathrm{X}$ & & \\
\hline $\begin{array}{l}\text { Predictors of female urban university students } \\
\text { intent to persist through graduation }\end{array}$ & $\begin{array}{l}\text { Wayne State U - } \\
2002 \\
4\end{array}$ & & & & \\
\hline $\begin{array}{l}\text { A study of principals' perceptions and knowledge } \\
\text { of sexual harassment in schools }\end{array}$ & $\begin{array}{l}\text { Wayne State U - } \\
2001 \\
5\end{array}$ & & & & $\mathrm{X}$ \\
\hline $\begin{array}{l}\text { Perceptions of high school females regarding } \\
\text { sexual harassment in public schools: Implications } \\
\text { for curriculum reform }\end{array}$ & $\begin{array}{l}\text { Wayne State U - } \\
1999 \\
6\end{array}$ & $\mathrm{X}$ & & & \\
\hline $\begin{array}{l}\text { An examination of the use of values to suggest a } \\
\text { blending and measuring of the philosophies of } \\
\text { John Dewey and Frederick Taylor in a collegiate } \\
\text { business curriculum am }\end{array}$ & $\begin{array}{l}\text { Wayne State U - } \\
1999 \\
7\end{array}$ & & $\mathrm{X}$ & & \\
\hline $\begin{array}{l}\text { Perceptions of job satisfaction among African } \\
\text { American women faculty at two Carnegie } 1 \\
\text { research institutions }\end{array}$ & $\begin{array}{l}\text { Wayne State U - } \\
1999 \\
8\end{array}$ & $\mathrm{X}$ & & & \\
\hline $\begin{array}{l}\text { The perception of faculty with regard to the } \\
\text { understanding and involvement in enrollment } \\
\text { management at Henry Ford community college am }\end{array}$ & $\begin{array}{l}\text { Wayne State U - } \\
1999 \\
9\end{array}$ & & $\mathrm{X}$ & & \\
\hline $\begin{array}{l}\text { Women middle managers: Barriers and } \\
\text { facilitators influencing career management }\end{array}$ & $\begin{array}{l}\text { Wayne State U - } \\
1999 \\
10\end{array}$ & $\mathrm{X}$ & & & \\
\hline $\begin{array}{l}\text { Gender equity, women's demystification and } \\
\text { Islam: a symbolic interactionist perspective }\end{array}$ & $\begin{array}{l}\text { Wayne State U - } \\
1998\end{array}$ & $\mathrm{X}$ & & & \\
\hline
\end{tabular}


GENDER REPRESENTATIONS IN ED.D. DISSERTATIONS

\begin{tabular}{|l|l|l|l|l|l|}
\hline & 11 & & & & \\
\hline Gender related perceptions of parental treatment & Wayne State U - & & & & X \\
of Arabic speaking fifth grade urban students & 1998 & & & & \\
& 12 Gender & & & & \\
& 5-F & & & & \\
& 5-LGTBIQ & & & & \\
& 2-O & & & \\
\hline
\end{tabular}




\section{GENDER REPRESENTATIONS IN ED.D. DISSERTATIONS}

Appendix J. Institutional Gender focus with \%, totals \& Carnegie type

\begin{tabular}{|c|c|c|c|c|c|}
\hline \multicolumn{2}{|c|}{ Institution } & \multirow{2}{*}{\begin{tabular}{|l|}
$\begin{array}{l}\% \text { Gender } \\
\text { focus }\end{array}$ \\
57.1
\end{tabular}} & \multirow{2}{*}{$\begin{array}{l}\text { Gender } \\
4\end{array}$} & \multirow{2}{*}{$\begin{array}{r}\text { Total } \\
\text { Ed.D } \\
7\end{array}$} & \multirow{2}{*}{$\begin{array}{l}\begin{array}{l}\text { Carnegie } \\
\text { type }\end{array} \\
\text { RUH }\end{array}$} \\
\hline 1 & University of Oregon & & & & \\
\hline 2 & Pennsylvania State University & 28.8 & 5 & 21 & RUVH \\
\hline 3 & Ohio University & 23.0 & 3 & 13 & RUH \\
\hline 4 & University of Cincinnati & 18.4 & 52 & 282 & RUVH \\
\hline 5 & University of Massachusetts-Amherst & 18.0 & 68 & 377 & RUVH \\
\hline 6 & Georgia Southern University & 16.4 & 24 & 146 & DRU \\
\hline 7 & University of Kentucky & 16.4 & 25 & 152 & RUVH \\
\hline 8 & Texas Women's University & 14.3 & 2 & 14 & DRU \\
\hline 9 & University of South Carolina & 14.3 & 16 & 112 & RUVH \\
\hline 10 & University of Massachusetts-Boston & 14.2 & 12 & 85 & DRU \\
\hline 11 & University of Texas Austin & 13.7 & 13 & 95 & RUVH \\
\hline 12 & University of North Carolina- Chapel Hill & 13.4 & 13 & 97 & RUVH \\
\hline 13 & University of California-Berkeley & 13.0 & 3 & 23 & RUVH \\
\hline 14 & Northern Illinois University & 12.7 & 77 & 607 & RUH \\
\hline 15 & University of Maine & 12.7 & 7 & 55 & RUH \\
\hline 16 & SUNY-Binghampton & 12.5 & 5 & 40 & RUH \\
\hline 17 & University of Akron & 12.5 & 8 & 64 & RUH \\
\hline 18 & Indiana University of Pennsylvania & 12.4 & 12 & 97 & DRU \\
\hline 19 & Rutgers-New Brunswick & 12.4 & 32 & 250 & RUVH \\
\hline 20 & Oregon State University & 11.8 & 9 & 76 & RUVH \\
\hline 21 & Texas A \& M- Main & 11.7 & 11 & 94 & RUVH \\
\hline 22 & University of California- LA \& Irvine & 11.6 & 31 & 268 & RUVH \\
\hline 23 & University of North Dakota & 11.4 & 5 & 44 & RUH \\
\hline 24 & Florida State & 11.3 & 7 & 62 & RUVH \\
\hline 25 & North Carolina State University & 11.0 & 33 & 299 & RUVH \\
\hline 26 & University of Arkansas & 10.8 & 12 & 111 & RUH \\
\hline 27 & New Mexico State & 10.6 & 7 & 66 & RUH \\
\hline 28 & Temple U & 10.3 & 32 & 310 & RUH \\
\hline \multicolumn{6}{|c|}{$2^{\text {nd }}$ Quartile } \\
\hline 29 & Morgan State University & 10.2 & 13 & 127 & DRU \\
\hline 30 & Arizona State & 10.1 & 28 & 276 & RUVH \\
\hline 31 & University of North Carolina-Greenville & 10.0 & 8 & 80 & RUH \\
\hline 32 & University of West Florida & 10.0 & 1 & 10 & DRU \\
\hline 33 & University of Northern Colorado & 9.8 & 17 & 173 & DRU \\
\hline 34 & University of Houston & 9.7 & 44 & 453 & RUH \\
\hline 35 & Central Michigan University & 9.4 & 3 & 32 & DRU \\
\hline 36 & University of Louisville & 9.4 & 9 & 96 & RUH \\
\hline 37 & Indiana University Purdue & 9.0 & 12 & 133 & RUH \\
\hline 38 & Texas Southern University & 9.0 & 15 & 167 & DRU \\
\hline 39 & University of Tennessee- Knoxville & 8.8 & 16 & 181 & RUVH \\
\hline 40 & San Diego State University & 8.7 & 2 & 23 & RUH \\
\hline 41 & South Carolina State & 8.7 & 13 & 150 & DRU \\
\hline 42 & University of Georgia & 8.6 & 19 & 222 & RUVH \\
\hline
\end{tabular}




\section{GENDER REPRESENTATIONS IN ED.D. DISSERTATIONS}

\begin{tabular}{|c|c|c|c|c|c|}
\hline 43 & University of Delaware & 8.5 & 13 & 153 & RUVH \\
\hline 44 & Northern Arizona University & 8.1 & 19 & 234 & RUH \\
\hline 45 & University of Memphis & 8.1 & 19 & 236 & RUH \\
\hline 46 & University of South Florida & 7.9 & 5 & 64 & RUVH \\
\hline 47 & University of Missouri-KC & 7.7 & 1 & 13 & RUH \\
\hline 48 & University of New Mexico & 7.7 & 5 & 65 & RUVH \\
\hline 49 & Utah State University & 7.7 & 1 & 13 & RUH \\
\hline 50 & Virginia Polytechnic & 7.7 & 16 & 208 & RUVH \\
\hline 51 & University of Kansas & 7.6 & 10 & 132 & RUVH \\
\hline 52 & Texas A \& M Commerce & 7.3 & 23 & 317 & DRU \\
\hline 53 & University of Texas El-Paso & 7.3 & 4 & 55 & RUH \\
\hline 54 & Sam Houston State University & 6.9 & 7 & 102 & DRU \\
\hline 55 & University of Alabama & 6.9 & 15 & 219 & RUH \\
\hline 56 & East Carolina University & 6.8 & 8 & 117 & DRU \\
\hline \multicolumn{6}{|c|}{$3^{\text {rd }}$ Quartile } \\
\hline 57 & Texas Tech University & 6.8 & 11 & 161 & RUH \\
\hline 58 & University of Massachusetts-Lowell & 6.8 & 10 & 148 & DRU \\
\hline 59 & University of Pittsburgh & 6.8 & 23 & 337 & RUVH \\
\hline 60 & Florida International & 6.7 & 14 & 208 & RUH \\
\hline 61 & Tennessee State University & 6.7 & 21 & 316 & DRU \\
\hline 62 & University of Nevada-Reno & 6.7 & 1 & 15 & RUH \\
\hline 63 & University of North Texas & 6.6 & 12 & 183 & RUH \\
\hline 64 & University of Southern Mississippi & 6.5 & 3 & 46 & RUH \\
\hline 65 & Ball State University & 6.4 & 12 & 187 & DRU \\
\hline 66 & University of Maryland & 6.3 & 3 & 48 & RUVH \\
\hline 67 & University of Utah & 6.3 & 2 & 32 & RUVH \\
\hline 68 & Wayne State & 6.3 & 12 & 189 & RUVH \\
\hline 69 & College of William and Mary & 6.2 & 4 & 65 & RUH \\
\hline 70 & University of Alabama-Bgham & 6.2 & 2 & 32 & RUVH \\
\hline 71 & University of California-Davis & 6.2 & 5 & 81 & RUVH \\
\hline 72 & Washington State University & 6.0 & 3 & 50 & RUVH \\
\hline 73 & Oklahoma State University & 5.9 & 25 & 424 & RUH \\
\hline 74 & East Tennessee State University & 5.8 & 15 & 258 & DRU \\
\hline 75 & University of Nebraska-Lincoln & 5.8 & 10 & 173 & RUVH \\
\hline 76 & Montana State University & 5.7 & 6 & 105 & RUVH \\
\hline 77 & University of Arizona & 5.7 & 4 & 70 & RUVH \\
\hline 78 & Bowling Green & 4.8 & 3 & 62 & RUH \\
\hline 79 & West Virginia University & 4.7 & 18 & 382 & RUH \\
\hline 80 & University of Nevada Las Vegas & 4.5 & 5 & 111 & RUH \\
\hline 81 & University of Washington & 4.3 & 3 & 69 & RUVH \\
\hline 82 & University of South Dakota & 4.2 & 18 & 426 & DRU \\
\hline 83 & University of Missouri-CD & 3.7 & 9 & 243 & RUVH \\
\hline 84 & University of North Carolina -Charlotte & 3.7 & 3 & 83 & DRU \\
\hline \multicolumn{6}{|c|}{$4^{\text {th }}$ Quartile } \\
\hline 85 & University of Virginia & 3.7 & 8 & 216 & RUVH \\
\hline 86 & Florida Atlantic-Boca & 3.6 & 5 & 141 & RUH \\
\hline
\end{tabular}




\section{GENDER REPRESENTATIONS IN ED.D. DISSERTATIONS}

\begin{tabular}{|l|l|l|l|r|l|}
\hline 87 & Kansas State & 3.4 & 3 & 88 & RUVH \\
\hline 88 & SUNY-Albany & 3.2 & 1 & 31 & RUVH \\
\hline 89 & University of Central Florida & 3.1 & 12 & 383 & RUH \\
\hline 90 & University of Michigan & 3.0 & 2 & 66 & RUVH \\
\hline 91 & Clemson University & 2.9 & 1 & 35 & RUH \\
\hline 92 & Portland State University & 2.9 & 2 & 69 & DRU \\
\hline 93 & Western Michigan University & 2.7 & 5 & 86 & RUH \\
\hline 94 & University of Wyoming & 2.6 & 1 & 39 & RUH \\
\hline 95 & Louisiana Tech & 2.4 & 1 & 41 & DRU \\
\hline 96 & Mississippi State & 2.4 & 1 & 41 & RUH \\
\hline 97 & SUNY Buffalo & 2.4 & 1 & 41 & RUVH \\
\hline 98 & Idaho State & 2.3 & 2 & 88 & DRU \\
\hline 99 & University of Florida & 1.6 & 2 & 127 & RUVH \\
\hline 100 & Texas A \& M Kingsville & 1.4 & 3 & 209 & DRU \\
\hline 101 & University of Arkansas & 1.4 & 1 & 72 & DRU \\
\hline 102 & Illinois State University & 1.3 & 2 & 153 & DRU \\
\hline 103 & University of Oklahoma & .002 & 1 & 449 & RUH \\
\hline 104 & George Mason University & 0 & 0 & 1 & RUH \\
\hline 105 & University of Connecticut & 0 & 0 & 12 & RUVH \\
\hline 106 & University of Idaho & 0 & 0 & 26 & RUH \\
\hline 107 & University of Mississippi & 0 & 0 & 36 & RUH \\
\hline 108 & University of Nebraska & 0 & 0 & 63 & RUH \\
\hline 109 & University of New Orleans & 0 & 0 & 2 & RUH \\
\hline 110 & University of Toledo & 0 & 0 & 12 & RUH \\
\hline 111 & University of Vermont/Agricultural & 0 & 0 & 3 & RUH \\
\hline 112 & Wichita University Kansas & 0 & 0 & 49 & RUH \\
\hline & & & & & \\
\hline
\end{tabular}


GENDER REPRESENTATIONS IN ED.D. DISSERTATIONS

Appendix K. List of 177 abstracts selected for examination \begin{tabular}{|l|}
\hline Male v Female Leaders (24 abstracts) \\
\hline An investigation of gender differences in motivation of senior administrators in
\end{tabular} Virginia community colleges using Herzberg's two factor theory East Tennessee State U2006

The contemporary manager: Exploring female and male leadership styles

East Tennessee State U2003

Relationships between gender and teacher's perceptions of principal eness in Georgia schools

Georgia

Southern

U-2002

The study of school climate, principals communication style, principal's sex and school level

Portland State U1999

An analysis of gender differences public school superintendents' conflict management modes in relation to synergistic leadership theory

Sam

Houston

$\mathrm{U}$

2004

Texas superintendent's perceptions of their superintendent preparation

Sam

programs: In general and by gender

Houston

U

1999

Teacher's perceptions of effectiveness of female and male principals

Tennessee

State-

2007

Perceived leadership effectiveness of male and female directors of schools in

West and East Tennessee

Tennessee

State-

2001

Perceived leadership effectiveness of male and female directors of schools

Tennessee

State-

2000

Leadership and followership: A gender perspective

Texas A

$\& \mathrm{M}$

Commerc

e-2007

Superintendent gender and student achievement: A postmodern perspective

Texas A 
GENDER REPRESENTATIONS IN ED.D. DISSERTATIONS

\begin{tabular}{|c|c|}
\hline & $\begin{array}{l}\text { \& } \mathrm{M} \\
\text { Commerc } \\
\mathrm{e}-2007\end{array}$ \\
\hline $\begin{array}{l}\text { Gender and conflict management styles of Texas secondary school assistant } \\
\text { principals: A descriptive study }\end{array}$ & $\begin{array}{l}\text { Texas A } \\
\& \mathrm{M} \\
\text { Commerc } \\
\text { e-2005 }\end{array}$ \\
\hline $\begin{array}{l}\text { A study of factors associated with gender specific superintendents in public } \\
\text { schools }\end{array}$ & $\begin{array}{l}\text { Texas A } \\
\& \mathrm{M} \\
\text { Kingsville } \\
-2002\end{array}$ \\
\hline $\begin{array}{l}\text { Are there differences in the perceived leadership practices of female and male } \\
\text { superintendents as identified by school committee members }\end{array}$ & $\begin{array}{l}\text { University } \\
\text { of } \\
\text { Massachu } \\
\text { setts- } \\
\text { Lowell- } \\
2007\end{array}$ \\
\hline Leadership style: Do male and female school superintendents lead differently? & $\begin{array}{l}\text { University } \\
\text { of } \\
\text { Massachu } \\
\text { setts- } \\
\text { Lowell- } \\
2004\end{array}$ \\
\hline Gender differences in principal motivations & $\begin{array}{l}\text { Florida } \\
\text { Internatio } \\
\text { nal U- }\end{array}$ \\
\hline $\begin{array}{l}\text { Perspectives of experienced female and male superintendents of large suburban } \\
\text { Illinois public school districts on the evolving role of the superintendent: } \\
\text { Implications for leadership }\end{array}$ & $\begin{array}{l}\text { Northern } \\
\text { Illinois } \\
\text { University } \\
-2000\end{array}$ \\
\hline $\begin{array}{l}\text { Perspectives of experienced female and male superintendents of small rural } \\
\text { Illinois public school districts on the evolving role of the superintendent: } \\
\text { Implications for leadership }\end{array}$ & $\begin{array}{l}\text { Northern } \\
\text { Illinois } \\
\text { University } \\
-2000\end{array}$ \\
\hline $\begin{array}{l}\text { Investigating the difference in leadership styles and effectiveness between male } \\
\text { and female public high school principals in Illinois }\end{array}$ & $\begin{array}{l}\text { Northern } \\
\text { Illinois } \\
\text { University } \\
-1998\end{array}$ \\
\hline A comparative analysis of leadership attitudes of male and female elementary & University \\
\hline
\end{tabular}




\section{GENDER REPRESENTATIONS IN ED.D. DISSERTATIONS}

\begin{tabular}{|c|c|}
\hline public school principals in Arkansas & $\begin{array}{l}\text { of } \\
\text { Arkansas- } \\
\text { Main } \\
1998 \\
\end{array}$ \\
\hline $\begin{array}{l}\text { A comparative study of the characteristics of male and female secondary } \\
\text { principals and aspirants in the State of Arkansas }\end{array}$ & $\begin{array}{l}\text { University } \\
\text { of } \\
\text { Arkansas- } \\
\text { Main- } \\
1998\end{array}$ \\
\hline $\begin{array}{l}\text { An examination of gender balance and other associated characteristics in the } \\
\text { administrative ranks of North Carolina community colleges }\end{array}$ & $\begin{array}{l}\text { North } \\
\text { Carolina } \\
\text { State- } \\
\text { Raleigh- } \\
1999\end{array}$ \\
\hline $\begin{array}{l}\text { The actual and ideal public relations role of the public school superintendent as } \\
\text { perceived by Texas male and female superintendents: A record of study }\end{array}$ & $\begin{array}{l}\text { Texas A } \\
\& \mathrm{M}-1998\end{array}$ \\
\hline $\begin{array}{l}\text { Gender and generational differences in the self-ratings of leadership practices } \\
\text { by elementary school administrators within four Florida counties }\end{array}$ & $\begin{array}{l}\text { U of S. } \\
\text { Florida } \\
2005\end{array}$ \\
\hline \multicolumn{2}{|l|}{ Black Males (43 abstracts) } \\
\hline $\begin{array}{l}\text { The under-representation of African American males in academically gifted } \\
\text { programs: The perceptions of teachers and administrators of barriers to } \\
\text { identification }\end{array}$ & $\begin{array}{l}\text { East } \\
\text { Carolina } \\
\text { U-2007 }\end{array}$ \\
\hline $\begin{array}{l}\text { The impact of preparedness, self-efficacy and math anxiety on the success of } \\
\text { African American males in developmental mathematics at a community } \\
\text { college }\end{array}$ & $\begin{array}{l}\text { Morgan } \\
\text { State U- } \\
2007\end{array}$ \\
\hline $\begin{array}{l}\text { Why can't brother man stay in school: A phenomenological study of Black } \\
\text { male student attrition at a Black commuter college }\end{array}$ & $\begin{array}{l}\text { Morgan } \\
\text { State U- } \\
2004\end{array}$ \\
\hline $\begin{array}{l}\text { In their own words: A phenomenological investigation of the lived experiences } \\
\text { of selected African-American male early school leavers in Washington D.C. }\end{array}$ & $\begin{array}{l}\text { Morgan } \\
\text { State U- } \\
2003\end{array}$ \\
\hline $\begin{array}{l}\text { A causal comparative study of instructional programs on the mathematical } \\
\text { achievements of elementary school African American male students }\end{array}$ & $\begin{array}{l}\text { South } \\
\text { Carolina } \\
\text { State- } \\
2005\end{array}$ \\
\hline $\begin{array}{l}\text { The effects of group counseling compared with individual counseling in the } \\
\text { reduction of at-risk behaviors using grade point average, discipline referrals } \\
\text { and attendance among } 6^{\text {th }} \text { grade Black males }\end{array}$ & $\begin{array}{l}\text { South } \\
\text { Carolina } \\
\text { State- } \\
2005 \\
\end{array}$ \\
\hline
\end{tabular}




\section{GENDER REPRESENTATIONS IN ED.D. DISSERTATIONS}

\begin{tabular}{|c|c|}
\hline $\begin{array}{l}\text { The impact of locus of control on the academic achievement of African } \\
\text { American males }\end{array}$ & $\begin{array}{l}\text { South } \\
\text { Carolina } \\
\text { State- } \\
2003\end{array}$ \\
\hline $\begin{array}{l}\text { The attitudes of rural eighth grade Black males towards academic learning and } \\
\text { it's impact on academic achievement }\end{array}$ & $\begin{array}{l}\text { South } \\
\text { Carolina } \\
\text { State- } \\
2002\end{array}$ \\
\hline $\begin{array}{l}\text { Group counseling compared with individual counseling in the reduction of at } \\
\text { risk behaviors in Black male students }\end{array}$ & $\begin{array}{l}\text { South } \\
\text { Carolina } \\
\text { State- } \\
2001\end{array}$ \\
\hline $\begin{array}{l}\text { Exploring the relationship between personal motivation, persistence, and } \\
\text { resilience and their effects on academic achievement among different groups of } \\
\text { African American males in high schools }\end{array}$ & $\begin{array}{l}\text { University } \\
\text { of } \\
\text { Maryland- } \\
2005\end{array}$ \\
\hline $\begin{array}{l}\text { Teacher perception of verbal reinforcement versus tangible reinforcement with } \\
\text { regard to academic achievement for the African-American middle school male }\end{array}$ & $\begin{array}{l}\text { Tennessee } \\
\text { State- } \\
2003\end{array}$ \\
\hline The retention of Black male students in Texas public community colleges & $\begin{array}{l}\text { Texas A } \\
\& \mathrm{M} \\
\text { Commerc } \\
\text { e-2001 }\end{array}$ \\
\hline $\begin{array}{l}\text { Black male student achievement: A synthesis of research in the "Journal of } \\
\text { Negro Education" }\end{array}$ & $\begin{array}{l}\text { Texas A } \\
\& \mathrm{M} \\
\text { Commerc } \\
\text { e-1998 } \\
19\end{array}$ \\
\hline $\begin{array}{l}\text { Establishing classroom contacts and interactions: White educators' attitudes } \\
\text { about early adolescent Black males }\end{array}$ & $\begin{array}{l}\text { University } \\
\text { of } \\
\text { Massachu } \\
\text { setts- } \\
\text { Boston- } \\
2006\end{array}$ \\
\hline $\begin{array}{l}\text { The involvement of African American Fathers in the educational lives of their } \\
\text { young children: Beliefs, practices, and experiences in one elementary school }\end{array}$ & $\begin{array}{l}\text { University } \\
\text { of } \\
\text { Massachu } \\
\text { setts- } \\
\text { Boston- } \\
2004\end{array}$ \\
\hline
\end{tabular}




\section{GENDER REPRESENTATIONS IN ED.D. DISSERTATIONS}

\begin{tabular}{|c|c|}
\hline $\begin{array}{l}\text { African-American males: What do schools and teachers do to enhance } \\
\text { academic achievement }\end{array}$ & $\begin{array}{l}\text { U of N. } \\
\text { Carolina- } \\
\text { Charlotte- } \\
2002\end{array}$ \\
\hline $\begin{array}{l}\text { Lasting legacies: The effects of natural mentors in the lives of at risk African - } \\
\text { American male adolescents }\end{array}$ & $\begin{array}{l}\text { Bowling } \\
\text { Green } \\
\text { State- } \\
2006\end{array}$ \\
\hline $\begin{array}{l}\text { The impact of reading instructional methodology on student achievement of } \\
\text { Black males based on the Florida comprehensive assessment test }\end{array}$ & $\begin{array}{l}\text { Florida } \\
\text { Atlantic } \\
\text { Boca } \\
2006\end{array}$ \\
\hline $\begin{array}{l}\text { A comparison of academic success variables of Black male high school } \\
\text { graduates with other racial and gender populations in the Broward County } \\
\text { School district Florida }\end{array}$ & $\begin{array}{l}\text { Florida } \\
\text { Atlantic } \\
\text { Boca }\end{array}$ \\
\hline $\begin{array}{l}\text { Raising Abel: What do African American single mothers do to raise successful } \\
\text { African American middle school boys ab }\end{array}$ & $\begin{array}{l}\text { Indiana U } \\
\text { Purdue- } \\
2003\end{array}$ \\
\hline $\begin{array}{l}\text { An analysis of adult African American men's perceived susceptibility of } \\
\text { prostate cancer and perceived benefits and barriers to participation in early } \\
\text { detection methods: Implications for community-based health promotion }\end{array}$ & $\begin{array}{l}\text { Northern } \\
\text { Illinois- } \\
2007 \\
\text { University }\end{array}$ \\
\hline $\begin{array}{l}\text { The African American church as a provider of nonformal adult education in the } \\
\text { Chicago community under the leadership of Pastor William Samuel Winston }\end{array}$ & $\begin{array}{l}\text { Northern } \\
\text { Illinois } \\
\text { University } \\
-2005\end{array}$ \\
\hline $\begin{array}{l}\text { Reaching and teaching the African-American male: Curriculum, learning } \\
\text { styles, teacher belief systems and practices }\end{array}$ & $\begin{array}{l}\text { Northern } \\
\text { Illinois } \\
\text { University } \\
-2001 \\
47\end{array}$ \\
\hline $\begin{array}{l}\text { Measuring the effectiveness of an Afrocentric male mentoring program with } \\
\text { adolescent African American males }\end{array}$ & $\begin{array}{l}\text { Northern } \\
\text { Illinois } \\
\text { University } \\
-2000\end{array}$ \\
\hline $\begin{array}{l}\text { Rediscovering the essential nature of African American male leadership: An } \\
\text { Afrocentric perspective }\end{array}$ & $\begin{array}{l}\text { Northern } \\
\text { Illinois } \\
\text { University } \\
-2000\end{array}$ \\
\hline
\end{tabular}




\section{GENDER REPRESENTATIONS IN ED.D. DISSERTATIONS}

\begin{tabular}{|c|c|}
\hline $\begin{array}{l}\text { There are no crystal stairs here: A study of African-American males in } \\
\text { traditional and non traditional program in a predominately White institution of } \\
\text { higher education }\end{array}$ & $\begin{array}{l}\text { Northern } \\
\text { Illinois } \\
\text { University } \\
-2000\end{array}$ \\
\hline $\begin{array}{l}\text { Social cognition and language: Abusive language and the African -American } \\
\text { male juvenile transgressor }\end{array}$ & $\begin{array}{l}\text { Northern } \\
\text { Illinois } \\
\text { University } \\
-1999\end{array}$ \\
\hline $\begin{array}{l}\text { African-American male per-service teachers' perceptions of elementary } \\
\text { education: A multiple case study }\end{array}$ & $\begin{array}{l}\text { Oklahoma } \\
\text { State- } \\
\text { Main- } \\
2002\end{array}$ \\
\hline $\begin{array}{l}\text { Factors that foster academic resilience in African American male middle } \\
\text { school students from low-socioeconomic, single parent homes }\end{array}$ & $\begin{array}{l}\text { University } \\
\text { of } \\
\text { Alabama- } \\
1999\end{array}$ \\
\hline $\begin{array}{l}\text { Factors that contribute to hazing practices by collegiate Black Greek letter } \\
\text { fraternities during membership intake activities }\end{array}$ & $\begin{array}{l}\text { University } \\
\text { of } \\
\text { Arkansas- } \\
\text { Main- } \\
2006\end{array}$ \\
\hline $\begin{array}{l}\text { An examination of time use patterns influence on achievement among African } \\
\text { American and Hispanic male high school student athletes }\end{array}$ & $\begin{array}{l}\text { University } \\
\text { of Central } \\
\text { Florida- } \\
2007\end{array}$ \\
\hline $\begin{array}{l}\text { John Henryism and occupational stress among African American higher } \\
\text { education faculty }\end{array}$ & $\begin{array}{l}\text { University } \\
\text { of } \\
\text { Houston- } \\
1998\end{array}$ \\
\hline $\begin{array}{l}\text { An analysis of the characteristics that lead to the disenfranchisement of African } \\
\text { Males between the ages of } 18 \text { to } 35\end{array}$ & $\begin{array}{l}\text { University } \\
\text { of } \\
\text { Memphis- } \\
2004\end{array}$ \\
\hline $\begin{array}{l}\text { Designed for failure: An analysis of African American male students } \\
\text { perception of the failure of traditional school structures to successfully educate } \\
\text { them }\end{array}$ & $\begin{array}{l}\text { University } \\
\text { of } \\
\text { Missouri- } \\
\text { Kansas } \\
\text { City-2007 }\end{array}$ \\
\hline Social reconstruction of African American males at an urban middle school & University \\
\hline
\end{tabular}


GENDER REPRESENTATIONS IN ED.D. DISSERTATIONS

\begin{tabular}{|c|c|}
\hline & $\begin{array}{l}\text { of } \\
\text { N.Carolin } \\
\mathrm{a}- \\
\text { Greensbor } \\
\text { o-2006 }\end{array}$ \\
\hline $\begin{array}{l}\text { Through their eyes: A look at the achievement and success of selected African } \\
\text { American male youths }\end{array}$ & $\begin{array}{l}\text { University } \\
\text { of } \\
\text { N.Carolin } \\
\text { a- } \\
\text { Greensbor } \\
\text { o-2006 }\end{array}$ \\
\hline $\begin{array}{l}\text { An examination of the graduation rates of the Division I African American } \\
\text { male basketball student-athlete }\end{array}$ & $\begin{array}{l}\text { University } \\
\text { of Texas- } \\
\text { El Paso- } \\
2004\end{array}$ \\
\hline $\begin{array}{l}\text { The personal and academic success of African American males with specific } \\
\text { learning disabilities }\end{array}$ & $\begin{array}{l}\text { Arizona } \\
\text { State- } \\
\text { Tempe- } \\
2004\end{array}$ \\
\hline The way out: African American male student athletes in higher education & $\begin{array}{l}\text { Arizona } \\
\text { State- } \\
\text { Tempe- } \\
2001\end{array}$ \\
\hline The impact of home environment of Black males not pursuing higher education & $\begin{array}{l}\text { Arizona } \\
\text { State } \\
\text { University } \\
-1998\end{array}$ \\
\hline $\begin{array}{l}\text { A qualitative study of resilience among African-American adolescent male } \\
\text { students in North Carolina }\end{array}$ & $\begin{array}{l}\text { North } \\
\text { Carolina } \\
\text { State- } \\
\text { Raleigh- } \\
2003\end{array}$ \\
\hline $\begin{array}{l}\text { Coping strategies: Adjustment, and persistence among Black men attending } \\
\text { predominately White colleges and universities }\end{array}$ & $\begin{array}{l}\text { Rutgers- } \\
\text { New } \\
\text { Brunswic } \\
\text { k-2004 }\end{array}$ \\
\hline $\begin{array}{l}\text { Effective library education for the inner city African American male: Key } \\
\text { elements of a team }\end{array}$ & $\begin{array}{l}\text { UC } \\
\text { Berkeley- } \\
2005\end{array}$ \\
\hline \multicolumn{2}{|l|}{ Latino/a (44 abstracts) } \\
\hline $\begin{array}{l}\text { Knowledge and perceptions held by Latino parents regarding the educational } \\
\text { services for LEP children with disabilities }\end{array}$ & $\begin{array}{l}\text { Illinois } \\
\text { State U- }\end{array}$ \\
\hline
\end{tabular}


GENDER REPRESENTATIONS IN ED.D. DISSERTATIONS

\begin{tabular}{|c|c|}
\hline & 1999 \\
\hline Factors affecting retention of $1^{\text {st }}$ year Latino students in a private university & $\begin{array}{l}\text { Morgan } \\
\text { State U- } \\
2006\end{array}$ \\
\hline $\begin{array}{l}\text { An investigation into the perceptions of Latino parents of young children in } \\
\text { urban, suburban and rural school settings }\end{array}$ & $\begin{array}{l}\text { Texas } \\
\text { Woman's } \\
\text { University } \\
-2001\end{array}$ \\
\hline $\begin{array}{l}\text { The kids on the other side of the hallway: Teacher's perspectives of the } \\
\text { academic achievement of Latino English language learners }\end{array}$ & $\begin{array}{l}\text { University } \\
\text { of } \\
\text { Massachu } \\
\text { setts- } \\
\text { Boston- } \\
2007\end{array}$ \\
\hline $\begin{array}{l}\text { Latina Presidents in community colleges: A quantitative study of the elements } \\
\text { of career advancement }\end{array}$ & $\begin{array}{l}\text { New } \\
\text { Mexico } \\
\text { State- } \\
\text { Main- } \\
2007\end{array}$ \\
\hline $\begin{array}{l}\text { Non United States born Latinos: A study of perceptions of barriers and } \\
\text { catalysts to educational success at a rural New Mexico Community college }\end{array}$ & $\begin{array}{l}\text { New } \\
\text { Mexico } \\
\text { State- } \\
\text { Main- } \\
2007\end{array}$ \\
\hline $\begin{array}{l}\text { A case study on language proficiency with Latino students in dual language } \\
\text { setting }\end{array}$ & $\begin{array}{l}\text { New } \\
\text { Mexico } \\
\text { State- } \\
\text { Main- } \\
2000\end{array}$ \\
\hline $\begin{array}{l}\text { College Latino students: Cultural integration, retention, and successful } \\
\text { completion }\end{array}$ & $\begin{array}{l}\text { Northern } \\
\text { Illinois } \\
\text { University } \\
-2005\end{array}$ \\
\hline $\begin{array}{l}\text { School organization of successful alternative high schools serving Latino } \\
\text { students in Chicago }\end{array}$ & $\begin{array}{l}\text { Northern } \\
\text { Illinois } \\
\text { University } \\
-2004\end{array}$ \\
\hline $\begin{array}{l}\text { Lessons learned while suspended between two cultures: The life history of a } \\
\text { Latina adult educator }\end{array}$ & $\begin{array}{l}\text { Northern } \\
\text { Illinois }\end{array}$ \\
\hline
\end{tabular}


GENDER REPRESENTATIONS IN ED.D. DISSERTATIONS

\begin{tabular}{|c|c|}
\hline & $\begin{array}{l}\text { University } \\
-2003\end{array}$ \\
\hline $\begin{array}{l}\text { A study of the relationship between selected independent variables and the } \\
\text { success of Latina/o students at a four year institution of higher learning in the } \\
\text { Midwest }\end{array}$ & $\begin{array}{l}\text { Northern } \\
\text { Illinois } \\
\text { University } \\
-2000\end{array}$ \\
\hline $\begin{array}{l}\text { Beginning reading: Linguistic units and instructional strategies that facilitate } \\
\text { word recognition in Latino kindegarten students who are learning to reading } \\
\text { Spanish }\end{array}$ & $\begin{array}{l}\text { University } \\
\text { of } \\
\text { Houston- } \\
2003\end{array}$ \\
\hline $\begin{array}{l}\text { Conversations about reading processes in Spanish and English among six } \\
\text { Latino/a eighth graders }\end{array}$ & $\begin{array}{l}\text { University } \\
\text { of } \\
\text { Houston- } \\
2002\end{array}$ \\
\hline $\begin{array}{l}\text { Investigating the cognitive reading strategies and motivation to read of } \\
\text { resilient, average, and no-resilient fourth-and fifth-grade Latino English } \\
\text { language learners }\end{array}$ & $\begin{array}{l}\text { University } \\
\text { of } \\
\text { Houston- } \\
2002\end{array}$ \\
\hline $\begin{array}{l}\text { Ethnic cleansing in the barrio: A critical ethnography of the politics, practices, } \\
\text { and pedantry of schooling urban Latino bilingual students }\end{array}$ & $\begin{array}{l}\text { University } \\
\text { of } \\
\text { Houston- } \\
2001\end{array}$ \\
\hline $\begin{array}{l}\text { Latino community college transfer students in engineering: Transition } \\
\text { experiences and academic success at a large research university }\end{array}$ & $\begin{array}{l}\text { Arizona } \\
\text { State- } \\
\text { Tempe- } \\
2007\end{array}$ \\
\hline Successful Latino students: A study of five Mexican American families & $\begin{array}{l}\text { Arizona } \\
\text { State- } \\
\text { Tempe- } \\
2006\end{array}$ \\
\hline The Latino/a faculty: A perilous journey to the ivory tower in higher education & $\begin{array}{l}\text { Arizona } \\
\text { State- } \\
\text { Tempe- } \\
2002\end{array}$ \\
\hline Popular education: Adult education for Latina's women empowerment & $\begin{array}{l}\text { Rutgers- } \\
\text { New } \\
\text { Brunswic } \\
\text { k-2005 }\end{array}$ \\
\hline Schools as resilient organizations: Supporting the mathematical resilience of & University \\
\hline
\end{tabular}


GENDER REPRESENTATIONS IN ED.D. DISSERTATIONS

\begin{tabular}{|c|c|}
\hline Latino eight graders & $\begin{array}{l}\text { of } \\
\text { California } \\
\text {-Berkeley- } \\
2007\end{array}$ \\
\hline $\begin{array}{l}\text { Meaning to read or reading for meaning: Promoting reading comprehension } \\
\text { proficiency of Latino English learners IRVINE }\end{array}$ & $\begin{array}{l}\text { University } \\
\text { of } \\
\text { California } \\
\text {-LA \& } \\
\text { Irvine - } \\
2007\end{array}$ \\
\hline $\begin{array}{l}\text { Raising the curtain on theatre arts for Latinos: Finding voice, cultural capital, } \\
\text { literacy, and ethnic identity in high school arts theatre classes IRVINE }\end{array}$ & $\begin{array}{l}\text { University } \\
\text { of } \\
\text { California } \\
\text {-LA \& } \\
\text { Irvine- } \\
2007\end{array}$ \\
\hline $\begin{array}{l}\text { Technology and equity: Explaining differences between elementary teachers } \\
\text { use of computers in low-income Latino and middle class-schools IRVINE \& } \\
\text { UCLA }\end{array}$ & $\begin{array}{l}\text { University } \\
\text { of } \\
\text { California } \\
\text {-LA \& } \\
\text { Irvine- } \\
2007\end{array}$ \\
\hline $\begin{array}{l}\text { Capturing the stories of non-college preparatory Latina/o high school } \\
\text { graduates :reclaiming their stake in education and their dreams UCLA }\end{array}$ & $\begin{array}{l}\text { University } \\
\text { of } \\
\text { California } \\
\text {-LA \& } \\
\text { Irvine- } \\
2007\end{array}$ \\
\hline $\begin{array}{l}\text { Mi fuerza/my strength: The academic and personal experiences of } \\
\text { Chicana/Latina transfer students in math and science IRVINE \& UCLA }\end{array}$ & $\begin{array}{l}\text { University } \\
\text { of } \\
\text { California } \\
\text {-LA \& } \\
\text { Irvine- } \\
2006\end{array}$ \\
\hline $\begin{array}{l}\text { The road less traveled: Latino students and the impact of studying abroad } \\
\text { UCLA }\end{array}$ & $\begin{array}{l}\text { University } \\
\text { of } \\
\text { California } \\
\text {-LA \& } \\
\text { Irvine- } \\
2006\end{array}$ \\
\hline Identifying characteristics of successful schools in Latino communities & University \\
\hline
\end{tabular}


GENDER REPRESENTATIONS IN ED.D. DISSERTATIONS

\begin{tabular}{|c|c|}
\hline IRVINE & $\begin{array}{l}\text { of } \\
\text { California } \\
\text {-LA \& } \\
\text { Irvine- } \\
2004\end{array}$ \\
\hline Finding their way: Experiences of first-generation Latina graduates UCLA & $\begin{array}{l}\text { University } \\
\text { of } \\
\text { California } \\
\text {-LA \& } \\
\text { Irvine- } \\
2004\end{array}$ \\
\hline $\begin{array}{l}\text { Lending a helping hand: Mentoring tomorrow's Latina and Latino leaders into } \\
\text { the } 21^{\text {st }} \text { century UCLA }\end{array}$ & $\begin{array}{l}\text { University } \\
\text { of } \\
\text { California } \\
\text {-LA \& } \\
\text { Irvine- } \\
2004\end{array}$ \\
\hline Understanding homework: Latino parent's perceptions UCLA & $\begin{array}{l}\text { University } \\
\text { of } \\
\text { California } \\
\text {-LA \& } \\
\text { Irvine- } \\
2002\end{array}$ \\
\hline $\begin{array}{l}\text { Effects of extending mathematics instruction through a Saturday academy to } \\
\text { limited English proficient Latino students in low performing schools IRVINE }\end{array}$ & $\begin{array}{l}\text { University } \\
\text { of } \\
\text { California } \\
\text {-LA \& } \\
\text { Irvine- } \\
1999\end{array}$ \\
\hline $\begin{array}{l}\text { Building bridges: Latino immigrant parents explore the home schooling } \\
\text { relationship UCLA }\end{array}$ & $\begin{array}{l}\text { University } \\
\text { of } \\
\text { California } \\
\text {-LA \& } \\
\text { Irvine- } \\
1999\end{array}$ \\
\hline $\begin{array}{l}\text { Math enrichment to prepare Latino high school students for university level } \\
\text { mathematics UCLA }\end{array}$ & $\begin{array}{l}\text { University } \\
\text { of } \\
\text { California } \\
\text {-LA \& } \\
\text { Irvine- } \\
1999\end{array}$ \\
\hline
\end{tabular}




\section{GENDER REPRESENTATIONS IN ED.D. DISSERTATIONS}

\begin{tabular}{|c|c|}
\hline $\begin{array}{l}\text { Recruiting teachers of color: College age Latino/a students share their voices } \\
\text { and recommendations for educator preparation programs }\end{array}$ & $\begin{array}{l}\text { University } \\
\text { of } \\
\text { Massachu } \\
\text { setts- } \\
\text { Amherst - } \\
2007\end{array}$ \\
\hline $\begin{array}{l}\text { Representin' for Latino students: Culturally responsive pedagogies, teacher } \\
\text { identities, and the preparation of teachers for urban schools }\end{array}$ & $\begin{array}{l}\text { University } \\
\text { of } \\
\text { Massachu } \\
\text { setts- } \\
\text { Amherst - } \\
2005\end{array}$ \\
\hline $\begin{array}{l}\text { The FotoDialogo Method: Using pictures and storytelling to promote dialogue } \\
\text { and self discovery among Latinas within a community based organization in } \\
\text { Massachusetts }\end{array}$ & $\begin{array}{l}\text { University } \\
\text { of } \\
\text { Massachu } \\
\text { setts- } \\
\text { Amherst- } \\
1999\end{array}$ \\
\hline $\begin{array}{l}\text { Latina Girls of Puerto Rican origin who Are successful in science and } \\
\text { mathematics high school courses }\end{array}$ & $\begin{array}{l}\text { University } \\
\text { of } \\
\text { Massachu } \\
\text { setts- } \\
\text { Amherst- } \\
1999\end{array}$ \\
\hline $\begin{array}{l}\text { Reflections on the development of learning community among a group of } \\
\text { traditional immigrant Latinas }\end{array}$ & $\begin{array}{l}\text { University } \\
\text { of New } \\
\text { Mexico- } \\
2005\end{array}$ \\
\hline $\begin{array}{l}\text { Latino/a students knowledge about American citizenship, citizenship education } \\
\text { and relevant socio cultural factors }\end{array}$ & $\begin{array}{l}\text { University } \\
\text { of N. } \\
\text { Carolina- } \\
\text { Chapel } \\
\text { Hill-2006 }\end{array}$ \\
\hline The schooling experiences of Latina immigrant high school students & $\begin{array}{l}\text { University } \\
\text { of N. } \\
\text { Carolina- } \\
\text { Chapel } \\
\text { Hill-2003 }\end{array}$ \\
\hline $\begin{array}{l}\text { Differences in language learning strategies between male and female and also } \\
\text { between Asian and Latino ESL students }\end{array}$ & $\begin{array}{l}\text { University } \\
\text { of } \\
\text { Tennessee }\end{array}$ \\
\hline
\end{tabular}


GENDER REPRESENTATIONS IN ED.D. DISSERTATIONS

\begin{tabular}{|c|c|}
\hline & $\begin{array}{l}- \\
\text { Knoxville } \\
-2000\end{array}$ \\
\hline $\begin{array}{l}\text { Fluid identities, adaptable lives: the impact of educational and career } \\
\text { experiences on the identity development of Latina corporate managers }\end{array}$ & $\begin{array}{l}\text { University } \\
\text { of Texas- } \\
\text { Austin- } \\
1999\end{array}$ \\
\hline $\begin{array}{l}\text { Latina/os constructing educational leadership: Cultivating the fields of } \\
\text { leadership }\end{array}$ & $\begin{array}{l}\text { University } \\
\text { of } \\
\text { Washingt } \\
\text { on- } \\
\text { Seattle- } \\
2007\end{array}$ \\
\hline Factors influencing the underrepresentation of Latinos in higher education & $\begin{array}{l}\text { Texas A } \\
\& \text { M } \\
\text { Kingsville } \\
\text {-2006 }\end{array}$ \\
\hline \multicolumn{2}{|l|}{ LGTBIQ (32 abstracts) } \\
\hline $\begin{array}{l}\text { The need for a diversity component, specific to gay and lesbian students, in } \\
\text { undergraduate teacher preparation programs according to selected eastern } \\
\text { North Carolina educators }\end{array}$ & $\begin{array}{l}\text { East } \\
\text { Carolina } \\
\text { U-2001 }\end{array}$ \\
\hline $\begin{array}{l}\text { Assessing principal's perceptions of heterosexism and homophobia in a large } \\
\text { urban public school district }\end{array}$ & $\begin{array}{l}\text { Texas A } \\
\& \text { M } \\
\text { Commerc } \\
\text { e-2005 }\end{array}$ \\
\hline $\begin{array}{l}\text { A case study of the perspectives of gay and lesbian teachers: Overcoming } \\
\text { heterosexism and homophobia in the school community }\end{array}$ & $\begin{array}{l}\text { University } \\
\text { of } \\
\text { Massachu } \\
\text { setts- } \\
\text { Boston- } \\
1999\end{array}$ \\
\hline Heteronormativity and teaching: A phenomenological study of lesbian teachers & $\begin{array}{l}\text { Florida } \\
\text { Internatio } \\
\text { nal U- } \\
2002\end{array}$ \\
\hline $\begin{array}{l}\text { The gay and lesbian counseling experience triad: Curriculum, service and } \\
\text { satisfaction }\end{array}$ & $\begin{array}{l}\text { Northern } \\
\text { Arizona } \\
\text { U-2003 }\end{array}$ \\
\hline $\begin{array}{l}\text { Gay and lesbian school administrators: Negotiating personal and professional } \\
\text { roles and responsibilities within hetero-normative organizations }\end{array}$ & $\begin{array}{l}\text { Northern } \\
\text { Illinois }\end{array}$ \\
\hline
\end{tabular}


GENDER REPRESENTATIONS IN ED.D. DISSERTATIONS

\begin{tabular}{|c|c|}
\hline & $\begin{array}{l}\text { University } \\
-2007\end{array}$ \\
\hline $\begin{array}{l}\text { Subcutaneous:The life experience of African American transsexual college } \\
\text { students }\end{array}$ & $\begin{array}{l}\text { Northern } \\
\text { Illinois } \\
\text { University } \\
-2007\end{array}$ \\
\hline Factors influencing condom use among Latino men who have sex with men & $\begin{array}{l}\text { Northern } \\
\text { Illinois } \\
\text { University } \\
-2006\end{array}$ \\
\hline Examining the lived experience of out gay and lesbian K-12 educators & $\begin{array}{l}\text { San Diego } \\
\text { State- } \\
2005\end{array}$ \\
\hline $\begin{array}{l}\text { Lesbian, gay, bisexual and transgender adult and youth perceptions on school } \\
\text { safety in central Pennsylvania }\end{array}$ & $\begin{array}{l}\text { Temple } \\
\text { University } \\
-2006\end{array}$ \\
\hline $\begin{array}{l}\text { Sexual orientation and multiperspective identity on a small Catholic campus: } \\
\text { An analysis of the cultural climate and multicultural organizational change }\end{array}$ & $\begin{array}{l}\text { Temple } \\
\text { University } \\
-2001\end{array}$ \\
\hline $\begin{array}{l}\text { Heterosexism within educational institutions: Coping efforts of lesbian, gay } \\
\text { and bisexual students in West Texas }\end{array}$ & $\begin{array}{l}\text { Texas } \\
\text { Tech U- } \\
1998\end{array}$ \\
\hline $\begin{array}{l}\text { The relationship between religious fundamentalism and moral development on } \\
\text { homophobia in college undergraduates }\end{array}$ & $\begin{array}{l}\text { Texas } \\
\text { Tech U- } \\
1998\end{array}$ \\
\hline $\begin{array}{l}\text { Complementarity in long term lesbian relationships and non-lesbian female } \\
\text { friendships }\end{array}$ & $\begin{array}{l}\text { University } \\
\text { of } \\
\text { Louisville } \\
-2000\end{array}$ \\
\hline Constructing the experiences of gay and lesbian high school students in Maine & $\begin{array}{l}\text { University } \\
\text { of Maine- } \\
2005\end{array}$ \\
\hline $\begin{array}{l}\text { The preparation of undergraduate social work students in same faith based } \\
\text { institutions for professional practice with gay and lesbian persons: A } \\
\text { qualitative study }\end{array}$ & $\begin{array}{l}\text { University } \\
\text { of } \\
\text { Memphis- } \\
2001\end{array}$ \\
\hline A feeling of belonging: Impacts of gay-straight alliances on high school & Arizona \\
\hline
\end{tabular}


GENDER REPRESENTATIONS IN ED.D. DISSERTATIONS

\begin{tabular}{|c|c|}
\hline students & $\begin{array}{l}\text { State- } \\
\text { Tempe- } \\
2007\end{array}$ \\
\hline $\begin{array}{l}\text { Out of the closet and onto Fraternity Row: An ethnographic study of } \\
\text { heterosexism and homophobia in a college fraternity community }\end{array}$ & $\begin{array}{l}\text { Florida } \\
\text { State- } \\
2006\end{array}$ \\
\hline $\begin{array}{l}\text { The interrelationship between being lesbian and its impact on community } \\
\text { college leadership }\end{array}$ & $\begin{array}{l}\text { Oregon } \\
\text { State U- }\end{array}$ \\
\hline Gay men at midlife and adult learning. An uneasy truce with heteronormativity & $\begin{array}{l}\text { Pennsylva } \\
\text { nia State- } \\
2007\end{array}$ \\
\hline $\begin{array}{l}\text { Gay straight alliances in high schools: A case study of four urban, public } \\
\text { schools UCLA }\end{array}$ & $\begin{array}{l}\text { University } \\
\text { of } \\
\text { California } \\
\text {-LA \& } \\
\text { Irvine- } \\
2006\end{array}$ \\
\hline $\begin{array}{l}\text { Urban cowgirls: How lesbians learn to negotiate the heterosexism of corporate } \\
\text { American }\end{array}$ & $\begin{array}{l}\text { University } \\
\text { of } \\
\text { Georgia- } \\
2000\end{array}$ \\
\hline $\begin{array}{l}\text { Living outside the circle: the politics of HIV/AIDS education and the } \\
\text { disenfranchisement of HIV-negative gay men }\end{array}$ & $\begin{array}{l}\text { University } \\
\text { of } \\
\text { Georgia- } \\
1999\end{array}$ \\
\hline $\begin{array}{l}\text { Strangers in good company: The accuracy of student's perception of peer } \\
\text { attitudes towards gays, lesbians and bisexuals }\end{array}$ & $\begin{array}{l}\text { University } \\
\text { of } \\
\text { Massachu } \\
\text { setts- } \\
\text { Amherst - } \\
2006\end{array}$ \\
\hline $\begin{array}{l}\text { Off that spectrum entirely: A study of female-bodied transgendered-identified } \\
\text { individuals }\end{array}$ & $\begin{array}{l}\text { University } \\
\text { of } \\
\text { Massachu } \\
\text { setts- } \\
\text { Amherst- } \\
2003\end{array}$ \\
\hline A description of gay/straight alliances in the public schools of Massachusetts & $\begin{array}{l}\text { University } \\
\text { of }\end{array}$ \\
\hline
\end{tabular}


GENDER REPRESENTATIONS IN ED.D. DISSERTATIONS

\begin{tabular}{|c|c|}
\hline & $\begin{array}{l}\text { Massachu } \\
\text { setts- } \\
\text { Amherst- } \\
2000\end{array}$ \\
\hline $\begin{array}{l}\text { A multicultural organization development examination of school based change } \\
\text { strategies to address needs of gay youth }\end{array}$ & $\begin{array}{l}\text { University } \\
\text { of } \\
\text { Massachu } \\
\text { setts- } \\
\text { Amherst - } \\
1998\end{array}$ \\
\hline Re-Sallying Quids: Resilience of queer youth in school & $\begin{array}{l}\text { University } \\
\text { of } \\
\text { Michigan } \\
-2001\end{array}$ \\
\hline $\begin{array}{l}\text { Activism for LGTB rights: How participation affects the lives of activist } \\
\text { educators }\end{array}$ & $\begin{array}{l}\text { University } \\
\text { of N. } \\
\text { Carolina- } \\
\text { Chapel } \\
\text { Hill-2005 }\end{array}$ \\
\hline $\begin{array}{l}\text { Attitudes of educators/administrators towards lesbian, gay, bisexual and } \\
\text { transgendered students }\end{array}$ & $\begin{array}{l}\text { University } \\
\text { of } \\
\text { Tennessee } \\
- \\
\text { Knoxville } \\
-2002\end{array}$ \\
\hline $\begin{array}{l}\text { Lesbian, gay, bisexual, and transgender equity issues: A study of preservice } \\
\text { teacher's perceptions of current practices in teacher education }\end{array}$ & $\begin{array}{l}\text { Washingt } \\
\text { on State- } \\
2002\end{array}$ \\
\hline $\begin{array}{l}\text { The impact of youth centered groups on the self-efficacy of gay and lesbian } \\
\text { youth }\end{array}$ & $\begin{array}{l}\text { Washingt } \\
\text { on State- } \\
2000\end{array}$ \\
\hline \multicolumn{2}{|l|}{ Title IX ( 15 abstracts) } \\
\hline $\begin{array}{l}\text { Complying with Title IX: An analysis of emergent leadership issued in an } \\
\text { NCAA Division I Institution }\end{array}$ & $\begin{array}{l}\text { Indiana U } \\
\text { of PA- } \\
2005\end{array}$ \\
\hline $\begin{array}{l}\text { Has Title IX enforcement had an adverse effect on the number of participation } \\
\text { opportunities at NCAA Division I institutions for male student athletes? }\end{array}$ & $\begin{array}{l}\text { Tennessee } \\
\text { State- } \\
2003\end{array}$ \\
\hline The effectiveness of NCAA Division I athletes program leadership in assuring & Northern \\
\hline
\end{tabular}


GENDER REPRESENTATIONS IN ED.D. DISSERTATIONS

\begin{tabular}{|c|c|}
\hline Title IX Compliance & $\begin{array}{l}\text { Arizona } \\
\text { U-2000 }\end{array}$ \\
\hline $\begin{array}{l}\text { Title IX Compliance: A comparative analysis of the perceptions of athletic } \\
\text { directors represented in the NEW Jersey State Interscholastic Athletic } \\
\text { Association (NJSIAA) and athletic directors represented in the National } \\
\text { Collegiate Athletic Association (NCAA) division III }\end{array}$ & $\begin{array}{l}\text { Temple } \\
\text { University } \\
-2000\end{array}$ \\
\hline $\begin{array}{l}\text { A history and analysis of sports related Title IX legislation and litigation from } \\
1972 \text { to } 1997\end{array}$ & $\begin{array}{l}\text { University } \\
\text { of } \\
\text { Alabama- } \\
1998\end{array}$ \\
\hline $\begin{array}{l}\text { An analysis of the perception of the degree of compliance of selected Texas } \\
\text { public high schools with Title IX of the Education Amendments of } 1972\end{array}$ & $\begin{array}{l}\text { University } \\
\text { of N. } \\
\text { Texas- } \\
2005\end{array}$ \\
\hline $\begin{array}{l}\text { The post Title IX generation: Perceptions and experiences of gender equity } \\
\text { among new university faculty }\end{array}$ & $\begin{array}{l}\text { University } \\
\text { of } \\
\text { Oregon- } \\
2004\end{array}$ \\
\hline $\begin{array}{l}\text { Teams on paper: Title IX compliance in the Maryland Junior College Athletic } \\
\text { Conference }\end{array}$ & $\begin{array}{l}\text { University } \\
\text { of } \\
\text { Delaware- } \\
1998\end{array}$ \\
\hline Title IX compliance and Georgia high school athletic programs ${ }^{\mathrm{d}}$ & $\begin{array}{l}\text { University } \\
\text { of } \\
\text { Georgia- } \\
1999\end{array}$ \\
\hline $\begin{array}{l}\text { Athletic gender equity policy: The potential for United States Title IX } \\
\text { directives in Canadian universities }\end{array}$ & $\begin{array}{l}\text { University } \\
\text { of } \\
\text { Nebraska- } \\
2006\end{array}$ \\
\hline Title IX intent vs action: Compliance and equity in Allegheny public schools ${ }^{\mathrm{d}}$ & $\begin{array}{l}\text { University } \\
\text { of } \\
\text { Pittsburgh } \\
-2000\end{array}$ \\
\hline $\begin{array}{l}\text { Women in collegiate sports: The struggle for equity since the } 1972 \text { Title IX } \\
\text { Education Amendment }\end{array}$ & $\begin{array}{l}\text { University } \\
\text { of } \\
\text { Pittburgh- } \\
1998\end{array}$ \\
\hline Title IX compliance in Virginia high schools ${ }^{d}$ & Virginia \\
\hline
\end{tabular}


GENDER REPRESENTATIONS IN ED.D. DISSERTATIONS

\begin{tabular}{|c|c|}
\hline & $\begin{array}{l}\text { Polytechni } \\
\text { c \& State } \\
\text { U-2006 }\end{array}$ \\
\hline $\begin{array}{l}\text { Perceptions of Title IX and gender equity: The influence of life histories, sports } \\
\text { experiences and campus initiatives }\end{array}$ & $\begin{array}{l}\text { SUNY } \\
\text { Binghamp } \\
\text { ton-2006 }\end{array}$ \\
\hline $\begin{array}{l}\text { Historical comparison of Florida and national Title IX compliance trends in } \\
\text { high school sports from 1985-2005 }\end{array}$ & $\begin{array}{l}\mathrm{U} \text { of } \\
\text { Central } \\
\text { Florida- } \\
2007\end{array}$ \\
\hline \multicolumn{2}{|l|}{ Feminist (19 abstracts ) } \\
\hline $\begin{array}{l}\text { An inquiry into the experiences of the African American women principal: } \\
\text { Critical race theory and Black feminist principles }\end{array}$ & $\begin{array}{l}\text { Georgia } \\
\text { Southern } \\
\text { U-2004 }\end{array}$ \\
\hline Postmodern feminist pedagogy in a first-year writing class ${ }^{\mathrm{e}}$ & $\begin{array}{l}\text { Georgia } \\
\text { Southern } \\
\text { U-2003 }\end{array}$ \\
\hline $\begin{array}{l}\text { Women in public middle school administration in Georgia: A feminist analysis } \\
\text { of the perceptions of women in power }\end{array}$ & $\begin{array}{l}\text { Georgia } \\
\text { Southern } \\
\text { U-2001 }\end{array}$ \\
\hline $\begin{array}{l}\text { Pre-service teacher's beliefs about teaching and learning before, during and } \\
\text { after the application of feminist pedagogies }\end{array}$ & $\begin{array}{l}\text { Texas A } \\
\& \mathrm{M} \\
\text { Commerc } \\
\text { e-2000 }\end{array}$ \\
\hline $\begin{array}{l}\text { Feminist and Eugenicist thinking in a woman educator: The case of Leta } \\
\text { Stetter Hollingworth }^{\text {af }}\end{array}$ & $\begin{array}{l}\text { Indiana U } \\
\text { Purdue- } \\
2003\end{array}$ \\
\hline $\begin{array}{l}\text { Empowerment of low-income women in India: Emergent feminist grassroots } \\
\text { leaders in Ahmedabad, Gujarat }\end{array}$ & $\begin{array}{l}\text { Northern } \\
\text { Illinois } \\
\text { University } \\
-2006\end{array}$ \\
\hline $\begin{array}{l}\text { Coming into their own: A study of a feminist adult education program in } \\
\text { Esteli, Nicaragua }\end{array}$ & $\begin{array}{l}\text { Northern } \\
\text { Illinois } \\
\text { University } \\
-2003\end{array}$ \\
\hline $\begin{array}{l}\text { An investigation into the illustrations of Snow } \\
\text { White and her stepmother in selected retellings of "Snow White and the Seven } \\
\text { Dwarfs" from } 1882 \text { to 1996:A feminist inquiry af }\end{array}$ & $\begin{array}{l}\text { Northern } \\
\text { Illinois } \\
\text { University } \\
-2001\end{array}$ \\
\hline
\end{tabular}


GENDER REPRESENTATIONS IN ED.D. DISSERTATIONS

\begin{tabular}{|c|c|}
\hline $\begin{array}{l}\text { A feminist phase theory exploration of the development of levels of gender } \\
\text { awareness in the superintendency }\end{array}$ & $\begin{array}{l}\text { Oklahoma } \\
\text { State- } \\
\text { Main- } \\
2000\end{array}$ \\
\hline $\begin{array}{l}\text { The selection of high school principals: An examination of the process using } \\
\text { feminist phase theory }\end{array}$ & $\begin{array}{l}\text { Oklahoma } \\
\text { State- } \\
\text { Main- } \\
1999\end{array}$ \\
\hline A postmodern feminist text analysis of the pedagogy of popular craft & $\begin{array}{l}\text { Oklahoma } \\
\text { State- } \\
\text { Main- } \\
1998\end{array}$ \\
\hline In their own voices: The impact of the feminist movement in adult education ${ }^{\mathrm{e}}$ & $\begin{array}{l}\text { University } \\
\text { of } \\
\text { Southern } \\
\text { Mississipp } \\
\text { i-2005 }\end{array}$ \\
\hline $\begin{array}{l}\text { A sense of entitlement to self in relationships: An elaboration of attachment } \\
\text { and feminist object relations theory }\end{array}$ & $\begin{array}{l}\text { Western } \\
\text { Michigan } \\
\text { University } \\
-1998\end{array}$ \\
\hline $\begin{array}{l}\text { Feminist popular education in Latin American: A case study on the political } \\
\text { empowerment of women in the Dominican republic }\end{array}$ & $\begin{array}{l}\text { SUNY- } \\
\text { Albany- } \\
1999\end{array}$ \\
\hline $\begin{array}{l}\text { African-American women in school psychology: The sociological framework } \\
\text { of Black feminist thought and development of role in practice }\end{array}$ & $\begin{array}{l}\text { University } \\
\text { of } \\
\text { Cincinnati } \\
\text {-1998 }\end{array}$ \\
\hline Negotiating feminist interests in elementary and secondary schools & $\begin{array}{l}\text { University } \\
\text { of Georgia } \\
-2002\end{array}$ \\
\hline $\begin{array}{l}\text { Making science accessible through collaborative science teacher action } \\
\text { research on feminist pedagogy }\end{array}$ & $\begin{array}{l}\text { University } \\
\text { of } \\
\text { Massachu } \\
\text { setts- } \\
\text { Amherst- } \\
2002\end{array}$ \\
\hline Adult literacy clients as authors: A feminist poststructuralist perspective & $\begin{array}{l}\text { University } \\
\text { of }\end{array}$ \\
\hline
\end{tabular}


GENDER REPRESENTATIONS IN ED.D. DISSERTATIONS

\begin{tabular}{|l|l|}
\hline & $\begin{array}{l}\text { Massachu } \\
\text { setts- } \\
\text { Amherst- } \\
2000\end{array}$ \\
\hline $\begin{array}{l}\text { Brick walls and broken mirrors: A case study of feminist and critical pedagogy } \\
\text { in graduate adult education }\end{array}$ & $\begin{array}{l}\text { University } \\
\text { of } \\
\text { S. } \\
\text { Carolina- } \\
\text { Columbia- } \\
2001\end{array}$ \\
\hline
\end{tabular}


GENDER REPRESENTATIONS IN ED.D. DISSERTATIONS

\section{APPENDIX L CODING MEMO 3 \# COMPLETE TEXTS LGTBIQ}

Shores (2007). A feeling of belonging: impacts of gay-straight alliances on high school students.

Doppler (2000). A description of gay-straight alliances in the public schools of Massachusetts.

Talone (2006). Gay-Straight alliances in the schools: A case study of four urban, public schools.

\begin{tabular}{|c|c|c|c|}
\hline LGTBIQ & Fear & Silencing & Discrimination \\
\hline Doppler & $\begin{array}{l}\text { Student afraid to } \\
\text { publicly identify w } \\
\text { GSA } \\
\text { Students afraid to } \\
\text { identify as gay } \\
\text { Students discuss } \\
\text { threats } \\
\text { Fear of physical } \\
\text { violence } \\
\text { Faculty fear loss of } \\
\text { jobs } \\
\text { Administrators } \\
\text { afraid of backlash }\end{array}$ & $\begin{array}{l}\text { Posters destroyed or } \\
\text { ripped down } \\
\text { Faculty deny } \\
\text { presence of gay } \\
\text { students } \\
\text { Refuse to read } \\
\text { announcements }\end{array}$ & $\begin{array}{l}\text { Students } \\
\text { intimidated } \\
\text { Students } \\
\text { ridiculed } \\
\text { Conflict in } \\
\text { school \& } \\
\text { community } \\
\text { Constant } \\
\text { administrative } \\
\text { hassles }\end{array}$ \\
\hline Shore & $\begin{array}{l}\text { Student afraid to } \\
\text { publicly identify w } \\
\text { GSA } \\
\text { Advisor afraid to } \\
\text { serve on committee } \\
\text { Fear of research } \\
\text { aggravating parents }\end{array}$ & $\begin{array}{l}\text { Posters destroyed or } \\
\text { ripped down } \\
\text { Security guards } \\
\text { disallow posters } \\
\text { Refusal to read } \\
\text { announcements } \\
\text { Faculty ask to be } \\
\text { removed from e- } \\
\text { mails } \\
\text { Researchers denied } \\
\text { interview access } \\
\text { Faculty peers ask } \\
\text { GSA advisors to } \\
\text { stop }\end{array}$ & $\begin{array}{l}\text { Students } \\
\text { intimidated } \\
\text { Students } \\
\text { ridiculed } \\
\text { Administrative } \\
\text { backlash to } \\
\text { faculty } \\
\text { Constant } \\
\text { administrative } \\
\text { hassles } \\
\text { Conflict in } \\
\text { school \& } \\
\text { community } \\
\text { Gay faculty: }\end{array}$ \\
\hline
\end{tabular}


GENDER REPRESENTATIONS IN ED.D. DISSERTATIONS

\begin{tabular}{|l|l|l|l|}
\hline & & & $\begin{array}{l}\text { parents disenroll } \\
\text { kids } \\
\text { Gay faculty: } \\
\text { admin disenroll } \\
\text { kids } \\
\text { Faculty refuse to } \\
\text { advise GSA } \\
\text { clubs } \\
\text { GSA faculty } \\
\text { receive review } \\
\text { warnings }\end{array}$ \\
& & & \\
\hline Talone & $\begin{array}{l}\text { Student afraid to } \\
\text { publicly identify w } \\
\text { GSA } \\
\text { Students report fear } \\
\text { of retaliation } \\
\text { Faculty fear career } \\
\text { repercussions }\end{array}$ & $\begin{array}{l}\text { Posters destroyed or } \\
\text { ripped down } \\
\text { Refusal to read } \\
\text { announcements } \\
\text { Parents disallow } \\
\text { students to join } \\
\text { Parents will not } \\
\text { listen/support } \\
\text { members }\end{array}$ & $\begin{array}{l}\text { Students } \\
\text { intimidated } \\
\text { Students } \\
\text { ridiculed } \\
\text { Homophobic } \\
\text { teaching } \\
\text { comments } \\
\text { Conflict in } \\
\text { school \& } \\
\text { community }\end{array}$ \\
& & & \\
\hline
\end{tabular}

\section{Tetreault Feminist Phase Theory}

Because these three studies represent LGTBIQ issues they implicitly fall into Tetreault's phase 4, feminist scholarship. However there was little discussion of any other intersectionalities. Doppler's study makes a mention of other identity variables when she states "Interviewees identified two groups who are underserved by GSA's, student of color and transgendered students" (p. 139). 
GENDER REPRESENTATIONS IN ED.D. DISSERTATIONS

All of the studies of GSA's conceptualized gender as a social construction, Tetreault Phase 3, and there was also some critique of gender as a social construction, Tetreault Phase 5.

There was no additional insight about gender conceptualization or cultural beliefs gained from these full text dissertations that was not identified in the abstracts. However reading the full text made you more aware of the overt oppression and often violent opposition faced by LGTBIQ students who are not conforming to the cultural gender belief that privileges heterosexuality. 
GENDER REPRESENTATIONS IN ED.D. DISSERTATIONS

APPENDIX M CODING MEMO \#3 DISSERTATION BLACK MALES

Crawford (2002). The attitudes of Rural eight grade black males toward academic learning and its impact on academic achievement.

Marshall (2003). The impact of locus of control on the academic achievement of African American males

Salley (2005). Exploring the relationship between personal motivation, persistence, and resilience, and their effects on academic achievement among different groups of African American Males in high schools.

\begin{tabular}{|l|l|l|l|}
\hline $\begin{array}{l}\text { Black } \\
\text { Males }\end{array}$ & Fear & Silencing & Discrimination \\
\hline Crawford & $\begin{array}{l}\text { Lose friends if } \\
\text { academic A+ }\end{array}$ & $\begin{array}{l}\text { Self-School=acting } \\
\text { white } \\
\text { Self-Assimilate to } \\
\text { survive } \\
\text { Low tracking \& } \\
\text { special ed }\end{array}$ & $\begin{array}{l}\text { Denial of equal } \\
\text { education } \\
\text { opportunities } \\
\text { Portrayed as } \\
\text { deviant/deficient } \\
\text { Portrayed } \\
\text { aggressive/violent }\end{array}$ \\
\hline Marshall & $\begin{array}{l}\text { Lose friends if } \\
\text { academic A+ }\end{array}$ & $\begin{array}{l}\text { Self-School=acting } \\
\text { white } \\
\text { Low tracking \& } \\
\text { special ed }\end{array}$ & $\begin{array}{l}\text { Denial of equal } \\
\text { education } \\
\text { opportunities } \\
\text { Portrayed as } \\
\text { deviant/deficient } \\
\text { Portrayed } \\
\text { aggressive/violent }\end{array}$ \\
\hline Salley & & $\begin{array}{l}\text { Self-School=acting } \\
\text { white }\end{array}$ & $\begin{array}{l}\text { Dequation } \\
\text { opportunities }\end{array}$ \\
\hline
\end{tabular}

The three studies examining achievement in black male students

offered varied representations in the studies framing of the problem and literature that perpetuate problematic cultural beliefs or supports the critique and disruption of them. Below is an example of the spectrum of these 


\section{GENDER REPRESENTATIONS IN ED.D. DISSERTATIONS}

differences as indicated in the discussion of the study rationale and significance.

Crawford 's (2002) discussion of the study's rationale and significance states the study is undertaken to determine" why Black male students achieve at lower rates than their White counterparts" (p.4).

Marshall's (2003) discussion of the study's rationale and significance states the study is undertaken to identify" factors that are needed to cause African American male students to perform better academically" (p.4.).

Sally's (2005) discussion of the study's rationale and significance states the study is undertaken to investigate differences in motivation, persistence, resilience among academically achieving Black males and identify quantitative and qualitative factors that might contribute to academic success" (p.1).

Another example of this varied level of representation and critique is prevalent in the literature reviews of the three studies. Crawford's (2002) literature review reports the prior literature on achievement issues of black males in very negative language without much critical examination or rebuttal to those studies. In contrast, Marshall's study includes several pages of strong rebuttal and critique of negative representations and 
GENDER REPRESENTATIONS IN ED.D. DISSERTATIONS

framings in the literature. Finally the Sally study takes the literature framing a bit further in that the discussion is primarily framed as a social problem experienced by many, including Black males.

\section{Tetreault Feminist Phase Theory}

This group of dissertations primarily represents Tetreault Phase 4, because it implicitly examines the intersection of race and gender. Although not much discussion was in the dissertations on how black males differ from black females, so gender was secondary to the examination of race.

However, these dissertations were selected because they examined race, so it was no surprise that this was the predominant theme. An examination of the entire text did not lead to much more information about gender beliefs and gender conceptualizations than what was represented in the abstracts. 
GENDER REPRESENTATIONS IN ED.D. DISSERTATIONS

APPENDIX N CODING MEMO \# 3 COMPLETE M v. F LEADERSHIP

Clisbee (2004). Leadership style: Do male and female school superintendents lead differently?

Hallorin (2007). Are there differences in the perceived leadership practices of female and male superintendents as identified by school committee members?

Pasteris (1998). Investigating the differences in leadership styles and effectiveness between male and female public high-school principals in Illinois?

\begin{tabular}{|c|c|c|c|}
\hline $\begin{array}{l}\text { Gendered } \\
\text { Leadership }\end{array}$ & Fear & Silencing & Discrimination \\
\hline Clisbee & $\begin{array}{l}\text { Lose } \\
\text { femininity } \\
\text { approval }\end{array}$ & $\begin{array}{l}\text { Gender inequity } \\
\text { not addressed } \\
\text { school } \\
\text { Women } \\
\text { contributions } \\
\text { ignored } \\
\text { Female } \\
\text { Impression } \\
\text { management } \\
\text { w/style }\end{array}$ & $\begin{array}{l}\text { Women denied } \\
\text { access to } \\
\text { leadership }\end{array}$ \\
\hline Hallorin & $\begin{array}{l}\text { Lose } \\
\text { femininity } \\
\text { approval } \\
\text { Pressure to } \\
\text { conform } \\
\text { To gender } \\
\text { roles }\end{array}$ & $\begin{array}{l}\text { Gender inequity } \\
\text { not addressed } \\
\text { school } \\
\text { Female } \\
\text { Impression } \\
\text { management } \\
\text { w/style } \\
\text { Exclusion to } \\
\text { networks } \\
\text { Women bullied } \\
\text { by school } \\
\text { committees } \\
\text { Conversations cut } \\
\text { off and ignored }\end{array}$ & $\begin{array}{l}\text { Women denied } \\
\text { access to } \\
\text { leadership } \\
\text { Leader =male } \\
\text { Males privileged } \\
\text { for hiring/post } \\
\text { war vets } \\
\text { Family duties for } \\
\text { women only } \\
\text { Women held to } \\
\text { higher standards }\end{array}$ \\
\hline
\end{tabular}


GENDER REPRESENTATIONS IN ED.D. DISSERTATIONS

\begin{tabular}{|l|l|l|l|}
\hline & & $\begin{array}{l}\text { by Board } \\
\text { members } \\
\text { Assertive women } \\
\text { sanctioned }\end{array}$ & \\
\hline Pasteris & $\begin{array}{l}\text { Lose } \\
\text { femininity } \\
\text { approval } \\
\text { Pressure to } \\
\text { conform to } \\
\text { gender roles }\end{array}$ & $\begin{array}{l}\text { Female } \\
\text { Impression } \\
\text { management } \\
\text { w/style } \\
\text { Men don't like } \\
\text { women leaders } \\
\text { who are assertive }\end{array}$ & $\begin{array}{l}\text { Women denied } \\
\text { access to } \\
\text { leadership } \\
\text { Males privileged } \\
\text { in hiring/Females } \\
\text { will get pregnant } \\
\text { \& leave }\end{array}$ \\
& & & \\
\hline
\end{tabular}

All three of these studies use a quantitative design to assess

perceived effectiveness of leaders and to assess if these perceptions are related to gender.

\section{Tetreault Feminist Phase Theory}

Most of the representations of the full text dissertations that can be examined under lens of Tetreault Feminist Phase Theory occurred in the literature review. Each of the studies included literature from phase 2.a that acknowledged male and female difference, and all three also represented 2.b, females were compared to male norms. However we must be mindful these 3 dissertations were purposefully selected for that purpose. 


\section{GENDER REPRESENTATIONS IN ED.D. DISSERTATIONS}

Additionally, they all had several representations in phase 3, a, gender as a social construction and Clisbee's dissertation strongly and explicitly critiqued the social construction of gender, 5.a.

It is interesting to note that the dissertation in this group, the dissertation written by a man, Pasteris, cited literature in a way that reflected males disapproval of female leaders. Some of these statements such as "what increases the cost of employing female executives is principally the clash of their perceptions, attitudes and behavior with males in male led organizations (p.5)" insinuates that the biggest problem women have is their inability to get along with men. or "male instructors tended to react negatively to serving under female supervisors" (p.8). Although the author is describing the study findings of others in his literature review, the language implies that naturally employers are unwilling to hire women because they cannot get along with men. It reinforces women as deficient, not the sexist beliefs of the male coworkers. 
GENDER REPRESENTATIONS IN ED.D. DISSERTATIONS

APPENDIX O. Tetreault coding MALE v FEMALE LEADERSHIP

\begin{tabular}{|c|c|c|c|}
\hline Gender focused dissertations & Institutions & Tetreault & \\
\hline $\begin{array}{l}\text { An investigation of gender differences in } \\
\text { motivation of senior administrators in Virginia } \\
\text { community colleges using Herzberg's two } \\
\text { factor theory }\end{array}$ & $\begin{array}{l}\text { East } \\
\text { Tennessee } \\
\text { State U-2006 }\end{array}$ & $2 . \mathrm{a}$ & $\begin{array}{l}\text { MF } \\
\text { Leader } \\
1\end{array}$ \\
\hline $\begin{array}{l}\text { The contemporary manager: Exploring female } \\
\text { and male leadership styles }\end{array}$ & $\begin{array}{l}\text { East } \\
\text { Tennessee } \\
\text { State U-2003 }\end{array}$ & $\begin{array}{l}2 . \mathrm{a} \\
3 . \mathrm{b}\end{array}$ & $\begin{array}{l}\mathrm{MF} \\
\text { Leader } \\
2\end{array}$ \\
\hline $\begin{array}{l}\text { Relationships between gender and teacher's } \\
\text { perceptions of principal effectiveness in } \\
\text { Georgia schools }\end{array}$ & $\begin{array}{l}\text { Georgia } \\
\text { Southern U- } \\
2002\end{array}$ & $2 . \mathrm{a}$ & $\begin{array}{l}\mathrm{MF} \\
\text { Leader } \\
3\end{array}$ \\
\hline $\begin{array}{l}\text { The study of school climate, principals } \\
\text { communication style, principal's sex and } \\
\text { school level }\end{array}$ & $\begin{array}{l}\text { Portland State } \\
\text { U-1999 }\end{array}$ & 2.a, 2.d & $\begin{array}{l}\mathrm{MF} \\
\text { Leader } \\
4\end{array}$ \\
\hline $\begin{array}{l}\text { An analysis of gender differences public school } \\
\text { superintendents' conflict management modes in } \\
\text { relation to synergistic leadership theory }\end{array}$ & $\begin{array}{l}\text { Sam Houston } \\
\text { U } \\
2004\end{array}$ & $2 . \mathrm{a}$ & $\begin{array}{l}\text { MF } \\
\text { Leader } \\
5\end{array}$ \\
\hline $\begin{array}{l}\text { Texas superintendent's perceptions of their } \\
\text { superintendent preparation programs: In } \\
\text { general and by gender }\end{array}$ & $\begin{array}{l}\text { Sam Houston } \\
\text { U } \\
1999\end{array}$ & $2 . a$ & $\begin{array}{l}\text { MF } \\
\text { Leader } \\
6\end{array}$ \\
\hline $\begin{array}{l}\text { Teacher's perceptions of effectiveness of } \\
\text { female and male principals }\end{array}$ & $\begin{array}{l}\text { Tennessee } \\
\text { State-2007 }\end{array}$ & $\begin{array}{l}2 . \mathrm{a} \\
3 . \mathrm{b}\end{array}$ & $\begin{array}{l}\text { MF } \\
\text { Leader } \\
7\end{array}$ \\
\hline $\begin{array}{l}\text { Perceived leadership effectiveness of male and } \\
\text { female directors of schools in West and East } \\
\text { Tennessee }\end{array}$ & $\begin{array}{l}\text { Tennessee } \\
\text { State-2001 }\end{array}$ & $\begin{array}{l}2 . \mathrm{a} \\
3 . \mathrm{b}\end{array}$ & $\begin{array}{l}\text { MF } \\
\text { Leader } \\
8\end{array}$ \\
\hline $\begin{array}{l}\text { Perceived leadership effectiveness of male and } \\
\text { female directors of schools }\end{array}$ & $\begin{array}{l}\text { Tennessee } \\
\text { State-2000 }\end{array}$ & 2.a, 2.b & $\begin{array}{l}\text { MF } \\
\text { Leader } \\
9\end{array}$ \\
\hline $\begin{array}{l}\text { Leadership and followership: A gender } \\
\text { perspective }\end{array}$ & $\begin{array}{l}\text { Texas A \& M } \\
\text { Commerce- } \\
2007\end{array}$ & $\begin{array}{l}2 . a \\
3 . b \\
4 . a\end{array}$ & $\begin{array}{l}\text { MF } \\
\text { Leader } \\
10\end{array}$ \\
\hline $\begin{array}{l}\text { Superintendent gender and student } \\
\text { achievement: A postmodern perspective }\end{array}$ & $\begin{array}{l}\text { Texas A \& M } \\
\text { Commerce- } \\
2007\end{array}$ & 2.a,2.b & $\begin{array}{l}\text { MF } \\
\text { Leader } \\
11\end{array}$ \\
\hline $\begin{array}{l}\text { Gender and conflict management styles of } \\
\text { Texas secondary school assistant principals: A }\end{array}$ & $\begin{array}{l}\text { Texas A \& M } \\
\text { Commerce- }\end{array}$ & $2 . \mathrm{a}$ & $\begin{array}{l}\text { MF } \\
\text { Leader }\end{array}$ \\
\hline
\end{tabular}


GENDER REPRESENTATIONS IN ED.D. DISSERTATIONS

\begin{tabular}{|c|c|c|c|}
\hline descriptive study & 2005 & & 12 \\
\hline $\begin{array}{l}\text { A study of factors associated with gender } \\
\text { specific superintendents in public schools }\end{array}$ & $\begin{array}{l}\text { Texas A \& M } \\
\text { Kingsville- } \\
2002\end{array}$ & 2.a,2.c & $\begin{array}{l}\text { MF } \\
\text { Leader } \\
13\end{array}$ \\
\hline $\begin{array}{l}\text { Are there differences in the perceived } \\
\text { leadership practices of female and male } \\
\text { superintendents as identified by school } \\
\text { committee members }\end{array}$ & $\begin{array}{l}\text { University of } \\
\text { Massachusett } \\
\text { s-Lowell- } \\
2007\end{array}$ & $\begin{array}{l}2 . \mathrm{a} \\
3 . \mathrm{b}\end{array}$ & $\begin{array}{l}\text { MF } \\
\text { Leader } \\
14\end{array}$ \\
\hline $\begin{array}{l}\text { Leadership style: Do male and female school } \\
\text { superintendents lead differently? }\end{array}$ & $\begin{array}{l}\text { University of } \\
\text { Massachusett } \\
\text { s-Lowell- } \\
2004\end{array}$ & $\begin{array}{l}2 . \mathrm{a} \\
3 . \mathrm{b}\end{array}$ & $\begin{array}{l}\mathrm{MF} \\
\text { Leader } \\
15\end{array}$ \\
\hline Gender differences in principal motivations & $\begin{array}{l}\text { Florida } \\
\text { International } \\
\text { U- }\end{array}$ & $\begin{array}{l}\text { 2a., } 2 . b \\
3 . d\end{array}$ & $\begin{array}{l}\text { MF } \\
\text { Leader } \\
16\end{array}$ \\
\hline $\begin{array}{l}\text { Perspectives of experienced female and male } \\
\text { superintendents of large suburban Illinois } \\
\text { public school districts on the evolving role of } \\
\text { the superintendent: Implications for leadership }\end{array}$ & $\begin{array}{l}\text { Northern } \\
\text { Illinois } \\
\text { University- } \\
2000\end{array}$ & $2 . \mathrm{a}$ & $\begin{array}{l}\text { MF } \\
\text { Leader } \\
17\end{array}$ \\
\hline $\begin{array}{l}\text { Perspectives of experienced female and male } \\
\text { superintendents of small rural Illinois public } \\
\text { school districts on the evolving role of the } \\
\text { superintendent: Implications for leadership }\end{array}$ & $\begin{array}{l}\text { Northern } \\
\text { Illinois } \\
\text { University- } \\
2000\end{array}$ & 2.a & $\begin{array}{l}\text { MF } \\
\text { Leader } \\
18\end{array}$ \\
\hline $\begin{array}{l}\text { Investigating the difference in leadership styles } \\
\text { and effectiveness between male and female } \\
\text { public high school principals in Illinois }\end{array}$ & $\begin{array}{l}\text { Northern } \\
\text { Illinois } \\
\text { University- } \\
1998\end{array}$ & $\begin{array}{l}2 . \mathrm{a} \\
3 . \mathrm{b}\end{array}$ & $\begin{array}{l}\text { MF } \\
\text { Leader } \\
19\end{array}$ \\
\hline $\begin{array}{l}\text { A comparative analysis of leadership attitudes } \\
\text { of male and female elementary public school } \\
\text { principals in Arkansas }\end{array}$ & $\begin{array}{l}\text { University of } \\
\text { Arkansas- } \\
\text { Main } \\
1998\end{array}$ & $\begin{array}{l}2 . \mathrm{a} \\
2 . \mathrm{b}\end{array}$ & $\begin{array}{l}\text { MF } \\
\text { Leader } \\
20\end{array}$ \\
\hline $\begin{array}{l}\text { A comparative study of the characteristics of } \\
\text { male and female secondary principals and } \\
\text { aspirants in the State of Arkansas }\end{array}$ & $\begin{array}{l}\text { University of } \\
\text { Arkansas- } \\
\text { Main-1998 }\end{array}$ & $\begin{array}{l}2 . \mathrm{a} \\
2 . \mathrm{b}\end{array}$ & $\begin{array}{l}\text { MF } \\
\text { Leader } \\
21\end{array}$ \\
\hline $\begin{array}{l}\text { An examination of gender balance and other } \\
\text { associated characteristics in the administrative } \\
\text { ranks of North Carolina community colleges }\end{array}$ & $\begin{array}{l}\text { North } \\
\text { Carolina } \\
\text { State- } \\
\text { Raleigh-1999 }\end{array}$ & $\begin{array}{l}2 . a \\
2 . b \\
2 . b \\
3 . c\end{array}$ & $\begin{array}{l}\text { MF } \\
\text { Leader } \\
22\end{array}$ \\
\hline
\end{tabular}


GENDER REPRESENTATIONS IN ED.D. DISSERTATIONS

\begin{tabular}{|l|l|l|l|}
\hline $\begin{array}{l}\text { The actual and ideal public relations role of the } \\
\text { public school superintendent as perceived by } \\
\text { Texas male and female superintendents: A } \\
\text { record of study }\end{array}$ & $\begin{array}{l}\text { Texas A \& } \\
\text { M-1998 }\end{array}$ & $2 . a$ & $\begin{array}{l}\text { MF } \\
\text { Leader } \\
23\end{array}$ \\
\hline $\begin{array}{l}\text { Gender and generational differences in the self } \\
\text { ratings of leadership practices by elementary } \\
\text { school administrators within four Florida } \\
\text { counties }\end{array}$ & $\begin{array}{l}\text { U of S. } \\
\text { Florida } \\
2005\end{array}$ & $\begin{array}{l}2 . a \\
4 . a\end{array}$ & $\begin{array}{l}\text { MF } \\
\text { Leader } \\
24\end{array}$ \\
\hline
\end{tabular}




\section{GENDER REPRESENTATIONS IN ED.D. DISSERTATIONS}

\section{APPENDIX P. Tetreault Coding BLACK MALES}

\begin{tabular}{|c|c|c|c|}
\hline Gender focused dissertation & Institutions & Tetreault & \\
\hline $\begin{array}{l}\text { The under-representation of African American } \\
\text { males in academically gifted programs: The } \\
\text { perceptions of teachers and administrators of } \\
\text { barriers to identification }\end{array}$ & $\begin{array}{l}\text { East Carolina } \\
\text { U-2007 }\end{array}$ & $\begin{array}{l}\text { 1.a, } 1 . \mathrm{b} \\
4 . \mathrm{a}\end{array}$ & $\begin{array}{l}\text { Black } \\
\text { M } 1\end{array}$ \\
\hline $\begin{array}{l}\text { The impact of preparedness, self-efficacy and } \\
\text { math anxiety on the success of African } \\
\text { American males in developmental mathematics } \\
\text { at a community college }\end{array}$ & $\begin{array}{l}\text { Morgan State } \\
\text { U-2007 }\end{array}$ & $\begin{array}{l}1 . a, 1 . b \\
4 . a\end{array}$ & $\begin{array}{l}\text { Black } \\
\text { M } 2\end{array}$ \\
\hline $\begin{array}{l}\text { Why can't brother man stay in school: A } \\
\text { phenomenological study of Black male student } \\
\text { attrition at a Black commuter college }\end{array}$ & $\begin{array}{l}\text { Morgan State } \\
\text { U-2004 }\end{array}$ & $\begin{array}{l}1 . \mathrm{a} \\
4 . \mathrm{a}\end{array}$ & $\begin{array}{l}\text { Black } \\
\text { M } 3\end{array}$ \\
\hline $\begin{array}{l}\text { In their own words: A phenomenological } \\
\text { investigation of the lived experiences of selected } \\
\text { African-American male early school leavers in } \\
\text { Washington D.C. }\end{array}$ & $\begin{array}{l}\text { Morgan State } \\
\text { U-2003 }\end{array}$ & $\begin{array}{l}2, \mathrm{a} \\
4 . \mathrm{a}\end{array}$ & $\begin{array}{l}\text { Black } \\
\text { M } 4\end{array}$ \\
\hline $\begin{array}{l}\text { A causal comparative study of instructional } \\
\text { programs on the mathematical achievements of } \\
\text { elementary school African American male } \\
\text { students }\end{array}$ & $\begin{array}{l}\text { South Carolina } \\
\text { State-2005 }\end{array}$ & $\begin{array}{l}1 . \mathrm{a} \\
4 . \mathrm{a}\end{array}$ & $\begin{array}{l}\text { Black } \\
\text { M } 5\end{array}$ \\
\hline $\begin{array}{l}\text { The effects of group counseling compared with } \\
\text { individual counseling in the reduction of at-risk } \\
\text { behaviors using grade point average, discipline } \\
\text { referrals and attendance among } 6^{\text {th }} \text { grade Black } \\
\text { males }\end{array}$ & $\begin{array}{l}\text { South Carolina } \\
\text { State-2005 }\end{array}$ & $\begin{array}{l}2 . \mathrm{a} \\
4 . \mathrm{a}\end{array}$ & $\begin{array}{l}\text { Black } \\
\text { M } 6\end{array}$ \\
\hline $\begin{array}{l}\text { The impact of locus of control on the academic } \\
\text { achievement of African American males }\end{array}$ & $\begin{array}{l}\text { South Carolina } \\
\text { State-2003 }\end{array}$ & $4 . \mathrm{a}$ & $\begin{array}{l}\text { Black } \\
\text { M } 7\end{array}$ \\
\hline $\begin{array}{l}\text { The attitudes of rural eighth grade Black males } \\
\text { towards academic learning and it's impact on } \\
\text { academic achievement }\end{array}$ & $\begin{array}{l}\text { South Carolina } \\
\text { State-2002 }\end{array}$ & $4 . \mathrm{a}$ & $\begin{array}{l}\text { Black } \\
\text { M } 8\end{array}$ \\
\hline $\begin{array}{l}\text { Group counseling compared with individual } \\
\text { counseling in the reduction of at risk behaviors } \\
\text { in Black male students }\end{array}$ & $\begin{array}{l}\text { South Carolina } \\
\text { State-2001 }\end{array}$ & $\begin{array}{l}2 . \mathrm{a} \\
4 . \mathrm{a}\end{array}$ & $\begin{array}{l}\text { Black } \\
\text { M } 9\end{array}$ \\
\hline $\begin{array}{l}\text { Teacher perception of verbal reinforcement } \\
\text { versus tangible reinforcement with regard to } \\
\text { academic achievement for the African-American } \\
\text { middle school male }\end{array}$ & $\begin{array}{l}\text { Tennessee } \\
\text { State-2003 }\end{array}$ & $\begin{array}{l}2 . \mathrm{a} \\
4 . \mathrm{a}\end{array}$ & $\begin{array}{l}\text { Black } \\
\text { M } 10\end{array}$ \\
\hline $\begin{array}{l}\text { The retention of Black male students in Texas } \\
\text { public community colleges }\end{array}$ & $\begin{array}{l}\text { Texas A \& M } \\
\text { Commerce- } \\
2001\end{array}$ & $\begin{array}{l}1 . \mathrm{a} \\
4 . \mathrm{a}\end{array}$ & $\begin{array}{l}\text { Black } \\
\text { M } 11\end{array}$ \\
\hline $\begin{array}{l}\text { Black male student achievement: A synthesis of } \\
\text { research in the "Journal of Negro Education" }\end{array}$ & $\begin{array}{l}\text { Texas A \& M } \\
\text { Commerce- } \\
1998\end{array}$ & $\begin{array}{l}1 . \mathrm{a} \\
4 . \mathrm{a}\end{array}$ & $\begin{array}{l}\text { Black } \\
\text { M } 12\end{array}$ \\
\hline
\end{tabular}




\section{GENDER REPRESENTATIONS IN ED.D. DISSERTATIONS}

\begin{tabular}{|c|c|c|c|}
\hline $\begin{array}{l}\text { Establishing classroom contacts and } \\
\text { interactions: White educators' attitudes about } \\
\text { early adolescent Black males }\end{array}$ & $\begin{array}{l}\text { University of } \\
\text { Massachusetts- } \\
\text { Boston-2006 }\end{array}$ & $\begin{array}{l}1 . \mathrm{a} \\
4 . \mathrm{a}\end{array}$ & $\begin{array}{l}\text { Black } \\
\text { M } 13\end{array}$ \\
\hline $\begin{array}{l}\text { The involvement of African American Fathers in } \\
\text { the educational lives of their young children: } \\
\text { Beliefs, practices, and experiences in one } \\
\text { elementary school }\end{array}$ & $\begin{array}{l}\text { University of } \\
\text { Massachusetts- } \\
\text { Boston-2004 }\end{array}$ & $\begin{array}{l}2 . \mathrm{a} \\
4 . \mathrm{a}\end{array}$ & $\begin{array}{l}\text { Black } \\
\text { M } 14\end{array}$ \\
\hline $\begin{array}{l}\text { African-American males: What do schools and } \\
\text { teachers do to enhance academic achievement }\end{array}$ & $\begin{array}{l}\text { U of N. } \\
\text { Carolina- } \\
\text { Charlotte-2002 }\end{array}$ & $\begin{array}{l}1 . \mathrm{a} \\
4 . \mathrm{a}\end{array}$ & $\begin{array}{l}\text { Black } \\
\text { M } 15\end{array}$ \\
\hline $\begin{array}{l}\text { Lasting legacies: The effects of natural mentors } \\
\text { in the lives of at risk African -American male } \\
\text { adolescents }\end{array}$ & $\begin{array}{l}\text { Bowling Green } \\
\text { State-2006 }\end{array}$ & $\begin{array}{l}2 . \mathrm{a} \\
4 . \mathrm{a}\end{array}$ & $\begin{array}{l}\text { Black } \\
\text { M } 16\end{array}$ \\
\hline $\begin{array}{l}\text { The impact of reading instructional } \\
\text { methodology on student achievement of Black } \\
\text { males based on the Florida comprehensive } \\
\text { assessment test }\end{array}$ & $\begin{array}{l}\text { Florida } \\
\text { Atlantic } \\
\text { Boca } \\
2006\end{array}$ & $\begin{array}{l}2, \mathrm{a} \\
4 . \mathrm{a}\end{array}$ & $\begin{array}{l}\text { Black } \\
\text { M } 17\end{array}$ \\
\hline $\begin{array}{l}\text { A comparison of academic success variables of } \\
\text { Black male high school graduates with other } \\
\text { racial and gender populations in the Broward } \\
\text { County School district Florida }\end{array}$ & $\begin{array}{l}\text { Florida } \\
\text { Atlantic } \\
\text { Boca }\end{array}$ & $\begin{array}{l}2 . \mathrm{a} \\
4 . \mathrm{a}\end{array}$ & $\begin{array}{l}\text { Black } \\
\text { M } 18\end{array}$ \\
\hline $\begin{array}{l}\text { Raising Abel: What do African American single } \\
\text { mothers do to raise successful African American } \\
\text { middle school boys ab }\end{array}$ & $\begin{array}{l}\text { Indiana U } \\
\text { Purdue-2003 }\end{array}$ & $\begin{array}{l}2 . a, 2 . c \\
3 . b \\
4 . a\end{array}$ & $\begin{array}{l}\text { Black } \\
\text { M } 19\end{array}$ \\
\hline $\begin{array}{l}\text { An analysis of adult African American men's } \\
\text { perceived susceptibility of prostate cancer and } \\
\text { perceived benefits and barriers to participation } \\
\text { in early detection methods: Implications for } \\
\text { community-based health promotion }\end{array}$ & $\begin{array}{l}\text { Northern } \\
\text { Illinois-2007 } \\
\text { University }\end{array}$ & $\begin{array}{l}2 . \mathrm{a} \\
4 . \mathrm{a}\end{array}$ & $\begin{array}{l}\text { Black } \\
\text { M } 20\end{array}$ \\
\hline $\begin{array}{l}\text { The African American church as a provider of } \\
\text { nonformal adult education in the Chicago } \\
\text { community under the leadership of Pastor } \\
\text { William Samuel Winston }\end{array}$ & $\begin{array}{l}\text { Northern } \\
\text { Illinois } \\
\text { University- } \\
2005\end{array}$ & $4 . \mathrm{a}$ & $\begin{array}{l}\text { Black } \\
\text { M } 21\end{array}$ \\
\hline $\begin{array}{l}\text { Reaching and teaching the African-American } \\
\text { male: Curriculum, learning styles, teacher belief } \\
\text { systems and practices }\end{array}$ & $\begin{array}{l}\text { Northern } \\
\text { Illinois } \\
\text { University- } \\
2001\end{array}$ & $\begin{array}{l}2 . \mathrm{a} \\
4 . \mathrm{a}\end{array}$ & $\begin{array}{l}\text { Black } \\
\text { M } 22\end{array}$ \\
\hline $\begin{array}{l}\text { Measuring the effectiveness of an Afrocentric } \\
\text { male mentoring program with adolescent } \\
\text { African American males }\end{array}$ & $\begin{array}{l}\text { Northern } \\
\text { Illinois } \\
\text { University- } \\
2000\end{array}$ & $\begin{array}{l}2 . \mathrm{a} \\
4 . \mathrm{a}\end{array}$ & $\begin{array}{l}\text { Black } \\
\text { M } 23\end{array}$ \\
\hline Rediscovering the essential nature of African & Northern & $1 . \mathrm{a}$ & Black \\
\hline
\end{tabular}




\section{GENDER REPRESENTATIONS IN ED.D. DISSERTATIONS}

\begin{tabular}{|c|c|c|c|}
\hline $\begin{array}{l}\text { American male leadership: An Afrocentric } \\
\text { perspective }\end{array}$ & $\begin{array}{l}\text { Illinois } \\
\text { University- } \\
2000\end{array}$ & $4 . a$ & M 24 \\
\hline $\begin{array}{l}\text { There are no crystal stairs here: A study of } \\
\text { African-American males in traditional and non } \\
\text { traditional program in a predominately White } \\
\text { institution of higher education }\end{array}$ & $\begin{array}{l}\text { Northern } \\
\text { Illinois } \\
\text { University- } \\
2000\end{array}$ & $\begin{array}{l}1 . \mathrm{a} \\
4 . \mathrm{a}\end{array}$ & $\begin{array}{l}\text { Black } \\
\text { M } 25\end{array}$ \\
\hline $\begin{array}{l}\text { Social cognition and language: Abusive } \\
\text { language and the African-American male } \\
\text { juvenile transgressor }\end{array}$ & $\begin{array}{l}\text { Northern } \\
\text { Illinois } \\
\text { University- } \\
1999\end{array}$ & 4.a & $\begin{array}{l}\text { Black } \\
\text { M } 26\end{array}$ \\
\hline $\begin{array}{l}\text { African-American male per-service teachers' } \\
\text { perceptions of elementary education: A multiple } \\
\text { case study }\end{array}$ & $\begin{array}{l}\text { Oklahoma } \\
\text { State-Main- } \\
2002\end{array}$ & $2 . a$ & $\begin{array}{l}\text { Black } \\
\text { M } 27\end{array}$ \\
\hline $\begin{array}{l}\text { Factors that foster academic resilience in } \\
\text { African American male middle school students } \\
\text { from low-socioeconomic, single parent homes }\end{array}$ & $\begin{array}{l}\text { University of } \\
\text { Alabama-1999 }\end{array}$ & $\begin{array}{l}2 . \mathrm{a} \\
4 . \mathrm{a}\end{array}$ & $\begin{array}{l}\text { Black } \\
\text { M } 28\end{array}$ \\
\hline $\begin{array}{l}\text { Factors that contribute to hazing practices by } \\
\text { collegiate Black Greek letter fraternities during } \\
\text { membership intake activities }\end{array}$ & $\begin{array}{l}\text { University of } \\
\text { Arkansas- } \\
\text { Main-2006 }\end{array}$ & $\begin{array}{l}1 . \mathrm{a} \\
4 . \mathrm{a}\end{array}$ & $\begin{array}{l}\text { Black } \\
\text { M } \\
29\end{array}$ \\
\hline $\begin{array}{l}\text { An examination of time use patterns influence } \\
\text { on achievement among African American and } \\
\text { Hispanic male high school student athletes }\end{array}$ & $\begin{array}{l}\text { University of } \\
\text { Central } \\
\text { Florida-2007 }\end{array}$ & $\begin{array}{l}2 . \mathrm{a} \\
4 . \mathrm{a}\end{array}$ & $\begin{array}{l}\text { Black } \\
\text { M } 30\end{array}$ \\
\hline $\begin{array}{l}\text { John Henryism and occupational stress among } \\
\text { African American higher education faculty am }\end{array}$ & $\begin{array}{l}\text { University of } \\
\text { Houston-1998 }\end{array}$ & $\begin{array}{l}1 . \mathrm{a} \\
4 . \mathrm{a}\end{array}$ & $\begin{array}{l}\text { Black } \\
\text { M } 31\end{array}$ \\
\hline $\begin{array}{l}\text { An analysis of the characteristics that lead to the } \\
\text { disenfranchisement of African Males between } \\
\text { the ages of } 18 \text { to } 35\end{array}$ & $\begin{array}{l}\text { University of } \\
\text { Memphis-2004 }\end{array}$ & $\begin{array}{l}2 . \mathrm{a} \\
4 . \mathrm{a}\end{array}$ & $\begin{array}{l}\text { Black } \\
\text { M } 32\end{array}$ \\
\hline $\begin{array}{l}\text { Designed for failure: An analysis of African } \\
\text { American male students perception of the failure } \\
\text { of traditional school structures to successfully } \\
\text { educate them }\end{array}$ & $\begin{array}{l}\text { University of } \\
\text { Missouri- } \\
\text { Kansas City- } \\
2007\end{array}$ & $\begin{array}{l}2 . \mathrm{a} \\
4 . \mathrm{a}\end{array}$ & $\begin{array}{l}\text { Black } \\
\text { M } 33\end{array}$ \\
\hline $\begin{array}{l}\text { Social reconstruction of African American } \\
\text { males at an urban middle school }\end{array}$ & $\begin{array}{l}\text { University of } \\
\text { N.Carolina - } \\
\text { Greensboro- } \\
2006\end{array}$ & $\begin{array}{l}2 . \mathrm{a} \\
4 . \mathrm{a}\end{array}$ & $\begin{array}{l}\text { Black } \\
\text { M } 34\end{array}$ \\
\hline $\begin{array}{l}\text { Through their eyes: A look at the achievement } \\
\text { and success of selected African American male } \\
\text { youths }\end{array}$ & $\begin{array}{l}\text { University of } \\
\text { N.Carolina - } \\
\text { Greensboro- }\end{array}$ & $\begin{array}{l}2 . \mathrm{a} \\
4 . \mathrm{a}\end{array}$ & $\begin{array}{l}\text { Black } \\
\text { M } 35\end{array}$ \\
\hline
\end{tabular}


GENDER REPRESENTATIONS IN ED.D. DISSERTATIONS

\begin{tabular}{|c|c|c|c|}
\hline & 2006 & & \\
\hline $\begin{array}{l}\text { An examination of the graduation rates of the } \\
\text { Division I African American male basketball } \\
\text { student-athlete }\end{array}$ & $\begin{array}{l}\text { University of } \\
\text { Texas-El Paso- } \\
2004\end{array}$ & $\begin{array}{l}\text { 1.a, } 1 . \mathrm{b} \\
4 . \mathrm{a}\end{array}$ & $\begin{array}{l}\text { Black } \\
\text { M } 36\end{array}$ \\
\hline $\begin{array}{l}\text { The personal and academic success of African } \\
\text { American males with specific learning } \\
\text { disabilities }\end{array}$ & $\begin{array}{l}\text { Arizona State- } \\
\text { Tempe-2004 }\end{array}$ & $\begin{array}{l}2 . \mathrm{a} \\
4 . \mathrm{a}\end{array}$ & $\begin{array}{l}\text { Black } \\
\text { M } 37\end{array}$ \\
\hline $\begin{array}{l}\text { The way out: African American male student } \\
\text { athletes in higher education }\end{array}$ & $\begin{array}{l}\text { Arizona State- } \\
\text { Tempe-2001 }\end{array}$ & $\begin{array}{l}\text { 1.a, } 1 . \mathrm{b} \\
4 . \mathrm{a}\end{array}$ & $\begin{array}{l}\text { Black } \\
\text { M } 38\end{array}$ \\
\hline $\begin{array}{l}\text { The impact of home environment of Black } \\
\text { males not pursuing higher education }\end{array}$ & $\begin{array}{l}\text { Arizona State } \\
\text { University- } \\
1998\end{array}$ & $\begin{array}{l}2 . \mathrm{a} \\
4 . \mathrm{a}\end{array}$ & $\begin{array}{l}\text { Black } \\
\text { M } 39\end{array}$ \\
\hline $\begin{array}{l}\text { A qualitative study of resilience among African- } \\
\text { American adolescent male students in North } \\
\text { Carolina }\end{array}$ & $\begin{array}{l}\text { North Carolina } \\
\text { State-Raleigh- } \\
2003\end{array}$ & $\begin{array}{l}2 . \mathrm{a} \\
4 . \mathrm{a}\end{array}$ & $\begin{array}{l}\text { Black } \\
\text { M } 40\end{array}$ \\
\hline $\begin{array}{l}\text { Coping strategies: Adjustment, and persistence } \\
\text { among Black men attending predominately } \\
\text { White colleges and universities }\end{array}$ & $\begin{array}{l}\text { Rutgers-New } \\
\text { Brunswick- } \\
2004\end{array}$ & $\begin{array}{l}2 . \mathrm{a} \\
4 . \mathrm{a}\end{array}$ & $\begin{array}{l}\text { Black } \\
\text { M } 41\end{array}$ \\
\hline $\begin{array}{l}\text { Exploring the relationship between personal } \\
\text { motivation, persistence, and resilience and their } \\
\text { effects on academic achievement among } \\
\text { different groups of African American males in } \\
\text { high schools }\end{array}$ & $\begin{array}{l}\text { University of } \\
\text { Maryland- } \\
2005\end{array}$ & $\begin{array}{l}2 . \mathrm{a} \\
4 . \mathrm{a}\end{array}$ & $\begin{array}{l}\text { Black } \\
\text { M } 42\end{array}$ \\
\hline $\begin{array}{l}\text { The impact of home environment of Black } \\
\text { males not pursuing higher education }\end{array}$ & $\begin{array}{l}\text { Arizona State } \\
\text { University- } \\
1998\end{array}$ & $\begin{array}{l}2 . \mathrm{a} \\
4 . \mathrm{a}\end{array}$ & $\begin{array}{l}\text { Black } \\
\text { M } 43\end{array}$ \\
\hline $\begin{array}{l}\text { Effective library education for the inner city } \\
\text { African American male: Key elements of a team }\end{array}$ & $\begin{array}{l}\text { UC Berkeley- } \\
2005\end{array}$ & $\begin{array}{l}2 . \mathrm{a} \\
4 . \mathrm{a}\end{array}$ & $\begin{array}{l}\text { Black } \\
\text { M } 44\end{array}$ \\
\hline
\end{tabular}


GENDER REPRESENTATIONS IN ED.D. DISSERTATIONS

APPENDIX Q LATINO/A abstracts

\begin{tabular}{|c|c|c|c|}
\hline Gender focused dissertation & Institutions & Tetreault & \\
\hline $\begin{array}{l}\text { Knowledge and perceptions held by Latino } \\
\text { parents regarding the educational services for } \\
\text { LEP children with disabilities }\end{array}$ & $\begin{array}{l}\text { Illinois State } \\
\text { U-1999 }\end{array}$ & $\begin{array}{l}\text { 1.a, } 1 . \mathrm{b} \\
2 . \mathrm{a}\end{array}$ & $\begin{array}{l}\text { Latino/a } \\
1\end{array}$ \\
\hline $\begin{array}{l}\text { Factors affecting retention of } 1^{\text {st }} \text { year Latino } \\
\text { students in a private university }\end{array}$ & $\begin{array}{l}\text { Morgan State } \\
\text { U-2006 }\end{array}$ & $\begin{array}{l}\text { 1.a,1.b } \\
\text { 2.a,4.a } \\
\text { Chowdery } \\
2006\end{array}$ & $\begin{array}{l}\text { Latino/a } \\
2\end{array}$ \\
\hline $\begin{array}{l}\text { An investigation into the perceptions of Latino } \\
\text { parents of young children in urban, suburban and } \\
\text { rural school settings }\end{array}$ & $\begin{array}{l}\text { Texas } \\
\text { Woman's } \\
\text { University- } \\
2001\end{array}$ & $\begin{array}{l}1 . a, 1 . b \\
\text { Robles, } \\
2001\end{array}$ & $\begin{array}{l}\text { Latino/a } \\
3\end{array}$ \\
\hline $\begin{array}{l}\text { The kids on the other side of the hallway: } \\
\text { Teacher's perspectives of the academic } \\
\text { achievement of Latino English language learners }\end{array}$ & $\begin{array}{l}\text { University of } \\
\text { Massachusett } \\
\text { s-Boston- } \\
2007\end{array}$ & 1.a, 1.b & $\begin{array}{l}\text { Latino/a } \\
4\end{array}$ \\
\hline $\begin{array}{l}\text { Latina Presidents in community colleges: A } \\
\text { quantitative study of the elements of career } \\
\text { advancement }\end{array}$ & $\begin{array}{l}\text { New Mexico } \\
\text { State-Main- } \\
2007\end{array}$ & $\begin{array}{l}\text { 2.a,2.c } \\
3 . c \\
4 . a\end{array}$ & $\begin{array}{l}\text { Latina/o } \\
5\end{array}$ \\
\hline $\begin{array}{l}\text { Non United States born Latinos: A study of } \\
\text { perceptions of barriers and catalysts to } \\
\text { educational success at a rural New Mexico } \\
\text { Community college }\end{array}$ & $\begin{array}{l}\text { New Mexico } \\
\text { State-Main- } \\
2007\end{array}$ & 1.a,1.b & $\begin{array}{l}\text { Latino } \\
6\end{array}$ \\
\hline $\begin{array}{l}\text { A case study on language proficiency with Latino } \\
\text { students in dual language setting }\end{array}$ & $\begin{array}{l}\text { New Mexico } \\
\text { State-Main- } \\
2000\end{array}$ & 1.a,1.b & $\begin{array}{l}\text { Latino/a } \\
7\end{array}$ \\
\hline $\begin{array}{l}\text { College Latino students: Cultural integration, } \\
\text { retention, and successful completion }\end{array}$ & $\begin{array}{l}\text { Northern } \\
\text { Illinois } \\
\text { University - } \\
2005\end{array}$ & $\begin{array}{l}\text { 1.a, 1.b } \\
\text { Hernande } \\
z, 2005\end{array}$ & $\begin{array}{l}\text { Latino } \\
8\end{array}$ \\
\hline $\begin{array}{l}\text { School organization of successful alternative high } \\
\text { schools serving Latino students in Chicago }\end{array}$ & $\begin{array}{l}\text { Northern } \\
\text { Illinois } \\
\text { University- } \\
2004\end{array}$ & 1.a, 1.b & $\begin{array}{l}\text { Latino/a } \\
9\end{array}$ \\
\hline $\begin{array}{l}\text { Lessons learned while suspended between two } \\
\text { cultures: The life history of a Latina adult } \\
\text { educator }\end{array}$ & $\begin{array}{l}\text { Northern } \\
\text { Illinois } \\
\text { University- } \\
2003\end{array}$ & $\begin{array}{l}\text { 2.a,2.c } \\
4 . \mathrm{a}\end{array}$ & $\begin{array}{l}\text { Latina } \\
10\end{array}$ \\
\hline $\begin{array}{l}\text { A study of the relationship between selected } \\
\text { independent variables and the success of Latina/o }\end{array}$ & $\begin{array}{l}\text { Northern } \\
\text { Illinois }\end{array}$ & $\begin{array}{l}2 . \mathrm{a} \\
4 . \mathrm{a}\end{array}$ & $\begin{array}{l}\text { Latina/o } \\
11\end{array}$ \\
\hline
\end{tabular}




\section{GENDER REPRESENTATIONS IN ED.D. DISSERTATIONS}

\begin{tabular}{|c|c|c|c|}
\hline $\begin{array}{l}\text { students at a four year institution of higher } \\
\text { learning in the Midwest }\end{array}$ & $\begin{array}{l}\text { University- } \\
2000\end{array}$ & & \\
\hline $\begin{array}{l}\text { Beginning reading: Linguistic units and } \\
\text { instructional strategies that facilitate word } \\
\text { recognition in Latino kindegarten students who } \\
\text { are learning to reading Spanish }\end{array}$ & $\begin{array}{l}\text { University of } \\
\text { Houston- } \\
2003\end{array}$ & 1.a,1.b & $\begin{array}{l}\text { Latino/a } \\
12\end{array}$ \\
\hline $\begin{array}{l}\text { Conversations about reading processes in Spanish } \\
\text { and English among six Latino/a eighth graders }\end{array}$ & $\begin{array}{l}\text { University of } \\
\text { Houston- } \\
2002\end{array}$ & $\begin{array}{l}2 . \mathrm{a} \\
4 . \mathrm{a}\end{array}$ & $\begin{array}{l}\text { Latino/a } \\
13\end{array}$ \\
\hline $\begin{array}{l}\text { Investigating the cognitive reading strategies and } \\
\text { motivation to read of resilient, average, and no- } \\
\text { resilient fourth-and fifth-grade Latino English } \\
\text { language learners }\end{array}$ & $\begin{array}{l}\text { University of } \\
\text { Houston- } \\
2002\end{array}$ & 1.a,1.b & $\begin{array}{l}\text { Latino/a } \\
14\end{array}$ \\
\hline $\begin{array}{l}\text { Ethnic cleansing in the barrio: A critical } \\
\text { ethnography of the politics, practices, and } \\
\text { pedantry of schooling urban Latino bilingual } \\
\text { students }\end{array}$ & $\begin{array}{l}\text { University of } \\
\text { Houston- } \\
2001\end{array}$ & 1.a, 1.b & $\begin{array}{l}\text { Latino/a } \\
15\end{array}$ \\
\hline $\begin{array}{l}\text { Latino community college transfer students in } \\
\text { engineering: Transition experiences and academic } \\
\text { success at a large research university }\end{array}$ & $\begin{array}{l}\text { Arizona } \\
\text { State-Tempe- } \\
2007\end{array}$ & $\begin{array}{l}\text { 1.a,1.b } \\
2 . \mathrm{a}\end{array}$ & $\begin{array}{l}\text { Latino/a } \\
16\end{array}$ \\
\hline $\begin{array}{l}\text { Successful Latino students: A study of five } \\
\text { Mexican American families }\end{array}$ & $\begin{array}{l}\text { Arizona } \\
\text { State-Tempe- } \\
2006\end{array}$ & 1.a,1.b & $\begin{array}{l}\text { Latino } \\
17\end{array}$ \\
\hline $\begin{array}{l}\text { The Latino/a faculty: A perilous journey to the } \\
\text { ivory tower in higher education }\end{array}$ & $\begin{array}{l}\text { Arizona } \\
\text { State-Tempe- } \\
2002\end{array}$ & $\begin{array}{l}2 . \mathrm{a} \\
4 . \mathrm{a}\end{array}$ & $\begin{array}{l}\text { Latino/a } \\
18\end{array}$ \\
\hline $\begin{array}{l}\text { Popular education: Adult education for Latina's } \\
\text { women empowerment }\end{array}$ & $\begin{array}{l}\text { Rutgers-New } \\
\text { Brunswick- } \\
2005\end{array}$ & 2.a & $\begin{array}{l}\text { Latina/o } \\
19\end{array}$ \\
\hline $\begin{array}{l}\text { Schools as resilient organizations: Supporting the } \\
\text { mathematical resilience of Latino eight graders }\end{array}$ & $\begin{array}{l}\text { University of } \\
\text { California- } \\
\text { Berkeley- } \\
2007\end{array}$ & 1.a,1.b & $\begin{array}{l}\text { Latino } \\
20\end{array}$ \\
\hline $\begin{array}{l}\text { Meaning to read or reading for meaning: } \\
\text { Promoting reading comprehension proficiency of } \\
\text { Latino English learners IRVINE }\end{array}$ & $\begin{array}{l}\text { University of } \\
\text { California- } \\
\text { LA \& } \\
\text { Irvine }-2007\end{array}$ & 1.a,1.b & $\begin{array}{l}\text { Latino/a } \\
21\end{array}$ \\
\hline $\begin{array}{l}\text { Raising the curtain on theatre arts for Latinos: } \\
\text { Finding voice, cultural capital, literacy, and ethnic } \\
\text { identity in high school arts theatre classes } \\
\text { IRVINE }\end{array}$ & $\begin{array}{l}\text { University of } \\
\text { California- } \\
\text { LA \& } \\
\text { Irvine-2007 }\end{array}$ & 1.a,1.b & $\begin{array}{l}\text { Latino/a } \\
22\end{array}$ \\
\hline
\end{tabular}


GENDER REPRESENTATIONS IN ED.D. DISSERTATIONS

\begin{tabular}{|c|c|c|c|}
\hline $\begin{array}{l}\text { Technology and equity: Explaining differences } \\
\text { between elementary teachers use of computers in } \\
\text { low-income Latino and middle class-schools } \\
\text { IRVINE \& UCLA }\end{array}$ & $\begin{array}{l}\text { University of } \\
\text { California- } \\
\text { LA \& } \\
\text { Irvine-2007 }\end{array}$ & 1.a,1.b & $\begin{array}{l}\text { Latino/a } \\
23\end{array}$ \\
\hline $\begin{array}{l}\text { Capturing the stories of non-college preparatory } \\
\text { Latina/o high school graduates :reclaiming their } \\
\text { stake in education and their dreams UCLA }\end{array}$ & $\begin{array}{l}\text { University of } \\
\text { California- } \\
\text { LA \& } \\
\text { Irvine-2007 }\end{array}$ & $\begin{array}{l}2 . \mathrm{a} \\
4 . \mathrm{a} \\
5 . \mathrm{a}\end{array}$ & $\begin{array}{l}\text { Latina/o } \\
24\end{array}$ \\
\hline $\begin{array}{l}\text { Mi fuerza/my strength: The academic and } \\
\text { personal experiences of Chicana/Latina transfer } \\
\text { students in math and science IRVINE \& UCLA }\end{array}$ & $\begin{array}{l}\text { University of } \\
\text { California- } \\
\text { LA \& } \\
\text { Irvine-2006 }\end{array}$ & $\begin{array}{l}2 . \mathrm{a} \\
4 . \mathrm{a}\end{array}$ & $\begin{array}{l}\text { Latina/o } \\
25\end{array}$ \\
\hline $\begin{array}{l}\text { The road less traveled: Latino students and the } \\
\text { impact of studying abroad UCLA }\end{array}$ & $\begin{array}{l}\text { University of } \\
\text { California- } \\
\text { LA \& } \\
\text { Irvine-2006 }\end{array}$ & 1.a,1.b & $\begin{array}{l}\text { Latina/o } \\
26\end{array}$ \\
\hline $\begin{array}{l}\text { Identifying characteristics of successful schools in } \\
\text { Latino communities IRVINE }\end{array}$ & $\begin{array}{l}\text { University of } \\
\text { California- } \\
\text { LA \& } \\
\text { Irvine-2004 }\end{array}$ & $\begin{array}{l}\text { 1.a,1.b } \\
\text { 2.a,2.c }\end{array}$ & $\begin{array}{l}\text { Latina/o } \\
27\end{array}$ \\
\hline $\begin{array}{l}\text { Finding their way: Experiences of first-generation } \\
\text { Latina graduates UCLA }\end{array}$ & $\begin{array}{l}\text { University of } \\
\text { California- } \\
\text { LA \& } \\
\text { Irvine-2004 }\end{array}$ & $\begin{array}{l}1 . \mathrm{a} \\
2 . \mathrm{a}\end{array}$ & $\begin{array}{l}\text { Latina/o } \\
28\end{array}$ \\
\hline $\begin{array}{l}\text { Lending a helping hand: Mentoring tomorrow's } \\
\text { Latina and Latino leaders into the } 21^{\text {st }} \text { century } \\
\text { UCLA }\end{array}$ & $\begin{array}{l}\text { University of } \\
\text { California- } \\
\text { LA \& } \\
\text { Irvine-2004 }\end{array}$ & $\begin{array}{l}2 . \mathrm{a} \\
4 . \mathrm{a} \\
5 . \mathrm{a}\end{array}$ & $\begin{array}{l}\text { Latina/o } \\
29\end{array}$ \\
\hline $\begin{array}{l}\text { Understanding homework: Latino parent's } \\
\text { perceptions UCLA }\end{array}$ & $\begin{array}{l}\text { University of } \\
\text { California- } \\
\text { LA \& } \\
\text { Irvine-2002 }\end{array}$ & 1.a,1.b & $\begin{array}{l}\text { Latino/a } \\
30\end{array}$ \\
\hline $\begin{array}{l}\text { Effects of extending mathematics instruction } \\
\text { through a Saturday academy to limited English } \\
\text { proficient Latino students in low performing } \\
\text { schools IRVINE }\end{array}$ & $\begin{array}{l}\text { University of } \\
\text { California- } \\
\text { LA \& } \\
\text { Irvine-1999 }\end{array}$ & $\begin{array}{l}\text { 1.a, } 1 . \mathrm{b} \\
2 . \mathrm{a}\end{array}$ & $\begin{array}{l}\text { Latino } \\
31\end{array}$ \\
\hline $\begin{array}{l}\text { Building bridges: Latino immigrant parents } \\
\text { explore the home schooling relationship UCLA }\end{array}$ & $\begin{array}{l}\text { University of } \\
\text { California- }\end{array}$ & 1.a,1.b & $\begin{array}{l}\text { Latino } \\
32\end{array}$ \\
\hline
\end{tabular}


GENDER REPRESENTATIONS IN ED.D. DISSERTATIONS

\begin{tabular}{|c|c|c|c|}
\hline & $\begin{array}{l}\text { LA \& } \\
\text { Irvine-1999 }\end{array}$ & & \\
\hline $\begin{array}{l}\text { Math enrichment to prepare Latino high school } \\
\text { students for university level mathematics UCLA }\end{array}$ & $\begin{array}{l}\text { University of } \\
\text { California- } \\
\text { LA \& } \\
\text { Irvine-1999 }\end{array}$ & 1.a, 1.b & $\begin{array}{l}\text { Latino } \\
33\end{array}$ \\
\hline $\begin{array}{l}\text { Recruiting teachers of color: College age Latino/a } \\
\text { students share their voices and recommendations } \\
\text { for educator preparation programs }\end{array}$ & $\begin{array}{l}\text { University of } \\
\text { Massachusett } \\
\text { s-Amherst - } \\
2007\end{array}$ & $\begin{array}{l}2 . \mathrm{a} \\
4 . \mathrm{a} \\
5 . \mathrm{a}\end{array}$ & $\begin{array}{l}\text { Latino/a } \\
34\end{array}$ \\
\hline $\begin{array}{l}\text { Representin' for Latino students: Culturally } \\
\text { responsive pedagogies, teacher identities, and the } \\
\text { preparation of teachers for urban schools }\end{array}$ & $\begin{array}{l}\text { University of } \\
\text { Massachusett } \\
\text { s-Amherst - } \\
2005\end{array}$ & 1.a,1.b & $\begin{array}{l}\text { Latino/a } \\
35\end{array}$ \\
\hline $\begin{array}{l}\text { The FotoDialogo Method: Using pictures and } \\
\text { storytelling to promote dialogue and self } \\
\text { discovery among Latinas within a community } \\
\text { based organization in Massachusetts }\end{array}$ & $\begin{array}{l}\text { University of } \\
\text { Massachusett } \\
\text { s-Amherst- } \\
1999\end{array}$ & $2 . \mathrm{a}$ & $\begin{array}{l}\text { Latina/o } \\
36\end{array}$ \\
\hline $\begin{array}{l}\text { Latina Girls of Puerto Rican origin who Are } \\
\text { successful in science and mathematics high } \\
\text { school courses }\end{array}$ & $\begin{array}{l}\text { University of } \\
\text { Massachusett } \\
\text { s-Amherst- } \\
1999\end{array}$ & $\begin{array}{l}2 . \mathrm{a} \\
4 . \mathrm{a}\end{array}$ & $\begin{array}{l}\text { Latina/o } \\
37\end{array}$ \\
\hline $\begin{array}{l}\text { Reflections on the development of learning } \\
\text { community among a group of traditional } \\
\text { immigrant Latinas }\end{array}$ & $\begin{array}{l}\text { University of } \\
\text { New Mexico- } \\
2005\end{array}$ & $\begin{array}{l}\text { 2.a,2.c } \\
\text { 3.c,3.d } \\
\text { 4.a }\end{array}$ & $\begin{array}{l}\text { Latina/o } \\
38\end{array}$ \\
\hline $\begin{array}{l}\text { Latino/a students knowledge about American } \\
\text { citizenship, citizenship education and relevant } \\
\text { socio cultural factors }\end{array}$ & $\begin{array}{l}\text { University of } \\
\text { N. Carolina- } \\
\text { Chapel Hill- } \\
2006\end{array}$ & $\begin{array}{l}\text { 2.a } \\
4 . \mathrm{a} \\
5 . \mathrm{a}\end{array}$ & $\begin{array}{l}\text { Latino/a } \\
39\end{array}$ \\
\hline $\begin{array}{l}\text { The schooling experiences of Latina immigrant } \\
\text { high school students }\end{array}$ & $\begin{array}{l}\text { University of } \\
\text { N. Carolina- } \\
\text { Chapel Hill- } \\
2003\end{array}$ & $\begin{array}{l}2 . \mathrm{a} \\
4 . \mathrm{a}\end{array}$ & $\begin{array}{l}\text { Latina/o } \\
40\end{array}$ \\
\hline $\begin{array}{l}\text { Differences in language learning strategies } \\
\text { between male and female and also between Asian } \\
\text { and Latino ESL students }\end{array}$ & $\begin{array}{l}\text { University of } \\
\text { Tennessee- } \\
\text { Knoxville - } \\
2000\end{array}$ & $\begin{array}{l}\text { 1.a,1.b } \\
\text { 2.a } \\
\text { 4.a }\end{array}$ & $\begin{array}{l}\text { Latino/a } \\
41\end{array}$ \\
\hline Fluid identities, adaptable lives: the impact of & University of & $2 . \mathrm{a}$ & Latina \\
\hline
\end{tabular}


GENDER REPRESENTATIONS IN ED.D. DISSERTATIONS

\begin{tabular}{|l|l|l|l|}
\hline $\begin{array}{l}\text { educational and career experiences on the identity } \\
\text { development of Latina corporate managers }\end{array}$ & $\begin{array}{l}\text { Texas- } \\
\text { Austin-1999 }\end{array}$ & $4 . \mathrm{a}$ & 42 \\
\hline $\begin{array}{l}\text { Latina/os constructing educational leadership: } \\
\text { Cultivating the fields of leadership }\end{array}$ & $\begin{array}{l}\text { University of } \\
\text { Washington- } \\
\text { Seattle-2007 }\end{array}$ & $\begin{array}{l}2 . \mathrm{a} \\
4 . \mathrm{a} \\
5 . \mathrm{a}\end{array}$ & $\begin{array}{l}\text { Latino/a } \\
43\end{array}$ \\
\hline $\begin{array}{l}\text { Factors influencing the underrepresentation of } \\
\text { Latinos in higher education }\end{array}$ & $\begin{array}{l}\text { Texas A \& M } \\
\text { Kingsville- } \\
2006\end{array}$ & $1 . \mathrm{a}, 1 . \mathrm{b}$ & 44 \\
\hline
\end{tabular}




\section{GENDER REPRESENTATIONS IN ED.D. DISSERTATIONS}

APPENDIX R LGTBIQ Tetreault coding

\begin{tabular}{|c|c|c|c|}
\hline Gender focused dissertation & Institution & Tetreault & \\
\hline $\begin{array}{l}\text { The need for a diversity component, specific to } \\
\text { gay and lesbian students, in undergraduate } \\
\text { teacher preparation programs according to } \\
\text { selected eastern North Carolina educators }\end{array}$ & $\begin{array}{l}\text { East } \\
\text { Carolina U- } \\
2001\end{array}$ & $\begin{array}{l}2 . \mathrm{a} \\
4 . \mathrm{a}\end{array}$ & $\begin{array}{l}\text { LGTBIQ } \\
1\end{array}$ \\
\hline $\begin{array}{l}\text { Assessing principal's perceptions of } \\
\text { heterosexism and homophobia in a large urban } \\
\text { public school district }\end{array}$ & $\begin{array}{l}\text { Texas A \& } \\
\text { M } \\
\text { Commerce- } \\
2005\end{array}$ & $4 . \mathrm{a}$ & $\begin{array}{l}\text { LGTBIQ } \\
2\end{array}$ \\
\hline $\begin{array}{l}\text { A case study of the perspectives of gay and } \\
\text { lesbian teachers: Overcoming heterosexism and } \\
\text { homophobia in the school community }\end{array}$ & $\begin{array}{l}\text { University of } \\
\text { Massachuset } \\
\text { ts-Boston- } \\
1999\end{array}$ & $\begin{array}{l}\text { 2.a, } \\
\text { 3.a } \\
4 . \mathrm{a}\end{array}$ & $\begin{array}{l}\text { LGTBIQ } \\
3\end{array}$ \\
\hline $\begin{array}{l}\text { Heteronormativity and teaching: A } \\
\text { phenomenological study of lesbian teachers }\end{array}$ & $\begin{array}{l}\text { Florida } \\
\text { International } \\
\text { U-2002 }\end{array}$ & $\begin{array}{l}2 . \mathrm{a} \\
3 . \mathrm{a} \\
4 . \mathrm{a}\end{array}$ & $\begin{array}{l}\text { LGTBIQ } \\
4\end{array}$ \\
\hline $\begin{array}{l}\text { The gay and lesbian counseling experience triad: } \\
\text { Curriculum, service and satisfaction }\end{array}$ & $\begin{array}{l}\text { Northern } \\
\text { Arizona U- } \\
2003\end{array}$ & $\begin{array}{l}2 . \mathrm{a} \\
4 . \mathrm{a}\end{array}$ & $\begin{array}{l}\text { LGTBIQ } \\
5\end{array}$ \\
\hline $\begin{array}{l}\text { Gay and lesbian school administrators: } \\
\text { Negotiating personal and professional roles and } \\
\text { responsibilities within hetero-normative } \\
\text { organizations }\end{array}$ & $\begin{array}{l}\text { Northern } \\
\text { Illinois } \\
\text { University- } \\
2007\end{array}$ & $\begin{array}{l}2 . \mathrm{a} \\
3 . \mathrm{a} \\
4 . \mathrm{a}\end{array}$ & $\begin{array}{l}\text { LGTBIQ } \\
6\end{array}$ \\
\hline $\begin{array}{l}\text { Subcutaneous:The life experience of African } \\
\text { American transsexual college students }\end{array}$ & $\begin{array}{l}\text { Northern } \\
\text { Illinois } \\
\text { University- } \\
2007\end{array}$ & $4 . \mathrm{a}$ & $\begin{array}{l}\text { LGTBIQ } \\
7\end{array}$ \\
\hline $\begin{array}{l}\text { Factors influencing condom use among Latino } \\
\text { men who have sex with men }\end{array}$ & $\begin{array}{l}\text { Northern } \\
\text { Illinois } \\
\text { University - } \\
2006\end{array}$ & $4 . \mathrm{a}$ & $\begin{array}{l}\text { LGTBIQ } \\
8\end{array}$ \\
\hline $\begin{array}{l}\text { Examining the lived experience of out gay and } \\
\text { lesbian K-12 educators }\end{array}$ & $\begin{array}{l}\text { San Diego } \\
\text { State-2005 }\end{array}$ & $2 . \mathrm{a}$ & $\begin{array}{l}\text { LGTBIQ } \\
9\end{array}$ \\
\hline $\begin{array}{l}\text { Lesbian, gay, bisexual and transgender adult } \\
\text { and youth perceptions on school safety in central } \\
\text { Pennsylvania }\end{array}$ & $\begin{array}{l}\text { Temple } \\
\text { University- } \\
2006\end{array}$ & $4 . \mathrm{a}$ & $\begin{array}{l}\text { LGTBIQ } \\
10\end{array}$ \\
\hline $\begin{array}{l}\text { Sexual orientation and multiperspective identity } \\
\text { on a small Catholic campus: An analysis of the }\end{array}$ & $\begin{array}{l}\text { Temple } \\
\text { University- }\end{array}$ & $\begin{array}{l}3 . \mathrm{a} \\
4 . \mathrm{a} \\
\end{array}$ & $\begin{array}{l}\text { LGTBIQ } \\
11\end{array}$ \\
\hline
\end{tabular}




\section{GENDER REPRESENTATIONS IN ED.D. DISSERTATIONS}

\begin{tabular}{|c|c|c|c|}
\hline $\begin{array}{l}\text { cultural climate and multicultural organizational } \\
\text { change }\end{array}$ & 2001 & & \\
\hline $\begin{array}{l}\text { Heterosexism within educational institutions: } \\
\text { Coping efforts of lesbian, gay and bisexual } \\
\text { students in West Texas }\end{array}$ & $\begin{array}{l}\text { Texas Tech } \\
\text { U-1998 }\end{array}$ & $\begin{array}{l}2 . \mathrm{a} \\
\text { 3. } \mathrm{a} \\
4 . \mathrm{a}\end{array}$ & $\begin{array}{l}\text { LGTBIQ } \\
12\end{array}$ \\
\hline $\begin{array}{l}\text { The relationship between religious } \\
\text { fundamentalism and moral development on } \\
\text { homophobia in college undergraduates }\end{array}$ & $\begin{array}{l}\text { Texas Tech } \\
\text { U-1998 }\end{array}$ & $\begin{array}{l}2 . \mathrm{a} \\
4 . \mathrm{a}\end{array}$ & $\begin{array}{l}\text { LGTBIQ } \\
13\end{array}$ \\
\hline $\begin{array}{l}\text { Complementarity in long term lesbian } \\
\text { relationships and non-lesbian female friendships }\end{array}$ & $\begin{array}{l}\text { University of } \\
\text { Louisville- } \\
2000\end{array}$ & $4 . \mathrm{a}$ & $\begin{array}{l}\text { LGTBIQ } \\
14\end{array}$ \\
\hline $\begin{array}{l}\text { Constructing the experiences of gay and lesbian } \\
\text { high school students in Maine }\end{array}$ & $\begin{array}{l}\text { University of } \\
\text { Maine-2005 }\end{array}$ & $\begin{array}{l}2 . \mathrm{a} \\
4 . \mathrm{a} \\
5 . \mathrm{a}\end{array}$ & $\begin{array}{l}\text { LGTBIQ } \\
15\end{array}$ \\
\hline $\begin{array}{l}\text { The preparation of undergraduate social work } \\
\text { students in same faith based institutions for } \\
\text { professional practice with gay and lesbian } \\
\text { persons: A qualitative study }\end{array}$ & $\begin{array}{l}\text { University of } \\
\text { Memphis- } \\
2001\end{array}$ & $\begin{array}{l}2 . \mathrm{a} \\
4 . \mathrm{a}\end{array}$ & $\begin{array}{l}\text { LGTBIQ } \\
16\end{array}$ \\
\hline $\begin{array}{l}\text { A feeling of belonging: Impacts of gay-straight } \\
\text { alliances on high school students }\end{array}$ & $\begin{array}{l}\text { Arizona } \\
\text { State- } \\
\text { Tempe-2007 }\end{array}$ & $4 . \mathrm{a}$ & $\begin{array}{l}\text { LGTBIQ } \\
17\end{array}$ \\
\hline $\begin{array}{l}\text { Out of the closet and onto Fraternity Row: An } \\
\text { ethnographic study of heterosexism and } \\
\text { homophobia in a college fraternity community }\end{array}$ & $\begin{array}{l}\text { Florida } \\
\text { State-2006 }\end{array}$ & $\begin{array}{l}\text { 1.b } \\
\text { 3.a,3.b } \\
\text { 4.a }\end{array}$ & $\begin{array}{l}\text { LGTBIQ } \\
18\end{array}$ \\
\hline $\begin{array}{l}\text { The interrelationship between being lesbian and } \\
\text { its impact on community college leadership }\end{array}$ & $\begin{array}{l}\text { Oregon State } \\
\text { U- }\end{array}$ & $4 . \mathrm{a}$ & $\begin{array}{l}\text { LGTBIQ } \\
19\end{array}$ \\
\hline $\begin{array}{l}\text { Gay men at midlife and adult learning. An } \\
\text { uneasy truce with hetero-normativity }\end{array}$ & $\begin{array}{l}\text { Pennsylvani } \\
\text { a State-2007 }\end{array}$ & $\begin{array}{l}2 . \mathrm{a} \\
3 . \mathrm{a} \\
4 . \mathrm{a}\end{array}$ & $\begin{array}{l}\text { LGTBIQ } \\
20\end{array}$ \\
\hline $\begin{array}{l}\text { Gay straight alliances in high schools: A case } \\
\text { study of four urban, public schools UCLA }\end{array}$ & $\begin{array}{l}\text { University of } \\
\text { California- } \\
\text { LA \& } \\
\text { Irvine-2006 }\end{array}$ & $4 . a$ & $\begin{array}{l}\text { LGTBIQ } \\
21\end{array}$ \\
\hline $\begin{array}{l}\text { Urban cowgirls: How lesbians learn to negotiate } \\
\text { the heterosexism of corporate American }\end{array}$ & $\begin{array}{l}\text { University of } \\
\text { Georgia- } \\
2000\end{array}$ & $\begin{array}{l}2 . \mathrm{a} \\
3 . \mathrm{a}\end{array}$ & $\begin{array}{l}\text { LGTBIQ } \\
22\end{array}$ \\
\hline $\begin{array}{l}\text { Living outside the circle: the politics of } \\
\text { HIV/AIDS education and the } \\
\text { disenfranchisement of HIV-negative gay men }\end{array}$ & $\begin{array}{l}\text { University of } \\
\text { Georgia- } \\
1999\end{array}$ & $4 . a$ & $\begin{array}{l}\text { LGTBIQ } \\
23\end{array}$ \\
\hline $\begin{array}{l}\text { Strangers in good company: The accuracy of } \\
\text { student's perception of peer attitudes towards } \\
\text { gays, lesbians and bisexuals }\end{array}$ & $\begin{array}{l}\text { University of } \\
\text { Massachuset } \\
\text { ts-Amherst - } \\
2006\end{array}$ & 4.a & $\begin{array}{l}\text { LGTBIQ } \\
24\end{array}$ \\
\hline $\begin{array}{l}\text { Off that spectrum entirely: A study of female- } \\
\text { bodied transgendered-identified individuals }\end{array}$ & $\begin{array}{l}\text { University of } \\
\text { Massachuset }\end{array}$ & $\begin{array}{l}2 . a \\
3 . a \\
\end{array}$ & $\begin{array}{l}\text { LGTBIQ } \\
25\end{array}$ \\
\hline
\end{tabular}


GENDER REPRESENTATIONS IN ED.D. DISSERTATIONS

\begin{tabular}{|c|c|c|c|}
\hline & $\begin{array}{l}\text { ts-Amherst- } \\
2003\end{array}$ & $\begin{array}{l}4 . \mathrm{a} \\
5 . \mathrm{b}\end{array}$ & \\
\hline $\begin{array}{l}\text { A description of gay/straight alliances in the } \\
\text { public schools of Massachusetts }\end{array}$ & $\begin{array}{l}\text { University of } \\
\text { Massachuset } \\
\text { ts-Amherst- } \\
2000\end{array}$ & 4.a & $\begin{array}{l}\text { LGTBIQ } \\
26\end{array}$ \\
\hline $\begin{array}{l}\text { A multicultural organization development } \\
\text { examination of school based change strategies to } \\
\text { address needs of gay youth }\end{array}$ & $\begin{array}{l}\text { University of } \\
\text { Massachuset } \\
\text { ts-Amherst - } \\
1998\end{array}$ & 4.a & $\begin{array}{l}\text { LGTBIQ } \\
27\end{array}$ \\
\hline $\begin{array}{l}\text { Re-Sallying Quids: Resilience of queer youth in } \\
\text { school }\end{array}$ & $\begin{array}{l}\text { University of } \\
\text { Michigan - } \\
2001\end{array}$ & $\begin{array}{l}3 . \mathrm{a} \\
5 . \mathrm{b}\end{array}$ & $\begin{array}{l}\text { LGTBIQ } \\
28\end{array}$ \\
\hline $\begin{array}{l}\text { Activism for LGTB rights: How participation } \\
\text { affects the lives of activist educators }\end{array}$ & $\begin{array}{l}\text { University of } \\
\text { N. Carolina- } \\
\text { Chapel Hill- } \\
2005\end{array}$ & $4 . a$ & $\begin{array}{l}\text { LGTBIQ } \\
29\end{array}$ \\
\hline $\begin{array}{l}\text { Attitudes of educators/administrators towards } \\
\text { lesbian, gay, bisexual and transgendered } \\
\text { students }\end{array}$ & $\begin{array}{l}\text { University of } \\
\text { Tennessee- } \\
\text { Knoxville- } \\
2002\end{array}$ & 3.a & $\begin{array}{l}\text { LGTBIQ } \\
30\end{array}$ \\
\hline $\begin{array}{l}\text { Lesbian, gay, bisexual, and transgender equity } \\
\text { issues: A study of preservice teacher's } \\
\text { perceptions of current practices in teacher } \\
\text { education }\end{array}$ & $\begin{array}{l}\text { Washington } \\
\text { State-2002 }\end{array}$ & $4 . a$ & $\begin{array}{l}\text { LGTBIQ } \\
31\end{array}$ \\
\hline $\begin{array}{l}\text { The impact of youth centered groups on the self- } \\
\text { efficacy of gay and lesbian youth }\end{array}$ & $\begin{array}{l}\text { Washington } \\
\text { State-2000 }\end{array}$ & $4 . a$ & $\begin{array}{l}\text { LGTBIQ } \\
32\end{array}$ \\
\hline
\end{tabular}


GENDER REPRESENTATIONS IN ED.D. DISSERTATIONS

APPENDIX S. Tetreault coding TITLE IX

\begin{tabular}{|c|c|c|c|}
\hline Gender focused dissertation & Institution & Tetreault & \\
\hline $\begin{array}{l}\text { Complying with Title IX: An analysis of emergent } \\
\text { leadership issued in an NCAA Division I Institution }\end{array}$ & $\begin{array}{l}\text { Indiana U } \\
\text { of PA-2005 } \\
2\end{array}$ & $2 . \mathrm{a}$ & $\begin{array}{l}\text { Title IX } \\
1\end{array}$ \\
\hline $\begin{array}{l}\text { Has Title IX enforcement had an adverse effect on } \\
\text { the number of participation opportunities at NCAA } \\
\text { Division I institutions for male student athletes? }\end{array}$ & $\begin{array}{l}\text { Tennessee } \\
\text { State-2003 } \\
11\end{array}$ & 1.a,1.b & $\begin{array}{l}\text { Title IX } \\
2\end{array}$ \\
\hline $\begin{array}{l}\text { The effectiveness of NCAA Division I athletes } \\
\text { program leadership in assuring Title IX Compliance }\end{array}$ & $\begin{array}{l}\text { Northern } \\
\text { Arizona U- } \\
2000 \\
13\end{array}$ & 2.a & $\begin{array}{l}\text { Title IX } \\
3\end{array}$ \\
\hline $\begin{array}{l}\text { Title IX Compliance: A comparative analysis of the } \\
\text { perceptions of athletic directors represented in the } \\
\text { NEW Jersey State Interscholastic Athletic } \\
\text { Association (NJSIAA) and athletic directors } \\
\text { represented in the National Collegiate Athletic } \\
\text { Association (NCAA) division III }\end{array}$ & $\begin{array}{l}\text { Temple } \\
\text { University- } \\
2000 \\
24\end{array}$ & 2.a & $\begin{array}{l}\text { Title IX } \\
4\end{array}$ \\
\hline $\begin{array}{l}\text { A history and analysis of sports related Title IX } \\
\text { legislation and litigation from } 1972 \text { to } 1997\end{array}$ & $\begin{array}{l}\text { University } \\
\text { of } \\
\text { Alabama- } \\
1998\end{array}$ & 2.a,2.b & $\begin{array}{l}\text { Title IX } \\
5\end{array}$ \\
\hline $\begin{array}{l}\text { An analysis of the perception of the degree of } \\
\text { compliance of selected Texas public high schools } \\
\text { with Title IX of the Education Amendments of } 1972\end{array}$ & $\begin{array}{l}\text { University } \\
\text { of N. } \\
\text { Texas-2005 }\end{array}$ & $\begin{array}{l}2 . \mathrm{a} \\
4 . \mathrm{a}\end{array}$ & $\begin{array}{l}\text { Title IX } \\
6\end{array}$ \\
\hline $\begin{array}{l}\text { The post Title IX generation: Perceptions and } \\
\text { experiences of gender equity among new university } \\
\text { faculty }\end{array}$ & $\begin{array}{l}\text { University } \\
\text { of Oregon- } \\
2004\end{array}$ & $\begin{array}{l}\text { 2.a, 2.b } \\
\text { 3.c }\end{array}$ & $\begin{array}{l}\text { Title IX } \\
7\end{array}$ \\
\hline $\begin{array}{l}\text { Teams on paper: Title IX compliance in the } \\
\text { Maryland Junior College Athletic Conference }\end{array}$ & $\begin{array}{l}\text { University } \\
\text { of } \\
\text { Delaware- } \\
1998\end{array}$ & 2.a & $\begin{array}{l}\text { Title IX } \\
8\end{array}$ \\
\hline $\begin{array}{l}\text { Title IX compliance and Georgia high school } \\
\text { athletic programs }\end{array}$ & $\begin{array}{l}\text { University } \\
\text { of Georgia- } \\
1999\end{array}$ & $\begin{array}{l}\text { 2.a } \\
\text { 3.a,3.b } \\
\text { 4.a }\end{array}$ & $\begin{array}{l}\text { Title IX } \\
9\end{array}$ \\
\hline $\begin{array}{l}\text { Athletic gender equity policy: The potential for } \\
\text { United States Title IX directives in Canadian } \\
\text { universities }\end{array}$ & $\begin{array}{l}\text { University } \\
\text { of } \\
\text { Nebraska- } \\
2006\end{array}$ & $2 . \mathrm{a}$ & $\begin{array}{l}\text { Title IX } \\
10\end{array}$ \\
\hline $\begin{array}{l}\text { Title IX intent vs action: Compliance and equity in } \\
\text { Allegheny public schools }\end{array}$ & $\begin{array}{l}\text { University } \\
\text { of } \\
\text { Pittsburgh- } \\
2000\end{array}$ & 2.a, 2.c & $\begin{array}{l}\text { Title IX } \\
11\end{array}$ \\
\hline Women in collegiate sports: The struggle for equity & University & 2.a, 2.b, & Title IX \\
\hline
\end{tabular}


GENDER REPRESENTATIONS IN ED.D. DISSERTATIONS

\begin{tabular}{|l|l|l|l|}
\hline since the 1972 Title IX Education Amendment & $\begin{array}{l}\text { of } \\
\text { Pittburgh- } \\
1998\end{array}$ & $2 . c$ & 12 \\
\hline Title IX compliance in Virginia high schools ${ }^{\text {d }}$ & $\begin{array}{l}\text { Virginia } \\
\text { Polytechnic } \\
\& \text { State U- } \\
2006\end{array}$ & $2 . \mathrm{a}$ & $\begin{array}{l}\text { Title IX } \\
13\end{array}$ \\
\hline $\begin{array}{l}\text { Perceptions of Title IX and gender equity: The } \\
\text { influence of life histories, sports experiences and } \\
\text { campus initiatives }\end{array}$ & $\begin{array}{l}\text { SUNY } \\
\text { Binghampt } \\
\text { on-2006 }\end{array}$ & $\begin{array}{l}\text { 2.a } 3 . a, 3 . b, \\
3 . c \\
5 . a, 5 . b\end{array}$ & $\begin{array}{l}\text { Title IX } \\
14\end{array}$ \\
\hline $\begin{array}{l}\text { Historical comparison of Florida and national Title } \\
\text { IX compliance trends in high school sports from } \\
\text { 1985-2005 }\end{array}$ & $\begin{array}{l}\text { U of } \\
\text { Central } \\
\text { Florida- } \\
\text { 2007 }\end{array}$ & $\begin{array}{l}\text { 2.a } \\
15\end{array}$ & 15 \\
\hline
\end{tabular}


GENDER REPRESENTATIONS IN ED.D. DISSERTATIONS

APPENDIX T. Tetreault coding FEMINIST

\begin{tabular}{|c|c|c|c|}
\hline Gender focused dissertation & Institution & Tetreault & \\
\hline $\begin{array}{l}\text { An inquiry into the experiences of the African } \\
\text { American women principal: Critical race theory } \\
\text { and Black feminist principles }\end{array}$ & $\begin{array}{l}\text { Georgia } \\
\text { Southern } \\
\text { U-2004 }\end{array}$ & $\begin{array}{l}2 . a, 2 . c \\
4 . a\end{array}$ & $\begin{array}{l}\text { Feminist } \\
1\end{array}$ \\
\hline $\begin{array}{l}\text { Postmodern feminist pedagogy in a first-year } \\
\text { writing class }\end{array}$ & $\begin{array}{l}\text { Georgia } \\
\text { Southern } \\
\text { U-2003 }\end{array}$ & $\begin{array}{l}4 . \mathrm{a} \\
5 . \mathrm{a}\end{array}$ & $\begin{array}{l}\text { Feminist } \\
2\end{array}$ \\
\hline $\begin{array}{l}\text { Women in public middle school administration } \\
\text { in Georgia: A feminist analysis of the } \\
\text { perceptions of women in power }\end{array}$ & $\begin{array}{l}\text { Georgia } \\
\text { Southern } \\
\text { U-2001 }\end{array}$ & $\begin{array}{l}\text { 2.a } \\
\text { 3.a,3.b } \\
3 . d\end{array}$ & $\begin{array}{l}\text { Feminist } \\
3\end{array}$ \\
\hline $\begin{array}{l}\text { Pre-service teacher's beliefs about teaching and } \\
\text { learning before, during and after the application } \\
\text { of feminist pedagogies }\end{array}$ & $\begin{array}{l}\text { Texas A \& } \\
\text { M } \\
\text { Commerce- } \\
2000\end{array}$ & 2.a & $\begin{array}{l}\text { Feminist } \\
4\end{array}$ \\
\hline $\begin{array}{l}\text { Feminist and Eugenicist thinking in a woman } \\
\text { educator: The case of Leta Stetter Hollingworth }\end{array}$ & $\begin{array}{l}\text { Indiana U } \\
\text { Purdue- } \\
2003\end{array}$ & $\begin{array}{l}\text { 2.a,2.b,2. } \\
\mathrm{c}\end{array}$ & $\begin{array}{l}\text { Feminist } \\
5\end{array}$ \\
\hline $\begin{array}{l}\text { Empowerment of low-income women in India: } \\
\text { Emergent feminist grassroots leaders in } \\
\text { Ahmedabad, Gujarat }\end{array}$ & $\begin{array}{l}\text { Northern } \\
\text { Illinois } \\
\text { University- } \\
2006\end{array}$ & $\begin{array}{l}2 . \mathrm{a} \\
3 . \mathrm{a} \\
4 . \mathrm{a} \\
5 . \mathrm{b}\end{array}$ & $\begin{array}{l}\text { Feminist } \\
6\end{array}$ \\
\hline $\begin{array}{l}\text { Coming into their own: A study of a feminist } \\
\text { adult education program in Esteli, Nicaragua }\end{array}$ & $\begin{array}{l}\text { Northern } \\
\text { Illinois } \\
\text { University- } \\
2003\end{array}$ & $\begin{array}{l}\text { 2.a, } 2 . b \\
3 . c\end{array}$ & $\begin{array}{l}\text { Feminist } \\
7\end{array}$ \\
\hline $\begin{array}{l}\text { An investigation into the illustrations of Snow } \\
\text { White and her stepmother in selected retellings } \\
\text { of "Snow White and the Seven Dwarfs" from } \\
\text { 1882 to 1996:A feminist inquiry af }\end{array}$ & $\begin{array}{l}\text { Northern } \\
\text { Illinois } \\
\text { University- } \\
2001\end{array}$ & $\begin{array}{l}2 . \mathrm{a} \\
\text { 3.a } \\
5 . \mathrm{b}\end{array}$ & $\begin{array}{l}\text { Feminist } \\
8\end{array}$ \\
\hline $\begin{array}{l}\text { A feminist phase theory exploration of the } \\
\text { development of levels of gender awareness in } \\
\text { the superintendency }\end{array}$ & $\begin{array}{l}\text { Oklahoma } \\
\text { State-Main- } \\
2000\end{array}$ & $\begin{array}{l}2 . a \\
3 . a \\
5 . b\end{array}$ & $\begin{array}{l}\text { Feminist } \\
9\end{array}$ \\
\hline $\begin{array}{l}\text { The selection of high school principals: An } \\
\text { examination of the process using feminist phase } \\
\text { theory }\end{array}$ & $\begin{array}{l}\text { Oklahoma } \\
\text { State-Main- } \\
1999\end{array}$ & $\begin{array}{l}2 . a \\
3 . a \\
5 . b\end{array}$ & $\begin{array}{l}\text { Feminist } \\
10\end{array}$ \\
\hline $\begin{array}{l}\text { A postmodern feminist text analysis of the } \\
\text { pedagogy of popular craft }\end{array}$ & $\begin{array}{l}\text { Oklahoma } \\
\text { State-Main- }\end{array}$ & $\begin{array}{l}\text { 3.a,3.b, } \\
\text { 3.c }\end{array}$ & $\begin{array}{l}\text { Feminist } \\
11\end{array}$ \\
\hline
\end{tabular}


GENDER REPRESENTATIONS IN ED.D. DISSERTATIONS

\begin{tabular}{|c|c|c|c|}
\hline & 1998 & & \\
\hline $\begin{array}{l}\text { In their own voices: The impact of the feminist } \\
\text { movement in adult education }\end{array}$ & $\begin{array}{l}\text { University } \\
\text { of Southern } \\
\text { Mississippi } \\
-2005\end{array}$ & $5 . \mathrm{a}$ & $\begin{array}{l}\text { Feminist } \\
12\end{array}$ \\
\hline $\begin{array}{l}\text { A sense of entitlement to self in relationships: } \\
\text { An elaboration of attachment and feminist object } \\
\text { relations theory }\end{array}$ & $\begin{array}{l}\text { Western } \\
\text { Michigan } \\
\text { University- } \\
1998\end{array}$ & $\begin{array}{l}2 . \mathrm{a} \\
4 . \mathrm{a}\end{array}$ & $\begin{array}{l}\text { Feminist } \\
13\end{array}$ \\
\hline $\begin{array}{l}\text { Feminist popular education in Latin American: } \\
\text { A case study on the political empowerment of } \\
\text { women in the Dominican republic }\end{array}$ & $\begin{array}{l}\text { SUNY- } \\
\text { Albany- } \\
1999\end{array}$ & $\begin{array}{l}2 . \mathrm{a} \\
4 . \mathrm{a}\end{array}$ & $\begin{array}{l}\text { Feminist } \\
14\end{array}$ \\
\hline $\begin{array}{l}\text { African-American women in school psychology: } \\
\text { The sociological framework of Black feminist } \\
\text { thought and development of role in practice }\end{array}$ & $\begin{array}{l}\text { University } \\
\text { of } \\
\text { Cincinnati- } \\
1998\end{array}$ & $\begin{array}{l}2 . \mathrm{a} \\
4 . \mathrm{a}\end{array}$ & $\begin{array}{l}\text { Feminist } \\
15\end{array}$ \\
\hline $\begin{array}{l}\text { Negotiating feminist interests in elementary and } \\
\text { secondary schools }\end{array}$ & $\begin{array}{l}\text { University } \\
\text { of Georgia } \\
-2002\end{array}$ & $\begin{array}{l}2 . a \\
\text { 3.a } \\
5 . \mathrm{b}\end{array}$ & $\begin{array}{l}\text { Feminist } \\
16\end{array}$ \\
\hline $\begin{array}{l}\text { Making science accessible through collaborative } \\
\text { science teacher action research on feminist } \\
\text { pedagogy }\end{array}$ & $\begin{array}{l}\text { University } \\
\text { of } \\
\text { Massachuse } \\
\text { tts- } \\
\text { Amherst- } \\
2002\end{array}$ & $\begin{array}{l}2 . \mathrm{a} \\
4 . \mathrm{a}\end{array}$ & $\begin{array}{l}\text { Feminist } \\
17\end{array}$ \\
\hline $\begin{array}{l}\text { Adult literacy clients as authors: A feminist } \\
\text { poststructuralist perspective }\end{array}$ & $\begin{array}{l}\text { University } \\
\text { of } \\
\text { Massachuse } \\
\text { tts- } \\
\text { Amherst- } \\
2000\end{array}$ & $\begin{array}{l}2 . \mathrm{a} \\
\text { 3.a } \\
5 . \mathrm{b}\end{array}$ & $\begin{array}{l}\text { Feminist } \\
18\end{array}$ \\
\hline $\begin{array}{l}\text { Brick walls and broken mirrors: A case study of } \\
\text { feminist and critical pedagogy in graduate adult } \\
\text { education }\end{array}$ & $\begin{array}{l}\text { University } \\
\text { of } \\
\text { S. Carolina- } \\
\text { Columbia- } \\
2001\end{array}$ & $\begin{array}{l}4 . \mathrm{a} \\
5 . \mathrm{a}\end{array}$ & $\begin{array}{l}\text { Feminist } \\
19\end{array}$ \\
\hline
\end{tabular}


GENDER REPRESENTATIONS IN ED.D. DISSERTATIONS

APPENDIX U. Male gender focused dissertations citing ethnicity

\begin{tabular}{|c|c|c|c|c|}
\hline Dissertation Title & $\begin{array}{l}\text { DRU- } \\
\text { Institutio } \\
n\end{array}$ & \# & Ethnicity & \\
\hline $\begin{array}{l}\text { The Church of the United Brethren in Christ } \\
\text { support of the community education work of } \\
\text { Moy Ling among the Chinese on Portland } \\
\text { Oregon, 1882-1931:Impications for a } \\
\text { missological understanding of partnership am }\end{array}$ & $\begin{array}{l}\text { Ball State } \\
\text { U-2005 } \\
2\end{array}$ & 1 & Chinese & Neutral/+ \\
\hline $\begin{array}{l}\text { The under-representation of African American } \\
\text { males in academically gifted programs: The } \\
\text { perceptions of teachers and administrators of } \\
\text { barriers to identification }\end{array}$ & $\begin{array}{l}\text { East } \\
\text { Carolina } \\
\text { U-2007 } \\
1\end{array}$ & 2 & Black & Neutral/+ \\
\hline $\begin{array}{l}\text { Knowledge and perceptions held by Latino } \\
\text { parents regarding the educational services for } \\
\text { LEP children with disabilities }\end{array}$ & $\begin{array}{l}\text { Illinois } \\
\text { State U- } \\
1999 \\
1\end{array}$ & 3 & Latino & Neutral/+ \\
\hline $\begin{array}{l}\text { The impact of preparedness, self-efficacy and } \\
\text { math anxiety on the success of African } \\
\text { American males in developmental mathematics } \\
\text { at a community college }\end{array}$ & $\begin{array}{l}\text { Morgan } \\
\text { State U- } \\
2007\end{array}$ & 4 & Black & Def/Dev \\
\hline $\begin{array}{l}\text { Factors affecting retention of } 1^{\text {st }} \text { year Latino } \\
\text { students in a private university }\end{array}$ & $\begin{array}{l}\text { Morgan } \\
\text { State U- } \\
2006\end{array}$ & 5 & Latino & Neutral/+ \\
\hline $\begin{array}{l}\text { Why can't brother man stay in school: A } \\
\text { phenomenological study of Black male student } \\
\text { attrition at a Black commuter college }\end{array}$ & $\begin{array}{l}\text { Morgan } \\
\text { State U- } \\
2004\end{array}$ & 6 & Black & Def/Dev \\
\hline $\begin{array}{l}\text { In their own words: A phenomenological } \\
\text { investigation of the lived experiences of selected } \\
\text { African-American male early school leavers in } \\
\text { Washington D.C. }\end{array}$ & $\begin{array}{l}\text { Morgan } \\
\text { State U- } \\
2003\end{array}$ & 7 & Black & Neutral/+ \\
\hline $\begin{array}{l}\text { A causal comparative study of instructional } \\
\text { programs on the mathematical achievements of } \\
\text { elementary school African American male } \\
\text { students }\end{array}$ & $\begin{array}{l}\text { South } \\
\text { Carolina } \\
\text { State-2005 }\end{array}$ & 8 & Black & Neutral/+ \\
\hline $\begin{array}{l}\text { The effects of group counseling compared with } \\
\text { individual counseling in the reduction of at-risk } \\
\text { behaviors using grade point average, discipline } \\
\text { referrals and attendance among } 6^{\text {th }} \text { grade Black } \\
\text { males }\end{array}$ & $\begin{array}{l}\text { South } \\
\text { Carolina } \\
\text { State-2005 }\end{array}$ & 9 & Black & Neutral/+ \\
\hline $\begin{array}{l}\text { The impact of locus of control on the academic } \\
\text { achievement of African American males }\end{array}$ & $\begin{array}{l}\text { South } \\
\text { Carolina } \\
\text { State-2003 }\end{array}$ & 10 & Black & Def/Dev \\
\hline
\end{tabular}




\section{GENDER REPRESENTATIONS IN ED.D. DISSERTATIONS}

\begin{tabular}{|c|c|c|c|c|}
\hline $\begin{array}{l}\text { The attitudes of rural eighth grade Black males } \\
\text { towards academic learning and it's impact on } \\
\text { academic achievement }\end{array}$ & $\begin{array}{l}\text { South } \\
\text { Carolina } \\
\text { State-2002 }\end{array}$ & 11 & Black & Def/Dev \\
\hline $\begin{array}{l}\text { Group counseling compared with individual } \\
\text { counseling in the reduction of at risk behaviors } \\
\text { in Black male students }\end{array}$ & $\begin{array}{l}\text { South } \\
\text { Carolina } \\
\text { State-2001 }\end{array}$ & 12 & Black & Neutral/+ \\
\hline $\begin{array}{l}\text { Teacher perception of verbal reinforcement } \\
\text { versus tangible reinforcement with regard to } \\
\text { academic achievement for the African-American } \\
\text { middle school male }\end{array}$ & $\begin{array}{l}\text { Tennessee } \\
\text { State-2003 }\end{array}$ & 13 & Black & Neutral/+ \\
\hline $\begin{array}{l}\text { The retention of Black male students in Texas } \\
\text { public community colleges }\end{array}$ & $\begin{array}{l}\text { Texas A \& } \\
\text { M } \\
\text { Commerce } \\
-2001\end{array}$ & 14 & Black & Neutral/+ \\
\hline $\begin{array}{l}\text { Black male student achievement: A synthesis of } \\
\text { research in the "Journal of Negro Education" }\end{array}$ & $\begin{array}{l}\text { Texas A \& } \\
\text { M } \\
\text { Commerce } \\
-1998\end{array}$ & 15 & Black & Neutral/+ \\
\hline $\begin{array}{l}\text { Factors influencing the underrepresentation of } \\
\text { Latinos in higher education }\end{array}$ & $\begin{array}{l}\text { Texas A \& } \\
\text { M } \\
\text { Kingsville } \\
-2006\end{array}$ & 16 & Latino & Neutral/+ \\
\hline $\begin{array}{l}\text { Factors that influence the future of African } \\
\text { American males in higher education in the State } \\
\text { of Texas }\end{array}$ & $\begin{array}{l}\text { Texas } \\
\text { Southern- } \\
2001\end{array}$ & 17 & Black & Neutral/+ \\
\hline $\begin{array}{l}\text { The effects of early violence intervention on } \\
\text { aggression and anti-social behavior among } \\
\text { African-American males }\end{array}$ & $\begin{array}{l}\text { Texas } \\
\text { Southern }\end{array}$ & 18 & Black & Def/Dev \\
\hline $\begin{array}{l}\text { The relationship between self-esteem, campus } \\
\text { climate and parental involvement on academic } \\
\text { achievement of African American boys }\end{array}$ & $\begin{array}{l}\text { Texas } \\
\text { Southern }\end{array}$ & 19 & Black & Def/Dev \\
\hline $\begin{array}{l}\text { An investigation into the perceptions of Latino } \\
\text { parents of young children in urban, suburban } \\
\text { and rural school settings }\end{array}$ & $\begin{array}{l}\text { Texas } \\
\text { Woman's } \\
\text { University } \\
-2001\end{array}$ & 20 & Latino & Neutral/+ \\
\hline $\begin{array}{l}\text { The kids on the other side of the hallway: } \\
\text { Teacher's perspectives of the academic } \\
\text { achievement of Latino English language learners }\end{array}$ & $\begin{array}{l}\text { University } \\
\text { of } \\
\text { Massachus } \\
\text { etts- } \\
\text { Boston- } \\
2007\end{array}$ & 21 & Latino & Neutral/+ \\
\hline
\end{tabular}


GENDER REPRESENTATIONS IN ED.D. DISSERTATIONS

\begin{tabular}{|c|c|c|c|c|}
\hline $\begin{array}{l}\text { Establishing classroom contacts and } \\
\text { interactions: White educators' attitudes about } \\
\text { early adolescent Black males }\end{array}$ & $\begin{array}{l}\text { University } \\
\text { of } \\
\text { Massachus } \\
\text { etts- } \\
\text { Boston- } \\
2006\end{array}$ & 22 & $\begin{array}{l}\text { White } \\
\text { Black }\end{array}$ & Neutral/+ \\
\hline $\begin{array}{l}\text { Veteran teacher attitudes towards Blacks and } \\
\text { Latinos in urban self-contained special } \\
\text { education high school classrooms }\end{array}$ & $\begin{array}{l}\text { University } \\
\text { of } \\
\text { Massachus } \\
\text { etts- } \\
\text { Boston- } \\
2005\end{array}$ & 23 & $\begin{array}{l}\text { Black } \\
\text { Latino }\end{array}$ & Neutral/+ \\
\hline $\begin{array}{l}\text { The involvement of African American Fathers in } \\
\text { the educational lives of their young children: } \\
\text { Beliefs, practices, and experiences in one } \\
\text { elementary school }\end{array}$ & $\begin{array}{l}\text { University } \\
\text { of } \\
\text { Massachus } \\
\text { etts- } \\
\text { Boston- } \\
2004\end{array}$ & 24 & Black & Neutral/+ \\
\hline $\begin{array}{l}\text { Factors that motivate Hispanic middle school } \\
\text { males to achieve academically }\end{array}$ & $\begin{array}{l}\text { University } \\
\text { of } \\
\text { Massachus } \\
\text { etts- } \\
\text { Lowell- } \\
2005\end{array}$ & 25 & $\begin{array}{l}\text { Hispanic } \\
\text { Latino }\end{array}$ & Neutral/+ \\
\hline $\begin{array}{l}\text { Exploratory study of the effects of parent } \\
\text { training on increasing Hispanic/Latino parent's } \\
\text { understanding, participation and satisfaction } \\
\text { with the Individual Education Program meeting }\end{array}$ & $\begin{array}{l}\text { U of N. } \\
\text { Carolina- } \\
\text { Charlotte- } \\
2007\end{array}$ & 26 & $\begin{array}{l}\text { Hispanic } \\
\text { Latino }\end{array}$ & Neutral/+ \\
\hline $\begin{array}{l}\text { African-American males: What do schools and } \\
\text { teachers do to enhance academic achievement }\end{array}$ & $\begin{array}{l}\text { U of N. } \\
\text { Carolina- } \\
\text { Charlotte- } \\
2002\end{array}$ & 27 & Black & Neutral/+ \\
\hline $\begin{array}{l}\text { A case study: An examination of literary } \\
\text { transaction of four Chinese-American male } \\
\text { children responding to selected children's books }\end{array}$ & $\begin{array}{l}\text { U of } \\
\text { Northern } \\
\text { Colorado- } \\
1998\end{array}$ & 28 & Chinese & Neutral/+ \\
\hline $\begin{array}{l}\text { Latino student leader perceptions of social } \\
\text { integration, academic success, and persistence } \\
\text { on college campuses }\end{array}$ & $\begin{array}{l}\text { University } \\
\text { of South } \\
\text { Dakota- } \\
2003\end{array}$ & 29 & Latino & Neutral/+ \\
\hline
\end{tabular}


GENDER REPRESENTATIONS IN ED.D. DISSERTATIONS

\begin{tabular}{|c|c|c|c|c|}
\hline Dissertation Title & $\begin{array}{l}\text { RUH- } \\
\text { Institutio } \\
n\end{array}$ & \# & ethnicity & \\
\hline $\begin{array}{l}\text { Lasting legacies: The effects of natural mentors } \\
\text { in the lives of at risk African -American male } \\
\text { adolescents }\end{array}$ & $\begin{array}{l}\text { Bowling } \\
\text { Green } \\
\text { State-2006 }\end{array}$ & 30 & Black & Neutral/t+ \\
\hline $\begin{array}{l}\text { The impact of reading instructional } \\
\text { methodology on student achievement of Black } \\
\text { males based on the Florida comprehensive } \\
\text { assessment test }\end{array}$ & $\begin{array}{l}\text { Florida } \\
\text { Atlantic } \\
\text { Boca } \\
2006\end{array}$ & 31 & Black & Neutral/+ \\
\hline $\begin{array}{l}\text { A comparison of academic success variables of } \\
\text { Black male high school graduates with other } \\
\text { racial and gender populations in the Broward } \\
\text { County School district Florida }\end{array}$ & $\begin{array}{l}\text { Florida } \\
\text { Atlantic } \\
\text { Boca }\end{array}$ & 32 & Black & Neutral/+ \\
\hline $\begin{array}{l}\text { Raising Abel: What do African American single } \\
\text { mothers do to raise successful African American } \\
\text { middle school boys }\end{array}$ & $\begin{array}{l}\text { Indiana U } \\
\text { Purdue- } \\
2003\end{array}$ & 33 & Black & Def/Dev \\
\hline $\begin{array}{l}\text { Non United States born Latinos: A study of } \\
\text { perceptions of barriers and catalysts to } \\
\text { educational success at a rural New Mexico } \\
\text { Community college }\end{array}$ & $\begin{array}{l}\text { New } \\
\text { Mexico } \\
\text { State- } \\
\text { Main- } \\
2007\end{array}$ & 34 & Latino & Neutral/+ \\
\hline $\begin{array}{l}\text { A case study on language proficiency with } \\
\text { Latino students in dual language setting }\end{array}$ & $\begin{array}{l}\text { New } \\
\text { Mexico } \\
\text { State- } \\
\text { Main- } \\
2000\end{array}$ & 35 & Latino & Neutral/+ \\
\hline $\begin{array}{l}\text { An analysis of adult African American men's } \\
\text { perceived susceptibility of prostate cancer and } \\
\text { perceived benefits and barriers to participation } \\
\text { in early detection methods: Implications for } \\
\text { community-based health promotion }\end{array}$ & $\begin{array}{l}\text { Northern } \\
\text { Illinois- } \\
2007 \\
\text { University }\end{array}$ & 36 & Black & Neutral/+ \\
\hline $\begin{array}{l}\text { A study of the relationship between resiliency } \\
\text { attitudes and selected risk factors of gang } \\
\text { involvement in adult Honduran males }\end{array}$ & $\begin{array}{l}\text { Northern } \\
\text { Illinois } \\
\text { University } \\
-2005\end{array}$ & 37 & $\begin{array}{l}\text { Honduran } \\
\text { Latino }\end{array}$ & Def/Dev \\
\hline $\begin{array}{l}\text { College Latino students: Cultural integration, } \\
\text { retention, and successful completion }\end{array}$ & $\begin{array}{l}\text { Northern } \\
\text { Illinois } \\
\text { University } \\
-2005\end{array}$ & 38 & Latino & Neutral/+ \\
\hline
\end{tabular}


GENDER REPRESENTATIONS IN ED.D. DISSERTATIONS

\begin{tabular}{|c|c|c|c|c|}
\hline $\begin{array}{l}\text { The African American church as a provider of } \\
\text { nonformal adult education in the Chicago } \\
\text { community under the leadership of Pastor } \\
\text { William Samuel Winston }\end{array}$ & $\begin{array}{l}\text { Northern } \\
\text { Illinois } \\
\text { University } \\
-2005\end{array}$ & 39 & Black & Neutral/+ \\
\hline $\begin{array}{l}\text { Exploring identities: An enquiry into the identity } \\
\text { reconstruction of adult immigrants of Filipino } \\
\text { heritage with implications for adult ESL } \\
\text { programs }\end{array}$ & $\begin{array}{l}\text { Northern } \\
\text { Illinois } \\
\text { University } \\
-2004\end{array}$ & 40 & Filipino & Neutral/+ \\
\hline $\begin{array}{l}\text { School organization of successful alternative } \\
\text { high schools serving Latino students in Chicago }\end{array}$ & $\begin{array}{l}\text { Northern } \\
\text { Illinois } \\
\text { University } \\
\text {-2004 }\end{array}$ & 41 & Latino & Neutral/+ \\
\hline $\begin{array}{l}\text { Reaching and teaching the African-American } \\
\text { male: Curriculum, learning styles, teacher belief } \\
\text { systems and practices }\end{array}$ & $\begin{array}{l}\text { Northern } \\
\text { Illinois } \\
\text { University } \\
-2001\end{array}$ & 42 & Black & Neutral// \\
\hline $\begin{array}{l}\text { Measuring the effectiveness of an Afrocentric } \\
\text { male mentoring program with adolescent } \\
\text { African American males }\end{array}$ & $\begin{array}{l}\text { Northern } \\
\text { Illinois } \\
\text { University } \\
-2000\end{array}$ & 43 & Black & Neutral/+ \\
\hline $\begin{array}{l}\text { There are no crystal stairs here: A study of } \\
\text { African-American males in traditional and non } \\
\text { traditional program in a predominately White } \\
\text { institution of higher education }\end{array}$ & $\begin{array}{l}\text { Northern } \\
\text { Illinois } \\
\text { University } \\
-2000\end{array}$ & 44 & Black & Neutral/+ \\
\hline $\begin{array}{l}\text { Social cognition and language: Abusive } \\
\text { language and the African-American male } \\
\text { juvenile transgressor }\end{array}$ & $\begin{array}{l}\text { Northern } \\
\text { Illinois } \\
\text { University } \\
-1999\end{array}$ & 45 & Black & Def/Dev \\
\hline $\begin{array}{l}\text { Malcolm X: An intellectual aesthetic for Black } \\
\text { adult education am }\end{array}$ & $\begin{array}{l}\text { Northern } \\
\text { Illinois } \\
\text { University } \\
-1998\end{array}$ & 46 & Black & Neutral/t+ \\
\hline $\begin{array}{l}\text { African-American male per-service teachers' } \\
\text { perceptions of elementary education: A multiple } \\
\text { case study }\end{array}$ & $\begin{array}{l}\text { Oklahoma } \\
\text { State- } \\
\text { Main- } \\
2002\end{array}$ & 47 & Black & Neutral// \\
\hline $\begin{array}{l}\text { Factors that foster academic resilience in } \\
\text { African American male middle school students }\end{array}$ & $\begin{array}{l}\text { University } \\
\text { of }\end{array}$ & 48 & Black & Neutral/+ \\
\hline
\end{tabular}


GENDER REPRESENTATIONS IN ED.D. DISSERTATIONS

\begin{tabular}{|c|c|c|c|c|}
\hline from low-socioeconomic, single parent homes & $\begin{array}{l}\text { Alabama- } \\
1999\end{array}$ & & & \\
\hline $\begin{array}{l}\text { Factors that contribute to hazing practices by } \\
\text { collegiate Black Greek letter fraternities during } \\
\text { membership intake activities }\end{array}$ & $\begin{array}{l}\text { University } \\
\text { of } \\
\text { Arkansas- } \\
\text { Main- } \\
2006\end{array}$ & 49 & Black & Def/Dev \\
\hline $\begin{array}{l}\text { An examination of time use patterns influence } \\
\text { on achievement among African American and } \\
\text { Hispanic male high school student athletes }\end{array}$ & $\begin{array}{l}\text { University } \\
\text { of Central } \\
\text { Florida- } \\
2007\end{array}$ & 50 & Black & Neutral/+ \\
\hline $\begin{array}{l}\text { An exploration of the factors contributing to } \\
\text { stress and burnout in male Hispanic middle } \\
\text { school teachers }\end{array}$ & $\begin{array}{l}\text { University } \\
\text { of } \\
\text { Houston- } \\
2006\end{array}$ & 51 & $\begin{array}{l}\text { Hispani } \\
\text { c } \\
\text { Latino }\end{array}$ & Neutral/+ \\
\hline $\begin{array}{l}\text { Beginning reading: Linguistic units and } \\
\text { instructional strategies that facilitate word } \\
\text { recognition in Latino kindegarten students who } \\
\text { are learning to reading Spanish }\end{array}$ & $\begin{array}{l}\text { University } \\
\text { of } \\
\text { Houston- } \\
2003\end{array}$ & 52 & Latino & Neutral/+ \\
\hline $\begin{array}{l}\text { Conversations about reading processes in } \\
\text { Spanish and English among six Latino/a eighth } \\
\text { graders }\end{array}$ & $\begin{array}{l}\text { University } \\
\text { of } \\
\text { Houston- } \\
2002\end{array}$ & 53 & Latino & Neutral/+ \\
\hline $\begin{array}{l}\text { Investigating the cognitive reading strategies } \\
\text { and motivation to read of resilient,average, and } \\
\text { no-resilient fourth-and fifth-grade Latino } \\
\text { English language learners }\end{array}$ & $\begin{array}{l}\text { University } \\
\text { of } \\
\text { Houston- } \\
2002\end{array}$ & 54 & Latino & Neutral/t+ \\
\hline $\begin{array}{l}\text { Ethnic cleansing in the barrio: A critical } \\
\text { ethnography of the politics, practices, and } \\
\text { pedantry of schooling urban Latino bilingual } \\
\text { students }\end{array}$ & $\begin{array}{l}\text { University } \\
\text { of } \\
\text { Houston- } \\
2001\end{array}$ & 55 & Latino & Neutral/+ \\
\hline $\begin{array}{l}\text { A comparison of Latino college graduates and } \\
\text { dropouts with regard to self-efficacy }\end{array}$ & $\begin{array}{l}\text { University } \\
\text { of } \\
\text { Houston- } \\
2001\end{array}$ & 56 & Latino & Neutral/+ \\
\hline $\begin{array}{l}\text { Examining the use of cognitive reading } \\
\text { strategies in Spanish and English by Latino } 4^{\text {th }} \\
\text { grade students in a late-exit bilingual program }\end{array}$ & $\begin{array}{l}\text { University } \\
\text { of } \\
\text { Houston- } \\
\text { 2000- }\end{array}$ & 57 & Latino & Neutral/+ \\
\hline
\end{tabular}


GENDER REPRESENTATIONS IN ED.D. DISSERTATIONS

\begin{tabular}{|c|c|c|c|c|}
\hline $\begin{array}{l}\text { A qualitative investigation of the short term } \\
\text { reentry experiences of male Indian graduate } \\
\text { students studying in the United States }\end{array}$ & $\begin{array}{l}\text { University } \\
\text { of } \\
\text { Houston- } \\
1999\end{array}$ & 58 & Indian & Neutral/+ \\
\hline $\begin{array}{l}\text { Latino parents perceptions about school and } \\
\text { home related literacy practices }\end{array}$ & $\begin{array}{l}\text { University } \\
\text { of } \\
\text { Houston- } \\
1999\end{array}$ & 59 & Latino & Neutral/+ \\
\hline $\begin{array}{l}\text { John Henryism and occupational stress among } \\
\text { African American higher education faculty am }\end{array}$ & $\begin{array}{l}\text { University } \\
\text { of } \\
\text { Houston- } \\
1998\end{array}$ & 60 & Black & Neutral/+ \\
\hline $\begin{array}{l}\text { Working class and working college: A case } \\
\text { study of first generation working class, first year } \\
\text { white male college students }\end{array}$ & $\begin{array}{l}\text { University } \\
\text { of } \\
\text { Louisville- } \\
2002\end{array}$ & 61 & White & Neutral/+ \\
\hline $\begin{array}{l}\text { An analysis of the characteristics that lead to the } \\
\text { disenfranchisement of African Males between } \\
\text { the ages of } 18 \text { to } 35\end{array}$ & $\begin{array}{l}\text { University } \\
\text { of } \\
\text { Memphis- } \\
2004\end{array}$ & 62 & Black & Neutral/+ \\
\hline $\begin{array}{l}\text { Perspective transformation among mainland } \\
\text { Chinese fathers interacting with the American } \\
\text { K-12 educational system }\end{array}$ & $\begin{array}{l}\text { University } \\
\text { of } \\
\text { Memphis- } \\
2004\end{array}$ & 63 & Chinese & Neutral/+ \\
\hline $\begin{array}{l}\text { Designed for failure: An analysis of African } \\
\text { American male students perception of the failure } \\
\text { of traditional school structures to successfully } \\
\text { educate them }\end{array}$ & $\begin{array}{l}\text { University } \\
\text { of } \\
\text { Missouri- } \\
\text { Kansas } \\
\text { City-2007 }\end{array}$ & 64 & Black & Neutral/+ \\
\hline $\begin{array}{l}\text { Social reconstruction of African American } \\
\text { males at an urban middle school }\end{array}$ & $\begin{array}{l}\text { University } \\
\text { of } \\
\text { N.Carolin } \\
\text { a - } \\
\text { Greensbor } \\
\text { o-2006 }\end{array}$ & 65 & Black & Neutral/+ \\
\hline $\begin{array}{l}\text { Through their eyes: A look at the achievement } \\
\text { and success of selected African American male } \\
\text { youths }\end{array}$ & $\begin{array}{l}\text { University } \\
\text { of } \\
\text { N.Carolin }\end{array}$ & 66 & Black & Neutral/+ \\
\hline
\end{tabular}


GENDER REPRESENTATIONS IN ED.D. DISSERTATIONS

\begin{tabular}{|c|c|c|c|c|}
\hline & $\begin{array}{l}\text { a- } \\
\text { Greensbor } \\
\text { o-2006 }\end{array}$ & & & \\
\hline $\begin{array}{l}\text { An examination of the graduation rates of the } \\
\text { Division I African American male basketball } \\
\text { student-athlete }\end{array}$ & $\begin{array}{l}\text { University } \\
\text { of Texas- } \\
\text { El Paso- } \\
2004\end{array}$ & 67 & Black & Neutral//+ \\
\hline $\begin{array}{l}\text { The present status of geography education in } \\
\text { boy's intermediate schools of Riyadh, Saudi } \\
\text { Arabia }\end{array}$ & $\begin{array}{l}\text { West } \\
\text { Virginia } \\
\text { University } \\
-2001\end{array}$ & 68 & Saudi & Neutral/+ \\
\hline Dissertation Title & $\begin{array}{l}\text { RUVH- } \\
\text { Institution }\end{array}$ & $F$ & & \# \\
\hline $\begin{array}{l}\text { Latino community college transfer students in } \\
\text { engineering: Transition experiences and } \\
\text { academic success at a large research university }\end{array}$ & $\begin{array}{l}\text { Arizona } \\
\text { State- } \\
\text { Tempe- } \\
2007 \\
1 \\
\end{array}$ & 69 & Latino & Neutral//+ \\
\hline $\begin{array}{l}\text { Successful Latino students: A study of five } \\
\text { Mexican American families }\end{array}$ & $\begin{array}{l}\text { Arizona } \\
\text { State- } \\
\text { Tempe- } \\
2006 \\
2\end{array}$ & 70 & Latino & Neutral//+ \\
\hline $\begin{array}{l}\text { The personal and academic success of African } \\
\text { American males with specific learning } \\
\text { disabilities }\end{array}$ & $\begin{array}{l}\text { Arizona } \\
\text { State- } \\
\text { Tempe- } \\
2004 \\
4\end{array}$ & 71 & Black & Neutral/+ \\
\hline $\begin{array}{l}\text { Profiles of Black Latinos in the academe: The } \\
\text { identity dilemma and the perception of self }\end{array}$ & $\begin{array}{l}\text { Arizona } \\
\text { State- } \\
\text { Tempe- } \\
2002 \\
6\end{array}$ & 72 & $\begin{array}{l}\text { Black } \\
\text { Latino }\end{array}$ & Neutral/+ \\
\hline $\begin{array}{l}\text { The way out: African American male student } \\
\text { athletes in higher education }\end{array}$ & $\begin{array}{l}\text { Arizona } \\
\text { State- } \\
\text { Tempe- } \\
2001 \\
7\end{array}$ & 73 & Black & Def/Dev \\
\hline $\begin{array}{l}\text { The impact of home environment of Black males } \\
\text { not pursuing higher education between } 18-22\end{array}$ & $\begin{array}{l}\text { Arizona } \\
\text { State- } \\
\text { Tempe- } \\
1998\end{array}$ & 74 & Black & Def/Dev \\
\hline
\end{tabular}


GENDER REPRESENTATIONS IN ED.D. DISSERTATIONS

\begin{tabular}{|c|c|c|c|c|}
\hline & 8 & & & \\
\hline $\begin{array}{l}\text { A qualitative study of resilience among African- } \\
\text { American adolescent male students in North } \\
\text { Carolina }\end{array}$ & \begin{tabular}{|l|} 
North \\
Carolina \\
State- \\
Raleigh- \\
2003 \\
2 \\
\end{tabular} & 75 & Black & Neutral/+ \\
\hline $\begin{array}{l}\text { Coping strategies: Adjustment, and persistence } \\
\text { among Black men attending predominately } \\
\text { White colleges and universities }\end{array}$ & $\begin{array}{l}\text { Rutgers- } \\
\text { New } \\
\text { Brunswic } \\
\text { k-2004 } \\
2\end{array}$ & 76 & Black & Def/Dev \\
\hline $\begin{array}{l}\text { Factors that foster academic resilience in African } \\
\text { American male middle school students from low } \\
\text { socioeconomic single parent homes }\end{array}$ & \begin{tabular}{|l|}
$\mathrm{U}$ \\
Alabama \\
Birmingha \\
$\mathrm{m}$ \\
1999 \\
1 \\
\end{tabular} & 77 & Black & Def/Dev \\
\hline $\begin{array}{l}\text { Educational leadership for school change: } \\
\text { Stories by six Latino elementary school } \\
\text { principals }\end{array}$ & $\begin{array}{l}\text { University } \\
\text { of } \\
\text { Arizona- } \\
2004 \\
1 \\
\end{array}$ & 78 & Latino & Neutral// \\
\hline $\begin{array}{l}\text { Schools as resilient organizations: Supporting } \\
\text { the mathematical resilience of Latino eight } \\
\text { graders }\end{array}$ & 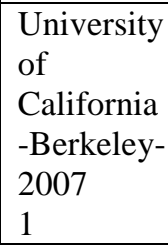 & 79 & Latino & Neutral/+ \\
\hline $\begin{array}{l}\text { Effective library education for the inner city } \\
\text { African-American male: Key elements of a } \\
\text { technology based program }\end{array}$ & 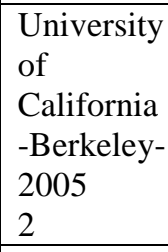 & 80 & Black & Neutral/+ \\
\hline $\begin{array}{l}\text { Effect of Hispanic national origin on salary } \\
\text { differential for male elementary school } \\
\text { principals: A structural analysis to explore the } \\
\text { existence of implications }\end{array}$ & $\begin{array}{l}\text { University } \\
\text { of } \\
\text { California } \\
\text {-Davis- } \\
2006 \\
1\end{array}$ & 81 & $\begin{array}{l}\text { Latino } \\
\text { Hispanic }\end{array}$ & Neutral/+ \\
\hline $\begin{array}{l}\text { Latinos and access to higher education: Factors } \\
\text { that prevent pursuit of a college degree in } \\
\text { California rural San Joaquin Valley }\end{array}$ & 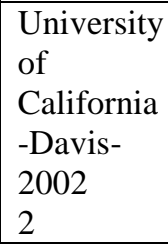 & 82 & Latino & Neutral/+ \\
\hline
\end{tabular}


GENDER REPRESENTATIONS IN ED.D. DISSERTATIONS

\begin{tabular}{|c|c|c|c|c|}
\hline $\begin{array}{l}\text { Raising the curtain on theatre arts for Latinos: } \\
\text { Finding voice, cultural capital, literacy, and } \\
\text { ethnic identity in high school arts theatre classes } \\
\text { IRVINE }\end{array}$ & $\begin{array}{l}\text { University } \\
\text { of } \\
\text { California } \\
\text {-LA \& } \\
\text { Irvine- } \\
2007 \\
1 \\
\end{array}$ & 83 & Latino & Neutral/+ \\
\hline $\begin{array}{l}\text { Technology and equity: Explaining differences } \\
\text { between elementary teachers use of computers in } \\
\text { low-income Latino and middle class-schools } \\
\text { IRVINE \& UCLA }\end{array}$ & $\begin{array}{l}\text { University } \\
\text { of } \\
\text { California } \\
\text {-LA \& } \\
\text { Irvine- } \\
2007\end{array}$ & 84 & Latino & Neutral/+ \\
\hline $\begin{array}{l}\text { The road less traveled: Latino students and the } \\
\text { impact of studying abroad UCLA }\end{array}$ & $\begin{array}{l}\text { University } \\
\text { of } \\
\text { California } \\
\text {-LA \& } \\
\text { Irvine- } \\
2006\end{array}$ & 85 & Latino & Neutral/+ \\
\hline $\begin{array}{l}\text { Identifying characteristics of successful schools } \\
\text { in Latino communities IRVINE }\end{array}$ & $\begin{array}{l}\text { University } \\
\text { of } \\
\text { California } \\
\text {-LA \& } \\
\text { Irvine- } \\
2004\end{array}$ & 86 & Latino & Neutral// \\
\hline $\begin{array}{l}\text { Understanding homework: Latino parent's } \\
\text { perceptions UCLA }\end{array}$ & $\begin{array}{l}\text { University } \\
\text { of } \\
\text { California } \\
\text {-LA \& } \\
\text { Irvine- } \\
2002\end{array}$ & 87 & Latino & Neutral/+ \\
\hline $\begin{array}{l}\text { Fourth and fifth grade Latino students } \\
\text { perceptions of a student at a university: An } \\
\text { examination of children's drawings and their } \\
\text { relationship to participation in an after school } \\
\text { club with university mentors IRVINE }\end{array}$ & $\begin{array}{l}\text { University } \\
\text { of } \\
\text { California } \\
\text {-LA \& } \\
\text { Irvine- } \\
2001\end{array}$ & 88 & Latino & Neutral/+ \\
\hline $\begin{array}{l}\text { An after school program for at -risk African } \\
\text { American boys UCLA }\end{array}$ & $\begin{array}{l}\text { University } \\
\text { of } \\
\text { California } \\
\text {-LA \& } \\
\text { Irvine- } \\
\end{array}$ & 89 & Black & Def/Dev \\
\hline
\end{tabular}


GENDER REPRESENTATIONS IN ED.D. DISSERTATIONS

\begin{tabular}{|c|c|c|c|c|}
\hline & 2000 & & & \\
\hline $\begin{array}{l}\text { Effects of extending mathematics instruction } \\
\text { through a Saturday academy to limited English } \\
\text { proficient Latino students in low performing } \\
\text { schools IRVINE }\end{array}$ & $\begin{array}{l}\text { University } \\
\text { of } \\
\text { California } \\
\text {-LA \& } \\
\text { Irvine- } \\
1999\end{array}$ & 90 & Latino & Neutral/+ \\
\hline $\begin{array}{l}\text { Building bridges: Latino immigrant parents } \\
\text { explore the home schooling relationship UCLA }\end{array}$ & $\begin{array}{l}\text { University } \\
\text { of } \\
\text { California } \\
\text {-LA \& } \\
\text { Irvine- } \\
1999\end{array}$ & 91 & Latino & Neutral/+ \\
\hline $\begin{array}{l}\text { Math enrichment to prepare Latino high school } \\
\text { students for university level mathematics UCLA }\end{array}$ & $\begin{array}{l}\text { University } \\
\text { of } \\
\text { California } \\
\text {-LA \& } \\
\text { Irvine- } \\
1999\end{array}$ & 92 & Latino & Neutral \\
\hline $\begin{array}{l}\text { Brother where art though? An examination of } \\
\text { the under representation of African American } \\
\text { male educators }\end{array}$ & $\begin{array}{l}\text { University } \\
\text { of } \\
\text { Cincinnati } \\
-2006\end{array}$ & 93 & Black & Def/Dev \\
\hline $\begin{array}{l}\text { Where do we go from here? Understanding the } \\
\text { impact of racism and its influence on African } \\
\text { American male superintendents }\end{array}$ & $\begin{array}{l}\text { University } \\
\text { of } \\
\text { Cincinnati } \\
-2006\end{array}$ & 94 & Black & Neutral/+ \\
\hline $\begin{array}{l}\text { A comparative study of addicted African } \\
\text { American males in two drug court programs }\end{array}$ & $\begin{array}{l}\text { University } \\
\text { of } \\
\text { Cincinnati } \\
-1999\end{array}$ & 95 & Black & Def/Dev \\
\hline $\begin{array}{l}\text { A descriptive study of the process that occurs } \\
\text { when adolescent African American males are } \\
\text { engaged in the study of multiethnic literature }\end{array}$ & $\begin{array}{l}\text { University } \\
\text { of } \\
\text { Cincinnati } \\
-1999\end{array}$ & 96 & Black & Neutral/+ \\
\hline $\begin{array}{l}\text { Learning and schooling experiences of Black, } \\
\text { deaf and hard-of-hearing adult male learners: A } \\
\text { narrative analysis }\end{array}$ & $\begin{array}{l}\text { University } \\
\text { of Georgia } \\
-2003\end{array}$ & 97 & Black & Neutral/+ \\
\hline
\end{tabular}


GENDER REPRESENTATIONS IN ED.D. DISSERTATIONS

\begin{tabular}{|c|c|c|c|c|}
\hline $\begin{array}{l}\text { A comparative study of the perceived experience } \\
\text { of black male student athletes attending a } \\
\text { historically Black university compared to those } \\
\text { attending a predominately white university }\end{array}$ & $\begin{array}{l}\text { University } \\
\text { of } \\
\text { Kentucky- } \\
2003\end{array}$ & 98 & Black & Neutral/+ \\
\hline $\begin{array}{l}\text { Exploring the relationship between personal } \\
\text { motivation, persistence, and resilience and their } \\
\text { effects on academic achievement among } \\
\text { different groups of African-American males in } \\
\text { high school }\end{array}$ & $\begin{array}{l}\text { University } \\
\text { of } \\
\text { Maryland } \\
-2005\end{array}$ & 99 & Black & Def/Dev \\
\hline $\begin{array}{l}\text { Representin' for Latino students: Culturally } \\
\text { responsive pedagogies, teacher identities, and } \\
\text { the preparation of teachers for urban schools }\end{array}$ & $\begin{array}{l}\text { University } \\
\text { of } \\
\text { Massachu } \\
\text { setts- } \\
\text { Amherst - } \\
2005\end{array}$ & 100 & Latino & Neutral/+ \\
\hline $\begin{array}{l}\text { The psychodynamics of white racism: an } \\
\text { historical exploration of white racial pathology } \\
\text { as elicited by prizefighters Jack Johnson and } \\
\text { Mohammed Ali am }\end{array}$ & $\begin{array}{l}\text { University } \\
\text { of } \\
\text { Massachu } \\
\text { setts- } \\
\text { Amherst - } \\
2005\end{array}$ & 101 & White & Def/Dev \\
\hline $\begin{array}{l}\text { Listening to the voices of inner city, low income, } \\
12^{\text {th }} \text { grade, Black males: A phenomenological } \\
\text { study if their educational experiences }\end{array}$ & $\begin{array}{l}\text { University } \\
\text { of } \\
\text { Massachu } \\
\text { setts- } \\
\text { Amherst- } \\
2004\end{array}$ & 102 & Black & Neutral/+ \\
\hline $\begin{array}{l}\text { Perceptions of Black male students and their } \\
\text { parents about the academic achievement gap } \\
\text { between Black and white students at the } \\
\text { elementary school level }\end{array}$ & $\begin{array}{l}\text { University } \\
\text { of } \\
\text { Massachu } \\
\text { setts- } \\
\text { Amherst- } \\
2002\end{array}$ & 103 & Black & Neutral/+ \\
\hline $\begin{array}{l}\text { Perceptions of young African American males } \\
\text { about rap music and its impact on their attitudes } \\
\text { about women }\end{array}$ & $\begin{array}{l}\text { University } \\
\text { of } \\
\text { Massachu } \\
\text { setts- }\end{array}$ & 104 & Black & Def/Dev \\
\hline
\end{tabular}


GENDER REPRESENTATIONS IN ED.D. DISSERTATIONS

\begin{tabular}{|c|c|c|c|c|}
\hline & $\begin{array}{l}\text { Amherst- } \\
1999\end{array}$ & & & \\
\hline $\begin{array}{l}\text { A survey of elementary teacher attitudes: } \\
\text { perceptions and knowledge of African American } \\
\text { male language usage in fourth grade classrooms }\end{array}$ & $\begin{array}{l}\text { University } \\
\text { of } \\
\text { Missouri- } \\
\text { Columbia } \\
-2005\end{array}$ & 105 & Black & Neutral/+ \\
\hline $\begin{array}{l}\text { Factors that influence Omaha public schools } \\
\text { African-American and Caucasian males } \\
\text { decisions to become educators }\end{array}$ & $\begin{array}{l}\text { University } \\
\text { of } \\
\text { Nebraska- } \\
2003\end{array}$ & 106 & $\begin{array}{l}\text { Black } \\
\text { White }\end{array}$ & Neutral/+ \\
\hline $\begin{array}{l}\text { How teachers in a resiliency building school } \\
\text { promote resiliency within African American } \\
\text { male students }\end{array}$ & $\begin{array}{l}\text { University } \\
\text { of N. } \\
\text { Carolina- } \\
\text { Chapel } \\
\text { Hill-2006 }\end{array}$ & 107 & Black & Neutral/+ \\
\hline $\begin{array}{l}\text { A multi-year study of the impact of retention on } \\
\text { elementary African American males } \\
\text { achievement in math and reading in one North } \\
\text { Carolina School District }\end{array}$ & $\begin{array}{l}\text { University } \\
\text { of N. } \\
\text { Carolina- } \\
\text { Chapel } \\
\text { Hill-2005 }\end{array}$ & 108 & Black & Neutral/+ \\
\hline $\begin{array}{l}\text { Social capital: The link that bridges risk to } \\
\text { resilience in primary grade African American } \\
\text { males }\end{array}$ & $\begin{array}{l}\text { University } \\
\text { of } \\
\text { Pittsburgh } \\
-2000\end{array}$ & 109 & Black & Neutral/+ \\
\hline $\begin{array}{l}\text { The relation between the perceptions of sixth } \\
\text { and seventh grade African American males and } \\
\text { the perceptions of their teachers of academic } \\
\text { ability, motivation, attitudes and efforts }\end{array}$ & $\begin{array}{l}\text { University } \\
\text { of } \\
\text { S. } \\
\text { Carolina- } \\
\text { Columbia- } \\
1998\end{array}$ & 110 & Black & Def/Dev \\
\hline $\begin{array}{l}\text { Ethnically diverse principals and male Hispanic } \\
\text { superintendents' perceptions of the } \\
\text { superintendent's leadership }\end{array}$ & $\begin{array}{l}\text { University } \\
\text { of Texas- } \\
\text { Austin- } \\
2006\end{array}$ & 111 & $\begin{array}{l}\text { Hispanic } \\
\text { Latino }\end{array}$ & Neutral/+ \\
\hline $\begin{array}{l}\text { African American male participation at Tomball } \\
\text { college: Barriers, outreach and retention }\end{array}$ & $\begin{array}{l}\text { University } \\
\text { of Texas- } \\
\text { Austin- } \\
2004\end{array}$ & 112 & Black & Neutral/+ \\
\hline
\end{tabular}


GENDER REPRESENTATIONS IN ED.D. DISSERTATIONS

\begin{tabular}{|l|l|l|l|l|}
\hline $\begin{array}{l}\text { Challenges of studying attributes associated with } \\
\text { African American males who are not successful } \\
\text { with testing measures }\end{array}$ & $\begin{array}{l}\text { Virginia } \\
\text { Polytechni } \\
\text { c \& State } \\
\text { U-2002 }\end{array}$ & 113 & Black & Def/Dev \\
\hline $\begin{array}{l}\text { Non-verbal behaviors of effective teachers of at- } \\
\text { risk African American male middle school } \\
\text { students }\end{array}$ & $\begin{array}{l}\text { Virginia } \\
\text { Polytechni } \\
\text { c \& State } \\
\text { U-2000 }\end{array}$ & 114 & Black & Neutral/+ \\
\hline $\begin{array}{l}\text { A qualitative study on the role of African } \\
\text { American fathers and their influence on their } \\
\text { child's early literacy development }\end{array}$ & $\begin{array}{l}\text { Wayne } \\
\text { State U - } \\
2005\end{array}$ & 115 & Black & Neutral \\
\hline
\end{tabular}

